\title{
41MV120: A Stratified Late Archaic Site in Maverick County, Texas
}

\section{Bradley J. Vierra}

Center for Archaeological Research

Follow this and additional works at: https://scholarworks.sfasu.edu/ita

Part of the American Material Culture Commons, Archaeological Anthropology Commons, Environmental Studies Commons, Other American Studies Commons, Other Arts and Humanities Commons, Other History of Art, Architecture, and Archaeology Commons, and the United States History Commons

Tell us how this article helped you.

This Article is brought to you for free and open access by the Center for Regional Heritage Research at SFA ScholarWorks. It has been accepted for inclusion in Index of Texas Archaeology: Open Access Gray Literature from the Lone Star State by an authorized editor of SFA ScholarWorks. For more information, please contact cdsscholarworks@sfasu.edu. 


\section{MV120: A Stratified Late Archaic Site in Maverick County, Texas}

\section{Licensing Statement}

This is a work produced for the Texas Department of Transportation (TxDOT) by the report producer. TxDOT and the report producer jointly own all rights, title, and interest in and to all intellectual property developed under TXDOT's contract with the report producer. The report may be cited and brief passages from this publication may be reproduced without permission provided that credit is given to both TxDOT and the report producer. Permission to reprint an entire chapter, section, figures or tables must be obtained in advance from either the Supervisor of the Archeological Studies Branch, Environmental Affairs Division, Texas Department of Transportation, 125 East 11th Street, Austin, Texas, 78701 or from the report producer. 


\title{
41MV120: A Stratified Late Archaic Site in Maverick County, Texas
}

\author{
Bradley J. Vierra
}

\author{
with contributions by C. Britt Bousman, John R. Cross, \\ J. Philip Dering, Wulf Gose, Anne A. Fox, Robert G. Howells, \\ Johanna Hunziker, David L. Nickels, Artie L. Metcalf, \\ Barbara A. Meissner, and Lee C. Nordt
}

\section{Robert J. Hard and C. Britt Bousman Prinicipal Investigators}

Texas Antiquities Permit No. 1622

Archaeological Survey Report, No. 251 Center for Archaeological Research The University of Texas at San Antonio
Archeology Studies Program, Report No. 7 Environmental Affairs Division Texas Department of Transportation 
The following information is provided in accordance with the General Rules of Practice and Procedure, Chapter 41.11 (Investigative Reports), Texas Antiquities Committee:

1. Type of investigation: Testing

2. Project name: Maverick

3. County: Maverick

4. Principal investigator: Robert J. Hard and C. Britt Bousman

5. Name and location of sponsoring agency: Texas Department of Transportation, Austin, Texas 78701

6. Texas Antiquities Permit No.: 1622

7. Published by the Center for Archaeological Research, The University of Texas at San Antonio, 6900 N. Loop 1604 W., San Antonio, Texas 78249-0658, 1998

A list of publications offered by the Center for Archaeological Research is available. Call (210) 458-4378; write to the Center for Archaeological Research, The University of Texas at San Antonio, 6900 N. Loop 1604 W., San Antonio, Texas 78249-0658; e-mail to car@lonestar.utsa.edu; or visit CAR's web site at http://www.csbs.utsa.edu/research/car/index.htm. 


\section{Abstract}

This report presents the findings of the data recovery program conducted at site $41 \mathrm{MV} 120$. The excavation was conducted under a contractual agreement with the Texas Department of Transportation under Texas Antiquities Permit number 1622. A total of 9,147 lithic artifacts, 30,903 $\mathrm{g}$ of fire-cracked rock, $1623 \mathrm{~g}$ of mussel shells, $457 \mathrm{~g}$ of snails, 43 macrobotanical samples, 79 historic artifacts, and 15 bones was recovered from these excavations. $41 \mathrm{MV} 120$ is a stratified Late Archaic site dating from ca. 2200-1200 B.P. It was periodically inundated by floodwaters from the Rio Grande which buried a series of occupational levels. The site appears to represent a long-term pattern of redundant reuse. It presumably reflects a short-term campsite from which local terrace gravels were used for core reduction and tool production. Several species of aquatic and terrestrial resources were exploited while residing at the camp, including shellfish and medium- to small-sized animals. 



\section{Contents}

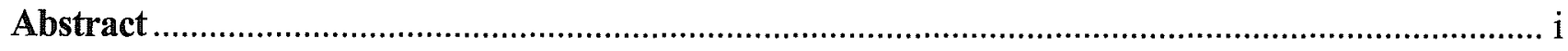

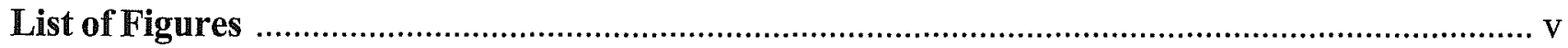

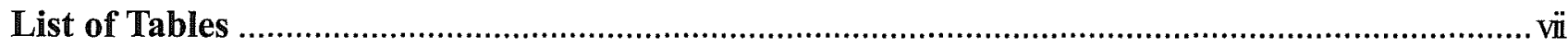

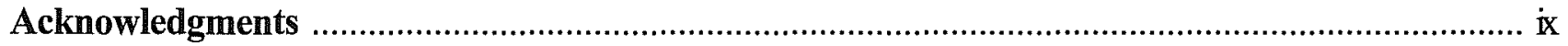

Chapter 1: Introduction

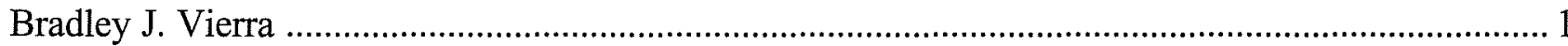

Chapter 2: Environmental Background

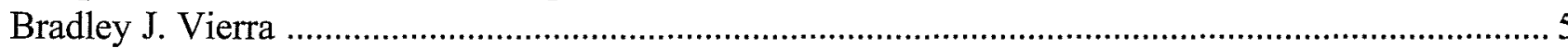

Chapter 3: Archaeological and Ethnohistorical Background

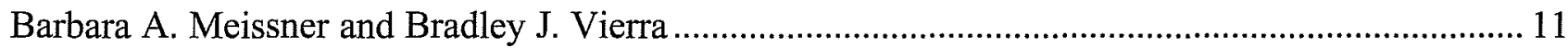

Chapter 4: Previous Investigations in Maverick County

Johanna M. Hunziker

Chapter 5: Research Design

C. Britt Bousman

Chapter 6: Methods

John R. Cross

Chapter 7: Geoarchaeology Of The Rio Grande and EIm Creek in the Vicinity of Site 41MV120

Lee C. Nordt

Chapter 8: Results of the Field Investigations

Bradley J. Vierra and John R. Cross

Chapter 9: Lithic Analysis

Bradley J. Vierra

Chapter 10: Fire-cracked Rock

David L. Nickels, Bradley J. Vierra, and Wulf Gose

\section{Chapter 11: Macrobotanical Remains}

J. Philip Dering

Chapter 12: Freshwater Mussel (Unionidae) Shell Remains

Robert G. Howells 


\section{Chapter 13: Gastropod Remains}

Artie L. Metcalf.

Chapter 14: Faunal Remains

Barbara A. Meissner

Chapter 15: Historic Artifacts

Anne A. Fox

Chapter 16: Site Structure

Bradley J. Vierra

Chapter 17: Evaluation of Research Issues

Bradley J. Vierra

Chapter 18: Recommendations for Future Research

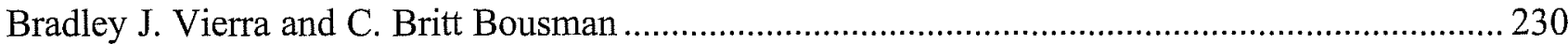

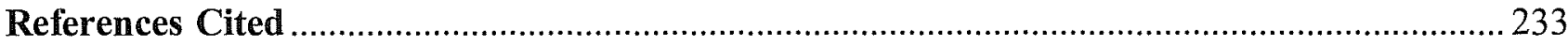

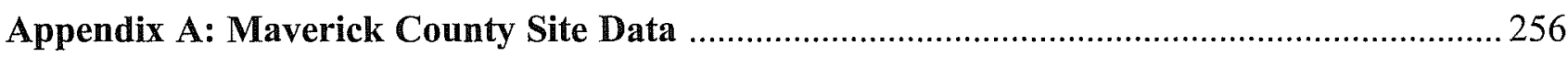

Appendix B: Geomorphological Data

Lee C. Nordt

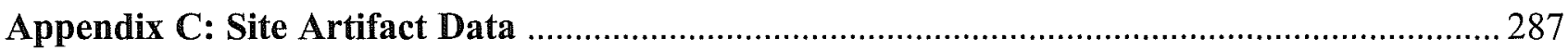

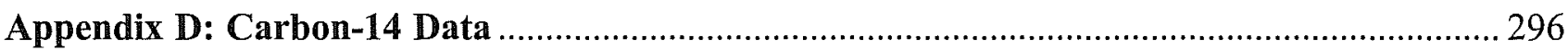

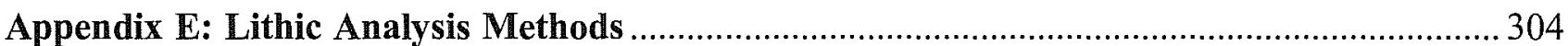

Appendix F: Archaeomagnetic Data

Wulf Gose

Appendix G: Mussel Shell Data

Robert G. Howells

Appendix H: Snail Data

Artie L. Metcalf 


\section{Figures}

1-1. Project location.

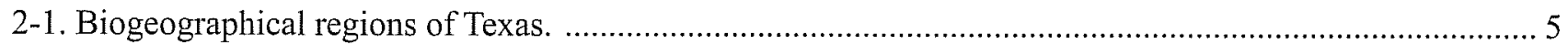

2-2. Paleoenvironmental and regional chronology for South and Central Texas. ..................................... 10

5-1. Location of initial TxDOT shovel tests and backhoe trenches. ............................................................ 26

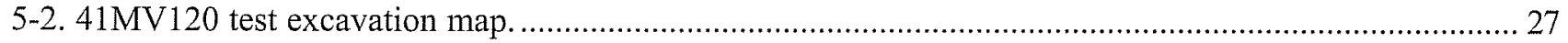

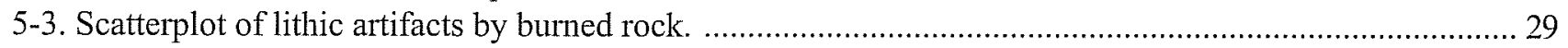

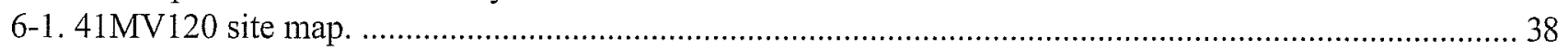

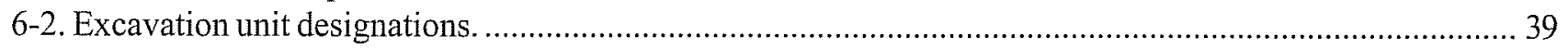

7-1. Geomorphic map of the Rio Grande and lower Elm Creek basin in the vicinity of

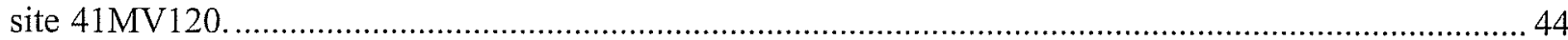

7-2. Geomorphic map of the upper Elm Creek drainage basin. ......................................................... 45

7-3. Regional alluvial stratigraphy of the Rio Grande based on deep sediment cores.............................. 48

7-4. Photographs of micromorphic thin sections showing progressive stages of clay clast destruction.

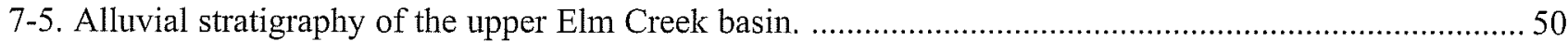

7-6. Alluvial stratigraphy at site 41MV120 constructed from BHTs................................................... 51

7-7. Photographs of micromorphic thin sections showing environments of deposition. ................................52

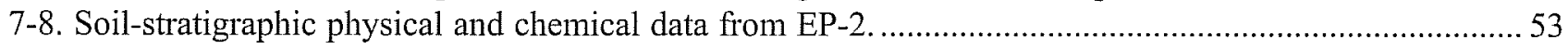

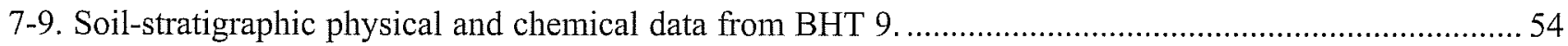

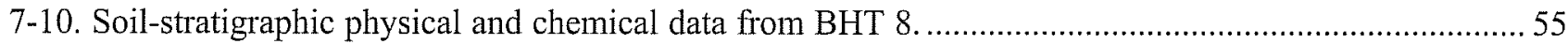

7-11. Soil-stratigraphic physical and chemical data from EP-1 .................................................... 57

7-12. Photographs of micromorphic thin sections showing different kinds of biological activity .................60

7-13. Photographs of micromorphic thin sections showing cultural debitage. ....................................... 61

7-14. Depth distribution of cultural material vs.alluvial stratigraphic column for BHTs 7 and $8 \ldots \ldots \ldots \ldots \ldots . . . .63$

7-15. Depth distribution of cultural material vs.alluvial stratigraphic column for BHTs 10 and 9...............65

7-16. Photographs of micromorphic thin sections showing characteristics of Elm Creek. .........................6 68

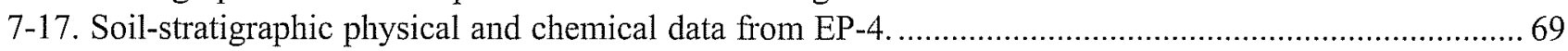

7-18. Soil-stratigraphic physical and chemical data from EP-3 .................................................... 70

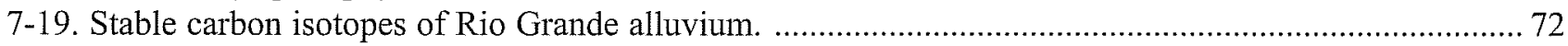

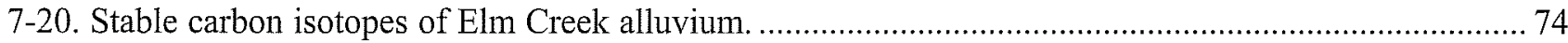

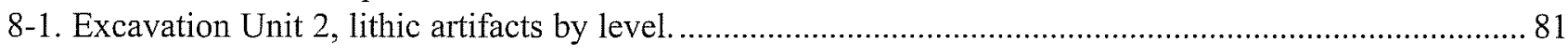

8-2. Excavation Unit 2, fire-cracked rock by level. ......................................................................... 81

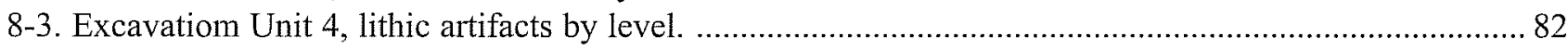

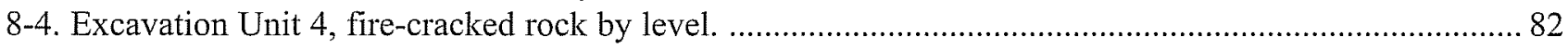

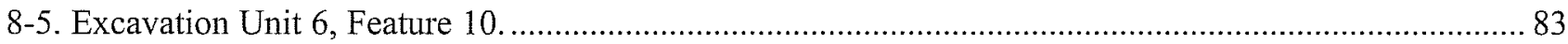

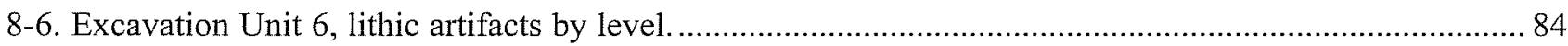

8-7. Excavation Unit 6, fire-cracked rock by level. .................................................................. 84

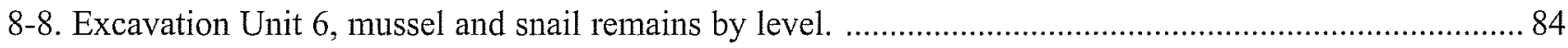

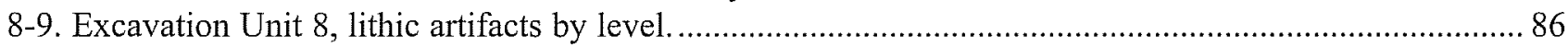

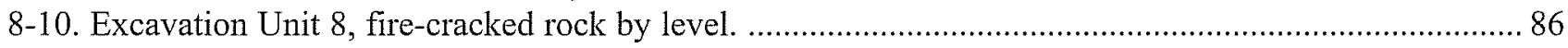

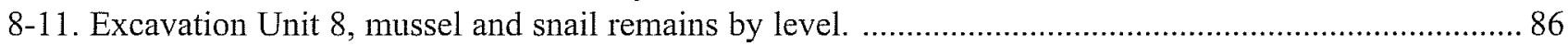

8-12. Excavation Unit 10, lithic artifacts by level.......................................................................... 87

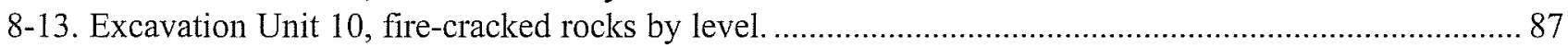

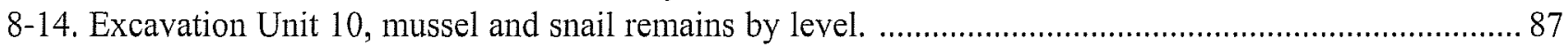

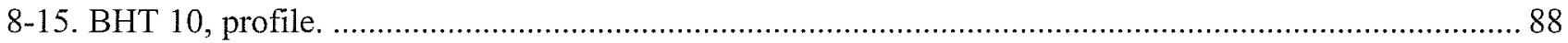




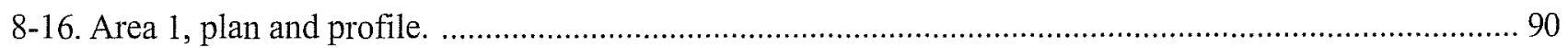

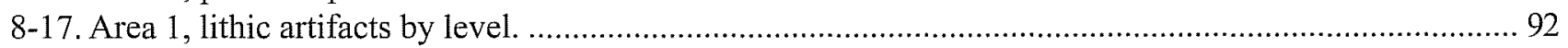

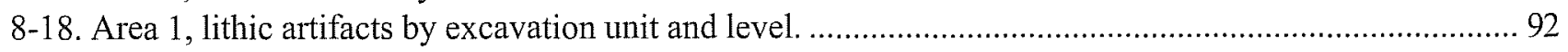

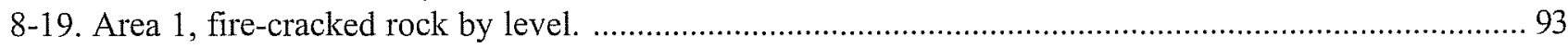

8-20. Area 1, fire-cracked rock by excavation and level. .......................................................................... 93

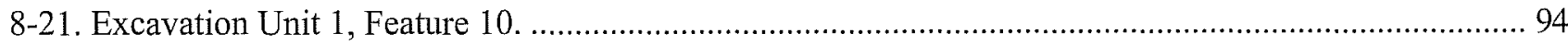

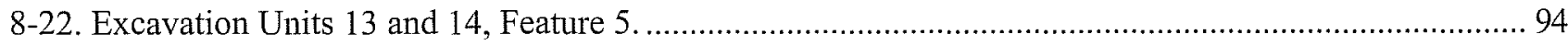

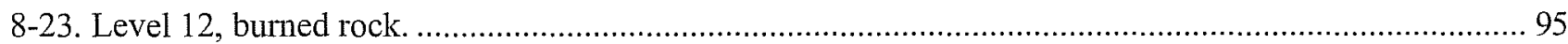

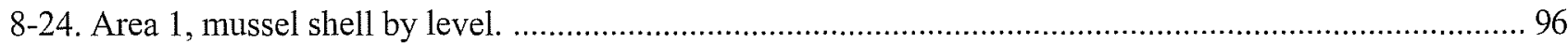

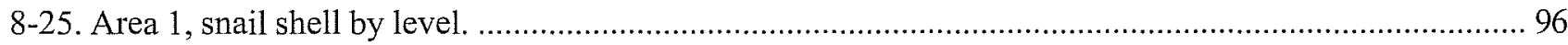

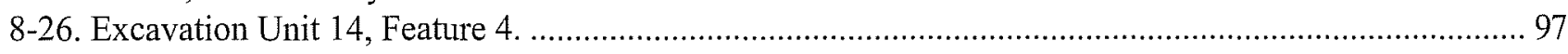

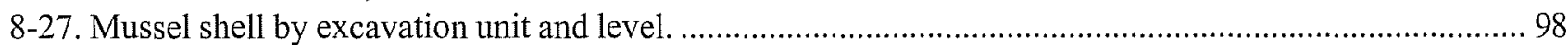

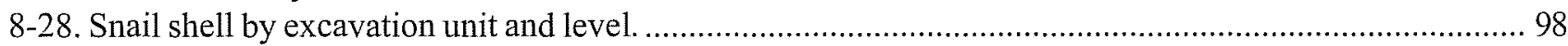

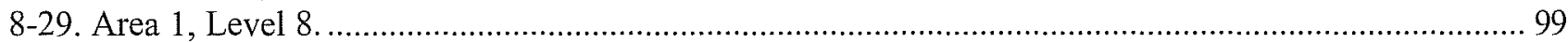

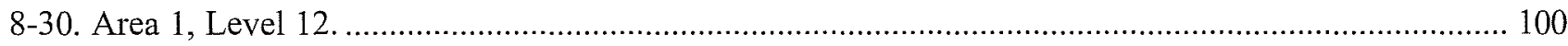

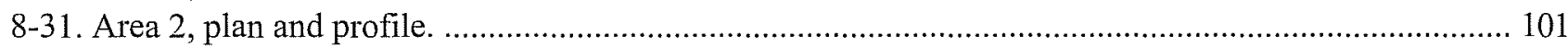

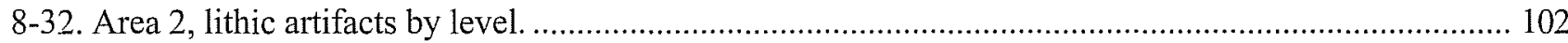

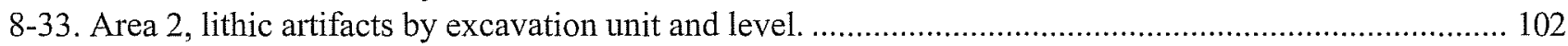

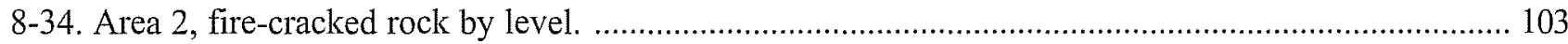

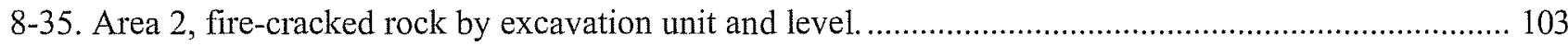

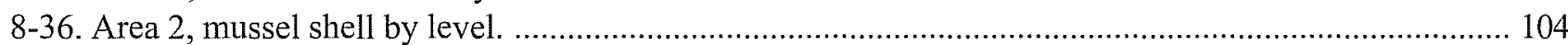

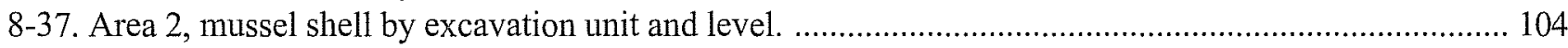

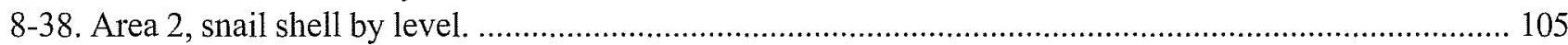

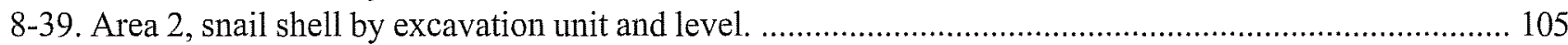

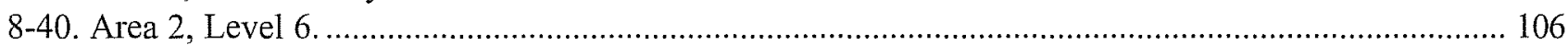

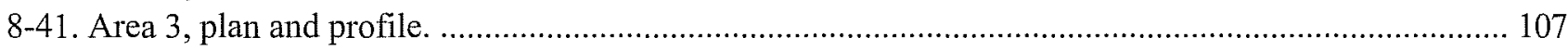

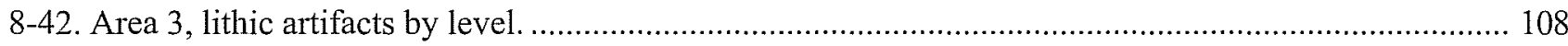

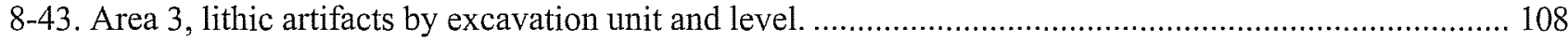

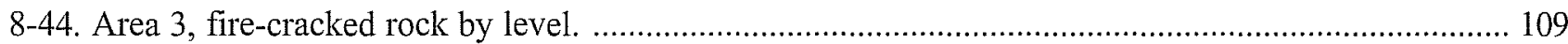

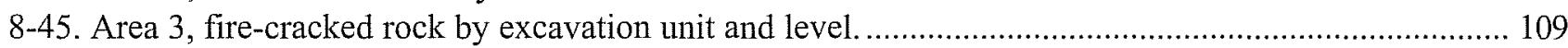

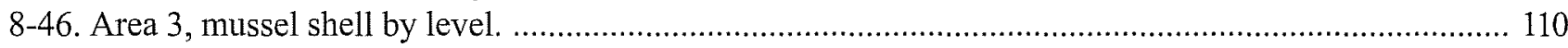

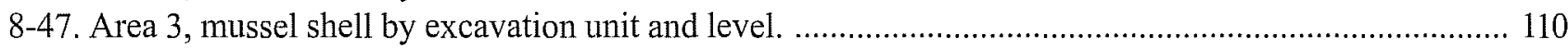

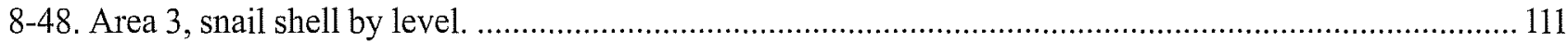

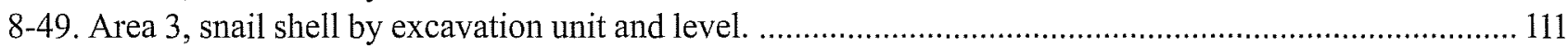

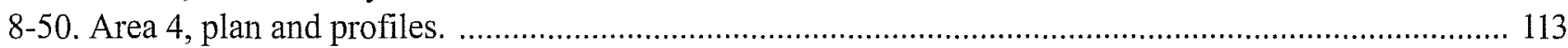

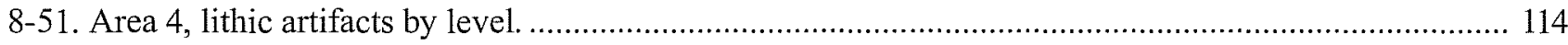

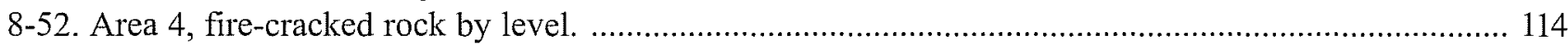

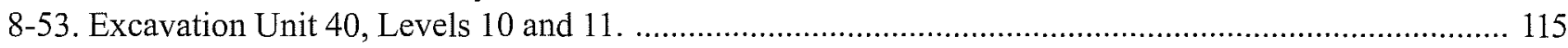

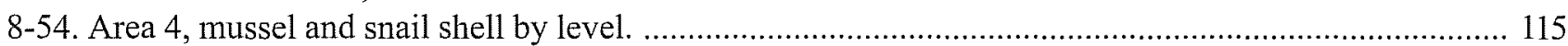

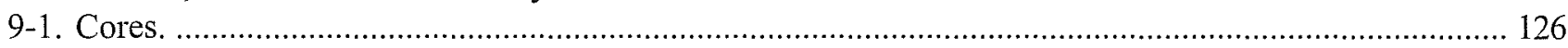

9-2. Core flake and biface flake lengths.

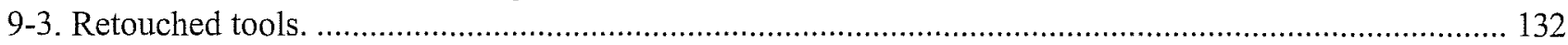

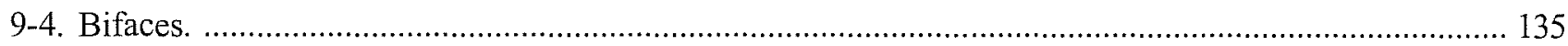

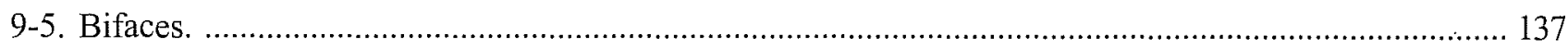

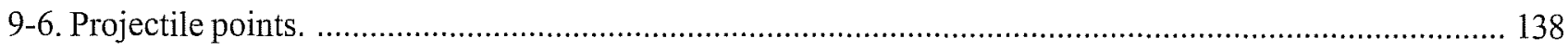

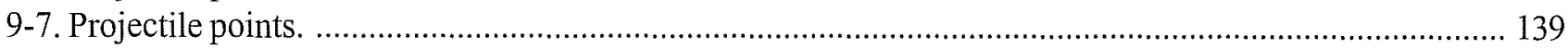

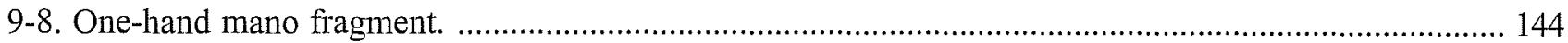

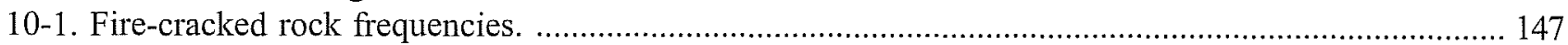

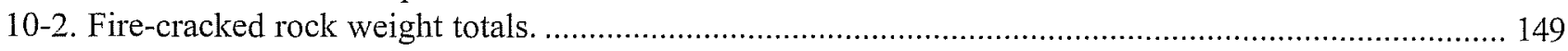




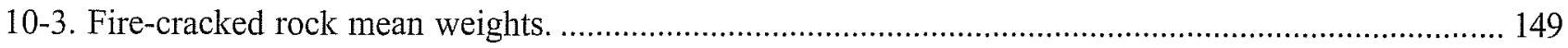

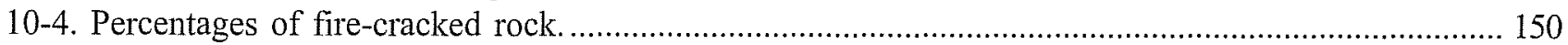

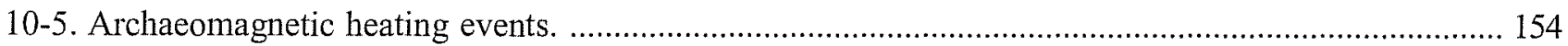

10-6. Vector component diagram representing intensity of magnetization. ............................................... 155

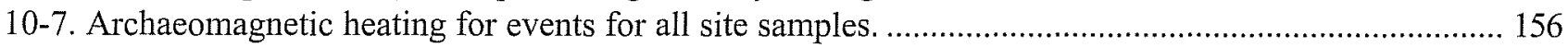

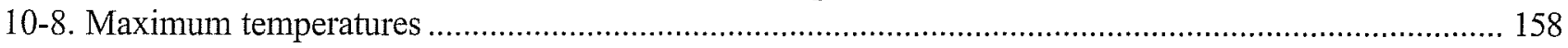

12-1. Unionid structures most useful in identification of shell fragments. .................................................. 167

16-1. Schematic distribution of projectile point types across site 41MV120 .............................................. 191

16-2. Scatter plot of number of lithic artifacts by burned rock weight (g) for individual levels. ...................... 192

16-3. Scatter plot of mussel shell weight $(\mathrm{g})$ by burned rock weight $(\mathrm{g})$ for individual levels. ......................... 195

16-4. Scatter plot of snail shell weight $(\mathrm{g})$ by mussel shell weight $(\mathrm{g})$ for individual levels. ........................... 195

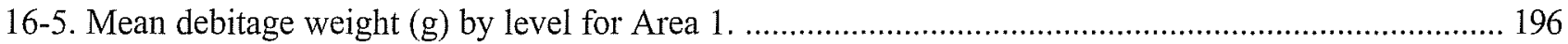

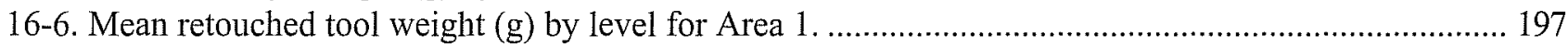

16-7. Lithic artifact frequencies by AU (shaded area) for Area 1.......................................................... 197

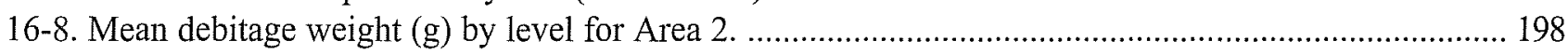

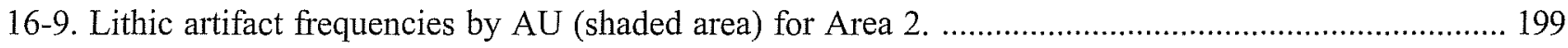

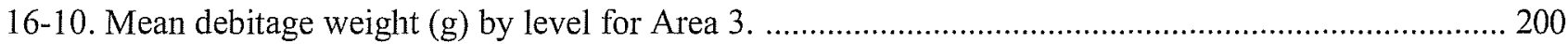

16-11. Lithic artifact frequencies by AU (shaded area) for Area 3........................................................... 200

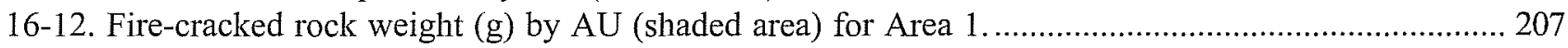

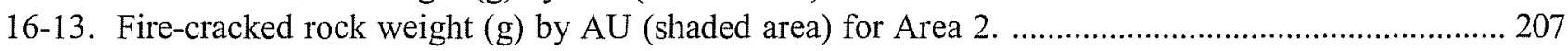

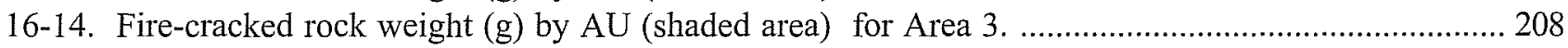

16-15. Mussel shell weight (g) by AU (shaded area) for Area 1................................................................. 210

16-16. Mussel shell weight (g) by AU (shaded area) for Area 2............................................................. 210

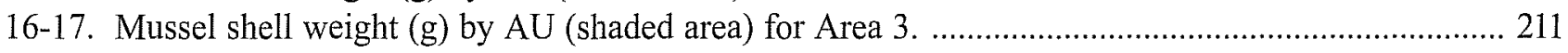

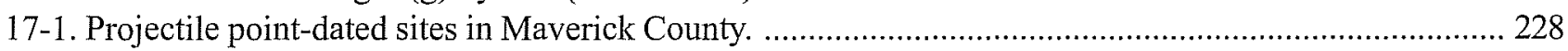

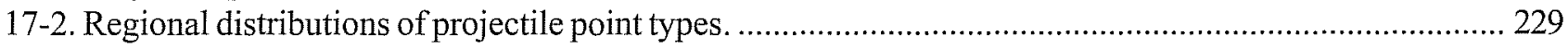

E-4. Conventions used for metrical attributes of retouched tools. ................................................................ 306 


\section{Tables}

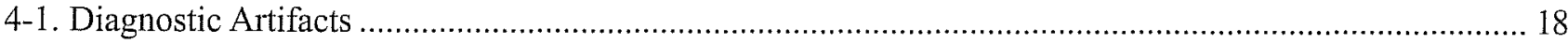

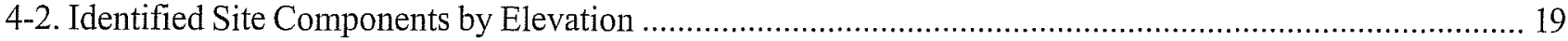

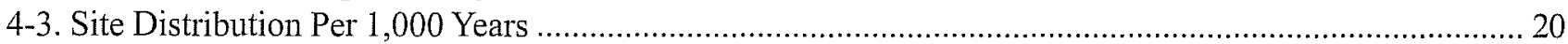

4-4. Site Components with Burned Rock Middens and Burned Rock Concentrations .................................... 21

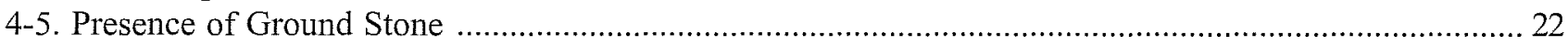

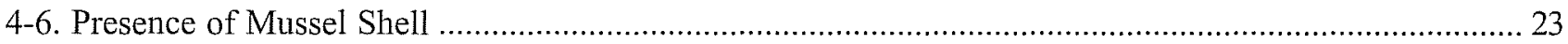

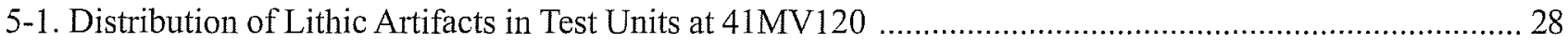

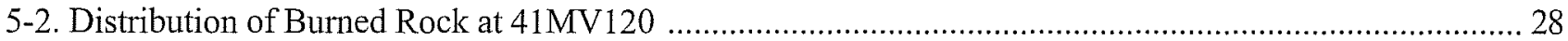

5-3. Percentage of Artifacts in Low- and High-density Zones .................................................................... 29

5-4. Distribution of Features and Radiocarbon Assays in Test Units at 41MV120 ….................................... 30

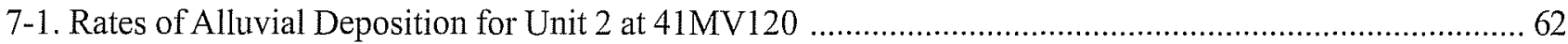

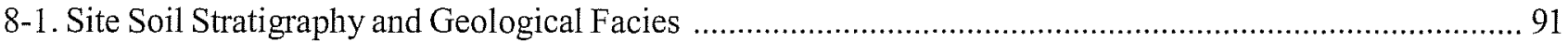

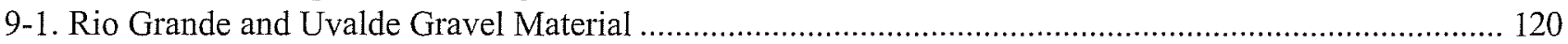

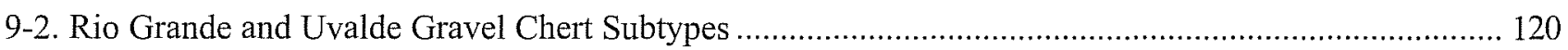

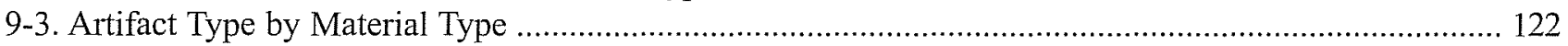

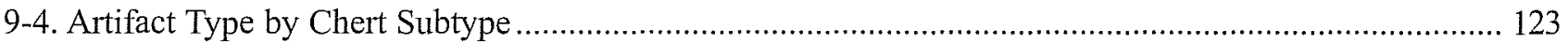

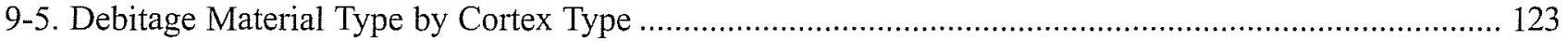

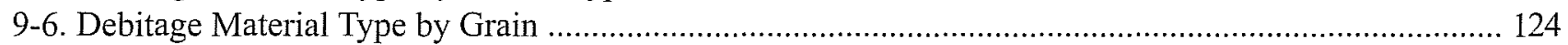

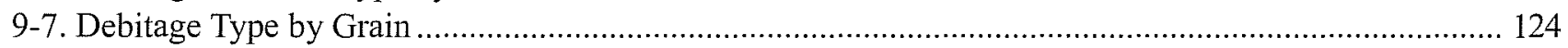

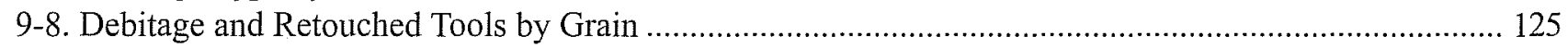

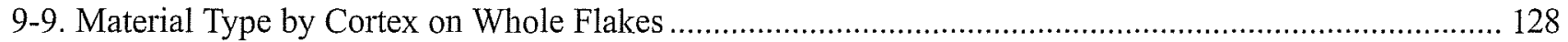

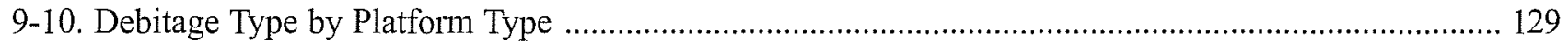

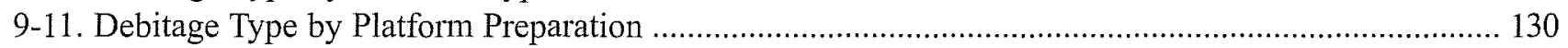

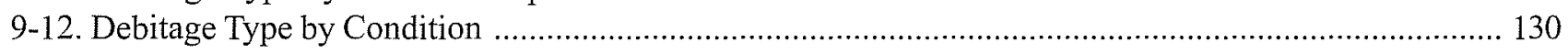

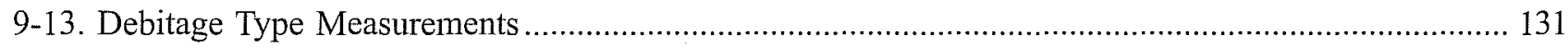

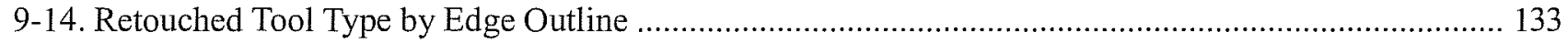

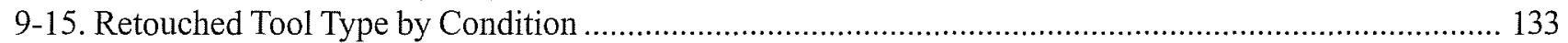

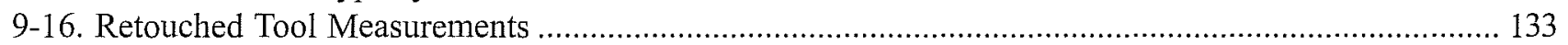

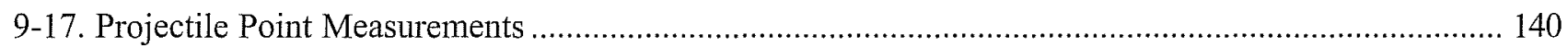

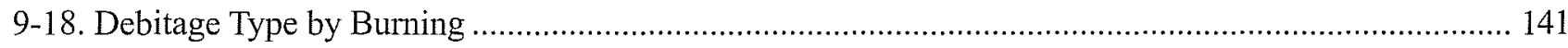

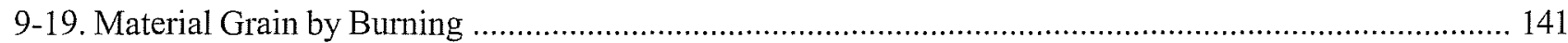

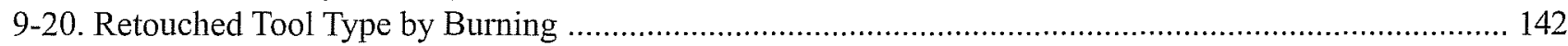

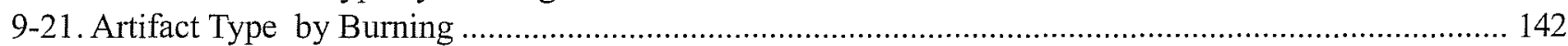

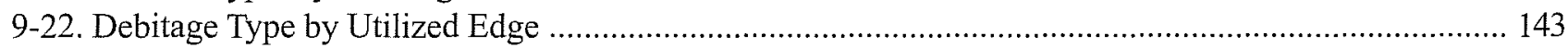

9-23. Location by Edge Outline for Use-damaged Debitage ....................................................................... 143

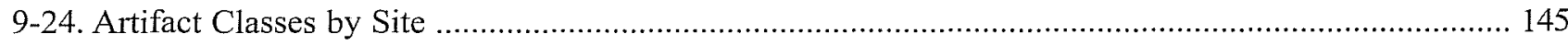

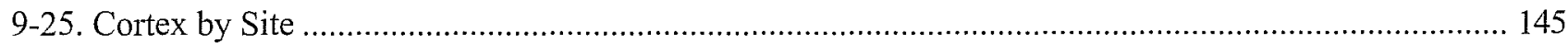

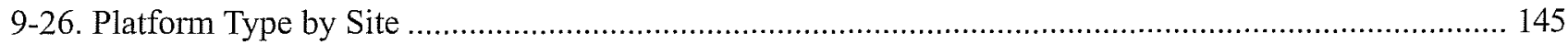

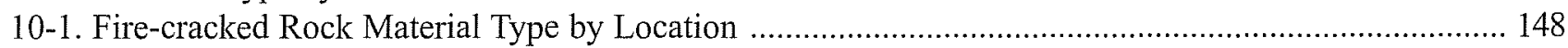

10-2. Fire-cracked Rock Total Weight (g) by Site Area ………........................................................... 150

10-3. Burned Rock Material Types by Higher Density Levels ................................................................. 151

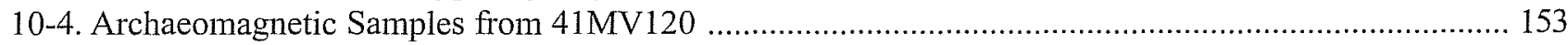

10-5. Archaeomagnetic Materials and Heated Temperatures ………..................................................... 158

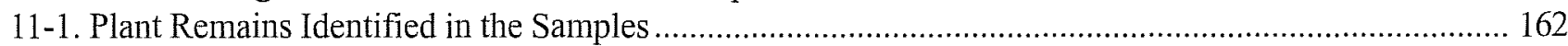

12-1. Freshwater Mussels (Family Unionidae) Reported in the Rio Grande Drainage .................................. 165 


\section{.}




\section{Acknowledgments}

The field personnel consisted of John Cross (project director), Cindy Tennis (field assistant), and the following crewmembers: John Arnn, Jeff Durst, Owen Ford, Ed Johnson, Kaylee McRae, Bruce Moses, Bobby Rector, and Andrew Scease. The laboratory personnel consisted of Jeff Durst, Anne Fox, Johanna Hunziker, and Kaylee McRae. The production of this report required the concerted effort of the CAR office staff. Bruce Moses, Chris Butler, Ed Johnson and Fernando Londoño worked on graphics and illustrations. Production and editing was the responsibility of Marcie Renner, James Rodriguez, and Lucy Vasquez, and the administrative staff included Sherri Suñaz and James Lincoln. Robert Hard and Britt Bousman acted as principal investigators. Britt Bousman and Steve Tomka provided advice and comments on various sections of the report.

This work was done with the cooperation and support of the Texas Department of Transportation. We would like to thank Nancy Kenmotsu, Ann Irwin, Lain Ellis, Al McGraw, Christine Ward, Glenn Goode, Chuy Gonzalez, Melvin Auldridge, and Paul Maslyk for their help. Several individuals in the Eagle Pass Maintenance Office also provided us with assistance including, Jesus Jimenez, Jose Luis Lira, Santiago de la Garza, and Cristobal Rodriguez. In addition, Joe Salinas from the Freer Maintenance Office was the Gradall operator, and Melisa Montemayor from the Laredo District Office coordinated various field logistics. Lain Ellis and Mike Davis were our contacts with the Texas Historical Commission, and Kevin Miller reviewed the report for the THC. We would also like to thank Mr. Albert Ellis, Mr. Harry Kelly, Mr. Victor Olivas, and Mr. Shelton Soret from Eagle Pass for their help. Margaret Hardt, the owner of De Los Santos Gravel Pit, graciously allowed us to collect cobbles for our raw material study.

Dr. Thomas Hester (UT-Austin and TARL), Dr. Michael B. Collins (TARL), and Dr. Stephen L. Black (TARL) aided in the identification of projectile points. Consultants on the project included Dr. Phil Dering (Texas A\&M), Dr. Robert Howells (Parks and Wildlife), Dr. James Jones (UT-San Antonio), Dr. Lee Nordt (Baylor), Dr. Wulf Gose (UT-Austin), Dr. Art Metcalf (UT-El Paso), and Dr. Eric Swanson (UT-San Antonio). Their help and advice was greatly appreciated. 



\section{Chapter 1: Introduction}

\section{Bradley J. Vierra}

This report presents the findings of a data-recovery program conducted at site $41 \mathrm{MV} 120$, Maverick County, Texas. The work was initiated by the Texas Department of Transportation (TxDOT) under a contractual agreement with the Center for Archaeological Research (CAR) of The University of Texas at San Antonio (UTSA). 41MV120 is a stratified Late Archaic site situated along road FM 1589 in Eagle Pass (Figure 1-1). Preliminary testing revealed the presence of intact features and subsurface cultural deposits. This, in conjunction with the aggrading nature of the deposits, indicated that the site contained the potential of representing one of the few recorded gisements (sensu Collins 1995:374) in South Texas. Excavations revealed that the site was periodically inundated by Rio Grande floodwaters, and that a series of occupational levels was preserved within the deposits. Information derived from this study will therefore make an important contribution towards our understanding of site formation processes, and the nature of prehistoric hunter-gatherer strategies in South Texas.

FM 1589 is located north of the city of Eagle Pass. The existing two-lane road was scheduled to be widened, and the bridge replaced at nearby Elm Creek. Site records indicated that two archeological sites41MV107 and 41MV109-had already been identified within the project area (Hubbard and Fox 1990). TxDOT archaeologists conducted a pedestrian survey of the right-of-way in April 1995, and recorded an additional site: 41MV120 (Ward 1995a). At this time, two backhoe trenches and 13 shovel tests were excavated at 41MV120. The backhoe trenches and five shovel tests located west and south of the road failed to expose any cultural remains; however, five of the eight shovel tests excavated north of the roadway did expose buried cultural deposits.

The road improvement was performed under the Antiquities Code of Texas and a Memorandum of Understanding between TxDOT and the Texas Historical Commission (THC). Test excavations were conducted at site 41MV120 by TxDOT archaeologists in May 1995 (Ward 1995b). Seven backhoe trenches, six 1-x-1 $\mathrm{m}$ test pits, and five shovel tests were excavated in the area north of the road. Cultural deposits were identified in four of the six backhoe trenches, and in all the test pits and shovel tests. Artifact density generally declined from east to west, with debitage, a few retouched tools, burned rock, mussel shells, snail shells, and bits of charcoal being recovered to a depth of about one meter. Although no diagnostic artifacts were found, four intact features were identified. Three of these were possible hearths, and one consisted of a mussel shell lens. Wood charcoal from a possible hearth and the mussel shell lens yielded radiocarbon dates of 1240 and 1460 B.P., respectively. TxDOT, therefore, recommended the site is eligible for inclusion in the National Register of Historic Places, and merits designation as a State Archeological Landmark, and that a data recovery program should be implemented. The THC concurred with TXDOT's recommendations. In consultation with the THC, TxDOT developed and implemented a data-recovery plan to mitigate the effects that road improvement activities would have on $41 \mathrm{MV} 120$.

The data-recovery program at $41 \mathrm{MV} 120$ was conducted by CAR under Texas Antiquities Permit number 1622. The permit was issued by the THC's Department of Antiquities Protection on December 8, 1995. The notice to proceed with the TxDOT project was received on December 12, 1995. Fieldwork commenced shortly thereafter on December 18, 1995, and continued through February 14, 1996. Robert J. Hard and C. Britt Bousman acted as principal investigators, and John R. Cross as project director. Six backhoe trenches and $391-x-1-m$ hand-dug units were excavated within the right-of-way. The hand excavations were situated in four block areas, with continuing excavations in four preexisting test pits. In total, 9,147 lithic artifacts, $30,903 \mathrm{~g}$ of fire-cracked rock, 1,623 $\mathrm{g}$ of mussel shells, $457 \mathrm{~g}$ of snails, 43 macrobotanical samples, 79 historic artifacts, and 15 bones were recovered from these 
This page has been

redacted because it

contains restricted

information. 
excavations. Cross supervised the lab processing and cataloging until his departure from CAR in May 1996. Bradley J. Vierra assumed responsibility as project director in January 1997, supervising the artifact and samples analyses and the completion of the site excavation report. All archaeological materials, field notes, photographs, and analysis data are curated at CAR.

\section{Report Organization}

This report presents the results of the data recovery program conducted at site $41 \mathrm{MV} 120$. Chapters $2-5$ provide reviews of current and past environmental setting, previous archaeological work, and current research issues for South Texas and the project area. South Texas is characterized by a gently rolling to flat topography dissected by intermittent streams, and bounded by the Rio Grande along its border with Mexico. It is a hot and dry land which is most commonly referred to as the Brush Country, but was probably a savanna with grasslands and wooded thickets in the past when the site was occupied. Very little paleoenvironmental work has been done in the region, and the archaeological record is also poorly documented. Paleoindian through Late Prehistoric remains have been recorded in Maverick County; however, most of these sites date to the Late Archaic period. Sites situated in riverine settings appear to be characterized by large surface scatters, those in streamside settings contain burned rock middens, and uplands sites represent lithic procurement locations. Site 41MV120 fits this general pattern. That is, it represents a portion of a much larger surface scatter situated in a riverine setting and dating to the Late Archaic period. The research design discusses several research contexts to be addressed by the data recovery program. These consist of studies concerned with past climatic and environmental change, site formation processes, and prehistoric adaptation and subsistence.

Chapters 6-8 present the excavation methods, geomorphological study, and results of the fieldwork. The field excavation strategy was designed to expand on the TxDOT test units which had uncovered buried cultural deposits. This was done in four block excavation areas which would provide contiguous information on the horizontal and vertical distribution of artifacts and features. Lee C. Nordt conducted the geomorphological study of the site and the local environs. The stratigraphic sequence at $41 \mathrm{MV} 120$ is the result of the shifting position of the Rio Grande channel relative to the site area. Underlying point-bar deposits reflect the presence of the Rio Grande channel in the immediate area of the site ca. 6000-3000 B.P. During the period of site occupation (ca. $2200-1200$ B.P.), the ancient confluence of Elm Creek and the Rio Grande moved about one kilometer to the south, with periodic flooding and burial of site deposits. By about 1000 B.P., the river channel was downcutting and therefore depositing very little sediment across the site. Instead, the surface is characterized by relative stability, with little evidence of human occupation. Excavations at 41MV120 recovered a large amount of cultural material, primarily lithic artifacts and burned rock, with some mussel and snail shells, and bits of charcoal and bone. Only a few relatively intact features were encountered, consisting mainly of isolated clusters of burned sandstone. Overall artifact density decreases from east to west across the site, with the area of highest density being situated adjacent to Elm Creek. Cultural remains were recovered up to $1.2 \mathrm{~m}$ in depth where excavations ceased. The middle and lower levels of the excavations exhibited the highest artifact densities.

The results of the artifact analyses and site structure studies are presented in Chapters 9-16. The lithic assemblage is characterized by core reduction and tool production activities. Prepared cores and large flake blanks were apparently brought to the site from a separate procurement location. Cherts cobbles were obtained from local terrace gravels, and heat treated to increase their knappability. The presence of early-, middle-, and late-stage bifaces attests to the manufacturing of these tools at the site. Various Late Archaic projectile points were identified, including Shumla, Ensor, Marcos, Montell, and Marshall. The points are heavily resharpened, and were discarded after breakage and exhaustion. The analysis indicates that cores, bifaces, and projectile points were presumably removed from the site for use during the remainder of the group's annual rounds.

Burned rock is distributed in varying densities across the site, with only a few intact features identified. These materials are composed of sandstone from local out- 
crops, and cobbles from terrace gravels. The cobbles are made of chert, limestone, rhyolite, quartzite, and other materials. Results of the archaeomagnetic analysis of core samples taken from the bumed rocks indicate that only five of 20 rocks remained in place. Most of these are included within clusters of burned sandstone. It appears that most of the intact features were heated to low temperatures, and the disturbed samples to higher temperatures. Sandstone might have primarily been used for domestic hearths, and the cobbles in small, lined ovens.

Forty-three macrobotanical samples were analyzed by J. Philip Dering. The majority of the charcoal was identified as mesquite. Samples taken from two burned stumps were identified as mesquite and acacia. Robert Howells identified three species of freshwater shellfish in the site collections. These species inhabit both stream and riverine habitats. Most of the individuals are smaller juveniles, indicating they were primarily collected from shallow waters. Only a few shells still retain their outer rings; however, those that do exhibit broad growth rings reflecting that they may have been collected during the warm growing season from spring to fall. Four species of terrestrial snails were identified by Art Metcalf. There are relatively few smaller individuals, and no aquatic species represented. This bias may indicate that snails were collected and consumed by the prehistoric site inhabitants. Only 15 animal bones were recovered during the excavations. The analysis conducted by Barbara A. Meissner revealed that most of these are unidentifiable fragments, with some mammal and frog bones. Anne A. Fox analyzed the historic artifacts, which consist of glass, metal, and ceramic items. They all date to the twentieth century, and are primarily limited to the upper levels of the excavations.

The site structure study conducted by Vierra reviews the geomorphological evidence in respect to the depositional sequence represented at the site, and the possible effects of periodic flooding on site cultural deposits. Analyses of scatterplots and artifact composition by individual levels reveals some of the intricacies in site structure and activity organization. A series of "sediment packages" was identified in the study of the distribution of mean debitage weight by level. These occur in 20-40-cm intervals across the site. These packages appear to relate to changes in alluvial sedimenta- tion rates, and the preservation of multiple occupation levels.

A series of explicit research questions based on the previously discussed research contexts are presented in Chapter 17. These questions are designed to evaluate the research issues raised in Chapter 5. These issues fall under the general research contexts of site formation processes, climate and environment, and subsistence and adaptation. More specifically, the context of site formation processes involves aspects of site geomorphology, paleotopography, chronology, and site occupational history. The climate and environment context reviews the geomorphological and archaeological evidence for past environmental conditions. The subsistence and adaptation context includes issues involving subsistence and seasonality, technology (i.e., thermal features and stone tool technology), site structure, site function, and regional land use. Recommendations for future research are given in the final chapter. Various data sets are provided in the appendixes. 


\section{Chapter 2: Environmental Background}

\section{Bradley J. Vierra}

\section{The South Texas Region}

Site 41MV120 is located in South Texas near Eagle Pass in Maverick County. The geographic region of South Texas covers roughly $80,000 \mathrm{~km}^{2}$, and is bounded on the west by the Lower Pecos region, on the north by the Edwards Plateau, on the east by the Lower Gulf of Mexico coast, and the south by the Rio Grande (Norwine 1995:138). This region can be further divided into the South Texas (or Rio Grande) Plain and the Coastal Plain (Arbingast et al. 1973), or the Mesquite-Chaparral savanna and coastal prairie (Tharp 1944). Other researchers separate the region into the Middle Nueces Zone, upland Brasada, and Rio Bravo (Rio Grande) corridor (McGraw et al. 1987); or the Nueces-Guadalupe Plain and Rio Grande Delta (Black 1989a). Figure 2-1 illustrates the Rio Grande Plain, the Nueces-Guadalupe Plain, and the Brasada/Sand Sheet, with adjacent Coastal Plain and Edwards Plateau.

South Texas is characterized by a gently rolling to flat topography dissected by intermittent streams. The region is most commonly referred to as the Brush Country due to a heavy cover of brushy vegetation. It is a hot and dry land, with a mixed biota including Neotropical with Sonoran and Austroriparian species (Blair 1950). The following environmental description provides a brief baseline study for understanding the context of huntergatherer land use in the arid South Texas region.

\section{Climate}

South Texas is a transition zone between the arid west and moist east, and the winterless tropical climates to the south and seasonal middle-latitudes to the north. Several features characterize the climate of the region: 1) a limited amount of available moisture, declining from east to west; 2) extreme inter-annual rainfall variability; and 3) high temperatures and rates of evapotranspiration (Norwine 1995).

The mean annual temperature for South Texas ranges from $66^{\circ}-73^{\circ} \mathrm{F}$, with the coolest temperatures in January and the hottest in July. Average temperatures for January range from $38^{\circ}-60^{\circ} \mathrm{F}$ and in July from $82^{\circ}-$ $86^{\circ} \mathrm{F}$. Roughly one-third to one-half of the year exhibits "hot days," with temperatures above $90^{\circ} \mathrm{F}$. The average number of freezing days is only 10 for the region (Norwine 1995). The weather station in Eagle Pass has a 40-year climatic record from 1939 to 1980 (Office of State Climatology 1987:339-340). The recorded high is $115^{\circ} \mathrm{F}$ and the low is $10^{\circ} \mathrm{F}$. The area exhibits a 285-day growing season, with frost- free days running from February 21 to December 3. The length of the growing season decreases from south to north with increasing seasonality and cooler temperatures.

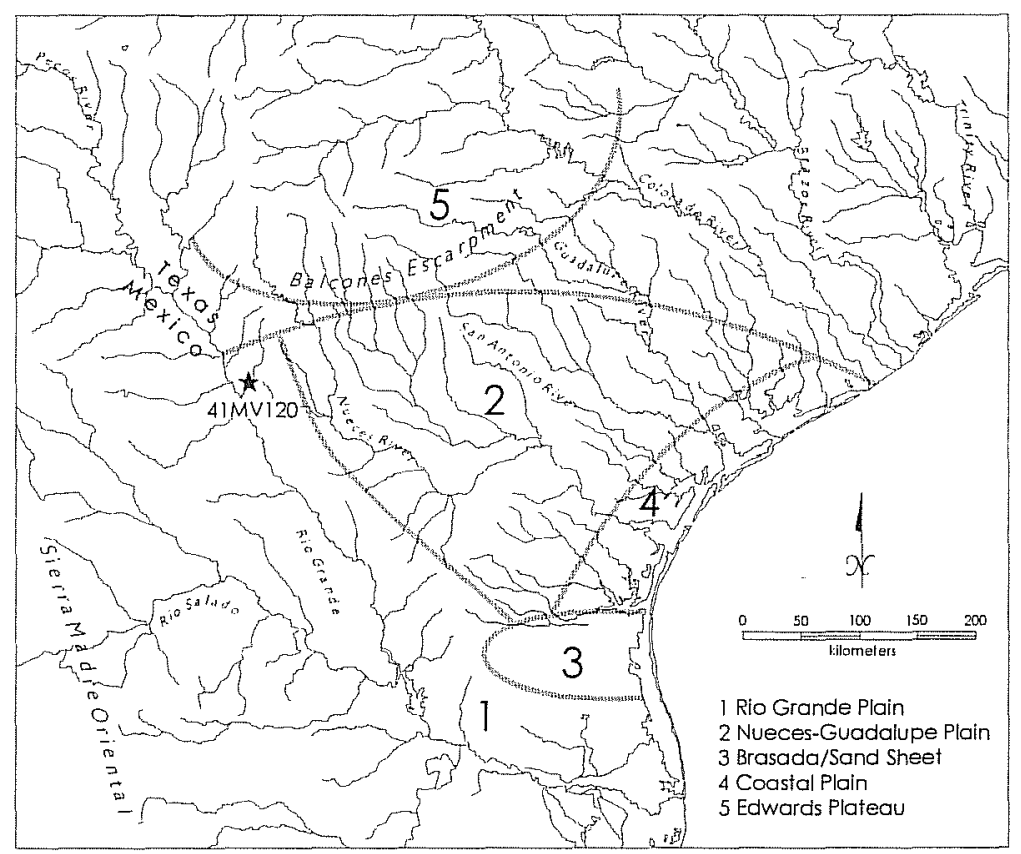

Figure 2-1. Biogeographical regions of Texas. 
The region is characterized by high inter-annual rainfall variability, with greater variation in the west. Norwine (1995:142-143) reports that the coefficients of variations (CV) average 30 percent in the east and 36 percent in the west. These CVs are only surpassed by rainfall patterns in tropical Brazil which exhibits CVs greater than 40 percent. Eagle Pass has a mean annual rainfall of $529 \mathrm{~mm}$ (20.8 inches), vs. $708 \mathrm{~mm}$ (27.9 inches) on the coast at Corpus Christi. The mean annual precipitation pattern at Eagle Pass shows a bimodal distribution of rainfall with peaks in May (810 $\mathrm{mm} ; 31.9$ inches) and September (730 mm; 28.7 inches). Thunderstorms account for most of this rainfall, and primarily occur from April to October and peak in May. The warm, moist air for these storms is derived from two sources: the Gulf coast carries southeasterly winds, and the Pacific Ocean southwesterly. Both can collide with cool dry continental air from the north, creating thunderstorms (Office of State Climatology 1987:339-340). Due to high evapotranspiration rates, these heavy rain months are the only time of the year when surplus water is produced. Given the extreme variation in annual rainfall, these surpluses are, however, only: produced during wet years.

\section{Hydrology}

The South Texas region is drained by the Nueces River and the Rio Grande, which trend southeast toward the Gulf of Mexico. The Nueces River, with the Frio River as a major tributary, is part of a watershed originating on the Edwards Plateau. Other streams which are part of this drainage system eventually flow into the Nueces River. A few streams west of Eagle Pass drain directly into the Rio Grande or the Pecos River, which runs into the Rio Grande above Del Rio. Smaller intermittent streams seasonally drain toward the Rio Grande from the adjacent upland areas to the west and east of the river; Elm Creek, located adjacent to site 41MV120, is one of these. The Rio Salado takes a southeastern route similar to the Nueces River, but on the Mexican side of the border. It drains various streams which originate in the mountainous areas of northeastern Mexico, and eventually empties into the Rio Grande near Falcon Reservoir.
In addition to the Rio Grande and local intermittent streams, springs in Maverick County provide sources of water (Brune 1981). Few springs are actively flowing in the county today, primarily due to the geological substrate being shales, and the easterly dip of the rock formation which carries underground water away from the area. In contrast, these features have produced a series of springs on the Mexican side of the border. The local Maverick County springs are found in sand and gravel terraces along the Rio Grande. Brune (1981:306-307) identifies five springs in the countyFrenchman Springs, Wipff Springs, Rosita Springs, Indio Springs, and Ojo Encinal - all but one of which are situated adjacent to the Rio Grande. More springs were undoubtedly present in the past, but have since dried up due to irrigation and overgrazing. All five springs were visited by Brune, who states that "many metates, manos and projectile points" were associated with several of them (Brune 1981:307). This indicates that springs were an important source of water for the prehistoric inhabitants of the area, and that they were repeatedly used as temporary campsites. Spring-fed pools or streams provide clean sources of water, in contrast to river water which can be turbid and may contain clay, silt particles, and debris.

Limited amounts of surface water may be present during wet years in playas or depressions in bedrock outcrops (tinajas), providing a temporary and seasonal water supply. These waters are conditioned by annual rainfall patterns, local thunderstorms, and runoff conditions.

\section{Geology}

Most of Maverick County is covered by two Upper Cretaceous geologic formations: the Escondido Formation and the Olmos Formation (Barnes 1976). The former contains clay, sandstone, siltstone, and limestone ranging from $60-270 \mathrm{~m}$ in thickness. The upper portion of the deposit is dominated by siltstones and limestones; whereas, the lower section contains mostly mudstones and sandstone. The Olmos Formation consists of clay, sandstone, and coal, with some silicified wood ranging from $120-150 \mathrm{~m}$ in thickness. Quaternary fluvatile terrace gravel deposits are also present along the Rio Grande (Barnes 1976). Field inspections by CAR indicate that 
the gravels consist mostly of chert, with some rhyolite, limestone, basalt, chalcedony, quartzite, volcanic breccia, sandstone, and silicified wood (see Chapter 9). Uvalde gravels are also present in a north-south trending band in the western section of the county. These lag gravels occur in the soils on upland interfluves which are underlain by the Escondido Formation. They typically contain chert, quartz, quartzite, limestone, and silicified wood. These gravels do not have a local origin, but probably originated through ancient alluvial processes across eastern New Mexico to central and southern Texas (Byrd 1971). CAR's field inspections of lag gravels along Highway 57 east of Eagle Pass indicate that they are primarily composed of chert, with less quartzite, basalt, limestone, silicified wood, chalcedony, andesite, and volcanic breccia (see Chapter 9). These all appear to have been derived from west, central, or south Texas sources.

\section{Soills}

The soils of the Rio Grande Plain in the area of Maverick County vary in respect to context. The uplands are generally characterized by deep sandy clay loams (Copita-Pryor-Dant association), deep silty clay loams (Elindio-Montell association), and deep clays (CatarinaMaverick association). Shallow gravelly loams and loams (Jimenez-Olmos-Zapata association) are present in terrace settings. In the floodplains of ephemeral drainages, the soils are characterized by deep sandy loams and loams (Brundage-Dant association); whereas, the Rio Grande valley floodplain contains deep sandy loams and silty clay loams (Lagloria-Laredo association) (Stevens and Arriaga 1977).

Site 41MV120 is specifically located on silty clay loam soils (Laredo series) overlying Rio Grande terraces. A representative profile is characterized by an A horizon which is a dark grayish brown silty clay loam about $45 \mathrm{~cm}$ thick; a B horizon of about $45 \mathrm{~cm}$ of silty clay loam; and an underlying $\mathrm{C}$ horizon which is a very pale brown silt loam with some threads and concretions of calcium carbonate. Inclusions of fine quartz, limestone, sandstone, igneous pebbles, snail fragments, and mica flakes are present in the soil profile (Stevens and Arriaga 1977:14-15).

\section{Flora}

The regional flora of South Texas has been classified as being part of the Tamaulipan biotic province extending out from northeast Mexico. This is the only part of Texas where some vegetation exhibits growth throughout the year (Blair 1950). Thorny brush is the dominant vegetation today, but this is a relatively recent occurrence, with a mix of woody and grassland species providing a savanna environment during prehistoric times (Archer 1995; Black 1989b; Hester 1980, 1995; Inglis 1964).

On sandy soils, the brush includes mesquite with mixed grasses. In contrast, clay soils support mesquite (Proposis juliflora), various species of Acacia, and mimosa, granjeno or desert hackberry (Celtis pallida), lignum vitae (Porliera angustifolia), cenizo (Leucophyllum texanum), white brush (Aloysia texana), prickly pear (Opuntia lindheeimeri), tasajillo (Opuntia leptocaulis), and species of Condalia and Castela (Blair 1950).

Vora's (1990a) study at the Santa Ana National Wildlife Refuge in Hildalgo County provides an excellent examination of Rio Grande plant ecology. Although the refuge is located some distance downriver from the Eagle Pass area, it provides one of the few detailed studies of Rio Grande flora. Vora identified several different plant communities in this area of the lower valley: 1) the Rio Grande riparian/river bank community with willow (Salix sp.), sugarberry (Celtis laevigata), cedar elm (Ulmus crassifolia), and Mexican ash (Fraxinums berlandieriana);2) the aquatic community with pondweeds (Potamogeton $\mathrm{sp}$.), and California bulrush (Scripus californicus); 3) the seasonally flooded community with huisache (Acacia smallii), sugarberry, and retama (Parkinsonia aculeata); 4) the floodplain bottomland community with cedar elm, tepeguaje (Leucaena pulverulenta), western soapberry (Sapindus drummondii), sugarberry, honey mesquite (Prosopis glandulosa), anacua (Ehretia anacua), persimmon (Diospyros texana), and granjeno; 5) the floodplain chaparral community with Texas ebony (Pithecellobium flexicaule), cedar elm, and honey mesquite; and 6) the upland brush community with mimosa (Mimosa malacophylla), blackbrush 
(Acacia rigidula), allthorn (Castela texana), cenizo, and granjeno.

Vora (1990b) also provides a rare view of seasonal patterns in plant growth and reproduction within the refuge. Rainfall and soil moisture are critical factors in annual plant growth. Three active periods of growth occur: first in February, then in late May to June, and finally from late September to November. Green fruits are already available by early April, with the greatest amount of edible fruits being present during the summer; however, some warm weather plants have two growing seasons, with a second crop of fruit becoming available during the late fall. Specifically in South Texas, green fruits are first observed on plants like the guayacan, Texas huisache, and Texas paloverde in April. By May fruits are visible on anacua, Mexican ash, retama, honey mesquite, brasil, Texas huisache, tepeguaje, Texas sugarberry, lotebush, granjeno, Texas persimmon, and colima. In June the Texas sabal palms begin to produce fruit, later in the month the fruits of the Texas huisache, retama, Texas prickly pear, anacua, brasil, coyotillo, lotebush, and coral bean are beginning to ripen. Then in July and August, most of the remaining fruits of the Texas sugarberry, guayacan, granjeno, Texas ebony, colima, blackbrush, cenizo, honey mesquite, Texas persimmon, black mimosa, and Texas paloverde are ripe. September rains initiate a period of new plant growth, and the cedar elm drops its fruit in late September/early October. By November a second crop of fruit has developed on the Texas persimmon, western soapberry, retama, brasil, Texas prickly pear, and tasajillo. Some legumes like Texas ebony and huisachillo continue to hold their pods through autumn and winter.

\section{Fauna}

The South Texas Plains exhibit some of the greatest mammalian species diversity in the state; other areas with high diversity include the Trans-Pecos, the Edwards Plateau, and the Rolling Plains. In contrast, the eastern areas of the state exhibit lower species diversity (Davis and Schimdler 1994). Sixty-one species of mammals, 36 snakes, 19 lizards, and several species of turtles, salamanders, and frogs are present in the region (Blair 1950).
The majority of the species are small-sized mammals including two species of cottontail (Sylvilagus), blacktailed jackrabbit (Lepus californicus), three species of ground squirrel (Spermophilus), the black-tailed prairie dog (Cynomys ludovicianus), five species of pocket gopher (Geomys), 10 species of mice (Perognathus, Chaeotodipus, Peromyscus, Baiomys, and Onychomys), two species of kangaroo rat (Dipodomys), porcupine (Erethizon dorsatum), beaver (Castor canadensis), ringtail (Bassariscus astutu), raccoon (Procyon lotor), white-nosed coati (Nasua narica), and three species of skunk (Mephitus). The few mediumsized mammals include the collared peccary (Tayassu tajacu), white-tailed deer (Odocoileus virginianus), and pronghorn (Antilocarpa americana), with numerous species of carnivores. The latter includes long-tailed weasel (Mustela frenata), gray fox (Urocyon cinereoargenteus), badger (Taxidea taxus), bobcat (Lynx mufus), ocelot (Felis pardalis), margay (Felis wiedii), coyote (Canis latrans), mountain lion (Felis concolor), and jaguarundi (Felis yagouaroundi) (Davis and Schimdler 1994).

Approximately 50 species of fish have been identified in the Lower Rio Grande including carp (Cyprinus), catfish (Ictalurus), minnows (Notropis), shiner (Notropis), shad (Alosa), suckers (Castostomus), the Rio Grande darter (Etheostoma grahami), and the Rio Grande perch (Cichlasoma cyanoguttatum) (Lee et al. 1980). Species abundance and diversity has probably declined during historic times due to flood-control measures, lowering of water tables, and pollution. Hubbs et al. (1991) note that about half of the Rio Grande species west of the Pecos River in the Chihuahua Desert region are extinct or endangered. Besides fish, 11 species of mussels have been identified in the Rio Grande: paper pondshell (Anodonta imbecillis), Tampico pearlymussel (Crytonnaias tampicoensis), yellow sandshell (Lampsilis teres), washboard (Megalonaisus nervosa), Texas hornshell (Popenaias popei), salina mucket (Potamilus salinasensis), two species of Quadrula, two species of Taxolasma, and Mexican fawnsfoot (Truncilla cognata) (Howells et al. 1996a). Snails are another mollusc present in the region, with eight species of terrestrial snails being represented, including two species of Rabdotus (Cheatum and Fullington 1971, 1973; Fullington and Pratt 1974). 
The Rio Grande valley is a natural flyway for birds, with 138 species being permanent or seasonal residents of the region. Many species are seasonal winter residents (e.g., ducks and doves), while others are summer (e.g., flycatchers), or summer and winter residents (e.g., sparrows) (Rappole and Blacklock 1994). Game species include wild turkey, waterfowl, quail, and dove, with the greatest numbers of species being located in the river valleys or wooded areas along streams (Texas Game, Fish, and Oyster Commission 1945).

\section{Paleoenvironment}

Little information is available concerning the paleoenvironmental conditions of South Texas. This is in part due to poor preservation conditions (e.g., high soil $\mathrm{pH}$ and low organic content), and the lack of environmental features conducive to preservation (e.g., dry caves, peat bogs, or lake deposits) (Bryant and Holloway 1985:60). Although some preliminary work has been done in the Choke Canyon Reservoir area (Hall et al. 1982, 1986), most of the regional paleoenvironmental studies have been conducted in Central Texas (Bousman 1997; Bryant 1977; Collins 1995; Holloway and Bryant 1984; Holloway et al. 1987; Johnson and Goode 1994; Nordt et al. 1994), with some in the Trans-Pecos (Shafer and Bryant 1977), and northeastern Mexico (Bryant and Riskind 1980; Van Davender 1990). In a tree-ring study, Stahle and Cleaveland (1993) were able to identify similarities in changing climatic conditions between northeastern New Mexico, South Texas, and Central Texas.

The general pattern outlined for Central Texas is broadly applicable to South Texas. Figure 2-2 depicts several paleoenvironmental reconstructions for the post- 12,000 B.P. period (Bousman 1997; Johnson 1995), and the regional archeological sequences for Central Texas (Collins 1995; Johnson and Goode 1994), South Texas (Hester 1995), and the Coastal Plain (Black 1989a).

The environment from ca. $12,000-800$ B.P. is characterized by mesic conditions associated with the end of Pleistocene and beginning of the Holocene (Figure 2-2). This is followed by a period of xeric conditions from about $8000-4500$ B.P., during which the region witnessed a moist peak at ca. 6000 B.P., and then an extreme dry and warm low denoted as the Altithermal ca. 5000 B.P. A general trend toward more mesic conditions is seen from about 4500 B.P. to the present, with peaks at ca. 3000 , 2000 , and recent. Holloway's (1986) study of charcoal samples from the Choke Canyon Reservoir sites indicated a stable environment for the past 6,000 years. This was based on the continual presence of several species from two habitats which were exploited for fuel wood. One of these habitats contained Acacia and Proposis (mesquite), and the other was a riparian setting with hickory, willow, and persimmon. This indicates that mesquite was already present in the area during prehistoric times and then later expanded out of the valleys into upland areas during historic times (Hester 1995).

Steele and Assad Hunter's (1986) faunal analysis identified the presence of species characteristic of the Tamaulipan Biotic Province on sites dating from Late Archaic to Late Prehistoric times (ca. 2400-300 B.P.); however, this fauna was more diverse than today, possibly indicating milder summers and winters. Hulbert's (1984) study of lagomorphs from central Texas sites identified three major period of climatic change during the Holocene: $9000-5000$ B.P., more mesic than today; 5000-3000 B.P., more xeric than today; and 3000-400 B.P., a climate similar to today's.

Robinson's (1982) study of phytoliths from the Choke Canyon Reservoir sites provides a more detailed paleoenvironmental reconstruction for the South Texas region. Based on his analysis of samples from several archeological sites, Robinson was able to define a longterm sequence of climatic change from 5300-1000 B.P. This sequence was generally characterized by xeric conditions, separated by two major mesic periods. The first mesic interval occurs from about $5330-4300$ B.P., and the second from ca. 3200-2500 B.P. This corresponds with the longer sequence defined in his earlier study of sites in Goliad County (Robinson 1979).

The phytoliths from trees and palms show a marked depression in their presence at ca. 5500 B.P. (Altithermal), bounded by peaks at about 7500 B.P. and from 2500 B.P. (Robinson 1979). In contrast, the tall grass phytoliths indicate the presence mesic intervals at about 5500 B.P., and 2500 B.P. to the present. These latter patterns are evident in the Choke Canyon study. 


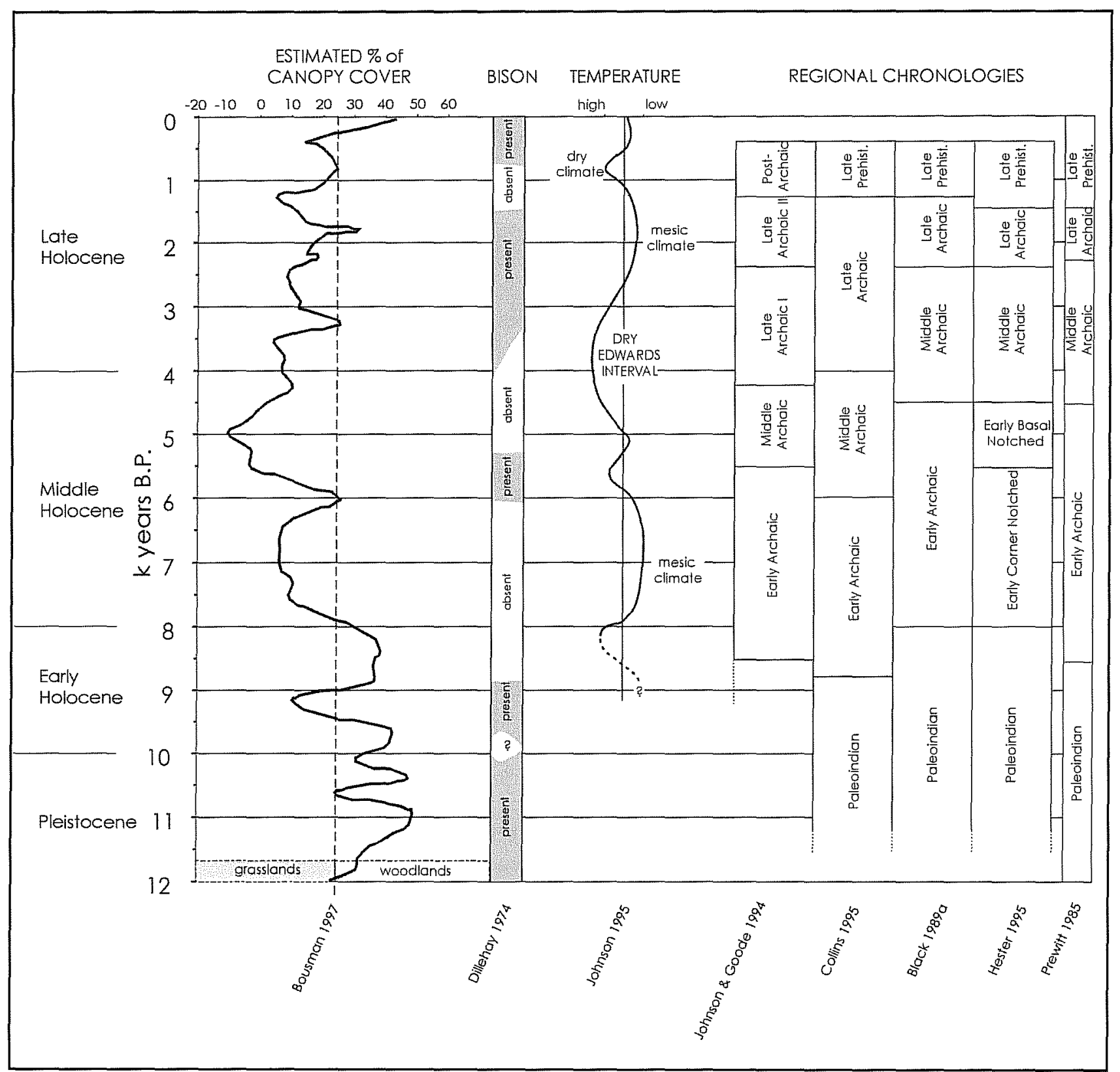

Figure 2-2. Paleoenvironmental and regional chronology for South and Central Texas.

\section{Summary}

The South Texas environment is characterized by the transition from winterless tropical climates in the south, to seasonal middle latitudes to in north. As such, the region is sensitive to changes in climate. We might therefore expect the northward expansion of species during times of decreased effective moisture and warmer tem- peratures, and the southward expansion of species during periods of increased effective moisture and cooler temperatures. These changes may have had drastic effects on regional resource structure and the land-use strategies implemented by the prehistoric inhabitants of the region. 


\section{Chapter 3: Archaeological and Ethnohistorical Background}

\section{Barbara A. Meissner and Bradley J. Vierra}

The archaeological and ethnohistorical background presented here is a general summary of what little systematic information is available about the prehistory and protohistory of South Texas. It should be noted, however, that this summary is based largely on data from the Central Texas region, northeast of Maverick County. Too little work has been done in the region in and around Maverick County to produce a well-defined culture history of the area based on local data (Black 1989a:48). The use of a culture history for the Rio Grande Plains that was originally developed in Central Texas has been considered acceptable in the past because of the similarity of many artifact assemblages, especially the projectile point forms, over much of both Central and South Texas (Black 1989b:48). Although Hester (1976:5) pointed out the need for a better understanding of regional variation in South Texas over 20 years ago, it is clear that this objective has not yet been reached. Recently, Hester (1995:433) stated, "the characteristics of the South Texas archaeological record, and the comparative lack of intensive excavations, all contribute to a chronology that remains poorly known."

The "characteristics" of South Texas sites which contribute to the problem include the fact that most sites are open campsites, often with completely superficial or very shallow artifact-bearing zones, which were either deposited on soils stable over thousands of years or are the result of serious erosion and deflation (Hester 1995:429). Many of these sites are "occupation zones," that is, long, narrow stretches along creek or river banks with a thin scatter of artifacts showing a wide variety of temporal diagnostics in a confusing horizontal array. While the formation of such zones is, in itself, a distinctive regional trait, the analysis of material from such sites is difficult (Hester 1995:430). The rarity of buried, undisturbed, stratified sites in the region has severely limited the kind of research necessary used to construct a regional chronology. Thus, the general chronology provided below is in serious need of confirmation or modification by continuing archaeological work.

\section{A Generalized Culture History for South Texas}

The chronological sequence for South Texas discussed here (see Figure 2-2) is based mainly on Black (1989a, 1989c), Collins (1995), Hester (1995), and Turpin (1995). Following Black (1989c:25), the term "interval" is used to avoid confusion with more formally defined temporal and cultural designations such as phase, aspect, or stage. All interval dates should be considered estimates.

\section{Paleoindian Interval (12,000-11,000 B.P. to 8000 B.P.)}

The early Paleoindian period is not well understood in South Texas. Much of what is known has been extrapolated from Central Texas and the Southern Plains (Black 1989a:48). An early Paleoindian presence in South Texas is represented almost entirely by surface finds of Clovis and Folsom points (Hester 1995:433434). Few recorded buried sites in the region contain unmixed evidence of Pleistocene inhabitants.

A recent examination of pollen evidence suggests that a severe dry period occurred in Central Texas between 12,500 and 12,000 B.P. (Bousman 1997). Isotopic evidence suggests this event also occurred in South Texas (Bousman 1992). Afterward the environment was more mesic, although considerable variability was seen during the next 3,000 years. At about 9000 B.P. was another very xeric period, followed by about 1,500 years of relatively mesic conditions. 
Little is known about subsistence during this period. The protected environment of the dry caves of the Trans Pecos has yielded some information about which animals were hunted. Burned and butchered Pleistocene species, including horse, camel, elephants, and bison, have been found with radiocarbon dates prior to 11,000 at Bonfire Shelter (Turpin 1995:543). The association of Clovis and Folsom points with some now-extinct megafauna species in other parts of North America has led to the belief that early Paleoindians were focused largely on hunting these large animals. Both Hester (1995:435) and Collins (1995:381), however, note that exploited food resources were actually more diverse, including not only the large Pleistocene herbivores but also smaller mammals, turtles, tortoises, alligators, and presumably numerous plant materials.

The extinction of many Pleistocene species of large mammals roughly 10,000 years ago coincided with the beginning of the later part of the Paleoindian interval. The common projectile points from this time are Golondrina, St. Mary's Hall, Scottsbluff, and Angostura (Hester 1995:435). Often associated with Paleoindian points are finely flaked end scrapers made on blades, and bifacial Clear Fork tools (Black 1989c). The levels of Hinds Cave (41VV456), in Val Verde County, which date to the latter part of the Paleoindian interval show a wide range of exploited species (Lord 1984:240). Twenty-nine taxa were identified, of which 21 were mammals, 4 were birds, 3 were reptiles, and 1 was fish. Of the identified mammal specimens, 12 were rats and mice, 7 were cottontail rabbits, and only one was deer. It should be noted that the vast majority of the rat and mice taxa do not occur naturally in the caves or rockshelters of the region. The excavation of a Golondrina component of Baker Cave in Val Verde County supports this model of diverse resource exploitation (Hester 1995).

The transition from the Paleoindian to the Archaic is poorly understood (Black 1989a:49; McKinney 1981). The shift from lanceolate to stemmed points at the end of the Paleoindian is clear, but the causes for this shift in technology are not. Another characteristic of the Archaic, as opposed to the Paleoindian interval, is the increasing regionalization of tool types, especially projectile points. While Clovis and Folsom points can be found over much of North America, the later Paleoindian points are less widespread in distribution. With the Early Archaic, the trend toward more regional distribution of tool types becomes clear.

\section{Early Archaic Interval (8000 B.P. to 4500 B.P.)}

Hester (1995:436) defines two widespread "horizons" for the Rio Grande Plains during the Early Archaic interval: the Early Corner Notched (8000-5500 B.P.) and the Early Basal Notched (5500-5000 B.P.). He believes that the distinctive Guadalupe biface may be associated with the former. The early corner-notched points include Uvalde, Martindale, and Baker. The early basal notched points include Bell and Andice.

The environment of Central Texas seems to have begun a long period of very dry conditions from about 7500 4500 B.P. The exceptions are a marked low at 5000 B.P. (Altithermal), and a brief respite around 6000 B.P. (Bousman 1997). Almost no direct evidence of Early Archaic subsistence is known in the vicinity of Maverick County. This is largely due to the paucity of excavated sites, and the poor preservation of faunal and plant remains on sites within the Rio Grande Plains region (Hester 1995:439). However, the faunal analysis from Early Archaic levels of Hinds Cave in Val Verde County indicates a wide variety of animals was being exploited (Lord 1984:246-247). Thirty-one Mammalia taxa were recovered, as well as 7 of birds, 2 of turtle, 1 each of lizards and frogs, and 5 of fish, for a total of 47 identified taxa. Among the mammals, rats and mice were represented by 16 specimens, cottontails and jack rabbits by 11 , and deer by only one.

Dillehay (1974) has shown that bison are largely absent from sites in the southem plains and South Texas during the earlier part of this period; however, Collins points out that bison were present in Central Texas during a mesic peak ca. 6000 B.P., when bison-hunting groups might have moved into the region (Collins 1995:384). Settlement patterns indicate sites are usually found on terraces near water or on the hilly areas overlooking valleys (Hester 1995:439). 


\section{Middle Archaic Interval (4500 B.P. to 2500 B.P.)}

There is a general consensus that the Middle Archaic saw an increase in population in Central and South Texas (Black 1989a:51, 1989c:28; Prewitt 1981:73). In South Texas this interval is characterized by the presence of Tortugas points, along with examples of the more widely used Pedernales, Langtry, and Bulverde points (Black 1989a:49; Hester 1995:438). Manos and metates are very common from this period, into the Late Archaic. In addition, distally beveled tools, tubular pipes, and triangular bifaces (which persist throughout the Archaic) are common (Black 1989c; Hester 1995).

A recent analysis of pollen data (Bousman 1997) suggests that the Middle Archaic in Central Texas became relatively more mesic from 4500 to about 2500 B.P., with a peak at 3500 B.P. Conditions began to dry out again ca. 2500 B.P., although this xeric phase was relatively mild. Robinson's (1979) study of phytoliths from Goliad County sites indicates an increase in arboreal species during this time.

Data from Choke Canyon, to the east of Maverick County, suggest a distinct subsistence strategy based on the intensive exploitation of vegetal resources, including acorns and mesquite beans (Hall et al. 1986:401). Although not as numerous or as large as those found in Central Texas, accumulations of burned rock are also found in the region, containing artifacts datable to this interval. A definite shift in utilization of vertebrates during the Middle Archaic is seen at Hinds Cave (Lord 1984:214-215). These levels contained 32 identified taxa of vertebrates, of which 18 were mammals, 4 were reptiles, and 7 were fish. Of the identified mammal specimens, 7 were rats and mice, 6 were rabbits and hares, and 3 were deer. This increase in deer and fish presumably reflects the importance of these species to the diet.

During the Middle Archaic, open campsites tend to occur on knolls and bluffs along stream channels and tributary settings (Black 1989a:49). In the later Middle Archaic period, sites are also commonly located on floodplains, low terraces, and natural levees (Hester 1995). The first large cemeteries appear during the later part of the Middle Archaic. The Loma Sandia site, for example, contained 205 burials, many of which had clusters of grave goods (Taylor and Highley 1995). Other burial sites, including unpublished data from Falcon Reservoir, also have grave goods (Hester 1995:440). Researchers suggest these cemeteries reflect a population increase and/or territorial constrictions (Black 1989c; Hester 1995; Story 1985).

\section{Late Archaic Interval (ca. 2500 B.P. to 1150 B.P.)}

The Late Archaic in South Texas is characterized by the presence of Shumla, Ensor, Montell, and Marcos points, and Olmos bifaces (Hester 1995:441). In and near Webb County, Desmuke, Matamoros, and Catan points are found. Large (15-20 cm long), thin, triangular bifaces are another Late Archaic tool found in the Rio Grande Plains area (Hester 1995:442). Corner-tang bifaces; Nueces scrapers, small distally beveled tools; and Olmos bifaces, small triangular gouge-like tools, are also common in South Texas (Black 1989c; Hester 1995). Bousman (1997) found evidence that most of the Late Archaic in Central Texas was relatively mesic, with a mesic peak at 1700 B.P., and a brief, mild, dry period near the end of the interval.

Subsistence was broadly based, with a wide range of animal bone present in sites, along with large amounts of freshwater mussel shell in some (Hester 1995:442). Manos and grinding slabs are common in South Texas at this time. Burned rock middens are not as prevalent as during the Middle Archaic, but continue in central and western South Texas during the Late Archaic (Goode 1991; Turpin 1995:550).

At Hinds Cave (41VV456), 28 taxa of vertebrates were identified in Late Archaic levels (Lord 1984), of which 15 were mammals, 4 were reptiles, and 6 were fish. Of the identified mammal specimens, 5 were rats and mice, 7 were rabbits and hares, and 2 were deer.

Late Archaic sites are usually located near stream channels. There is a continuation of the large cemeteries seen in the Middle Archaic. The number and variety of 
grave inclusions increase in the later Archaic burials (Black 1989b; Hester 1995).

\section{Late Prehistoric (ca. 1150 B.P. to 350 B.P.)}

At about 1150 B.P., a distinctive shift in artifact assemblages occurred across Central and South Texas: the use of atlatl dart points is replaced by the bow and arrow. This early period of the Late Prehistoric in Central Texas is termed the Austin interval (1150600 B.P.). During this period the first evidence of bonetempered pottery is found in association with expanding-stem arrow points. Edwards, Granbury, and Scallorn arrow points are commonly found in early Late Prehistoric sites; the latter, in particular, can be found over most of the state. Edwards points have been found largely in the Rio Grande Plains, although they are occasionally seen elsewhere (Prewitt 1995:102). The relationship of this point to Scallorn points and other Austin interval arrow points is still to be worked out (Hester 1995:443).

Pollen evidence (Bousman 1997) suggests that most of the Late Prehistoric in Central Texas was considerably more moist than the end of the Late Archaic, with the exception of another, although less intense, dry period at about 400 B.P. Another distinct change in lithic tool assemblages is seen. Arrow point forms shift from expanding-stem types, such as Edwards and Scallorn, to contracting stem types such as Perdiz and Cliffton (Black 1989c). The latter part of the Late Prehistoric in Central and South Texas is termed the Toyah interval. This interval is characterized by Perdiz and Cliffton arrow points (often in association with bison bones or kill sites), beveled bifaces, drills, small scrapers, a flake-blade lithic technology, and bone-tempered ceramics (Prewitt 1981). Tools made from bison bone are also common.

The sharp increase in frequency of bison bone in Toyah sites is distinctive, suggesting that the importance of hunting of large game increased (Dillehay 1974; Huebner 1991a), although small mammals, riverine species, mussels, and land snails continue to be important contributions to the diet (Hester and Hill 1975a; Prewitt 1981). The levels of Hinds Cave which can be attributed to the Late Prehistoric interval contain 27 taxa of vertebrates, of which 16 are mammals, 4 are reptiles, and 5 are fish. There is a distinct difference in the utilization of mammals compared to lower levels. Only 1 of the identified specimens is rats and mice, while 9 are rabbits and hares and 5 are deer.

Turpin (1995:550) believes that the changes evident in the Trans Pecos at the beginning of the Late Prehistoric are the result of the influx of a new ethnic group into the region. She points to the introduction of two new, yet fully developed rock art styles as a major indicator of new peoples in the area. She also notes that open camps with what appear to be pole supports for hide or brush-covered dwellings are dated to the Late Prehistoric (Turpin 1995:552). The adoption of the bow and arrow and the beginnings of a ceramic technology in South Texas could be, as Turpin suggests, the result of an influx of new groups, or it could be a technological change which made its way through many different ethnic groups across Central and South Texas, driven by changing needs. Exactly what forces would have led to this change is a major research question for the region.

\section{The Protohistoric of South Texas}

A discussion of the effects of European contact on the local Native Americans in Maverick County is beyond the scope of this report. The interested reader is referred to Campbell $(1975,1979,1983,1988)$, Campbell and Campbell (1981, 1985), Newcomb (1961, 1993), and Salinas (1990). The ethnohistorical evidence provides some information about the indigenous populations residing in South Texas during the early sixteenth through early eighteenth centuries; however, we must be cautious about projecting this information into the past. In the century before the first Spanish settlement, the Native Americans of South and Central Texas had undergone serious disruptions as a result of an influx of groups fleeing the disturbances caused by the Spanish among the natives of Northern Mexico; another influx, from the north, of groups being pushed south by the Apaches; and, perhaps most importantly, by the European diseases that were spreading through the area, often well in advance of the Europeans themselves. These displaced groups were "often fragmented, 
and their populations declined" (Campbell and Campbell 1985:1). Although the ethnohistoric record provides hints of the Native American's successful adaptation to the environment of South Texas, it remains for the archaeologist to provide details.

Campbell and Campbell (1981) provide an excellent review of early-sixteenth-century accounts of Cabeca de Vaca's trek across southern Texas. This information provides a glimpse into the protohistoric life of hunting-and-gathering groups within the region. Twenty-three named groups (or bands) are mentioned within a roughly 300 -mile-long area, including territories adjacent to the coast, along the Guadalupe and Nueces rivers, and near the Rio Grande at modern Falcon Reservoir.

The seasonal transhumance pattern exemplified by groups in the latter two areas provides tentative information on the relationship between resource structure and seasonal mobility on the South Texas Plain. Groups living in the vicinity of the Guadalupe and Nueces rivers followed a pattern of seasonal movement along the river valleys from fall to spring. In the summer they moved approximately 80 to 100 miles south to prickly pear collection areas. Snails were also collected at the summer prickly pear patches. Here they resided for about three months until returning north to their respective river valleys. Pecans were collected in the fall; hunting trips were made to adjacent upland areas in the spring and fall; and winter was a time of scarcity when roots were heavily exploited. Fish were seasonally obtained from residual floodwater pools in April and May, and various small animals, with some deer and occasional bison, were hunted.The annual range of these groups included approximately 5,000 square miles, with population sizes ranging from about 100 to 300 individuals. These populations tended to be dispersed from fall to spring, and aggregated during the summer. It was at these aggregations that mates were obtained and trading occurred. Occasionally conflicts arose over access to specific prickly pear patches. Overall, these hunter-gatherers were quite mobile, carrying portions of their brush structures with them from place to place, and not storing foods for extended periods of time.
The information on groups residing near the Rio Grande is limited to the summer when de Vaca passed through the region. He notes that the area was covered with dense vegetation, and that camps were situated in wooded areas along tributaries to the Rio Grande. Wild foods exploited included the prickly pear, various seeds, and mesquite pods (a resource not exploited by groups to the north).

The remainder of the ethnohistoric information on hunter-gatherers in South Texas is derived from mission records and accounts taken during the seventeenth and eighteenth centuries. The indigenous cultures of the region were extinct by ca. 1800 , having died or been assimilated into Hispanic society. Campbell (1979) provides information on various groups living at three missions near Guerrero, Mexico, about 30 miles downstream from Eagle Pass, Texas. Eighty-eight named groups are mentioned in respect to the missions. Limited information is available on pre-mission territory size and subsistence practices; it is, however, difficult to evaluate the effect of regional displacement and circumscription on this information. Nonetheless, these data describe a general north-south seasonal transhumance pattern for the groups.

The maximum range for all the mentioned groups includes lands ranging from the Rio Salado in Mexico to the south, and the southern periphery of Edwards Plateau on the north. Temporary camps were situated in wooded areas near springs or streams. The groups were highly mobile, exploiting a variety of seasonally available wild foods, including small animals (e.g., rabbits, mice, and lizards), insects, fish, deer, bison, plant roots, maguey, prickly pear, and mesquite. Prickly pear and mesquite were summer foods, whereas roots and maguey were exploited in the winter. Fish were shot with a bow and arrow, or netted from the Rio Grande. When bison are mentioned, it usually states that they were hunted north of the Rio Grande. Pecans were also collected by groups ranging northeast to the Frio and Nueces rivers.

The ethnohistoric record paints a picture of South Texas as a broad region characterized by the presence of summer resource areas on the Rio Grande plains, surrounded by fall resources to the north, northeast, and 
south. Seasonal rounds involved visits to areas with prickly pear or mesquite during the summer, and nuts in the fall. The latter included pecans, but acorns may also have been collected along the escarpment to the north, and pine nuts in the foothills along the Rio Salado to the south or perhaps in relic communities in the Edwards Escarpment canyon lands. Various roots were exploited in the winter, and small animals were an important source of food throughout the year. Groups were highly mobile, and did not store food for any length of time. Residences were often situated in wooded locations near water. 


\section{Chapter 4: Previous Investigations in Maverick County}

\section{Johanna M. Hunziker}

Site forms and archaeological reports of all known prehistoric sites in Maverick County were reviewed to provide a summary from which a general overview of settlement patterns, site functions, and site locations could be established. Although it was not possible to review all site information for the adjacent regions of South Texas, this data should contribute to a better understanding of prehistoric cultural manifestations on a broad scale on the lower Rio Grande Plains as well as the more specific region of western Maverick County.

Previous archaeological work in Maverick County has concentrated on a few large projects in close proximity to the Rio Grande and Eagle Pass. The largest of these projects is the Dos Republicas Coal Mine, located approximately eight kilometers northeast of Eagle Pass (Espey, Huston and Associates 1981; Uecker 1994; Uecker and Warren 1994). Nearly all the sites recorded in this project area are located on terraces or ridges along Elm Creek and its tributaries.

The second largest project was a survey done by J. P. Nunley in 1975 for the Guerrero Gateway project, which included areas of Maverick County along the Rio Grande south of Eagle Pass. Nearly all the sites recorded during this survey are on the second terrace of the Rio Grande or along Cueras Creek, some 20-50 m lower in elevation than much of the Dos Republicas project area. Elevations for each site were not recorded for the Guerrero project, but most of the sites are located below $215 \mathrm{~m}$. The rest of the sites included in the study are within close proximity to the city of Eagle Pass, or north of Eagle Pass along streams and tributaries of the Rio Grande. This presents a somewhat biased sample of sites from a small number of regions along the western side of the county.

The site information used in the following analyses was obtained from 190 of the slightly more than 200 recorded sites in Maverick County. Archaeological survey reports and site forms were reviewed for information concern- ing site size, site type, setting, elevation, and recovered diagnostic artifacts (see Appendix A). The level of detail included in reports and on site forms varied greatly, which made it impossible to include all sites in many of the analyses. Sample size varies depending on which attributes are being examined (e.g., elevation, presence of diagnostic artifacts or features). In each case the number of sites included in any comparison is a relatively small portion of the total number of sites reviewed, and sample size is stated. Information was also limited by the fact that only about 76 of the sites have had any subsurface testing, most information is from surface surveys.

All sites reviewed are open air campsites and lithic procurement/quarry sites. All campsites that were not lithic procurement/quarry sites were classified as lithic scatters. No attempt was made to designate large campsites from temporary campsites, or other possible forms, due to varying detail in the site descriptions.

In Appendix A, two sites numbers appear twice: 41MV71 and 41MV72. These trinomials were assigned to two sites on the Cueras Creek by Nunley (1975a) and again to two mesa top sites just east of Eagle Pass by Brown (1979). This does not affect the following analyses and is mentioned here simply to point out that it is not an error.

\section{Chronology}

Diagnostic artifacts were recorded on 56 of the sites. Forty-four different point types ranging in time from late Paleoindian to Late Prehistoric, in addition to Clearfork and Guadalupe tools, have been identified from the available site information. Table 4-1 summarizes the occurrence of each type of point on a site, not the total number of points recovered. The most commonly occurring types are Ensor and Frio points followed by 
Table 4-1. Diagnostic Artifacts

\begin{tabular}{|l|c|}
\hline Diagnostics & No. of sites \\
\hline Abasolo & 4 \\
\hline Almagre & 4 \\
\hline Angostura & 3 \\
\hline Bell & 2 \\
\hline Bulverde & 3 \\
\hline Carrizo & 1 \\
\hline Castroville & 3 \\
\hline Catan & 2 \\
\hline Clearfork tool & 4 \\
\hline Conejo & 2 \\
\hline Darl & 1 \\
\hline Desmuke & 1 \\
\hline Early Barbed & 1 \\
\hline Edgew ood & 6 \\
\hline Ellis & 1 \\
\hline Ensor & 10 \\
\hline Fairland & 2 \\
\hline Figueroa & 5 \\
\hline Fresno & 1 \\
\hline Frio & 10 \\
\hline Golondrina & 1 \\
\hline Gower & 3 \\
\hline Guadalupe tool & 2 \\
\hline Kinney & 1 \\
\hline La Jita & 1 \\
\hline \hline
\end{tabular}

\begin{tabular}{|l|c|}
\hline \multicolumn{1}{|c|}{ Diagnostics } & No. of sites \\
\hline Langtry & 5 \\
\hline Lerma & 3 \\
\hline Marcos & 8 \\
\hline Marshall & 3 \\
\hline Martindale & 2 \\
\hline Matamoros & 7 \\
\hline Montell & 3 \\
\hline Paisano & 1 \\
\hline Palmillas & 2 \\
\hline Pandale & 5 \\
\hline Pandora & 2 \\
\hline Pedernales & 2 \\
\hline Perdiz & 3 \\
\hline Sabinal & 1 \\
\hline Scallorn & 6 \\
\hline Shumla & 1 \\
\hline Tortugas & 2 \\
\hline Toyah & 1 \\
\hline Triangular & 4 \\
\hline Val Verde & 1 \\
\hline Zavala & 3 \\
\hline arrow/preform & 8 \\
\hline unident. arrow & 3 \\
\hline Total & 150 \\
\hline \hline
\end{tabular}

Marcos, Matamoros, Edgewood, Scallorn, Langtry, Pandale, and Figueroa. Other than Pandale, Langtry, and Scallorn, these points represent the Late Archaic, which is the most common time component identified on recorded sites in Maverick County. The only anomalous feature is the low occurence of Pedernales points (Prewitt 1995). Pedernales points are common in adjacent counties, especially Uvalde County. This apparent lack of Pedernales points may in part be due to the paucity of archaeological work done to date in Maverick County which has been concentrated along the western edge of the county.

Nearly half the prehistoric sites with diagnostic artifacts are single-component sites $(n=27)$. Of these, one is Late Paleoindian, seven are Early Archaic, six are
Middle Archaic, 10 are Late or Transitional Archaic, and three are Late Prehistoric. The majority of the multicomponent sites are Middle Archaic through Late Prehistoric, seven are Late Archaic to Late Prehistoric, six are Middle to Late Archaic, six are Early Archaic through Late Prehistoric, and the remainder date to a variety of combinations of time periods.

\section{Site Distribution}

The sites for which temporal affiliation and elevation were known $(\mathrm{n}=51)$ were broken down by temporal components and then by elevation (Table 4-2). The 51 sites contained 94 different components. The most frequently 
occurring time component was Late Archaic (36 percent), followed by Middle Archaic (23 percent), and then equal numbers of Early Archaic and Late Prehistoric components (19 percent each).

More than half the sites are located at an elevation of $230 \mathrm{~m}$. This is primarily due to sampling bias since many of the sites are situated within the Dos Republicas project area. Nonetheless, if we look at the presence or absence of particular temporal components over the range of elevations, some general trends are evident. Early and Late Archaic sites are present at varying elevations; whereas Middle Archaic sites tend to be located at higher elevations, and Late Archaic sites at lower elevations.

The most interesting pattern is that for the Late Prehistoric components. Here we see a drop in the number of identified Late Prehistoric components as compared to the Late Archaic, with nearly all of the Late Prehistoric components occurring on sites situated at lower elevations in creek side settings (223-237 m). This pattern may not be due simply to project sampling bias.
For example, of the 42 sites recorded by Nunley ( 1975 site forms) at relatively lower elevations on the second terrace of the Rio Grande, none contained any diagnostic artifacts. Nunley (1975:47) simply refers to most of these sites as being Archaic in age; however, he also mentions the lack of Late Prehistoric sites within the project area as possibly being due to the depopulation of the area before protohistoric times.

\section{Temporal Site Density Distributions}

If we look at the number of sites per 1,000 years (Table 4-3), we see a very different pattern than that identified above. This is a site density measurement that is standardized, albeit crudely, by time. In this comparison, I use the time spans given in Chapter 3. The overall average number of sites per 1,000 years is 8.1 and, starting in the Middle Archaic period, the individual stage averages are all above this number. These data suggest that there is not a significant drop in site numbers between the Late Archaic and Late Prehistoric periods as sug-

Table 4-2. Identified Site Components by Elevation

\begin{tabular}{|c|c|c|c|c|c|c||}
\hline Elev. (m) & $\begin{array}{c}\text { Late } \\
\text { Paleo. }\end{array}$ & $\begin{array}{c}\text { Early } \\
\text { Archaic }\end{array}$ & $\begin{array}{c}\text { Middle } \\
\text { Archaic }\end{array}$ & $\begin{array}{c}\text { Late } \\
\text { Archaic }\end{array}$ & $\begin{array}{c}\text { Late } \\
\text { Prehist. }\end{array}$ & Totals \\
\hline 216 & & & & 1 & & 1 \\
\hline 217 & & & & 1 & & 1 \\
\hline 223 & & & & 1 & 1 & 2 \\
\hline 224 & & 1 & & 2 & 1 & 4 \\
\hline 226 & & & & 1 & & 1 \\
\hline 227 & & 1 & & 1 & 1 & 3 \\
\hline 229 & & 1 & & 2 & & 3 \\
\hline 230 & 2 & 8 & 12 & 14 & 12 & 48 \\
\hline 232 & & & 1 & 1 & 1 & 3 \\
\hline 233 & & & 1 & & & 1 \\
\hline 235 & & 1 & & & & 1 \\
\hline 237 & & 1 & & 2 & 1 & 4 \\
\hline 238 & & 1 & 2 & 1 & & 4 \\
\hline 240 & & 1 & 1 & 1 & & 3 \\
\hline 242 & & & 1 & 2 & & 3 \\
\hline 244 & & & 1 & 1 & & 2 \\
\hline 246 & & & 1 & 1 & & 2 \\
\hline 249 & & 1 & & & & 1 \\
\hline 250 & & 2 & 2 & 2 & 1 & 7 \\
\hline Totals & 2 & 18 & 22 & 34 & 18 & 94 \\
\hline
\end{tabular}


gested by the raw number of sites, but there may be a shift in the number of sites. The shifts in the number of sites per 1,000 years can be due to a number of factors (e.g., population shifts, changes in settlement patterns, shifts in occupation length, changes in task group organization, and resource fluctuations).

\section{Site Size}

Information on site size is presented in respect to three general settings: the Rio Grande floodplain and first two terraces; along creek and tributary banks and terraces; and on upland ridges, slopes, and plains. These upland settings are relative to the local geography, and are all below $275 \mathrm{~m}$. Sites can be divided into three zones based on the elevational data presented in Table 4-1. Zone I contains sites located at $235 \mathrm{~m}$ or less. This include sites on the Rio Grande floodplain and its lower terraces, as well as the lower terraces of its tributaries. Zone II contains sites between 235 and $248 \mathrm{~m}$. This includes sites located along higher creek terraces and upland slopes. Lastly, Zone III contains sites located at or above 248 $\mathrm{m}$, which generally occur on ridge tops and upland slopes where lag gravels are exposed.

Average site size for Zone I sites, situated at lower elevations on floodplains and creek terraces, is 54,376.9 $\mathrm{m}^{2}$. Forty of the sites with diagnostic artifacts are Zone I sites, and range in time from the Late Paleoindian through the Late Prehistoric.

The average size of Zone II sites is $6,507.3 \mathrm{~m}^{2}(\mathrm{n}=20)$. Eleven of the sites within this elevation range contain diagnostic artifacts, of which 10 date from the Middle to Late Archaic.

The Zone III sites average $10,667.3 \mathrm{~m}^{2}$. These sites tend to be rather large scatters of lithic debris, some with burned rock and tools representing other activities at the site. Nearly 70 percent of the 27 recorded sites in Zone III were classified as lithic procurement/ quarry sites. Recorded site size is based on the arbitrary designation of site boundaries, when in fact nearly any area with exposed gravels has evidence of procurement activities (Espey, Huston and Associates 1981). These lithic procurement areas tend to be quite large in South Texas, comprising up to 1,500 acres in some locations (608 hectares) (Hester 1995:430). Only five of the Zone III sites contain diagnostic artifacts. These consist of an Early Archaic, a late Paleoindian through Middle Archaic, a Terminal Archaic, an Early Archaic through Late Prehistoric, and an undetermined Archaic site.

The sites in Maverick County surveyed here suggest a settlement pattern similar to Hester's (1976:6, 1995: 430-431) savanna adaptation of South Texas. That is, large base camp sites located on floodplains and paralleling stream courses, with smaller campsites and lithic reduction stations occurring on higher gravel terraces and ridges with surface lag gravel deposits. Unfortunately there is very little information about sites located on the upland plains, due to the lack of surveyed sites on the eastern side of Maverick County. The sites reviewed here are all at relatively lower elevations due to the physiography of the region. Any uplands referred to in the site descriptions are relative to the surrounding region.

Table 4-3. Site Distribution Per 1,000 Years

\begin{tabular}{|c|c|c|c|}
\hline Stage & \# of Sites & Year Span & Sites $/ 1,000$ yrs \\
\hline Late Prehistoric & 18 & 800 & 22.5 \\
\hline Late Archaic & 34 & 1350 & 25.2 \\
\hline Middle Archaic & 22 & 2000 & 11.0 \\
\hline Early Archaic & 18 & 3500 & 5.0 \\
\hline Paleoindian & 2 & 4000 & 0.5 \\
\hline Total & 94 & 11,650 & 8.1 \\
\hline
\end{tabular}




\section{Site Function}

Differences in site function across temporal components or elevation was approached by looking at site type; presence of features, such as burned rock middens, groundstone, freshwater mussel shell, or burials; and diagnostics in respect to elevation. Elevation was not given for all sites, like many of those recorded by Nunley in 1975, but since most of these sites were located on the first or second terrace of the Rio Grande, they were designated as occurring at or below $215 \mathrm{~m}$ based on the few specific elevations given on the site forms. Sites from Nunley's survey that were recorded as ridge or upland settings were excluded.

\section{Burned Rock}

Three burned rock "middens" and nine burned rock concentrations were identified from the 190 reviewed sites. The burned rock concentrations were differentiated from burned rock scatters and disarticulated hearths on the site forms and in reports. Two of the reported burned rock middens occur on sites with Late Archaic to Late Prehistoric components at $230 \mathrm{~m}$ and $237 \mathrm{~m}$ elevations (Table 4-4). The third was recorded at $246 \mathrm{~m}$ on a Middle to Late Archaic site. Indeed, most of the dateable sites with burned rock appear to be Late Archaic in age.
Eight of the sites with burned rock are situated at elevations above $235 \mathrm{~m}$ (Zone II), with four below (Zone I). The presence of the burned rock middens and concentrations at higher elevations suggests specific site function involving intensive resource processing at these Late Archaic sites. However, this pattern may also just reflect the high frequency of Late Archaic sites identified within Maverick County.

\section{Ground Stone}

Ground stone artifacts were recovered from 17 of the sites and are distributed across a wide range of elevations (Table 4-5). Ten of the sites with ground stone present occur on Zone I sites, five on Zone II sites, and two on Zone III sites. Two-thirds of the ground stone located on sites with identified time components occur in Middle to Late Archaic contexts, and the only two single-component sites with ground stone were both Late Archaic. Seven of the sites containing ground stone also had intact hearths, a burned rock concentration, and a burned rock midden. The burned rock concentration and midden were from Late Archaic through Late Prehistoric components. If we assume the presence of ground stone indicates plant processing at the site, it is not surprising that most of the sites with ground stone occur in areas such as creek terraces and floodplains with a greater variety of vegetation.

Table 4-4. Site Components with Burned Rock Middens and Burned Rock Concentrations

\begin{tabular}{|c|c|c|c|c|c|c|c|}
\hline Elev. (m) & unknown & $\begin{array}{c}\text { Early } \\
\text { Archaic }\end{array}$ & $\begin{array}{l}\text { Mid. } \\
\text { Archaic }\end{array}$ & $\begin{array}{l}\text { Mid./Lt. } \\
\text { Archaic }\end{array}$ & $\begin{array}{c}\text { Lt. } \\
\text { Archaic }\end{array}$ & $\begin{array}{l}\text { Lt. Archaic/ } \\
\text { Lt. Prehist. }\end{array}$ & Totals \\
\hline$<215$ & 1 & & & & & & 1 \\
\hline 230 & 1 & & & & & $1^{*}$ & 2 \\
\hline 235 & 1 & & & & & & 1 \\
\hline 237 & & 1 & & & & $1^{*}$ & 2 \\
\hline 240 & & & & 1 & & & 1 \\
\hline 242 & & & & & 1 & & 1 \\
\hline 244 & 1 & & 1 & 1 & & & 3 \\
\hline 246 & & & & $1^{*}$ & & & 1 \\
\hline Totals & 4 & 1 & 1 & 3 & 1 & 2 & 12 \\
\hline
\end{tabular}

Note: The asterisks denote burned rock middens. 


\section{Freshwater Mussel Shell}

The presence of mussel shell was recorded on 42 of the reviewed sites. As expected, mussel shell only occurs on (or was only recorded for) those sites at elevations below $240 \mathrm{~m}$, adjacent to creek drainages and the Rio Grande floodplain (Table 4-6). Nearly 60 percent $(n=25)$ of the sites with mussel shell present occur above $215 \mathrm{~m}$ along creek and tributary terraces. Though mussel shell occurs more frequently on sites located on the first or second terrace of the Rio Grande-14 out of the 31 sites ( 45 percent) located at $215 \mathrm{~m}$ or less as opposed to 23 out of 64 sites ( 35 percent) located between $216 \mathrm{~m}$ and $235 \mathrm{~m}$ - it is clear that freshwater mussels were readily exploited wherever they occurred. Only three sites were identified as having dense concentrations of shell or possible shell middens. Two of these sites are of unknown age on the Rio Grande second terrace, and the third is on a creek terrace at $223 \mathrm{~m}$ and has Early and Late Archaic points.

\section{Burials}

Four of the sites contained burials, but there is no mention of any diagnostic artifacts from these sites. All four of the sites are located on the second terrace of the Rio Grande, the only one with an elevation given was at $183 \mathrm{~m}$ (Nunley 1975b).

\section{Summary}

This review of the current Maverick County site data base identified several preliminary settlement patterns. Information was presented on prehistoric site chronology, distribution, size, and function. The majority of the sites in Maverick County date to the Late Archaic, with diagnostic points from this period being the most common. There are fewer Middle Archaic, Early Archaic, and Late Prehistoric sites, with only two Paleoindian sites being recorded. However, site density estimates, when time controlled, suggest that the greatest densities were during the Late Archaic and Late Prehistoric periods. The prehistoric sites are distributed in riverine, streamside, and upland settings, ranging from 216-250 $\mathrm{m}$ in elevation. Most of the sites are situated at an elevation of $230 \mathrm{~m}$; however, this is due to the sampling bias introduced by the large-scale survey conducted in the Dos Republicas mine. Otherwise, there are a few Early Archaic sites and numerous Late Archaic sites located at lower and higher elevations. In

Table 4-5. Presence of Ground Stone

\begin{tabular}{|c|c|c|c|c|c|c|c|}
\hline $\begin{array}{l}\text { Elev. } \\
(\mathrm{m})\end{array}$ & unknown & $\begin{array}{c}\text { Early-Mid. } \\
\text { Archaic }\end{array}$ & $\begin{array}{l}\text { Early Archaic- } \\
\text { Lt. Prehist. }\end{array}$ & $\begin{array}{l}\text { Mid.-Lt. } \\
\text { Archaic }\end{array}$ & $\begin{array}{l}\text { Lt. } \\
\text { Archaic }\end{array}$ & $\begin{array}{l}\text { Lt. Archaic- } \\
\text { Lt. Prehist. }\end{array}$ & Totals \\
\hline 216 & 1 & & & & & & 1 \\
\hline 217 & 1 & & & & 1 & & 2 \\
\hline 218 & 1 & & & & & & 1 \\
\hline 220 & 1 & & & & & & 1 \\
\hline 229 & 1 & & & & & & 1 \\
\hline 230 & & & 1 & 2 & & & 3 \\
\hline 235 & 1 & & & & & & 1 \\
\hline 237 & & & & & & 1 & 1 \\
\hline 238 & 1 & & & 1 & & & 2 \\
\hline 242 & & & & & 1 & & 1 \\
\hline 243 & & & & 1 & & & 1 \\
\hline 250 & & 1 & & & & & 1 \\
\hline 274 & 1 & & & & & & 1 \\
\hline Totals & 8 & 1 & 1 & 4 & 2 & 1 & 17 \\
\hline
\end{tabular}


Table 4-6. Presence of Mussel Shell

\begin{tabular}{|c|c|c|c|c|c|c|c|c|c|}
\hline $\begin{array}{c}\text { Elev. } \\
(\mathbf{m})\end{array}$ & unknown & $\begin{array}{c}\text { Early } \\
\text { Archaic }\end{array}$ & $\begin{array}{l}\text { Early-Lt. } \\
\text { Archaic }\end{array}$ & $\begin{array}{l}\text { Early A rchaic- } \\
\text { Lt. Prehist. }\end{array}$ & $\begin{array}{l}\text { Mid.- } \\
\text { Lt. Archaic }\end{array}$ & $\begin{array}{l}\text { Lt. } \\
\text { Archaic }\end{array}$ & $\begin{array}{l}\text { Lt. Archaic- } \\
\text { Lt. Prehist. }\end{array}$ & $\begin{array}{l}\text { Lt. } \\
\text { Prehist. }\end{array}$ & Totals \\
\hline$<215$ & $14:=$ & & & & & & & & 14 \\
\hline 183 & 1 & & & & & & & & 1 \\
\hline 198 & 1 & & & & & & & & 1 \\
\hline 207 & 1 & & & & & & & & 1 \\
\hline 216 & & & & & & 1 & & & 1 \\
\hline 217 & 1 & & & & & 1 & & & 2 \\
\hline 220 & 1 & & & & & & & & 1 \\
\hline 222 & 1 & & & & & & & & 1 \\
\hline 223 & 1 & & $1^{*}$ & & & & 1 & & 3 \\
\hline 227 & & & & & & & 1 & & 1 \\
\hline 229 & 1 & & & & & & & & 1 \\
\hline 230 & 2 & 1 & 1 & 2 & 1 & & 1 & 1 & 9 \\
\hline 232 & & & & & & & 1 & & 1 \\
\hline 234 & 1 & & & & & & & & 1 \\
\hline 235 & 2 & & & & & & & & 2 \\
\hline 238 & & & & & 1 & 1 & & & 2 \\
\hline Totals & 27 & 1 & 2 & 2 & 2 & 3 & 4 & 1 & 42 \\
\hline
\end{tabular}

Note: The asterisks denote the mussel shell concentrations. 
contrast, the Middle Archaic sites are primarily restricted to higher elevations, and the Late Prehistoric sites to lower elevations.

Obviously the prehistoric landscape was a dynamic one; however, it is beyond the scope of this chapter to discuss the affects of the changing landscape on differential site preservation and visibility. This topic is addressed by Nordt in Chapter 7 with the results of his geomorphological study of the area. Nordt also presents possible explanations for the observed site distributions.

Site location and size for the Maverick County data conform to Hester's $(1976,1995)$ settlement pattern model for South Texas. The sites on the floodplains and creek terraces are considerably larger than those on upland slopes and ridges. For the Maverick County data there appear to be three site types based on location: the large base camps on floodplains and creek terrace (Zone 1), smaller camps along higher creek and tributary terraces (Zone II), and large lithic procurement sites on ridges and upland slopes (Zone III). Vierra discusses the implications of the 41MV120 data recovery program in respect to Hester's settlement model in Chapter 17.

Some variations in assemblage content may reflect differences in site function. For example, burned rock middens and burned rock concentrations are located along creeks and tributaries at higher elevations (i.e., Zone II). This may reflect the intensified procurement of plant resources in these settings. On the other hand, ground stone artifacts are mostly present on riverine and streamside sites in Zones I and II. In contrast, almost 90 percent of the sites containing mussel shell remains are situated in Zone I. The general site activity pattern within the county is for more mussel shell remains in Zone I, burned rock in Zone II, and lithic procurement in Zone III.

The patterns and interpretations expressed here are based on a limited data set and are only a small part of a much larger picture. These data were assembled to describe the prehistoric occupations in Maverick County and is not meant to stand alone, but to provide a baseline from which to compare site 41MV120. Although the latter fits the general patterns outlined above, the results of the project geomorphological and archaeological investigations will help fill in specific details which are currently lacking in the Maverick County data base. 


\section{Chapter 5: Research Design}

\section{Britt Bousman}

\section{Summary of Preliminary Investigations at $41 \mathrm{MV} 120$}

In April 1995, TxDOT archaeologists conducted a pedestrian survey of $1.77 \mathrm{~km}$ along the right-of-way of FM 1589 near the intersection of US 277 near Eagle Pass, Maverick County (Ward 1995b). A previous survey in the area had already located two large surface sites - 41MV107 and 41MV109 - on the eastern side of Elm Creek (Hubbard and Fox 1990). Christine Ward's survey along FM 1589 recorded a single lithic scatter to the west of Elm Creek (41MV120). The site consisted of a surface scatter of debitage, a core, a biface, and pieces of burned rock distributed to the north of the road. As such, it appeared to represent part of a large palimpsest or "occupation zone" which continued across Elm Creek.

During the survey, TxDOT excavated two backhoe trenches on the eastern and northwestern perimeters of the site. No subsurface cultural deposits were exposed in these trenches. A series of 13 shovel tests was also dug across the entire length of the site (Figure 5-1). Five shovel tests were placed on the south and west sides of the "L" bend in the road. These failed to locate any subsurface cultural remains. Eight shovel tests were then placed to the north of the road, four immediately adjacent to the road and four along the outside edge of the right-of-way. The tests located adjacent to the road also failed to expose any subsurface cultural deposits; however, three of the four tests situated along the periphery of the right-of-way did identify buried cultural remains. These pits were dug to a maximum depth of approximately $50 \mathrm{~cm}$ below the present ground surface, with artifacts being recovered down to $35 \mathrm{~cm}$. This material consisted of debitage and burned rock, with no diagnostic artifacts being present. No map was prepared of these investigations, but further testing was recommended based on the shovel test results.
The additional testing was conducted by TxDOT in May 1995. Seven backhoe trenches, six 1-x-1-m units, and five shovel tests were excavated in the northern and eastern rights-of-way (Figure 5-2; Ward 1995a). Four of the six backhoe trenches (BHT) exposed subsurface cultural remains including debitage, burned rock, charcoal, and mussel shell to a depth of approximately one meter. Most of this material was uncovered in BHTs 1 and 2 located on the eastern section of the site. No cultural remains were unearthed in BHTs 3 and 5 at the western end, and only small amounts of material were present in BHTs 4 and 6 north of the bend of the road. Buried features were exposed in two trenches. Feature 1 consists of a mussel shell lens in BHT 1, and Features 2 and 3 were interpreted as burned pits in BHT 2.

Three 1-x-1-m test units (TUs 1-3) were placed adjacent to BHTs 1 and 2 where Features $1-3$ had been found. TU 4 was located between the two trenches to identify the stratigraphic relationship between the two areas. TU 6 and the shovel tests were located in the western area of the site to define the western limits of the site. TU 5 was an isolated unit placed on the east side of the road, north of the bend, to investigate this portion of the site area. Subsurface cultural remains were identified in all the TUs and shovel tests; however, artifact densities generally declined from east to west. TU 3 contains the highest artifact densities, and TU 2 a medium artifact density. TUs $1,4,5$, and 6 are characterized by low artifact densities, and only a few artifacts were recovered from the shovel tests. A third feature (Feature 4), also interpreted as a pit, was exposed in TU 6, and left in situ for future excavation.

A preliminary assessment of the site geologic context defined two stratigraphic units. The first unit reflects disturbed sediments to a depth of about $40 \mathrm{~cm}$, and the second unit undisturbed sediments with intact archeological materials to approximately $120 \mathrm{~cm}$ below the present surface. 
This page has been

redacted because it

contains restricted

information. 


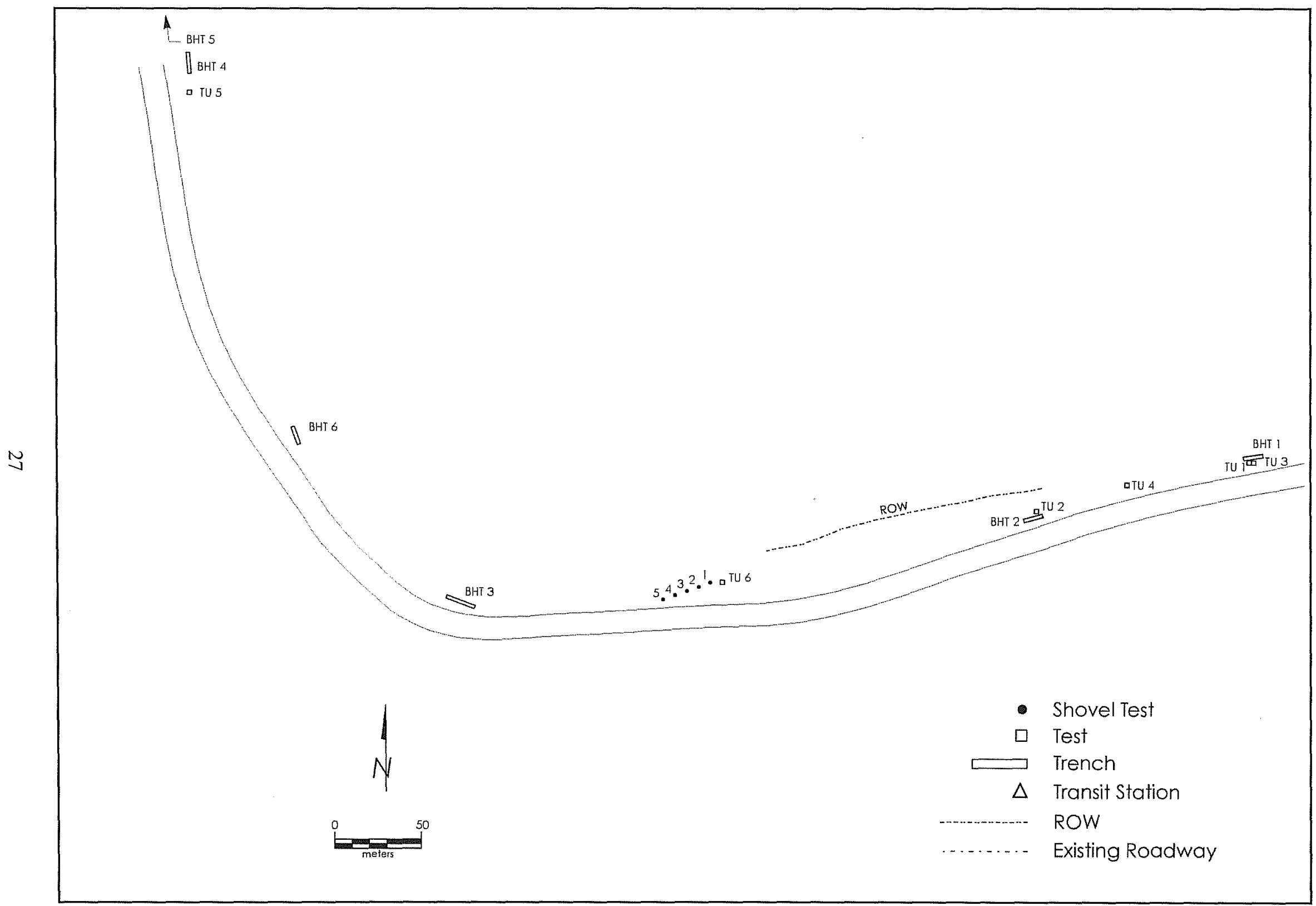

Figure 5-2. 41MV120 test excavation map. 
Table 5-1. Distribution of Lithic Artifacts in Test Units at 41MV120

Shaded cells represent high-density areas.

\begin{tabular}{|c|c|c|c|c|c|c|}
\hline Level & TU 1 & TU 2 & TU 3 & TU 4 & TU 5 & TU 6 \\
\hline 1 & 8 & 0 & 5 & 3 & 1 & 5 \\
\hline 2 & 3 & 5 & 2 & 2 & 1 & 6 \\
\hline 3 & 2 & 4 & 8 & 3 & 1 & 11 \\
\hline 4 & 4 & 19 & 2 & 5 & 2 & 3 \\
\hline 5 & 3 & 20 & 6 & 6 & 7 & 2 \\
\hline 6 & 2 & 20 & 3 & 4 & 12 & \\
\hline 7 & 9 & 32 & 5 & 12 & 12 & \\
\hline 8 & & 31 & 73 & 5 & & \\
\hline 9 & & 13 & 169 & 12 & & \\
\hline 10 & & 13 & 153 & 11 & & \\
\hline 11 & & & 105 & & & \\
\hline 12 & & & 17 & & & \\
\hline
\end{tabular}

The distribution of burned rock at the site is shown in Table 5-2. No well-defined burned rock features (i.e., hearths) were recovered, and the distribution of burned rock is characterized as scattered. Most of the levels lack burned rock; nevertheless, two groups can be defined: one with low density, and the other characterized by a higher density. Also, a general relationship exists between the number of lithic artifacts and the number of burned rock. Figure 5-3 illustrates this relationship and shows that three distribution patterns exist between the number of lithic artifacts and the number of burned rocks in each level. The first pattern is marked by low frequencies of both. The second pattern is defined by relatively low numbers of lithic artifacts and fairly high numbers of burned rock. The third pattern is characterized by high numbers of lithic artifacts and high numbers of burned rock. This latter pattern is only present in TU 3 (Levels 8-11).

Several explanations for these patterns are possible. The low artifact/high burned rock group may represent formalized and well-constructed hearths or some other type of heating features that have been disturbed. Alternatively, it is entirely possible that the approach to cooking by these Late Archaic hunter-gatherers did not include formalized, well-constructed burned rock features, and that informal or unprepared hearths with only a few (if any) burned rocks were used. If this is the case, then the thinly scattered burned rocks could represent a loose cluster of in situ cooking features. The high artifact/ high burned rock pattern might represent some type of midden accumulation with burned rocks and artifacts in

Table 5-2. Distribution of Burned Rock at 41MV120

Shaded cells represent high-density areas.

\begin{tabular}{|c|c|c|c|c|c|c|}
\hline Level & TU 1 & TU 2 & TU 3 & TU 4 & TU 5 & TU 6 \\
\hline 1 & & & & 3 & & 7 \\
\hline 2 & & & & & & 19 \\
\hline 3 & & & & & & 8 \\
\hline 4 & & + & 1 & 3 & & 1 \\
\hline 5 & 2 & 10 & & 2 & 2 & 3 \\
\hline 6 & 1 & 14 & & 1 & 2 & \\
\hline 7 & & 24 & & 3 & 2 & \\
\hline 8 & & 18 & 4 & 4 & & \\
\hline 9 & & 12 & 11 & 2 & & \\
\hline 10 & & 4 & 17 & & & \\
\hline 11 & & & 9. & & & \\
\hline 12 & & & 3 & & & \\
\hline
\end{tabular}




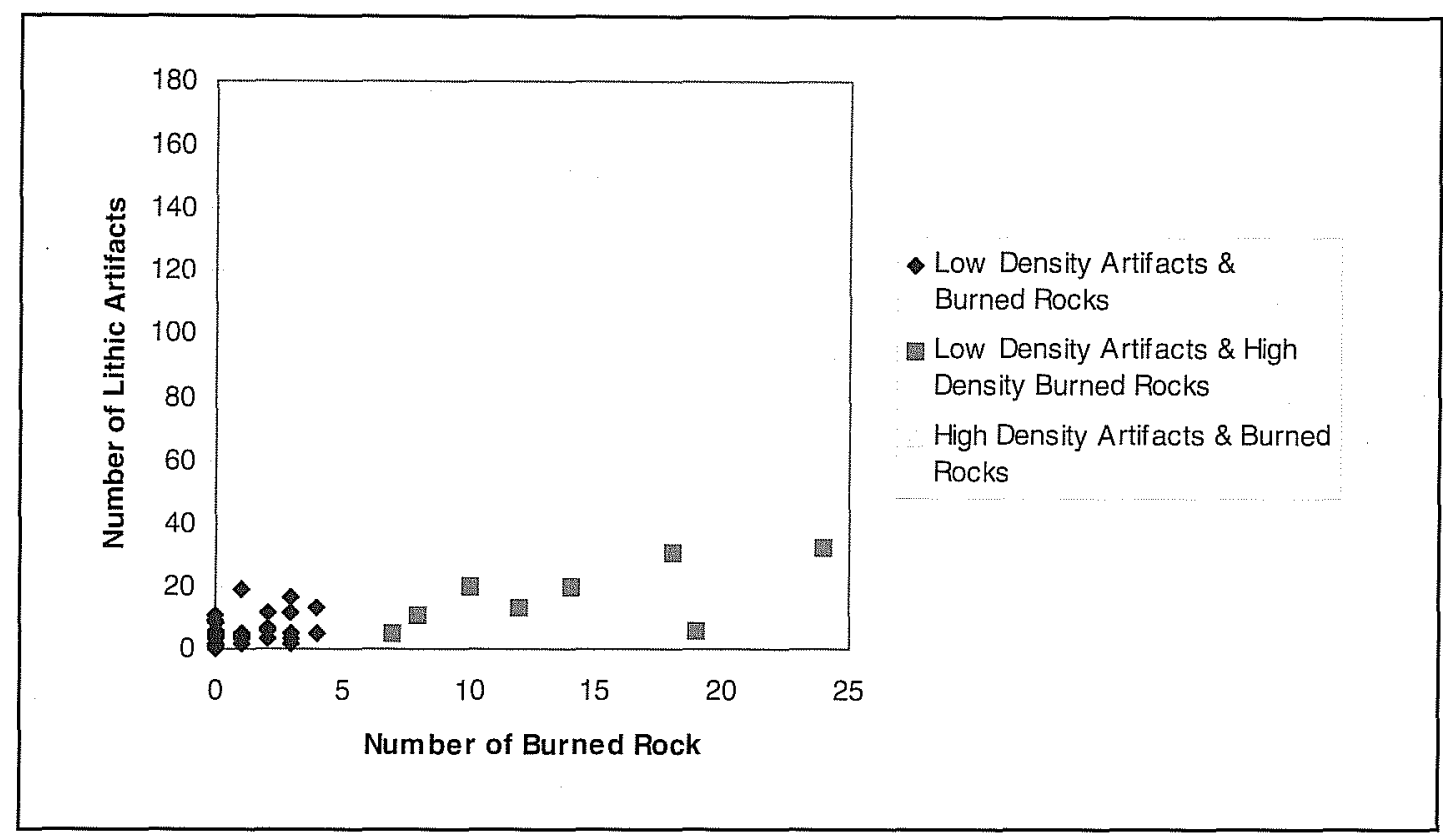

Figure 5-3. Scatterplot of lithic artifacts by burned rock.

a secondary refuse context or perhaps a vertically dispersed concentration of lithic manufacturing debris. The low artifact/low burned rock pattern is representative of many short-term hunter-gatherer occupation sites (Spurling and Hayden 1984).

The structure of the artifact assemblage (Table 5-3) suggests that these three portions of the site were used somewhat differently. Artifacts in the low-density levels contain higher frequencies of modified flakes or pebbles, tested cobbles, and cores, while the high-artifactdensity levels have very high frequencies of lithic debitage although modified flakes/pebbles and cores are present. It is not unreasonable to suggest that the high-density areas are a function of more intensive lithic manufac- turing activities that result in the discard of large numbers of flakes, while the low-density areas have less intense stone tool-manufacturing activities. The higher frequencies of modified flakes and pebbles, tested cobbles, and cores in the low-density portions of the site may reflect a wider range of activities in these areas even though these activities do not produce as much refuse as does stone tool manufacturing.

The distribution of features requires some comment. Feature 1 is a discrete mussel shell lens with charcoal, burned rock, and lithic debris. It measures up to three meters in diameter. Charcoal from this feature has been dated by radiocarbon and the resulting age estimate is 1285-990 years B.P. (tree-ring calibrated). Feature 1

Table 5-3. Percentage of Artifacts in Low- and High-density Zones

\begin{tabular}{|l|c|c|c|c|c|c|}
\cline { 2 - 6 } & $\begin{array}{c}\text { Lithic } \\
\text { Debitage }\end{array}$ & $\begin{array}{c}\text { Modified } \\
\text { Flakes/Pebbles }\end{array}$ & $\begin{array}{c}\text { Tested } \\
\text { Cobbles }\end{array}$ & Cores & $\begin{array}{c}\text { Core } \\
\text { Fragments }\end{array}$ & Total \\
\hline $\begin{array}{l}\text { Low Artifacts } \\
\text { and Low Burned Rocks }\end{array}$ & 90.4 & 3.8 & 3.4 & 1.9 & 0.5 & 208 \\
\hline $\begin{array}{l}\text { Low Artifacts and } \\
\text { High Burned Rocks }\end{array}$ & 96.4 & 2.2 & 0.7 & 0 & 0.7 & 139 \\
\hline $\begin{array}{l}\text { High Artifacts and } \\
\text { High Burned Rocks }\end{array}$ & 98.4 & 1.2 & 0 & 0.4 & 0 & 499 \\
\hline
\end{tabular}


is located in Levels 6-7 of TU 3 and these levels have very few lithic artifacts or burned rock (Table 5-4). Features 2 and 3 were identified as burned pits filled with ash and charcoal in TU2. Burning episodes clearly occurred in place at these features, but it is not obvious whether these features are cultural or natural. It is possible that these could be burned tree stumps. Such natural features are common at the Wilson-Leonard site in central Texas (Collins et al. 1993) Feature 4 is a ring of ash and charcoal found in TU 6, and this might also be a natural burn feature.

41MV120 represents a late Holocene prehistoric site or occupation zone (McGraw 1995) within a terrace of the Rio Grande. Archaeological materials occur in low-and high-density areas or zones, and at least one and perhaps four intact cultural features were recorded. The artifact assemblage lacks formalized stone tools, but lightly modified flakes, cores, tested cobbles; and lithic debitage were present. Assemblage level comparisons between high-and low-density levels indicate that differences exist between these, and they seem to be behaviorally significant.

\section{Research Avenues}

Archaeological sites are evaluated according to Section 106 of the National Historic Preservation Act based upon the concept of significance. In order for a site to be considered significant, it must be greater than 50 years of age, exhibit integrity, and have the potential for contributing knowledge to scientific research. Ideally, fully developed research questions are published, shared, and discussed among the archaeological and preservation communities. Historic contexts provide an objective means by which archaeological sites can be evaluated, facilitate common research goals among diverse organizations, and preclude the need for each project to independently derive every pertinent historic context and research question. Unfortunately, however, only two regional historic contexts have been published by the Texas Historic Commission for eastern Texas (Kenmotsu and Perttula 1993; Mercado-Allinger et al. 1996), although others are in the implementation and planning stages. Potter et al. (1995) have developed two historic contexts for prehistoric sites in the San Antonio area which are clearly applicable to the investigations at Maverick County. The first concerns past environmental change, the second considers prehistoric human life ways or adaptations. Potter et al. (1995) identified two study units for the past environmental change context. The first is paleoclimatic change and its influence on the biotic landscape; the second study unit concerns changes in paleotopography and their influence on site visibility and integrity. The following discussion utilizes and addresses the historic contexts developed by Potter et al. (1995), and elaborates on one additional context.

Table 5-4. Distribution of Features and Radiocarbon Assays in Test Units at 41MV120

\begin{tabular}{|c|c|c|c|c|c|c|}
\hline Level & TU 1 & TU 2 & TU 3 & TU 4 & TU 5 & TU 6 \\
\hline \multicolumn{7}{|l|}{1} \\
\hline \multicolumn{7}{|l|}{2} \\
\hline \multicolumn{7}{|l|}{3} \\
\hline 4 & & $1460 \pm 50$ B.P. & & & & \\
\hline 5 & & Fea. 2 & & & & Fea, 4 \\
\hline 6 & & Fea. 2 & $\begin{array}{c}\text { Fea. } 1 \\
(1285-990 \text { BP })\end{array}$ & & & \\
\hline 7 & Fea. 1 & Fea. 2 & $\begin{array}{l}1240 \pm 60 \text { B.P } \\
\text { B. P., Fea. } 1 \text {. }\end{array}$ & & & \\
\hline 8 & & Fea. 2 & & & & \\
\hline 9 & & & & & & \\
\hline 10 & & Fea 3 & & & & \\
\hline 11 & & & & & & \\
\hline 12 & & & & & & \\
\hline
\end{tabular}




\section{Past Climate and Environmental Change}

Potter et al. (1995) summarize recent studies of Late Pleistocene and Holocene climatic and environmental change in South Texas. At the height of the Late Pleistocene, some 18,000 years ago, ice sheets extended south into the United States and average annual temperatures were at least $5^{\circ} \mathrm{C}\left(9^{\circ} \mathrm{F}\right)$ colder than present. A number of animals were present that are now extinct, and the distribution of plants and animals was very different than those we see today. At the end of the Pleistocene, about 10,000 years ago, large portions of the ice sheets melted, temperatures increased dramatically, a number of animals became extinct, and the distribution of plants and animals began to reorganize along modern patterns. The last 10,000 years, the period after the Pleistocene, is called the Holocene. Around 5000 B.P. in the mid-Holocene, a pronounced dry and perhaps hot interval existed. Some researchers suggest this is a single period called the Altithermal, but the timing, severity, and regional climatic variability are debated. After the mid-Holocene dry interval, modern climatic and environmental patterns were established.

Ethnographic and ethnoarchaeological research indicates that fluctuating climatic regimes alter the flora and fauna exploited by hunters and gatherers for food and materials, and thus directly affect their life ways (Binford 1980; Kelly 1995). Thus, obtaining local data on changing past environments is critical for understanding the patterns recovered in the archaeological record. Paleoenvironmental data contained in alluvial deposits at 41MV120 are directly relevant to further advances for this historic context. Floral and faunal remains can provide information on past environments, and the potential is high at $41 \mathrm{MV} 120$ for recovering sediment samples appropriate for stable carbon isotope analysis. This technique can be used to evaluate biomass shifts in plant communities between $\mathrm{C}_{3}, \mathrm{C}_{4}$, and CAM plants.

\section{Site Formation Processes}

Site formation processes, the second study unit context identified by Potter et al. (1995), encompass the study of how archaeological sites are created, altered, and preserved in geological contexts. Thus this historic context has human behavioral, geological, and biological aspects. Recent investigations (McGraw 1995) offer evidence for suggesting rapid alluviation and burial of prehistoric occupational debris in Holocene terraces of the Rio Grande. This has important implications for understanding the site formation processes as well as the evidence for prehistoric climatic regimes and past environmental patterns. Other studies, outlined below, investigate the manner in which archaeological site preservation is influenced by human processes. The integrity, environmental setting, preservation, and archaeological context of $41 \mathrm{MV} 120$ provide an exciting potential for contributing to our understanding of site formation processes in the South Texas region.

\section{Alluvial Geology}

Potter et al. (1995) suggest that alluvial terraces with intact vertical stratigraphy are particularly informative property types (depositional contexts). Exploration and analysis of sediments from alluvial terraces can contribute to this historic contex and to Past Climatic and Environmental Change. Issues related to alluvial sedimentation rates, changes in landform alteration and its affect on site visibility, and the preservation and detection of intact and presumably shortterm occupations by rapidly aggrading deposits can be evaluated at $41 \mathrm{MV} 120$ with recovered archaeological, biological, and geological data. Even with the limited test excavations, charcoal for radiocarbon dating and botanical analysis have been recovered from four features. Additional geological documentation and radiocarbon dating of the strata composing the terrace will allow better assessment of alluvial sedimentation rates, and the timing and intensity of the human occupations, and is thus critical for understanding site formation processes. Also, a preliminary assessment of the project area suggests that a lower and a higher terrace exist in the immediate area. 


\section{Features and Burned Rock Scatters}

Detailed examination of features and burned rock scatters can yield significant data concerning their formation, use, abandonment, and geological context. As discussed above, two general types of features were recorded at $41 \mathrm{MV} 120$. The first was a lens of freshwater mussel shell approximately three meters in diameter. This is most likely an in situ, single-event placement of mussel shell which provides an avenue for a variety of analytical approaches. It may be important that the mussel shell lens is above the highartifact-density levels in TU 3. The other features (bumed areas with oxidized sediment, ash, and charcoal) are not clearly of human origin, but this can be determined by additional fieldwork, excavation, and analysis. In terms of site formation processes, the human-made and natural features provide an anchor for the geological sequence and the general context of archaeological materials. If all features are human-made, then they can also act as anchors for spatial analysis (see below). If they are natural, then they will provide excellent chronological and paleoenvironmental data which can be linked directly to the archaeological remains and the alluvial depositional system.

The scattered burned rock is a third source of evidence present at this site that may result from human-made features. As discussed above, it is possible that some of the burned rock is from disturbed informal hearths that required little obvious organization and construction. A third possibility is that burned rock and other artifacts were discarded in refuse areas. The site presents a setting where specific questions concerning burned rock feature formation can be addressed in a setting with sparse materials.

One of the most useful techniques used recently for analyzing burned rock features is archaeomagnetic analysis (Cheek et al. 1980; Collins et al. 1990). Limestone and sandstone contain magnetic minerals in great enough concentrations to allow high resolution measurements. The theory behind this method of analysis is that the magnetic pole is constantly moving, and at times ii even flips so that magnetic north is in the southern hemisphere. During most of the Pleistocene and all of the Holocene, magnetic north has meandered slowly and unpredictably around the North Pole. When the sediment that eventually becomes limestone or sandstone is first deposited, most of the magnetic minerals are aligned on the azimuth and dip of the current magnetic pole, and the stone retains this original alignment. If a stone is heated in a hearth or oven, and attains a high enough temperature to relax the original alignment, then the magnetic particles are free to realign on the new magnetic pole. When the rock cools, the particles "freeze" on this new alignment. Until recently these minor wanderings and realignments were used by archaeologists only to date features. By knowing the position (azimuth and dip) of the magnetic pole at different periods of time, the magnetic alignment of a feature can be compared to the known wanderings and estimates made for the age of the heating event.

Recently, and more importantly for the current investigation, archaeomagnetic analysis allows archaeologists to assess the context of a feature, and thus the context of the site and sedimentary deposits. If a burned rock feature was heated to a high temperature, cooled in place, and never disturbed, then the magnetic alignments of all of the bumed rocks should be the same and pointing to the magnetic pole at the time the feature was in use. If, on the other hand, the accumulation of burned rocks is not an intact burned rock feature but rather a trash dump (secondary disposal area) or disturbed feature, then the magnetic alignments of the burned rocks will vary. Some rocks in a single feature may still retain their original orientations, while others could be disturbed resulting in more complex patterns of variation.

Identifying intact features vs.secondary disposal dumps or disturbed features is very important because hunters and gatherers who "camp-out" their entire lives organize their activities around household hearths, while large cooking ovens may or may not be on the periphery and trash middens are usually away from household hearths on the edge of the camp (Bartram et al. 1991; O'Connell 1987; O'Connell et al. 1991; Stevenson 1991; Yellen 1977). Archaeomagnetic assay also allows for a more sophisticated analysis of the burned rock features by incorporating stepped-heating measurement. This indicates how hot the rocks were heated and if the rocks were heated more than once. Thus reuse of individual rocks can sometimes be determined. 
Recent applications have resulted in the dissection of prehistoric hearths and ovens. For example, at the Wilson-Leonard site, the tops of Early Archaic cooking ovens are completely disturbed, but portions of the bottoms are intact (Takac 1995). Also at the WilsonLeonard site, individual scattered burned rocks in Paleoindian levels could be confidently identified as heated and cooled in place, and interpreted as unprepared hearths. At Wurzbach Parkway in San Antonio, intact Middle Archaic hearths were found adjacent to burned rock dumps that represent the refuse created by unpacking a cooking oven (Takac 1995). Thus the accurate identification of a hearth or any other burned rock feature is critically important, especially in respect to the spatial analysis of a site.

On the human side of the equation, Stevenson (1991) summarizes the human behaviors that influence site formation processes involved in determining artifact distributions around hunter-gatherers' hearths. A series of unintentional (trampling and children's play) and intentional (expedient cleaning, systematic refuse disposal) processes result in spatial size-sorting of artifacts. Small artifacts are more likely to escape cleaning, secondary removal, or a variety of unintentional processes. Thus smaller items are discarded and remain in the locations of original use (Binford 1983; O'Connell 1987; Stevenson 1991). Stevenson (1991) effectively argues that the longer a site is occupied, the greater the degree of size sorting. Keeley (1991), using edge wear analysis and refitting of lithic artifacts, demonstrates this process on a prehistoric site where certain artifacts were moved while others remained in the original locus of use.

\section{Prehistoric Adaptations and Subsistence}

The second historic context applicable to the investigations at 41MV120 concerns prehistoric human adaptation and subsistence (Potter et al. 1995). Many hundreds of generations of Native American hunters and gatherers utilized the south Texas landscape over the last 11,000 years. Anthropologists who have studied living hunterand-gatherer societies around the world know that their life ways are intimately related to the types of natural resources they use and the ways in which they exploit these resources. For example, hunters and gatherers who subsist primarily on plant foods and small animals will organize themselves very differently from a group which relies largely on bison hunting. Archaeologists suspect that Native American adaptations to the south Texas region changed over the course of the millennia as the environment and populations shifted, but our substantive knowledge is still minimal (Hester 1995).

The research questions that are part of this historic context involve identifying the food and material resources that were used at specific points in time and, equally important, how they were utilized. This is important for understanding the scale of mobility for hunter-gatherer groups, and the role the site played within a regional settlement system. The data needed to address these questions can be derived from the recovery of archaeological plant and bone samples, detailed examination of the characteristics of burned rocks, life-history analysis of stone tools, and spatial analysis of human-created features and their associated artifacts.

\section{Prehistoric Subsistence}

Two sources of data are currently used to investigate prehistoric subsistence and economic practices: preserved floral and faunal remains. Some charcoal was recovered during the testing of 41MV120, and the recovery of bone was limited to freshwater mussel shell lens (Feature 1). Careful excavation of features and flotation of sediment samples could provide additional animal and plant remains that produce high-resolution evidence of Late Archaic subsistence and economic behaviors. The recovery of identifiable charred plant parts in and around the burned features provides the best direct indicator of plant species utilized for food and campfire fuel. These data have direct implications for the function of the features and season of use. While preservation of charred plant parts in South Texas is generally poor, the testing phase of investigations recovered botanical samples, indicating that the potential was good for further recovery. Second, features provide an anchor for interpreting the spatial patterns of other types of archaeological evidence such as artifacts and faunal or floral remains. The current standard method for recovering charred plant remains is 
flotation. Sediments from features are collected in bulk and gently poured into swirling water; charred plant parts will float and can be skimmed off, dried, and identified.

Faunal remains also are important in the analysis of past human exploitation habits. This includes species and skeletal element identification, analysis of relative dietary importance, meat butchering and transport, seasonality, and paleoenvironmental implications. Recent controlled experiments that varied screen mesh size $(1 / 4$-inch, $1 / 8$-inch and $1 / 16$-inch window screen) demonstrate that $1 / 8$-inch screen results in a significant increase in the recovery of small animal bones (Shaffer 1992). The use of smaller mesh sizes results in a much more reliable picture of the subsistence practices of prehistoric societies.

\section{Technological Organization}

A second dimension that provides information on our knowledge of prehistoric human adaptations is the study of how prehistoric hunters and gatherers manufactured, used, maintained, and discarded their stone tools and other technological devices (including cooking features). In recent years, archaeologists have begun to focus on the organization required to construct technology. Most effort has focused on extractive tools, especially weapons (Bleed 1986; Vierra 1995), but efforts have also focused on maintenance tools (Bousman 1993). Furthermore, while cooking features have not been the primary source of data for developing models of technological organization, the Texas archaeological record suggests that much can be learned from their systematic study and analysis. Of primary concern in this organization-of-technology approach is the cost and benefit of tools, equipment, and facilities.

\section{Capacity for Features}

Recent analysis of intensive plant processing and construction of large cooking features in the northwest United States indicates that 1 ) rocks as heating elements are not necessary for cooking foods for short periods, ca. 24 hours or less; 2) collecting rocks for cooking fea- tures requires a great deal of work; and 3) the thermal properties of rock allows for cooking over long periods of time, 24-48 hours, since rock acts as a heating element (Thoms 1989). Review of capacity planning models indicates that as larger and larger packets of food are cooked together, larger and larger cooking features will be constructed in order to reduce the food-per-unit costs of processing. In other words, small amounts of food can be cooked most efficiently in small cooking features, and large amounts of food, perhaps for larger groups of people, can be cooked most efficiently in large cooking features. Thus the size of a cooking feature is a proxy measure of the amount of food cooked in that feature.

The concept of capacity planning for cooking features is important because if hunters and gatherers are exploiting foods in bulk and storing large quantities of food for lean seasons (a very important dimension according to current hunter-gatherer theory), then the capacity-planning models strongly suggest that evidence should be present in the features. If prehistoric hunter-gatherers are exploiting food daily and in small quantities, then the cooking features should also reflect limited quantities of food preparation and the effort expended on processing foods. The number and size of burned rock features might also provide evidence on hunter-gatherer group size.

\section{Tool Design, Manufacture, Maintenance, Curation, and Discard}

In the last few years archaeologists have discovered that the design, manufacture, and use of artifacts by hunters and gatherers is strongly conditioned by their exploitation patterns. Tools are often designed with a balance of three design goals: expediency, reliability, and maintainability, and their use reflects their continuing roles in the exploitation of resources (Binford 1973; Bleed 1986; Bousman 1993). This research is important because stone tools are not readily altered by decay processes after the tool is discarded, and the abundance of stone tools on many prehistoric sites makes them a ready source of information.

In summary, this research suggests that hunting and gathering groups-collectors (sensu Binford 1980)who depend on exploiting resources in bulk and stor- 
ing large quantities of food, use tools that tend to emphasize reliable and maintainable qualities. The tools used to directly acquire food from the environment (extractive tools) are often complex and specialized, but parts are replaced often if they appear to be at risk of failure. The maintenance tools (tools used to make or maintain tools or equipment) of these groups often are intensively maintained and used until the tools are exhausted. Collectors manufacture and repair their tools during intensive periods, known as gearing-up sessions, dedicated entirely to technological activities.

At the other end of the spectrum, groups that do not exploit food resources in bulk and do not store food for lean seasons-foragers- employ a very different strategy toward their tool manufacture, use, repair, and discard. Their extractive tools are intensively maintained and kept in working order as long as possible, while their maintenance tools are often made on the spot and used only for the immediate task. Thus they favor extractive tools that emphasize maintainability, and maintenance tools that emphasize expediency. Repair and replacement occurs sporadically, when and where needed. This pattern of work is called makeand-mend.

Prehistoric tool use seems to be very sensitive to changes in the patterns of resource exploitation (Bousman 1991), because the costs and benefits (often called utility) of tool designs that shift between reliability (high cost, high utility), maintainability (moderate cost, moderate but renewable utility), and expediency (low cost, low utility) are very different for these specific goals. At 41MV120 the analysis of lithic artifacts, chipped stone, and ground stone will utilize the concepts of tool design and capacity planning to analyze specific attributes that can provide information on the exploitation of resources by prehistoric hunters and gatherers.

\section{Spatial Analysis}

A third source of data that can be used to address the human adaptation and subsistence historic contexts is the spatial distribution of artifacts and features within the site. Recent archaeological and ethnoarchaeological research has resulted in a rapidly growing body of knowledge that provides powerful analytic tools used to understand prehistoric life ways. Numerous studies have developed methods for analyzing and interpreting the spatial patterns of artifacts and other archaeological materials in such settings (Hietala 1984; Kroll and Price 1991; O'Connell 1987). The application of these methods at $41 \mathrm{MV} 120$ could provide important new evidence on the intrasite spatial organization of Late Archaic hunters and gatherers in south Texas. The moderate accumulation of burned rocks may have resulted from a wide range of activities over brief episodes. The intrasite spatial study undertaken at the Mariposa site in Zavala County provides a local example (Montgomery 1978).

Not only can spatial analysis discriminate between these types of site uses, but it may also detect differences in the overall organization of the group. It appears that groups reliant upon larger amounts of stored food (Binford's collectors) will have a different camp layout than groups who do not (foragers). For example, O'Connell (1987) argues that foragers and collectors have different internal site structure. Foragers (e.g. the !Kung Bushmen of the Kalahari and the Alyawara Aborigines of Australia) have household clusters at residential camps with little internal complexity, while collectors (e.g., the Nunamiut Eskimos of Alaska) have more complex residential camps that are more highly structured. At forager residential sites, research demonstrates that length of occupation, number of occupants, seasonal variation in weather, degree of food sharing between households, reliance on food storage, and perhaps risk from larger predators are the most important determinants of site structure and size (O'Connell 1987; Yellen 1977). A critical aspect of this type of research is discriminating between archaeological deposits which are the product of reoccupations and those that are the product of a single occupation. Studying the internal organization of hunter-gatherer campsites is a productive approach for discriminating between single occupation, multiple occupations and aggregation (Vierra 1985). This issue is discussed above in the second historic context, Site Formation Processes. Site $41 \mathrm{MV} 120$ is promising in this regard due to the possibility that archaeological materials were rapidly buried, thus reducing the likelihood that multiple reoccupations are collapsed together. 
In order for spatial analysis to be conducted, largeblock hand excavations must be undertaken ( $\mathrm{O}^{\prime} \mathrm{Connell}$ 1987). Site $41 \mathrm{MV} 120$ is an ideal candidate for this type of research since multiple intact features are found with associated artifacts in contexts that are not deeply buried. The recovery of a diverse artifact assemblage, particularly smaller artifacts and faunal and floral remains, will potentially allow for the identification of significant spatial patterns that can be related to an array of activities and depositional contexts. Additionally, other significant features might be exposed such as storage pits or house remains. These are commonly associated with cooking features among ethnographically documented modern hunters and gatherers. Although house remains have yet to be identified in South Texas, they have been found in the Texas coastal area, west central Texas, and the lower Plains (Boyd et al. 1993; Ricklis and Gunter 1986; Treece et al. 1993).

\section{Summary}

Through the systematic recovery of paleoenvironmental, geological, and archaeological data, 41MV120 has the potential to contribute substantial data toward the understanding of three significant research issues: past environmental change, site formation processes, and human adaptations. Important avenues for investigating paleoenvironmental change include additional geological analysis of the Rio Grande alluvial terrace system, as well as stable isotope analysis of samples from the site. Detailed geological information and archaeomagnetic studies of burned rock will provide information that will allow for an analysis of site formation processes. Site formation processes are critical for assessing the context of the archaeological materials and essential if spatial analysis is undertaken. Other types of evidence must be collected to address the historic context concerned with prehistoric adaptations and subsistence. These include plant and bone samples, detailed examination of the characteristics of features and burned rock scatters, life-history analysis of stone tools, and spatial analysis of features and associated artifacts. By investigating a variety of dimensions relevant to the organization of work and space, subtle shifts in adaptation will be discernible. 


\section{Chapter 6: Methods}

\section{John R. Cross}

The field, laboratory, and analytical methods used during the CAR data-recovery program at 41MV120 were implemented to achieve the goals outlined in the research design. These methods are described in this chapter.

\section{Field Methods}

\section{Backhoe Trenches}

During the early stages of the project, six backhoe trenches (BHTs) were excavated by CAR to depths ranging from $1.5-2.0 \mathrm{~m}$. The trenches were numbered in order, beginning with 7 to avoid confusion with TxDOT backhoe trenches 1-6 (Ward 1995a). Observations on the vertical and horizontal distribution of cultural materials and the stratigraphic relationships and physical characteristics of sediments within the trenches guided the subsequent placement of excavation units. No attempt was made to screen the soils removed from the backhoe trenches, although trench excavations were monitored by CAR personnel who inspected the emerging trench profile and backdirt for cultural material or for soil anomalies that might indicate the presence of features.

\section{Excavation Units}

One of the goals of the program was to locate and complete the excavation of TxDOT's $1-\mathrm{x}-1-\mathrm{m}$ test units to a uniform depth of $1.2 \mathrm{~m}$ below the present ground surface. The maximum depth of construction impacts to the site had been determined by TxDOT to be one meter. Excavation to a depth of $1.2 \mathrm{~m}$ provided a stratigraphic context for understanding the lower levels within the impact zone. The units were completed following a strategy of excavating in 10-cm arbitrary levels, and screening all sediments through $1 / 4$-inch square hardware cloth. The $10-\mathrm{cm}$ levels are consistent with the stratigraphic controls of the significance testing program implemented by TxDOT's cultural resources staff (Ward 1995a).

The CAR proposal for data recovery at $41 \mathrm{MV} 120$ called for block excavations to expose possible living surfaces and to obtain information on the spatial context of prehistoric activities. Early in the field investigations, a large drainage pipe was discovered running east-west through the middle of the site. After consultation with TxDOT and Texas Historic Commission archaeologists, the strategy was modified to accommodate the spatial distribution of the utility line trench at the site. Instead of a single large block, several smaller blocks of 1-x-1-m units were positioned to explore areas of high artifact density. Excavation units (EUs) were numbered sequentially as they were laid out, continuing the series of test units (TUs) initiated by TxDOT. To minimize confusion in the ensuing discussions, all 1-x-1-m unitsTxDOT's and CAR's - are referred to as EUs.

The block excavations were situated in four separate areas of the site (Figure 6-1). Area 1 is a linear-shaped block located at the eastern end of the site containing EUs 1 and 3 and EUs 12-15, 31-36, and 43 (Figures 6-1 and 6-2). Area 2 is a square block situated in the central section of the site, containing EU 7 and EUs 16 21 and 37-38. Area 3 is a an L-shaped block located in the western section of the site, containing EU 11 and EUs 22-27, and 41-42. Area 4 includes two small block excavations situated on the western end of the site. One of these consists of four units (EU 9 and EUs 28-30), and the other of two units (EUs 39-40). EUs 27 and 35 in Areas 3 and 1 respectively, were not excavated.

The standard excavation unit was a 1-x-1-m square, hand-excavated in $10-\mathrm{cm}$ levels to a depth of $1.2 \mathrm{~m}$ below ground surface. The bottom of each $10-\mathrm{cm}$ level was marked in the four corners of an excavation unit by broad-headed nails and flagging tape. This allowed direct measurement of the actual levels used in the excavation of the site (a critical distinction from an ide- 


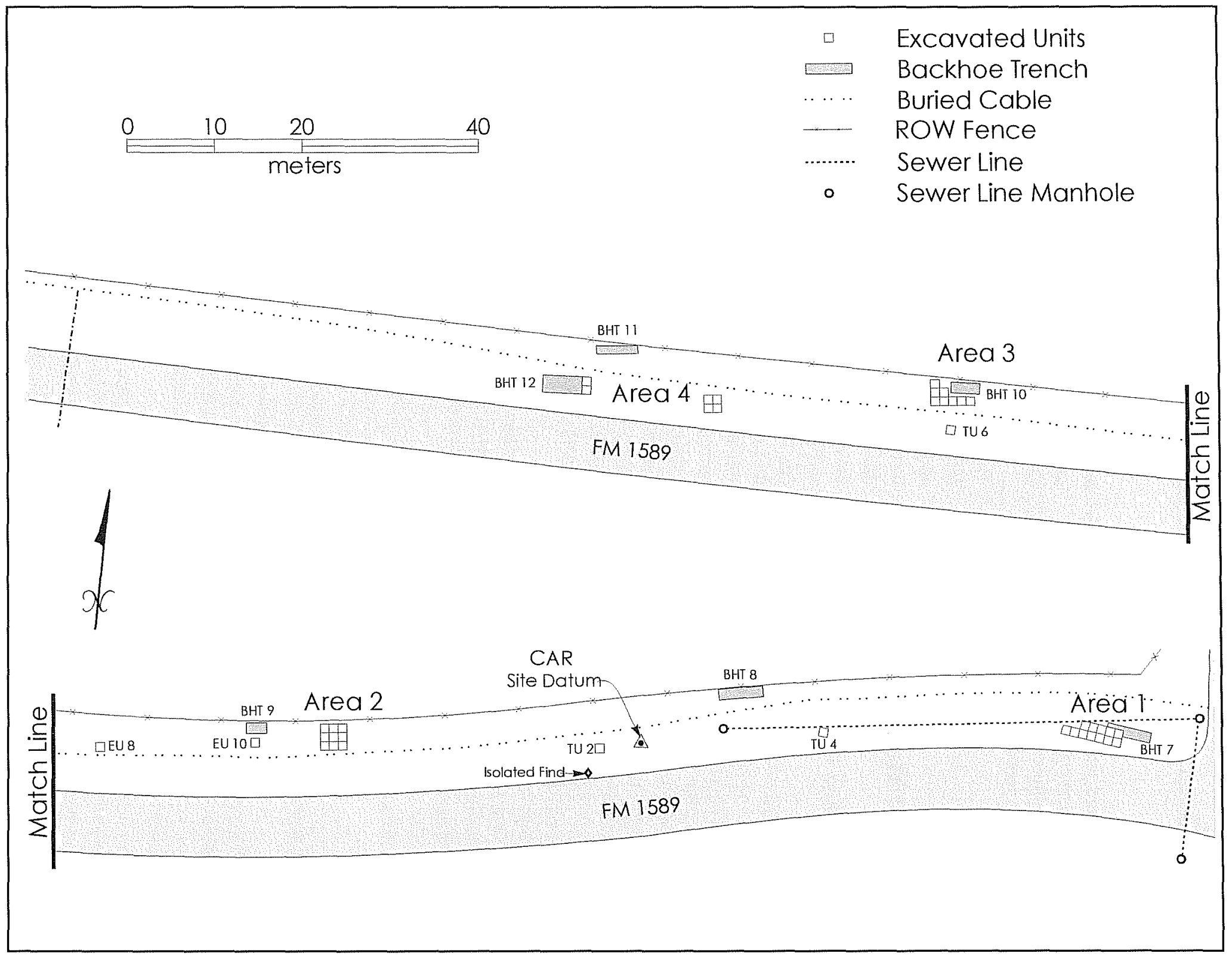

Figure 6-1. 41MV120 site map. 


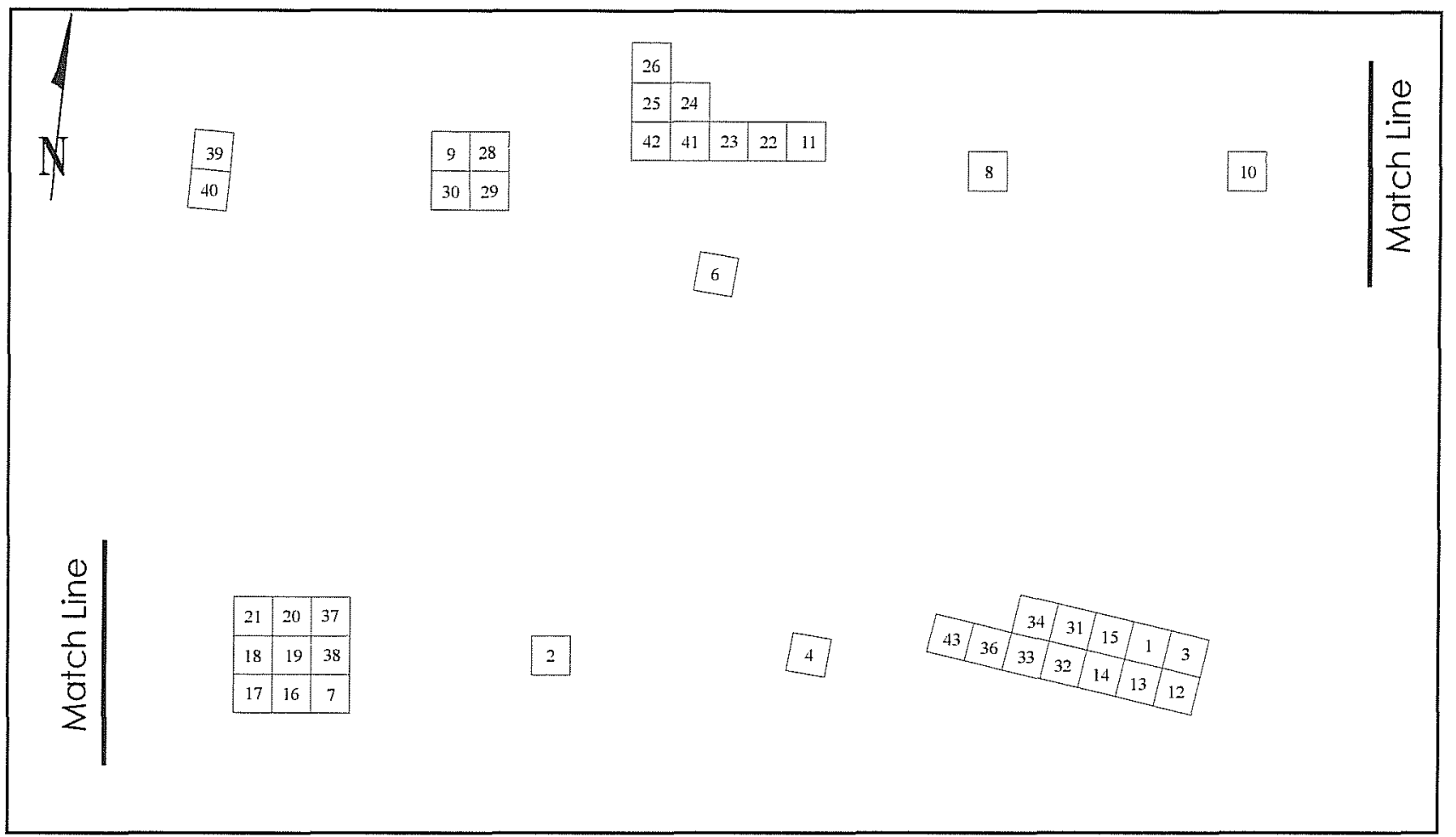

Figure 6-2. Excavation unit designations.

alized series of $10-\mathrm{cm}$ levels when volumetric comparisons are being made between levels or units).

The sediments deposited at the site through flood events of the Rio Grande showed little contrast in soil color - the entire range of soil color for the site could be described within $1 / 2$ of a Munsell color distinction. Subtle distinctions in color could be identified in profiles that had been freshly excavated and recorded under favorable conditions of lighting and moisture. In most cases, the observable distinctions were rhythmic lighter and darker soil zones that were provisionally interpreted as "packages" of accumulation and subsequent weathering of multiple flooding events. Very small nodules and stringers of redeposited calcium carbonate were occasionally observed, although the general absence of visible stringers suggested that the sediments had accumulated fairly rapidly and steadily, in lowenergy depositional environments, and that active bioturbation of the sediments masks the visible evidence. Sediments within the project area had experienced compaction to a depth of $50-60 \mathrm{~cm}$ through vehicular traffic, construction equipment, and maintenance equipment. Picks were used to loosen the compacted soils in the upper levels of the excavation units along the shoulder of FM 1589. A Gradall supplied by the Freer TxDOT office was also used to remove portions of the upper disturbed levels in EUs 18, 21, 24, 25, 31 , $32,33,34,36,41,42$, and 43 . In addition, the upper levels were removed from EUs 39 and 40 by a backhoe, and in EUs 14, 15, and 26 by hand, but were not screened.

Initially, all soils from the excavations were wetscreened through $1 / 8$-inch hardware cloth to retrieve small artifacts and fragments of bone. Water for the screening operation was pumped from a TxDOT water truck using a gasoline-powered 2 -inch trash pump. The pump outlet was fitted with a converter and yadapter for the attachment of two 1-inch hoses with variable-spray nozzles. Runoff from the water screening setup ran directly into a sump (measuring approximately $2 \times 3 \times 1.75 \mathrm{~m}$ deep) to avoid any ecological impacts to the waters of Elm Creek.

The procedures used in the field were adjusted in response to changing conditions, an emerging understand- 
context, and the initial recovery rates for artifacts. At one point, excavation proceeded by 5 - $\mathrm{cm}$ levels to establish whether or not the vertical distribution of cultural materials corresponded to slightly darker soil zones in the stratigraphic sections that might have indicated incipient soil development on a comparatively stable surface. After sufficient data had been collected to address the issue, excavations resumed using $10-\mathrm{cm}$ levels. Five-cm levels were excavated at the bottoms of EUs 7, 8, 10, and 11, and EUs 12 and 14 in Area 1, and EUs 28-30 in Area 4. The plan to wet-screen all sediments through $1 / 8$-inch mesh was revised in light of the extremely low recovery rates for bone during the first few weeks of the project. Instead, a 25 percent sample of soil from each level was wet-screened through the $1 / 8$-inch mesh; the remainder was dry-screened through $1 / 4$-inch hardware cloth. The 25 percent sample was determined empirically and defined operationally as three 12-quart buckets of soil for each 10-cm level and one-and-a-half 12-quart buckets for each $5-\mathrm{cm}$ level.

\section{Collection of Materials}

Artifacts recovered during excavation or dry-screening were placed in zipper-lock-closure polyethylene bags with an acid-free paper label containing provenience information (site, lot number, EU number, level, depth, feature number, description of contents, the excavator, and the date). The kinds of materials collected included flaked stone tools and tool fragments, cores, lithic debitage, ground-stone tools and tool fragments, fire-cracked rock, fieshwater mollusk shell, and bone. Complete, or nearly complete, snail shells were also collected as possible indicators of local paleoenvironmental conditions. Samples of charred material were collected for radiocarbon dating and for macrobotanical identification. Charcoal samples were wrapped in aluminum foil packets which were then placed in polyethylene bags. Historic artifacts were collected only from subsurface contexts.

Each bucket of soil to be water-screened was identified by a piece of colored flagging tape on which was written the unit number, the level, and depth from which the soil was derived. Each unit was assigned one of eight different colors of flagging tape that uniquely iden- tified it among the units being excavated actively. The corners of a unit were marked at the bottom of each level with flagging tape and a nail, again color-coded to the unit. The redundancy of the system provided cross-checks for photographic documentation and water-screening. Artifacts recovered during the wetscreening were placed in a plastic bag along with the colored flagging tape on which unit, level, and depth information had been written. Each evening, the bags were opened and the artifacts were spread out to air dry. At that time, the wet-screened artifacts were assigned lot numbers within the series designated for the respective units, acid-free paper labels were completed with the relevant provenience data, and the artifacts were returned to new zipper-closure polyethylene bags.

\section{Lot Numbers}

Lot numbers were assigned to each excavation unit or trench in consecutive blocks of 25. A lot number refers to a unique bag collected in the field from a particular context, regardless of its contents. The primary significance of a lot number was that it identified artifacts or samples from a particular unit and level (and feature, if applicable). A lot may contain a single artifact, a sample, or a grouping of artifacts and ecofacts from a single context. The contents of each bag/lot number were recorded in the field on an inventory/bag tracking sheet. The system was designed to be flexible and to preserve information about the context of recovery, and not solely provenience information. For example, artifacts recovered from a particular level within a given unit as it was being excavated would be assigned a lot number. Artifacts recovered from the water-screening of soils from that level and unit were assigned a different lot number. At the end of each day, each lot was considered "closed" and new numbers were used the following day. This system greatly reduced the chances for error by restricting lot numbers to the collection efforts of a single person on a single day from a unique context, following the individual excavator's "common-sense" lumping or splitting logic. In this way, lot numbers closely matched the categories and groupings used in field notes. In addition, the nature of the water-screening operation (the processing of soils from a number of units in quick succession) required a procedure by which artifacts could be 
rapidly and unambiguously assigned to a particular context. The lot numbers became part of the permanent artifact catalogue number. Not all lot numbers were used, since the number of bags for a given unit was rarely divisible by 25 (the increment of numbers on an inventory/bag tracking sheet). A master list of the lot numbers assigned to excavation units was maintained in the field, and provided a quick reference in the event that unit provenience was not recorded on an artifact tag.

\section{EDM Mapping}

Existing conditions (reference points and topography) and the spatial positions of excavation units, backhoe trenches, features, and artifacts recovered in situ were determined with a Sokkia Set 5A EDM Total Station. Since Ward's (1995a) site datum could not be relocated, CAR crew established a new site datum in the east-central part of the site, with an arbitrary elevation of $100 \mathrm{~m}$. A second station was established toward the western end of the site. All measurements at the site were taken from these two stations or from transit points. Locational data were stored on a Sokkia SDR33256K data collector and downloaded for use in mapping and spreadsheet program formats. Maps showing existing conditions, the location of excavation units, features, and artifact clusters were created from these data.

\section{Documentation of Field Investigations}

Excavation unit and feature forms printed on acid-free paper were used to document the field excavations. Photography (color slides and black-and-white prints) was also used to record the excavations, the site setting, archaeological features and artifacts in situ, and stratigraphic profiles. Site plan maps and stratigraphic profiles were drawn on 1- $\mathrm{mm}$ acid-free graph paper. Plan views of excavation units recorded the location, orientation, structure, and content of features at the site. Profiles were also drawn for each excavation unit and backhoe trench, indicating the stratigraphic relationships of soil/sediment units, visible evidence for bioturbation, the position of nails used to mark the boundary between excavated levels, and the presence of cultural material.

\section{Archaeomagnetism Samples}

Archaeomagnetism samples were collected for rocks that showed indications of having been burned or were in contexts where exposure to a fire was suspected. The magnetic orientation of particles in rocks that have been heated are realigned with each heating event to the position of the earth's magnetic pole. Individual burned rocks preserve a record of the temperature to which they were heated and may retain the archaeomagnetic signatures of multiple heating events. A comparison of the magnetic orientations of rocks associated with a single feature may reveal the degree of postdepositional disturbance to the feature (e.g., Gose 1994).

Rocks selected for archaeomagnetic sampling were drilled using an E-Z Core Rock Drill (Model D-2801) from Pomeroy Industries Unlimited, which was fitted with a $1 \frac{1}{8}$-inch notched diamond core bit. The tubular drill bit isolated a "plug" of stone, which was then scored with a brass wire at an angle and orientation that could be measured with a specially designed goniometer. The rock was not drilled completely through, leaving the "plug" attached to the main mass of the rock. It was important to maintain the in situ orientation of the rock during drilling and measurement. When the rock was displaced during the drilling process, further attempts to drill the rock were abandoned and the sample was not collected. For each sample, the following information was recorded: unit, level, northing, easting, elevation, angle (read from a level Brunton compass mounted on the goniometer), and dip (as measured by the goniometer). The archaeomagnetism sample number was written on each specimen using a permanent marker, and the relative vertical position was indicated on the "plug" by one or more "V" markings. This was a precautionary measure in the event that the "plug" separated from the rest of the rock in transit or in the lab. Samples were submitted to Dr. Wulf Gose of the Department of Geological Sciences at The University of Texas at Austin for analysis. The results of this analysis are presented in Chapter 10. 


\section{Geomorphological Investigations}

On-site geomorphological investigations were undertaken by Dr. Lee C. Nordt of the Department of Geology at Baylor University while the archaeological fieldwork was in progress. The preliminary interpretations of the site's geomorphological and sedimentological history played an important role in shaping the operational model of the site's age, structure, and paleoenvironmental setting. The project geomorphologist provided detailed soil descriptions for one or more profiles for each trench, noting subtle distinctions in soil color and texture, as well as the development of visible soil carbonate stringers or nodules and evidence for bioturbation. The elevations of the boundaries between soil horizons were measured with the EDM Total Station. Column soil samples were taken from BHTs 8 and 9.

Off-site geomorphological investigations focused on the relationships between the geomorphological and geochronological relationships of 41MV120 to Elm Creek, the Rio Grande channel at the time the site was occupied, and the evolving Rio Grande terrace system. Five geological cores were drilled by the Bureau of Economic Geology, University of Texas at Austin, in the area of the site. Three of these are located on the Rio Grande floodplain, and the other two on terrace deposits along upper Elm Creek. An additional profile was described in an elevated terrace over looking the Rio Grande floodplain. Results of the geomorphological study of the site are presented in Chapter 7.

\section{Laboratory Methods}

\section{Artifact Catalogue}

At the CAR laboratory facility, the contents of artifact lots were checked against the field bag tracking/inventory sheets. Artifacts were washed using soft-bristle brushes and allowed to air dry. Artifacts from a single bag/lot were then grouped according to material category, counted, weighed, and re-bagged in clean polyethylene bags with zipper-lock closures. Non-cultural material was discarded and noted on the laboratory inventory sheet. Data from the laboratory inventory sheets were entered in a Windows EXCEL spreadsheet format. The quantified listing of materials formed the basis for the site catalogue and for subsequent analyses.

Catalogue numbers were written on all stone tools (or tool fragments) and on 10 percent of all flakes. Bones, freshwater mollusk shells, and land snails were generally too highly fragmented or fragile to have catalogue numbers written directly on them. For these items, an acid-free paper tag with the corresponding catalogue number written on it was enclosed in the plastic bag containing the artifact(s).

\section{Curation}

Artifacts, samples, field records, and photographic documentation for the data recovery excavations of 41MV120 are permanently curated at the CAR facility at UTSA. Color slides, negatives, and black-andwhite contact sheets have been placed in archival-quality polyethylene sheets and are arranged in a numbered series corresponding to a photo log. Artifacts and samples are stored in polyethylene bags accompanied by labels printed on acid-free paper. Artifacts are grouped by class (e.g., cores, debitage, retouched tools, bone, and botanical), and excavation unit in acid-free archival storage boxes. 


\section{Chapter 7: Geoarchaeology Of The Rio Grande and Elm Creek in the Vicinity of Site 41 MV120}

\section{Lee C. Nordt}

\section{Introduction}

Little is known about the geologic evolution of stream systems in South Texas. Geoarchaeological investigations at site $41 \mathrm{MV} 120$ offered an opportunity to study the late Quaternary geologic history of the Rio Grande and Elm Creek with ${ }^{14} \mathrm{C}$ dating, petrographic thin section interpretations, physical and chemical soil-stratigraphic analysis, and stable carbon isotope analysis. This in turn permitted interpretations about the relationship between geological processes and prehistoric site formation and preservation potentials.

The approach of this investigation was to analyze the regional Quaternary history of the Rio Grande and Elm Creek, place the context of site 41MV120 within the geological framework, and interpret the microstratigraphy of the site itself. Specific objectives were to: 1) identify periods of alluvial deposition, erosion, and soil formation; 2) infer environments of deposition; 3) determine the numerical chronology of geomorphic events; and 4) infer prehistoric settlement patterns and subsistence strategies.

\section{Regional Setting}

\section{Geomorphology}

The lower reach of the study area includes site 41MV120, which is situated near the confluence of Elm Creek and the Rio Grande (Figure 7-1). Here, the Rio Grande is a meandering river with an entrenched floodplain confined to the modern meander belt. The meander belt is mapped as a Holocene floodplain deposit (Barnes 1976). This is consistent with the mapping of weakly developed entisols for the same area (Stevens and Arriaga 1977). The upper reach of the study area encompasses the upper Elm Creek basin (Figure 7-2). Elm Creek is a low order meandering stream. The Elm Creek meander belt and adjacent floodplain are mapped as Pleistocene terraces (Barnes 1976). However, weakly developed inceptisols (Stevens and Arriaga 1977) suggest that the Elm Creek valley is filled with Holocene deposits

\section{Geology}

The Rio Grande and Elm Creek in the study area dissect uplands underlain by Cretaceous and Pleistocene deposits (Figures 7-1 and 7-2). The Cretaceous Olmos and San Miguel formations, and Upson Clay, out crop in the Elm Creek basin (Barnes 1976). Shallow aridisols commonly form in this area (Stevens and Arriaga 1977). Cretaceous units and soils contribute clay, sandstone, siltstone, limestone, ferruginous concretions, and some coal to the Elm Creek drainage, and locally to the Rio Grande. In addition, the Rio Grande contributes a variety of other Cretaceous sediments, pre-Cretaceous sediments, and igneous rocks from northwest Texas.

The Uvalde Gravel forms a veneer of Pleistocene alluvium over Cretaceous deposits in the uplands on the north side of the Elm Creek valley (Figures 7-1 and 7-2). The Uvalde Gravel contributes caliche-cemented cherts, quartz, and other igneous rocks to the Elm Creek and Rio Grande drainages. Mollisols with calcic or petrocalcic subsoils occur in this area (Stevens and Arriaga 1977). The local geological materials provided numerous resources for prehistoric utilization. Chert and quartzite from the Uvalde Gravel may have been used as a lithic source, sandstone and limestone for hearth construction, and coal for burning. However, outcrops of coal in the area are minor. 


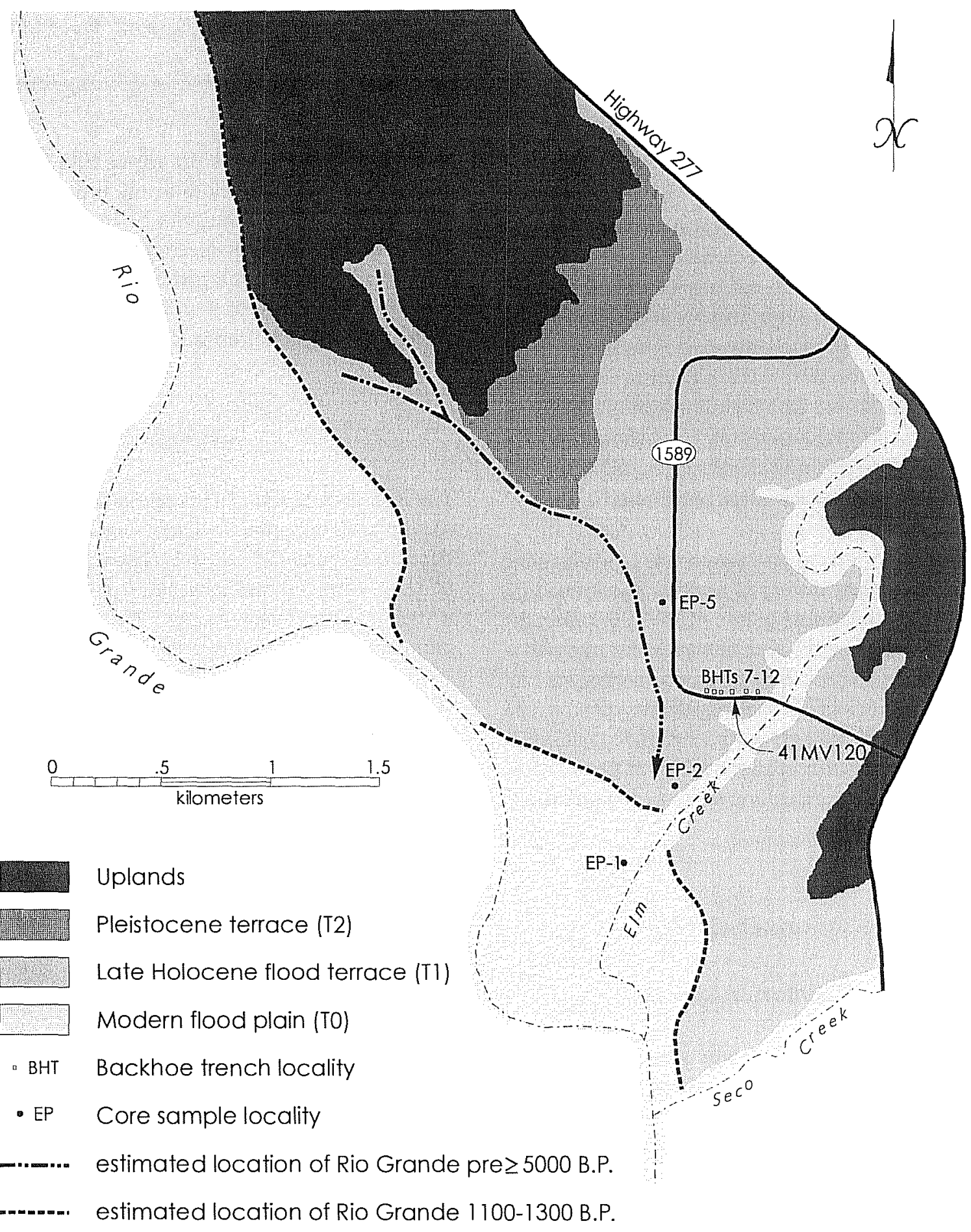

Figure 7-1. Geomorphic map of the Rio Grande and lower Elm Creek basin in the vicinity of site $41 M V 120$. 

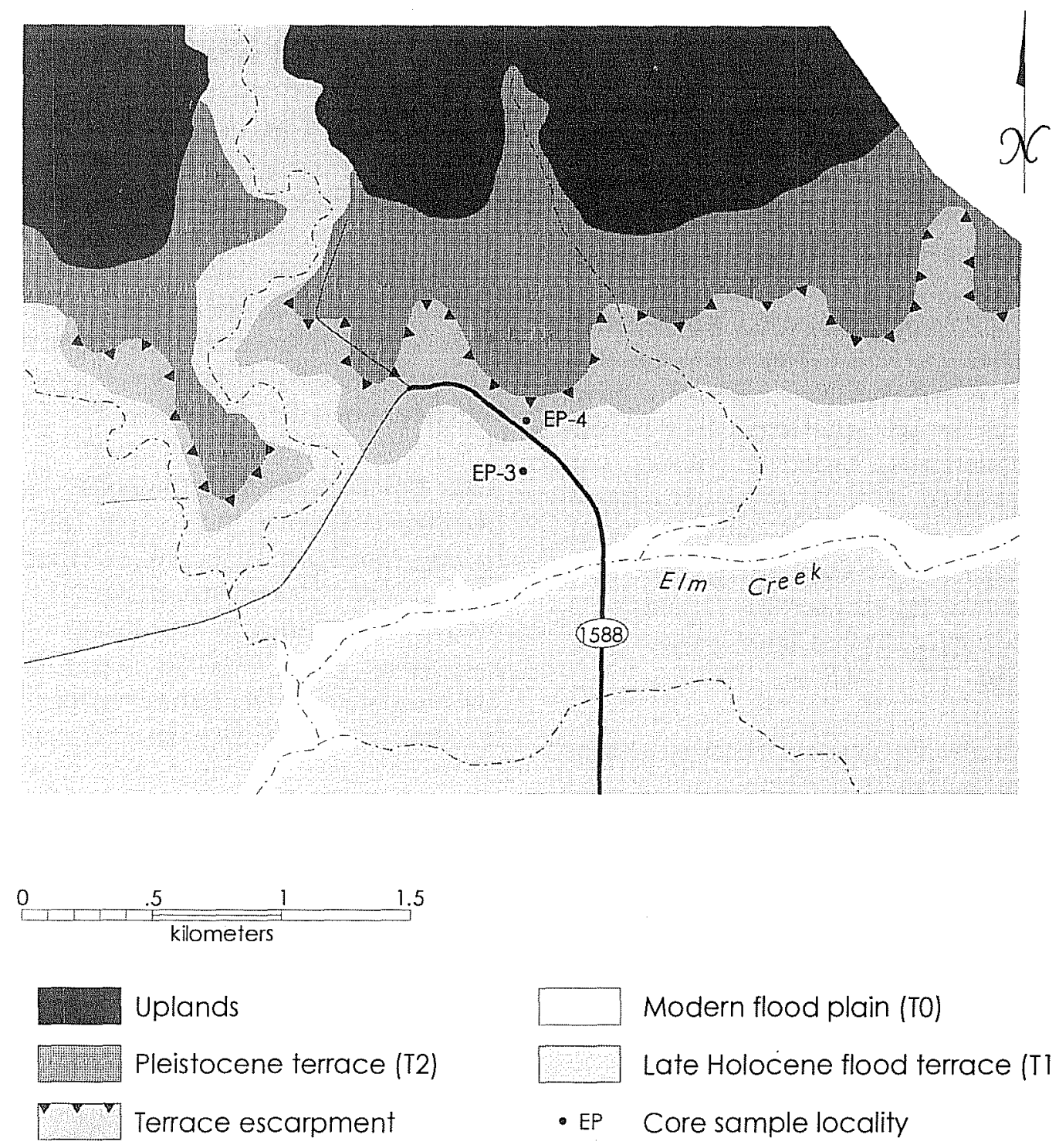

Figure 7-2. Geomorphic map of the upper Elm Creek drainage basin.

\section{Methods}

A geomorphic map was constructed for the study area using U. S. Geological Survey topographic maps, the local soil survey of Maverick County (Stevens and Arriaga 1977), and field reconnaissance. Soil-stratigraphic data were collected from five deep sediment cores (EP-1 through EP-5) and five backhoe trenches (BHT 7 through BHT 12) (Figures 7-1 and 7-2). The sediment cores were taken with a truck-mounted drill rig provided by the Bureau of Economic Geology of
The University of Texas at Austin. Backhoe trenches were excavated with a Gradall. Soil-stratigraphic descriptions were written following standards and procedures of the Soil Survey Division Staff (1993) and Folk (1980). Alluvial stratigraphic units were defined as unconformably bound packages of sediment similar to allostratigraphic units (Soil Stratigraphic Code 1983). Subdivisions into horizons were based principally on differences in color, texture, calcium carbonate content, soil structure, and sedimentary structures. 
Carbon-14 dating on charcoal $(n=6)$, wood $(n=2)$, and bulk sediment humates $(n=2)$ were performed by Beta Analytic (Beta) and the Institute for Arctic and Alpine Research (NSRL). All results were performed by accelerator mass spectrometry, corrected for variations in ${ }^{13} \mathrm{C}$ content, and reported in radiocarbon years. Two charcoal ages determined from the previous archaeological testing phase were also used.

Bulk samples $(\mathrm{n}=51)$ were collected from selected backhoe trenches (BHT 8 and BHT 9) and deep cores (EP1 through EP-4) for soil-stratigraphic characterization. Analyses were performed by the Texas A\&M University Soil Characterization Laboratory. Texture was determined by pipette; $\mathrm{pH}$ in 1:1 soil-water solution; $\mathrm{CaCO}_{3}$ equivalent gasometrically by the Chittick method; and organic carbon as the difference between total carbon determined by dry combustion and $\mathrm{CaCO}_{3}$ equivalent as determined by the Chittick method (Hallmark et al. 1986).

Selected bulk sediment aggregates with contextual integrity were sampled for petrographic thin sections from selected horizons of most backhoe trenches (BHTs 8 , 9, 10, and 12) and deep sediment cores (EP-1-EP-4). Samples $(n=27)$ were vacuum-impregnated with epoxy and cut to a thickness of 30 microns by Spectrum Petrographics. Thin sections were described according to the system of Brewer (1976) using a polarizing petrographic microscope.

Samples $(n=48)$ for determination of stable isotope ratios of organic carbon were collected from selected backhoe trenches (BHTs 8 and 9) and deep cores (EP1-EP-4). Analysis was performed on bulk sediment samples by the Mass Spectrometry Laboratory at Texas A\&M University. Pretreatment included the physical removal of roots and the chemical removal of carbonate carbon with $\mathrm{HCl}$. The pretreated bulk sample was then combusted with $\mathrm{CuO}$ to transform organic carbon into $\mathrm{CO}_{2}$ (Boutton 1991a). Values were expressed in delta ( $\circlearrowright$ ) notation in parts per thousand (\%o) relative to the Pee Dee Belemnite (PDB) standard.

\section{Alluvial Stratigraphy of the Rio Grande}

Four landforms were mapped in the lower study area along the Rio Grande and lower Elm Creek basin: the uplands, a Pleistocene terrace (T2), a Holocene flood terrace (T1), and the modern floodplains (T0) (Figure7-1). The T1 landform was mapped as a flood terrace because of minimal soil development and preservation of sedimentary stratification within the upper soil profiles. These characteristics reflect periodic, but perhaps rare, flooding across the $\mathrm{T} 1$ terrace.

Three Holocene alluvial stratigraphic units were also identified in the lower project area: Unit 1 (early Holocene), Unit 2 (late Holocene), and Unit 3 (modern). Unit 1 is deeply buried beneath the T1 flood terrace, whereas Unit 2 forms the constructional $\mathrm{T} 1$ flood terrace surface. Unit 3 forms the modern T0 floodplain. The alluvial units were also subdivided into channel (c), point bar (p), and floodbasin (f) facies.

\section{T2 Terrace}

The oldest alluvial deposit identified in the project area was associated with the dissected T2 terrace which, according to its orientation, parallels the axis of Elm Creek (Figure 7-1). The Jimeniz soil series is mapped on the T2 terrace (Stevens and Arriaga 1977). This soil has a petrocalcic subsoil horizon (caliche) and classifies as a Petrocalcic Calciustoll. This degree of soil development indicates a Pleistocene age for formation of the $\mathrm{T} 2$ terrace based on soil-carbonate chronosequences established in the southwestern U. S. (Machette 1985).

\section{T1 Flood Terrace}

The T1 flood terrace in the lower study area forms a continuous surface between the Holocene valleys of the Rio Grande and Elm Creek (Figure 7-1). The terrace is situated $12-14 \mathrm{~m}$ above the modern low water channels of the stream network. The east to northeast margin of the Rio Grande valley is marked approximately by abandoned Channel 1 where it impinges the 
Uplands and T2 Pleistocene terrace, extends to Elm Creek near site 41MV120, and continues across Elm Creek towards Seco Creek (Figure 7-1). The Elm Creek valley has been widening from northwest to southeast with meander belt migration. No topographic break separates the Rio Grande and Elm Creek flood terrace valleys. Surface depositional features other than abandoned Channel 1 have not been preserved.

Drill core sites EP-1, EP-2, EP-5, and BHTs 7-12 revealed three Holocene alluvial stratigraphic units beneath the T1 flood terrace of Elm Creek and the Rio Grande (Figure 7-1). As discussed previously, from oldest to youngest they are: Unit 1, Unit 2, and Unit 3.

\section{Unit 1}

Unit $I$ is truncated and deeply buried beneath the T1 flood terrace (Figure 7-3: EP-2). It has a channel and point bar facies assemblage. The channel facies consists of subrounded and grain supported pebbles (Appendix B1). Interbedded brown and olive brown clays and loams make up the point bar facies (Figure 7-4a; Appendix B2). The lithology of Unit 1 is more typical of Elm Creek alluvium because of olive colors, a greater abundance of chert, and more ferruginous pebbles. This unit extends into the upper Elm Creek basin where it forms the constructional T1 flood terrace at EP-3 and EP-4 (Figure 7-5).

A bulk sediment ${ }^{14} \mathrm{C}$ humate age of $6010 \pm 60$ (Beta104968) was obtained from the point bar facies of Unit 1 (Figure 7-3: EP-2). Consequently, Elm Creek was migrating in the vicinity of EP-2 approximately 6000 B.P. (Figure 7-1). It follows that the confluence of Elm Creek and the Rio Grande was south to southwest of EP-2 at that time. The extent of Unit 1 deposits beneath the $\mathrm{T} 1$ flood terrace is unknown, other than they do not exist in the vicinity of EP-5 (Figures 7-1 and 7-3).

\section{Unit 2}

Unit 2 unconformably overlies Unit 1 and forms the constructional $\mathrm{T} 1$ flood terrace surface in the lower study area (Figures 7-1, 7-3, 7-6: EP-2, EP-5, BHTs $7-12)$. In general, Unit 2 fines upward from lower point bar sands (pale brown to brown) to floodbasin silt loams and silty clay loams (brown to very dark grayish brown) (Appendixes B1 and B3). EP-5 exposed a thick point bar facies in Unit 2-p (Figure 7-3), which may coincide with its location adjacent to abandoned Channel 1 (Figure 7-1). The point bar facies has well sorted sands, trace amounts of mica, and minimal biological activity (Figure 7-7c; Appendix B2). The upper part of Unit 2, designated Unit 2-f, has been pedogenically altered to a weakly expressed A-Bw soil profile (Appendixes B1 and B3) that classifies as a Mollisol (haplustoll). Soil properties associated with Unit 2-f typically contain fine, moderately sorted quartz and carbonate clasts, trace amounts of heavy minerals, appreciable biological activity, and an abundance of cracking clay clasts of slack water origin (Figure 7-4c, d; Appendix B2).

The fining upward sequence of Unit 2 is displayed in EP-2 and BHT 9 by increasing clay and silt content and decreasing sand content (Figures 7-8 and 7-9). The high clay content and low sand content of the point bar facies in Unit 1 distinguishes it from Unit 2 (Figure 7-8). Carbonate distribution with depth in Unit $2 \mathrm{mim}-$ ics the percentage of silt, indicating that most of the carbonate is in the silt fraction. Based on the shape of the depth-curve, and absence of secondary carbonate nodules, virtually no carbonate has been redistributed in the soil profile. Furthermore, organic carbon content increases in the upper profiles of EP-2 and BHT 9 , probably in response to decreasing flood deposition and increasing organic inputs from plants after the Rio Grande down cut and formed the modern T0 floodplain (Figures 7-8 and 7-9).

BHT 8 shows soil characteristics similar to BHT 9 and EP-2, except for a weakly expressed buried Ab1 paleosol that interrupts the sequence (Figure 7-10). As a result, there are two generalized fining upward sequences for clay and sand and two increases in organic carbon content. The Ab1 paleosol indicates that during deposition of Unit 2-f, flooding and sedimentation slowed in the vicinity of BHTs 7, 8, 10, and 12 .

Based on the ${ }^{14} \mathrm{C}$ age obtained from Unit 1 in EP-2, deposition of Unit 2 began sometime after 6000 B.P. (Figure 7-3). Deposition continued until approximately 1200 B.P. based on ${ }^{14} \mathrm{C}$ ages and time-diagnostic artifacts from BHTs 7-12 (Figure 7-6) and a ${ }^{14} \mathrm{C}$ age from 


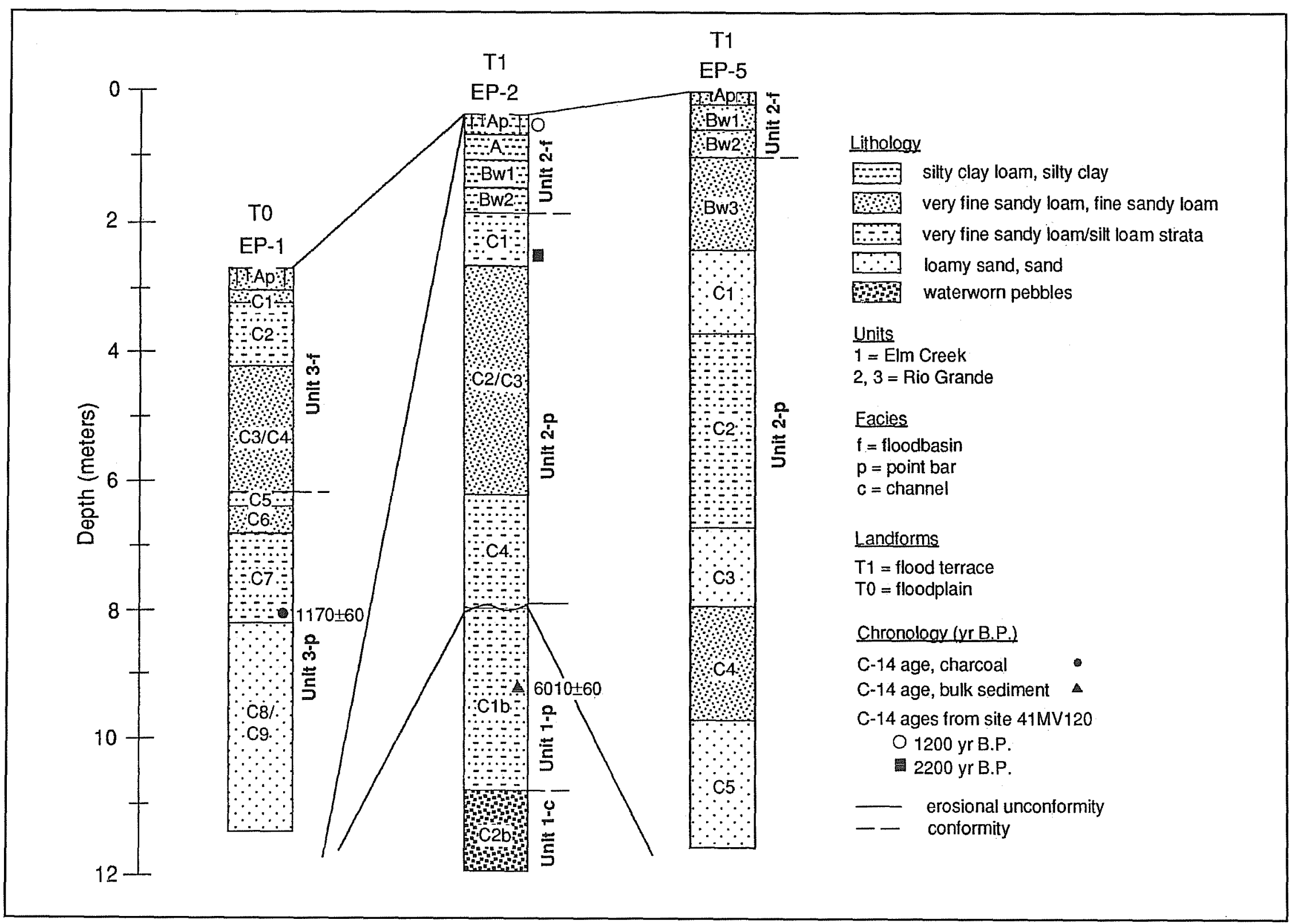

Figure 7-3. Regional alluvial stratigraphy of the Rio Grande based on deep sediment cores. 


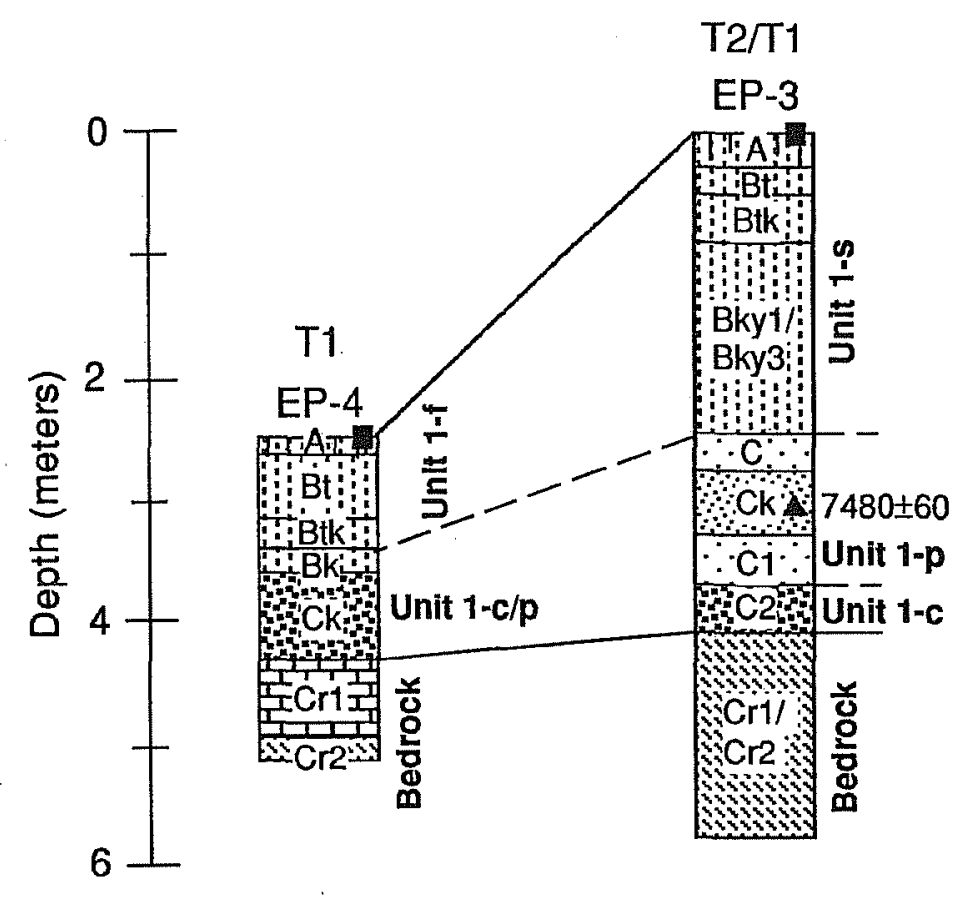

\section{Lithology}

[:5:i] sandy clay loam, clay loam

3 very fine sandy loam, fine sandy loam

$\because \because$ loamy sand, sand

\begin{tabular}{ll} 
Facies & Landforms \\
\cline { 2 - 2 }$=$ floodbasin & T2/T1 terrace escarpment \\
$\mathrm{p}=$ point bar & $\mathrm{T} 1$ terrace \\
$\mathrm{c}=$ channel & \\
$\mathrm{s}=$ colluvium & \\
- & erosional unconformity \\
- & conformity
\end{tabular}

\section{Chronology (yr B.P.)}

C-14 age, bulk sediment

cultural artifacts (4000-1000 yr B.P.)

sandstone/shale bedrock

$$
\text { - conformity }
$$

Figure 7-5. Alluvial stratigraphy of the upper Elm Creek basin. 

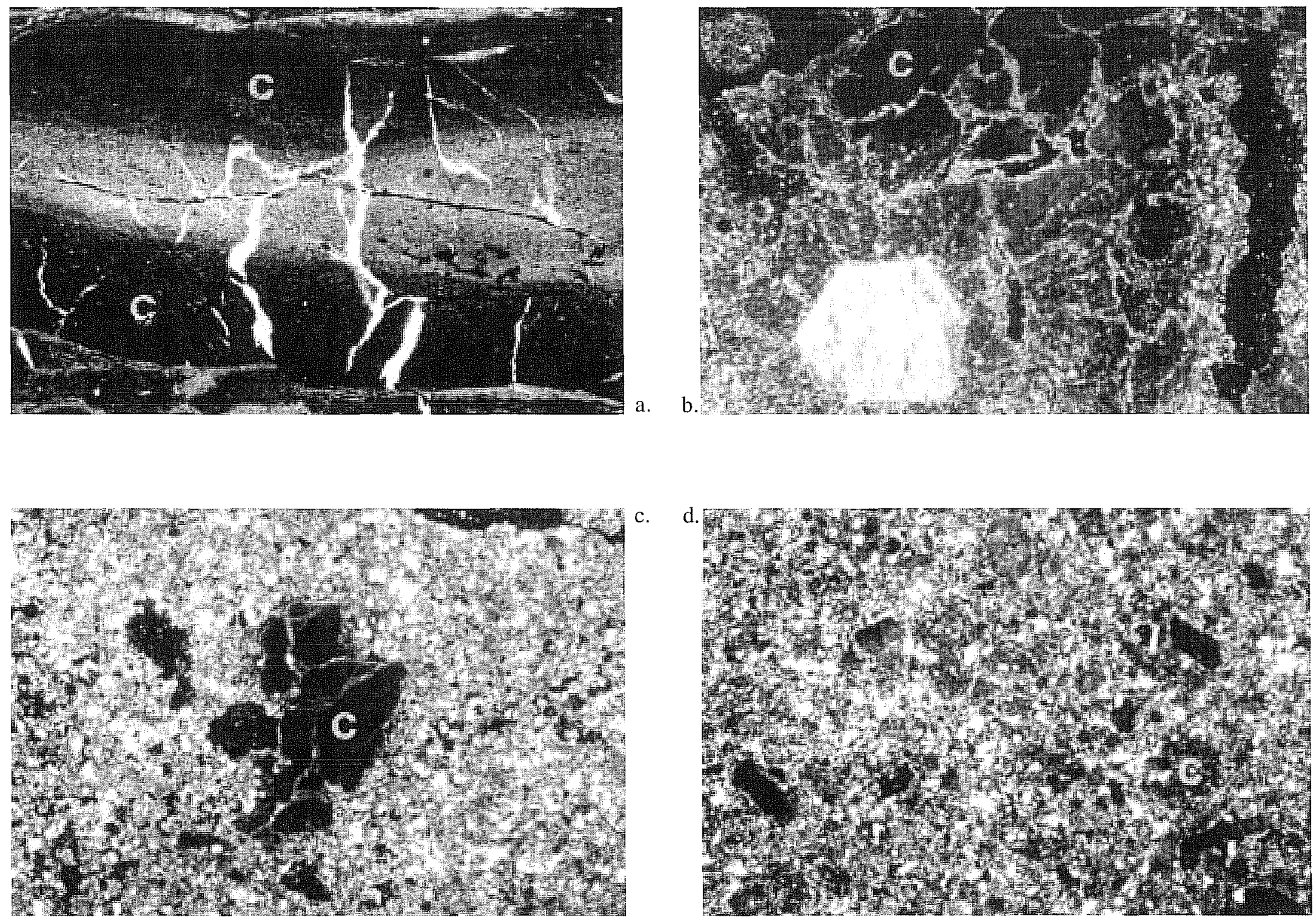

Figure 7-4. Photographs of micromorphic thin sections showing progressive stages of clay clast destruction. a. EP-1 (plane light); b. EP-2 (polarized light); c, d. BHT 8 (polarized light). c=clay clast. 


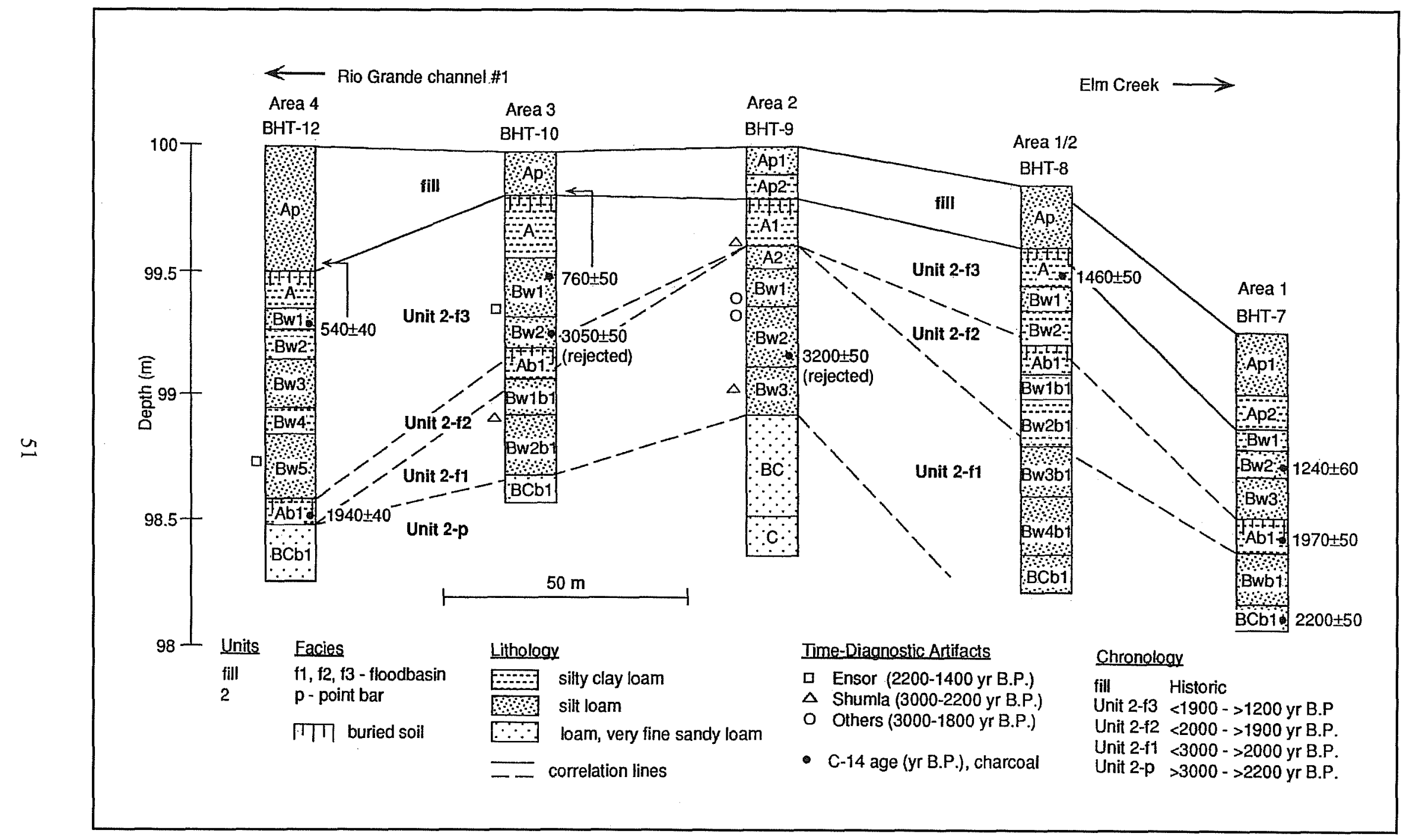

Figure 7-6. Alluvial stratigraphy at site 41MV120 constructed from BHTs. Descriptions from BHTs 10 and 12 were modified from archaeological field notes. 

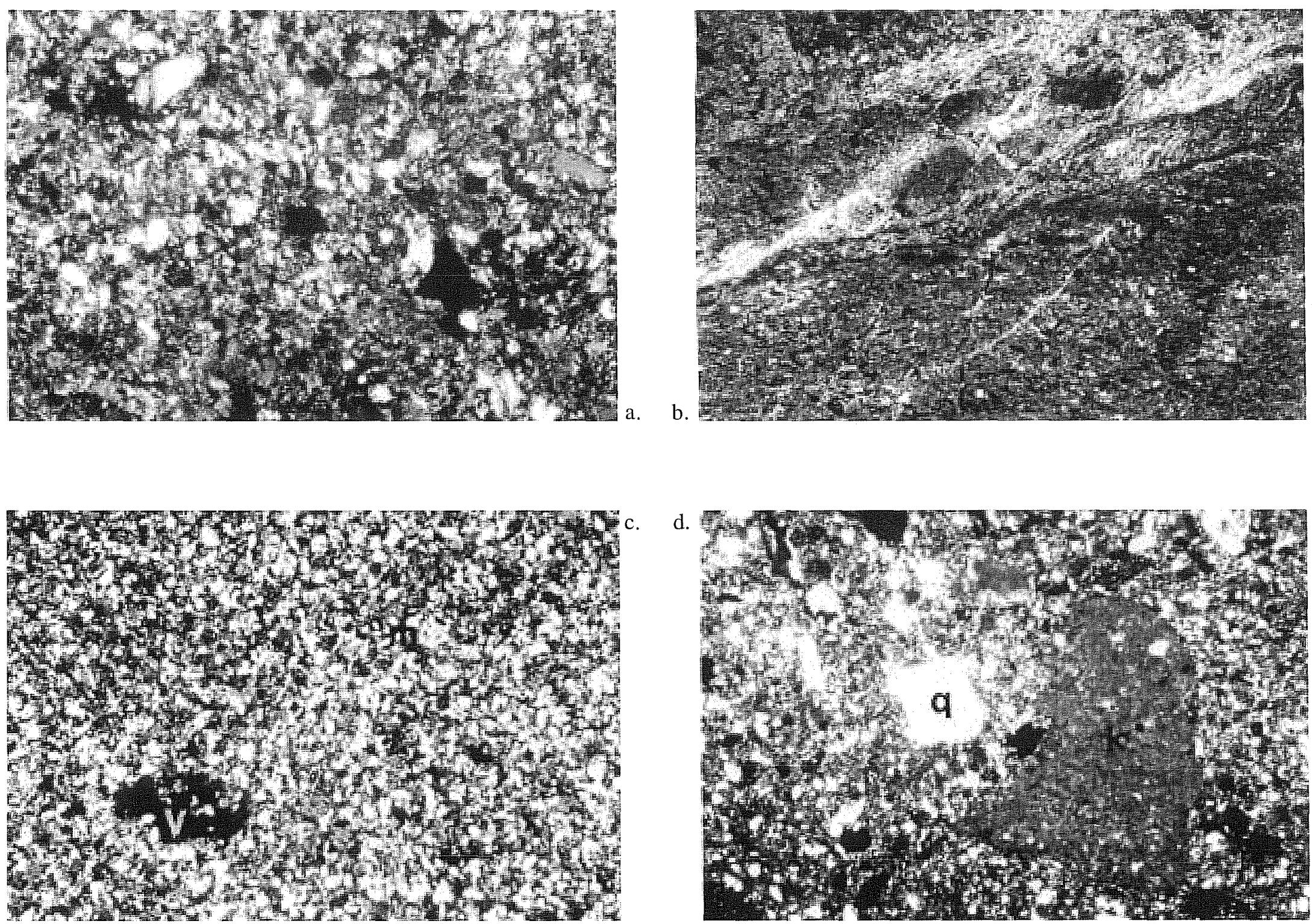

Figure 7-7. Photographs of micromorphic thin sections showing environments of deposition. a, b. EP-1; c, d. BHT 9 (all with polarized light). $\mathrm{q}=$ quartz; $\mathrm{m}=$ mica; $\mathrm{v}=\mathrm{vugh} ; \mathrm{k}=$ primary carbonate nodule; $\mathrm{c}=$ charcoal. 


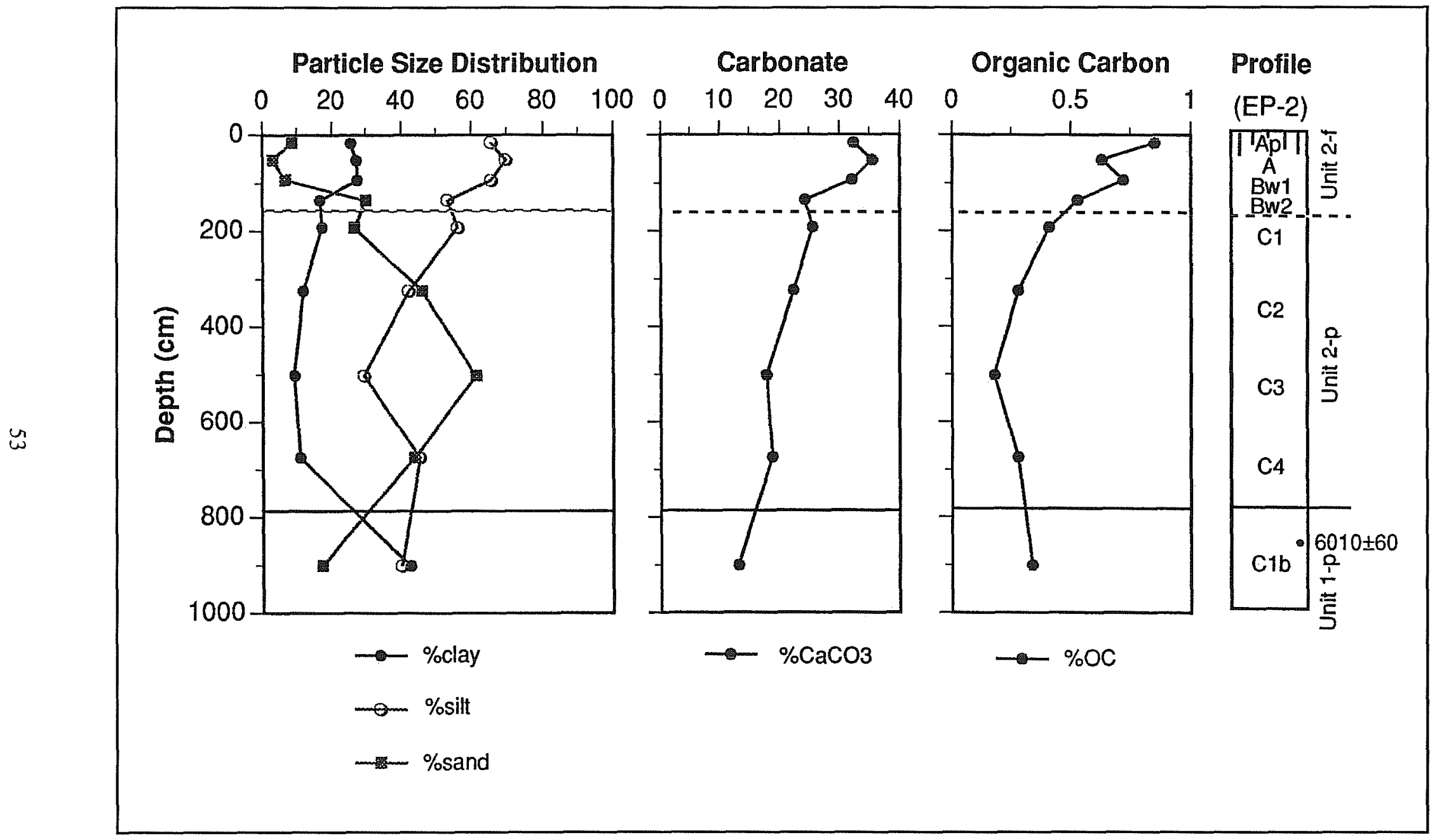

Figure 7-8. Soil-stratigraphic physical and chemical data from EP-2. 


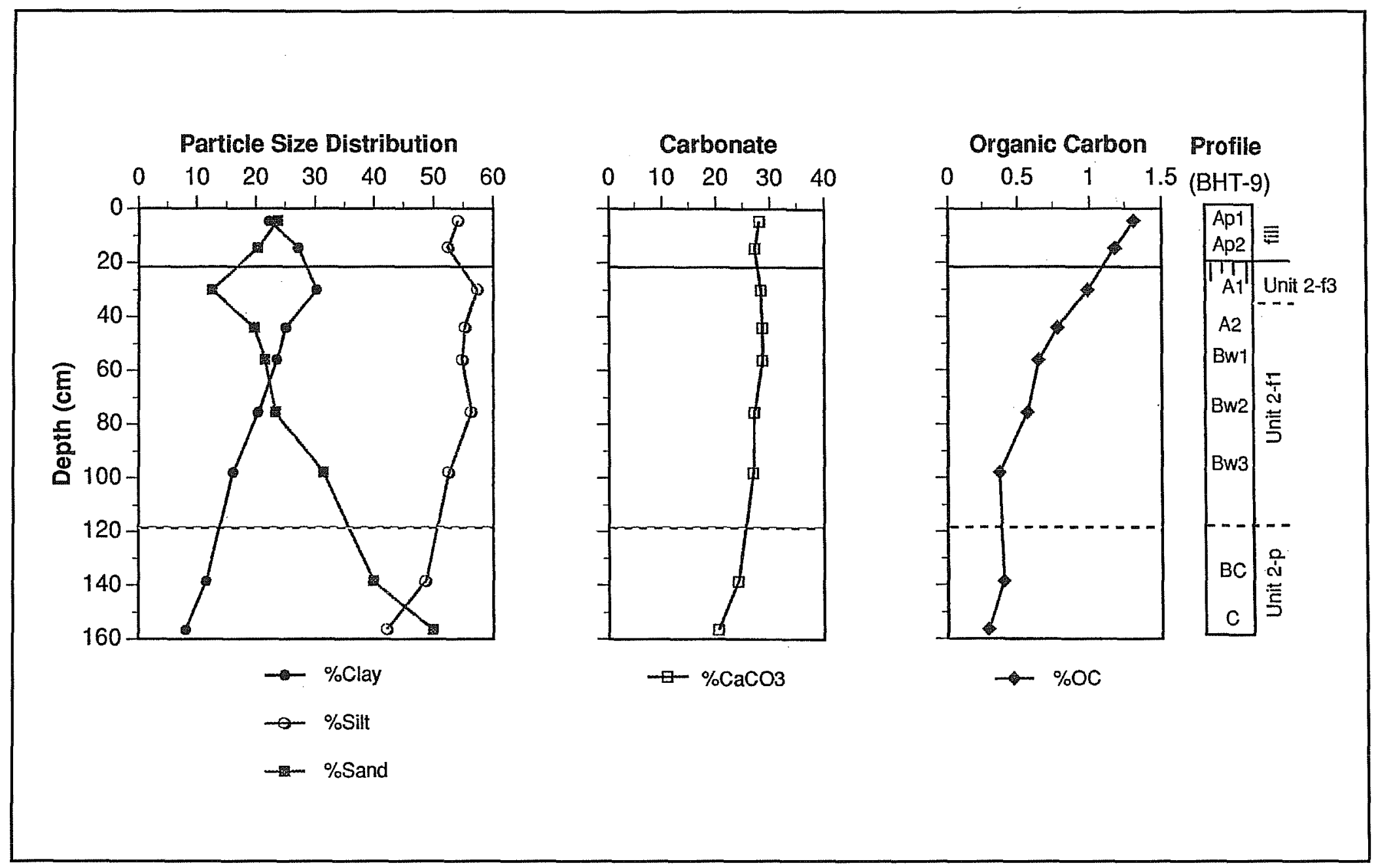

Figure 7-9. Soil-stratigraphic physical and chemical data from BHT 9. 


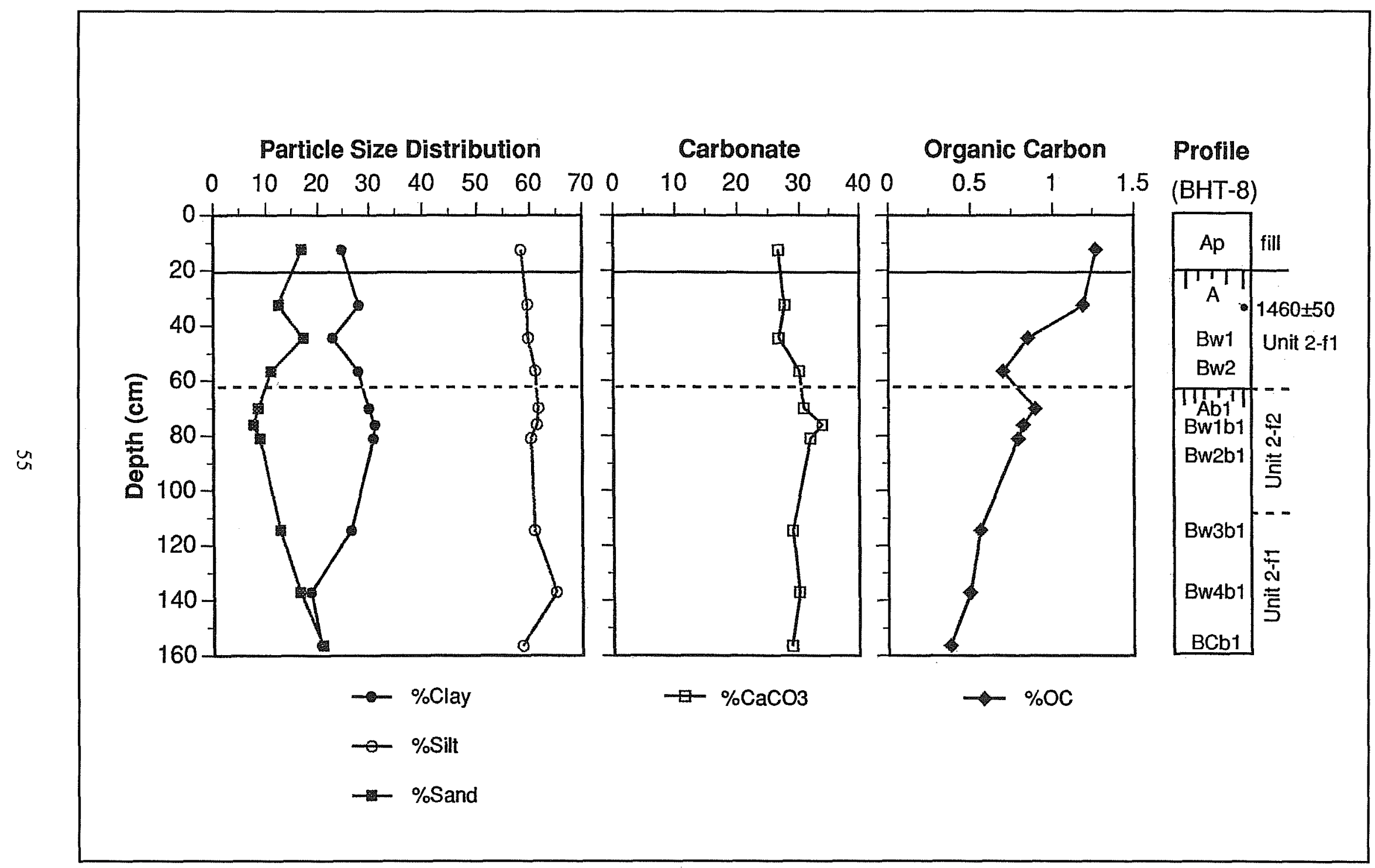

Figure 7-10. Soil-stratigraphic physical and chemical data from BHT 8. 
Unit 3 in EP-1 (Figure 7-3). Two tree stumps (or roots) dated to $540 \pm 40$ B.P. (Beta 104967) and $760 \pm 50$ B.P. (Beta 104966) in BHTs 12 and 10, respectively (Figure 7-6). These materials post-dated prehistoric occupation of the site and were probably woody plants growing on the Rio Grande and Elm Creek T1 flood terrace in response to reduced sedimentation rates after the Rio Grande had down cut and began forming the T0 floodplain. The $3200 \pm 50$ and $3050 \pm 50$ B.P. ${ }^{14} \mathrm{C}$ ages in BHTs 9 and 10, respectively, were rejected because they came from dispersed charcoal of unknown origin and because the ages were inconsistent with the alluvial chronology established in BHT 7, 8, and 12 based on hearth charcoal ${ }^{14} \mathrm{C}$ ages and time-diagnostic artifacts (Figure 7-6).

Channel 1 represents an abandoned channel segment or oxbow of the Rio Grande, or an abandoned tributary of the Rio Grande or Elm Creek (Figure 7-1). A thick point bar facies exposed in EP-5 and partly in BHT 9 (Figures 7-3 and 7-6), indicates that the channel may have been occupied by the Rio Grande at one time. The channel was probably active during, and sometime after, 6000 B.P. and joined with Elm creek somewhere between EP-1 and EP-2. It is unclear whether the channel was active at the time of prehistoric occupation at site $41 \mathrm{MV} 120$. If not, however, it may have been filling with floodbasin alluvium from periodic flooding.

\section{T0 Floodplain}

The T0 surface forms the actively aggrading floodplains of the Rio Grande and Elm Creek (Figure 7-1). The T0 floodplain is situated 9-11 $\mathrm{m}$ above the adjacent low water channels within the modern meander belts. Meander scroll topography (ridge and swale) is still evident within the modern meanders. Unit 3 forms the constructional flood surface of T0 and is laterally inset to the T1 flood terrace and deposits (Figure 7-3: EP-1). It consists of interbedded silty clay loams to sands, with colors of very pale brown to dark grayish brown (Appendixes B1 and B3). Finer-grained deposits occur more in the upper floodbasin facies (3-f) than in the lower point bar facies (3-p). Pedogenesis has been minimal with development of A-C soil profiles that classify as Entisols (ustifluvent). Fine-grained layers typically display horizontal laminations, soft sediment deformation, and iron reduction zones from a fluctuating water table (Figure 7-7b; Appendix B2). Coarse-grained layers have properties similar to the point bar facies in Unit 2 (Figure 7-7a; Appendix B2). In contrast to Unit 2 , Unit 3 is more stratified with respect to particle size distribution, carbonate content, and organic carbon content (Figure 7-11). Furthermore, organic carbon and carbonate contents are less in Unit 3 than in Unit 2. In sum, these characteristics reflect minimal pedogenesis and frequent flooding of varying magnitudes within a narrowly confined floodplain.

A dispersed charcoal ${ }^{14} \mathrm{C}$ age from deep in EP-1 suggests that deposition of Unit 1 was underway by $1170 \pm 60$ B.P. (NSRL-3536) (Figure 7-3). A topographic escarpment between the T1 flood terrace and the T0 floodplain indicates that a period of channel incision occurred prior to deposition of Unit 3. The ${ }^{14} \mathrm{C}$ ages from Unit 2 and Unit 3 show that channel downcutting and formation of the escarpment occurred sometime between approximately 1100 and 1300 B.P. The meander belt configuration at the time of downcutting is shown by the shape of the escarpment (Figure 7-1: Channel 2). Geomorphic relations also show that Elm Creek joined with the outside meander of Channel 2 (Rio Grande) at the time of channel incision. Afterward, the Elm Creek and Rio Grande confluence began migrating to the southwest, perhaps in response to greater channel gradient and channel power of Elm Creek. The modern meanders of the Rio Grande have thus been migrating at a rate of $60-70 \mathrm{~m}$ per 100 years based on the relation between ${ }^{14} \mathrm{C}$ dating and the width of the meander belt.

The confluence of Elm Creek and the Rio Grande in the project area appears to have remained somewhere between EP-2 and EP-1 during the 6000-1100 B.P. interval (Figure 7-1). In contrast, Channel 1 just to the north of the site, migrated from the valley wall back to the T1/T0 escarpment at Channel 2 prior to downcutting. Consequently, with respect to channel meandering, site $41 \mathrm{MV} 120$ formed in a relatively stable geomorphic position. 


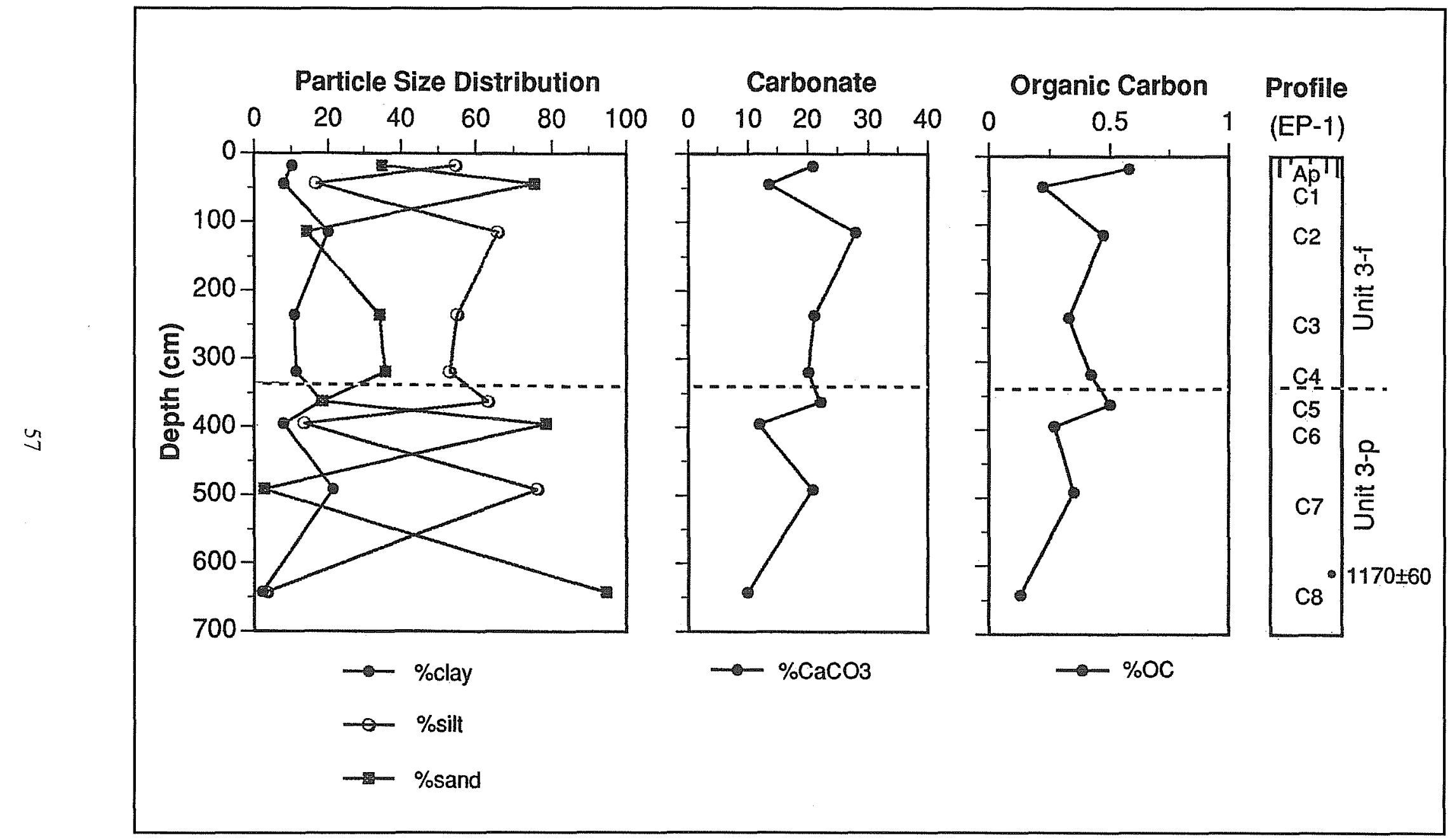

Figure 7-11. Soil-stratigraphic physical and chemical data from EP-1. 


\section{Regional Correlation}

The most comprehensive local geologic investigation of the Rio Grande occurred just north of Laredo (Garner 1997). Here, two alluvial terraces and two alluvial floodplains were identified. The T4 terrace was the most widespread, located $16-18 \mathrm{~m}$ above the modern lowwater channel, and dated to between 5300 and 2300 B.P. The T3 terrace occurred locally, was situated 12-14 $\mathrm{m}$ above the modern low water channel, and dated to 1500-500 B.P. in the upper two meters. Cultural materials were discovered in the T3 and T4 terrace deposits. The $\mathrm{T} 2$ and $\mathrm{T} 1$ floodplains were frequently flooded and situated less than $10 \mathrm{~m}$ above the modern low-water channel. No ${ }^{14} \mathrm{C}$ ages were obtained from these deposits.

Just south of Laredo, Evans (1961) identified two terraces and three flood benches within the modern valley of the Rio Grande. The Zapata terrace was located an average of $20 \mathrm{~m}$ above the modern low-water channel. Basal gravel deposits of this terrace contained extinct late Pleistocene fauna, whereas the upper silty material yielded Holocene cultural artifacts. The Rosita terrace had an average elevation of $14 \mathrm{~m}$ above the Rio Grande. Cultural material was discovered throughout this terrace fill. The flood benches were recently deposited and less than $10 \mathrm{~m}$ above the river. Caran (1993) studied the geomorphology of the Rio Grande in the vicinity of Eagle Pass. He recognized three alluvial landforms above the modern low-water channel of the Rio Grande: T1, 7 m; T2, 7-10 m; T3, 10-15 m. The T1 landform represented the modern floodplain, whereas the $\mathrm{T} 2$ terrace was apparently deposited by a local flood event. The $\mathrm{T} 2$ terrace was estimated to be $1,000-2,000$ years old based on stratigraphic position and correlation to unpublished ${ }^{14} \mathrm{C}$ ages from another Rio Grande sequence. The T3 terrace was thought to be middle Holocene in age.

The Holocene alluvial stratigraphy of the Rio Grande in the project area can be correlated to previous geologic investigations. The highest terraces within the Holocene valley of the Rio Grande from Eagle Pass to Laredo date to the middle to late Holocene. However, the high Holocene terrace near Eagle Pass occurs at lower elevations than similar age terraces near Laredo. Deposits dating from late Holocene to modern also occur at lower elevations near Eagle Pass than at Laredo. The $\mathrm{T} 0$ floodplain of the current project area was split into local flood benches in the other study areas. In sum, these data show that terrace correlation within the Rio Grande basin is not possible if based solely on elevation above the low-water channel. Apparently, the terrace sequence near Laredo is confined to a restriction in the Rio Grande valley. The broader valley in the project area has probably permitted more lateral channel migration and a subsequent decrease in downstream gradient. Other possibilities for the lack of terrace correlation are tectonic activity, differential terrace preservation, and enhanced downcutting in recent times that increased the downstream gradient of the modern channel relative to the terraces. Further naming of terraces along the Rio Grande is discouraged until a regional investigation of its Quaternary history is conducted.

\section{Geoarchaeology of Site 41MV120}

\section{Stratigraphy}

The alluvial stratigraphy associated with site $41 \mathrm{MV} 120$ was exposed in BHTs 7-12 (Figures 7-1 and 7-6). The site was buried within a floodbasin facies (f) of Unit 2 situated on top of a point bar facies (p). The floodba$\sin$ facies was subdivided into three lithofacies: Unit 2-f1, Unit 2-f2, and Unit 2-f3, from oldest to youngest.

\section{Unit 2-p}

Unit 2-p is the oldest deposit associated with site 41MV120 (Figure 7-6). As exposed in BHTs 9, 10, and 12 , this unit appears to represent a point bar that forms the structural foundation for the overlying floodbasin deposits and part of the site. As revealed in the backhoe trenches, the subsurface shape of the point bar indicates that it may parallel Elm Creek or abandoned Channel 1 of the Rio Grande (Figures 7-1 and 7-6). Textures range from loams to very fine sandy loams with low organic carbon contents (Figure 7-9; Appendixes B1 and B3) and minor biological activity (Figure 7-7c; Appendix B2). 


\section{Unit 2-f1}

Unit 2-fl was exposed in all backhoe trenches, except BHT 12 where it pinches out between BHTs 10 and 12 (Figure 7-6). This unit conformably overlies Unit 2-p and consists of silt loam textures and low organic carbon contents (Figures 7-9 and 7-10; Appendixes B1 and B3). In BHT 9, Unit 2-f1 represents a continuation of a fining upward sequence from Unit 2-p (Figure 7-9). Cracking clay clasts, horizontal and dipping laminations, and biological activity also increase from bottom to top within the unit (Figures 7-4c; 7-12a, c, d; 7-13c; Appendix B2).

\section{Unit 2-f2}

Unit 2-f2 encompasses the buried Ab1 paleosol in BHTs 7, 8, 10, and 12 (Figure 7-6). This unit represents a slowly aggrading flood drape that buried the two older facies (2-p, 2-f1), except across the intervening point bar exposed in BHT 9. Textures were all silty clay loams with moderate to high organic carbon levels (Figure 7-10; Appendixes B1 and B3). Also occurring were few gypsum crystals, few cracked clay fragments and horizontal laminations, and high biological activity (Figures 7-13a, b, d; Appendix B2).

\section{Unit 2-f3}

Unit 2-f3 buries all other stratigraphic units across the site, and prior to road construction, probably formed the ground surface of the T1 flood terrace (Figure 7-6). This unit represents a return to more rapid aggradation, but mainly of floodbasin origin. In general, textures fine upward with organic carbon contents increasing upward (Figures 7-9 and 7-10; Appendixes B1 and B3). Also occurring were few cracked clay clasts and laminations, and moderate to high biological activity (Figures 7-4d, 10b; Appendix B2).

\section{Fill}

The upper part of Unit 2-f3 was partially excavated and back filled during construction of FM 1589. The backfill material denoted by Ap horizons covers Unit 2-f3 across the site (Figure 7-6). Textures range from silt loam to silty clay loam with high organic carbon contents (Figures 7-9 and 7-10; Appendixes B1 and B3). There is also a greater abundance of medium and coarse sands than in the other units (Appendix B3). Furthermore, the fill material is poorly sorted; has fragments of unweathered basalt, rhyolite, and limestone; and high bioturbation (Figure 7-7d; Appendix B2).

\section{Rates of Sedimentation}

Carbon-14 ages and time-diagnostic artifacts show that floodbasin deposition of Unit 2-f occurred between approximately 2200 and 1200 B.P. The timing of deposition for each lithofacies of Unit 2-f was estimated to be: Unit 2-f1, <3000 to $>2000$ B.P.; Unit 2-f2, <2000 to $>1900$ B.P.; and Unit 2-f3, $<1900$ to $>1200$ B.P. (Figure 7-6). By determining the age range of each lithofacies in relation to corresponding facies thickness, rates of sedimentation were calculated for each lithofacies (Table 7-1). Average rates of alluvial deposition decreased in the order of Unit 2-f1, Unit 2f-3, and Unit $2 \mathrm{f}-2$. However, standard deviations were high, indicating variability in sedimentation rates both laterally and vertically across the site. On average, Unit 2-f1 depositional rates were 3.5 times faster than Unit $2 \mathrm{f}-2(2 \mathrm{f}-1 / 2-\mathrm{f} 2$ ratio), and 1.5 times greater than Unit 2-f3 (2f-1/2-f3 ratio) (Table 7-1).

Variation in calculated rates of deposition across the site were not unexpected. Rates of deposition for Unit 2-fl were rapid indicating a continuum of upper point bar deposition. Unit 2-f2 had significantly slower depositional rates signifying a period of reduced flood deposition and enhanced pedogenesis. Unit 2-f3 shows higher depositional rates on the west end of the site, but relatively intermediate rates overall. These variations may be related to shifting of the position of abandoned Channel 1 or Elm Creek in relation to the site (Figure 7-1). 

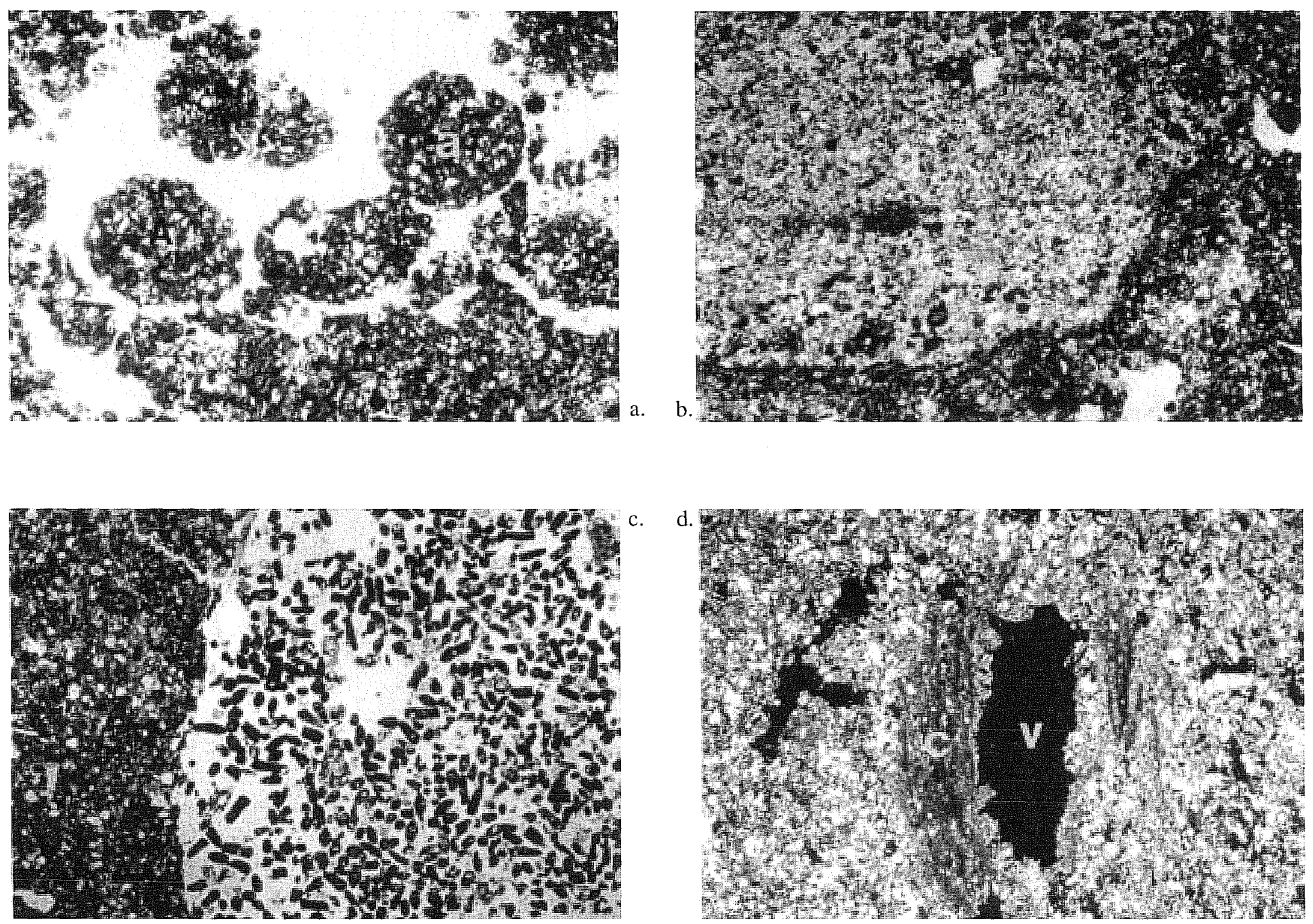

Figure 7-12. Photographs of micromorphic thin sections showing different kinds of biological activity. a, c, d. BHT 9; b. BHT 8. a=aggrotubule (earthworms); $g=$ granotubule (ants?); v=vugh; $\mathrm{c}=$ clay clast. 

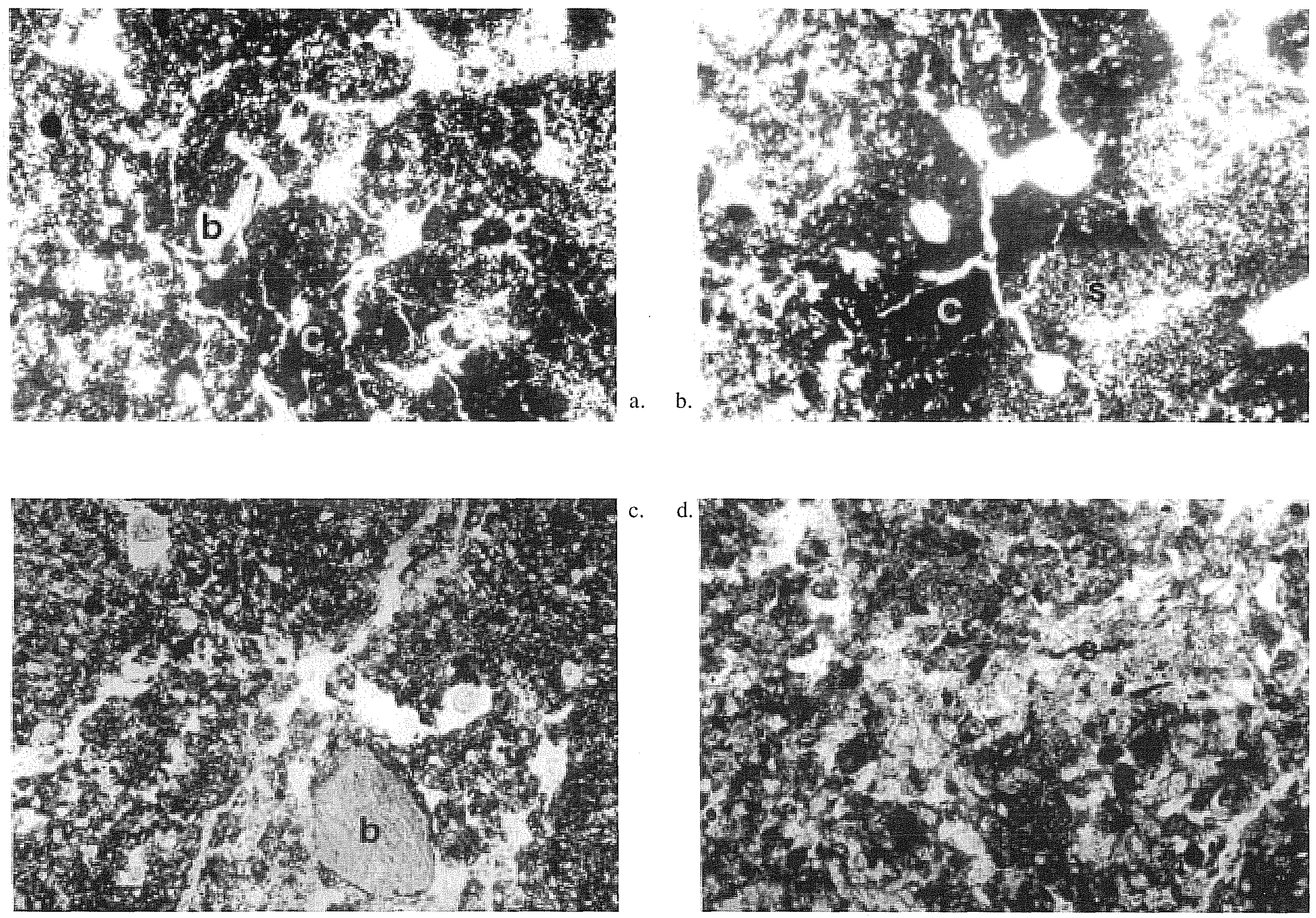

Figure 7-13. Photographs of micromorphic thin sections showing cultural debitage. a. BHT 12 (plane light); b. BHT 12 (polarized light);

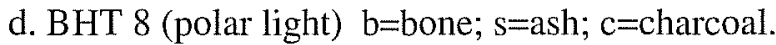




\section{Site Formation}

\section{Background}

The alluvial depositional record often conditions the spatial and temporal distribution of the archaeological record (Ferring 1986). To test this hypothesis at site 41MV120, artifact densities for flake weight, flake number, and burned rock weight were averaged for each level for each block of archaeological excavation units (Areas 1-3). Artifact densities for each level of each block were plotted against the alluvial stratigraphic record constructed from adjacent backhoe trenches. Artifact densities were subsequently recalculated per lithofacies of Unit 2-f using the depositional ratios from Table 7-1. For example, in order for the artifact density to be the same for Unit 2f-1 and Unit $2 \mathrm{f}-2$ in BHT 7 , the amount of cultural debitage would have to be 8.9 times greater in Unit 2-f2 than in Unit 2-f1 (Table $7-1)$. Three hundred thin section point counts were conducted for charcoal abundance in selected horizons of BHTs $8,9,10$, and 12 . These results were also plotted against adjusted rates of alluvial deposition.

Recalculated artifact densities were highly dependent on the reliability of inferred depositional rates for each lithofacies of Unit 2-f. Without more refined dating, these rates were subject to error, but are believed to show the correct relative trends in artifact densities. Rates of alluvial deposition were based on accepted ${ }^{14} \mathrm{C}$ ages, time-diagnostics artifacts, and correlation of the lithofacies across the site.

\section{Results}

The flake-weight distribution in Unit 2-f of BHT 7 displays fluctuations between depths of 120 and $50 \mathrm{~cm}$, before sharply decreasing in the upper part (Figure $7-14 a$ ). The number of flakes increases from a depth of 120 to $80 \mathrm{~cm}$ and then abruptly decreases above a depth of $80 \mathrm{~cm}$ (Figure 7-14b). The weight of burned rock shows an overall increase from a depth of 120 to $70 \mathrm{~cm}$, which then decreases sharply (Figure 7-14c).

Rates of deposition in Unit 2f-1 were nearly 9 times greater than in Unit $2 \mathrm{f}-2$ (2-f1/2-f 2 ratio), and nearly 3 times greater than Unit $2-\mathrm{f} 3(2-\mathrm{f} 1 / 2 \mathrm{f}-3$ ratio) (Table 7-1). As a consequence, adjusted values for flake weight, flake number, and burned rock weight decrease appreciably above depths of 90 to $100 \mathrm{~cm}$ in BHT 7 (Figure $7-14 a, b, c)$. Because the stratigraphic sequence in BHT 8 is similar to that in BHT 7, correlation of cultural materials from one to the other seems reasonable. Thin section point counts of charcoal from BHT 8 suggest that the maximum adjusted percentage occurs within the same depth range as the most intense cultural activity, as determined by debitage abundance in BHT 7 (Figure 7-14d). In sum, the most intense cultural activity, based on debitage and charcoal abundance, appears to have occurred in Unit 2-fl of BHT 7, and perhaps BHT 8 as well. This corresponds with a 2200 and 2000 B.P. time interval. Occupation, as determined in Unit 2-f1, continued after 2000 B.P. and up until around 1200 B.P., but at a lower level of intensity.

Table 7-1. Rates of Alluvial Deposition for Unit 2 at 41MV120

\begin{tabular}{|c|c|c|c|c|c|}
\hline \multirow{2}{*}{ BHT } & \multicolumn{2}{|c|}{ Rates of Deposition (cm/100yr) } & \multicolumn{2}{c|}{ Ratios } \\
\cline { 2 - 6 } & Unit 2f-1 & Unit 2f-2 & Unit 2f-3 & 2f-1/2f-2 & 2f1/2f-3 \\
\hline 7 & 12.5 & 1.4 & 4.4 & 8.9 & 2.8 \\
\hline 8 & - & 5.0 & 4.7 & - & - \\
\hline 9 & 6.8 & - & 2.4 & - & 2.4 \\
\hline 10 & 4.0 & 1.2 & 3.9 & 3.3 & 1.0 \\
\hline 12 & - & 1.2 & 11.3 & - & - \\
\hline A verage & $\mathbf{7 . 8}$ & $\mathbf{2 . 2}$ & $\mathbf{5 . 3}$ & $\mathbf{3 . 5}$ & $\mathbf{1 . 5}$ \\
\hline 1-sigma & $\mathbf{3 . 5}$ & $\mathbf{1 . 6}$ & $\mathbf{3 . 1}$ & & \\
\hline
\end{tabular}




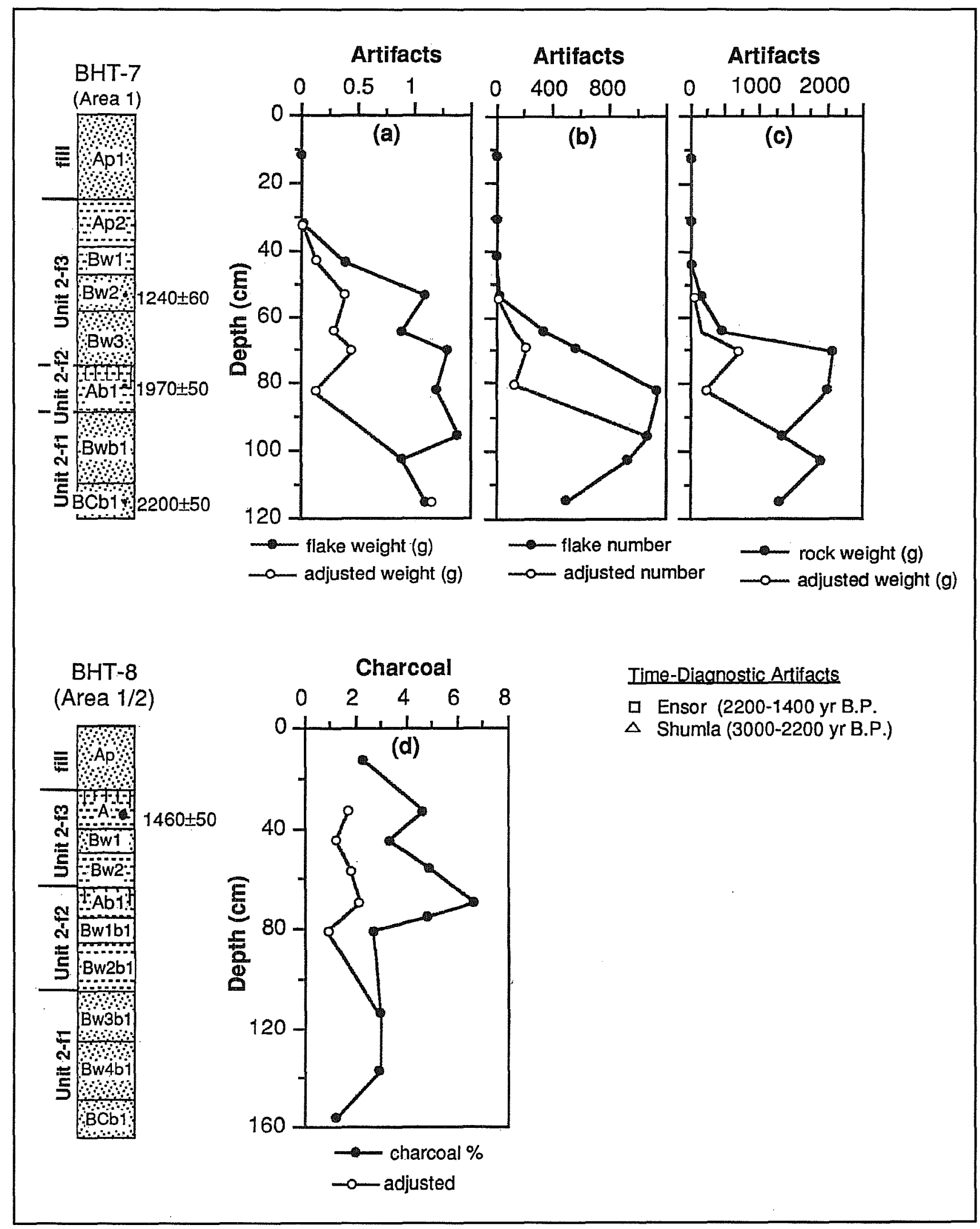

Figure 7-14. Depth distribution of cultural material vs. alluvial stratigraphic column for BHTs 7 and 8. 
The alluvial stratigraphy exposed in BHT 10 was also similar to those of BHTs 7 and 8. In contrast, rates of deposition were nearly identical between Unit 2-f1 and Unit 2f-3 in BHT 10 (Table 7-1). As a result, adjustments in artifact densities were only needed for Unit 2f2. Adjusted flake weight was relatively uniform throughout the profile of BHT 10 (Figure 7-15a), whereas flake number and rock weight showed peaks between depths of 70 and $50 \mathrm{~cm}$ (Figure 7-15b, c). Combining flake number and burned rock weight, the most intense occupational period appears to have occurred in the lower part of Unit 2-f3 between 1900 B.P. and perhaps 1500 B.P. An intact hearth was found within this same depth-zone and, as revealed in thin section (not shown), the number of microscopic charcoal fragments was no more than non-hearth zones in other areas. This explains why charcoal was not visible in the field for this feature. As with BHT 7, cultural activity was at a minimum during formation of the $\mathrm{Ab} 1$ paleosol. Artifacts in the overlying road fill were probably in a secondary context.

Overall, rates of deposition in BHT 9 were higher than the other backhoe trenches because of the presence of a thick section of the rapidly aggrading Unit 2-f1 lithofacies and the absence of the slowly aggrading Unit 2-f2 lithofacies (Table 7-1). Overall, adjusted artifact densities in BHT 9 were highest in Unit 2-fl between a depth of 70 and $40 \mathrm{~cm}$ (Figure 7-15a, b, c). This zone also coincides with peak charcoal abundance (Figure $7-15 \mathrm{~d}$ ). Above a depth of $50 \mathrm{~cm}$ there is a significant decrease in artifact density and charcoal abundance. Combining the three data sets suggests that the most intense cultural activity in BHT 9 occurred in Unit 2-f1 between depths of 70 and $40 \mathrm{~cm}$, or between approximately 2500 and 2000 B.P; however, occupation proceeded up until 1200 B.P. (Unit 2-f3), but at a lower level of intensity. Artifacts in the Ap horizons were probably in a secondary context from road construction.

In sum: 1) occupation appears to have occurred continuously from $<3000$ to 1200 B.P. across the site; 2) intense cultural activity occurred deeper in BHTs 7 , 8 , and 10 than in BHT 9; 3) occupation in BHT 9 was most intense somewhat earlier than the other two areas, between about 2500 and 2000 B.P.; 4) occupation in BHT 7 peaked between approximately 2200 and
2000 B.P. and decreased considerably after 1900 B.P.; and 5) cultural activity was somewhat uniformly distributed throughout the BHT 10 profile between $<3000$ and 1200 B.P., but peaked between 1900 and 1500 B.P.

\section{Preservation Potentials}

The point bar facies of Unit 2-p rapidly aggraded shortly before 2200 B.P. at site $41 \mathrm{MV} 120$ (Figure 7-6). There is little evidence for hunter and gatherer activity at the site at this time. This deposit, however, could contain undiscovered buried Middle and Late Archaic features. Contextual integrity would probably be high because of rapid burial and the near absence of biological activity.

By 2200 B.P. the channel that deposited the point bar facies had shifted away from the site and began depositing the Unit 2-f1 lithofacies (Figure 7-6). This episode of deposition eventually buried the point bar. Because deposition of Unit 2-f1 was rapid and in an overbank setting, preservation potentials were probably high. Bioturbation, however, was somewhat greater in this unit than in Unit 2-p, which would have increased post depositional disturbance. Overall, these factors would have permitted preservation of relatively discrete occupation zones in a primary context. Furthermore, occupation intensities were determined to be relatively high at the site in Unit 2-f1 between 2200 and 2000 B.P.

Between 2000 and 1900 B.P., flood frequency decreased at site 41MV120 possibly because Channel 1, or Elm Creek, had migrated farther away from the site. Reduced sedimentation resulted in accumulation of Unit 2-f2 and formation of the fine-grained Ab1 paleosol (Figure 7-6). This flood drape buried Unit 2-f1 only on the margins of the point bar, indicating that flood magnitudes were relatively low. Preservation potentials of discrete components in a primary context in Unit 2-f2 would thus have been lower because of mixing of occupation zones within a thin layer that accumulated during a 1,000-year interval. Furthermore, post-depositional bioturbation was high in this unit. Figure 7-4 demonstrates how a clayey flood drape evolves into small dispersed clay clasts with intense bioturbation. Artifacts may be moved from a primary 


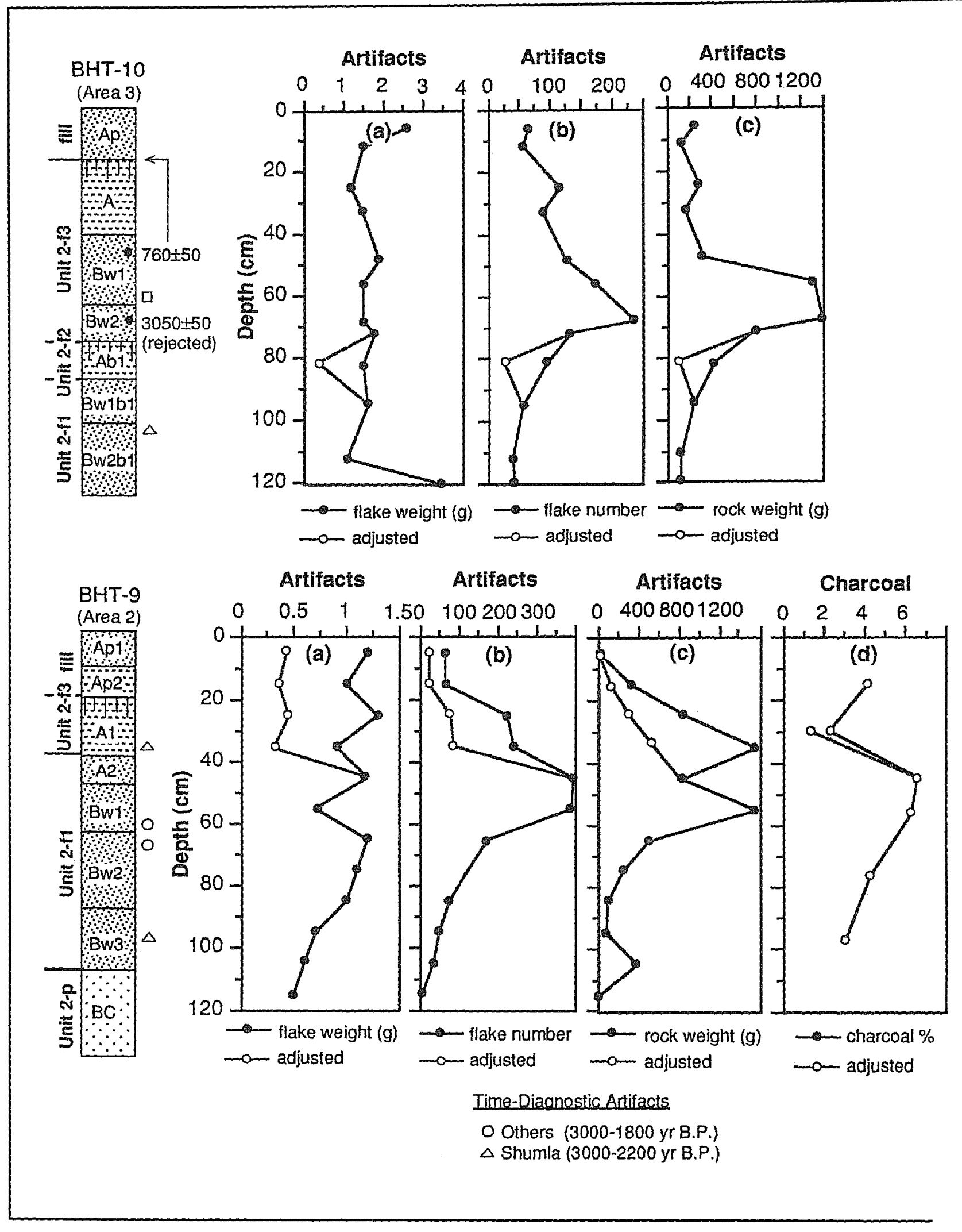

Figure 7-15. Depth distribution of cultural material vs. alluvial stratigraphic column for BHTs 10 and 9. 
to a secondary context in the same manner. Vestiges of intense biological activity remain in the form of aggrotubules and granotubules (Figure 7-12). These factors, coupled with low cultural activity at this time, points to relatively low preservation potentials across the site. Regardless, an intact hearth was discovered in BHT 12 in the Ab1 paleosol. BHT 12 had an abundance of charcoal, ash, and bone, as observed in thin section (Figure 7-13a, b). Charcoal fragments deposited culturally tend to be more angular than detrital charcoal grains.

Between 1900 and 1200 B.P., aggradational rates again increased, resulting in deposition of the Unit $2 \mathrm{f}-3$ lithofacies (Figure 7-6). The cause of renewed deposition could reflect migration of Channel 1 back toward the vicinity of the site (Figure 7-1), or an increase in channel discharge and flood frequency. In fact, because Unit 2-f3 thickens between BHTs 10 and 12, its rapid rate of aggradation in this area may have been because of its proximity to Channel 1 . It is unclear whether this channel was an active meander of the Rio Grande during prehistoric occupation, or whether it had already been abandoned. Preservation potentials in a primary context in Unit 2-f3 should be greatest on the west and east end of the site where the unit is thickest. In the middle of the site, Unit 2- $\mathrm{f} 3$ becomes compressed to a narrow zone where it buries the point bar facies. Here, cultural components dating to a longer time interval will be compressed into a thin sediment layer. Thus, preservation potentials of discrete occupation zones will be lower in this area.

During prehistoric occupation of site 41MV120, the confluence of Elm Creek and the Rio Grande appears to have remained somewhere between EP-1 and EP-2 (Figure 7-1). Consequently, a shifting stream confluence had no influence on prehistoric adaptation strategies. The site probably formed in relation to water resources provided by Elm Creek and abandoned Channel 1. Even if Channel 1 was not active at the time of occupation, it would have been slowly filling with overbankalluvium, perhaps while maintaining a water supply. This area would then have provided two water sources for subsistence with the Elm Creek and Rio Grande confluence not far away. Thin sections from the project area suggest that the floodbasin sediments associated with the site were deposited primarily by Rio Grande flood waters. This conclusion was based on sediment Munsell colors with high chromas, low sand contents, and the near-absence of chert fragments. Chert fragments, in particular, are characteristic of Elm Creek alluvium because of exposure of the Uvalde Gravel in the surrounding Elm Creek drainage basin.

Abandonment of site 41MV120 appears to have coincided with channel incision of the Rio Grande and Elm Creek near 1200 B.P. After downcutting and migration of the channel network away from the site, flood frequency and flood deposition would have decreased in the area. Interestingly, cultural activity seems to have decreased in response to decreased flooding between 2000 and 1900 B.P. (Ab1 paleosol) and after 1200 B.P. If these factors influenced human adaptation strategies, then flooding, rather than long-term landscape stability, was viewed as favorable by prehistoric people.

\section{Alluvial Stratigraphy of Elm Creek}

Three alluvial landforms were identified in the upper Elm Creek drainage basin: a Pleistocene T2 terrace, a Holocene T1 terrace, and the T0 floodplain (Figure 7-2). One alluvial stratigraphic unit, associated with the T1 flood terrace, was described with exposures provided by EP-3 and EP-4 (Figure 7-5). Inferences about the other landforms and alluvial deposits were made from topographic maps, soil maps, field reconnaissance, and correlation to the deep sediment core (EP2) taken in the T1 flood terrace of the Rio Grande.

\section{T2 Terrace}

The highest and oldest alluvial landform on Elm Creek is the T2 terrace on the north side of the valley (Figure $7-2$ ). It is situated approximately $12-13 \mathrm{~m}$ above the modern low-water channel. The major soil mapped on the $\mathrm{T} 2$ terrace is the Elindio series (Stevens and Arriaga 1977). This soil classifies as a calciustoll with 5-10 percent accumulations of secondary carbonate nodules in the subsoil

Based on stratigraphic position and degree of soil development, the T2 terrace is probably Pleistocene, or perhaps early Holocene, in age. The degree of soil development associated with the T2 Pleistocene terrace 
downstream near the confluence with the Rio Grande (Figure 7-1) suggests that it may be older than the T2 terrace in the upper basin (Figure 7-2).

\section{T1 Flood Terrace}

The $\mathrm{T} 1$ flood terrace is situated approximately $7-8 \mathrm{~m}$ above the modern low water channel of Elm Creek (Figure 7-2). Unit 1 alluvium was identified and described in EP-3 and EP-4 cores taken from the T1terrace on the north side of Elm Creek (Figure 7-5). Unit 1 was also identified in EP-2 of the T1 flood terrace of the Rio Grande (Figure 7-16a). Both sediment cores along Elm Creek revealed that Unit 1 was unconformably overlying Cretaceous bedrock. Unit 1 in EP-4 consisted of an assemblage of basal channel and point bar facies overlain by a floodbasin facies. The channel/point bar facies consisted of grain supported and subrounded pebbles, an abundance of chert (Figure 7-16b), and minor amounts of ferruginous clasts (Appendixes B1 and B3). The floodbasin facies has weathered to an A-Bt-Btk-Bk soil profile with textures of sandy clay loam and colors of very dark to light olive brown. The soil profile in EP-4 shows a slight increase in total clay and fine clay content with depth suggesting clay translocation (Figure 7-17). More importantly, there has been a significant amount of soluble salt redistribution (Figure 7-16c, d), with maximum accumulation of secondary carbonate (Btk and Bk) and gypsum (Bky1) occurring in the subsoil (Figure 7-17).

EP-3 was taken from the escarpment separating the Pleistocene T2 terrace and the T1 flood terrace (Figure 7-2). Here, Unit 1 also unconformably buried Cretaceous bedrock (Figure 7-5). Furthermore, the channel and point facies have similar textures, colors, and pebble characteristics as Unit 1 in EP-4 (Figure 7-18; Appendixes B1 and B3). Also, the absolute elevations of the lower facies are similar. The lower facies of Unit 1 in EP-3 shows considerable stratification indicating greater fluctuations in flood magnitudes than along the Rio Grande.

The upper half of Unit 1 (1-s) in EP-3 is probably colluvial slope wash because of its position on a sloping terrace escarpment. The Unit 1-s colluvial facies has been pedogenically altered to an A-Bt-Btk-Bky soil profile (Figure 7-18; Appendixes B1 and B3). As with EP-4, total and fine clay movement has occurred with some carbonate redistribution with depth. In addition, gypsum has accumulated in the B horizons. The source for gypsum was probably from the colluvial parent material or from a high ground water table that was present prior to channel downcutting and formation of the $\mathrm{TO}$ floodplain.

Clay movement and carbonate redistribution in Unit 1 suggest that pedogenesis has been ongoing on the $\mathrm{T} 1$ terrace of Elm Creek much longer than on the T1 flood terrace of the Rio Grande near site 41MV120. Furthermore, $\mathrm{a}{ }^{14} \mathrm{C}$ sample from deep in the point bar facies of Unit 1 in EP-3 dated to $7480 \pm 60$ B.P. (Figure 7-5). Time-diagnostic artifacts dating to as early as the Middle Archaic were also discovered on the T1 terrace of Elm Creek just upstream from the upper project area (Uecker 1994). In sum, these chronological indices demonstrate that deposition of Unit 1 along Elm Creek was ongoing by approximately 7500 B.P. and had terminated by approximately 4000 B.P. This is consistent with the degree of soil development for the $\mathrm{T} 1$ terrace.

\section{T0 Floodplain}

The T0 floodplain of Elm Creek is confined to a narrow and entrenched meander belt. Channel cutbank exposures revealed stratified alluvial deposits consisting of brown to dark brown sandy clay loams with siliceous and ferruginous pebbles and coal. The T0 floodplain deposit is younger than 4000 B.P. based on the chronology established for the T1 terrace. However, stratification and minimal pedogenesis indicate that the floodplain and associated deposits may be less than 1000 years old.

\section{Preservation Potentials}

The Pleistocene T2 terrace along Elm Creek was probably formed prior to the arrival of prehistoric people in Texas. Consequently, palimpsest sites spanning the last $10,000-12,000$ years may be preserved on the $\mathrm{T} 2$ terrace. Deposition of Unit 1 began in the early Holocene and continued until around 4000 B.P. in the Elm Creek 

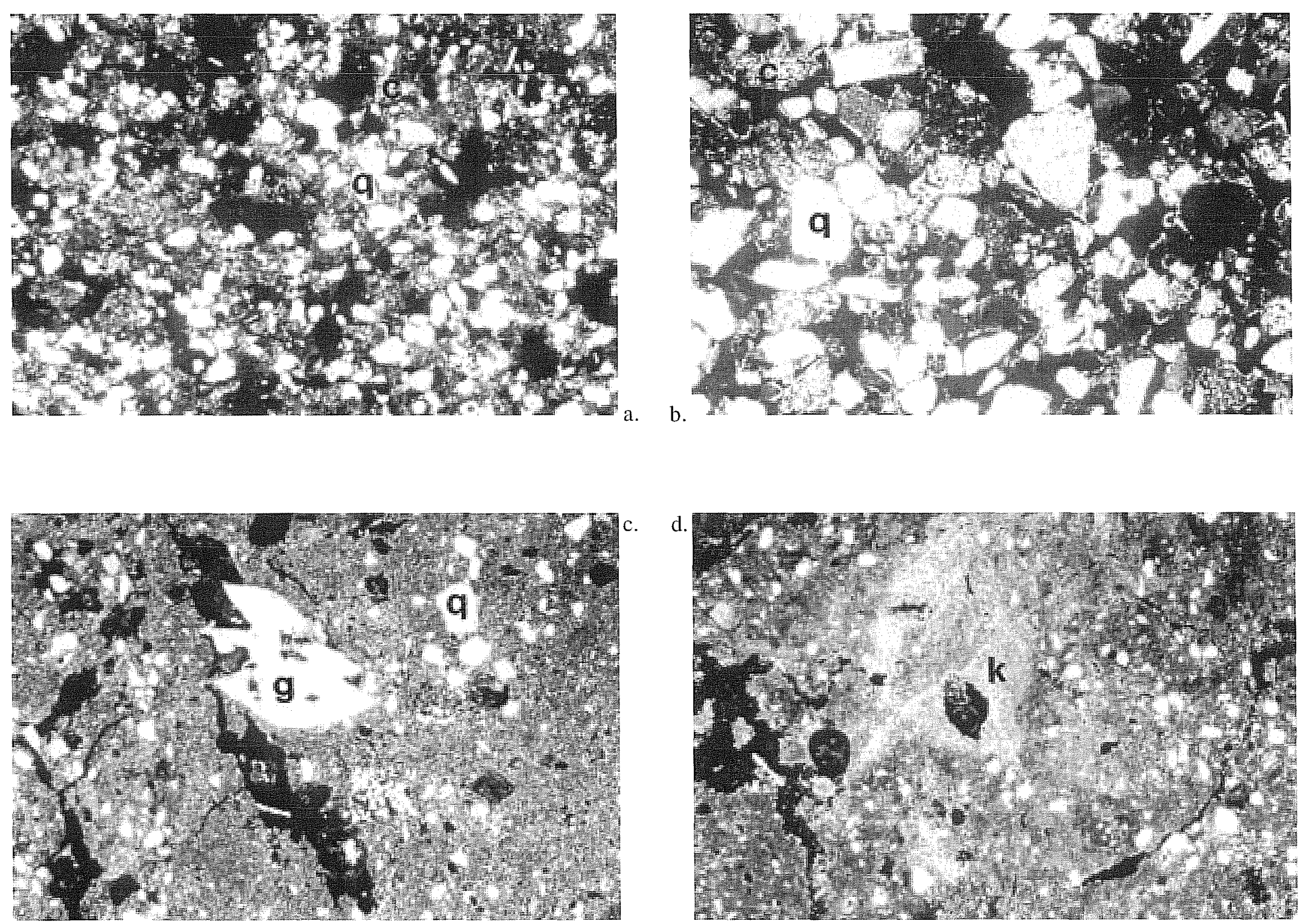

Figure 7-16. Photographs of micromorphic thin sections showing characteristics of Elm Creek. a. EP-2; b, c, d. EP-3 (all polarized light). $\mathrm{c}=$ chert; q=quartz; $\mathrm{g}=$ gypsum; $\mathrm{k}=$ calcan. 


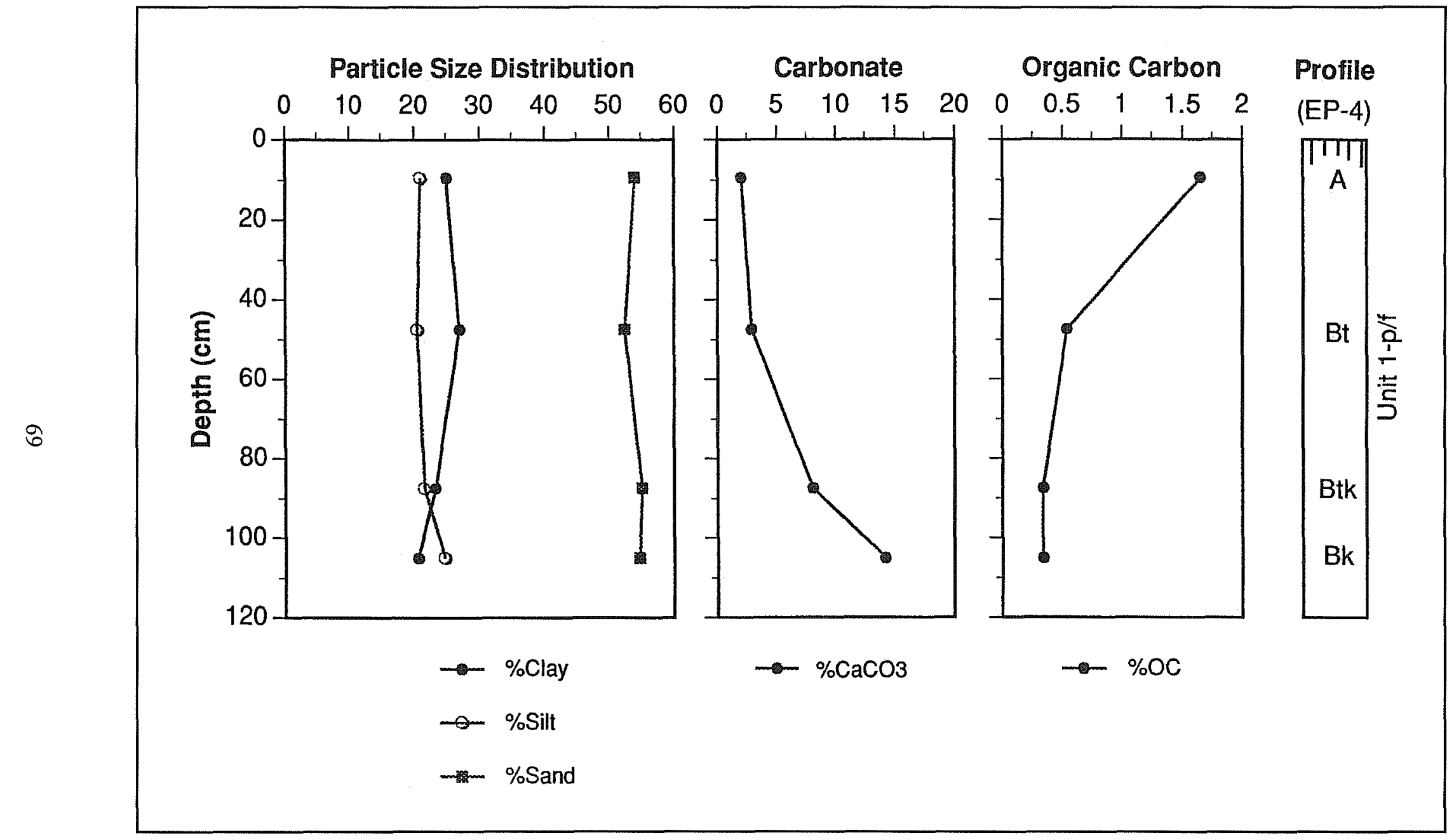

Figure 7-17. Soil-stratigraphic physical and chemical data from $E P-4$. 


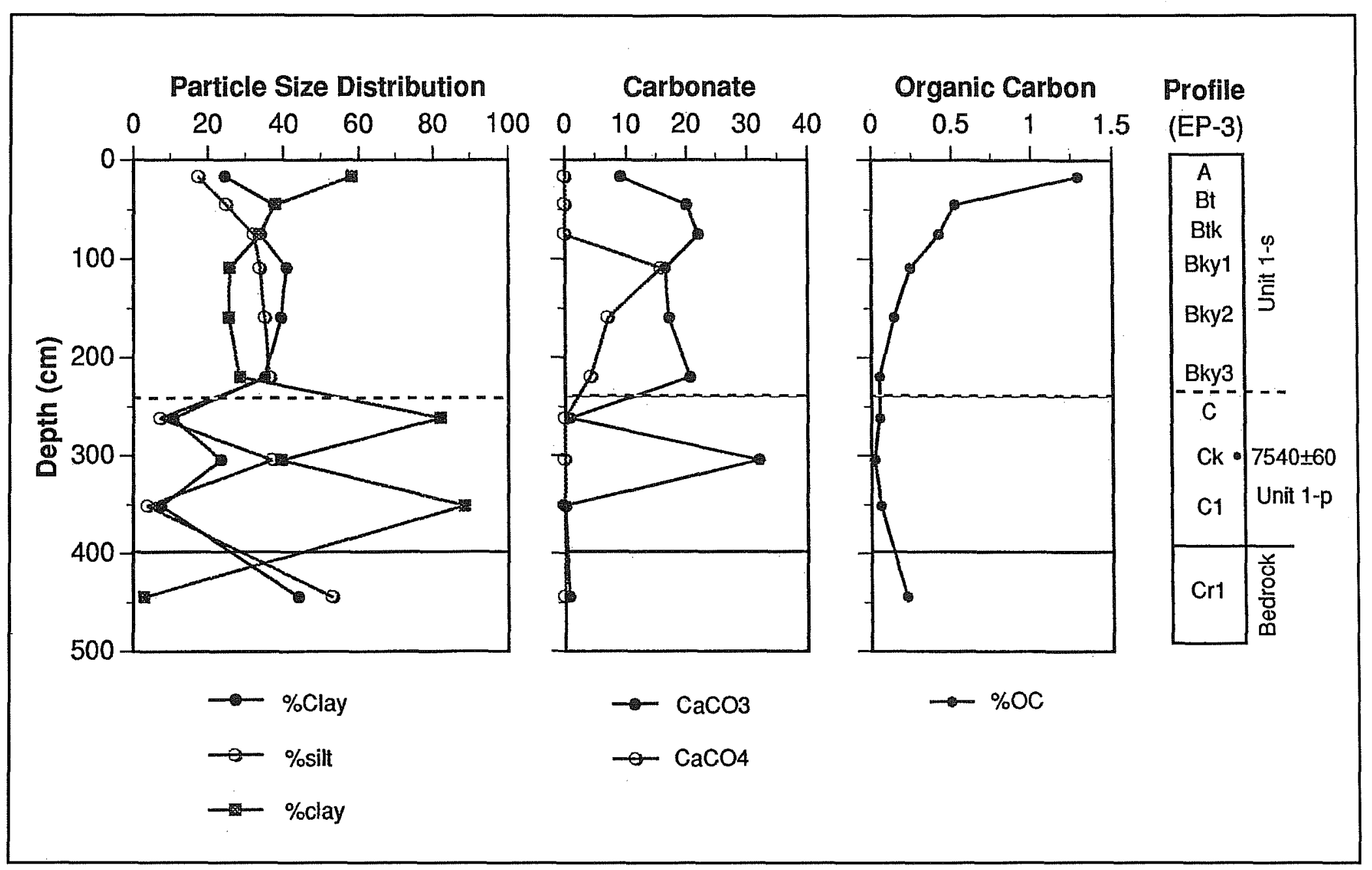

Figure 7-18. Soil-stratigraphic physical and chemical data from EP-3. 
drainage basin. Buried Early Archaic, and perhaps even Paleoindian, occupations could be discovered in Unit 1 deposits. Contextual integrity of the sites would be greater in the fine-grained floodbasin, colluvial, and point bar facies than in channel deposits.

Because the $\mathrm{T} 1$ terrace has been stable since 4000 B.P., surface sites dating from the Middle Archaic to present could be preserved on its surface. Discovery of surface or buried sites associated with the T0 floodplain will be minimal because of low surface area and sediment volume.

\section{Paleoenvironmental Interpretations}

Stable carbon isotope ratios have been used to reconstruct paleoenvironments in alluvial settings of Texas (Humphrey and Ferring 1994; Nordt et al. 1994). Stable isotopes of organic and inorganic carbon determines the proportion of $\mathrm{C}_{3}$ and $\mathrm{C}_{4}$ plants that contribute to soil biomass production (Boutton 1991b). The $\mathrm{C}_{4}$ plants are warm season grasses with ${ }^{13} \mathrm{C}$ values of approximately -13 , whereas $C_{3}$ plants consist of cool season grasses, trees, and shrubs with ${ }^{13} \mathrm{C}$ values of about -27 (Boutton 1991b). The $\mathrm{C}_{4}$ species abundance (Terri and Stowe 1976) and soil biomass production (Boutton et al. 1980) in the North American Great Plains responds positively to ambient temperature. Thus, the proportion of $\mathrm{C}_{4}$ plant contributions to soil $\gamma^{13} \mathrm{C}$ values is an indictor of relative temperature change.

In contrast to the North American Great Plains, paleoenvironmental work on alluvial fans in the Chihuahuan Desert of New Mexico shows a strong positive correlation between drier climatic conditions and $\mathrm{C}_{3}$ xerophyte abundance (Cole and Monger 1994). Regardless, $\mathrm{C}_{4}$ grassland prairies still exist today in broad alluvial valleys of southern New Mexico. This suggests that $\mathrm{C}_{4}$ grasses may have dominated soil biomass production throughout the Holocene, even in regions drier than the Elm Creek and Rio Grande study area.

Maps of potential natural vegetation show that the study area of Elm Creek and the Rio Grande is situated in a mixed grassland (Shelford 1963). Consequently, $\mathrm{C}_{4}$ grasses were probably present throughout the Holocene, even during dry periods, and contributed more belowground biomass production to the soil organic matter pool than any $\mathrm{C}_{3}$ xerophytic species. Therefore, an increase in $\mathrm{C}_{4}$ plant abundance, as determined isotopically, is considered a response to warmer temperatures in the project area. The abundance of $\mathrm{C}_{3}$ xerophytic shrubs in the uplands of the project today is probably a result of over grazing and fire reduction and not a reflection of climate change.

Organic carbon in floodplain settings can be deposited with sediment during alluvial deposition or incorporated into the sediment post-depositionally during pedogenesis (Nordt et al. 1994). Along the Rio Grande, organic carbon is undoubtedly derived from a combination of these two sources. Fine-grained sediments tend to complex organic carbon and can carry an isotopic signal for great distances during alluvial transport. Thus, clayey alluvial sediments within large drainage basins can have ${ }^{13} \mathrm{C}$ values out of equilibrium with the local climate. Given the relatively low clay contents and moderate depositional rates of Rio Grande alluvium in the study area, most of the organic carbon was probably incorporated into the sediments post-depositionally in association with soil forming processes. Accordingly, $\delta^{13} \mathrm{C}$ values are believed to reflect local vegetation and climate conditions. Along Elm Creek, detrital organic carbon sources were derived from within a relatively small drainage basin that does not cross climatic or vegetation boundaries. Therefore, detrital organic carbon should not be out of equilibrium with that generated by pedogenesis in relation to local climate conditions.

\section{Rio Grande}

Depth plots of ${ }^{13} \mathrm{C}$ values from EP-1, EP-2, BHT 8, and $\mathrm{BHT} 9$ show $\mathrm{C}_{4}$ abundance for the $\mathrm{T} 1$ flood terrace and T0 floodplain during the late Holocene in the Rio Grande basin (Figure 7-19). The isotopic record for the period between approximately $<6000$ and $>2200$ B.P. is recorded in Unit 2-p of EP-2 and BHT 9 (Figure $7-19)$. These $\delta^{13} \mathrm{C}$ values range from about $-22 \%$ to $-19 \%$ moving from lower to upper depths within the Unit 2-p facies. In the Unit 2-f floodbasin facies exposed in EP-2, BHT 8, and BHT 9, the isotopic record spans 


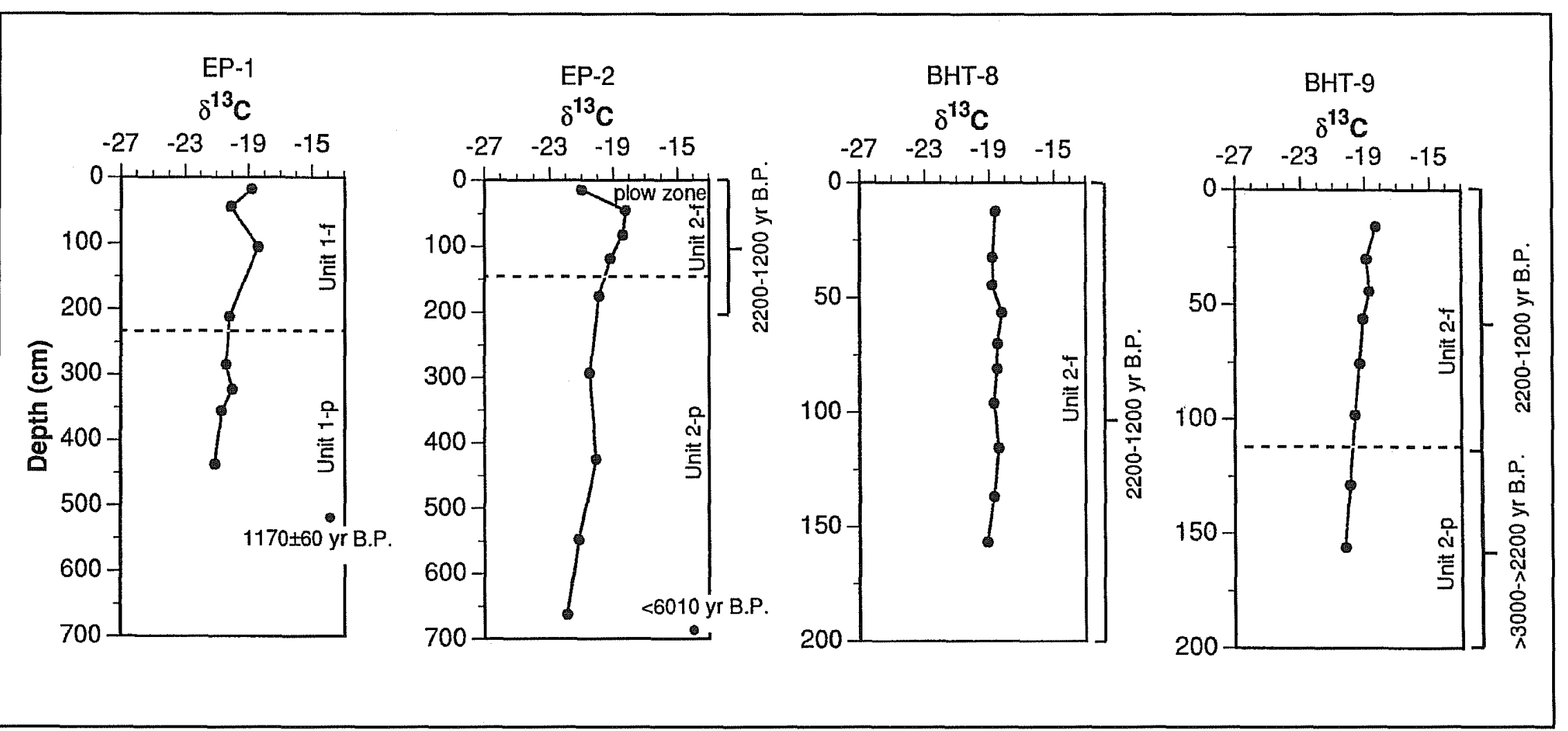

Figure 7-19. Stable carbon isotopes of Rio Grande alluvium. 
the time period between approximately 2200 and 1200 B.P. Here, ${ }^{13} \mathrm{C}$ values increase from about $-19 \%$ to $-18 \%$ from the lower to upper part of the facies (Figure 7-19). The sharp decrease in ${ }^{13} \mathrm{C}$ values for the upper horizon of EP-2 was probably from recent cropping of cotton, a $\mathrm{C}_{3}$ plant.

Isotopic values for the last 1,000 years are shown in Unit 3 of EP-1 (Figure 7-19). The ${ }^{13} \mathrm{C}$ trend from bottom to top of the profile is similar to that for Unit 2. Isotopic fluctuations in Unit 1 may partly reflect sediment stratification, rather than $\mathrm{C}_{4}$ variations in relation to climate.

Carbon-13 results from Unit 2 suggest that between $<6000$ and 1200 B.P. the proportion of $\mathrm{C}_{4}$ plant biomass production gradually increased by $20-30$ percent. A similar trend was observed during the period after 1200 B.P. in Unit 3. These trends could have occurred for one of two reasons. First, temperatures during these intervals could have been gradually increasing and corresponding to decreasing flood sedimentation rates during deposition of the Unit 2-f and Unit 1-f floodba$\sin$ facies. However, rather than a change in climate, vertical building of the Rio Grande floodplain by longterm sedimentation, or by shifting of the position of channel meanders, could also lead to reduced flooding, drier local conditions, and an increase in $\mathrm{C}_{4}$ plant abundance.

The second possibility for increasing $\mathrm{C}_{4}$ abundance from lower to upper parts of Unit 2 and Unit 1 could be that the point bar facies (2-p, 1-p) were favorable for plants growing in a riparian setting. In this case, regional climatic conditions could have been masked by local conditions. Because redoximorphic features (anaerobic) were not observed in any horizons from Unit 2 or Unit 3, it is unlikely that water tables were ever high for significant periods during deposition of these units. This may eliminate the riparian explanation for lower $\mathrm{C}_{4}$ abundance in the point bar facies of Unit 2 and Unit 3.

To summarize, the abundance of $\mathrm{C}_{4}$ plant biomass production for the late Holocene along the Rio Grande varied between $-22 \%$ and $-18 \%$. This is a relatively narrow range demonstrating that about an equal abundance of $\mathrm{C}_{3}$ and $\mathrm{C}_{4}$ plants were growing during this time. This provides powerful evidence for the presence of a mixed grass prairie during much of the late Holocene in the project area. Furthermore, an abundance of warm season $\mathrm{C}_{4}$ grasses indicates that there was an open vegetation canopy. Whereas some of the $\mathrm{C}_{3}$ species could have been trees or desert shrubs, some were undoubtedly cool season grasses in order to have maintained a low canopy cover. In substantiation of this hypothesis, the soils of the $\mathrm{T} 1$ flood terrace are Mollisols. These soils form only in association with below-ground biomass production consistent with grassland prairies. It is unclear whether slight warming trends occurred between about 2200 and 1200 B.P. and sometime after 1000 B.P., or whether $\mathrm{C}_{4}$ abundance at these times reflected differences in depositional facies and water table levels.

\section{EIm Creek}

The isotopic record along Elm Creek extends back to at least 7500 B.P. as shown in Unit 1 of EP-3 (Figure $7-20) .{ }^{13} \mathrm{C}$ values at this time show that $\mathrm{C}_{4}$ abundance constituted only about $20-30$ percent of total biomass production. Shortly after 7500 B.P., $\mathrm{C}_{4}$ plant abundance sharply increased as demonstrated by maximum ${ }^{13} \mathrm{C}$ values of -15 between depths of 30 and $75 \mathrm{~cm}$. This indicates the presence of a grassland prairie comprised of 80 to 90 percent $C_{4}$ grasses. The uppermost isotopic value in EP-3 then shifts back to approximately -18. In Unit 1 of EP-4, the depth-curve for ${ }^{13} \mathrm{C}$ values is very similar to those in EP-3. In the uppermost horizon, however, the isotopic value shifts back nearly -22 . This is consistent with a greater percentage of $C_{3}$ woody shrubs occurring in the vicinity of EP-3.

Low $\mathrm{C}_{4}$ abundance near, and prior to, 7500 B.P. suggests that temperatures were relatively cool in the early Holocene in the project area. A sharp increase in $\mathrm{C}_{4}$ abundance indicates that temperatures were rapidly increasing shortly after 7500 B.P. Because deposition of Unit 1 along Elm Creek terminated by approximately 4000 B.P., ${ }^{13} \mathrm{C}$ values for this time interval are compressed in the upper $50 \mathrm{~cm}$ of the soil profiles in EP-3 and EP-4. Therefore, it is difficult to determine if the shift to lower $\mathrm{C}_{4}$ abundance in the upper profiles occurred sometime during the late Holocene in response to a return to cooler temperatures, or during Historic 


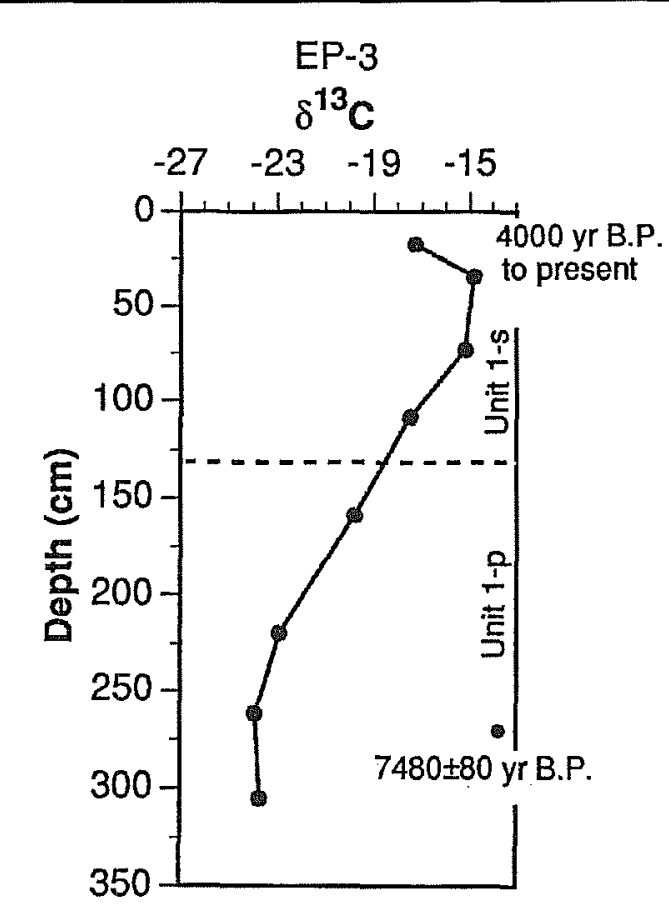

Figure 7-20. Stable carbon isotopes of Elm Creek alluvium.

These climatic interpretations for the study area generally correlate with paleoenvironmental investigations in other parts of southwest Texas. Bryant and Holloway (1985) conducted a paleoenvironmental review of southwest Texas based on fossil pollen. They concluded that a late-glacial mosaic of woodlands, parklands, and scrub grasslands was gradually replaced by a dominance of scrub grasslands between 10,000 and 7000 B.P. Fossil pollen at this time, however, still contained enough

times in response to brush encroachment and agriculture. If correlation to the late Holocene isotopic record along the Rio Grande is valid, then the shift to decreasing $\mathrm{C}_{4}$ abundance along Elm Creek probably occurred around 4000 B.P. and was in response to cooler temperatures. Regardless, an open canopy grassland prairie existed in the middle to late Holocene along Elm Creek because of relatively high ${ }^{13} \mathrm{C}$ values and the presence of Mollisols.

\section{Correlation}

Preliminary isotopic interpretations for the project area along the Rio Grande and Elm Creek suggest that: 1) low $\mathrm{C}_{4}$ plant abundance and relatively cool temperatures persisted in the early Holocene; 2) $\mathrm{C}_{4}$ plant abundance and temperatures increased appreciably between 7500 B.P., and perhaps 4000 B.P.; 3) $\mathrm{C}_{4}$ plant abundance decreased with a return to cooler temperatures after 4000 B.P.; and 4) possible brief warming intervals occurred between 2200 and 1200 B.P. and sometime after 1000 B.P. pine to suggest that temperatures were relatively cool and moist, at least locally. Toomey et al. (1993) also interpreted relatively moist conditions between about 10,000 and 7000 B.P. based on packrat midden studies in west-central Texas. These interpretations are consistent with a relatively cool early Holocene interval in the project area of Elm Creek and the Rio Grande, as determined isotopically.

Bryant and Holloway (1985) concluded that by 6000 B.P. conditions had become considerably warmer and drier in southwest Texas based largely on prehistoric hunter and gatherer use of plants and animals from xeric habitats. This is consistent with a drier trend that began around 7000 B.P. in west-central Texas (Toomey et al. 1993; Toomey, personal communication 1994) based on packrat midden evidence. Isotopic evidence in the Elm Creek and Rio Grande study area also indicate that conditions were becoming warmer by 7000 B.P.

An aridic trend continued in southwest Texas during last 4000 years according to Bryant and Holloway (1985). An exception occurred around 2500-3000 B.P. 
during a brief return to mesic conditions as inferred by an increase in grass and pine pollen. Toomey et al. (1993) showed a drying interval between 7000 and 3000 B.P., after which there was a return to moist conditions between 3000 and 1000 B.P.

Because of discrepancies, the late Holocene paleoclimatic record is more difficult to correlate in southwest Texas. In the study area, it appears that temperatures became cooler after 4000 B.P., except for possible short warming intervals between 2200 and 1200 B.P. and sometime after 1000 B.P. The earlier warm period correlates with the work of Bryant and Holloway (1985), but not with Toomey et al. (1993). In contrast, all three paleclimatic investigations suggest warmer conditions after 1000 B.P. Another isotopic interpretation is possible for the late Holocene climate record of the Elm Creek and Rio Grande project area because: 1) a grassland prairie dominated by $\mathrm{C}_{4}$ grasses may have been present on the $\mathrm{T} 1$ terrace of Elm Creek during the last 4,000 years because flooding had terminated, thus creating drier conditions locally even in the presence of a regional mesic interval; and 2) periodic flooding on the Rio Grande T1 flood terrace may have induced mesic conditions locally such that $C_{4}$ grass abundance was suppressed even in the presence of a regional drying trend. More isotopic and other sources of paleoenvironmental data is needed to resolve this issue, but there is no evidence for high water tables in the Rio Grande floodplain during the late Holocene. It seems safe to say that climatic conditions in the late Holocene were intermediate to those inferred for the early and middle Holocene in the project area.

\section{Regional Geoarchaeological Implications}

Prehistoric settlement patterns are often influenced by environmental conditions related to stream evolution and resource availability. Within the Elm Creek and Rio Grande drainage basins in the project area, prehistoric hunters and gatherers were strongly adapted to the location of the stream network. A diachronic landscape reconstruction model will be presented to analyze potential changes in settlement pattern for five points in time within the alluvial setting of the study area: 8000 B.P., 4000 B.P., 2000 B.P., and 500 B.P.

\section{B.P.}

In the early Holocene the Rio Grande and Elm Creek confluence was probably located near the T2 Pleistocene terrace along the northern valley wall of Elm Creek (Figure 7-1). Early Holocene sediments along the Rio Grande may have been deposited in the vicinity of its confluence with Elm Creek. However, there is no record of alluvium dating to this time period in the study area, probably because of erosional events that occurred later in the Holocene.

Approximately 8000 B.P., Elm Creek was depositing Unit 1 and beginning construction of what is now the T1 terrace. Consequently, Late Paleoindian and Early Archaic sites were likely preserved in Unit 1 alluvium. These sites probably represent short-term encampments that were subsequently buried in stratified contexts of an aggrading floodplain. Lithic resources could have been procured from the Uvalde Gravel in the adjacent uplands to the north. Although resources directly related to Elm Creek were probably utilized, some riparian activity probably occurred along the Rio Grande, some four kilometers to the southwest. The climate was relatively cool at this time and supported a prairie consisting of $\mathrm{C}_{4}$ grasses, and perhaps $\mathrm{C}_{3}$ cool season grasses and trees.

\section{B.P.}

Near 4000 B.P., Elm Creek down cut and transformed its early Holocene floodplain into the T1 terrace. Settlement patterns would have then adjusted to an area of reduced flooding, lower water tables, and greater landscape stability. Because lateral erosion was minor, most of the T1 terrace was preserved and available for occupation. Long-term encampments could have been perceived as an adaptation strategy to increased landscape stability. Because construction of the T1 terrace had terminated, site preservation would have shifted from discrete buried contexts within Unit 1 alluvium to mixed assemblages compressed onto the stable $\mathrm{T} 1$ terrace surface. 
Flood frequency and magnitude may have been increasing along the Rio Grande near 4000 B.P. (Patton and Dibble 1982), possibly resulting in widespread valley erosion and removal of the Early Archaic cultural record. This period of erosion also would have removed most of the early Holocene Unit 1 alluvium of Elm Creek near its confluence with the Rio Grande between EP-1 and EP-2 (Figure 7-1). Further evidence for widespread erosion is the absence of terraces along the Rio Grande in the study area that date to the middle Holocene.

Near the end of a prolonged xeric period in the study area, temperatures were still warm at 4000 B.P. This event may have limited local water resources and the availability of wood as a fuel source. Frequent, high magnitude floods along the Rio Grande may have forced long-term prehistoric occupation into the upper Elm Creek basin. This may account for the large number of Middle Archaic sites on the T1 terrace of Elm Creek (Uecker 1994). Utilization of upland lithic resources was undoubtedly still ongoing.

\section{B.P.}

At 2000 B.P. geomorphic conditions had not changed significantly along Elm Creek because the channel had remained within a narrow meander belt in the middle of the alluvial valley. As a result, assemblages of sites spanning the Middle and Late Archaic were becoming mixed on the T1 terrace surface. The confluence of Elm Creek and the Rio Grande was still to the southwest of site $41 \mathrm{MV} 120$ (Figure 7-1).

By 2000 B.P. widespread erosion along the Rio Grande had terminated (Patton and Dibble 1982) and was followed by relatively slow floodbasin accumulation of Unit 2-f in the project area. This occurred as the Rio Grande meander belt to the north of site 41MV120 continued to migrate to the west and southwest to near the T1 and T0 escarpment(Figure 7-1). The Rio Grande and Elm Creek confluence, however, was still in the vicinity of EP-1 and EP-2 (Figure 7-1). A reduction in flood frequency may have attracted human settlement to the Rio Grande floodplain at 2000 B.P. For riparian resources, the Rio Grande may have now been viewed as more favorable because sites could have formed near the confluence of two streams with less likelihood of high magnitude floods affecting the area. In contrast, lithic materials were still more accessible for people camping on the $\mathrm{T} 1$ terrace of Elm Creek.

Although flood sedimentation along the Rio Grande was slowing in the late Holocene, it was still ongoing. Continued flooding is consistent with an overall late Holocene mesic interval as interpreted by stable carbon isotopes. In contrast to Elm Creek, sites along the Rio Grande at this time were buried in stratified contexts within the upper two meters of Unit 2-f. An example of this geomorphic and archaeological interaction is site 41MV120. Also, because of continued flooding, surface visibility of the Late Archaic record along the Rio Grande will be obscured.

\section{B.P.}

By 500 B.P. the stream network in the project area had incised, resulting in: 1) transformation of the former floodplain into the $\mathrm{T} 1$ flood terrace along the Rio Grande in response to reduced flooding; 2) construction of a new T0 floodplain at a lower elevation along the Rio Grande; and 3) development of a deeply entrenched meander belt and narrow floodplain along Elm Creek. Thus, the Late Prehistoric cultural record will be preserved near the surface of the T1 flood terrace of the Rio Grande. In the Elm Creek basin, Late Prehistoric assemblages were mixed with Archaic components on the stable T1 terrace. Site 41MV120 was also abandoned at this time.

\section{Conclusions}

For the prehistoric cultural record, the Holocene geologic history of Elm Creek and the Rio Grande in the project area has biased preservation potentials, influenced settlement patterns, and played a role in subsistence strategies. The most important bias on preservation potentials was the recognition that: 1) the Late Paleoindian and Early Archaic records will be preserved in buried contexts only along Elm Creek (Unit 1);2) the archaeological record dating from the Late Archaic to Late Prehistoric will be buried only along the Rio Grande (Unit 2); and 3) mixed surface 
assemblages dating from the Middle Archaic to Late Prehistoric will only be preserved on the stable T1 terrace in the Elm Creek basin. Whether early Holocene deposits were ever present along the Rio Grande in the project area, or whether they were eroded in the middle Holocene, is unclear.

In the Elm Creek basin subsistence strategies in the Early Archaic were probably related to riparian zones of Elm Creek locally, and the Rio Grande regionally, some four kilometers to the west. Regardless, water supply and woody species were probably less available at this time because of a climatic transition from cool to warm. Lithic resources were readily available to the north of the alluvial valley of Elm Creek.

Settlement patterns may have shifted to the Rio Grande floodplain in the late Holocene because of reduced flood magnitudes and an associated decrease in channel erosion. Reduced flood erosion after 4000 B.P. may have occurred in response to a return to more mesic climate conditions. Within this model of landscape evolution, site 41MV120 may represent a shift in settlement to the Rio Grande floodplain during the late Holocene. Prehistoric hunters and gatherers may have exploited the area because of slow flood aggradation situated near the confluence of two streams. Aggradation also buried late Holocene components in the area. In contrast to Early Archaic sites along Elm Creek, sites ranging from the Middle Archaic to Late Prehistoric along the Rio Grande had a greater availability of water, but a greater distance to lithic resources. 


\title{
Chapter 8: Results of the Field Investigations
}

\author{
Bradley J. Vierra and John R. Cross
}

\section{Introduction}

The Center for Archaeological Research conducted field excavations at site 41MV120 from December 18, 1995, to February 14,1996 . This work was undertaken as a result of a road-widening project administered by the Texas Department of Transportation (TxDOT) along FM 1589. Six backhoe trenches and 39 square meters of hand-dug units were excavated within the right-ofway.

Excavations were limited to an area approximately $400 \mathrm{~m}$ long and $10 \mathrm{~m}$ wide along the north side of FM 1589 (Figure 6-1). Rather than defining the overall extent of the site, the excavation sampled cultural deposits that undoubtedly represent a portion of a larger spatial distribution. TxDOT's significance testing had identified the area of greatest artifact density in the eastern portion of the site (near Elm Creek), and the assumption that the artifact density would decrease with distance from Elm Creek guided the initial plan for the data recovery. Subsequent archaeological and geomorphological studies indicate that the 41MV120 was situated adjacent to Elm Creek, but that the confluence of Elm Creek and the Rio Grande was located further south. Artifact densities do decline with greater distance from Elm Creek, indicating that the site occupations were primarily oriented toward the creek.

Prior to the initiation of excavations at the site, representatives from Southwestern Bell Telephone and the Eagle Pass Water District delineated on the ground surface the location of their respective utility lines. Southwestern Bell's telephone cable had been buried in a comparatively narrow and shallow trench, and ran east-west for the length of the project area. The course of the cable trench deviated somewhat from the main axis of the roadway (Figure 6-1). A sewer line belonging to the Eagle Pass Water District is aligned with the center of the right-of-way. At the western end of the line (south of BHT 8), flow from an incoming line from the northwest turns east toward Area 1; at the eastern manhole cover, an outlet pipe carries the flow southeast under FM 1589. The sewer pipe was laid in a trench approximately $2.5 \mathrm{~m}$ deep and $.5 \mathrm{~m}$ wide. According to the representative from the Water District, the sewer line had been in place for two or three years prior to the initiation of the data recovery fieldwork.

TxDOT archaeologists were not aware of the existence of the sewer line when they conducted their excavations in the spring of 1995 (C. Ward, personal communication 1995). On the basis of CAR'S field investigations, the angle and placement of TxDOT's backhoe trench (BHT) 1 nearly exactly matched the footprint of the sewer line trench. As a result, TxDOT crews were able to record undisturbed stratigraphic profiles without being aware that they had dug through disturbed sediments within the backhoe trench. The location of these utility lines constrained the size, shape, and orientation of excavation units that could be placed at the east end of the site during the data recovery.

CAR crews established two EDM stations using a SOKKIA Set 5A EDM Total Station and a Sokkia SDR33256K data recorder. Using the total station, CAR personnel resurveyed the position of TxDOT units and trenches and mapped the location of existing conditions, such as the edge of the paved roadway, surveyors' nails in the highway centerline, wooden survey lathes, the position of the buried telephone cable, the location of manhole covers for the sewer line, the fence line that formed the northern boundary of the project area, and a TxDOT bronze benchmark on the western bank of Elm Creek.

Initial excavation efforts were directed to completing TxDOT EUs 1, 2, 4, and 6 to a depth of $1.2 \mathrm{~m}$ below ground surface. Artifact recovery during the significance testing phase had not diminished in the lowest levels excavated by TxDOT crews (ranging from 70$100 \mathrm{~cm}$ in depth). CAR had proposed excavating previous test units to a uniform depth at which artifact densities could be shown to diminish, thus indicating a 
period of low site use. Excavation to a depth of $1.2 \mathrm{~m}$ provided a slight buffer in monitoring the distribution of cultural materials below the one-meter depth estimated by TXDOT as the maximum depth of impact for the proposed improvements to FM 1589.

A grader/maintainer from the Eagle Pass Office of TXDOT was used to scrape the area in the vicinity of TxDOT BHT1 and EUs 1 and 3. The removal of $5-10 \mathrm{~cm}$ of compacted fill was sufficient to identify the darker outlines of the backfilled test units and trench, and excavation proceeded by hand from that point. It quickly became apparent that TxDOT's BHT 1 lay on the alignment with the trench that had been excavated for the sewer line several years before. A series of backhoe trenches (BHTs 7-11) was also excavated to obtain a clearer picture of the stratigraphy across the site. BHT 7 was excavated immediately to the east of EUs 1 and 3, leaving a narrow balk separating the trench from BHT 1. The location for the trench had been selected in an effort to identify one or more lenses of freshwater mussels that had been identified during the excavation of BHT 1 (Ward 1995b). BHTs 8-11 were excavated at intervals along the fence line that formed the northern boundary of the project area. Upon walkover inspection, it became apparent that the rightof-way had been contoured to promote runoff. This was confirmed by conversations with TxDOT personnel. The area closest to the fence had not been disturbed to an appreciable degree by road maintenance activities. The decision to place the trenches along the fence line was based on the expectation that these portions of the site were more likely than other areas to contain deposits that were substantially intact. The upper levels of the BHTs located along the fence line revealed the presence of an extensive (and active) network of animal burrows. Bioturbation, particularly by burrowing insects and mammals, was evident across the site and extended to more than a meter in depth in some locations. Forty-two historic artifacts were recovered from the excavations, most of which were present in the upper $30 \mathrm{~cm}$ of fill $(\mathrm{n}=25)$, with fewer from $30-60 \mathrm{~cm}(\mathrm{n}=11)$, and less from $60-120 \mathrm{~cm}(\mathrm{n}=6)$.

In general, the BHTs exhibited very slight differences in soil texture and color (within $1 / 2$ of a Munsell Color value) in stratigraphic section. The distribution of cultural material (debitage, fire-cracked rock, charcoal, and freshwater mussel) exhibited a weakly developed vertical zonation. This vertical distribution was sufficient to show that cultural material had been deposited in several episodes separated by events that deposited silty sediments but were not strongly correlated with the slightly darker bands of soil that might have indicated incipient soil formation on a stable surface. Very fine sandy sediments were identified at depths ranging from $70-140 \mathrm{~cm}$ in all excavation units except those located at the far western end of the site. Nordt interprets these fine sediments as the upper zone of a pointbar deposit (see Chapter 7). The area of maximum topographic elevation at the site corresponds to that portion of the site where the point bar is closest to the present ground surface. Artifact counts-particularly of larger objects such as fire-cracked rock and big flakes-dropped off markedly when point-bar deposits were encountered.

At the western end of the site in BHTs 11 and 12 and EUs 39 and 40 (Figure 6-1), stratigraphic sections revealed similar rhythmic sedimentation "packages" as in the rest of the site, but overall sediments were less compacted and did not exhibit a well-defined blocky structure. Despite reaching depths of $1.5 \mathrm{~m}$ in this part of the site, excavators did not encounter the fine sandy point-bar sediments that had been so readily identifiable elsewhere at the site.

\section{Excavation Units}

The data from archaeological excavations at 41MV120 may be examined at a number of levels, determined in large part by the size and placement of excavation units. On the basis of TxDOT's significance testing program and CAR's initial excavations, four block areas with contiguous $1-\mathrm{x}-1-\mathrm{m}$ excavation units were laid out (Figure 6-1). The blocks were intended to explore different dimensions of site structure and to obtain greater contextual information for the features and artifact concentrations that had been identified in EUs 1-11. These blocks provided three-dimensional views on the distribution of material culture at the site. The blocks of contiguous $1-\mathrm{x}-1 \mathrm{~m}$ units contain a durable record of activities at a particular spot through time. In a simple sense, this includes lithic reduction, domestic, and food consumption activities. For example, lithic reduction 
is represented by the by-products of core reduction and tool production/maintenance, and food consumption by mussel and snail shell remains. Domestic activities are reflected in the presence of burned rock which can be associated with the use of hearths and/or food processing features.

Within each block, the 1-x-1-m square provided a smaller analytical unit for examining qualitative and quantitative variation in material culture. The clustered distribution of artifacts or features gives important clues to the kinds of activities that took place at the site. In addition to the horizontal control of 1-x-1-m units, CAR crews maintained vertical controls through excavation of $5-\mathrm{cm}$ and $10-\mathrm{cm}$ levels.

Given the mechanisms of sediment accumulation at the site (i.e., flooding episodes of the Rio Grande and/or Elm Creek), there was a stratigraphic segregation of cultural materials reflecting different periods of site use. Therefore, a $10-\mathrm{cm}$ level within a 1-x-1-m square was the standard unit for specifying archaeological context and for sorting, quantifying, and comparing materials from the site. The boundaries established by a system of levels and square units are arbitrary and were used to provide controls on archaeological contexts and provenience.

One of the initial tasks undertaken by CAR crews was the continuation of TxDOT test units to a uniform depth of $1.2 \mathrm{~m}(120 \mathrm{~cm})$ below the present ground surface. EUs 1, 2, 4, and 6 were relocated and excavated in 10$\mathrm{cm}$ levels to this depth. A second priority was the testing of areas of the site that had not been examined by the TxDOT work. This was accomplished through the excavation of a series of backhoe trenches (BHT $7-12$ ) and the placement of five $1-x-1-\mathrm{m}$ units (EUs $7-11$ ) in portions of the site that had not been tested previously. Drawing on the information obtained from these units, TxDOT's test units, and the backhoe trenches, four areas were selected for block excavation (Figure 6-2):

1) An eastern block of 10 additional $1-x-1 \mathrm{~m}$ units to obtain a broader spatial context for the high artifact densities noted in EUs 1 and 3.
2) A central block measuring $3 \times 3 \mathrm{~m}$ in the area of the highest elevation of point bar deposits (in an effort to sample the cultural record of the site's occupation in the "stratigraphically compressed" sediments above the point-bar deposits).

3) A block of eight contiguous $1-x-1-m$ units placed along the south and west margins of BHT $10 \mathrm{in}$ an attempt to obtain contextual information for a series of stratigraphically separated clusters of firecracked rock visible in the north wall of BHT 10.

4) Two small blocks at the west end of the site, one involving the expansion of EU 9 to a $2-\mathrm{x}-2-\mathrm{m}$ block to provide contextual data for an Ensor point and a preform recovered from EU 9, and two 1-x-1-m units placed at the east end of BHT 12. Each of these blocks is discussed in detail below.

\section{Isolated Units}

In addition to the block excavation areas, there were several isolated $1-\mathrm{x}-1 \mathrm{~m}$ units and backhoe trenches dug in separate locations on the site (EUs 2, 4, 6, 8, and 10 ; BHTs 8,9 , and 11). The excavation of TxDOT's EUs 1-6, and CAR's EUs 7-11 and BHTs 7-11 formed the basis for decisions about where to locate larger excavation blocks. Several 1-x-1-m units and backhoe trenches were not included in these blocks, and are discussed here as "Isolated Units." Level numbers used in this chapter are not the original field designations. Since both $5-$ and $10-\mathrm{cm}$ levels were excavated in the field, the original levels have been combined into a series of 10-cm levels from top to bottom of each excavation unit. See Appendix $C$ for information on artifact classes by excavation unit, and the conversions used for the original and revised levels (i.e. level vs. level2, respectively).

\section{1-x-1 m Units}

\section{Excavation Unit 2}

EU 2 is located to the immediate east of Area 2. The unit had been excavated to a depth of $98 \mathrm{~cm}$ below surface by TxDOT crews. CAR excavations contin- 
ued to a depth of $120 \mathrm{~cm}$ in two levels $(12 \mathrm{~cm}$ and 10 $\mathrm{cm}$, respectively). One hundred fifty-two pieces of debitage were recovered, with an overall artifact density of 126.7 artifacts per cubic meter. Figure 8-1 illustrates the distribution of debitage by level for EU2. As shown, the area of highest artifact density occurs from Levels 4-8 with peaks at Levels 5 and 8 . This corresponds with the distribution of burned rock by level, which also exhibits peaks in Levels 5 and 8 (Figure 8-2). Most of the burned rock consists of sandstone in both levels (986.6 vs. $255.3 \mathrm{~g}$ ), with less chert (23.3 vs. $183.3 \mathrm{~g}$ ).
Only very small amounts of mussel $(0.3 \mathrm{~g})$ and snail $(3.0 \mathrm{~g})$ shell were recovered from the bottom of the excavations in Level 12. A piece of mesquite charcoal (Lot 3) was also identified in Level 12. The unit appears to exhibit a similar long-term pattern of activityuse with lithic reduction and burned rock activities being represented in the two primary components. The mixing of these two activities in the same levels indicates dumping or post-depositional disturbance. In addition, limited evidence of mussels and snails is seen at the base of the sequence.
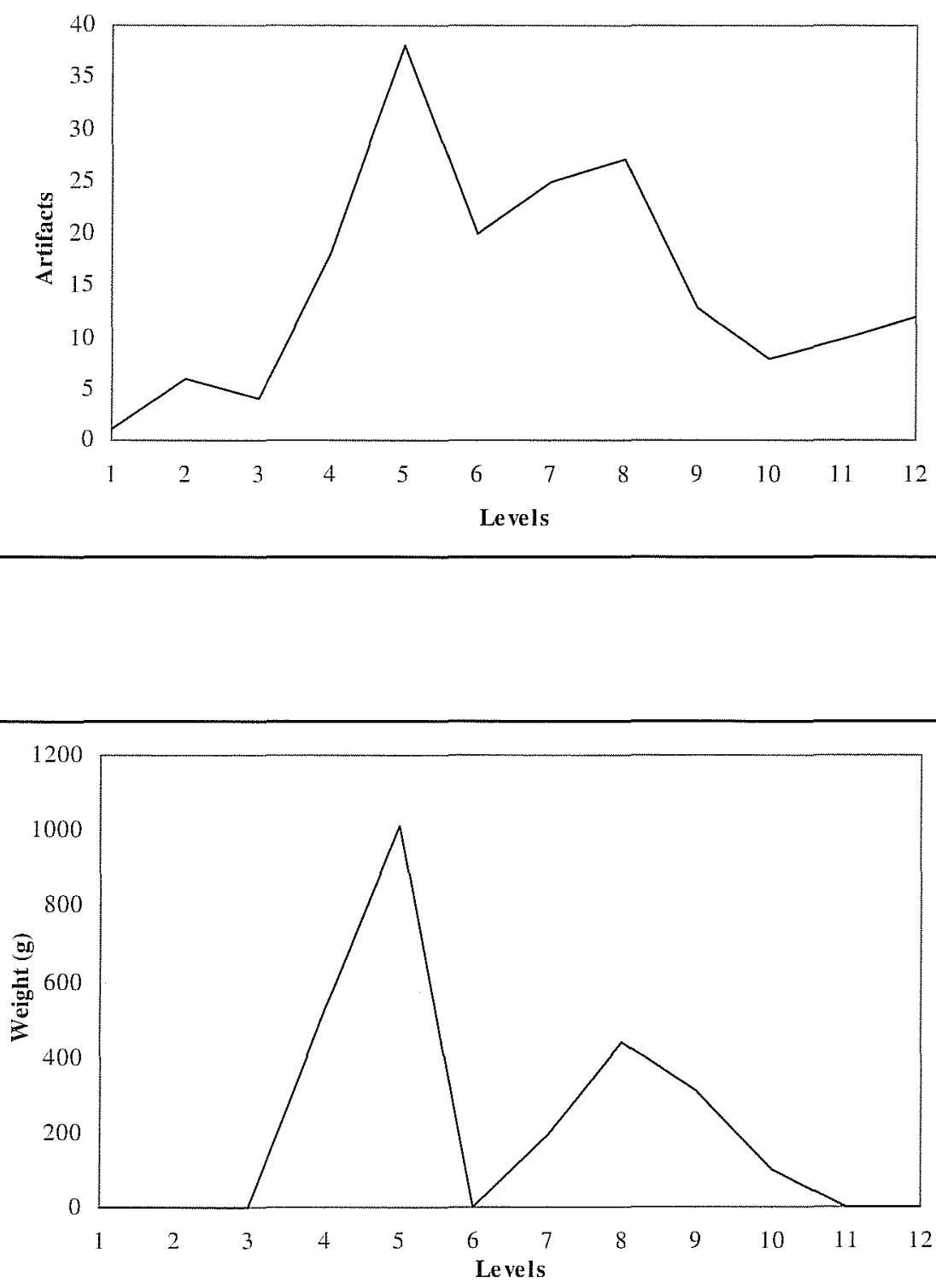

Figure 8-1. Excavation Unit 2, lithic artifacts by level.
Figure 8-2. Excavation Unit 2, fire-cracked rock by level. 


\section{Excavation Unit 4}

EU 4 is situated to the immediate west of Area 1. The unit had been excavated to a depth of $100 \mathrm{~cm}$ below the surface during the testing phase. CAR crews continued the excavations to a depth of $120 \mathrm{~cm}$ in two 10 $\mathrm{cm}$ levels. The northern quarter of EU 4 fell within the limits of the sewer line trench that had been excavated several years earlier. The darker color of the soil and the less compact texture of the soil in this portion of the unit suggested that this was the case. This interpretation was confirmed by plotting the position of EU 4 against the known location of the sewer line. Eightysix pieces of debitage were recovered, with an overall artifact density of 71.7 artifacts per cubic meter. Figure 8-3 illustrates the distribution of debitage by level.
The pattern exhibited is quite different from the one observed in EU 2. Artifact densities exhibit a rhythmic pattern with multiple peaks at Levels 4, 7, 9, and 11 . This long-term pattern of lithic reduction seems to vary somewhat inversely from that exhibited by the firecracked rock. That is, most of the burned rock is present in Levels 7 and 8, with smaller peaks in Levels 4, 9, and 10 (Figure 8-4). The burned rock in Level 7 is composed of sandstone (109.9 g) and limestone (104.0 g); whereas, the fire-cracked rock in Level 8 consists of mostly limestone (143.6 g) with less sandstone $(20.8 \mathrm{~g})$, chert $(5.5 . \mathrm{g})$, and rhyolite $(3.8 \mathrm{~g})$. It therefore appears that the activities represented in the area of EU 4 might have changed somewhat through time. This consists of mostly lithic reduction in Level 4, followed by burned rock-related activities in Levels 7 and
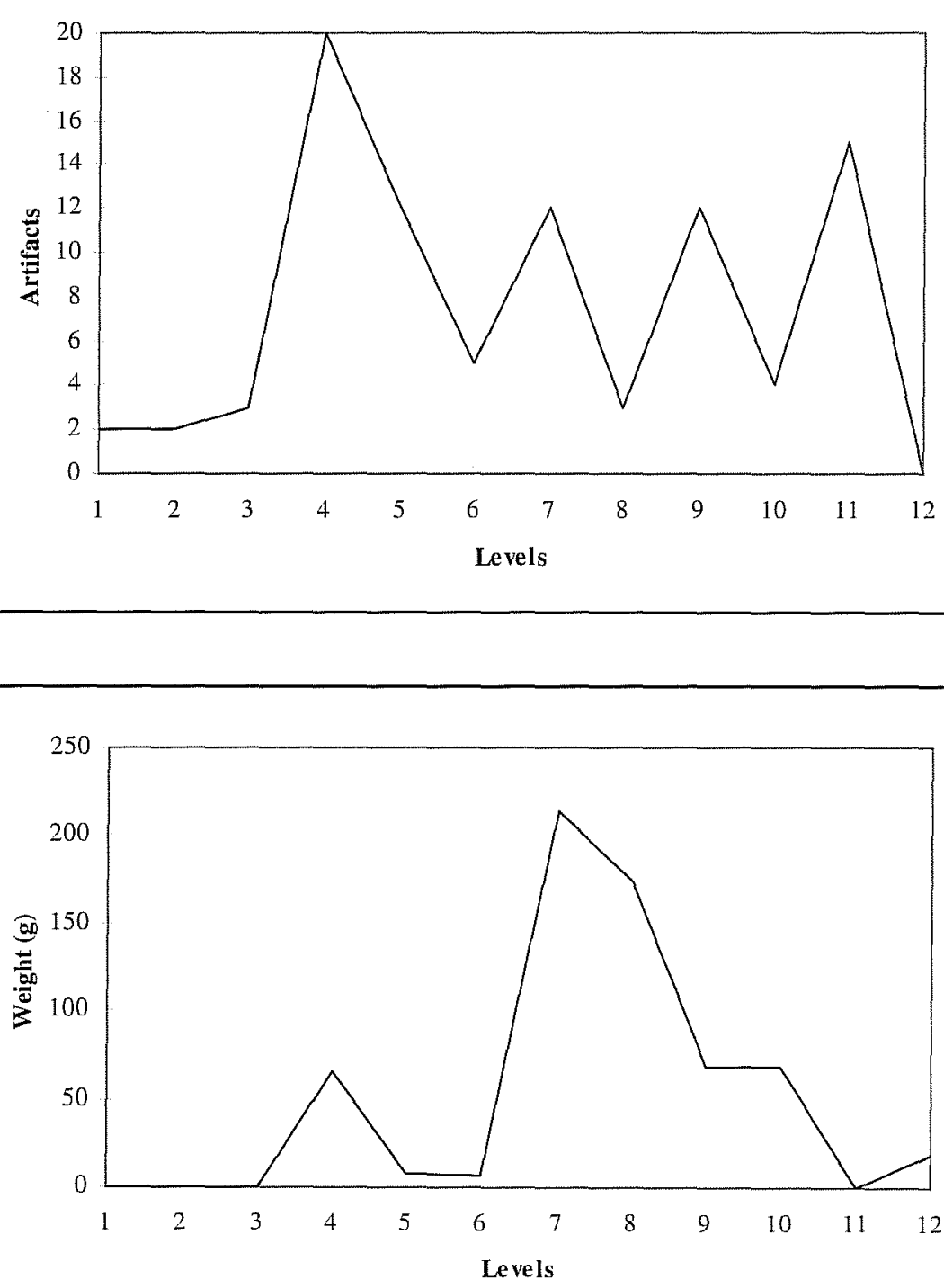

Figure 8-3. Excavatiom Unit 4, lithic artifacts by level.

Figure 8-4. Excavation Unit 4, fire-cracked rock by level. 
8 , and then switching back to mostly lithic reduction in Levels 9-11. Only a few mussel and snail remains were recovered from Levels 11 and $12(9.9 \mathrm{~g}$ and $5.0 \mathrm{~g}$, respectively). This latter pattern is similar to that witnessed in EU 2.

\section{Excavation Unit 6}

EU 6 is located to the immediate south of Area 3. TxDOT crews had excavated the initial five levels of this unit. At that point they exposed a concentration of burned wood, which they left in situ for data recovery investigations. CAR exposed the feature at an approximate depth of $56 \mathrm{~cm}$, and continued excavations to $120 \mathrm{~cm}$. One biface fragment and 126 pieces of debitage were recovered from the unit, providing an overall artifact density of 107.5 artifacts per cubic meter. The charred wood and heat-altered sediments in association with it were designated Feature 1 . They were removed from Levels $6-8$. The feature was drawn in plan and profile (Figure 8-5), samples of the wood were taken for species identification and radiocarbon dating, and a four-liter flotation soil sample was collected. The presence of fire-altered sediment adjacent to the large pieces of charred wood indicates that in situ burning had occurred. The sediment that had been exposed to the heat of a fire formed durable and compact masses that contrasted with the blocky-textured silts and silty loams of the surrounding sediments in color and hardness. One hundred twenty-seven pieces of charred mesquite wood, and 169 pieces of uncharred wood and root were identified in flotation sample Lot 59. The feature appears to represent a burned mesquite tree stump. A piece of burned wood yielded a standard radiocarbon date of $760 \pm 50$ B.P. (Beta-104966).

The distribution of artifacts in the upper portion of the unit has presumably been affected by the presence of the mesquite stump. Nonetheless, peaks in artifact density occur at Levels 3, 6, 7, and 9-12 (Figure 8-6). The middle peak corresponds to the levels which contained the burned stump; however, most of the burned rock was recovered from Level 3, with smaller peaks in Levels 7 and 11 (Figure 8-7). Most of the fire-cracked rock in Level 3 consists of sandstone $(79.5 \mathrm{~g})$, with less chert $(29.0 \mathrm{~g})$ and silicified wood $(30.7 \mathrm{~g})$. This is the only silicified wood identified among the bumed rock materials recovered from the site. The majority of mussel and snail remains were found in Levels 6 and 7 adjacent to the tree stump (Figure 8-8).

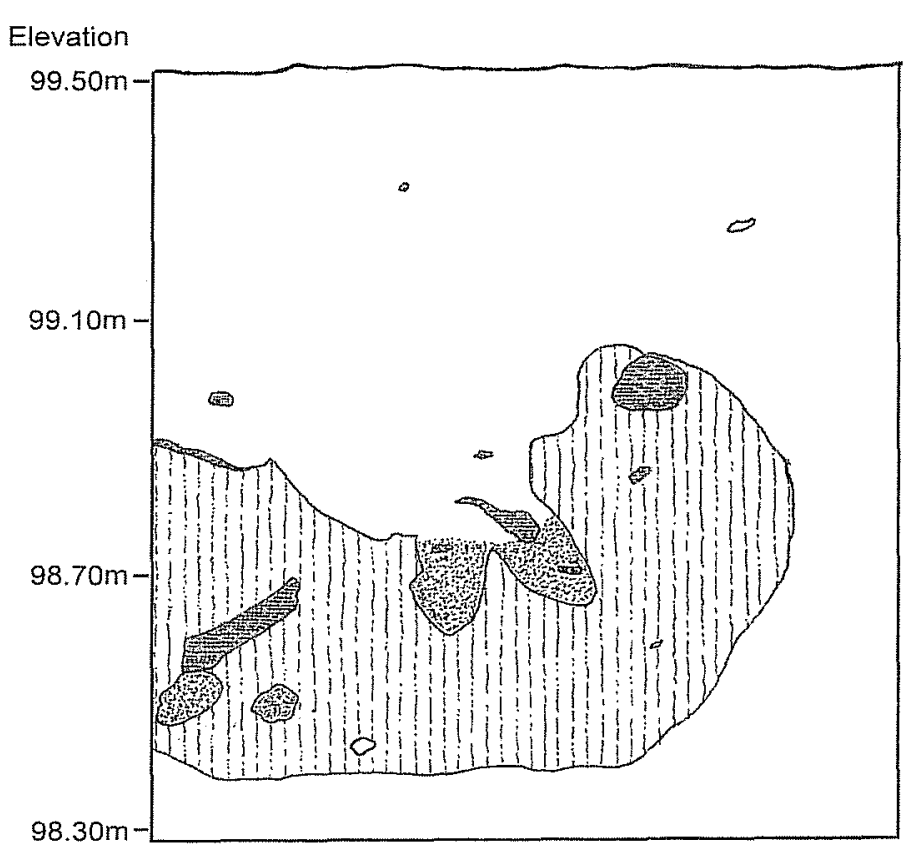

Charcoal

Ash and charcoal

[1] Oxidized sediment

Figure 8-5. Excavation Unit 6, Feature 10. 


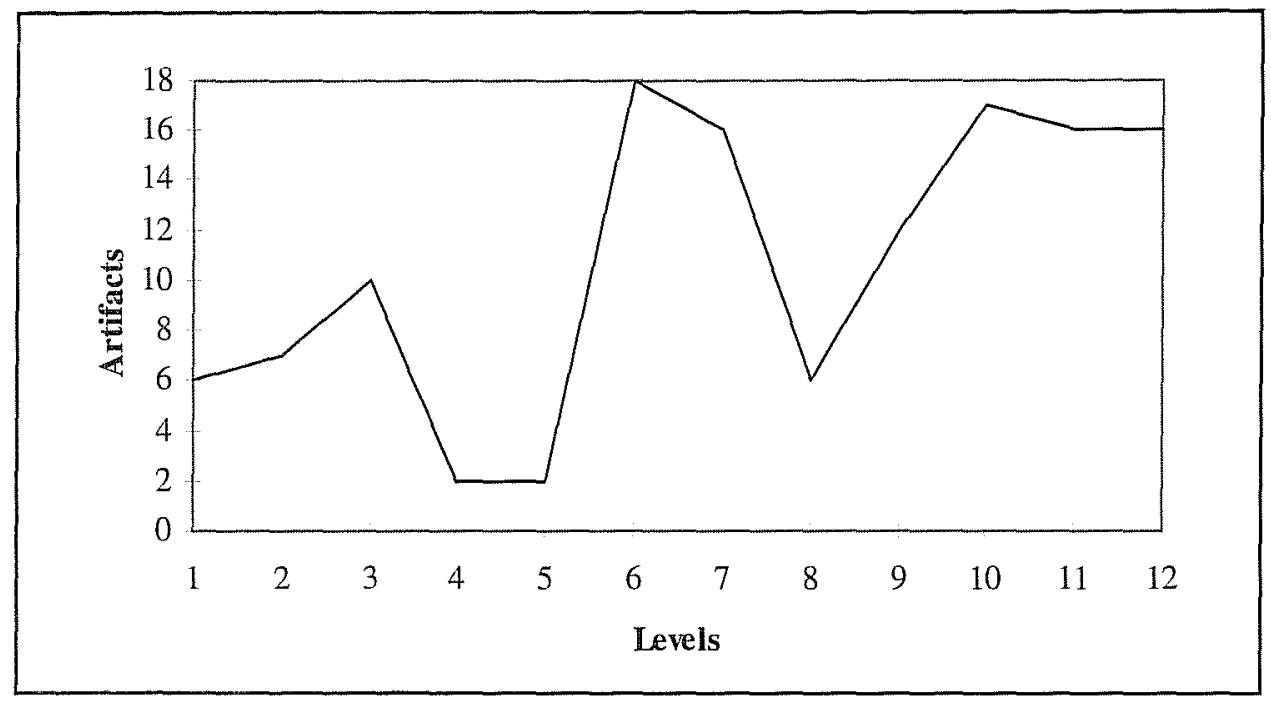

Figure 8-6. Excavation Unit 6, lithic artifacts by level.

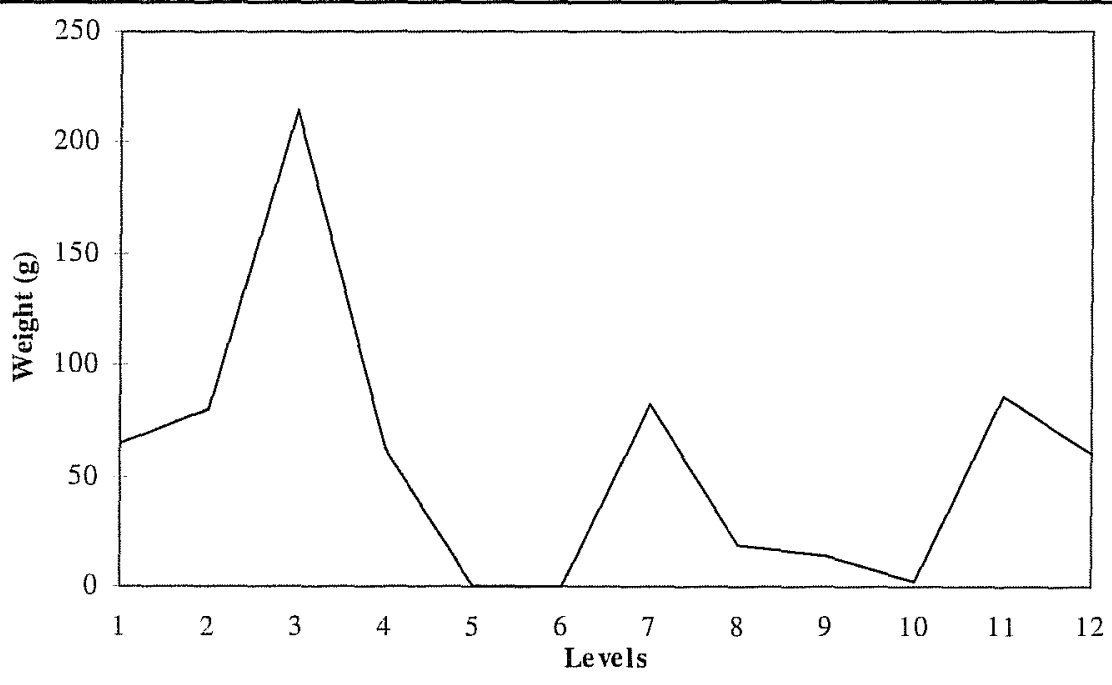

Figure 8-7. Excavation

Unit 6, fire-cracked rock by level.

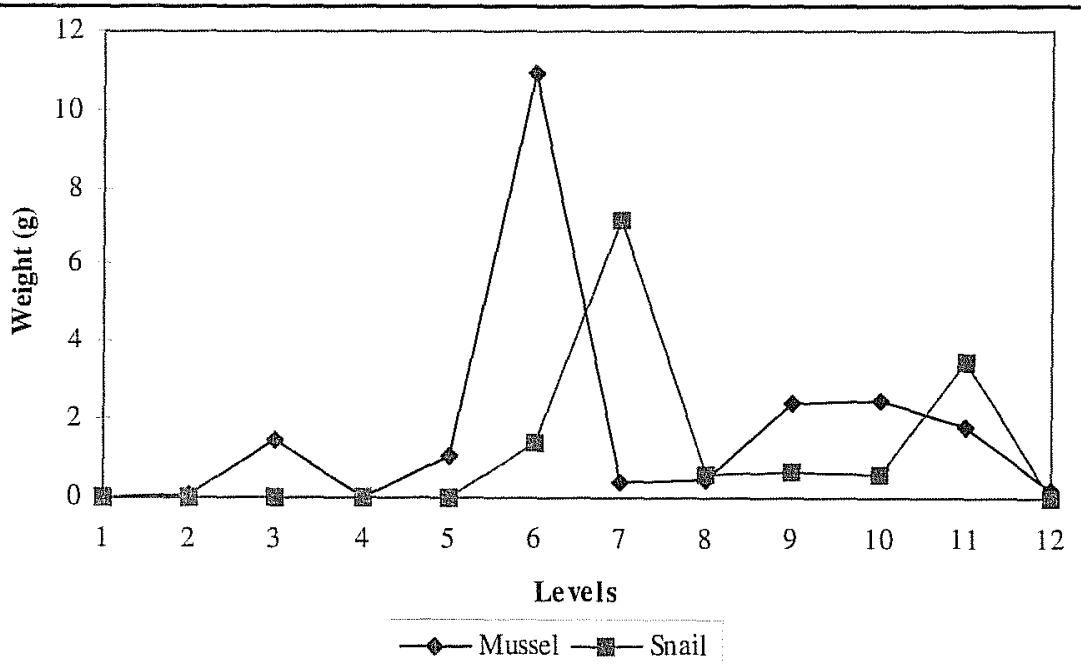

Figure 8-8. Excavation Unit 6, mussel and snail remains by level. 


\section{Excavation Unit 8}

EU 8 is situated to the immediate east of Area 3. Excavations in this unit were initiated by CAR. The upper 70 $\mathrm{cm}$ of the unit were removed in 10-cm levels, and the lower $70-120 \mathrm{~cm}$ in $5-\mathrm{cm}$ levels. Three brown and clear glass fragments were found in the upper $30 \mathrm{~cm}$ of the unit, indicating a degree of recent disturbance.

Scattered pieces of charcoal were also collected from the upper levels of the unit, although the presence of historic artifacts in the same levels raises doubts about any possible association with the prehistoric site occupation. The variable compactness of sediment in the upper $30 \mathrm{~cm}$ and the presence of a rodent burrow support the interpretation of an upper zone of bioturbation. Two biface fragments, 531 pieces of debitage, and one notched flake were recovered, for an artifact density of 445.0 artifacts per cubic meter. The majority of this material is present in Level 3 , with declining densities through the remainder of the unit (Figure 89); however, the retouched tools were found in Levels 1,5, and 10. A point-bar deposit was encountered at approximately $100 \mathrm{~cm}$ depth below the surface, being accompanied by the final drop in artifact density.

In contrast to the lithic artifacts, the fire-cracked rock is distributed in more of a rhythmic pattern through the deposits, with peaks at Levels $6,8,10$, and 12 (Figure 8-10). There are some marked differences in the composition of the burned rock between Levels 6 and 10, which contain most of this material. Level 6 primarily consists of chert $(115.1 \mathrm{~g})$, with less sandstone $(48.6 \mathrm{~g})$ and limestone $(11.8 \mathrm{~g})$; whereas, Level 10 contains mostly limestone ( $158.5 \mathrm{~g}$ ), with some sandstone (27.7 g), rhyolite (27.7 g), and chert (1.7 g). Most of the mussel and snail shells are present in Level 3 , with a second peak of mussel shell in Level 8 (Figure 8-11). Two pieces of mesquite charcoal (Lots 104 and 108) and an undetermined piece of wood charcoal were identified in Level 2, and a single piece of mesquite charcoal was recovered from Level 3 (Lot 115). EU 8 is characterized by an emphasis on lithic reduction, with some mussel and snails in the upper portion of the sequence. This pattern shifts to burned rock activities with some mussel shell in the middle and lower sections.

\section{Excavation Unit 10}

EU 10 is located to the east of EU 8 and Area 1. It was excavated in 10-cm levels from $0-20 \mathrm{~cm}$, and in $5-\mathrm{cm}$ levels from $20-120 \mathrm{~cm}$. Bioturbation was limited to the upper $40 \mathrm{~cm}$ of fill, although no historic artifacts were recovered. One core, 466 pieces of debitage, and seven retouched tools were recovered from the unit, for an artifact density of 395.0 artifacts per cubic meter. The retouched tools consist of two retouched flakes, one notched flake, one uniface, and two biface fragments. The artifacts are primarily distributed through Levels 2,3 , and 6, with declining densities from Levels 7-12 (Figure 8-12). The burned rock exhibits a similar distribution with peaks in Levels 3 and 5 (Figure 8-13), with both concentrations being dominated by sandstone. Level 3 contains sandstone $(107.5 \mathrm{~g})$, with less rhyolite $(58.8 \mathrm{~g})$, and limestone $(8.9 \mathrm{~g})$; whereas, Level 5 contains sandstone $(195.9 \mathrm{~g})$ with some limestone $(3.8 \mathrm{~g})$. Very few mussel and snail remains are present; however, mussel shells are found in Levels 2, 3, 5, and 10, and snail shells in Level 7 (Figure 8-14). The upper portion of the sequence exhibits a combination of lithic reduction and burned rock activities, with some evidence of mussel consumption. In contrast, the lower portion of the sequence is characterized by a much lower use intensity, with some snails and mussels.

\section{Backhoe Trenches}

A series of six backhoe trenches (BHTs 7-12) was excavated to further define the nature and extent of the subsurface deposits. The results of the geomorphological study of these trenches is presented in the previous chapter; however, since a feature was exposed within BHT 10 , the nature of the deposits and the feature is discussed here.

BHT 10 was excavated in the west-central area of the site, north of EU 6. The trench is about $4.5 \mathrm{~m}$ long and $1.5 \mathrm{~m}$ deep. As described in Chapter 7, eight stratigraphic horizons were defined in the trench (including disturbed fill), with a variety of cultural material being exposed (Figure 8-15). This consists of burned rock, debitage, charcoal, and mussel and snail shells. Tiny pieces of bone were also identified during the soil pet- 


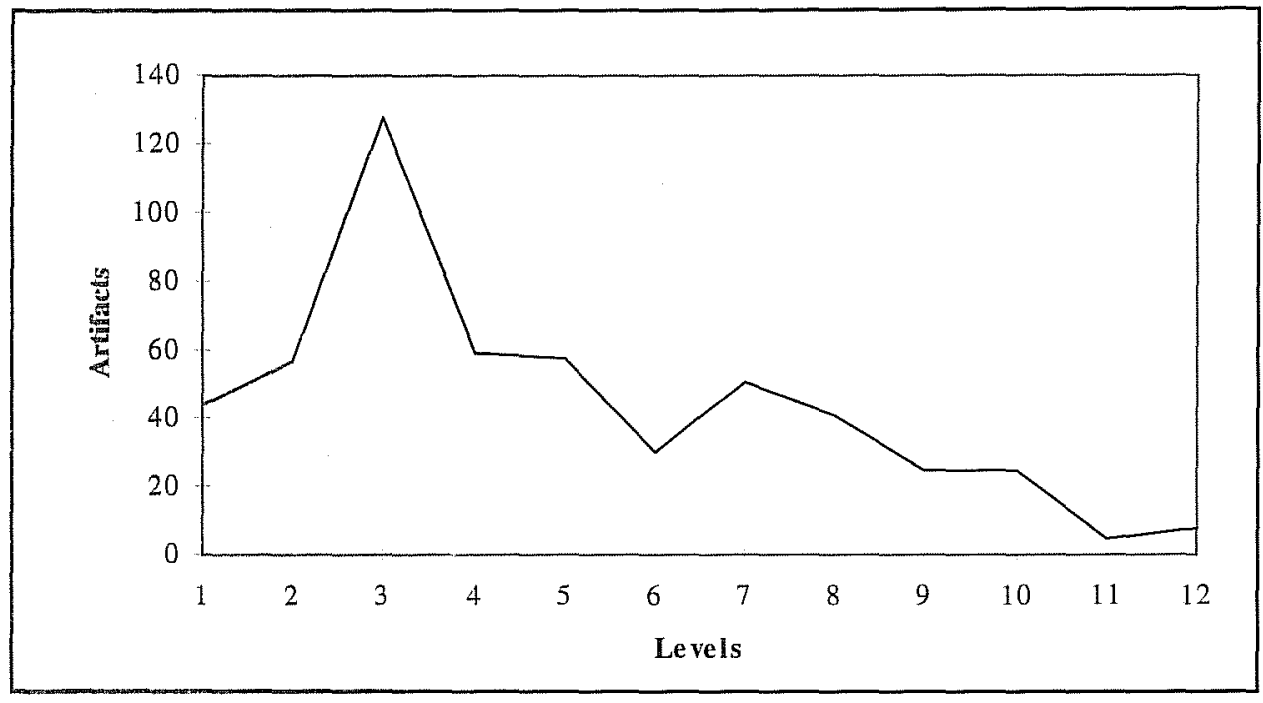

Figure 8-9. Excavation Unit 8, lithic artifacts by level.

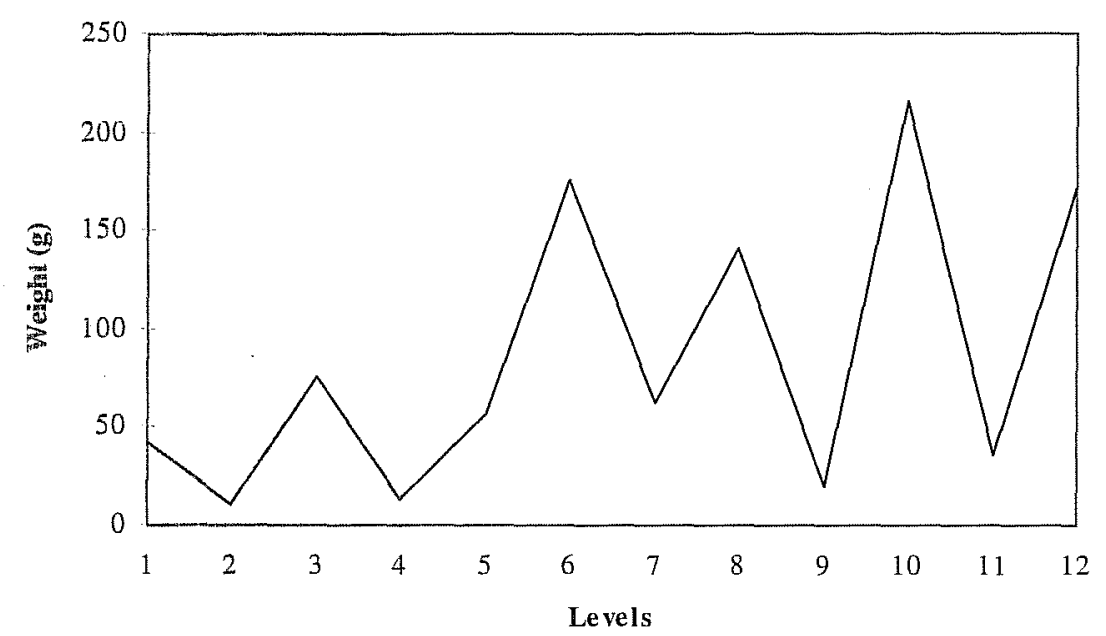

Figure 8-10. Excavation Unit 8, fire-cracked rock by level.

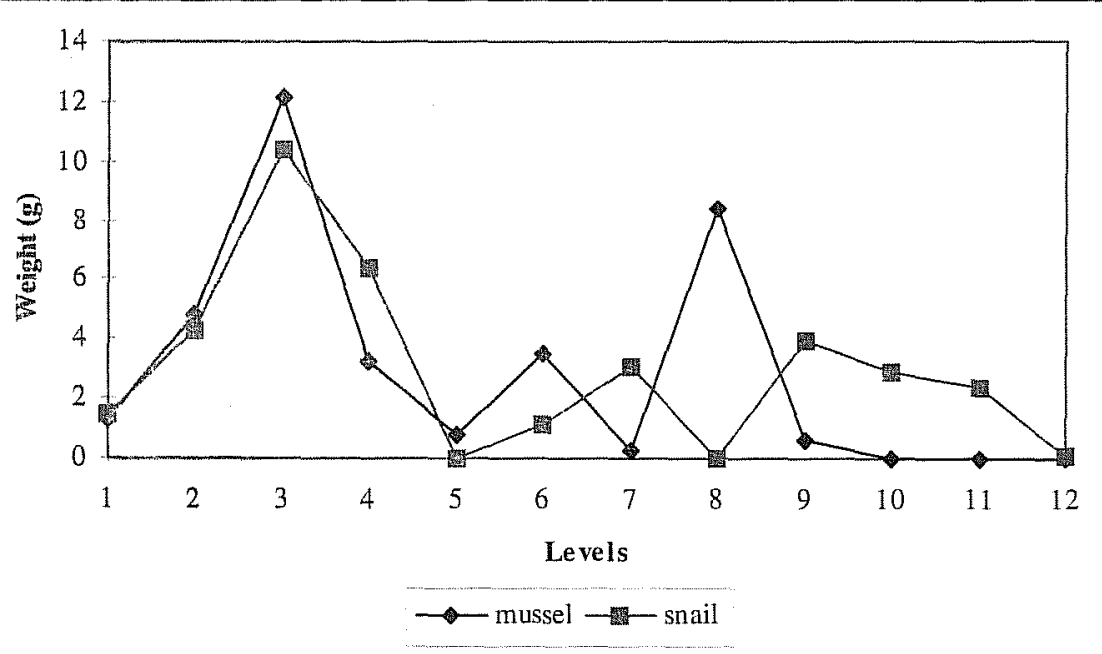

Figure 8-11. Excavation Unit 8, mussel and snail remains by level. 


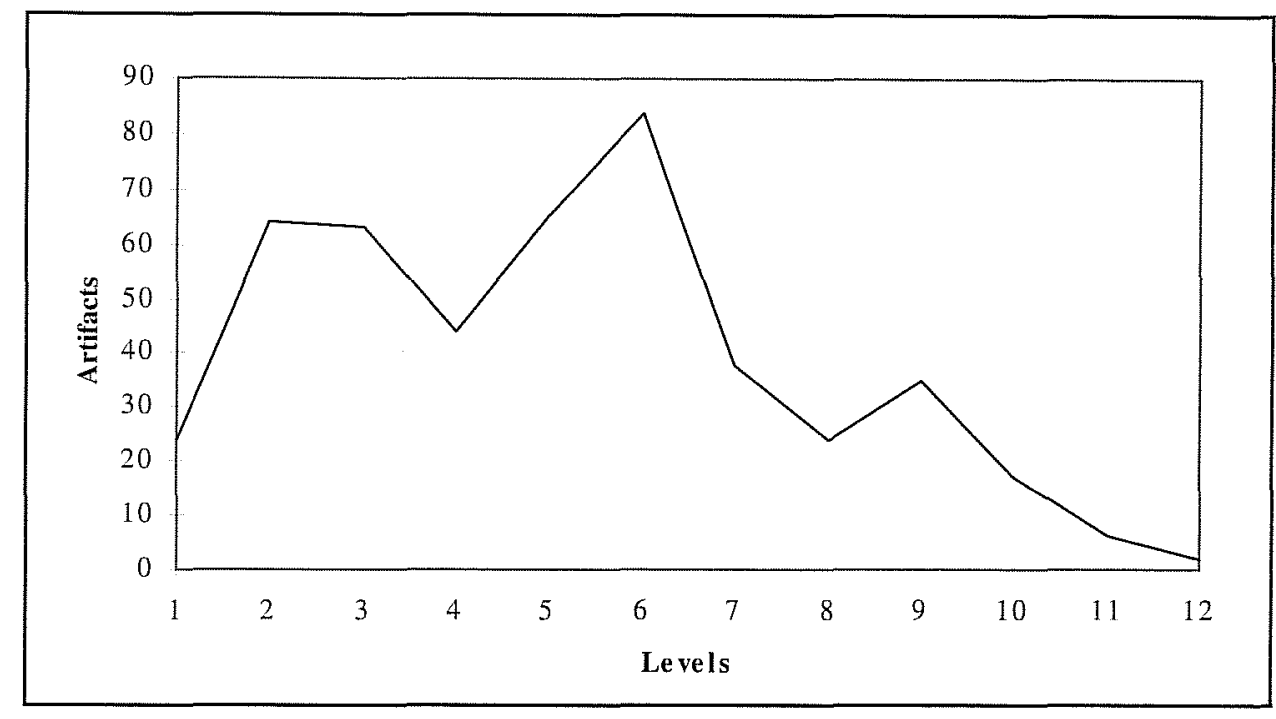

Figure 8-12. Excavation Unit 10, lithic artifacts by level.

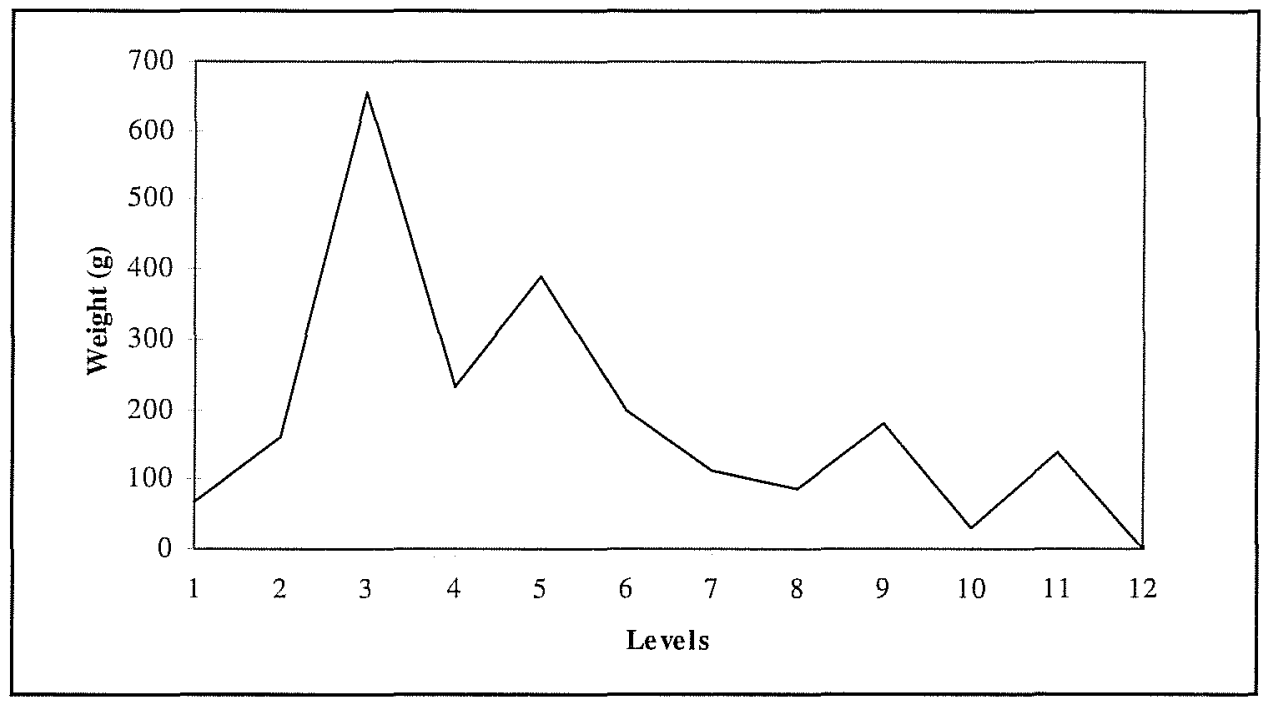

Figure 8-13. Excavation Unit 10, fire-cracked rocks by level.

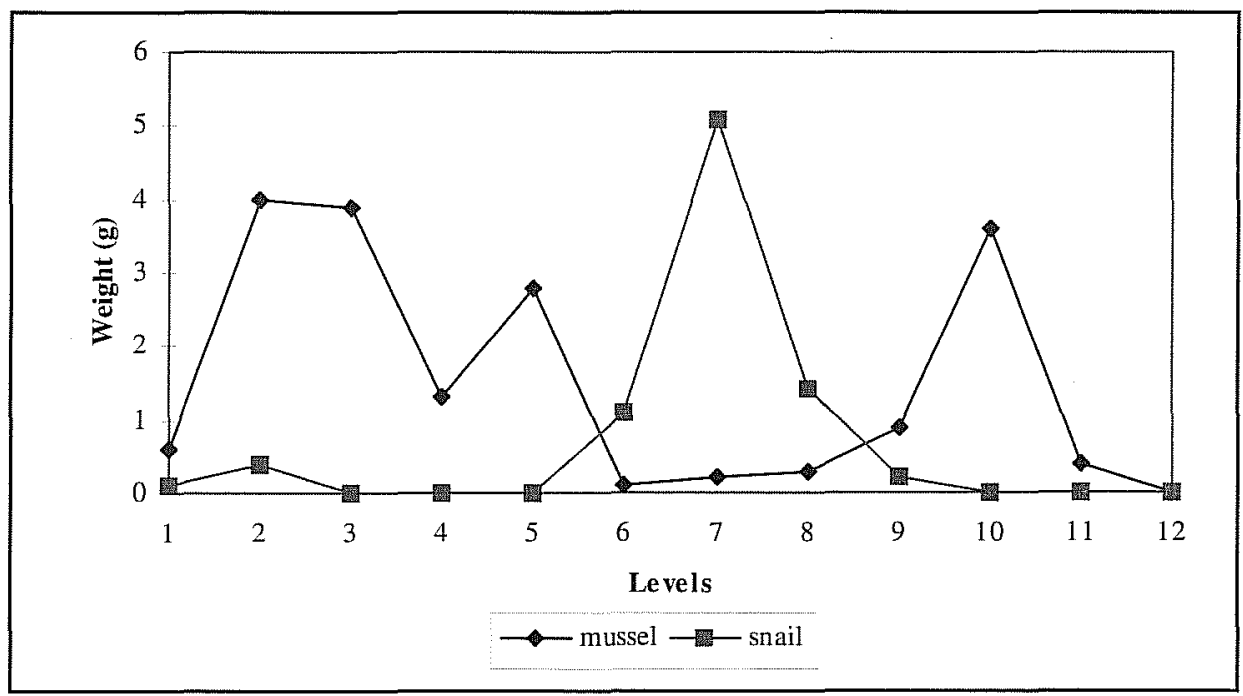

Figure 8-14. Excavation Unit 10, mussel and snail remains by level. 


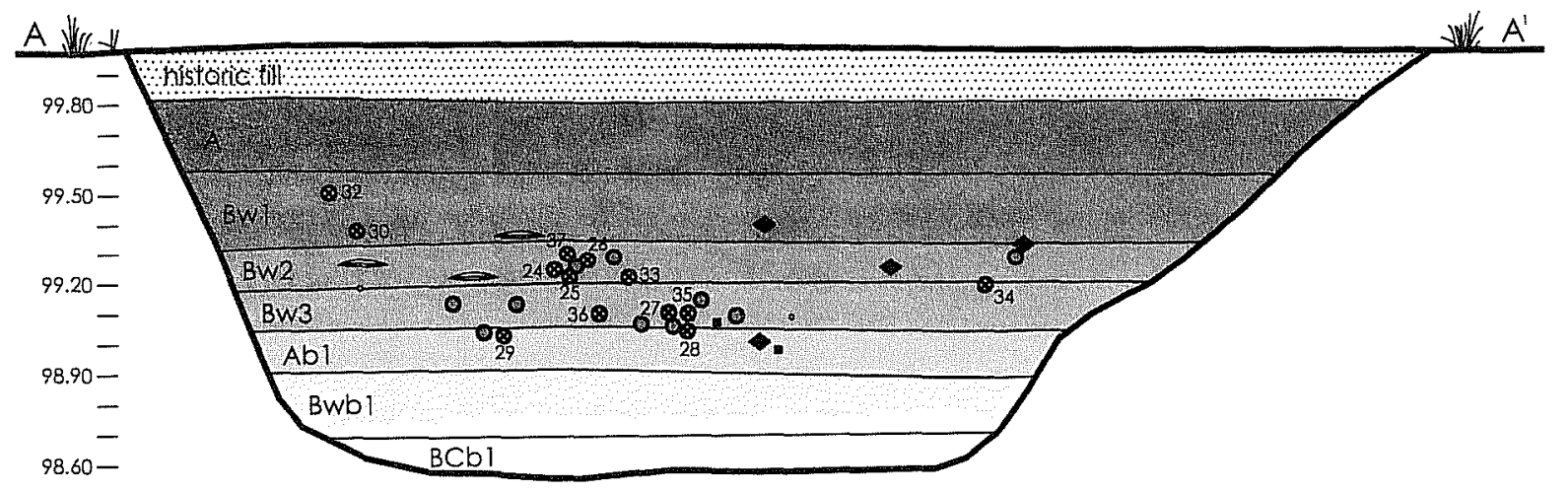

$\underbrace{.50}_{\text {meters }} \quad 1 \quad 2$

- Archaeomagnetic Samples

- Fire-cracked Rock

- Chert Debitage

- Charcoal

- Mussel Shell

- Snail

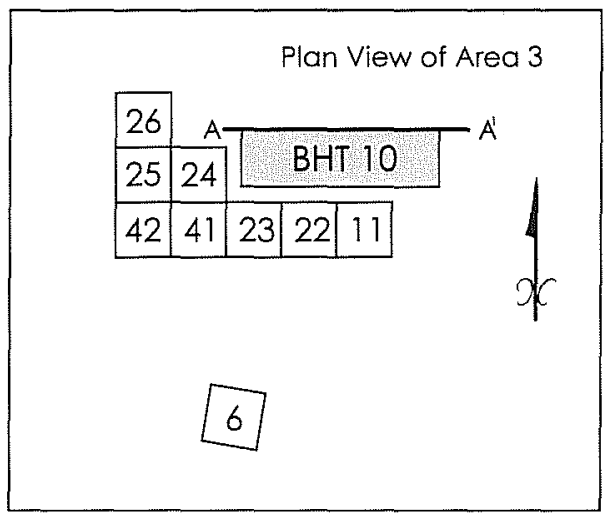

Figure 8-15. BHT 10, profile.

rographic analysis. Most of the artifactual material is concentrated in approximately $40 \mathrm{~cm}$ of the B horizon situated in the middle of the profile (i.e., Bw2 and Bw3). Twenty-three pieces of burned sandstone, designated Feature 10, were plotted on the trench profile. Most of these are clustered together in the center of the trench, with several outlying pieces.
Nine archaeomagnetic samples $(24-28,33$, and 35$37)$ were taken from the feature and four $(29,30,32$, and 34) from surrounding isolated rocks; however, only six of the feature samples $(24-25,27 \mathrm{a}, 27 \mathrm{~b}, 28$, and 29) were suitable for analysis. The majority of the suitable samples (25, 27 and 29) are in situ, with Samples 24 and 28 having moved somewhat since 
being heated. It seems probable that the upper group of samples $(24,25,26$, and 37) in the Bw2 horizon represent part of a feature, with Sample 25 still being in place. On the other hand, the lower group of samples $(27,28$, and 35$)$ in the Bw3 horizon are probably from a separate feature, with Sample 27 still being in place. Isolated Sample 29 may be the remnant of a third feature which was mostly removed during the excavation of the trench. This burned rock is located at the top of the Abl paleosol. See Chapter 10 for a discussion of the results of the archaeomagnetic study, and Appen$\operatorname{dix} \mathrm{F}$ for the individual sample data.

A set of 1-x-1-m units was located to the immediate south of BHT 10 to further explore the nature of these features. This block excavation was designated as Area 3 , and is discussed in a subsequent section.

\section{Excavation Blocks}

\section{Area 1}

Area 1 is a linear block excavation located in the eastern portion of the site. This block expanded the area of high artifact density that had been identified during the earlier testing of the site in EUs 1 and 3 and BHT 1. The overall shape of the block reflected the constraints imposed by the edge of the road to the south and the sewer line trench to the north. Before the sewer line trench was discovered during fieldwork, a larger block had been planned for this portion of the site. Twelve square meters were excavated within this block, consisting of EUs 1 and 3, and EUs 12-15, 31-34, 36, and 43 (Figure 8-16). The initial work undertaken in this eastern block was the definition of the TxDOT trench and test units. A grader/maintainer supplied by the Eagle Pass TxDOT Office was used to scrape $5-10 \mathrm{~cm}$ of disturbed fill from the area of the earlier excavations. The outlines of the TxDOT test units were clearly visible as darker and less compacted soil than the undisturbed surrounding soils. Fill was removed from EUs 1 and 3 to depths of $60 \mathrm{~cm}$ and $120 \mathrm{~cm}$, respectively (i.e., the limits of the previous excavations). CAR crew members continued the excavation of EU 1 to a depth of $120 \mathrm{~cm}$ in $10-\mathrm{cm}$ increments. The upper $40 \mathrm{~cm}$ of fill was removed without screening in the eastern half of Area 1 in units 12-15, and the upper
$60 \mathrm{~cm}$ of fill in the western half of the area in units 31-43. These deposits were considered disturbed, containing very low artifact densities. The general stratigraphic sequence consists of an upper disturbed zone, a compact silt, a silt, and the underlying sands of a point-bar deposit (Figure 8-16). Floodplain units defined within the area consist of $2 p, 2-f 1,2-f 2,2-f 3$, and fill (Chapter 7). Table 8-1 correlates the information on geological facies and soil horizons by $10-\mathrm{cm}$ levels within BHT 7. The point-bar deposits were encountered in the three units excavated to depths of 130$140 \mathrm{~cm}$ (EUs 12, 31, and 43). These lower depths exhibited a marked decrease in the presence of cultural material.

\section{Lithic Artifacts}

Three cores, 25 retouched tools, one mano fragment, and 4,538 pieces of debitage were recovered from the excavations in Area 1. This represents an overall artifact density of 551.9 artifacts per cubic meter; however, artifact density does vary by excavation unit, ranging from 406.3 to 750.0 . Four units contain the highest artifact densities encountered on the site, with more than 650 artifacts per cubic meter. These consist of EUs 32, 33, and 36, which are contiguous units in the western section of the area, and EU 12 which is situated at the eastern end of the excavation block. The artifacts are primarily distributed through Levels 9-11, with a slight dip in Level 10 (Figure 8-17). The majority of the EUs exhibit this pattern, with the exception of EUs 12 and 14 which have peaks in Levels 10 and 12 (Figure 8-18). This may be due to undulations in the soil profile, with these two units being offset by $10 \mathrm{~cm}$.

\section{Burned Rock and Features}

The burned rock distribution is similar to that exhibited by the lithic artifacts, with peaks in Levels 8 and 9 and 11 (Figure 8-19). This pattern is consistent throughout the excavation block, with distinctive peaks in Level 8 of EU 31, Level 10 EU 1, and Level 11 in EU 3 (Figure 8-20); however, rock composition does vary between the levels in these two units. Most of the burned rock in Level 8 of EU 31 is composed of chert 


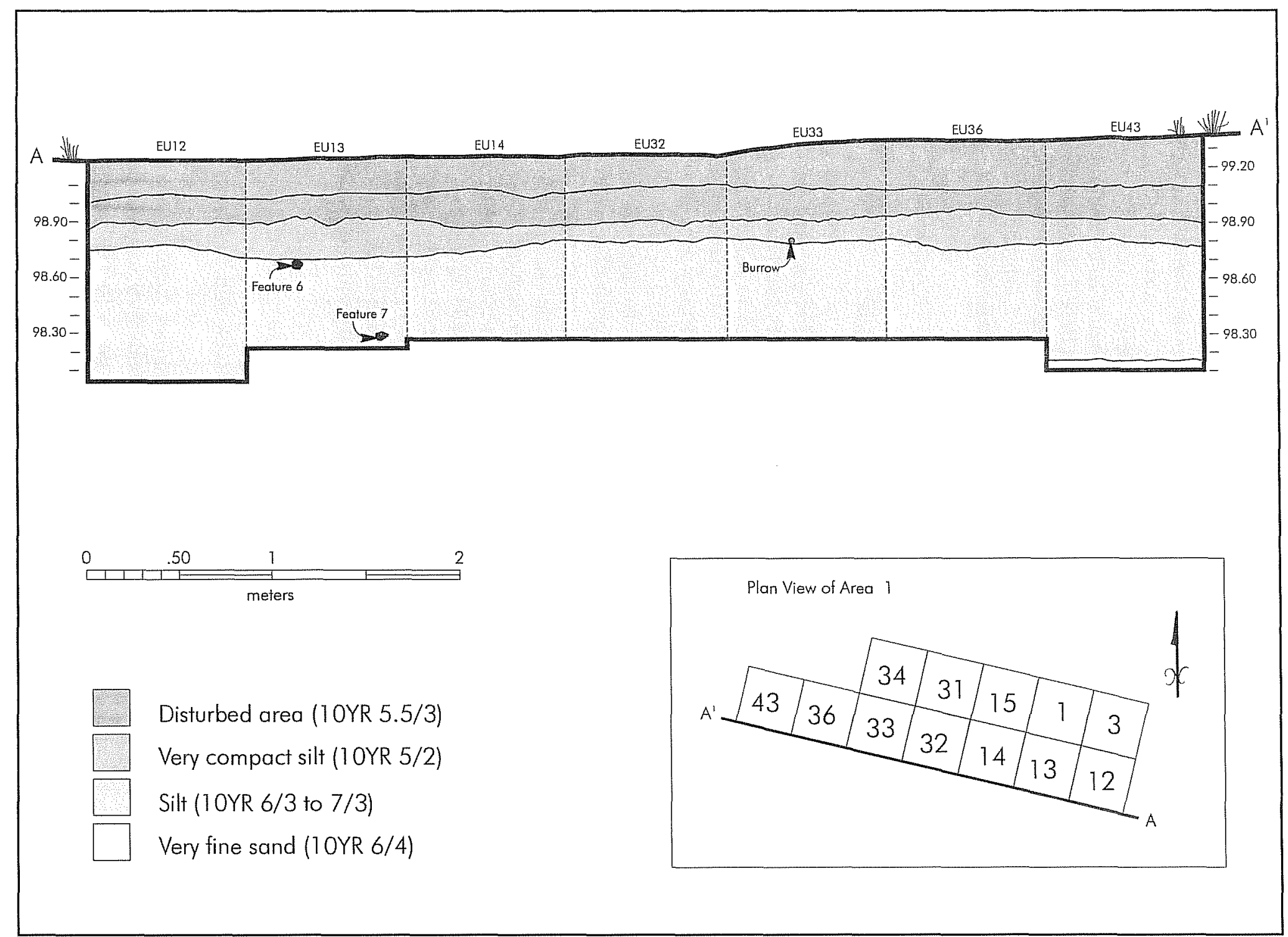

Figure 8-16. Area 1, plan and profile. 
Table 8-1. Site Soil Stratigraphy and Geological Facies

\begin{tabular}{|c|c|c|c|c|c|c|c|c|}
\hline \multirow{2}{*}{ Level } & \multicolumn{2}{|c|}{ Area 1 (BHT 7) } & \multicolumn{2}{|c|}{ Area 2 (BHT 9) } & \multicolumn{2}{|c|}{ Area 3 (BHT 10) } & \multicolumn{2}{|c|}{ Area 4 (BHT 12) } \\
\hline & Strata & Facies & Strata & Facies & Strata & Facies & Strata & Facies \\
\hline 1 & Ap 1 & \multirow[t]{5}{*}{ Fill } & Ap 1 & \multirow[t]{3}{*}{ Fill } & Ap & \multirow[t]{2}{*}{ Fill } & Ap & \multirow[t]{6}{*}{ Fill } \\
\hline 2 & Ap 1 & & $\begin{array}{l}\text { Ap1, } \\
\text { Ap2 }\end{array}$ & & Ap & & Ap & \\
\hline 3 & Ap 1, & & Ap2 & & A & \multirow[t]{8}{*}{$2 \cdot \mathrm{f}$} & Ap & \\
\hline & & & A1 & \multirow[t]{2}{*}{ 2-f3 } & & & & \\
\hline 4 & Ap2 & & A1 & & A & & Ap & \\
\hline 5 & $\begin{array}{l}\text { Bw1, } \\
\text { Bw2 }\end{array}$ & \multirow[t]{4}{*}{$2 \cdot+3$} & $\mathrm{~A} 2$ & \multirow[t]{9}{*}{$2-\mathrm{f1}$} & A, & & Ap & \\
\hline 6 & $\mathrm{Bw} 2$ & & Bw1 1 & & Bw1 & & A & $2 \cdot \mathrm{f} 3$ \\
\hline 7 & $\mathrm{Bw3}$ & & $\begin{array}{l}\text { Bw1; } \\
\text { Bw2 }\end{array}$ & & $\begin{array}{l}\text { Bw1, } \\
\text { Bw2 }\end{array}$ & & $\begin{array}{l}\text { A, } \\
\text { Bw1 }\end{array}$ & \\
\hline \multirow[t]{2}{*}{8} & Bw3, & & \multirow[t]{2}{*}{$\mathrm{Bw} 2$} & & \multirow[t]{2}{*}{$\mathrm{Bw} 2$} & & \multirow{2}{*}{$\begin{array}{l}\text { Bw1, } \\
\text { Bw2 }\end{array}$} & \\
\hline & $\mathrm{Ab} 1$ & \multirow[t]{2}{*}{$2-f 2$} & & & & & & \\
\hline 9 & $\mathrm{Abl}$ & & $\mathrm{Bw} 2$ & & $\mathrm{Ab} 1$ & $2-f 2$ & $\begin{array}{l}\mathrm{Bw2} \\
\mathrm{B} w 3\end{array}$ & \\
\hline \multirow[t]{2}{*}{10} & \multirow[t]{2}{*}{ Bwb1 } & \multirow[t]{3}{*}{ 2-f1 } & Bw3 & & $\mathrm{Ab} 1$ & & \multirow[t]{2}{*}{ Bw3 } & \\
\hline & & & & & $\mathrm{BW} / \mathrm{lbl}$ & $2-\mathrm{fl}$ & & \\
\hline 11 & Bcbl & & Bw3 & & $\begin{array}{l}\mathrm{Bw} 1 \mathrm{bl} 1 \\
\mathrm{Bw} 2 \mathrm{bl}\end{array}$ & & $\begin{array}{l}\text { Bw3, } \\
\text { Bw4 }\end{array}$ & \\
\hline 12 & \multirow{9}{*}{\multicolumn{2}{|c|}{ unexcavated }} & $\mathrm{BC}$ & \multirow[t]{8}{*}{$2-p$} & $\mathrm{Bw} 2 \mathrm{bl}$ & & Bw4 & \\
\hline 13 & & & BC & & $\mathrm{Bw} 2 \mathrm{~b} 1$ & & Bw5 & \\
\hline 14 & & & $\mathrm{BC}$ & & BCb1 & 2-p & $B \times 5$ & \\
\hline \multirow[t]{2}{*}{15} & & & \multirow[t]{2}{*}{$\mathrm{BC}$} & & \multirow[t]{2}{*}{ Bcb1 } & & Bw5 & \\
\hline & & & & & & & $\mathrm{Ab1}$ & $2-f 2$ \\
\hline \multirow[t]{2}{*}{16} & & & \multirow{2}{*}{$\mathrm{BC}$} & & \multirow{4}{*}{\multicolumn{2}{|c|}{ unexcavated }} & $\mathrm{Ab} 1$ & \\
\hline & & & & & & & $\mathrm{BCb1}$ & 2-p \\
\hline 17 & & & C & & & & BCbl & \\
\hline 18 & & & \multicolumn{2}{|c|}{ unexcavated } & & & BCbI & \\
\hline
\end{tabular}



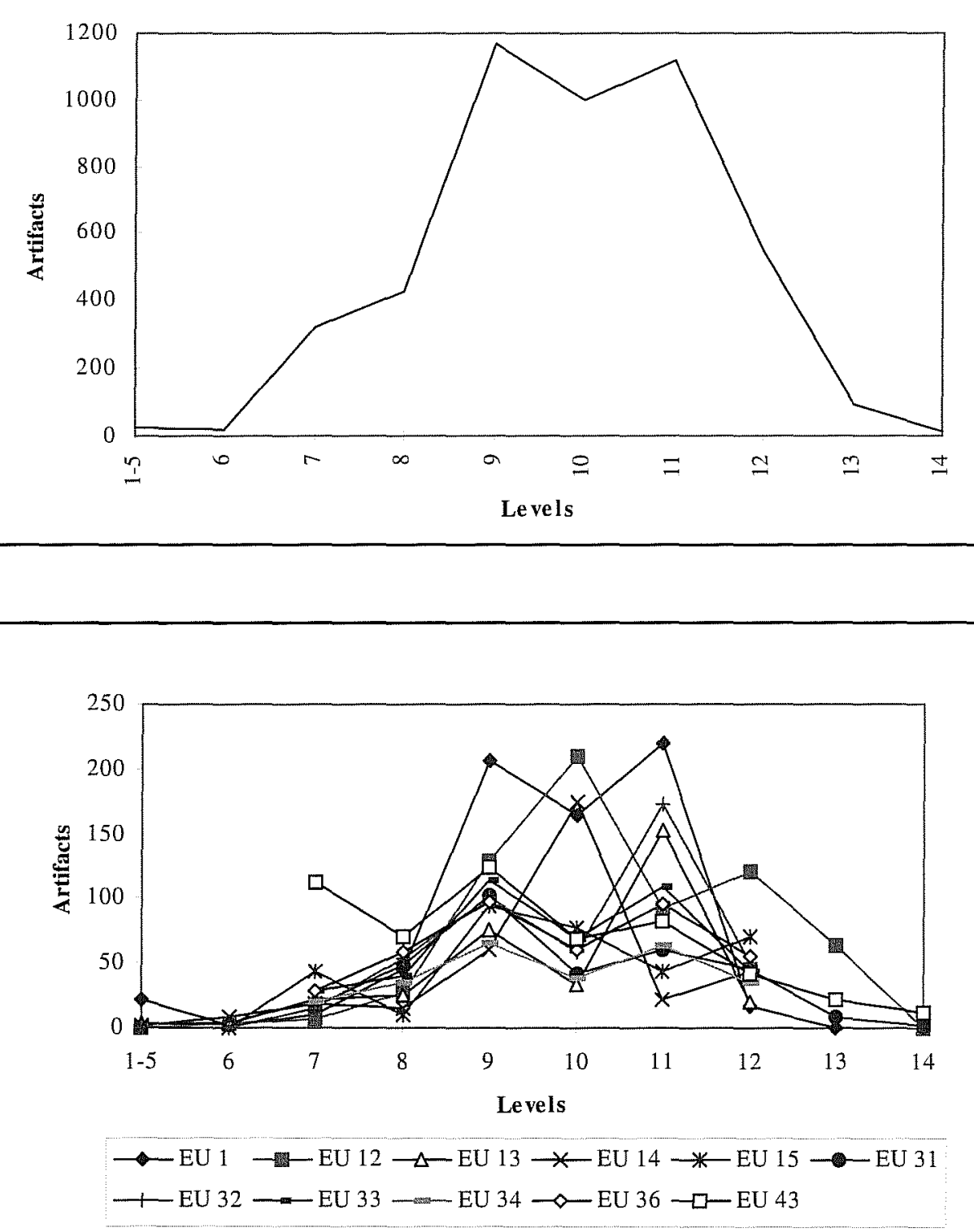

Figure 8-17. Area 1, lithic artifacts by level.
Figure 8-18. Area 1, lithic artifacts by excavation unit and level.
(406.4 g), with less sandstone (270.5 g), limestone $(133.8 \mathrm{~g})$, and rhyolite $(16.0 \mathrm{~g})$. In contrast, all the burned rock in Level 10 of EU 1 is burned sandstone $(954.1 \mathrm{~g})$ associated with a possible hearth (Feature 2); whereas, the burned rock in Level 11 consists of sandstone (201.1 g), limestone (194.8 g), rhyolite $(133.3 \mathrm{~g})$, and chert $(37.1 \mathrm{~g})$. Sandstone is locally available as tabular materials from bedrock outcrops. The remaining materials can be obtained from local terrace gravels. The mixture of burned sandstone with chert, limestone, and rhyolite in Levels 8 and 11 may reflect the disturbed and/or discarded remains of hearth elements and boiling stones. Besides the cluster of burned sandstone present in Level 10 of EU 1, clusters of fire- cracked rock were also identified in Level 8 of EU 13, and Level 12 of several units located at the western end of the block.

Feature 2 consists of a cluster of burned sandstone in Level 10 of EU 1 (Figure 8-21). Two archaeomagnetic samples were taken from the feature (Lots 1 and 2); however, only one of these was suitable for analysis. The results of this analysis indicates that the rock has moved since being heated. This, in conjunction with the linear distribution of the scatter, indicates that the feature represents the disturbed remains of a hearth or possibly a dump. 

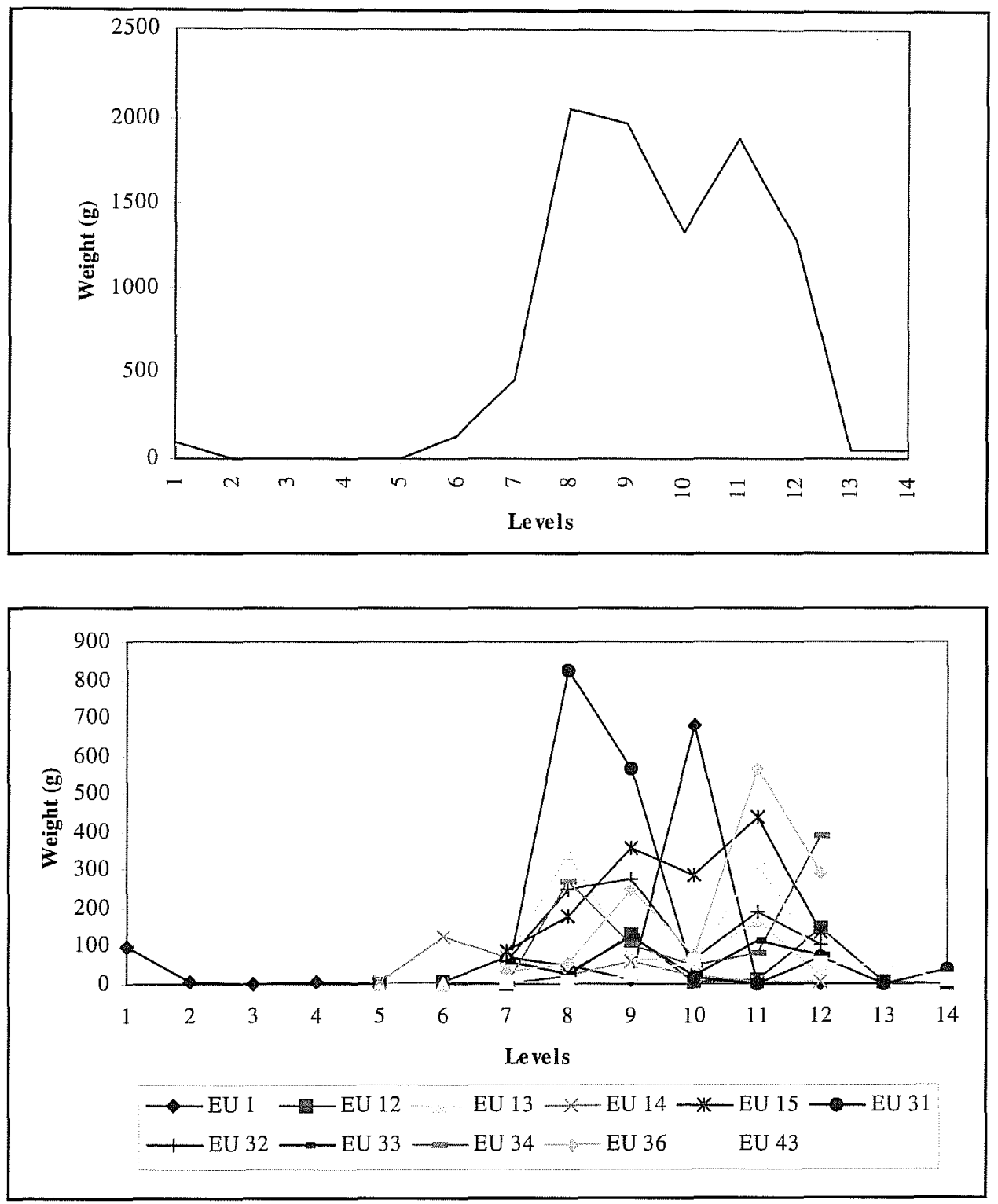

Figure 8-19. Area 1, firecracked rock by level.
Figure 8-20. Area 1, firecracked rock by excavation and level.
Feature 5 consists of a concentration of 10 pieces of burned sandstone situated between EUs 13 and 14 in Level 8 (Figure 8-22). Results of the archaeomagnetic analysis of Samples 4, 9, 10, and 11 indicate that the pieces have moved since originally being heated. Sample 4 appears less disturbed than Sample 11, which is inverted. This feature probably reflects the disturbed remains of a hearth, although the rocks are still tightly clustered.

Feature 6 is a small concentration of charcoal-stained soil. It was identified in the south-wall profile of $\mathrm{EU}$ 13 , being about $10 \mathrm{~cm}$ in diameter, and located $61-74$ $\mathrm{cm}$ below the surface (Levels 7 and 8; Figure 8-16). A sample was collected from the feature; however, no carbonized remains were present.

Feature 7 is also a small concentration of charcoalstained soil which was exposed on the south wall of EU 13. It, too, is about $10 \mathrm{~cm}$ in diameter, but is situated at a lower depth of 113-118 cm (Level 12; Figure 8-16). A sample collected from this feature also failed to produce any carbonized remains.

Several small isolated clusters of burned sandstone are present in the western half of the excavation block in Level 12 of EUs 32-34, 36, and 43 (Figure 8-23). Results of the archaeomagnetic analysis indicate that 


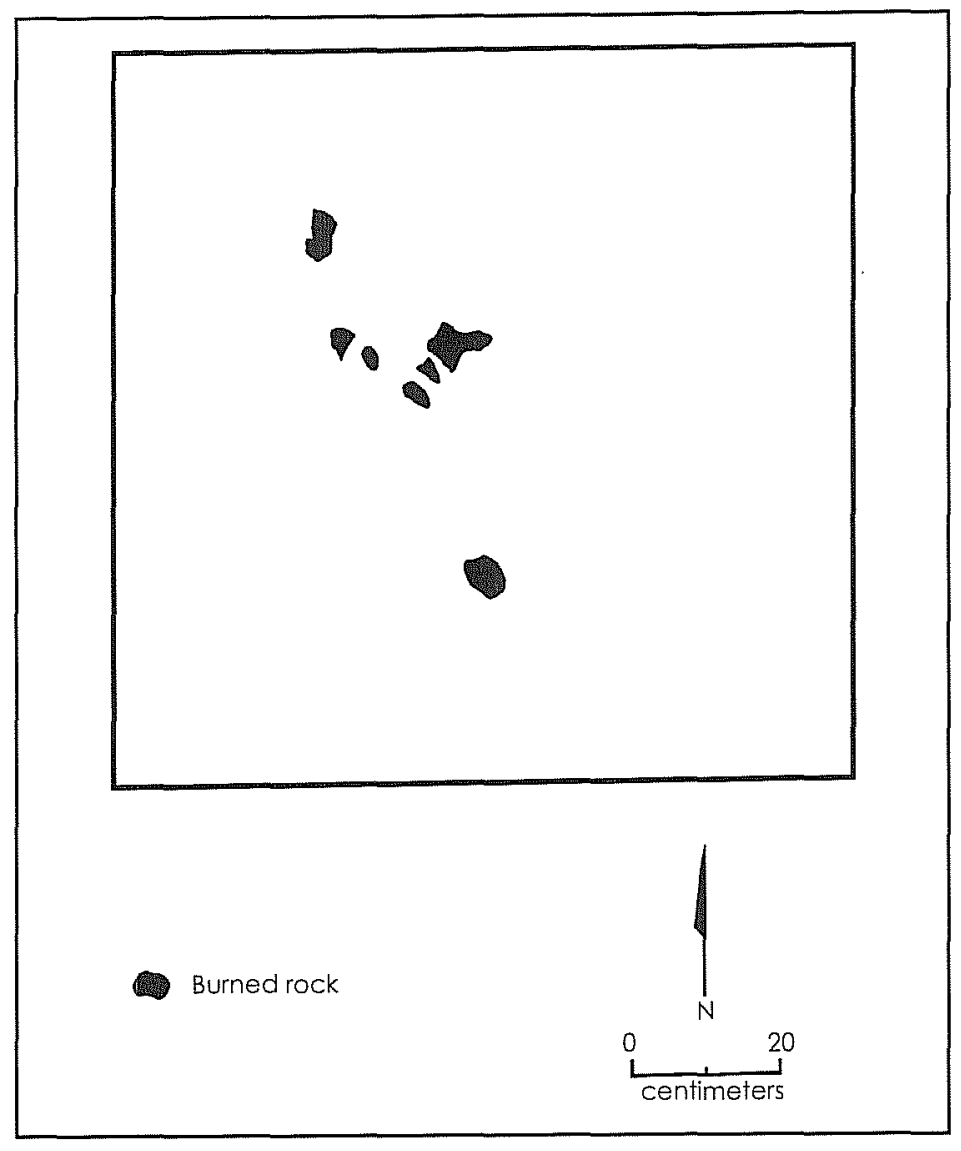

Figure 8-21. Excavation Unit 1,

Feature 10.

Figure 8-22. Excavation Units 13 and 14, Feature 5.

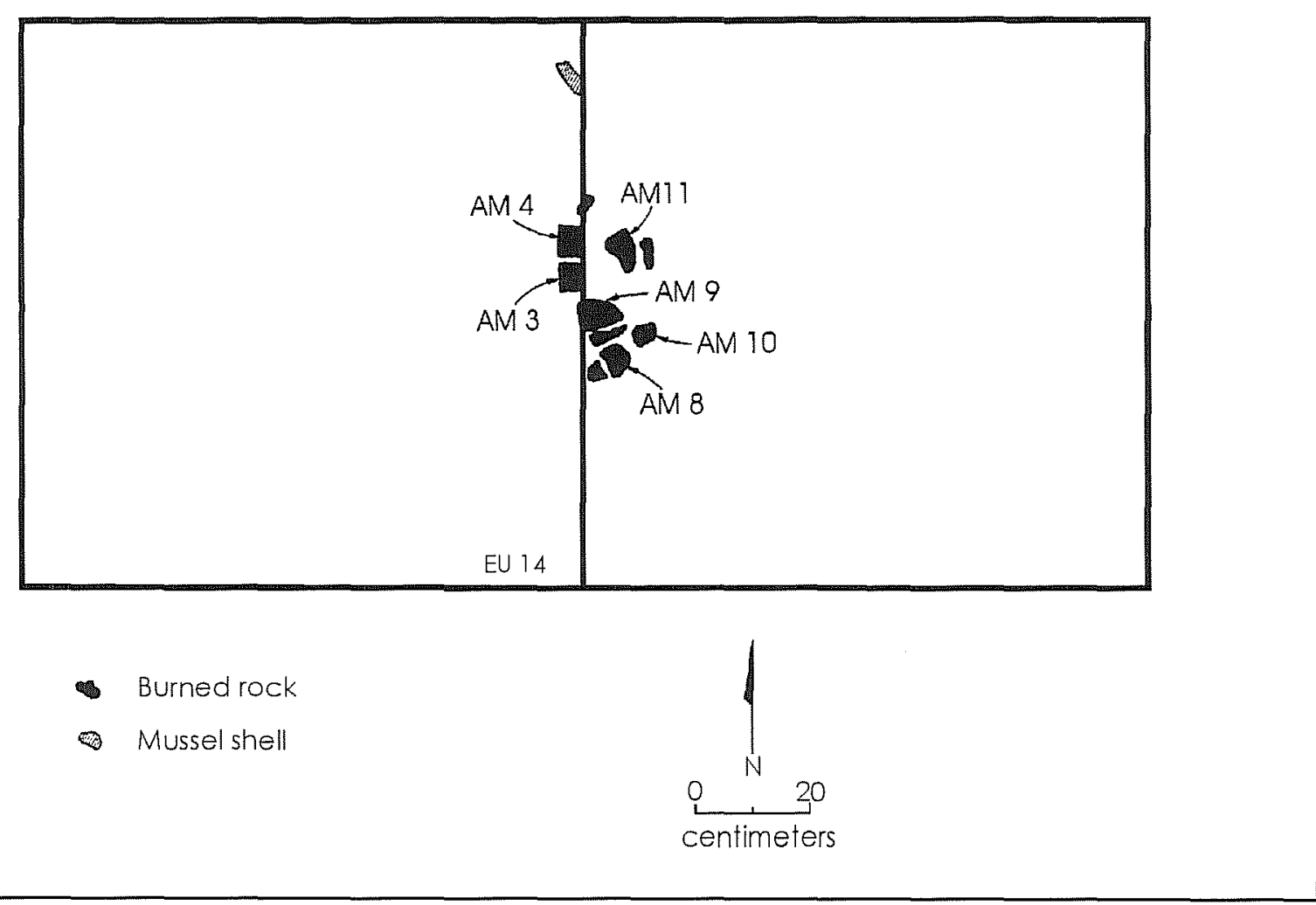




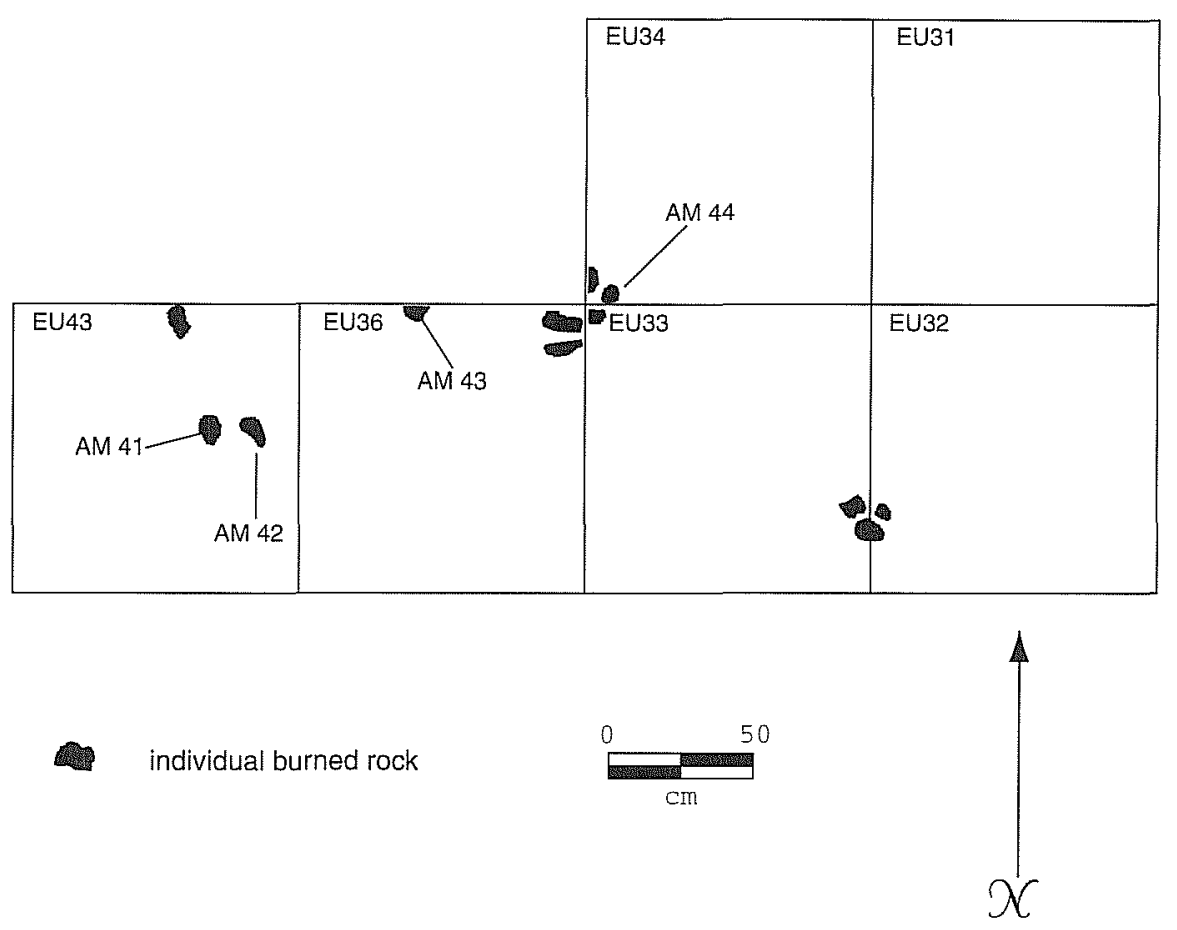

Figure 8-23. Level 12, bumed rock.

Samples 41 and 42 are inverted, and have moved since being burned. These rocks are obviously disturbed. In contrast, Sample 44 appears to be in situ, indicating that this cluster may represent the remains of a hearth. Unfortunately, no charcoal was present within this cluster. Sample 43 has moved slightly, and may be associated with the nearby intact feature, or some other unexcavated feature located to the immediate north. No archaeomagnetic samples were taken from the small cluster located between EUs 32 and 33.

\section{Mussel and Snail Remains}

Mussel shell remains are primarily present in Levels 9 and 10, and snail shell remains in Levels 9 and 12 (Figures 8-24 and 8-25). This generally corresponds with the distribution of lithic artifacts, and burned rock.
Previous excavations by TxDOT identified the presence of a mussel shell lens (Feature 1) in Level 6 of EU 3 (Ward 1995a). No further evidence of this feature was encountered in the adjacent EUs 1 and 12. A single small cluster of four mussel shells and two flakes was designated Feature 4 in Level 9 of EU 14 (Figure 8-26); however, a plot of excavation unit by level illustrates that there considerably more shell in Level 10 (Figure 8-27). In addition, the distribution also exhibits a peak in Level 12 of adjacent EU 15. This concentration is located to the east of the burned rock clusters previously discussed for this level. The plot of excavation unit by level for the snail shells indicates the presence of individual peaks at Levels 9 (EUs 1, 33, and 36), 11 (EU 33), and 12 (EUs 15 and 36) (Figure 8-28). The EU 36 peak in Level 12 is situated among the burned rock clusters located at the western end of the block. Nonetheless, the maximum peak in Level 12 of EU 36 is only $10.0 \mathrm{~g}$. It would only take 

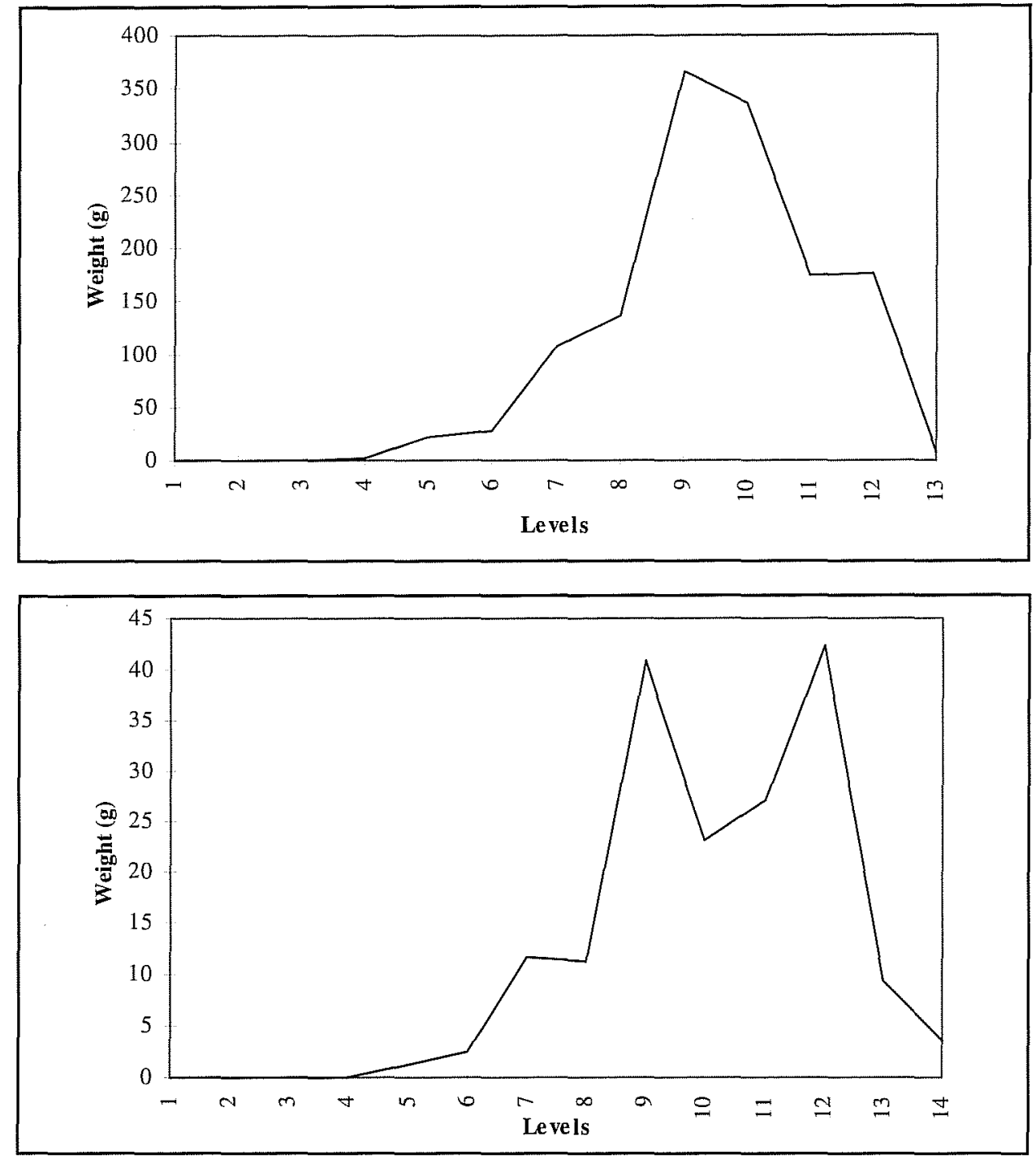

Figure 8-24. Area 1, mussel shell by level.

Figure 8-25. Area 1, snail shell by level. three or four adult Rabdotus shells to weigh the $10 \mathrm{~g}$, so there are actually few snail shells represented in each individual level.

\section{Macrobotanical Remains}

Five macrobotanical samples were collected from Area 1. These consist of small pieces of charcoal which were recovered from EU 13 (Level 11), EU 15 (Level 9), EU 33 (Level 12), EU 34 (Level 9) and EU 36 (Level 7). Three of the samples (Lots 765, 1105, and 1280) are mesquite, and the other two (Lots 1260 and 1304) are arboreal legumes (i.e., mesquite or acacia; see Chapter 11). The samples from EU 13 and 34 are associated with a small amount of fire-cracked rock, and a large amount of mussel shell. In contrast, the sample from EU 15 is associated with a moderate amount of burned rock, and very little mussel shell. The sample from EU 36 contains little fire-cracked rock or mussel shell. Lastly, the sample from EU 33 is situated in the vicinity of the burned rock clusters in EU 33, 43, and 44 , and is associated with a large amount of snail shell.

\section{Chronology}

The previous studies indicate variations in the vertical and horizontal distribution of artifacts and features across Area 1 . The levels with the highest densities of lithic artifacts are 9 and 11, with most of the fire-cracked rock present in Levels 8,9,11, and 12. The mussel shell is 


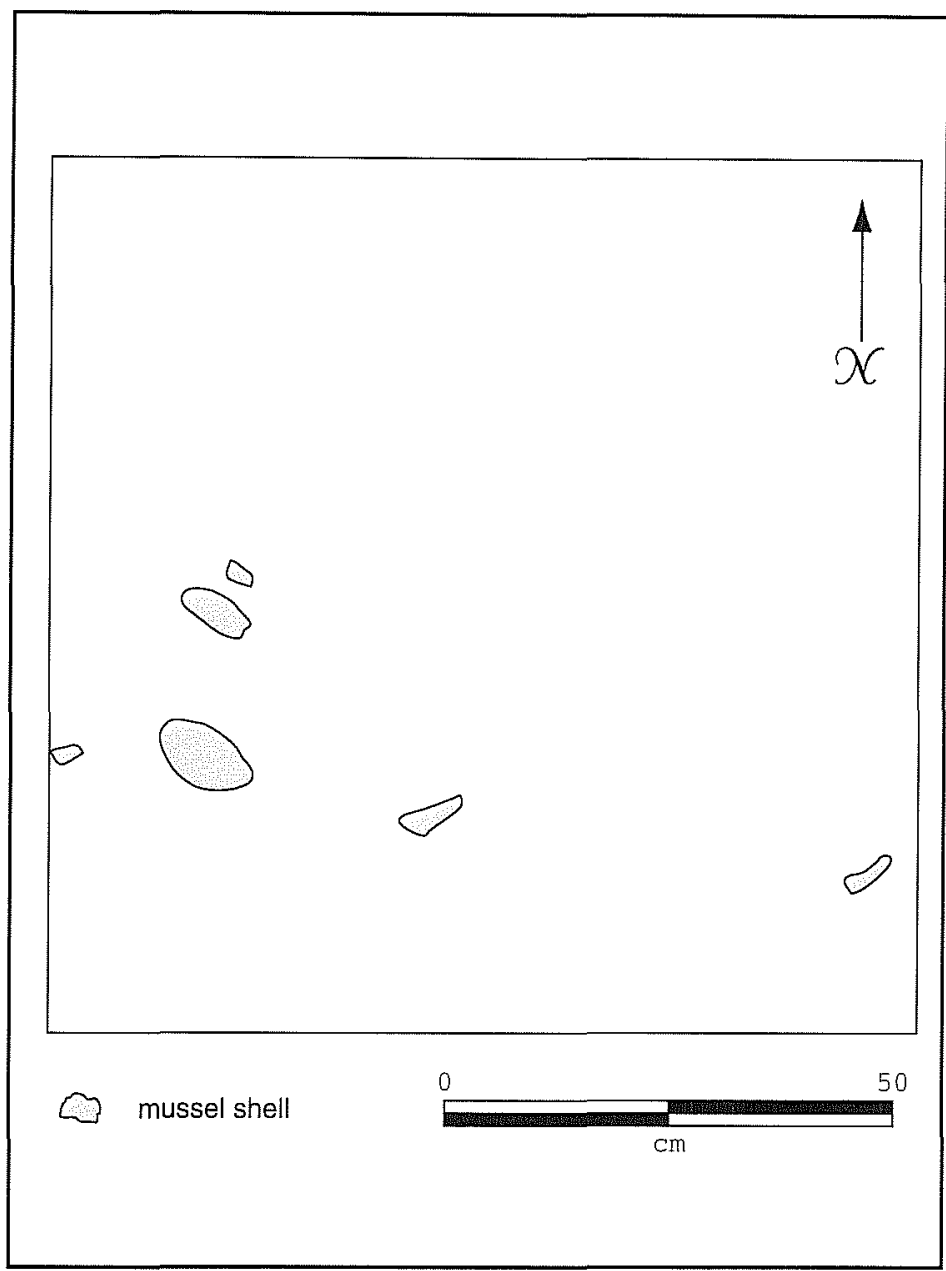

Figure 8-26. Excavation Unit 14, Feature 4. vided a date of $2200 \pm 50$ B.P. (NSRL-3535) for Level 12. Together this suite of dates provides a consistent temporal sequence for the Area 1.

Diagnostic Late Archaic projectile points were recovered from Levels 9, 11, and 12. These consist of a Marcos point in EU 32 (Level 9; Lot 1079), a Langtry point in EU 31 (Level 11; Lot 1060), a Shumla point in EU 33 (Level 12; Lot 1259), and a Desmuke point in EU 12 (Level 12 ; Lot 567). The Marcos point is indirectly associated with the radiocarbon date from Level 9 in adjacent EU 15; however, the Shumla point is directly associated with the date obtained from a piece of charcoal recovered from the same level and excavation unit. The Desmuke point is also situated in Level 12, but four meters to the east. The date range of 1240-2200 B.P. and the presence of Shumla, Desmuke, Langtry, and Marcos point types supports a Late Archaic temporal designation for the Area 1 sequence. Shumla, Marcos, Montell, and Ensor points were found stratigraphically underlying the Late Prehistoric occupation at site $41 \mathrm{ZV} 10$ in nearby Zavala County; however, the Ensor and Montell points were situated above the Shumla and Marcos points (Hester 1978:42-43). This contrasts with Area 1, where the Marcos point is located above the Shumla point. primarily found in Levels 9 and 10, and the snail shells in Levels 9 and 12. Overall, Levels 9 and 11 consistently contain the highest artifact densities throughout the block excavation area, with moderate densities being present in Levels 8, 10, and 12. The levels with the lowest densities are situated above Level 8 and below Level 12. Features were identified in Level 6 of EU 3 (mussel shell lens), Level 8 of EU 13 (hearth), Level 9 of EU 14 (mussel shells), Level 10 of EU 1 (hearth), and Level 12 in the western units (hearths). The cluster of mussel shells in Level 9 was the only feature identified in Levels 9 and 11 which otherwise exhibit the highest artifact densities.

A charcoal sample from the mussel shell lens in TxDOT's EU 3 provided a date of $1240 \pm 50$ B.P. (Beta-82290) for Level 6(Ward 1995a). The mesquite charcoal from Level 9 in EU 15 yielded a date of $1970 \pm 50$ B.P. (NSRL-3534). Lastly, a piece of mesquite charcoal from EU 33 pro-

\section{Site Structure}

Variations in the horizontal and vertical distribution of artifacts and features across Area 1 attest to the complexity of formation processes involved in the creation of the archaeological record. These include the differential spatial organization of campsite activities, as well as various post-occupational processes. Nonetheless, if we focus on the levels which contain relatively intact features, we can begin to discern a regular pattern in campsite organization.

The remains of a possible hearth (Feature 5) were unearthed in Level 8 of EUs 13 and 14. Feature 5 consists of an isolated cluster of 10 pieces of burned sandstone. The archaeomagnetic analysis of several pieces of sandstone indicates that the feature is dis- 


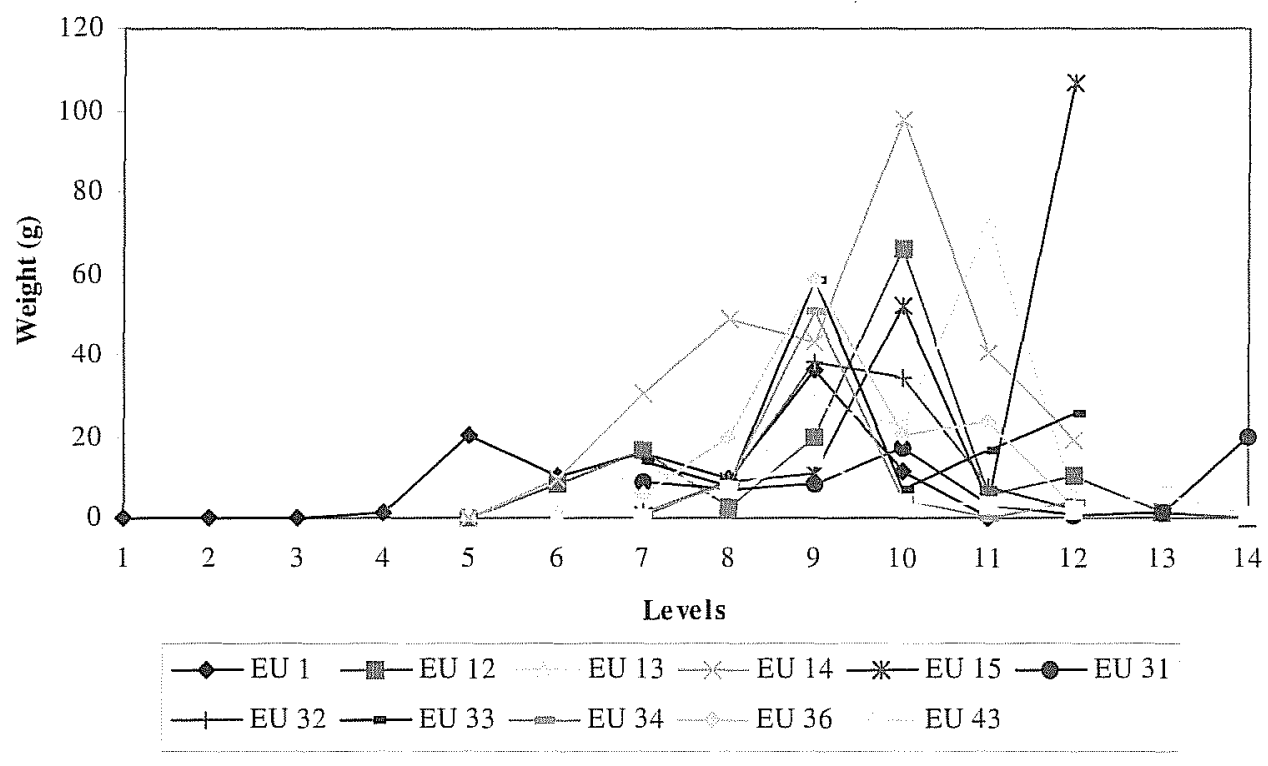

Figure 8-27. Mussel shell by excavation unit and level.

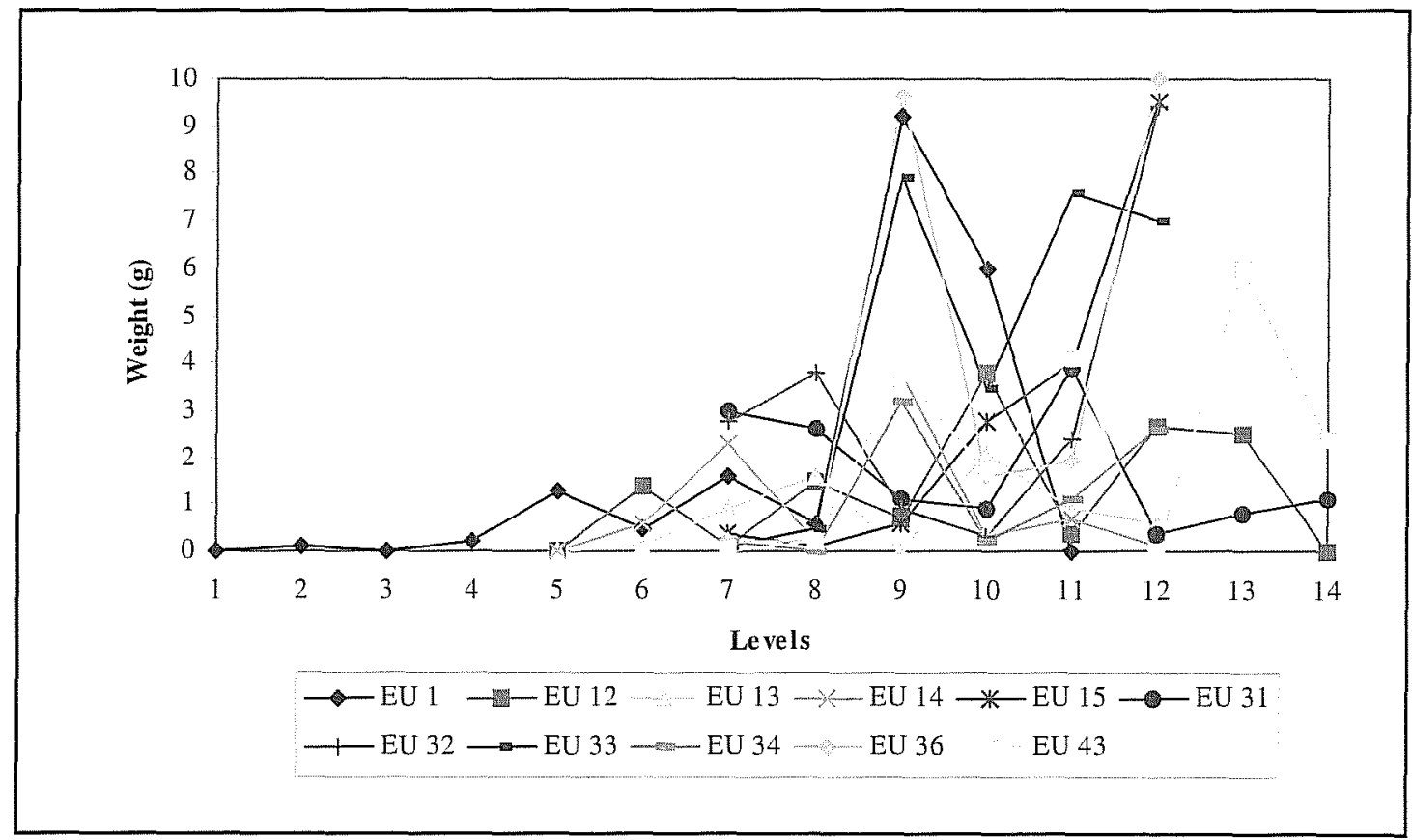

Figure 8-28. Snail shell by excavation unit and level.

turbed; however, it still retains a tight clustering. Artifact densities are relatively lower throughout Level 8 when compared to Levels 9-12. Artifact concentrations, as defined by isolated peaks in individual EUs, can be found in several of the units. For example, mussel shell remains are primarily represented in EU 14 where the hearth is partially located (Figure 8-29). A one-hand mano fragment was recovered from EU 1 located to the immediate north of the feature. Concentrations of snail shells are located in EUs 31 and 32. EU 31 also contains most of the fire-cracked rock, which is comprised of a mixture of chert and sandstone. This presumably reflects the discarded and/or disturbed remains of hearth elements or perhaps a pro- 


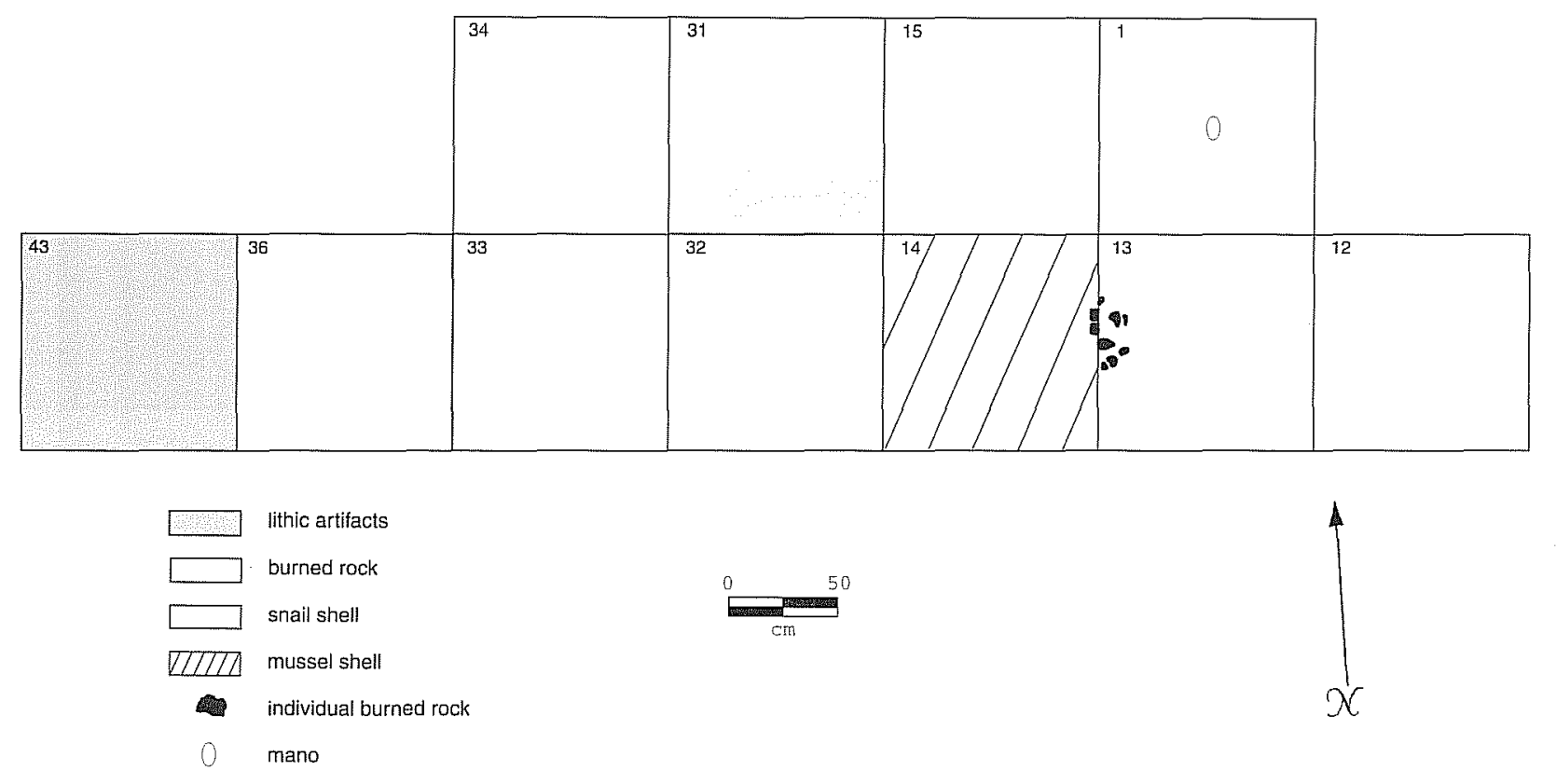

Figure 8-29. Area 1, Level 8.

cessing feature. Lithic artifacts are distributed in low densities throughout the area, but the highest concentration of lithics is in EU 43 at the west end of the block. Two hematite nodules were recovered from adjacent EU 36. One to three hearths may be present in Level 12 of EUs 32, 33, 34, and 36. This level is characterized by moderate artifact densities, but lower than those in Levels 9 and 11. A concentration of snail shell remains is present in the immediate vicinity of the features in EU 36 (Figure 8-30). EU 15 contains a mixture of mussel shell and snail remains, and adjacent EU 1 has burned rock. The latter consists of mostly chert (285.7 g), with some sandstone (160.6 g). The concentration of lithic reduction debris is centered in EU 12 at the east end of the excavation block. A Shumla projectile point is situated adjacent to the features in EU 33, and a Desmuke point in the EU 12 lithic reduction locus.

Even though these two occupational levels are situated in the upper and lower portions of the sequence, they both exhibit a similar internal structure. There is a central hearth with a shell cluster present in the area im- mediately surrounding the feature(s). Other artifacts found in the immediate area include a projectile point and one hand-mano fragment. Moving a few meters away from the hearths, we find a mussel and shell concentration situated adjacent to a fire-cracked rock cluster. This burned rock consists of a mixture of chert and sandstone, presumably reflecting the discarded and/or disturbed remains of hearth elements, processing features, or boiling stones. The proximity of the shells to the burned rock may indicate that these food items had been cooked prior to consumption, with the remains being dumped adjacent to each other. Lastly, the lithic reduction locus is situated at the furthest distance from the hearth areas.

\section{Area 2}

Area 2 is a square, $3-\mathrm{x}-3-\mathrm{m}$ excavation block located in the central area of the site. It is composed of EUs 7 , $16,17,18,19,20,21,37$, and 38 (Figure 8-31). The block expanded on the excavation of EU 7 which had 

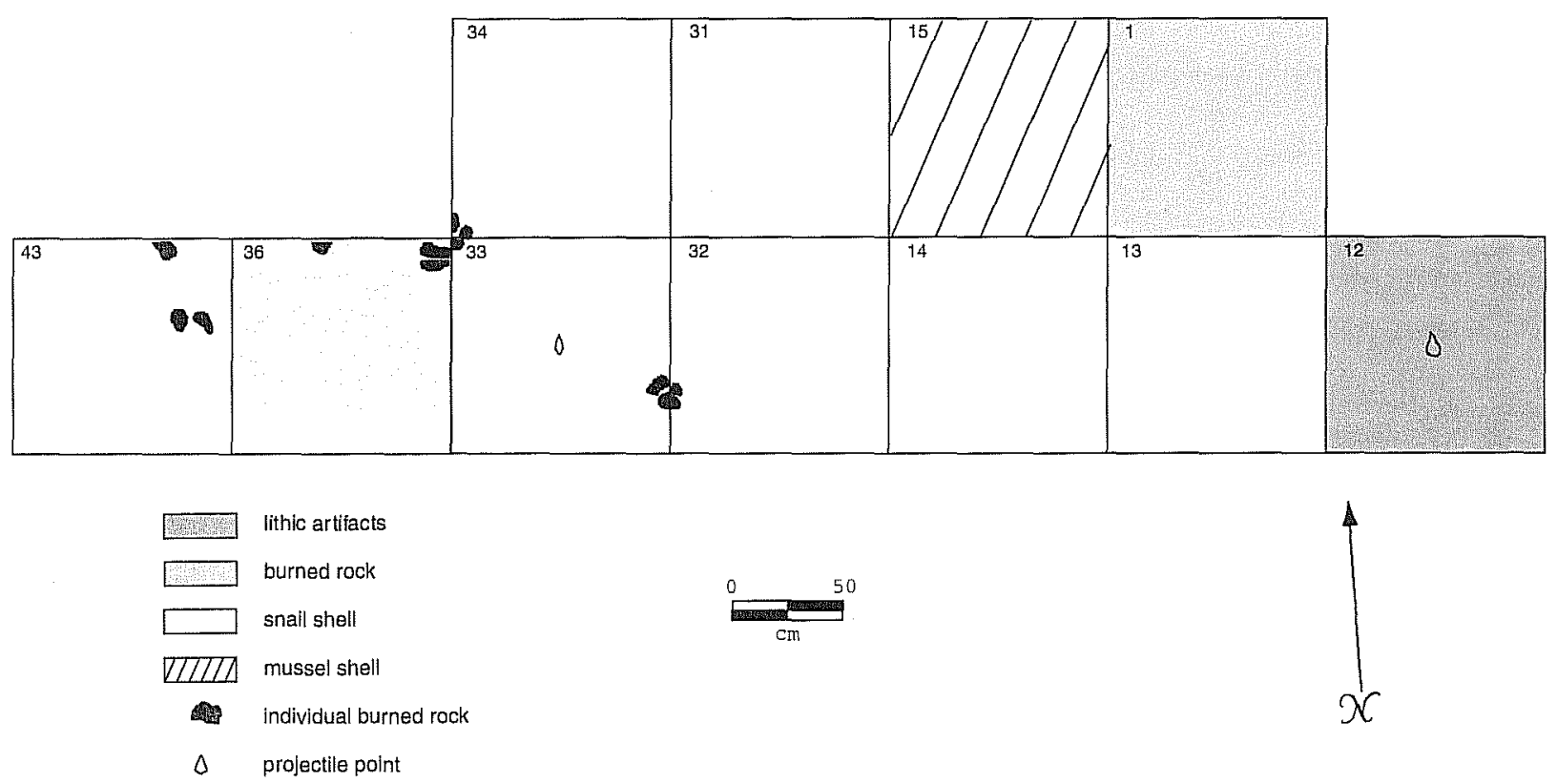

Figure 8-30. Area 1, Level 12.

revealed the presence of a fine sandy point-bar deposit beginning at depths between 75 and $80 \mathrm{~cm}$. In Figure 8-31 it is marked as the bottom unit (very fine sand). The density of cultural material fell off dramatically once the fine sands of the point bar were encountered. The topography clearly indicates that the point bar surface slopes downward to the west and east, a trend that is mirrored in the topography of the present ground surface. That is, the point of maximum elevation at the site occurs slightly to the west of the central block, and the ground slopes gently to the west and east from this point.

The decision to open a block of $1-\mathrm{x}-1 \mathrm{~m}$ units around EU 7 was based on the expectation that a compressed cultural sequence might exist within the one-meter zone above the point bar. EUs 7, 16, 19, 20, and 37 were hand-excavated to a depth of $120 \mathrm{~cm}$. The point bar deposits were encountered at $60-70 \mathrm{~cm}$ depths in each of these units. The subsequent excavations of EUs 17 , 21 , and 38 were terminated at a depth of $100 \mathrm{~cm}$, and EU 18 was excavated to a depth of $80 \mathrm{~cm}$, since a pattern of reduced artifact densities had been demon- strated for the upper point-bar deposits. In EUs 18 and 21 , a Gradall was used to remove the upper $20-30 \mathrm{~cm}$ of highly compacted sediment. Evidence of bioturbation consisted of isolated rodent burrows and termite nests to a depth of $100 \mathrm{~cm}$; however, only the top 20-30 cm was consistently disturbed. The general stratigraphic sequence consists of a compact silt, silty sand, and the fine sands of the point-bar deposit (Figure 8-31). Floodplain units defined within the area consist of 2-p, 2-f1, 2-f2, and fill (Chapter 7). Table 8-1 correlates the information on soils and geological sediments by $10-\mathrm{cm}$ levels within BHT 9 .

\section{Lithic Artifacts}

Three cores, 25 retouched tools, and 1,825 pieces of debitage were recovered from the excavations of Area 2. Individual excavation unit artifact densities range from 142.2-368.0 artifacts per cubic meter, with an overall block density of 199.2. This is markedly lower than the density exhibited in Area 1, which was not 


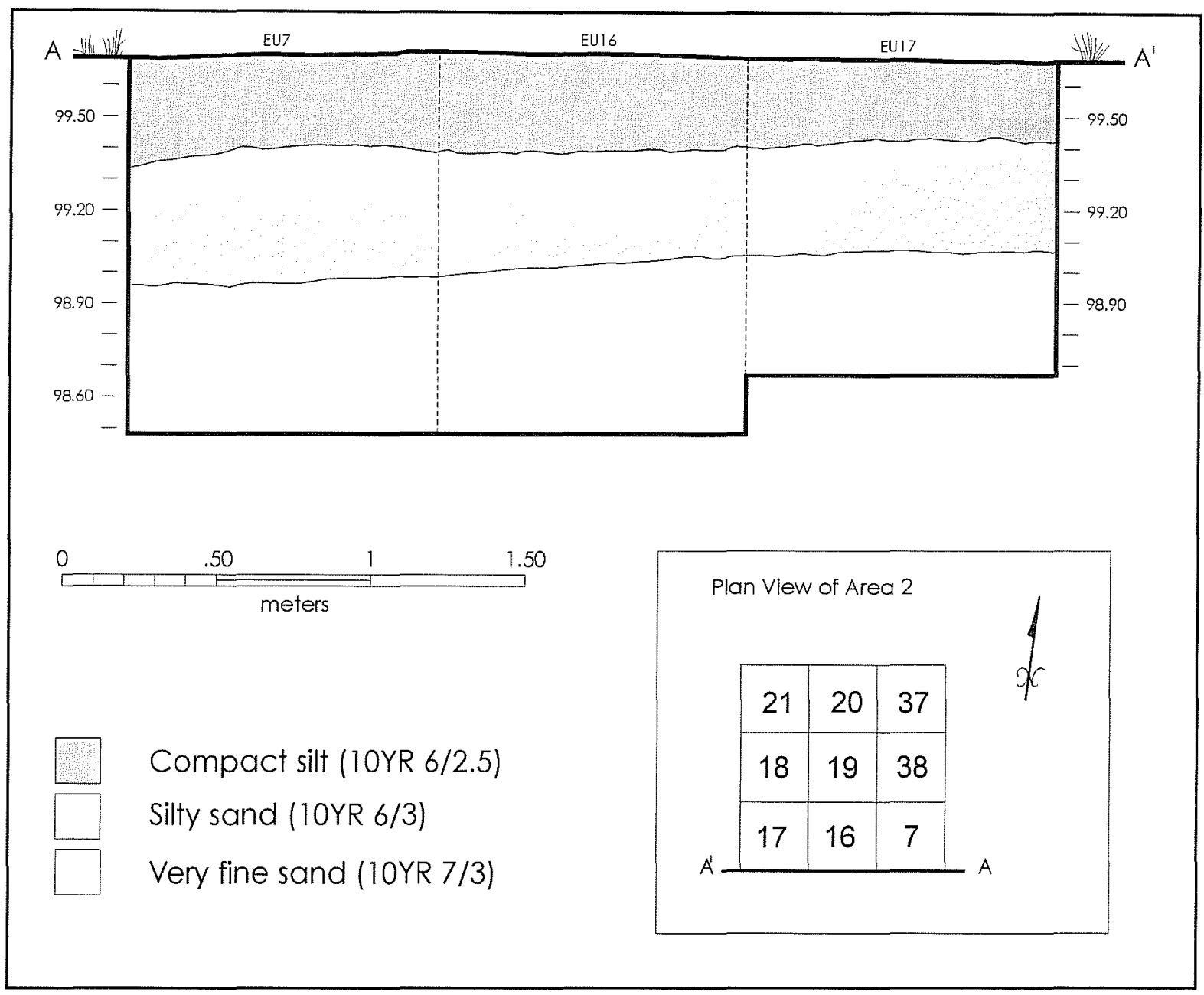

Figure 8-31. Area 2, plan and profile.

expected since this was a compressed sequence. Most of the lithic artifacts are concentrated in Levels 5 and 6 (Figure 8-32). The distribution exhibits individual peaks in Level 3 (EU 7), Level 5 (EU 18), and Level 6 (EU 7, 20, and 21) (Figure 8-33). Artifact density subsequently declines from Levels 7-12 within the point bar deposits; however, there is a lower peak in Level 8 (EU 20).

\section{Burned Rock}

The burned rock exhibits a different distributional pattern from that displayed by the lithic artifacts. The majority of the burned rock is found in Levels 4 and 6 , declining in Levels $7-10$, with a small peak in Level 11 (Figure 8-34). Most of the fire-cracked rock from
Level 4 is derived from EUs 16 and 20 which are 10cated on opposite sides of the block, and Level 6 from EU 38 (Figure 8-35). EU 16 also displays a smaller peak in Level 2, and EU 7 in Level 11. Level 11 in EU 7 is actually situated at the bottom of the silty sand deposit and not within the sands of the point bar.

The lithic material composition varies between the burned rock concentrations. Most are composed of sandstone with chert, limestone, and rhyolite. For example, the majority of the burned rock in Level 2 (EU 16) is composed of sandstone (67.6 g), with less chert $(24.9 \mathrm{~g})$ and limestone $(11.9 \mathrm{~g})$. In Level 4 (EU 16 and 20) the rock consists of sandstone (491.8 g), but with some chert (240 g), rhyolite (201 $\mathrm{g}$ ), and limestone (65.3 g). Level 6 (EU 38) is similar to Level 2 , being composed of mostly sandstone 

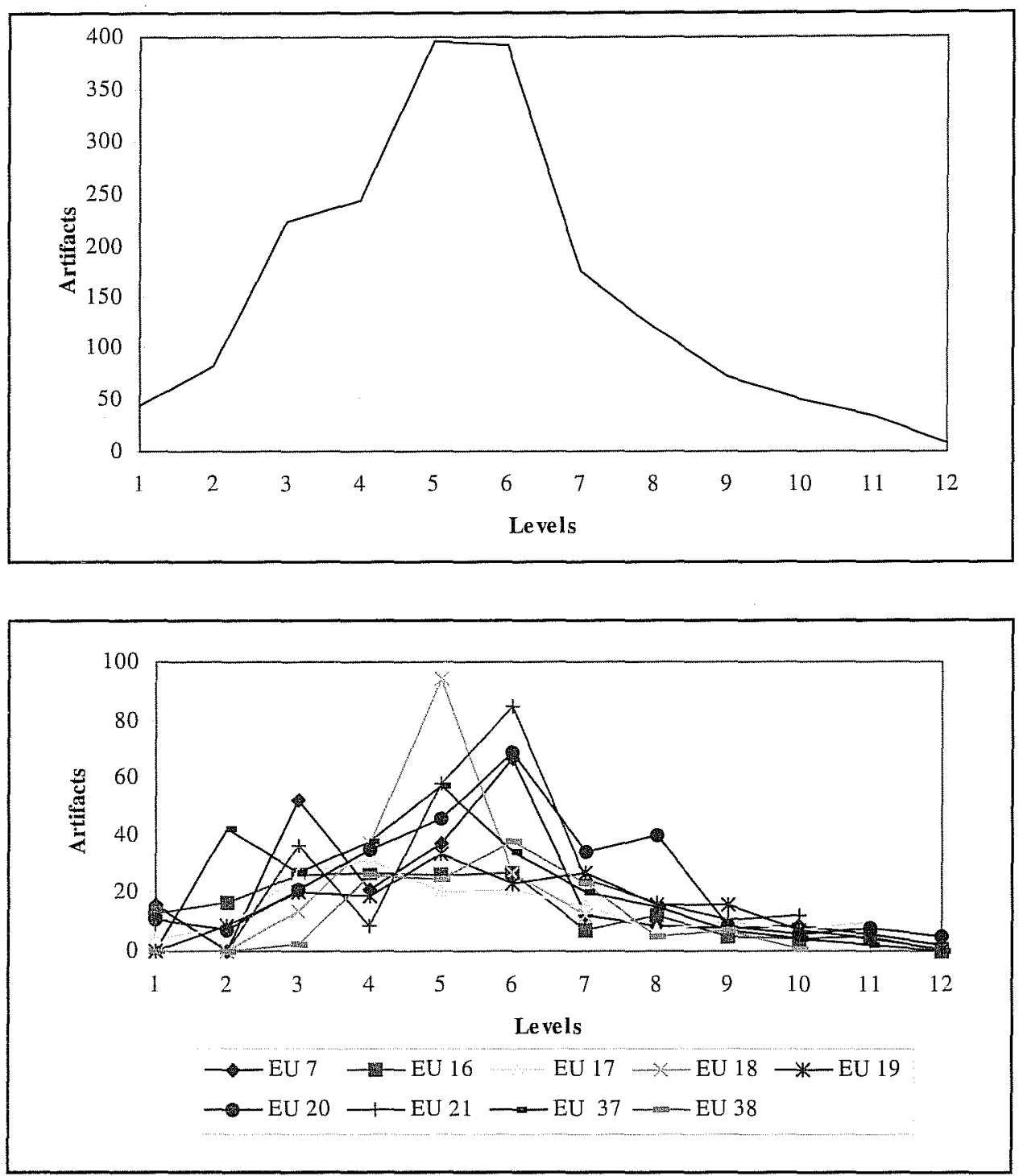

Figure 8-32. Area 2, lithic artifacts by level.

Figure 8-33. Area 2, lithic artifacts by excavation unit and level.
$(499.9 \mathrm{~g})$ with less limestone $(15.4 \mathrm{~g})$ and chert $(4.6 \mathrm{~g})$. In contrast, the burned rock in Level 11 (EU 7) consists mostly of rhyolite $(211.5 \mathrm{~g})$ with a little sandstone $(5.8 \mathrm{~g})$.

An archaeomagnetic sample was taken from a piece of burned sandstone in Level 6 of EU 38 (Sample 23). The rock appears to be slightly disturbed, but its orientation has not significantly changed since being heated. This indicates that the concentration of burned sandstone in this level may actually represent the remains of a hearth.

\section{Mussel, Snail, and Faunal Remains}

There are far fewer mussel shell remains in Area 2 than in Area 1. The maximum weight for any single level is $17.7 \mathrm{~g}$ vs. $106.7 \mathrm{~g}$ for Area 1 . On the other hand, the maximum amount of snail remains present in the two areas is the same, with $10.0 \mathrm{~g}$ and $10.5 \mathrm{~g}$ in Areas 1 and 2 , respectively. The increased amounts of mussel shell in Area 1 is presumably due to its proximity to Elm Creek; whereas, terrestrial snails could be procured from the landscape surrounding either area.

Most of the Area 2 mussel shells are located in Level 3 , with less in Levels 4-6 (Figure 8-36). The concentration in Level 3 is situated in EU 37, and the smaller concentrations in Levels $4-6$ in EUs 7, 20, and 3 

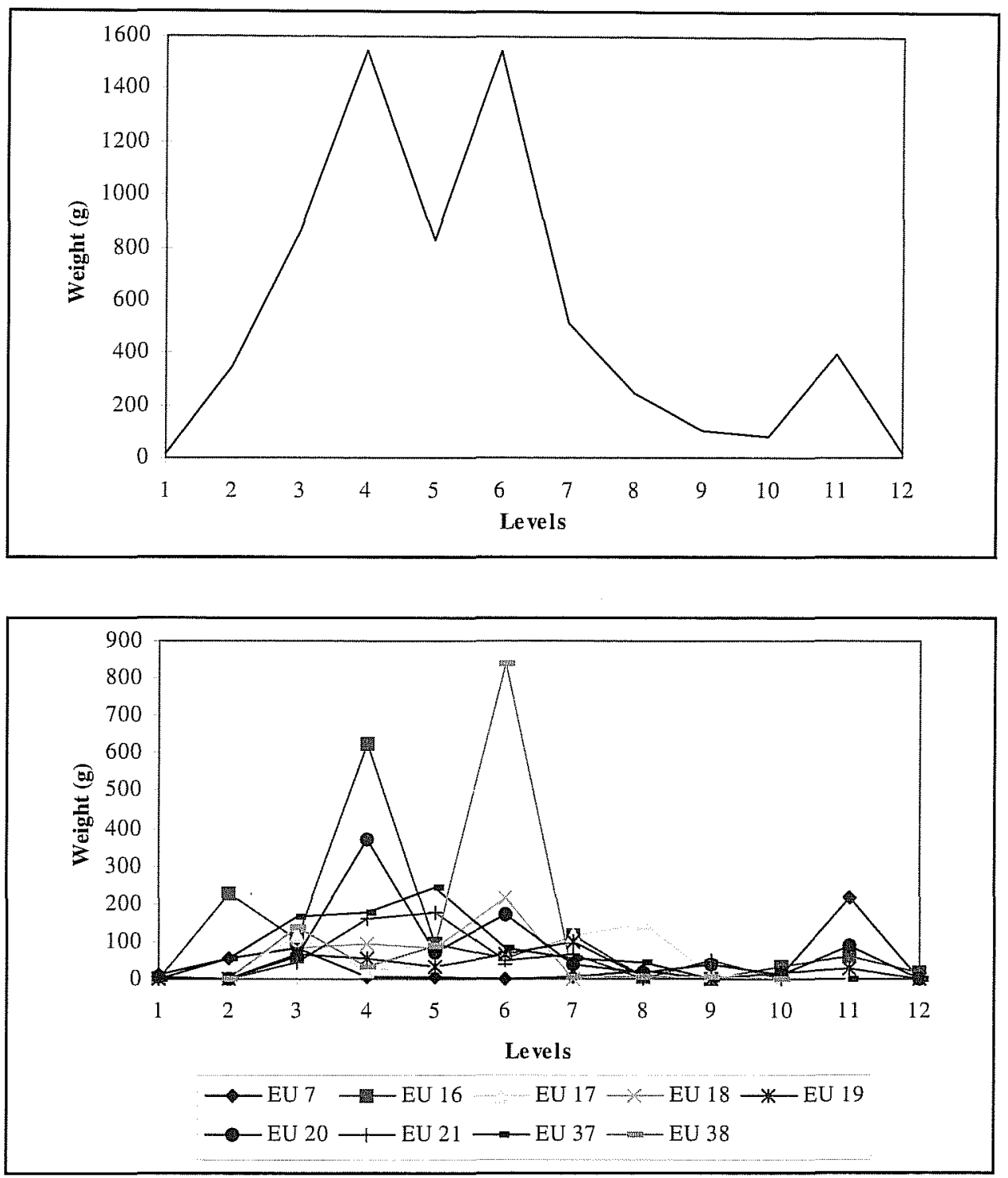

Figure 8-34. Area 2, firecracked rock by level.
Figure 8-35. Area 2, firecracked rock by excavation unit and level.
(Figure 8-37). There are very few mussel shell remains in Levels 7-12, with a slight concentration in Level 12 of EU 38.

The snail remains exhibit a different distribution from those displayed by the mussel shells. Snail shells were primarily recovered from Levels 3,4 , and 6 , with smaller peaks in Levels 9 and 11 (Figure 8-38). Nonetheless, these latter peaks are comprised of only one or two shells. A closer inspection of the distribution by unit indicates that the peak in Level 3 is from EU 7, the one in Level 4 is from EU 18, and the one in Level 6 is actually derived from several different units (Figure 8-39). The presence of a few snail shells in the lower levels do not correspond to any of the other artifacts classes; however, the shells in Level 11 of EU 16 are located adjacent to EU 7 which contains burned rock in the same level. A single small mammal bone fragment was recovered from EU 16 (Level 3). This bone exhibits possible chopping marks.

\section{Macrobotanical Remains}

Most of the macrobotanical remains recovered from Area 2 were found in Levels 3 and 4 . These consist of small pieces of charcoal which are present in undisturbed, or only slightly disturbed, contexts. Mesquite charcoal was identified in Level 3 of EU 7 (Lot 429) and Level 4 of EU 16 (Lot 632), acacia charcoal in Level 4 of EU 19 (Lot 780), and undetermined 

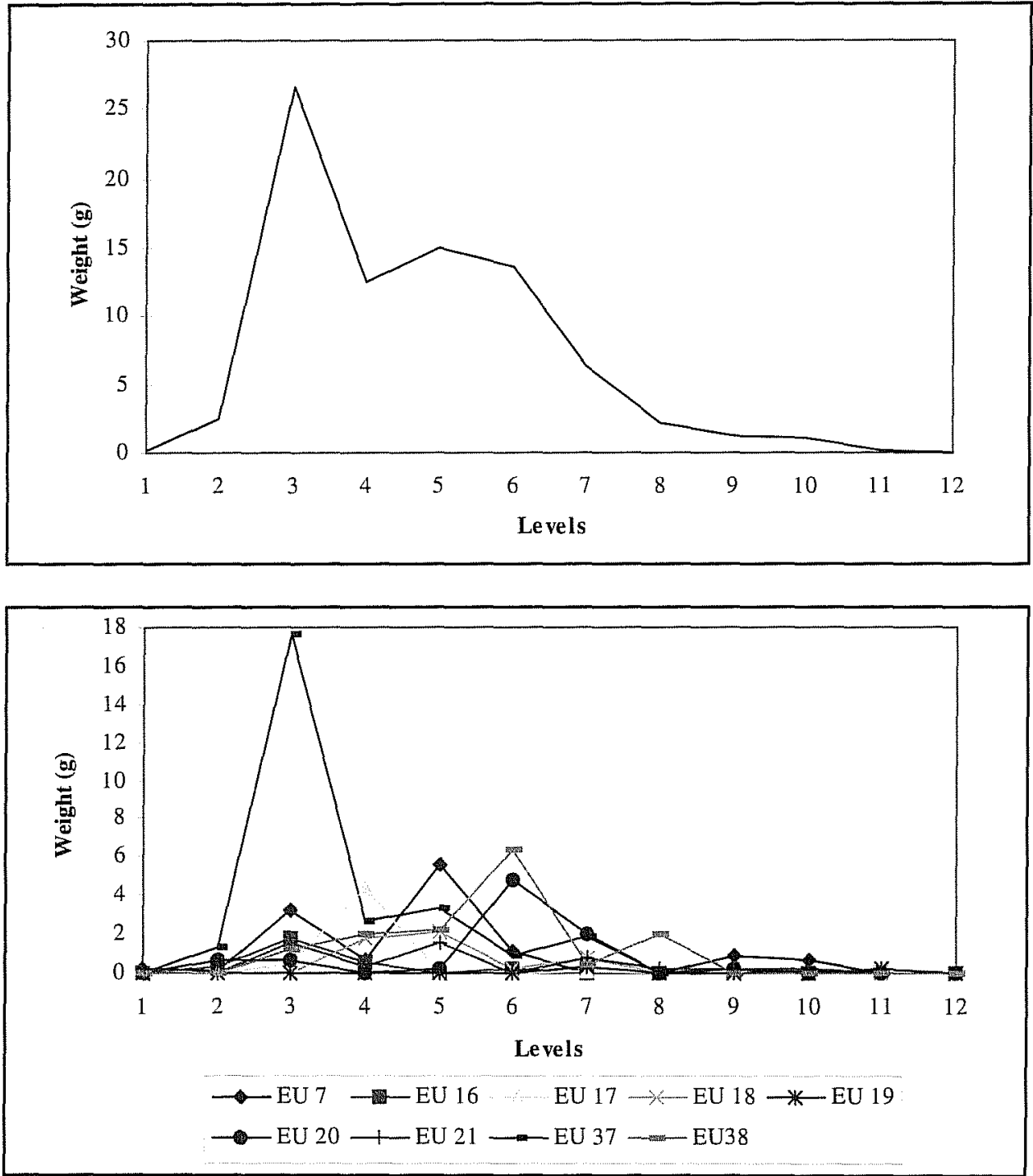

Figure 8-36. Area 2, mussel shell by level.

Figure 8-37. Area 2, mussel shell by excavation unit and level. wood charcoal in Level 3 of EUs 16 and 19 (Lots 631 and 778). An unburned pecan shell fragment was found in Level 7 of EU 19; however, the level is noted as being partially rodent disturbed. The only other macrobotanical item recovered in the lower levels is a piece of mesquite charcoal from Level 9 in EU 7 (Lot 88).

\section{Chronology}

Distinct variations are seen in the vertical distribution of artifacts throughout Area 2, with Levels 4 and 6 exhibiting the greatest densities artifacts. TxDOT's
EU 2 is located approximately 20 m east of the Area 2 excavation block. A charcoal sample from Level 4 in this test pit yielded a date of $1460 \pm 50$ B.P. (Beta-82289). Mesquite charcoal from EU 7 provides a date of $3200 \pm 50$ B.P. (NSRL-3531) for Level 9 within the block excavation. Level 9 in EU 7 is located near the bottom of the silty sand deposit which overlies the point bar. The break between the silty sand and underlying point bar deposits is situated between Levels 10 and 11 in this unit. The upper date is similar to the 1240 B.P. date obtained from Level 6 in Area 1; however, the lower date is much older than the 2200 B.P. date from Level 12 in Area 1. It is possible that the charcoal is derived from the point bar sands which was transported up 

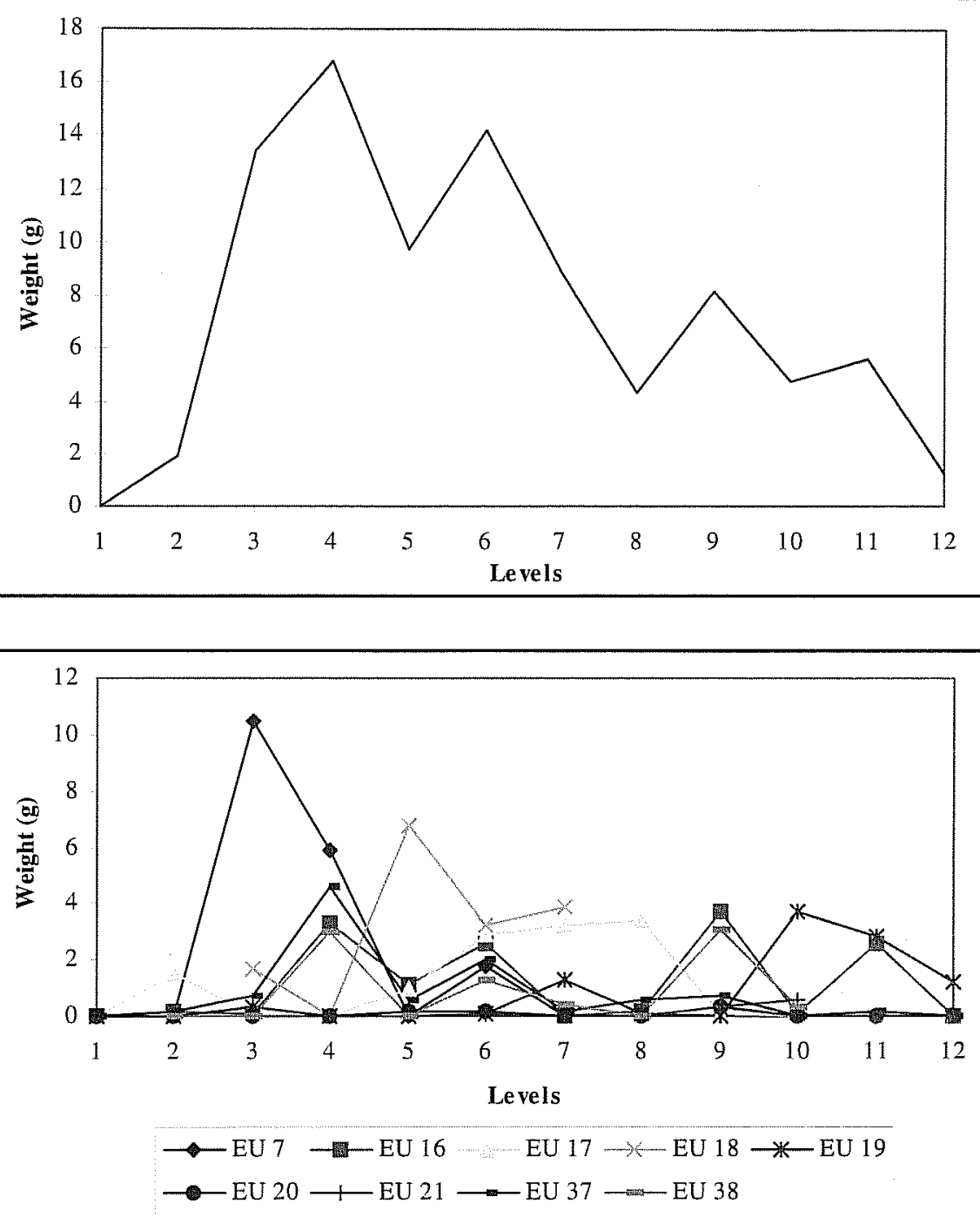

Figure 8-38. Area 2, snail shell by level.

Figure 8-39. Area 2, snail shell by excavation unit and level. into Level 7 in adjacent EU 16; however, there are also lithic artifacts and mussel shell remains present in the same level as the dated piece of charcoal. Another possibility is that this represents old wood scavenged from the floodplain or adjacent terraces.

Diagnostic Late Archaic projectile points were recovered from Levels 4, 6, 7, and 10. These consist of a Marshall point in Level 6 (EU 37; Lot 597), a Montell point in Level 7 (EU 16; Lot 1127), and Shumla points in Levels 4 (EU 16; Lot 633) and 10 (EU 20; Lot 688). An untyped stemmed point, similar to a Uvalde, was also recovered from Level 3 (EU 37; Lot 953). The points recovered from Levels 7 and 10 are located in the upper portion of the point bar deposits. Rodent disturbance is noted in Levels 6-9 in EU 16, which could have affected the provenience of the Montell point. Although no rodent disturbance is mentioned for Level 10 in EU 20, field notes do state that several pieces of debitage were found in a "vertical orientation" indicating the possibility of artifact movement or redeposition. The Shumla point in this level consists of a large notching flake which could be more susceptible to movement. None of the projectile points is directly associated with the two radiocarbon dates. If the dates are an accurate temporal indicator of the stratigraphic sequence, then the lower levels may be much older than what is represented in Area 1. 


\section{Site Structure}

If we assume the sandstone concentration in Level 6 of EU 38 represents a hearth, then we can view the distribution of material in this level in respect to this focal point. We find the heaviest concentration of lithic reduction debris in EUs 7, 20, and 21 (Figure 8-40). Most of the mussel shell is also present in EUs 20 and 38, with only a few snail shells in EUs 16, 17, and 18 . There is no clear pattern in site structure within this level, at least when compared to the patterns observed in Area 1. Level 6 does exhibit some rodent disturbance, but this is limited to EUs 16, 17, and 19.

\section{Area 3}

Area 3 is an L-shaped excavation block situated in the western section of the site. It is composed of EUs 11, 22-26, 41, and 42 (Figure 8-41). The block expanded around the western end of BHT 10 where a burned rock lens (Feature 10) had been exposed in the south wall profile. Excavations were intended to identify the nature and extent of the burned-rock deposits; however, hand excavations failed to yield any further evidence of this feature in adjacent units. EUs 11, 22, 23, and 26 were excavated by hand, with the upper $30-40$ $\mathrm{cm}$ of fill being a compact disturbed deposit. Active rodent burrowing was identified in EU 26. Given the presence of these disturbed levels, a Gradall was subsequently used to remove the top $30-40 \mathrm{~cm}$ of fill in the remaining units (i.e., EUs 24, 25, 41, and 42). The general stratigraphic sequence consists of two layers of silt, a silty sand, and the point-bar deposits (Figure 8-41). The fine sand of the point bar deposits was only exposed in the bottom of EU 22 about $90-100 \mathrm{~cm}$ below the surface, although it does appear on the south block profile. The point bar, therefore, apparently dips down toward the north. Floodplain units defined within the area consist of 2-p, 2-f1, 2-f2, 2-f3, and fill (Chapter 7). Table 8-1 correlates the information on geological sediments and soil horizons by $10-\mathrm{cm}$ levels within BHT 10.

\section{Lithic Artifacts}

Six cores, 13 retouched tools, and 1,289 pieces of debitage were recovered from the block excavations. This yields an overall artifact density of 190.7 artifacts per cubic meter, ranging from 134.3 to 263.3 per excavation unit. These densities are slightly less than those observed in Area 2, but are markedly lower than those in Area 1. Most of the lithic artifacts are present in Levels 5-8, with a small peak in Level 3 (Figure 8-42). An evaluation of varying artifact frequencies by individual excavation units indicates the prevalence of lithic artifacts in the middle levels is found in most

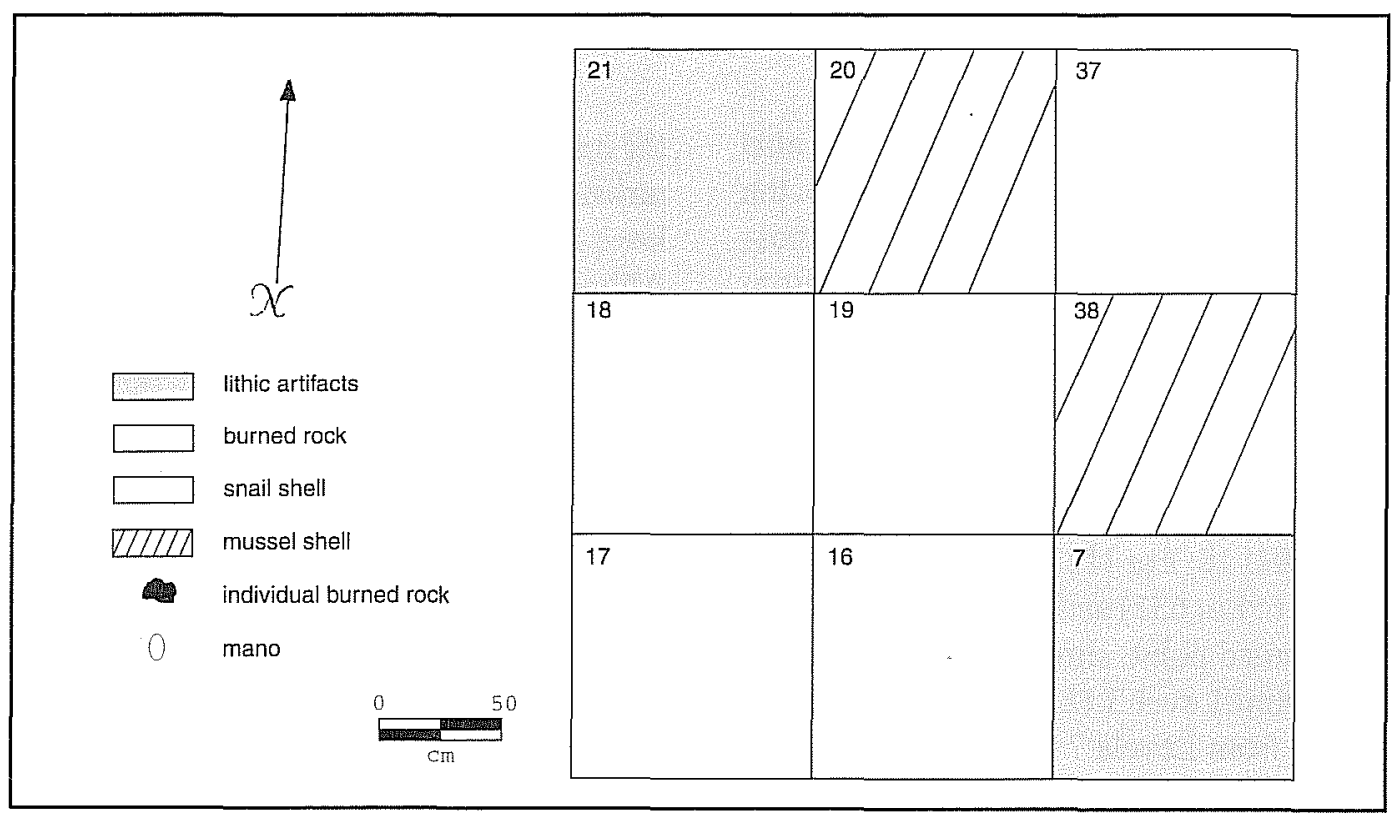

Figure 8-40. Area 2, Level 6. 


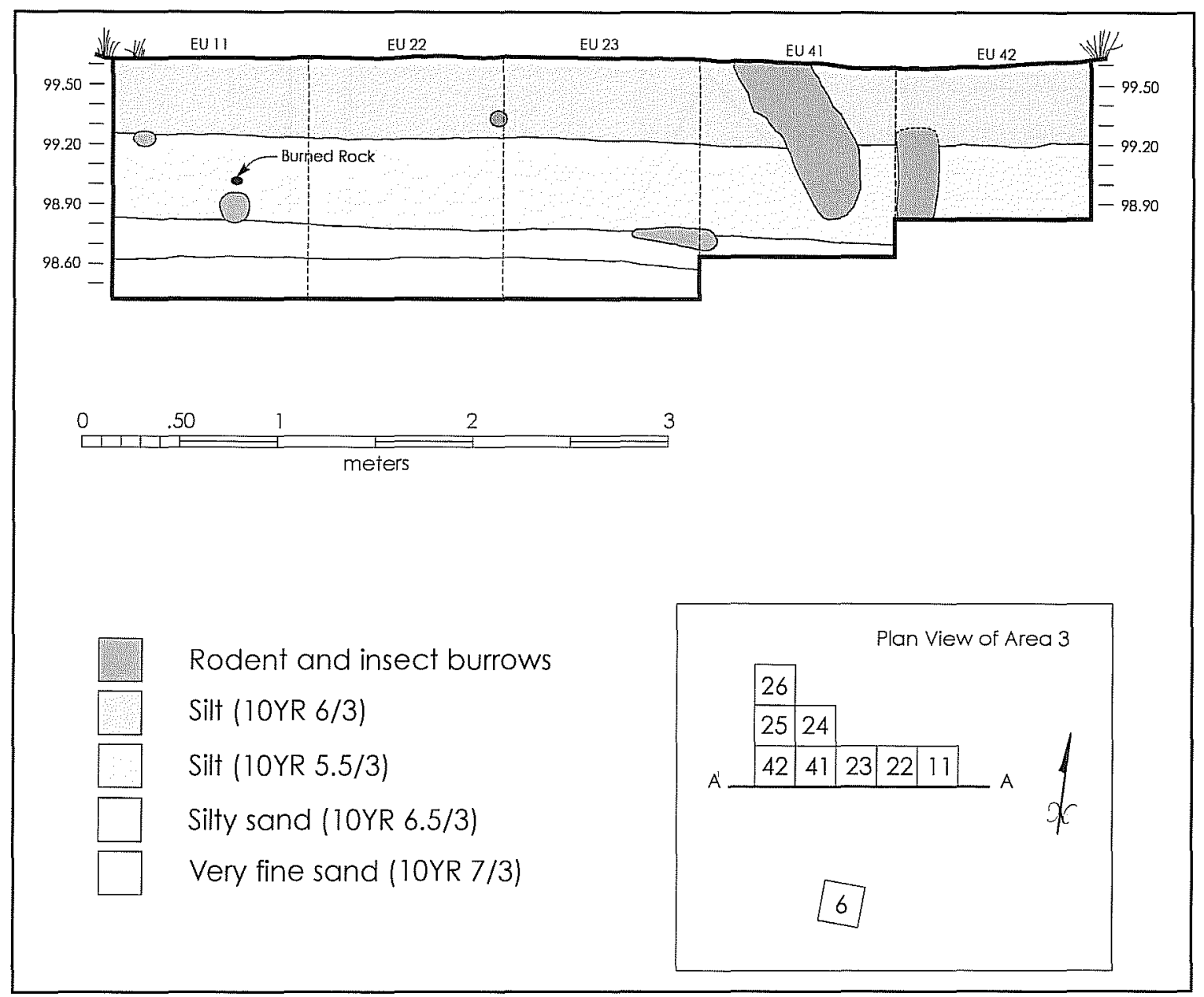

Figure 8-41. Area 3, plan and profile.

of the units (Figure 8-43). EU 11 contains relatively higher frequencies in Levels $1-6$, and then peaks in Level 7. The smaller peak in Level 3 is represented by adjacent EUs 22 and 23 .

\section{Burned Rock}

The burned rock exhibits a similar distribution to the lithic artifacts, with most of the burned rock being present in Levels 6-8 (Figure 8-44). The levels with higher artifact densities correspond to specific excavation units. That is, the burned rock from Level 6 is primarily found in EU 24, and the rock in Levels 7 and 8 in EUs 11 and 22 (Figure 8-45). Otherwise, the remaining units contain relatively little burned rock. Feature 10 in BHT 10 is situated approximately 70
$80 \mathrm{~cm}$ below the surface, or roughly in Level 7 where the highest density of burned rock is also present within the block excavation.

Two somewhat different patterns emerge when the composition of the burned rock is compared in Levels 6-8. In Level 6 of EU 24, the burned rock is dominated by sandstone $(210.0 \mathrm{~g})$, with some limestone (79.6 g) and chert $(35.9 \mathrm{~g})$. Level 7 in EUs 11 and 22 exhibits a similar pattern, consisting of mostly sandstone $(699.3 \mathrm{~g})$, with less limestone $(149.6 \mathrm{~g})$ and chert $(81.8 \mathrm{~g})$. In contrast, Level 8 in EU 11 contains roughly equal proportions of sandstone $(169.7 \mathrm{~g})$ and limestone (200.4 g), with less chert (11.9 g).

Archaeomagnetic samples were taken from two pieces of burned sandstone exposed in the northeast corner 

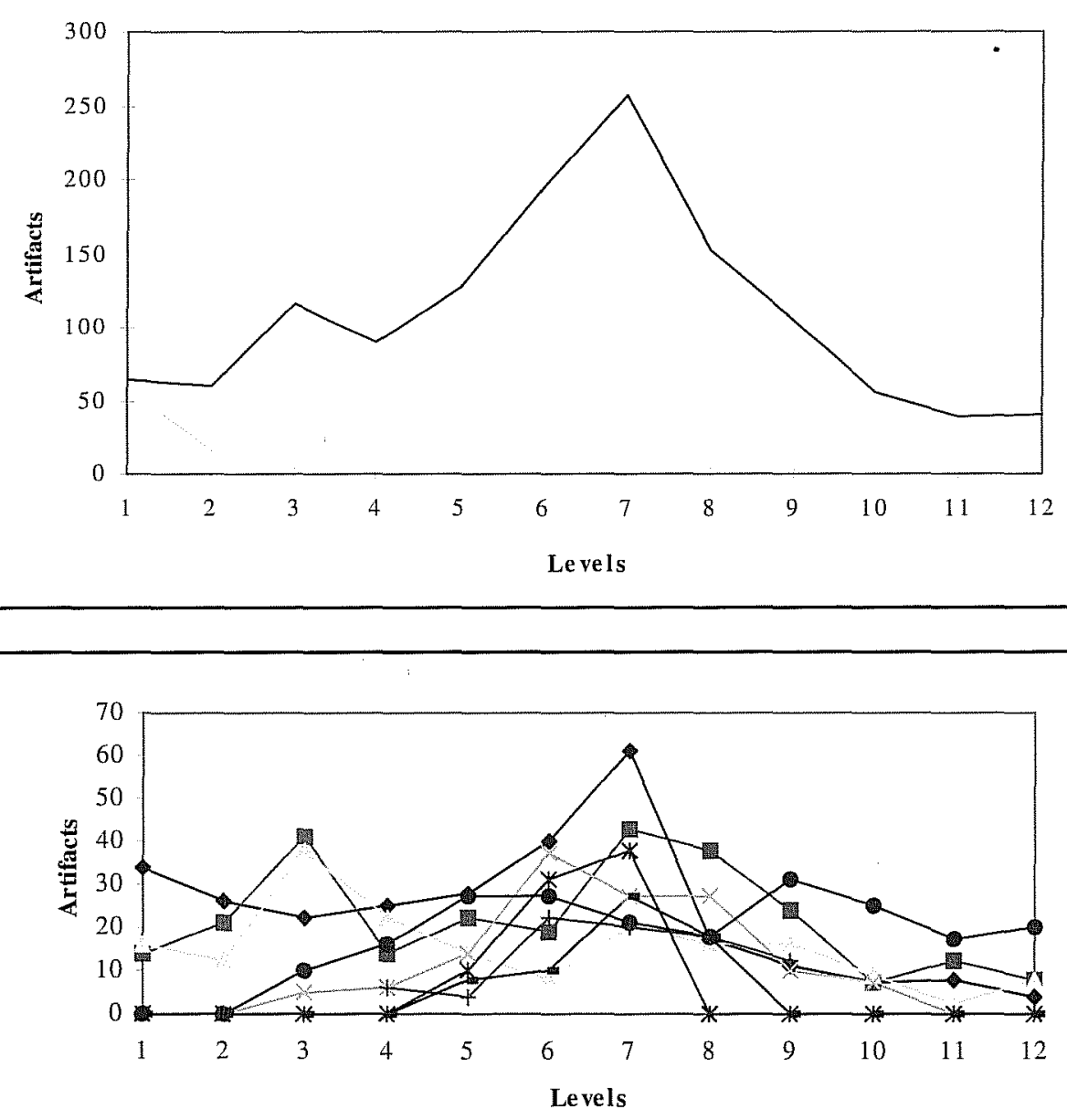

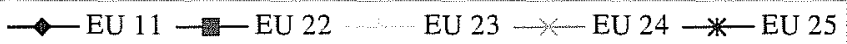

$\longrightarrow$ EU $26 \longrightarrow$ EU $41 \longrightarrow$ EU 42

Level 8 in EU 26. Sample 14 was unsuitable for analysis, with the core having broken upon redrilling. The analysis of Sample 3 indicates that this rock has moved since being burned. A total of $59.1 \mathrm{~g}$ of burned sandstone, $43.4 \mathrm{~g}$ of chert, and $1.3 \mathrm{~g}$ of rhyolite was recovered from Level 8 in EU 26. These rocks could represent a disturbed hearth, a processing feature, or a discard pile.

Feature 10 in adjacent BHT 10 has already been described; however, it seems appropriate to note that the remains of possibly two or three intact hearths were identified about $70-80 \mathrm{~cm}$ below the surface. This elevation correlates with Levels 7 and 8 in adjacent EUs 11 and 22, which also contain the highest densities of burned rock. The rock in these units may therefore be associated with the use of these features.
Figure 8-42. Area 3, lithic artifacts by level.

Figure 8-43. Area 3, lithic artifacts by excavation unit and level.

\section{Macrobotanical Remains}

Macrobotanical remains were recovered from Levels 4, 8, and 11 in EUs 11 and 22. As previously noted, both units contain high densities of burned rock; however, little burned rock was actually recovered from Levels 4 and 11, with far more in Level 8. Two pieces of mesquite charcoal were identified in Level 4 from EU 11 (Lot 363), and 22 (Lot 811); whereas, the wood charcoal from lower Level 8 in EU 22 (Lot 820) and Level 11 in EU 11 (Lot 661) were too small for identification. Although some small unburned seeds were collected from Level 12 in EU 26, these appear to be associated with a modern ant nest. 

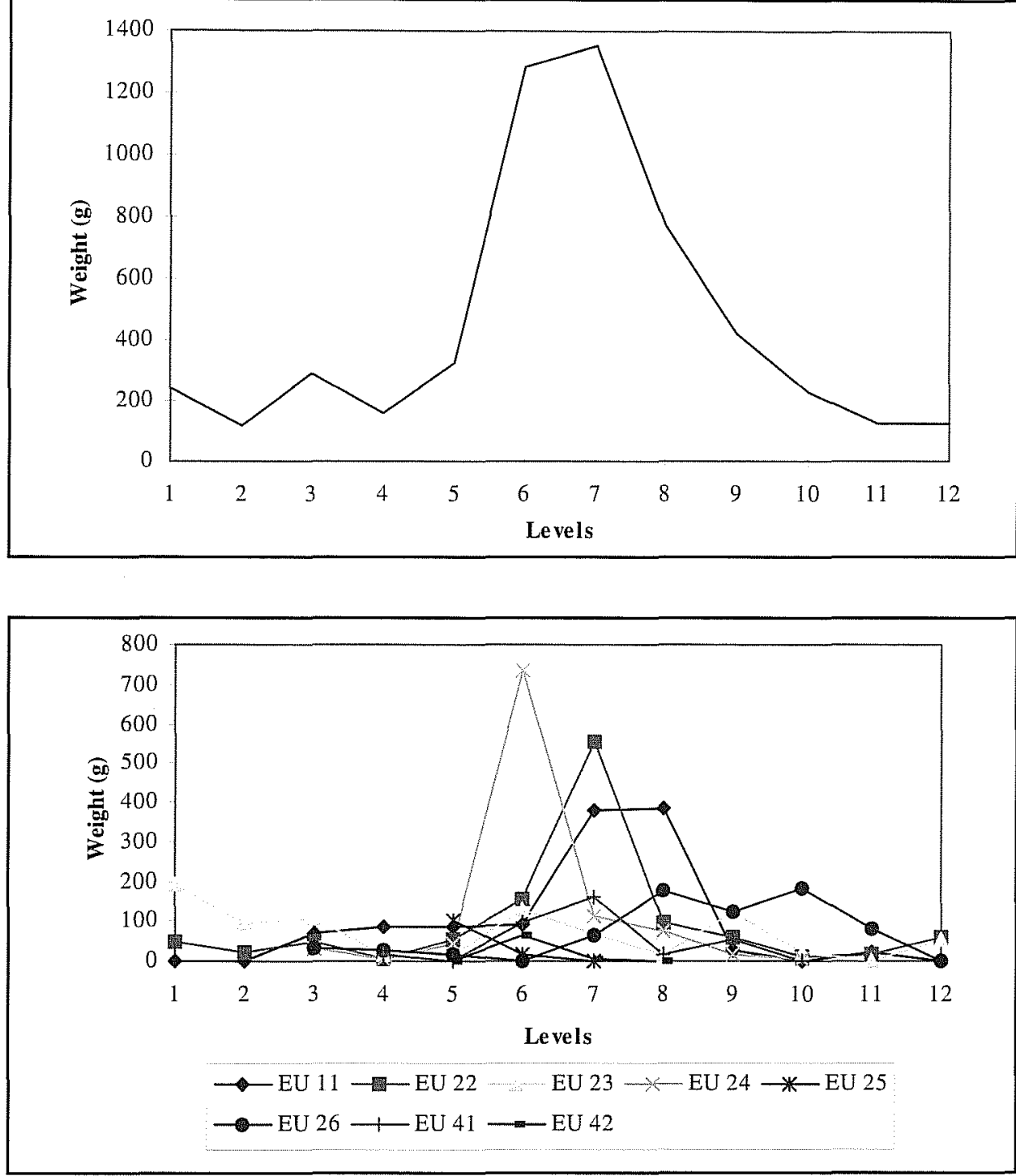

Figure 8-44. Area 3, firecracked rock by level.

Figure 8-45. Area 3, firecracked rock by excavation unit and level.

\section{Mussel, Snail, and Faunal Remains}

Relatively few mussel shell remains are present in Area 3 , thereby continuing the pattern observed in Area 2. Area 3 exhibits a maximum mussel shell weight per level of $21.6 \mathrm{~g}$, as compared to $17.7 \mathrm{~g}$ in Area 2, and $106.7 \mathrm{~g}$ in Area 1. In contrast, all three areas contain relatively similar amounts of snail shells, with maximum weights per level of $10.0 \mathrm{~g}, 10.5 \mathrm{~g}$, and $7.7 \mathrm{~g}$ in Areas 1, 2, and 3, respectively.

The distribution of mussel and snail shell remains differs from that observed for the lithic artifacts and burned rock, and from each other. The majority of the mussel shell remains are present in Level 5 , with practically all of these derived from EU 22 (Figures 8-46 and $8-47$ ). Otherwise, very few mussel shells are present in the remaining levels.

The snail shells exhibit a wider distribution than the mussels, being represented in Levels 5-12 (Figure 8-48); however, these remains are distributed through numerous excavation units, indicating that each level actually contains very few shells (Figure 8-49). For example, EUs 11 and 24 contain some the highest densities of snail shell weights in Level 4 (7-8 g); however, an inspection of each bag indicates that only three large and one or two small individuals are represented. 

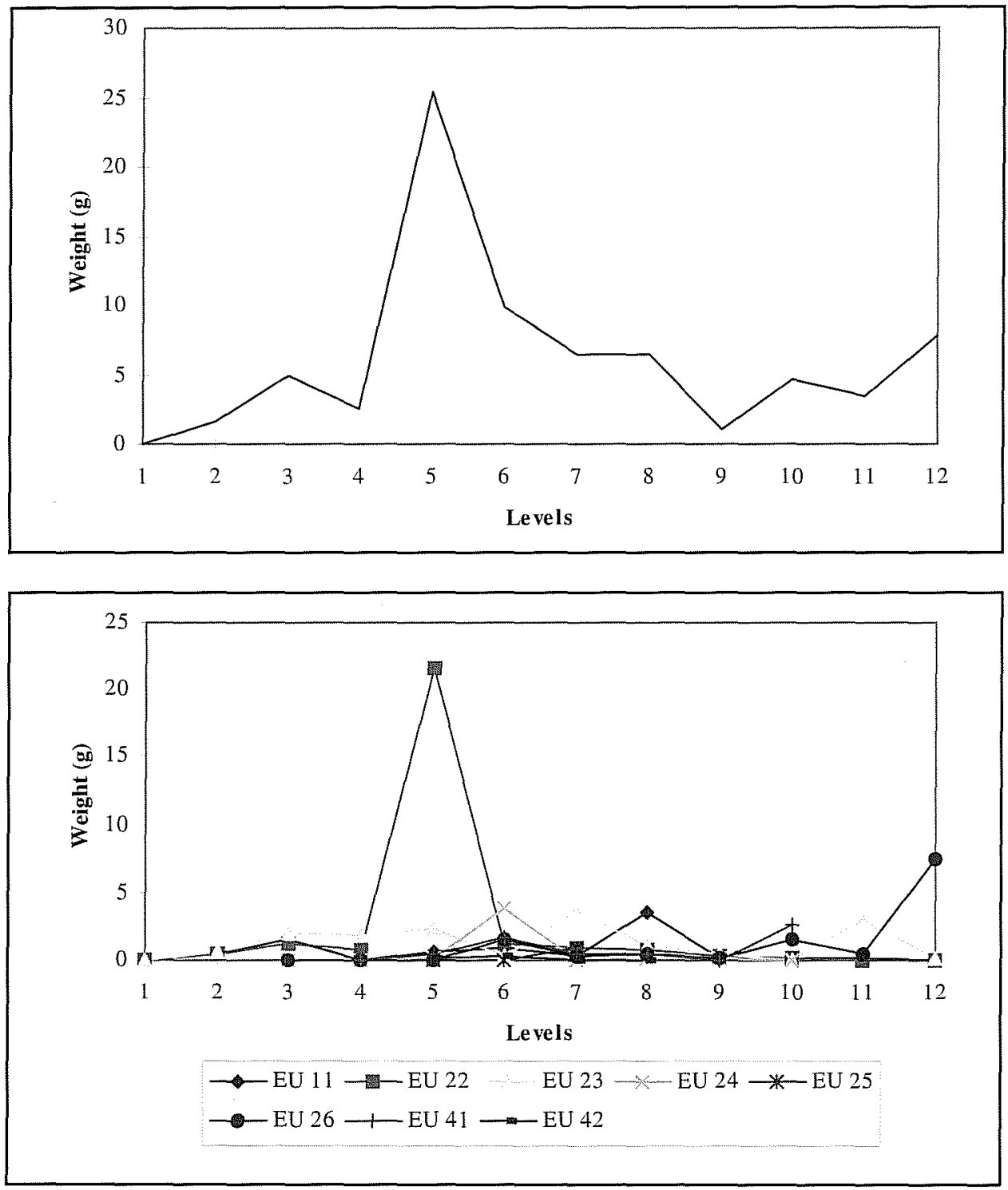

Figure 8-46. Area 3, mussel shell by level.

Figure 8-47. Area 3, mussel shell by excavation unit and level.
Four frog bones were recovered from EU 11, Level 7. The bones are unburned, and it is unclear as to whether they are of a cultural or natural origin. Two small mammal bone fragments were recovered from Levels 1 and 2 in EU 11. One of these fragments exhibits possible chopping marks.

\section{Chronology}

The middle section of the sequence, including Levels $5-8$, contains the highest densities of artifacts. TxDOT's EU 6 is located to the immediate south of the block excavation area. A burned mesquite tree stump was exposed about $50 \mathrm{~cm}$ below the surface (Level 5). A charcoal sample from the stump yielded a date of $760 \pm 50$ B.P. (Beta-104966). In contrast, a piece of wood charcoal from the bottom of the high artifact density zone in Level 8 (EU 22) provided a date of $3050 \pm 50$ B.P. (NSRL-3533). This older date is similar to the 3200 B.P. date from Level 9 in Area 2. Both of the ca. 3000 B.P. dates are much older than the 2200 B.P. date from Level 12 in Area 1.

Diagnostic Late Archaic projectile points were recovered from Levels 7 and 11, which borders the 3050 B.P. date obtained from Level 8. These consist of an Ensor point from EU 25 (Lot 1279) and a Shumla point from EU 23 (Lot 1279), respectively. The Shumla point is 

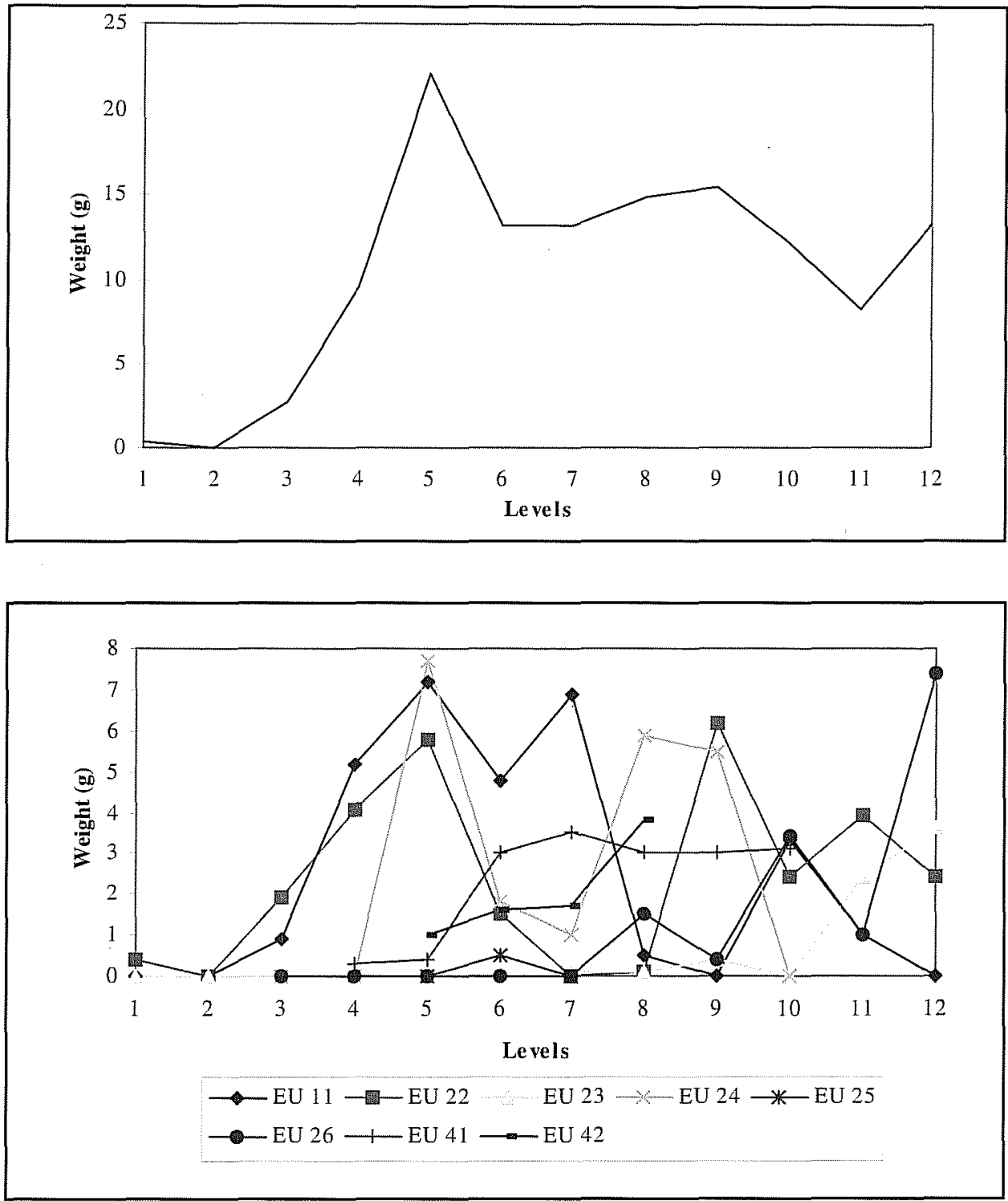

Figure 8-48. Area 3, snail shell by level.
Figure 8-49. Area 3, snail shell by excavation unit and level. situated in the lower part of the sequence as observed in Areas 1 and 2; however, no Ensor points were recovered from the eastern sections of the site.

\section{Site Structure}

The only possible intact features identified in Area 3 were exposed in the southern profile of BHT 10 . These consist of two clusters of burned rock situated about $70-80 \mathrm{~cm}$ below the surface. This roughly correlates with the high artifact density levels in adjacent EUs 11, 22, and 23 (Levels 7 and 8). A review of the previous artifact density plots by level indicates that EUs 11 and 22 consistently contain concentrations of lithic artifacts and burned rock in Levels 7 and 8; whereas, EUs 23 and 26 exhibit the lowest densities for these two levels. The majority of the burned rock in Level 7 of EUs 11 and 22 is composed of sandstone, compared to a mixture of sandstone and limestone in Level 8 . These are possibly the result of separate occupations and/or dumping episodes associated with the use of the nearby features. The western periphery of the concentration is defined by the low artifact densities represented in EUs 23 and 26. Very little mussel shell is present, but most of the shell in Level 7 is situated in EU 23 and EU 11 for Level 8. EU 11 also contains most of the snail shells for Level 7, and EU 24 for Level 8. The Ensor point was found in EU 25 of Level 7. 
Level 7 does exhibit somewhat of a complementary spatial pattern. Feature 10, consisting of two partially in situ hearths, is located in the southern profile of BHT 10. EUs 11 and 22 are situated to the immediate south of the feature, containing concentrations of lithic artifacts and burned rocks. The presence of both these artifacts types in the same locus implies reuse and dumping. The western limits of the concentration are defined along EUs 23, 24, and 26. Some mussel shell is present in EU 23 adjacent to the burned rock dump, and a projectile point in EU 25 which otherwise contains very little cultural material.

\section{Area 4}

Area 4 consists of two separate block excavations located at the western end of the site. BHT 12 was originally excavated in this area as a sump hole - a partial solution to the logistical problems posed by the slow percolation of water in the sump at the east end of the site and the need to water screen. An examination of the sump trench profile, however, revealed the presence of a zone of charcoal, fire-cracked rock, and flakes at a depth of about $1.10 \mathrm{~m}$ below ground surface. Two 1-x-1-m excavation units (EUs 39 and 40) were placed within the trench at the east end to further define the nature of the cultural deposits. In addition, a 2-x-2-m block excavation was located five meters east of BHT 12. This block consisted of EUs 9 and 28-30. Levels 1-8 were excavated within the block, and Levels 7-13 in adjacent EUs 39 and 40. The generalized stratigraphic profile for both blocks is composed of silt with lenses characterized by subtle changes in coloration (Figure 8-50). Floodplain units defined within the area consist of 2-p, 2-f2, 2-f3, and fill (Chapter 7). Table 8-1 correlates the information on geological sediment by $10-\mathrm{cm}$ levels within BHT 12 .

\section{Lithic Artifacts}

Four retouched tools and 34 pieces of debitage were recovered from the block excavations in Area 4. This provides an overall artifact density of 0.85 artifacts per cubic meter, ranging from $0.0-18.0$. This is the lowest artifact density represented on the site, continuing the generalized pattern of decreasing artifact density from east to west. Most of the lithic artifacts were recovered from the upper levels of the block excavations, with only a few artifacts present in the lower levels of adjacent EUs 39 and 40 (Figure 8-51). The tools consist of a biface, a possible reworked Shumla point, and a Ensor point found in upper Levels 3 and 4, and an Ensor point present in lower Level 12. The biface may represent a projectile point preform.

\section{Burned Rock}

Almost no burned rock was recovered from the upper levels of the block excavations; however, a concentration of burned rock is present in Levels 10 and 11 of EUs 39 and 40 (Figure 8-52). The majority of the burned rock from both of these levels consists of sandstone (551.8 and 598.1 g), with less limestone, chert and rhyolite; however, there is more limestone represented in Level 10 (208.3 g) than in Level 11 (4.7 g), with very little chert $(7.0 \mathrm{vs} .32 .0 \mathrm{~g})$ and rhyolite $(8.4$ vs. $0.0 \mathrm{~g}$ ) in either level.

Two isolated pieces of burned rock were mapped and archaeomagnetic samples were taken from Levels 10 (Lots 18 and 22), and three samples from Level 11 (Lots 19-21) (Figure 8-53). Samples 18 and 20-22 are sandstone and Sample 19 is limestone. Two of the samples were submitted for analysis. Sample 18 is disturbed, with the rock having moved about $180^{\circ}$, and subsequently inverted. Sample 20 has moved only slightly since being burned.

Feature 8 is a burned acacia stump about $70 \mathrm{~cm}$ below the surface at the bottom of BHT 12. It was partially exposed along the north wall of EU 39 (Figure 8-50). The soil surrounding the stump is heavily burned for a depth of about $85 \mathrm{~cm}$. The center is filled with a mix of ash stained soil and large chunks of charcoal.

Feature 9 is the remains of another burned tree stump which was removed during the excavation of the backhoe trench. The stump was initially exposed just below the present surface, extending down for another $75 \mathrm{~cm}$. It was situated at the eastern end of the trench, above EU 40. 


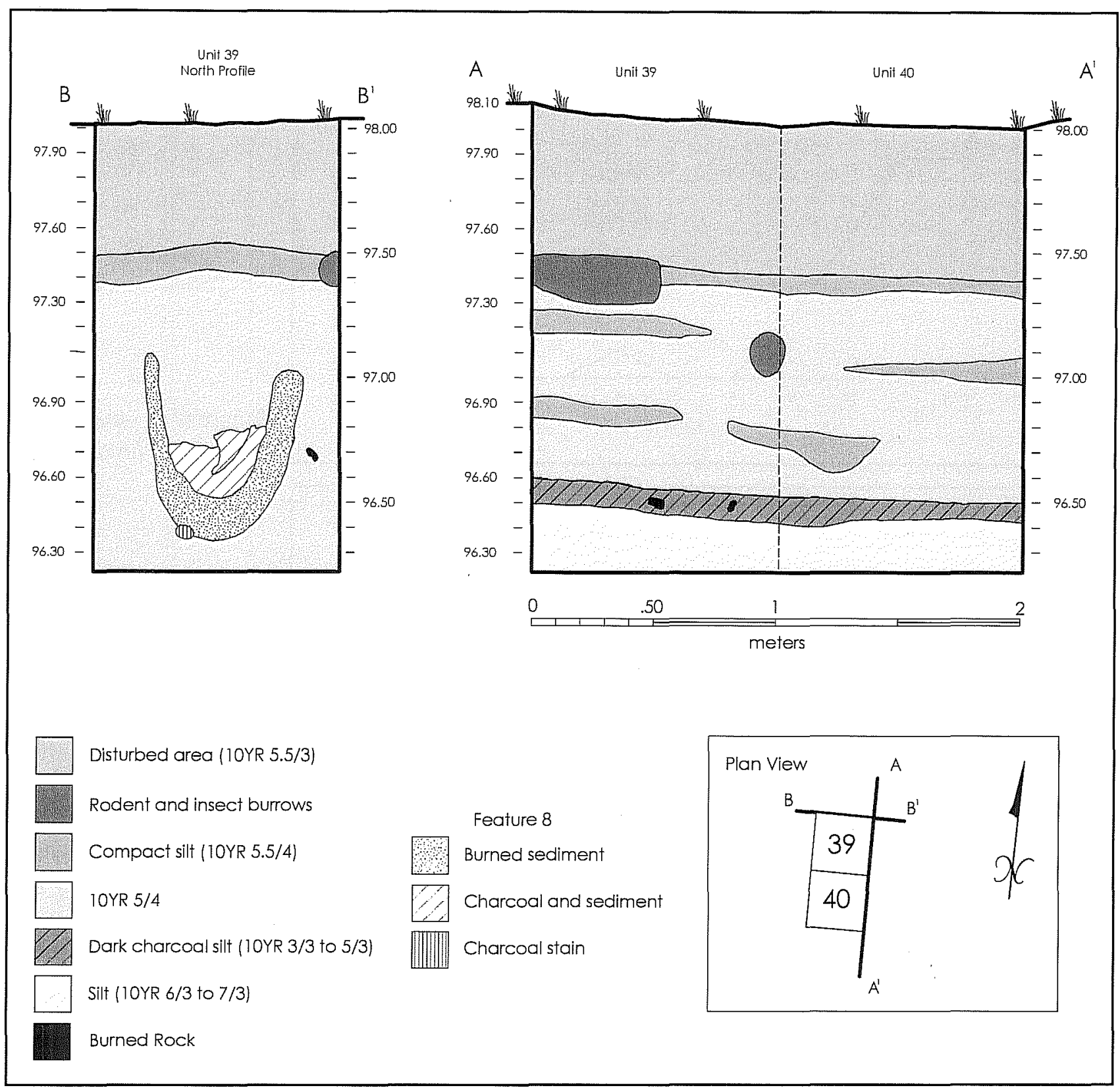

Figure 8-50. Area 4, plan and profiles.

\section{Macrobotanical Remains}

Five macrobotanical samples were collected from the block excavations in Area 4. Two of these were recovered from Level 8 . The latter consist of mesquite charcoal from EUs 9 (Lot 140) and 40 (Lot 1028). As previously mentioned, Feature 8 consists of an acacia tree stump, with samples taken from Levels 7-9 (Lot 1001 ) and 10 (Lot 1002). Lastly, a piece of unidenti- fied wood was recovered from Level 13 in EU 39. None of these samples was obtained from Levels 10 or 11 , which contain the highest densities of burned rock. Besides the hand-excavated samples, several pieces of charcoal were also found in BHT 12. These consist of two pieces of mesquite (Lots 702 and 703), a piece of acacia (Lot 704), and a piece of legume wood charcoal (Lot 701). The latter was obtained from a charcoal- stained lens which was excavated in adjacent EUs 39-40. 

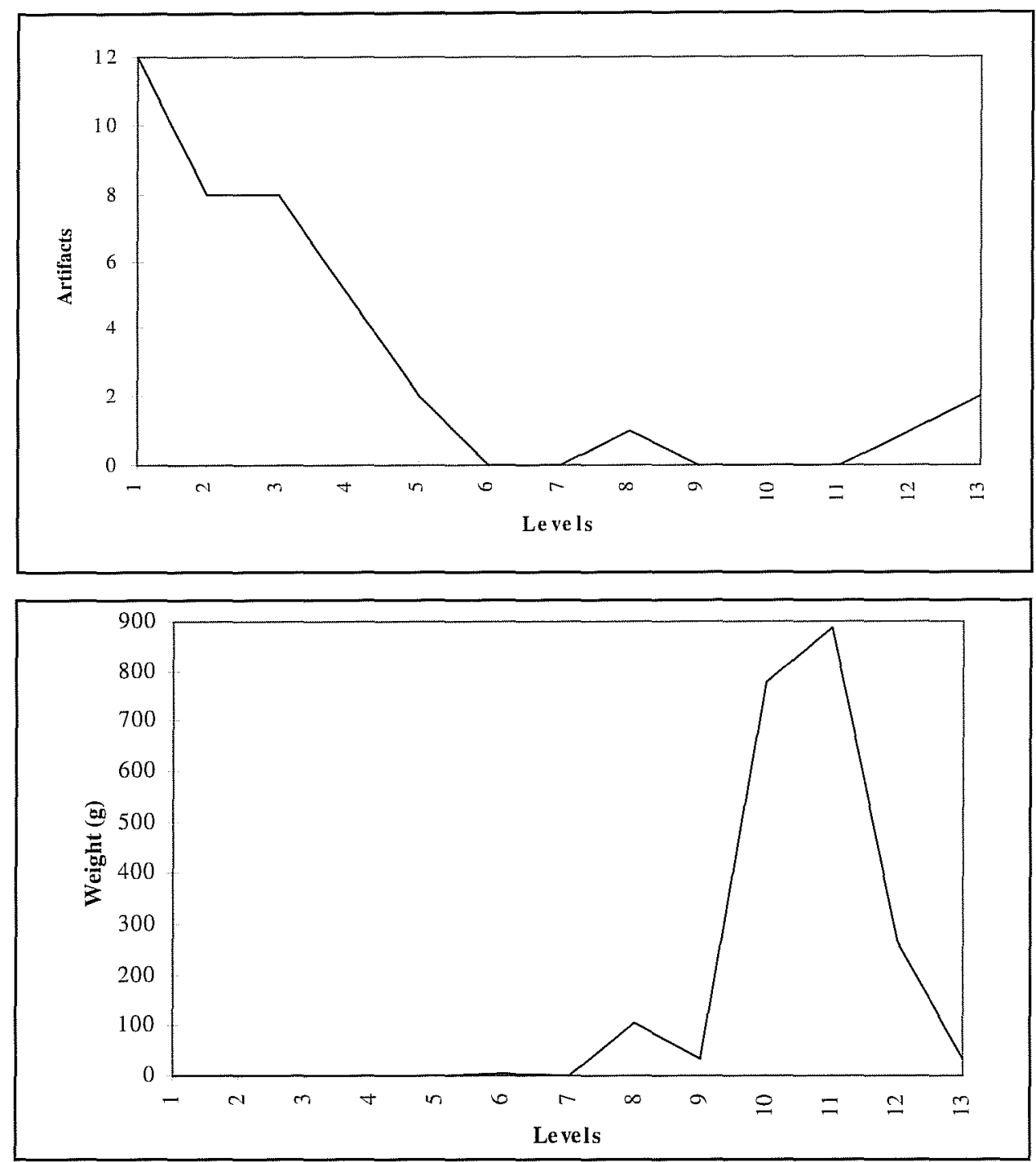

Figure 8-51. Area 4, lithic artifacts by level.

Figure 8-52. Area 4, firecracked rock by level.

\section{Mussel and Snail Remains}

Relatively few mussel and snail remains were recovered from the excavations in Area 4. Most of the snail remains are present in Levels $1-8$ of EUs 9 and 28-30 (Figure 8-54). In contrast, the majority of the mussel shell remains are situated in Level 12 of EU 39, with a few in Level 3 of EU 9. The peak in Level 12 consists of $5.2 \mathrm{~g}$ of shell; whereas, the maximum peak in Area 3 was composed of $21.6 \mathrm{~g}$ of mussel shell. This reflects the continuing east-west decline in mussel shell as the distance from Elm Creek increases. Level 12 does contain some burned rock, but much less than what is present in overlying Levels 10 and 11. It is, however, the level which includes the charcoal stained lens.

\section{Chronology}

The majority of the artifacts are present in the upper levels of the block excavation, with some mussel shell and a projectile point present in Level 12. The top of an acacia stump (Feature 8) was exposed about $70 \mathrm{~cm}$ below the surface in EU 39. A sample of charcoal from the burned stump yielded a radiocarbon date of $540 \pm 40$ B.P. (Beta-104967). A charcoal stained lens was initially identified in BHT 12. Excavations in EUs 39 and 40 further delineated the extent of this thin stratum in Level 12. Feature 8 appears to cut down through the level where the lens is found. A legume charcoal sample collected from the charcoal stained lens yielded a date of $1940 \pm 40$ B.P. (NSRL-3532). 


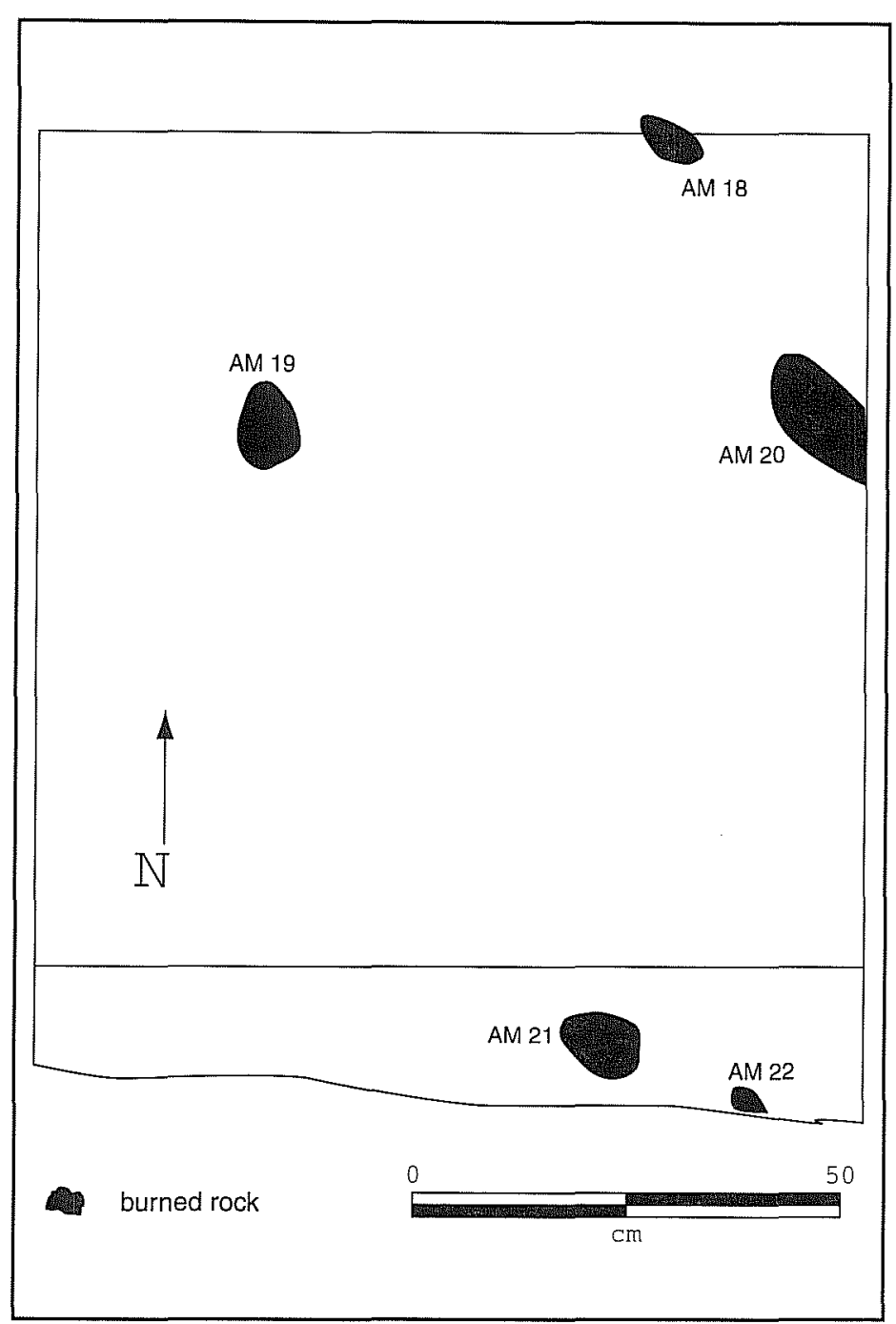

Figure 8-53. Excavation Unit 40, Levels 10 and 11.
Diagnostic Late Archaic projectile points were recovered from Levels 2 and 12; both are Ensor points (Lot 129, 1036). A possible reworked Shumla point (Lot 505) was found in Level 4. The radiocarbon date from Level 12 is directly associated with the Ensor point found in the same charcoal stained lens. This date of 1940 B.P. is similar to the 1970 B.P. date obtained from Level 9 in Area 1. A Marcos point was present in the same level as this latter date.

\section{Site Structure}

The paucity of artifacts present in Area 4 reflects a general low level of occupational intensity. This section of the site is probably situated peripherally to the main occupation areas which were 10cated further east. Most of the lithic artifacts were recovered from the upper levels of the block excavation; however, more retouched tools per debitage are found in Area 4 than in the other excavation blocks: 8.5 pieces of debitage per retouched tool in Area 4, vs. 181.5, 73.0, and 99.1 in Areas 1-3, respectively.

The main focus of activities in Area 4 is located in the lower levels of EUs 39 and 40. This includes the burned rock concentrations which are situated in Levels 10 and 11. This material does not appear be in situ, but presumably reflects the remains of a disturbed feature and/or dump. Rock

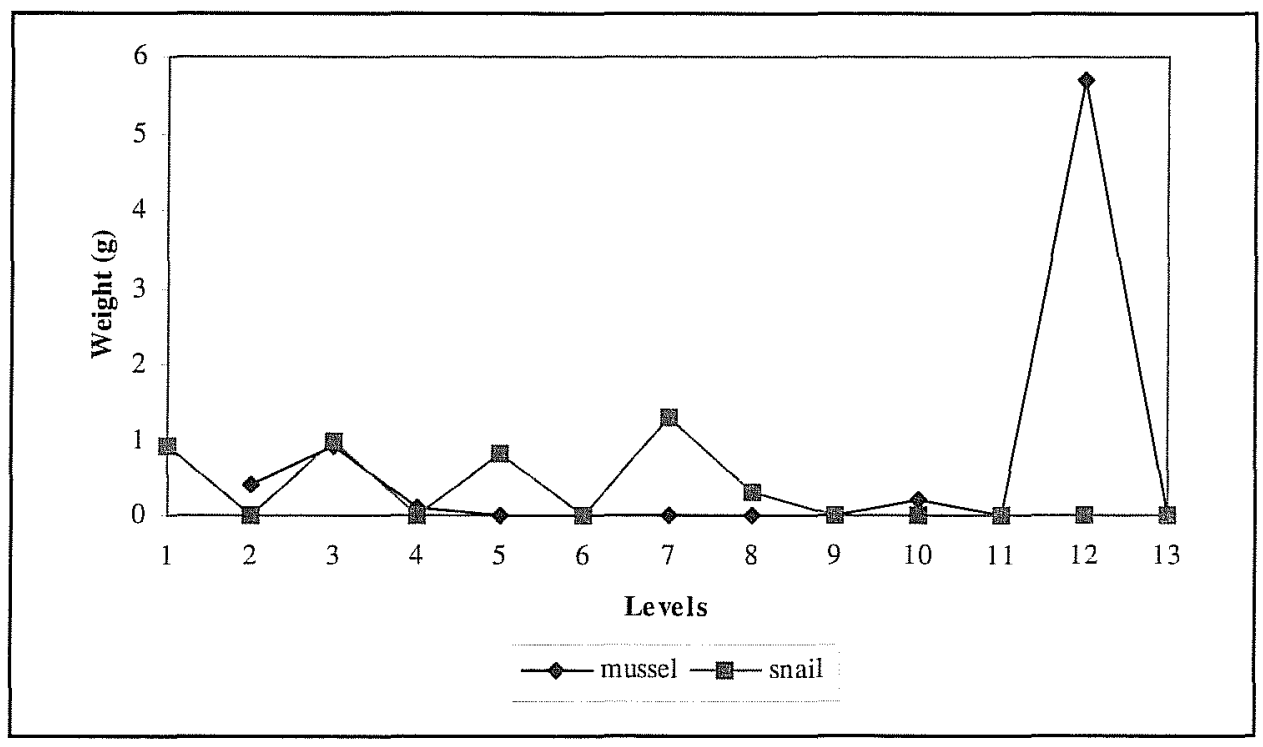

Figure 8-54. Area 4, mussel and snail shell by level. 
composition does vary somewhat by level. That is, both levels contain mostly sandstone, but with more limestone in Level 10. This contrasting pattern could be the result of differing occupational episodes.

Relatively little mussel or snail shell is represented within the area; however, most of the mussel shell is situated in Level 12 of EU 39 with a charcoal stained lens, some burned rock, and an Ensor projectile point. In contrast, the few snail shells present are situated in the upper levels of the excavation block. 


\section{Chapter 9: Lithic Analysis}

\section{Bradley J. Vierra}

\section{Introduction}

This chapter presents the results of the analyses of 9,147 lithic artifacts recovered from the excavations conducted at site 41MV120. The assemblage consists of 9,050 pieces of debitage, 15 cores, 79 retouched tools, a mano fragment, and two pieces of hematite. The total hand excavated area consists of $38 \mathrm{~m}^{2}$, which were dug to a depth of approximately $1.2 \mathrm{~m}$. The excavation units were located in four separate blocks and five isolated $1-\mathrm{x}-1-\mathrm{m}$ test pits. Information is provided on sampling techniques, analytical methods, results of the lithic analysis, a study of intra-site spatial patterning, and regional site comparisons. $41 \mathrm{MV} 120$ represents one of the few stratified open air sites excavated in South Texas. The information derived from this analysis will therefore make an important contribution toward our understanding of prehistoric hunter-gatherer technology and land use in this area of Texas.

\section{Sampling}

All the cores, retouched tools and ground-stone artifacts recovered during the excavations were analyzed. Since both $1 / 8$ - and $1 / 4$-inch mesh sizes were used to screen soil in the field, all the debitage recovered from $1 / 8$ - inch mesh was rescreened in the laboratory with $1 / 4$-inch mesh to obtain a consistently screened sample. Given the large number of debitage recovered, a twolevel sampling design was developed for the analysis of these artifacts. This sampling method was developed to collect information on both assemblage composition and site structure. The first level sampling procedure involves a rough-sort analysis of all the debitage from the site. This simply consists of recording debitage type and material type for the artifacts. Included in this analysis were all the cores and debitage recovered from TxDOT EUs 1, 2, 4, and 6 (Ward 1995a). Since CAR continued the excavations in these units, the upper levels were also studied to provide for a consistent analysis format throughout the entire unit.

The second level sampling procedure involves the detailed attribute analysis of debitage selected from the four block-excavation areas on the site (Figure 6-2). Areas 1-4 consist of $11,9,8$, and 6 EUs, respectively. A six-unit sampling area was selected within each of the excavation blocks to provide equal spatial coverage . In Area 1, this consists of EUs 13, 14, 15, 31,32 , and 34 . EUs $14,15,31$, and 32 provide a $2-x-2-m$ square section situated in the center of the block, and EUs 13 and 34 add lateral extensions on opposite ends of the block. EUs 7, 16, 19, 20,37, and 38 were selected for analysis in Area 2 . They comprise a 2-x-3-m rectangular section along the eastern side of the block. In Area 3, EUs 11, 22, 23, 24, 26, and 41 were analyzed. They provide an east-west linear series of four EUs (11, 22, 23, and 41), and a north-south series of three EUs $(24,26$, and 46). A total of 4,500 (49.7 percent) of the site debitage was analyzed as a result of this sampling strategy; however, the sampling intensity does vary within each of the excavation blocks: Area 1 ( 73.0 percent; $n=3,313$ ), Area 2 (67.5 percent; $n=1,233$ ), Area 3 (62.9 percent; $n=1,149$ ), and Area 4 (100.0 percent; $n=35$ ).

\section{Analytical Methods}

The lithic analysis methods were designed to collect the information necessary to address the research issues presented in Chapter 5. Explicit artifact definitions are presented in this section, and more detailed information on the specific attributes recorded is given in Appendix E. In addition, data on the field collections of Rio Grande and Uvalde Gravels is also presented in this section. These field collections were made in order to document local raw material sources, raw material variation, and range in cobble size. 


\section{Definitions and Attributes}

\section{Cores and Hammerstones}

Cores $(n=13)$ are nodules that have faceted platforms from which specific kinds of flakes are removed. They are subdivided into unidirectional, bidirectional, multidirectional, and fragment types. Tested materials $(\mathrm{n}=0)$ are nodules with a single flake removed from an unprepared cortical platform at one or more isolated locations. They probably represent nodules that have been tested for material quality and were then rejected. Cobble unifaces $(\mathrm{n}=2)$ have two or more flakes unifacially removed along a single edge margin, usually at one end of a pebble or cobble. Cobble unifaces probably represent unprepared cobble cores. A hammerstone $(\mathrm{n}=0)$ is a nodule that exhibits battering on an otherwise unmodified cortical portion of its surface. This battering usually occurs on the end or along the perimeter of the pebble or cobble.

\section{Debitage}

Debitage consists of the by-products of core reduction and tool production. Flakes are pieces of material that have been detached from a core or tool by percussion or pressure, as opposed to angular debris $(n=1,160)$ which are pieces that are incidentally broken off during core reduction. These pieces of shatter lack definable flake characteristics, such as a platform, bulb of percussion, ventral/dorsal surfaces, and proximal/distal ends.

Core flakes $(n=3,493)$ are flakes that have been detached from a core. A polythetic set (Clark 1968:3637) of attributes for core flakes consists of a single or dihedral platform; a platform angle of greater than $75^{\circ}$; cortex present on dorsal surface; dorsal scars that may be absent, parallel or perpendicular to the platform; a thickness of greater than about five millimeters; a pronounced bulb of percussion; and an eraillure scar. To be classified as a core flake, the flake must exhibit at least five of the seven defining attributes.

Bipolar flakes ( $\mathrm{n}=0$ ) are flakes that have been detached from a core through the use of a bipolar reduction technique. That is, the core is set on an anvil and struck with the percussor (Crabtree 1972:42). The resultant flake differs from a core flake in that it may have two bulbs of percussion, eraillures and/or scaling/crushing at one or both opposing ends. No bipolar flakes were identified during this analysis.

Core trimming ( $c t$ ) flakes $(\mathrm{n}=24$ ) are pieces that have been struck at a $90^{\circ}$ angle to the major flaking axis of the core, along the edge of the core platform and dorsal flaking surface. They are sometimes referred to as platform renewal or rejuvenation flakes, since they often remove the step fractures than can occur adjacent to the edge of the platform. They may also represent an attempt to change the orientation of the core, by preparing and reorienting a new flaking surface that is perpendicular to the previous major flaking axis. Core trimming flakes are similar to uniface rejuvenation flakes (Highley 1995:482), but none of the latter were identified during this analysis. Core tablets $(\mathrm{n}=0)$ are also flakes that have been struck perpendicular to the major flaking axis of a core; however, they have been struck just below the platform to remove the whole striking platform from the core (Marks 1976:374).

Opposing core (oc) flakes ( $\mathrm{n}=3$ ) have been detached from the bottom of a core by striking it at a $90^{\circ}$ angle to the major flaking axis. This then acts to create a platform from which flakes are removed in the opposite direction from previous removals. They may also reflect a type of overshot flake which has removed the bottom of the core (Montgomery 1978:67). These flakes exhibit marked ventral curvature, and multiple dorsal flakes scars which radiate towards a single termination at its distal end.

Blades $(\mathrm{n}=4)$ are specialized forms of flakes that are twice as long as they are wide, with parallel lateral sides, and one or more parallel dorsal arises (Bordes 1981:16). Biface flakes $(n=756)$ are flakes that have been detached from a bifacially retouched artifact. A polythetic set of attributes for biface flakes consists of a multi-faceted platform, a lipped platform, a platform angle of less than $75^{\circ}$, a weak bulb of percussion, cortex absent on dorsal surface, dorsal scars that are roughly parallel to each other and perpendicular to the platform, a thickness of less than five millimeters that is relatively even from proximal to distal ends, and a pronounced ventral curvature (Acklen et al. 1983). A 
flake must exhibit at least five of the eight attributes to be classified as a biface flake.

Overstruck flakes $(\mathrm{n}=2)$ are flakes removed from the edge of a biface, but go over and beyond the face of the artifact detaching a portion of the opposite edge. Notching flakes $(\mathrm{n}=3)$ are flakes which exhibit a negative dorsal scar originating from the platform, a small indentation at the platform, a convex ventral profile, and a salient bulb of percussion (Titmus 1985:251-252).

Uniface flakes $(n=14)$ are flakes which have been detached from a unifacially retouched artifact (Shafer 1970). A polythetic set of attributes for uniface flakes consists of a single-faceted platform, a platform angle of greater than $60^{\circ}$, dorsal scars that are parallel to each other and perpendicular to the platform, a single distal scar on the dorsal surface of the flake (sometimes separated by an arris), and marked ventral curvature.

Burin spalls $(\mathrm{n}=2)$ are pieces that have been struck from the edge of a flake, so the resulting scar (or facet) approaches $90^{\circ}$ to the plane of the blank from which it was removed. Pot lids $(\mathrm{n}=62)$ are Hertzian cones produced when siliceous rocks are subjected to heat. Hammerstone (hs) flakes $(\mathrm{n}=1)$ are flakes with cortex on the platform and dorsal surface, with the platform being heavily battered. Undetermined flake fragments are fragments for which flake type could not be determined.

\section{Retouched Tools}

Retouched tools are the result of the secondary percussion or pressure flaking of a piece in order to produce a specific tool shape. Marginally retouched flakes $(n=9)$ are flakes with retouch that extends over less than one-third of the surface of the artifact (Chapman and Schutt 1977:86). This is non-invasive retouch which is limited to the edge margin, but may be unidirectional or bidirectional. Notches $(\mathrm{n}=10)$ are flakes with one or two contiguous notches along the edge of the piece; whereas, denticulates $(n=0)$ are flakes with three or more contiguous notches along the edge of the piece (GEEM 1975). Perforators and gravers are flakes with unidirectionally retouched projections. Gravers $(n=0)$ exhibit a blunt end and perforators ( $n=1)$ a pointed end. Burins $(\mathrm{n}=1)$ are flakes which have had a portion of their edge removed (Crabtree 1972:48).

Unifaces $(n=10)$ are artifacts which exhibit retouch scars over one-third or more of only one of their surfaces. This type of retouch can be defined as invasive. Unifaces exhibit initial edge retouch and lack a formal overall shape. In contrast, scrapers $(\mathrm{n}=0)$ are specialized forms of unifaces which exhibit secondary edge retouch producing a formal shaped tool with an edge angle between about $60-80$ percent.

Bifaces $(\mathrm{n}=31)$ are artifacts which exhibit retouch scars extending over one-third or more of both their opposing surfaces (Chapman and Schutt 1977:93). Generalized bifaces tend to be ovate or lanceolate in shape, with edge angles between about $30-50^{\circ}$. Drills and projectile points are specialized forms of bifaces. Drills $(n=0)$ are bifacially retouched flakes that are twice as long as they are wide, about as thick as they are wide and often exhibit a diamond-shaped cross-section. Projectile points $(\mathrm{n}=16)$ are bifaces that exhibit hafting modifications that distinguish a stem from the blade.

\section{Ground Stone}

Ground stone tools are artifacts that exhibit ground and/ or abraded surfaces. Manos $(\mathrm{n}=1)$ are cobbles or slabs with at least one surface characterized by one or more smooth facets produced through grinding. They were hand-held objects that were primarily used to crush and grind vegetal foodstuffs against a metate (Chapman and Schutt 1977:95; Christenson 1987:44). One-hand manos are less than $170 \mathrm{~mm}$ in length, and two-hand manos have a length equal to or greater than $170 \mathrm{~mm}$. Undetermined manos are fragments where the projected length of the artifact could not be determined. Metates $(n=0)$ are artifacts characterized by at least one large grinding surface upon which vegetal foodstuffs may have been crushed and ground with a mano. They generally have a grinding surface greater than $450 \mathrm{~cm}^{2}$ in size (Christenson 1987:47). Undetermined ground stone $(\mathrm{n}=0)$ are unclassifiable ground stone fragments. These fragments often exhibit a single flat grinding surface. 


\section{Field Collections of Rio Grande and Uvalde Gravels}

Field collections were made of Rio Grande and Uvalde gravels to provide baseline data of the material composition and size range represented by these possible lithic sources. A sample of cobbles was collected from Rio Grande gravels near site 41MV120. A dragline working in a nearby quarry along the river dredged up buried gravels during the field excavations. Two hundred eleven cobbles were randomly selected from the resulting gravel pile. Most of the cobbles are composed of chert (69.1 percent), with less rhyolite, limestone, basalt, chalcedony, quartzite, quartz, volcanic breccia, and sandstone (Table 9-1). The chert can be subdivided into 12 subclasses. Most of the cherts consist of a light $\tan$ /gray variety (43.8 percent), with fewer gray banded, light tan/gray with dark brown adjacent to the cortex, white, clastic, gray, light tan/gray with reddish purple, brown, red, light tan/gray fossiliferous with white inclusions, black, and yellow (Table 9-2). The

Table 9-1. Rio Grande and Uvalde Gravel Material

\begin{tabular}{|c|c|c|}
\hline \multirow{2}{*}{ Material Type } & \multicolumn{2}{|c|}{ Source } \\
\hline & $\begin{array}{c}\text { Rio } \\
\text { Grande } \\
\text { Gravels }\end{array}$ & $\begin{array}{l}\text { Uvalde } \\
\text { Gravels }\end{array}$ \\
\hline basalt & 2 & 5 \\
\hline andesite & 0 & 1 \\
\hline rhyolite & 28 & 0 \\
\hline volcanic breccia & 1 & 1 \\
\hline sandstone & 1 & 0 \\
\hline limestone & 28 & 2 \\
\hline chalcedony & 2 & 1 \\
\hline chert & 146 & 64 \\
\hline silicified wood & 0 & 2 \\
\hline quartzite & 2 & 5 \\
\hline quartz & 1 & 0 \\
\hline column total & 211 & 81 \\
\hline
\end{tabular}

Table 9-2. Rio Grande and Uvalde Gravel Chert Subtypes

\begin{tabular}{|l|c|c|}
\hline \multirow{2}{*}{ Chert Subtype } & \multicolumn{2}{c|}{ Source } \\
\cline { 2 - 3 } & $\begin{array}{c}\text { Rio Grande } \\
\text { Gravels }\end{array}$ & $\begin{array}{c}\text { Uvalde } \\
\text { Gravels }\end{array}$ \\
\hline light tan/gray & 64 & 40 \\
\hline gray banded & 19 & 0 \\
\hline tan/gray with dark brown & 13 & 0 \\
\hline white & 9 & 11 \\
\hline clastic & 9 & 0 \\
\hline gray & 7 & 3 \\
\hline tan/gray with reddish purple & 6 & 2 \\
\hline brown & 6 & 1 \\
\hline red & 5 & 7 \\
\hline tan/gray fossiliferous & 4 & 0 \\
\hline black & 3 & 0 \\
\hline yellow & 1 & 0 \\
\hline column total & $\mathbf{1 4 6}$ & $\mathbf{6 4}$ \\
\hline
\end{tabular}

cobbles have a mean length of $91.0 \mathrm{~mm}(\mathrm{sd}=30.6)$, and a mean weight of $490.3 \mathrm{~g} \mathrm{(} \mathrm{sd}=738.4)$. Lengths range from $11-197 \mathrm{~mm}$ and weights from $51-7,972 \mathrm{~g}$.

A sample of 81 nodules was collected from surface lag Uvalde Gravels along Highway 57 east of Eagle Pass. Most of these also consist of chert (79.0 percent), with fewer quartzite, basalt, limestone, silicified wood, chalcedony, andesite, and volcanic breccia (Table 9-1). The cherts can be subdivided into subtypes similar to those present in the Rio Grande gravels (Table 9-2). These primarily consist of the light tan/gray (62.5 percent), with less, white, red, gray, light tan/gray with reddish purple, and brown. The nodules have a mean maximum length of $85.1 \mathrm{~mm}$ (sd=27.4), and weight of 431.1 $\mathrm{g}(\mathrm{sd}=398.0)$. Lengths range from $31-166 \mathrm{~mm}$, and weights from 45-2206 g. Overall, the Uvalde Gravels contain some of the same materials as that represented in the Rio Grande gravels, but in differing proportions; however, there are no rhyolite and much less limestone represented in the Uvalde Gravels. In addition, the gray banded, dark brown adjacent to cortex, fossiliferous, black and yellow chert subtypes are missing in our Uvalde gravel sample. This may in part be due to 
sample size, although the gray banded chert is the second most predominant in the Rio Grande gravels. Otherwise, the Uvalde Gravels are slightly smaller in size.

\section{Analysis}

The analysis section is divided into three parts: material selection, tool production/maintenance, and tool use. The material selection section describes the variation in lithic raw materials used and the possible sources for these materials. The tool production/maintenance section provides information on core reduction techniques, stages of reduction represented, and evidences of tool production/maintenance. The section on tool use presents information on possible tool function, including presence/absence of use wear on chipped stone artifacts, and the nature of ground-stone tool use. Each part is further divided in respect to core, debitage, retouched tools, and other artifacts (e.g., ground stone).

\section{Material Selection}

\section{Cores/Debitage}

Table 9-3 presents the information on artifact type by material type for the entire site assemblage. As can be seen, the majority of the debitage is made of chert $(86.0$ percent), with less chalcedony, salt/pepper rhyolite, jasper, rhyolite, quartz, quartzite, limestone, silicified wood, and sandstone. The chert category can be divided into 11 visually distinctive subtypes: light $\tan /$ gray, light tan with reddish purple, gray banded, gray, tan fossiliferous, white, brown, clastic, black, red and a light tan/gray with dark brown banding adjacent to the cortex. Table 9-4 shows the variation in chert subtypes for the site assemblage. The chert debitage primarily consist of the light tan/gray variety (72.4 percent), with less gray, tan fossiliferous, white, red, light $\tan$ /gray with reddish purple, brown, gray banded, and black. At least some of this black chert may actually represent silicified wood, since the small amount of silicified wood identified in the collection is also black in color.
The cores exhibit a pattern similar to that of the debitage, with all but one being made of chert, one of rhyolite and the cobble unifaces of salt/pepper rhyolite and rhyolite. About half(46.1 percent) of the cores are made of the light tan/gray chert, with the remaining being gray, $\tan$ fossiliferous, light tan with reddish purple, and red.

Most of the varieties represented among the light tan/ gray cherts probably reflect color variations from the same source(s). Other colors have to some degree been affected by burning (e.g., gray, white, and red). With the exception of the salt/pepper rhyolite, jasper, and a black silicified wood, examples of all the remaining types were identified in source materials collected from Rio Grande and Uvalde gravels in the area. The single piece of tabular silicified wood identified in the Uvalde gravels is a brownish gray and is coarser in texture than the black silicified wood present in the archeological materials. Although not identified in the cobble sample collected from local Rio Grande gravels, a brown silicified wood was observed in other local gravel terraces.

Cortex can be a good indicator of possible sources for the lithic materials reduced on the site. Cortex type was monitored during the detailed analysis of the debitage (Table 9-5). It is only present on 14.7 percent of the debitage, but most of this is water-worn cortex (96.3 percent), with very little nodular and tabular cortex. Water-worn cortex is present on all of the defined lithic material types, including the jasper and salt/pepper rhyolite. The dominance of this cortex type indicates that most of the archeological materials were probably obtained from local gravel sources. This is supported by the fact that eight cores ( 61.5 percent) and both cobble unifaces solely exhibit Water-worn cortex. The closest source is the gravels along the Rio Grande which are situated about $800 \mathrm{~m}$ southwest of the site, or various older terraces in the area. In addition, Uvalde Gravels are also present about $15-20 \mathrm{~km}$ to the north or west of the site. The presence of nodular cortex on chert, chalcedony, rhyolite, and salt/pepper rhyolite indicates that these materials could have been obtained from their original sources, or from secondary gravel sources where they had been transported shorter distances and had not yet developed a distinctive waterworn cortex. Tabular cortex is present on a piece of 


\section{Table 9-3. Artifact Type by Material Type}

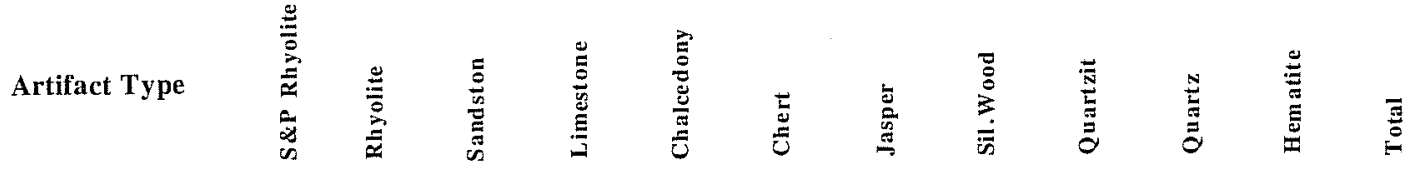

\section{Debitage}

\begin{tabular}{|c|c|c|c|c|c|c|c|c|c|c|c|c|}
\hline Angular debris & 32 & 52 & 4 & 18 & 26 & 977 & 2 & 4 & 18 & 27 & 0 & 1160 \\
\hline Core flake & 22 & 172 & 0 & 10 & 150 & 3058 & 51 & 0 & 12 & 18 & 0 & 3493 \\
\hline Blade & 0 & 0 & 0 & 0 & 1 & 3 & 0 & 0 & 0 & 0 & 0 & 4 \\
\hline Biface flake & 1 & 6 & 0 & 0 & 84 & 533 & 16 & 0 & 0 & 0 & 0 & 756 \\
\hline Uniface flake & 0 & 0 & 0 & 0 & 0 & 14 & 0 & 0 & 0 & 0 & 0 & 14 \\
\hline Notching flake & 0 & 0 & 0 & 0 & 0 & 3 & 0 & 0 & 0 & 0 & 0 & 3 \\
\hline Core trimming flake & 0 & 0 & 0 & 0 & 1 & 23 & 0 & 0 & 0 & 0 & 0 & 24 \\
\hline Burin spall & 0 & 0 & 0 & 0 & 0 & 2 & 0 & 0 & 0 & 0 & 0 & 2 \\
\hline Pot lid & 0 & 0 & 0 & 0 & 1 & 60 & 1 & 0 & 0 & 0 & 0 & 62 \\
\hline Hammerstone flake & 0 & 0 & 0 & 0 & 1 & 0 & 0 & 0 & 0 & 0 & 0 & 1 \\
\hline Overstruck flake & 0 & 0 & 0 & 0 & 1 & 1 & 0 & 0 & 0 & 0 & 0 & 2 \\
\hline Opposing core flake & 0 & 0 & 0 & 0 & 0 & 3 & 0 & 0 & 0 & 0 & 0 & 3 \\
\hline Und. flake fragment & 11 & 86 & 0 & 1 & 245 & 3114 & 64 & 0 & 2 & 3 & 0 & 3526 \\
\hline Subtotal & 66 & 316 & 4 & 29 & 510 & 7791 & 134 & 4 & 33 & 48 & $\mathbf{0}$ & 9050 \\
\hline
\end{tabular}

\section{Cores}

Core

Cobble uniface

Subtotal

Retouched Tools

\begin{tabular}{|c|c|c|c|c|c|c|c|c|c|c|c|}
\hline Retouched flake & 0 & 0 & 0 & 0 & 0 & 9 & 0 & 0 & 0 & 0 & 0 \\
\hline Notch & 0 & 0 & 0 & 0 & 0 & 10 & 0 & 0 & 0 & 0 & 0 \\
\hline Biface & 0 & 0 & 0 & 0 & 2 & 29 & 0 & 0 & 0 & 0 & 0 \\
\hline Projectile Point & 0 & 0 & 0 & 0 & 0 & 16 & 0 & 0 & 0 & 0 & 0 \\
\hline Uniface & 0 & 0 & 0 & 0 & 0 & 10 & 0 & 0 & 0 & 0 & 0 \\
\hline Perforator & 0 & 0 & 0 & 0 & 0 & 10 & 0 & 0 & 0 & 0 & 0 \\
\hline Burin & 0 & 0 & 0 & 0 & 0 & 1 & 0 & 0 & 0 & 0 & 0 \\
\hline Uniface/Notch & 0 & 0 & 0 & 0 & 0 & 1 & 0 & 0 & 0 & 0 & 0 \\
\hline Subtotal & 0 & 0 & 0 & 0 & 2 & 77 & 0 & $\mathbf{0}$ & 0 & $\mathbf{0}$ & 0 \\
\hline
\end{tabular}

\section{Other Artifacts}

$$
\text { Mano }
$$

Hematite nodule

Subtotal

Total

$\begin{array}{cccccccccccc}0 & 0 & 0 & 1 & 0 & 0 & 0 & 0 & 0 & 0 & 0 & 1 \\ 0 & 0 & 0 & 0 & 0 & 0 & 0 & 0 & 0 & 0 & 2 & 2 \\ \mathbf{0} & \mathbf{0} & \mathbf{0} & \mathbf{1} & \mathbf{0} & \mathbf{0} & \mathbf{0} & \mathbf{0} & \mathbf{0} & \mathbf{0} & \mathbf{2} & \mathbf{3} \\ \mathbf{6 7} & \mathbf{3 1 8} & \mathbf{4} & \mathbf{2 0} & \mathbf{5 1 2} & \mathbf{7 8 8 1} & \mathbf{1 3 4} & \mathbf{4} & \mathbf{3 3} & \mathbf{4 9} & \mathbf{2} & \mathbf{9 1 4 7}\end{array}$


Table 9-4. Artifact Type by Chert Subtype

\begin{tabular}{|c|c|c|c|c|c|c|c|c|c|c|}
\hline \multirow{2}{*}{$\begin{array}{c}\text { Debitage } \\
\text { Type }\end{array}$} & \multicolumn{10}{|c|}{ Chert Subtype } \\
\hline & $\begin{array}{l}\text { Tan/ } \\
\text { gray }\end{array}$ & $\begin{array}{c}\text { Tan } \\
\text { reddish } \\
\text { purple }\end{array}$ & Banded & Gray & $\begin{array}{l}\text { Fossil- } \\
\text { iferous }\end{array}$ & White & Brown & Black & Red & $\begin{array}{c}\text { Tan/gray } \\
\text { brown } \\
\text { banding }\end{array}$ \\
\hline angular debris & 335 & 12 & 4 & 469 & 21 & 46 & 27 & 9 & 52 & 2 \\
\hline core flake & 2329 & 78 & 59 & 191 & 197 & 59 & 64 & 15 & 43 & 23 \\
\hline blade & 2 & 0 & 0 & 0 & 0 & 0 & 0 & 0 & 0 & 0 \\
\hline biface flake & 530 & 13 & 1 & 25 & 50 & 11 & 8 & 0 & 8 & 3 \\
\hline uniface flake & 9 & 1 & 0 & 2 & 1 & 1 & 0 & 0 & 0 & 0 \\
\hline notching flake & 2 & 0 & 0 & 0 & 0 & 0 & 0 & 0 & 0 & 0 \\
\hline ct flake & 22 & 0 & 0 & 0 & 0 & 0 & 0 & 1 & 0 & 0 \\
\hline bur in spall & 1 & 0 & 0 & 1 & 0 & 0 & 0 & 0 & 0 & 0 \\
\hline pot lid & 21 & 1 & 0 & 29 & 1 & 2 & 2 & 0 & 4 & 0 \\
\hline hs flake & 0 & 0 & 0 & 0 & 0 & 0 & 0 & 0 & 0 & 0 \\
\hline und. fragment & 2474 & 40 & 16 & 232 & 148 & 81 & 43 & 6 & 70 & 4 \\
\hline over-struck & 0 & 0 & 0 & 0 & 1 & 0 & 0 & 0 & 0 & 0 \\
\hline oc flake & 2 & 0 & 0 & 0 & 1 & 0 & 0 & 0 & 0 & 0 \\
\hline column total & 5727 & 145 & 80 & 949 & 420 & 200 & 144 & 31 & 177 & 32 \\
\hline
\end{tabular}

Table 9-5. Debitage Material Type by Cortex Type

\begin{tabular}{|l|c|c|c|c|}
\hline \multirow{2}{*}{\multicolumn{1}{|c|}{ Material Type }} & \multicolumn{4}{c|}{ Cortex Type } \\
\cline { 2 - 5 } & Absent & Nodular & Tabular & Waterworn \\
\hline rhyolite & 17 & 1 & 0 & 16 \\
\hline salt/pepper rhyolite & 116 & 1 & 0 & 25 \\
\hline limestone & 10 & 0 & 0 & 6 \\
\hline chalcedony & 225 & 2 & 0 & 15 \\
\hline jasper & 37 & 0 & 0 & 9 \\
\hline chert & 3412 & 18 & 1 & 549 \\
\hline silicified wood & 0 & 0 & 1 & 1 \\
\hline quartzite & 12 & 0 & 0 & 12 \\
\hline quartz & 8 & 0 & 0 & 6 \\
\hline column total & $\mathbf{3 8 3 7}$ & $\mathbf{2 2}$ & $\mathbf{2}$ & $\mathbf{6 3 9}$ \\
\hline
\end{tabular}


black chert and silicified wood. This supports the previous comment that some of the artifacts classified as black chert may actually be made of black silicified wood. It is undetermined whether the black silicified wood was obtained from local or nonlocal sources.

The quality of lithic raw material is an important factor affecting possible tool use-life. Higher-quality materials are generally selected for use in the production of curated tools with increased use-lives (e.g., bifaces), and lower-quality materials for use in the production of shortlived unretouched flake tools (Bamforth 1986; Goodyear 1979; Vierra 1993a, 1993b). Grain size was monitored as an indirect measure of material quality. Most of the debitage can be characterized as exhibiting a mediumgrain texture ( $n=3,712 ; 82.5$ percent), with much less fine-grained $(n=529)$ and coarse-grained $(n=258)$ materials. There are, however, important differences in respect to the various material types. Table 9-6 presents the information on debitage material type by grain. All the chalcedony debitage are fine grained, and the jasper a mixture of fine and medium grain. The chert is distributed among fine, medium, and coarse grain. Both the salt/pepper rhyolite and the silicified wood are medium and coarse grained, and the rhyolite, quartzite, and quartz are all coarse grained.

Table 9-6. Debitage Material Type by Grain

\begin{tabular}{|l|c|c|c|}
\hline \multirow{2}{*}{ Material Type } & \multicolumn{3}{c|}{ Material Grain } \\
\cline { 2 - 4 } & Fine & Medium & Coarse \\
\hline rhyolite & 0 & 0 & 34 \\
\hline salt/pepper rhyolite & 1 & 45 & 96 \\
\hline limestone & 0 & 0 & 16 \\
\hline chalcedony & 239 & 3 & 0 \\
\hline jasper & 5 & 35 & 0 \\
\hline chert & 284 & 3619 & 77 \\
\hline silicified wood & 0 & 1 & 1 \\
\hline quartzite & 0 & 0 & 24 \\
\hline quartz & 0 & 4 & 10 \\
\hline column total & $\mathbf{5 2 9}$ & $\mathbf{3 7 0 7}$ & $\mathbf{2 5 8}$ \\
\hline
\end{tabular}

A chi-square test was run on a contingency table of flake type (i.e., core and biface flakes) by material grain to determine if different raw material qualities were being selected for core reduction vs. tool production (Table 9-7). There is a significant difference between flake type and material grain (chi-sq=170.7, df=8, $\mathrm{p}<0.01$ ). Adjusted residuals were therefore calculated to determine which of the cells were contributing to the significant chi-square value. Adjusted residuals greater than 1.96 or -1.96 are significant at the .05 level (Haberman 1973). There is more angular debris made of medium- and coarse-grained materials than expected, more core flakes of medium-grained materials, and more biface flakes and undetermined flake fragments of fine-grained materials. Higher-quality materials appear to have been differentially selected for the production of retouched tools.

\section{Retouched Tools}

The retouched tools are made of higher quality materials like chert $(n=77)$ and chalcedony $(n=2)$. In respect to the chert subtypes, most of the artifacts were manufactured on the light tan/gray (63.7 percent), with fewer on the fossiliferous, light tan/gray with reddish purple, gray banded, gray, clastic, and red varieties. All vari-

\section{Table 9-7. Debitage Type by Grain}

Top value in cell represent artifact count, and bottom value represents adjusted residuals.

Significant $(\mathrm{p}<0.05)$ positive values are shown in bold.

\begin{tabular}{|l|c|c|c|}
\hline \multirow{2}{*}{ Debitage Type } & \multicolumn{3}{|c|}{ Material Grain } \\
\cline { 2 - 4 } & Fine & Medium & Coarse \\
\hline \multirow{2}{*}{ angular debris } & 150 & 409 & 50 \\
& -6.1 & $\mathbf{2 . 3}$ & $\mathbf{4 . 8}$ \\
\hline \multirow{2}{*}{ core flake } & 197 & 1791 & 157 \\
& -5.1 & 1.7 & 4.4 \\
\hline \multirow{2}{*}{ biface flake } & 93 & 281 & 14 \\
& $\mathbf{7 . 8}$ & -5.5 & -1.9 \\
\hline \multirow{2}{*}{ und. fragment } & 216 & 1170 & 36 \\
& 4.9 & -0.3 & -7.6 \\
\hline \multirow{2}{*}{ other } & 8 & 62 & 1 \\
& -0.1 & 1.1 & -1.6 \\
\hline column total & $\mathbf{5 2 9}$ & $\mathbf{3 7 1 3}$ & $\mathbf{2 5 8}$ \\
\hline
\end{tabular}

Chi $-\mathrm{sq}=170.7, \mathrm{df}=8, \mathrm{p}=<0.01$ 
eties of chert are represented among the debitage on the site; however, it appears that gray and white chert were more highly selected for the production of debitage than retouched tools, although samples sizes are small.

Only five (6.3 percent) of the retouched tools exhibit cortex. This consists of a mix of nodule $(n=3)$ and water-worn $(n=2)$ cortex. This contrasts markedly with the distribution of cortex on the debitage where waterworn cortex comprises 96.3 percent of the cortex. The pattern of relatively more nodule cortex on retouched tools could reflect a selective bias for raw materials which were also covered by this cortex. This consists of fossiliferous light tan/gray and gray banded materials which are present in the local Rio Grande gravels, but were not observed in the Uvalde gravels; however, it seems more likely that the high percentage of nodule cortex simply reflects the small size of the sample.

The majority of the retouched tools were manufactured of medium-grained materials ( $\mathrm{n}=74 ; 92.5$ percent), with fewer of fine-grained $(n=6)$. Unlike the debitage, no coarse-grained materials were used in the production of retouched tools. A chi-square test of a contingency table of debitage and retouched tools by material grain indicates a significant difference between the variables (Table 9-8). Relatively more medium-grained materials were used for the retouched tools than expected and more coarse-grained materials for the debitage.

Table 9-8. Debitage and Retouched Tools by Grain

Top value in cell represent artifact count, and bottom value represents adjusted residuals.

Significant $(\mathrm{p}<0.05)$ positive values are shown in bold.

\begin{tabular}{|l|c|c|c|}
\hline \multirow{2}{*}{ Artifact Type } & \multicolumn{3}{|c|}{ Grain } \\
\cline { 2 - 4 } & Fine & Medium & Coarse \\
\hline \multirow{2}{*}{ debitage } & 529 & 3713 & 258 \\
& 1.2 & -2.3 & $\mathbf{2 . 2}$ \\
\hline \multirow{2}{*}{ retouched tools } & 6 & 74 & 0 \\
& -1.2 & $\mathbf{2 . 3}$ & -2.2 \\
\hline
\end{tabular}

Chi-sq $=6.7, \mathrm{df}=2, \mathrm{p}=<0.03$

\section{Other Artifacts}

Only one ground-stone artifact was identified during the analysis. This consists of a one-hand mano fragment made of limestone. Two pieces of hematite were also recovered from the excavations (EU 36, Level 8). These are unmodified nodules, one of which has been gnawed by a rodent. Nonetheless, they are situated on a surface with a relatively intact hearth, and presumably represent manuports brought to the site. Hematite nodules were also recovered from the Mariposa site in nearby Zavala County (Montgomery 1978).

\section{Production/Maintenance}

\section{Cores}

The analysis of the cores indicates that several different reduction techniques were used at the site. Of the 13 cores identified, three are single-directional, six are bi-directional, and four are undetermined fragments. The single-directional cores were reduced from a single face, and two along adjacent faces. Three of the bidirectional cores are bifacial cores, one is an opposeddifferent-face, and the other two are oriented at $90^{\circ}$. Most of the cores were produced on split cobbles (or pebbles) and large flakes; whereas, the bifacial cores were manufactured on large flakes. All the cores have single-faceted platforms, with only one single-directional core exhibiting a prepared (i.e., abraded) platform. Besides the cores, there are two cobble unifaces present in the assemblage. These are cobbles from which flakes were removed from unprepared cortical platforms.

Three basic flake core reduction techniques appear to be represented: 1) the removal of flakes from one or two separate faceted platforms on split cobbles or large flakes, 2) bifacially reduced large flakes, and 3) the simple reduction of unprepared cobbles (Figure 9-1). The bifacial cores could represent rejects of bifaces at a very early stage. The cobble unifaces reflect slightly differing reduction tactics based on raw material shape. One of these is characterized by the reduction of wide spherical-shaped cobbles by removing several flakes across the width of the cobble, and then continuing 

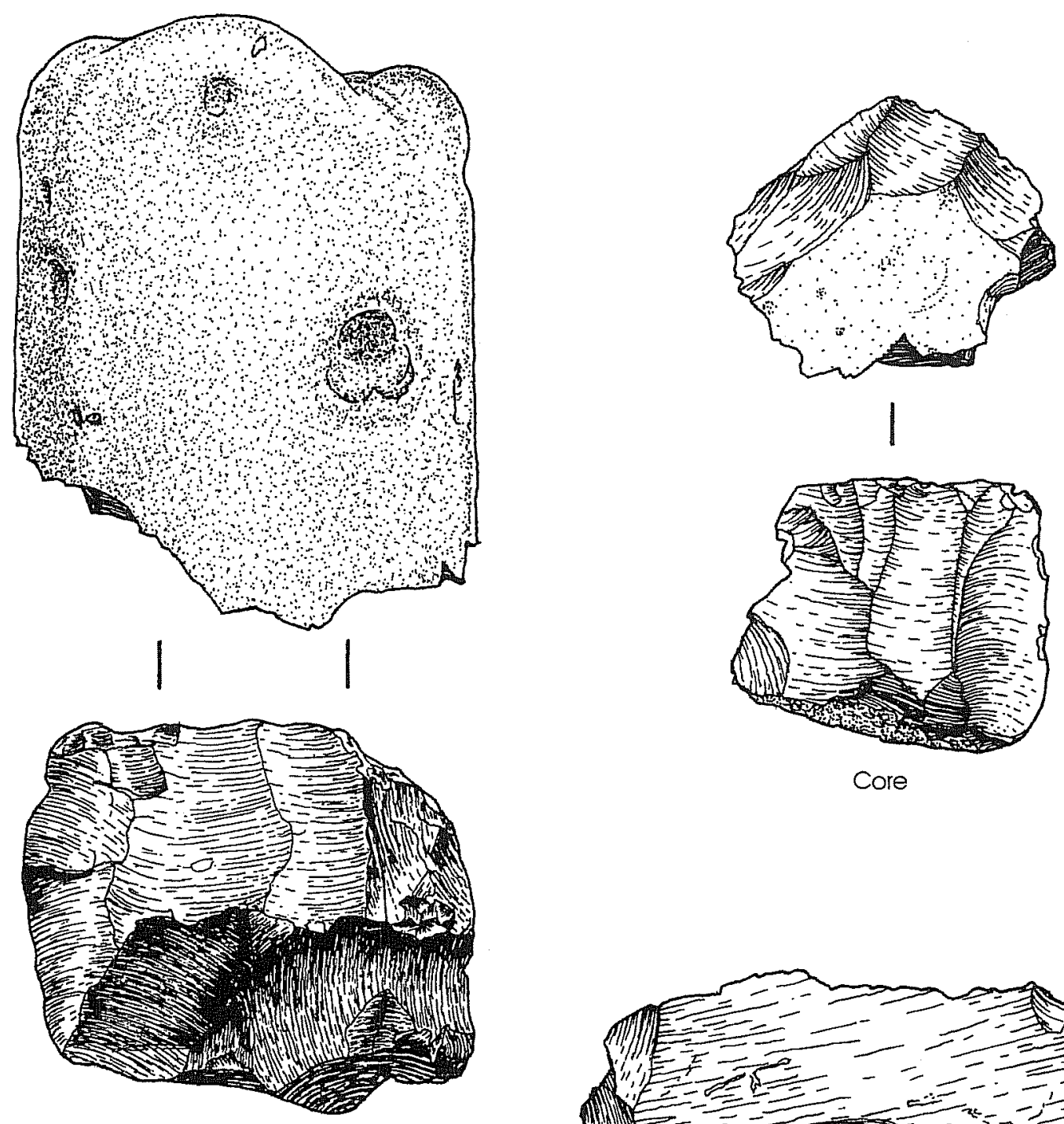

Cobble Uniface
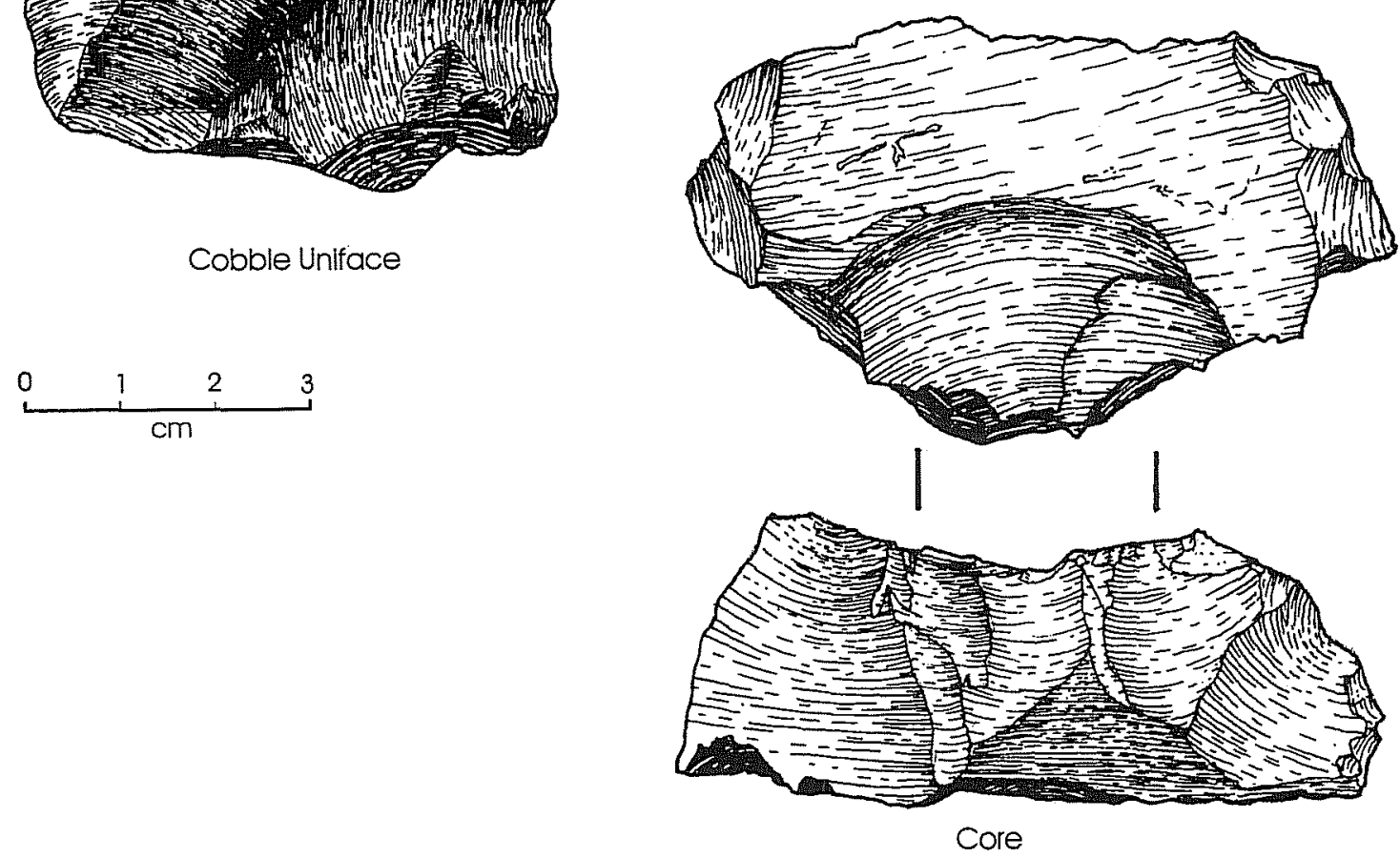

Figure 9-1. Cores. 
these removals in a sequence through to the opposite end of the cobble. In contrast, the narrower lenticular or cigar-shaped cobbles are reduced by the removal of a single flake across the width of the cobble, in sequence from end to end.

Cores appear to have been discarded for two primary reasons: exhaustion $(n=4)$, and breakage $(n=5)$. Most of the core fragments appear to have been broken during reduction, including one which broke along an inherent material flaw. The remaining four cores were classified as still usable. One of the cobble unifaces was still useable, with the other being the exhausted portion of a lenticular-shaped cobble. The whole cores $(\mathrm{n}=8)$ exhibit a mean major flaking surface length of $35.5 \mathrm{~mm}$ ( $\mathrm{sd}=9.9$ ), width of $44.3 \mathrm{~mm}(\mathrm{sd}=12.9)$, core thickness of $28.6 \mathrm{~mm}$ ( $\mathrm{sd}=14.6$ ), and weight of $49.4 \mathrm{~g}$ ( $\mathrm{sd}=26.8$ ). The exhausted cores have a mean weight of $31.2 \mathrm{~g}(\mathrm{sd}=11.5)$, the still useable cores of $67.7 \mathrm{~g}$ $(\mathrm{sd}=25.3)$, and the core fragments of $64.9 \mathrm{~g}(\mathrm{sd}=51.2)$. The core fragments generally reflect split cobbles that broke during the reduction process, and were subsequently discarded. This accounts for the similar size of the core fragments and still useable cores. In contrast, the useable cobble unifaces are larger with a flaked surface length of $45 \mathrm{~mm}$, width of $61 \mathrm{~mm}$ wide, a cobble thickness of $75 \mathrm{~mm}$ and weight of $374.4 \mathrm{~g}$. Not unsurprisingly, exhausted cobble unifaces are smaller with an average flaked surface $21 \mathrm{~mm}$ long, $45 \mathrm{~mm}$ wide, a cobble thickness of $34 \mathrm{~mm}$, and weight of $44.8 \mathrm{~g}$.

The mean flaking surface length of the cores and the cobble uniface is approximately $35-45 \mathrm{~mm}$. This is larger than the mean lengths of core flakes $(19.3 \mathrm{~mm})$, and similar to the mean lengths of utilized flakes, retouched flakes, notches, and unifaces (31.0-45.2 mm); however, it is much smaller than the mean length of the bifaces $(68.0 \mathrm{~mm})$, and especially the early stage bifaces which can be $85 \mathrm{~mm}$ long. It seems likely that platform cores may have been used to produce flakes and tool blanks with maximum lengths of approximately $45 \mathrm{~mm}$. On the other hand, the large flakes used for some of the bifacial cores may have also been used for the production of bifacial tools.

As previously noted, a sample of collected Rio Grande river gravels exhibited a mean maximum length of 91.0 $\mathrm{mm}$, and weight of $490.3 \mathrm{~g}$. The cobble uniface approximates the mean length and weight of the river cobbles, however, the cores from 41MV120 are much smaller than the cobbles. Flakes could have been removed from the larger cobbles for the production of bifaces; whereas, split cobbles could have been used for the smaller platforms cores. The smaller size of some cores may be the result of their being manufactured at some distance from the site, reduced over time, and eventually discarded in this location when new raw materials became available.

At least four different reduction trajectories could be represented at the site: platform core-flake-tool, bifacial core-flake-tool, large flake-tool, and cobble unifaceflake. These possibilities are discussed further in the following debitage and retouched tool sections.

\section{Debitage}

The debitage primarily consist of undetermined flake fragments (38.9 percent) and core flakes (38.5 percent), with fewer pieces of angular debris, biface flakes, pot lids, core trimming flakes, uniface flakes, and other flake types (Table 9-3). They indicate that a range of core reduction and tool production/maintenance activities occurred at the site. Core maintenance is particularly represented by core flakes, angular debris, core trimming flakes and opposing core flakes; whereas, tool production/maintenance is evidenced by the biface, uniface, notching, and overstruck flakes. The uniface flakes were removed from both the end and lateral sides of the tool during the manufacturing process (e.g., see Shafer 1970). Although no hammerstones were recovered from the site, a single hammerstone flake does provide some direct evidence of their presence.

Almost 15 percent (14.7 percent) of the debitage exhibit some cortex. Table 9-9 summarizes the presence of cortex by material type for whole flakes only, by primary (100 percent cortex), secondary (1-99 percent cortex) and tertiary flakes ( 0 percent cortex). The majority of the whole flakes lack cortex (77.2 percent) with fewer secondary and primary flakes. The overall cortical:noncortical ratio is 0.27 , but it differs in respect to specific material types (although some types exhibit small samples sizes). Higher ratios reflect an 
Table 9-9. Material Type by Cortex on Whole Flakes

\begin{tabular}{|l|c|c|c|}
\hline \multirow{2}{*}{ Material type } & \multicolumn{3}{c|}{ Cortex } \\
\cline { 2 - 4 } & Primary & Secondary & Tertiary \\
\hline rhyolite & 0 & 2 & 0 \\
\hline salt/pepper rhyolite & 0 & 14 & 27 \\
\hline limestone & 0 & 3 & 1 \\
\hline chalcedony & 0 & 7 & 64 \\
\hline jasper & 0 & 2 & 12 \\
\hline chert & 4 & 162 & 622 \\
\hline quartzite & 0 & 0 & 1 \\
\hline quartz & 0 & 2 & 2 \\
\hline column total & 4 & 190 & 729 \\
\hline
\end{tabular}

emphasis on the earlier segment of the core reduction process, and lower ratios on the later portion of the core reduction and/or tool production/maintenance sequence. Coarse-grained materials such as limestone (3.0) and quartz (1.0) exhibit higher ratios reflecting the production of flakes during early core reduction. Fine-grained materials like chalcedony $(0.10)$ and jasper (0.16) exhibit lower ratios which indicate a greater emphasis on tool production/maintenance. The medium-grained materials, such as chert $(0.27)$, reflect both core reduction and tool production; whereas, the medium/coarse-grained salt/pepper rhyolite (0.51) exhibits a somewhat higher ratio and an emphasis on core reduction.

This pattern is further corroborated in respect to the relationship between flakes and angular debris. Angular debris is generally a by-product of core reduction, and flakes by both core reduction and tool production/ maintenance (Prentiss and Romansky 1989; Tomka 1989:139). The flake:angular debris ratio for the assemblage is 8.4. A review of Table 9-3 indicates the presence of relatively more angular debris for coarsegrained materials, including rhyolite (1.0), quartzite (0.9), limestone (2.2), and quartz (3.6). In contrast, the least amount of angular debris is present for chalcedony (18.7) and jasper (i.e., no angular debris), with cherts (8.31) and salt/pepper rhyolite (5.0) situated in between. This negative correspondence between flakes and angular debris is also pronounced when simply looking at the presence of biface flakes vs. angular debris. Biface flake:angular debris ratios are lower for salt/pepper rhyolite $(0.1)$ and rhyolite $(0.3)$, with no biface flakes being present on limestone, silicified wood, quartzite, and quartz materials. Chalcedony (3.2) and jasper (8.0) have higher ratios, and chert (0.6) an intermediate ratio. More angular debris was presumably being produced during the process of hard hammer core reduction which also created flakes with marked bulbs of percussion; whereas, the majority of the biface flakes exhibit lipped platforms characteristic of the soft hammer (i.e., billet) reduction of bifacial cores and bifaces (e.g., see Hayden and Hutchings 1989).

The information on flake type by platform type is presented in Table 9-10. The majority of the core flakes, blades, and uniface flakes exhibit single-faceted platforms, and the biface flakes multi-faceted platforms. These multi-faceted platforms were presumably removed from later-stage bifaces, in contrast to the singleplatform biface flakes which can have been detached from bifacial cores or early-stage bifaces. The singleplatform biface flakes tend to exhibit platforms with angles of about $60-75^{\circ}$ and marked lipping; whereas, the core flakes exhibit platforms of about $75-90^{\circ}$ and a marked bulb of percussion. Cortical platforms were only present on core flakes; however, core flakes made of chert (1.1 percent) and chalcedony/jasper (5.7 percent) exhibit far fewer cortical platforms than the other materials (19.2 percent). It would appear that the fine/ medium-grained materials were being brought to the site as prepared cores, and medium/coarse-grained materials as cobbles. All the prepared cores identified at the site are made of chert, and the cobble unifaces of rhyolite.

Cortex placement was recorded on whole flakes. Most of the cortex is situated on the platform $(n=117)$ and dorsal surface $(n=67)$, with fewer orange rind flakes $(n=19)$ and cortex on both the platform and dorsal surface $(n=4)$. Orange-rind flakes are flakes with cortex solely along their edges. The presence of cortex on the platform and/or dorsal surface of flakes reflects early stage core reduction. When the cortex is present only on the platform or as an orange rind, this reflects a cobble uniface reduction technique. Those orange rinds with cortex partially extending along the flake perimeter were probably produced as a result of reducing cobble unifaces, and orange rinds around the total perimeter of the flake appear to be a by-product of reducing lenticular- 
Table 9-10. Debitage Type by Platform Type

\begin{tabular}{|l|c|c|c|c|c|}
\hline \multirow{2}{*}{ Debitage Type Platform Type } \\
\cline { 2 - 6 } & Absent & Cortical & Single-faceted & Dihedral & Multi-faceted \\
\hline angular debris & 0 & 0 & 0 & 0 & 0 \\
\hline core flake & 710 & 219 & 1004 & 88 & 79 \\
\hline blade & 0 & 0 & 4 & 0 & 0 \\
\hline biface flake & 27 & 0 & 107 & 15 & 227 \\
\hline uniface flake & 2 & 0 & 6 & 0 & 0 \\
\hline ct flake & 0 & 0 & 9 & 0 & 0 \\
\hline burin spall & 0 & 0 & 2 & 0 & 0 \\
\hline pot lid & 4 & 0 & 0 & 0 & 2 \\
\hline hs flake & 0 & 1 & 0 & 0 & 0 \\
\hline und. fragment & 1381 & 1 & 5 & 0 & 1 \\
\hline overstruck & 1 & 0 & 1 & 0 & 0 \\
\hline oc flake & 1 & 0 & 0 & 0 & 0 \\
\hline column total & $\mathbf{2 1 2 6}$ & $\mathbf{2 2 1}$ & $\mathbf{1 1 3 8}$ & $\mathbf{1 0 3}$ & $\mathbf{3 0 9}$ \\
\hline
\end{tabular}

shaped cobbles. Both of these cobble uniface forms are present in the site assemblage.

Table 9-11 presents information on flake type by platform preparation. Most of the core flakes (73.2 percent) do not exhibit any form of platform preparation. The biface flakes, on the other hand, exhibit numerous abraded and/or retouched platforms ( 94.6 percent). The difference between abraded vs. retouched/abraded platforms on biface flakes, is that the former were presumably removed from bifacial cores or early-stage bifaces with single-faceted platforms, and the latter from later stage bifaces with multi-faceted platforms. Abrasion on the core flakes typically originates along the intersection of the platform and dorsal surface, continuing onto the platform. Abrasion on the biface flakes was more commonly situated along the remnant edge of the biface (e.g., see Sheets 1973).

Information on flake condition is provided in Table 9-12. Most of the flakes (75.6 percent) are broken, although the breakage patterns do differ by debitage type. For example, core flakes are often broken in half, with mostly proximal and distal segments. The biface flakes are primarily represented by the proximal section of the flake, in contrast to the undetermined flake fragments which are dominated by midsections and distal fragments. Undetermined flake fragments were often small flake fragments which were difficult to assign to a specific debitage category. The fact that most of the biface flakes are proximal sections, and that the undetermined flake fragments are midsections and distal segments, indicates that many of the latter fragments may represent portions of small biface retouch flakes (e.g., see Sullivan and Rosen 1985). Some of the proximal biface flake fragments exhibit a snap break and overhang which could be the result of flaking with a billet.

Table 9-13 presents the information on debitage length dimensions by debitage type. Core and biface flakes exhibit similar mean lengths of $19.3 \mathrm{~mm}$ and $19.8 \mathrm{~mm}$, respectively. Figure 9-2 illustrates the distribution of core and biface flake lengths. As can be seen, there are relatively more biface flakes in the $21-31 \mathrm{~mm}$ range, and an absence of biface flakes in the larger 61-70 $\mathrm{mm}$ range. As previously discussed in respect to the cores, even the core flakes lack the larger sizes sufficient for producing bifaces; however, they do exhibit a size range appropriate for unretouched flake use, and some retouched tools. These data support the interpretation that larger flakes were being brought onto the 
Table 9-11. Debitage Type by Platform Preparation

\begin{tabular}{|l|c|c|c|c|c|}
\hline \multirow{2}{*}{ Debitage Type } & \multicolumn{5}{|c|}{ Platform Preparation } \\
\cline { 2 - 6 } & None & Abraded & Retouched & $\begin{array}{c}\text { Retouched/ } \\
\text { abraded }\end{array}$ & n/a \\
\hline angular debris & 0 & 0 & 0 & 0 & 474 \\
\hline core flake & 1018 & 363 & 3 & 6 & 755 \\
\hline blade & 2 & 2 & 0 & 0 & 0 \\
\hline biface flake & 19 & 110 & 9 & 211 & 39 \\
\hline uniface flake & 4 & 2 & 0 & 0 & 3 \\
\hline ct flake & 9 & 0 & 0 & 0 & 1 \\
\hline burin spall & 2 & 0 & 0 & 0 & 0 \\
\hline pot lid & 0 & 0 & 0 & 2 & 40 \\
\hline hs flake & 1 & 0 & 0 & 0 & 0 \\
\hline und. fragment & 5 & 1 & 0 & 1 & 1415 \\
\hline overstruck & 1 & 0 & 0 & 0 & 1 \\
\hline oc flake & 0 & 0 & 0 & 0 & 1 \\
\hline column total & $\mathbf{1 0 6 1}$ & $\mathbf{4 7 8}$ & $\mathbf{1 2}$ & $\mathbf{2 2 0}$ & $\mathbf{2 7 2 9}$ \\
\hline
\end{tabular}

Table 9-12. Debitage Type by Condition

\begin{tabular}{|l|c|c|c|c|c|}
\hline \multirow{2}{*}{ Debitage Type } & \multicolumn{5}{|c|}{ Condition } \\
\cline { 2 - 6 } & Whole & Proximal & Midsection & Distal & Latera I \\
\hline angular debris & 474 & 0 & 0 & 0 & 0 \\
\hline core flake & 775 & 593 & 256 & 465 & 55 \\
\hline blade & 2 & 2 & 0 & 0 & 0 \\
\hline biface flake & 160 & 194 & 7 & 24 & 3 \\
\hline uniface flake & 5 & 2 & 0 & 2 & 0 \\
\hline ct flake & 9 & 1 & 0 & 0 & 0 \\
\hline burin spall & 2 & 0 & 0 & 0 & 0 \\
\hline pot lid & 38 & 2 & 0 & 1 & 0 \\
\hline hs flake & 1 & 0 & 0 & 0 & 0 \\
\hline und. fragment & 18 & 22 & 460 & 917 & 4 \\
\hline overstruck & 1 & 0 & 0 & 1 & 0 \\
\hline oc flake & 0 & 0 & 0 & 1 & 0 \\
\hline column total & $\mathbf{1 4 8 5}$ & $\mathbf{8 1 6}$ & $\mathbf{7 2 3}$ & $\mathbf{1 4 1 1}$ & $\mathbf{6 2}$ \\
\hline
\end{tabular}


Table 9-13. Debitage Type Measurements

\begin{tabular}{|l|c|c|c|}
\hline \multirow{2}{*}{ Debitage Type } & \multicolumn{3}{|c|}{ Measurement } \\
\cline { 2 - 4 } & $\begin{array}{c}\text { mean length } \\
\text { (mm) }\end{array}$ & sd & $\mathbf{n}=$ \\
\hline core flake & 19.2 & 10.0 & 767 \\
\hline blade & 45.0 & 31.1 & 2 \\
\hline biface flake & 19.8 & 9.6 & 158 \\
\hline uniface flake & 13.7 & 6.0 & 6 \\
\hline ct flake & 29.1 & 7.8 & 9 \\
\hline burin spall & 25.5 & 3.5 & 2 \\
\hline hs flake & 36.0 & 0.0 & 1 \\
\hline overstruck & 15.0 & 0.0 & 1 \\
\hline
\end{tabular}

site for the production of bifaces. A few core flakes are represented in this larger size range. If nodules had been used for the production of bifaces (i.e., bifacial core-tool trajectory), then single-faceted biface flakes produced earlier during the reduction process should be larger than multi-faceted biface flakes produced later. This does not seem to be the case, with both single and multi-faceted biface flakes exhibiting similar mean lengths of $19.4 \mathrm{~mm}(\mathrm{sd}=8.6)$ and $20.6 \mathrm{~mm}(\mathrm{sd}=10.4)$, respectively.

\section{Retouched Tools}

Seventy-nine retouched tools were recovered and analyzed from the excavations. These consist of a range of formal and informal tools consisting of marginally retouched flakes, notches, a perforator, a burin, unifaces, bifaces, and projectile points.

\section{Marginally Retouched Flakes}

The marginally retouched flakes were primarily produced on core flake blanks, although two are on biface thinning flakes (Figure 9-3; 41/1332, 16/636). All the flakes exhibit a single lateral retouched edge which is most often straight in outline (Table 9-14). Eight of these edges are unidirectionally retouched and one is bidirectionally retouched. Five of the unidirectionally retouched edges were worked on the ventral surface, and three on the dorsal surface. The mean edge angle for the unidirectionally retouched edges is $64.3^{\circ}$ ( $\mathrm{sd}=7.6$ ), and the single bidirectional edge exhibits an angle of $70^{\circ}$. Most of the retouched flakes are broken, with only two whole artifacts (Table 9-15). Broken pieces primarily exhibit transverse snaps $(n=4)$ which could reflect manufacturing, use, or post-depositional breakage. The other two fragments exhibit twisting (perverse) transverse breaks which are the result of manufacturing error (e.g., see Crabtree 1972; Johnson 1979). Table 9-16 presents metrical data for the whole retouched tools (excluding projectile points).

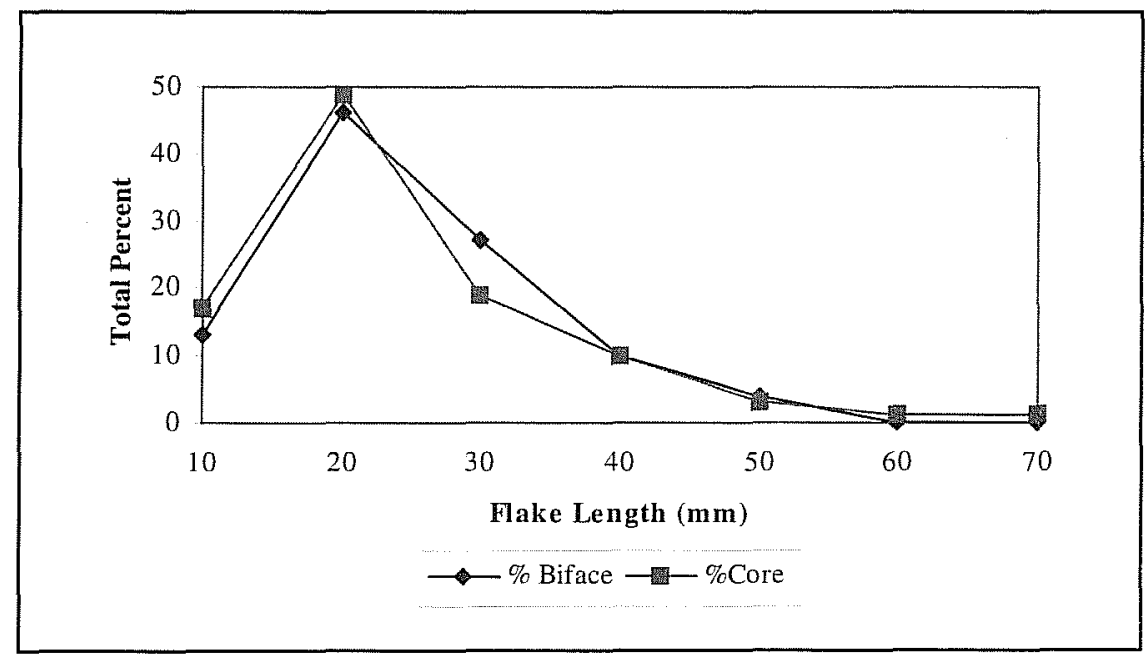

Figure 9-2. Core flake and biface flake lengths. 


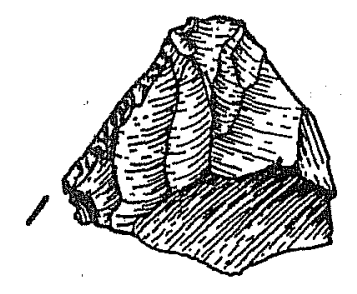

Retouched flake 16/636

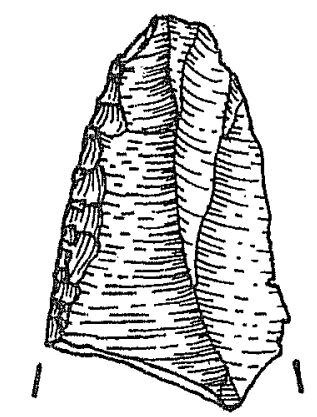

Retouched flake $41 / 1332$
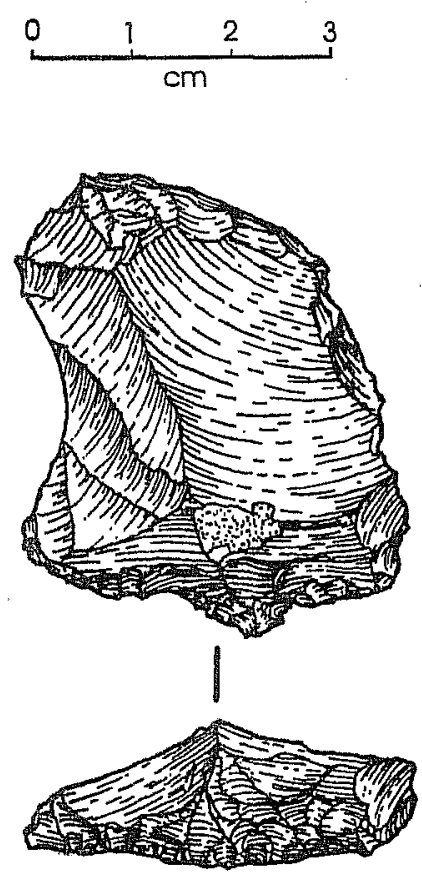

Uniface 26/609

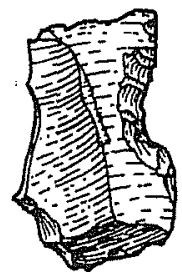

Notch 8/104

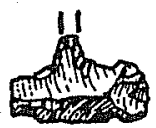

Perforator $26 / 613$

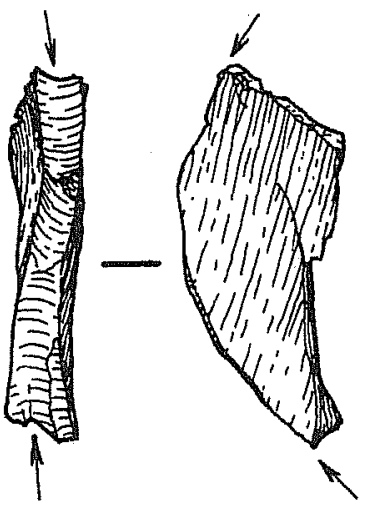

Burln $37 / 963$

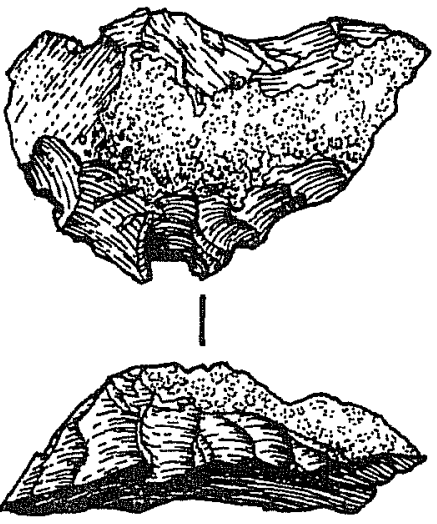

Uniface 10/456

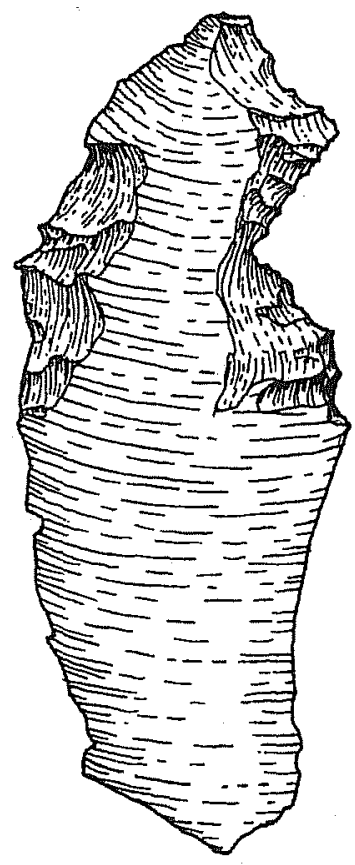

Notch $37 / 962$

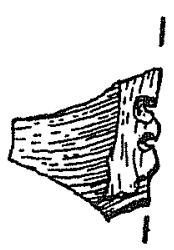

Denticulate 32/1080

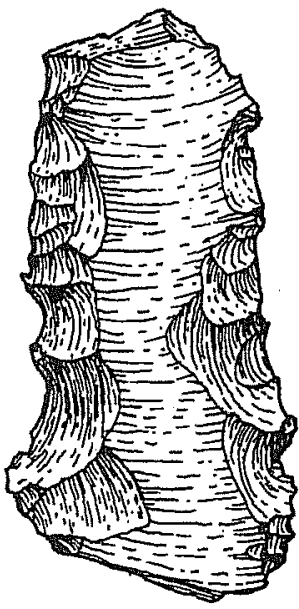

Uniface $10 / 3390$

Figure 9-3. Retonched tools. 
Table 9-14. Retouched Tool Type by Edge Outline

\begin{tabular}{|l|c|c|c|c|c|}
\hline \multirow{2}{*}{ Retouched Tool } & \multicolumn{5}{|c|}{ Edge Outline } \\
\cline { 2 - 6 } & Straight & Concave & Convex & $\begin{array}{c}\text { Concave/ } \\
\text { convex }\end{array}$ & Projection \\
\hline retouched flake & 6 & 0 & 1 & 2 & 0 \\
\hline notch & 0 & 7 & 0 & 3 & 0 \\
\hline burin & 1 & 0 & 0 & 0 & 0 \\
\hline uniface & 5 & 0 & 3 & 2 & 0 \\
\hline notch/uniface & 0 & 2 & 1 & 0 & 0 \\
\hline column total & $\mathbf{1 2}$ & $\mathbf{9}$ & $\mathbf{5}$ & $\mathbf{7}$ & $\mathbf{0}$ \\
\hline
\end{tabular}

Table 9-15. Retouched Tool Type by Condition

\begin{tabular}{|l|c|c|c|c|c|}
\hline \multirow{2}{*}{ Retouched Tool } & \multicolumn{5}{|c|}{ Condition } \\
\cline { 2 - 6 } & Whole & Proximal & Midsection & Distal & Lateral \\
\hline retouched flake & 2 & 4 & 1 & 1 & 0 \\
\hline notch & 7 & 1 & 2 & 0 & 0 \\
\hline perforator & 0 & 0 & 0 & 1 & 0 \\
\hline burin & 0 & 0 & 1 & 0 & 0 \\
\hline uniface & 5 & 3 & 0 & 2 & 0 \\
\hline notch/uniface & 1 & 0 & 0 & 0 & 0 \\
\hline biface & 3 & 8 & 10 & 6 & 3 \\
\hline projectile point & 4 & 6 & 6 & 0 & 1 \\
\hline column total & $\mathbf{2 2}$ & $\mathbf{2 2}$ & $\mathbf{2 0}$ & $\mathbf{1 0}$ & 4 \\
\hline
\end{tabular}

Table 9-16. Retouched Tool Measurements

\begin{tabular}{|l|c|c|c|c|}
\hline \multirow{2}{*}{ Retouched Tool } & \multicolumn{4}{|c|}{ Measurements } \\
\cline { 2 - 5 } & $\begin{array}{c}\text { Mean } \\
\text { Thickness }\end{array}$ & $\begin{array}{c}\text { Mean } \\
\text { Width }\end{array}$ & $\begin{array}{c}\text { Mean } \\
\text { Length }\end{array}$ & $\mathbf{n}=$ \\
\hline retouched flake & $5.0(1.4)$ & $19-5(0.7)$ & $31.0(1.4)$ & 2 \\
\hline notch & $4.7(1.8)$ & $21.7(7.7)$ & $40.4(21.9)$ & 7 \\
\hline burin & $4.0(0.0)$ & $29.0(0.0)$ & $55.0(0.0)$ & 1 \\
\hline uniface & $12.0(5.0)$ & $33.2(9-0)$ & $45.2(3.3)$ & 4 \\
\hline notch/uniface & $15.0(0.0)$ & $18.0(0.0)$ & $31.0(0.0)$ & 1 \\
\hline biface & $10.1(5.3)$ & $42.0(13.3)$ & $68.0(13.6)$ & 6 \\
\hline
\end{tabular}




\section{Notches}

Notches (or spokeshaves) were usually manufactured on core flake blanks (Figure 9-3; 8/104, 37/962), with one being made on a biface thinning flake. All notches exhibit a single retouched edge which is concave in outline and is generally located along the lateral side of the flake. Most of these edges are retouched on the dorsal surface $(n=7)$ with fewer on the ventral $(n=3)$. They exhibit a mean angle of $61.5^{\circ}(\mathrm{sd}=17.9)$. The majority of the notches are whole, with three fragments exhibiting transverse snaps (Table 9-15). Two of the flake fragments have contiguous notches which may reflect that they were part of a denticulate. These are shallow notches $(1-2 \mathrm{~mm})$ which probably represent part of a serrated edge (Figure 9-3; 32/1080).

Notches and marginally retouched flakes are similar in respect to flake blank type, the use of unidirectional retouch, and the presence of steeper edge angles; however, they do differ in the placement of the retouch and condition. That is, notches are primarily retouched on the dorsal surface of the flake, and the flakes are mostly unbroken. Unlike the retouched flakes, however, some of the notched flakes do have dorsal surface cortex.

\section{Perforators and Burins}

A single perforator was identified during the analysis. It consists of a core flake midsection with a lateral projection created by two adjacent alternating blows (Figure 9-3; 26/613). The tip of the projection is broken. The burin was manufactured on the broken midsection of a core flake. It was burinated from opposite directions along the same edge of the flake, and can therefore classified as a multiple burin on a break (Figure 9-3; 37/963).

\section{Unifaces}

The unifaces were manufactured on core flake blanks. This was most often accomplished by retouching the lateral edge of the flake $(n=7)$, with only two being retouched on flake ends All but one of the laterally retouched pieces have a single worked edge, with the other having two opposite retouched edges (Figure 9-3; 10/ $3390)$. Flakes with more acute edge angles $\left(45-65^{\circ}\right)$ tend to be on thinner flakes $(4-15 \mathrm{~mm})$ and more obtuse edge angles $\left(60-75^{\circ}\right)$ on thicker flakes (13-17 $\mathrm{mm}$ ). Both of the retouched ends are on thicker flakes with edge angles of 60 and $75^{\circ}$ (Figure 9-3; 10/456, 26/ 609). A composite notch/uniface tool was also identified during the analysis. The notch is situated along the lateral edge of the flake, and the uniface at the distal end. The unifaces are equally distributed between whole and broken artifacts (Table 9-15). The three proximal fragments are laterally retouched flakes, and the distal fragments are retouched ends. All of these fragments exhibit transverse snaps. No formal scrapers were identified during the analysis.

\section{Bifaces}

Three stages of biface production were identified during the analysis. Early stage bifaces $(n=3)$ are $21-23$ $\mathrm{mm}$ thick and exhibit edge angles from $65-75^{\circ}$. One of these is a whole ovate biface which was produced on a large core flake (Figure 9-4; 36/1309). The blank is oriented so that a single-faceted platform is situated at the base of the biface. A width:thickness ratio of 2.47 is consistent with an early-stage biface (Callahan 1979:10,18). In addition to this biface, two other fragments are also represented. One of these is a very large overstruck flake which removed a sizeable portion of the opposite edge of the biface. The other is a distal fragment with a transverse snap that appears to be a manufacturing break. There is no clear evidence that bifaces were directly produced from nodules. Rather the core, debitage and early stage bifaces indicate that large flakes were used as blanks. As previously noted, however, some flakes removed from bifacial cores were used to produce expedient retouched tools (i.e., marginally retouched flakes and notches).

Middle stage bifaces $(n=13)$ are $8-17 \mathrm{~mm}$ thick and exhibit edge angles from $50-60^{\circ}$. One of these is a whole ovate biface which is burned (Figure 9-4; 12/ 574). A width:thickness ratio of 2.25 is, however, consistent with an early-stage biface. Several biface fragments exhibit transverse twisted breaks which indicate that they were broken during manufacturing. One large ovate biface was broken in half with both pieces being 


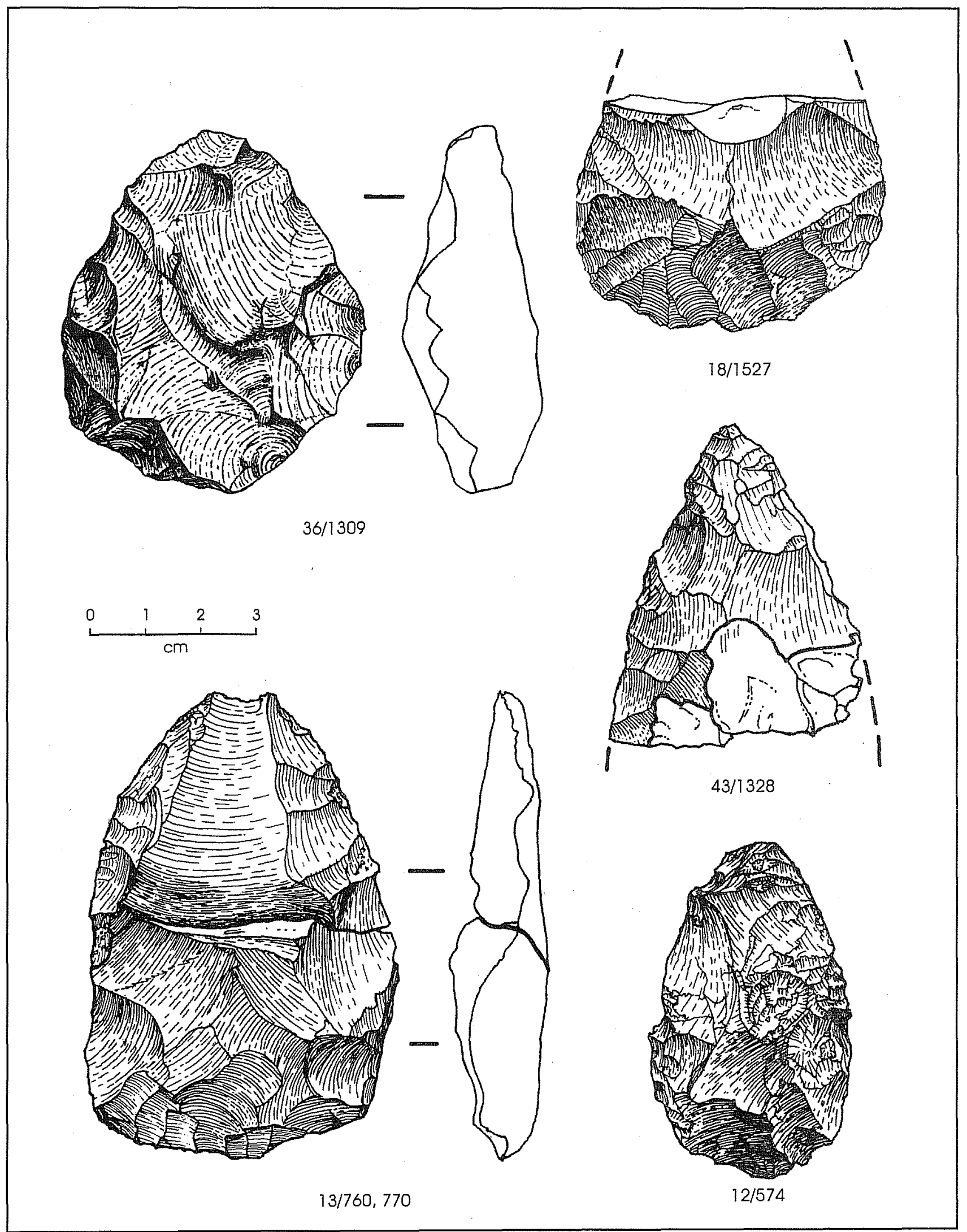

Figure 9-4. Bifaces. 
recovered (Figure 9-4; 13/760, 13/770). This biface has a width:thickness ratio of 3.66 which is indicative of middle stage reduction. Two broken ovate-shaped biface bases also exhibit twisted breaks (Figure 9-4; 18/1527). In contrast, several biface tips and bases have transverse snaps (Figure 9-4; 43/1328, Figure 9-5; 11/ 354). A biface midsection also exhibits transverse snaps on both of ends. It has a width:thickness ratio of 2.75 which is within the range of early-stage bifaces; however, the lateral edges of this biface appear exhibit some rounding, indicating that it was possibly hafted when broken. Five wedge-shaped midsections (Figure 9-5; $10 / 339$ ) presumably represent manufacturing or possibly post-depositional breaks.

Late-stage bifaces $(n=8)$ are 4-7 mm thick and exhibit edge angles from $30-45^{\circ}$. Whole ovate and triangularshaped bifaces (Figure 9-5; 9/136, 24/1151) may represent unfinished preforms The ovate biface is smaller than the middle-stage bifaces, and has a width:thickness ratio of 5.00 reflecting a late stage of production. The triangular biface has a broken tip and corner which appear to be post-depositional breaks. It may been discarded because of failed attempts at thinning the central portion of the artifact. Several base fragments from lanceolate-shaped bifaces are also represented. One of these is a laterally snapped square-shaped base (Figure $9-5 ; 41 / 1204)$. It has a width:thickness ratio of 5.22 which indicates a late stage of manufacture. In addition, there are two small corner fragments of squarebased bifaces. These artifacts exhibit evidence of polish and micro-scarring reflecting that they were probably broken within the haft. One biface tip (Figure 9-5; 38/ 1130) exhibits a snap break which could due to use or post-depositional processes. A second fragment is the reworked tip of a biface or projectile point with an oblique twisted break (Figure 9-5; 8/123) This artifact presumably broke while the artifact was being reworked. Lastly, there are two small wedge-shaped midsections that may represent late stage manufacturing products.

Seven small biface fragments could not be assigned to any production stage. These include four wedge-shaped midsections, two distal, and a proximal fragment.

\section{Projectile Points}

A variety of projectile points is represented in the assemblage: Shumla, Ensor, Desmuke, Langtry, Montell, Marcos, and Marshall, as well as an untyped stemmed point and triangular point (Figures 9-6 and 9-7). The points were identified by several researchers including Thomas Hester, Michael Collins, Glenn Goode, and Stephen Black. Type descriptions follow those given by Turner and Hester (1993). Metrical and descriptive data for the projectile points are provided in Table 9-17.

The Shumla points (Figure 9-6) are triangular in shape with straight to convex edge outlines. Basal notches form a rectangular stem, with short and long barbs. The base is slightly convex in outline. Two of the points have impact fractures and broken barbs (33/1259 and 23/876). The third point has a reworked blade, impact fracture, and broken barbs (16/633). One point fragment may represent a heavily reworked Shumla point (29/505). The remaining portion exhibits resharpening which has removed most of the blade, leaving what appears to be two broken barbs and a stem. A large notching flake may represent a barb removed from a Shumla point (20/688).

The Ensor points (Figure 9-6) have short bases, long blades with straight/convex outlines, shallow side notches, and straight to slightly concave bases. Two of the points are broken. One is a base fragment with a transverse snap that appears to be use-breakage (91/ 129). The other is broken mid-blade exhibiting an oblique snap which may be due to resharpening, since the point is beveled along the edge (40/1036). The remaining point is whole, except for a slightly reworked corner of the base (25/1279). The tip exhibits burination scars on both sides of the face which reflect limited impact scarring.

The Desmuke point (Figure 9-7; 12/567) is a small leaf-shaped point with a contracting stem. It has a broken tip and is beveled along one edge. The Langtry point (Figure $9-7 ; 31 / 1060$ ) has a slightly concave blade outline, and a distinctive barb. The blade is alternately beveled, and the tip is broken. The stem contracts and has a concave base which is thinned. The Montell point (Figure 9-7; 38/1127) was extensively reworked, and 


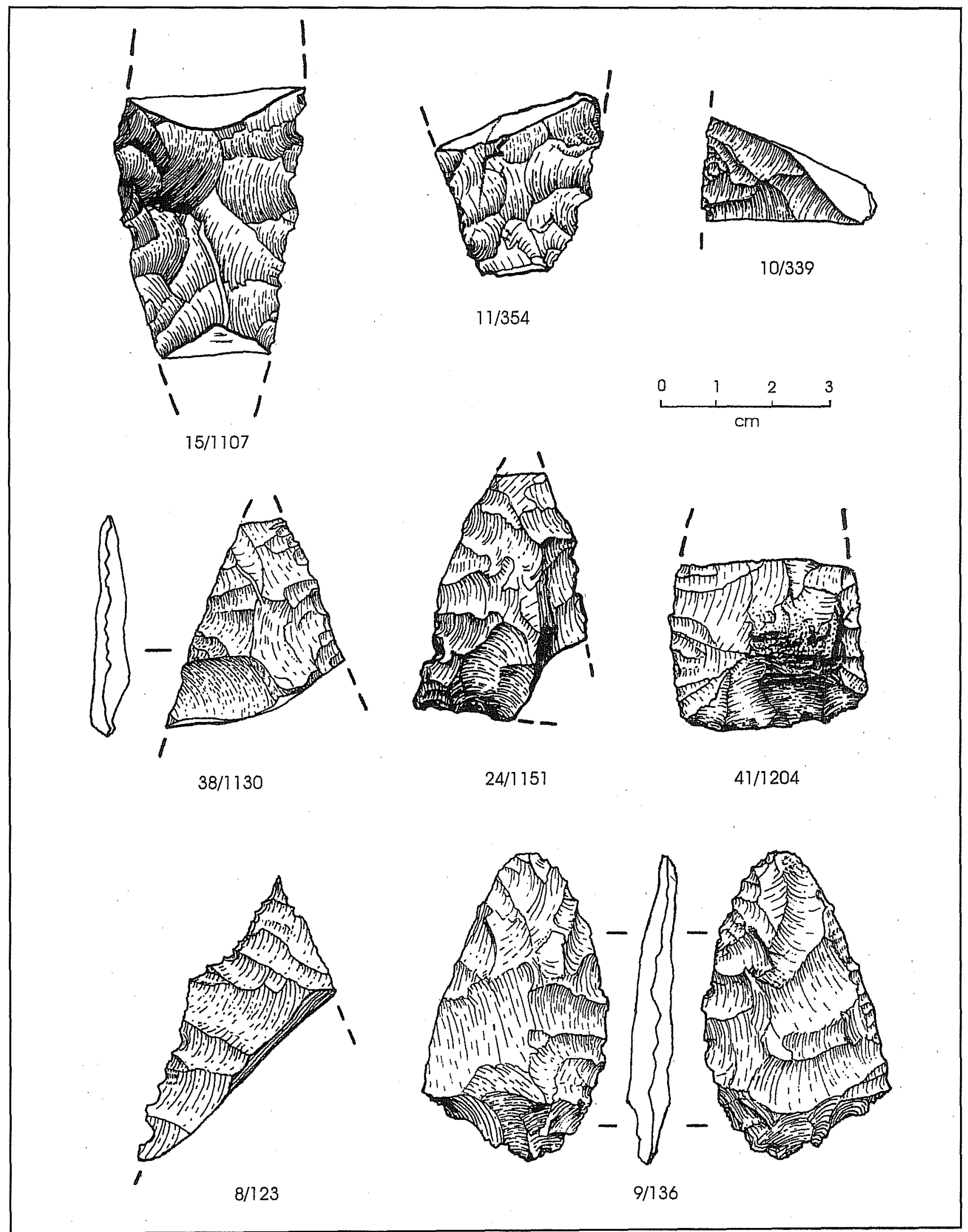

Figure 9-5. Bifaces. 


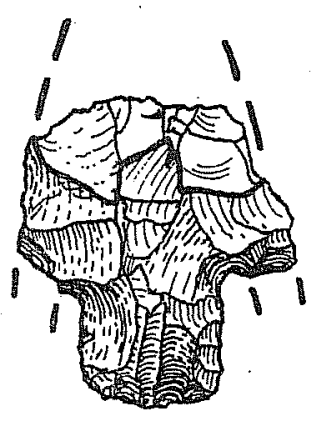

Shumla 33/1259

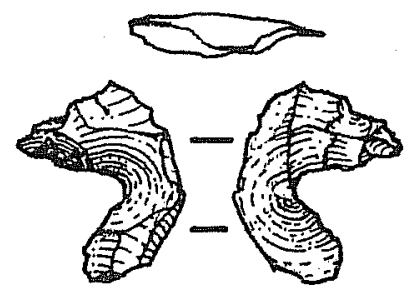

Shumla notch flake $20 / 688$

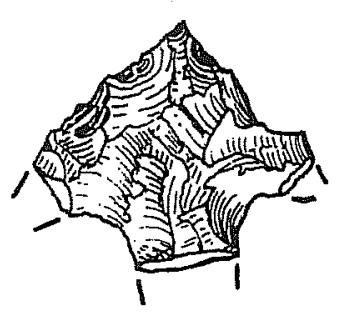

Reworked shumla 29/505

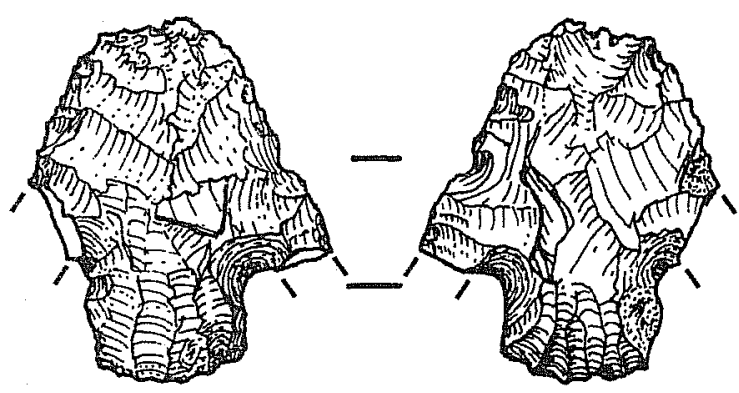

Shumla 16/633
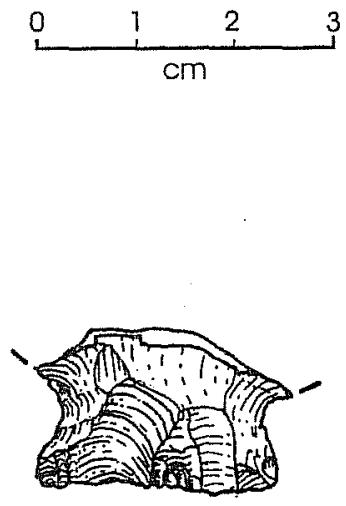

Ensor $9 / 129$

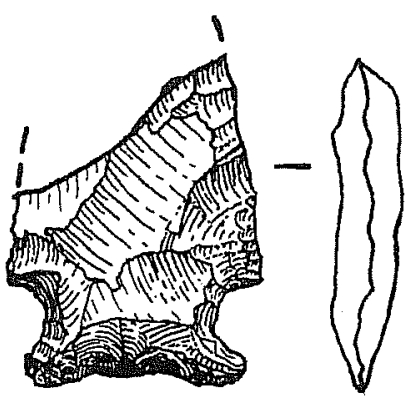

Ensor $40 / 1036$

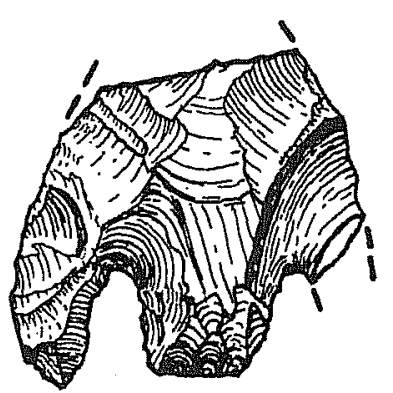

Shumla 23/876

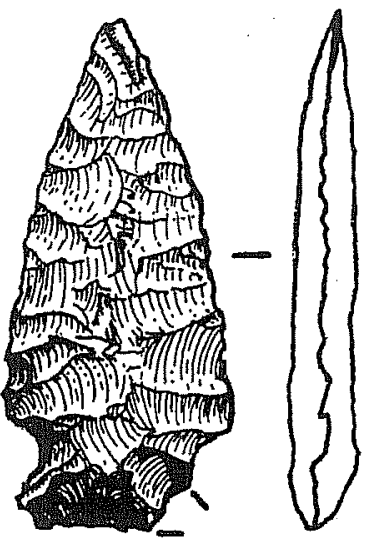

Ensor 25/1279

Figure 9-6. Projectile points. 


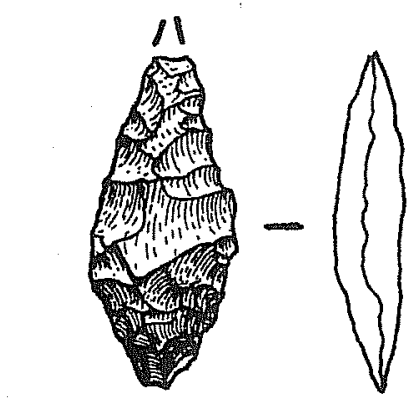

Desmuke 12/567

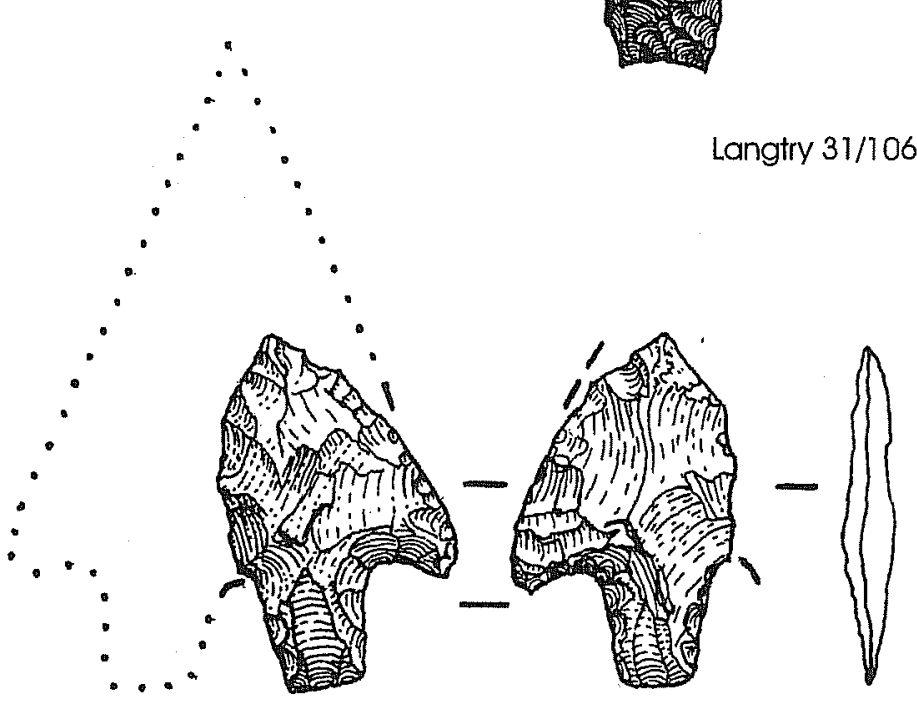

Reworked Montell 38/1127
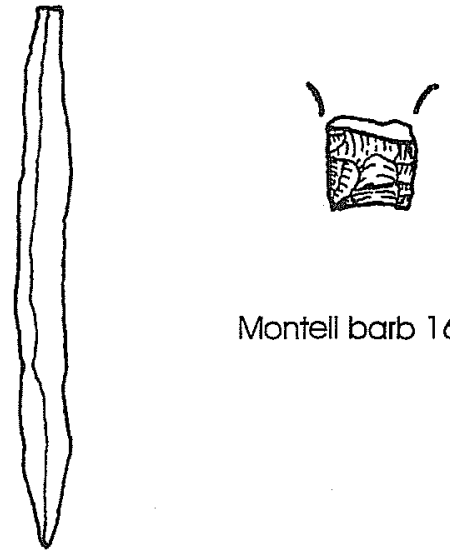

Montell barb 16/638

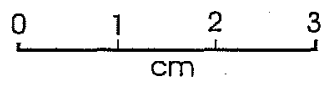

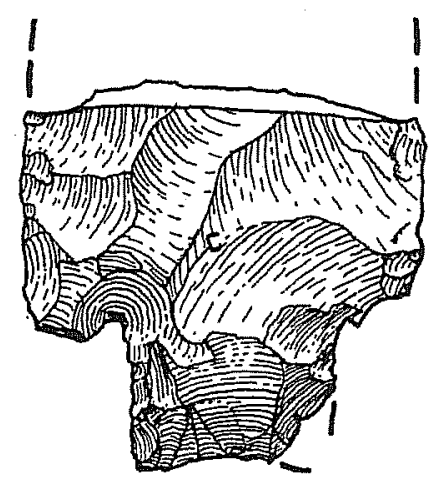

Marshall $37 / 957$

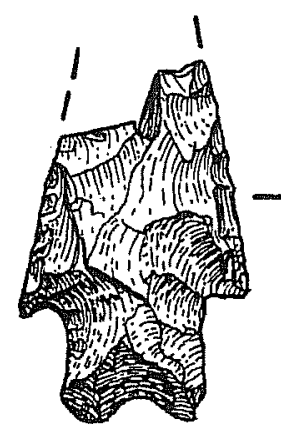

Stemmed $37 / 953$

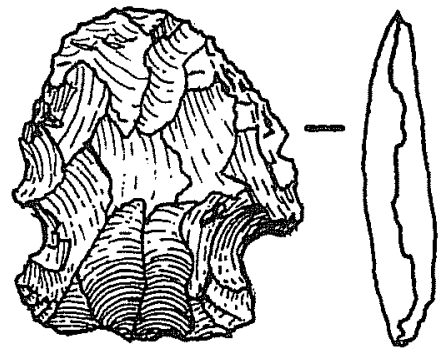

Marcos 32/1079

\footnotetext{
Figure 9-7. Projectile points.
} 
Table 9-17. Projectile Point Measurements

\begin{tabular}{|c|c|c|c|c|c|c|c|c|c|c|}
\hline 只 & $\stackrel{\overrightarrow{0}}{\Theta}$ & 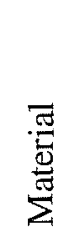 & ن̃ & 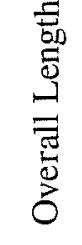 & 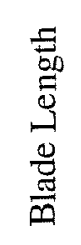 & 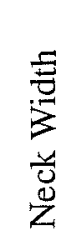 & 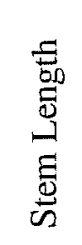 & 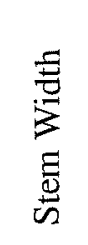 & 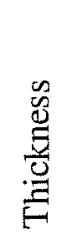 & $\begin{array}{l}\vec{E} \\
\frac{50}{00} \\
\frac{D}{3}\end{array}$ \\
\hline surface & 1476 & 271 & lateral & 33.5 & 33.5 & - & - & - & 6.0 & 5.0 \\
\hline 9 & 129 & 275 & proximal & - & - & 20.3 & 10.9 & 23.6 & 6.1 & 3.0 \\
\hline 12 & 567 & 271 & whole & 33.3 & 22.0 & 16.0 & 11.3 & - & 6.2 & 3.0 \\
\hline 16 & 633 & 274 & midsection & - & - & 16.2 & 11.9 & 16.3 & 6.3 & 6.8 \\
\hline 23 & 876 & 271 & midsection & - & - & 13.1 & 12.0 & 12.3 & 6.9 & 7.3 \\
\hline 25 & 1279 & 27.1 & whole & 51.2 & 50.7 & 15.1 & 10.9 & - & 6.0 & 6.8 \\
\hline 29 & 505 & 271 & midsection & - & - & 11.4 & - & - & 5.6 & 3.2 \\
\hline 31 & 1060 & 271 & midsection & - & - & 18.5 & 17.0 & 12.6 & 5.8 & 7.2 \\
\hline 32 & 1079 & 272 & whole & 33.6 & 21.8 & 20.2 & 11.8 & 24.3 & 6.8 & 6.7 \\
\hline 33 & 1259 & 271 & proximal & - & - & 14.1 & 12.7 & 14.2 & 5.1 & 4.6 \\
\hline 37 & 953 & 274 & proximal & - & - & 13.7 & 12.8 & 14.1 & 4.9 & 3.9 \\
\hline 37 & 957 & 271 & proximal & - & - & 20.7 & 15.4 & 20.1 & 6.8 & 11.9 \\
\hline 38 & 1127 & 271 & whole & 35.8 & 27.0 & 11.0 & 13.1 & 10.4 & 4.7 & 3.1 \\
\hline 40 & 1036 & 271 & proximal & - & - & 17.7 & 10.2 & 23.2 & 6.7 & 6.1 \\
\hline
\end{tabular}

the blade is greatly shortened, with a single remaining lateral barb and stem. A small stem fragment (Figure $9-7$; 16/638) may also represent a tiny portion of a Montell point. The Marcos point (Figure 9-7; 32/1079) has been heavily resharpened, much like one of the Shumla points. Its triangular shape has been rounded by the resharpening, but it still exhibits corner notching, an expanding stem, and a straight base. The Marshall point (Figure 9-7; 37/957) is a base fragment with a snapped blade and barb. It is much larger than other points represented at the site. An untypeable stemmed point (Figure 9-7; 37/953) is similar in form to Early Archaic bifurcated stem types, but it lacks stem grinding and is technologically more similar to Late Archaic types. It has a blade with a straight edge, shoulders with a slight barb, a straight stem, and a concave base. The tip is broken with a snap fracture. Two small burinations extend down from the break, with one along an edge, and the other down the face. An untypeable triangular point (Figure 9-7; surface/1476) exhibits alternating beveled edges, an impact fracture on the tip, and a broken corner.

\section{Burning and Possible Heat Treatment}

\section{Cores}

Five (38.4 percent) of the cores exhibit evidence of burning, with neither of the cobble unifaces being burned. The burned cores consist of a single-face core, a multi-face core, a bifacial core, a $90^{\circ}$ core, and a core fragment. They are lightly burned, with no obvious crackling or pot lids present. They are all made of chert, with colors ranging from tan to reddish purple to gray. These cores appear to have been heat treated. 


\section{Debitage}

Slightly more than 24 percent ( 24.2 percent) of the debitage is burned; however, this percentage excludes pot lids which make up about one percent of the total debitage. Not all the debitage exhibit similar amounts of burning. A chi-square test of a contingency table for the debitage classes by burning shows a significant difference in the distribution of burning between the types (Table 9-18; chi-sq=282.3; df=8; $<<0.01$ ). Burning was separated into "heavily burned" and "lightly burned" groups for this chi-square analysis. Heavily burned refers to items which exhibit discoloration, crackling and pot lids vs. lightly burned which is characterized by items which exhibit a glossy luster and greasy feel. There are more unburned angular debris and core flakes than expected, more heavily burned "other" flakes (i.e., pot lids), and more lightly burned biface flakes. The latter presumably represents the heat treatment of materials used for tool production.

Variations also exist in respect to the relationship between the presence/absence of burning and material grain. A chi-square test of a contingency of material grain by burning (Table 9-19) shows a significant relationship between these variables (chi-sq $=92.8, \mathrm{df}=2$,

Table 9-18. Debitage Type by Burning

Top value in cell represent artifact count, and bottom value represents adjusted residuals.

Significant $(\mathrm{p}<0.05)$ positive values are shown in bold.

\begin{tabular}{|l|c|c|c|}
\hline \multirow{2}{*}{ Debitage Type } & \multicolumn{3}{|c|}{ Burning } \\
\cline { 2 - 4 } & Absent & Heavy & Light \\
\hline \multirow{2}{*}{ angular debris } & 209 & 26 & 9 \\
& $\mathbf{2 . 6}$ & 1.4 & -4.4 \\
\hline \multirow{2}{*}{ core flake } & 1722 & 160 & 262 \\
& $\mathbf{2 . 0}$ & -1.8 & -0.9 \\
\hline \multirow{2}{*}{ biface flake } & 300 & 13 & 75 \\
& -0.9 & -3.7 & $\mathbf{4 . 1}$ \\
\hline \multirow{2}{*}{ und. fragment } & 1123 & 113 & 186 \\
& -0.1 & -0.5 & 0.5 \\
\hline \multirow{2}{*}{ other } & 15 & 38 & 9 \\
& -10.7 & $\mathbf{1 5 . 3}$ & 0.4 \\
\hline
\end{tabular}

Chi-sq $=282.3, \mathrm{df}=8, \mathrm{p}=<0.01$
Table 9-19. Material Grain by Burning

Top value in cell represent artifact count, and bottom value represents adjusted residuals.

Significant $(\mathrm{p}<0.05)$ positive values are shown in bold.

\begin{tabular}{|l|c|c|}
\hline \multirow{2}{*}{ Material Grain } & \multicolumn{2}{|c|}{ B urning } \\
\cline { 2 - 3 } & Absent & Present \\
\hline \multirow{2}{*}{ fine } & 440 & 89 \\
& $\mathbf{4 . 6}$ & -4.6 \\
\hline \multirow{2}{*}{ medium } & 2692 & 1021 \\
& -8.8 & $\mathbf{8 . 8}$ \\
\hline \multirow{2}{*}{ coarse } & 248 & 10 \\
& $\mathbf{8 . 0}$ & -8.0 \\
\hline
\end{tabular}

Chi-sq $=92.8, \mathrm{df}=2, \mathrm{p}=<0.01$

$\mathrm{p}<0.01)$. There are more burned medium-grained, and unburned fine- and coarse-grained debitage than expected. This pattern presumably indicates that mediumgrained materials were being heat-treated to improve their knappability. In contrast, fine-grained materials do not need to be altered, and heating coarse-grained materials will not substantially increase their knappability.

\section{Retouched Tools}

Most of the retouched tools (67.0 percent), bifaces ( 71 percent) and projectile points ( 81.2 percent) are burned, in contrast to the remaining tool types which include only slightly more burned ( 56.2 percent) vs. unburned artifacts (Table 9-20). Burning primarily consists of a distinctive luster and greasy feeling, although some pieces exhibit reddish or pink discoloration which may be due to heat treatment (e.g., see Hester and Collins 1974). This relatively high percentage of burned artifacts stands in contrast to that represented by the cores and debitage. A chi-square test of artifact type by burning indicates a significant difference between these categories (Table 9-21; chi-sq $=71.6, d f=2, p<0.01$ ). There is more unburned debitage than expected, and more burned retouched tools than expected. This corresponds with the bias towards burned biface flakes among the debitage. Indeed, 70 percent of the bifaces are burned. Most of these are lightly burned, but a middle-stage 
Table 9-20. Retouched Tool Type by Burning

\begin{tabular}{|l|c|c|}
\hline \multirow{2}{*}{ Retouched Tool } & \multicolumn{2}{|c|}{ Burning } \\
\cline { 2 - 3 } & Absent & Present \\
\hline retouched flake & 1 & 8 \\
\hline notch & 5 & 5 \\
\hline perforator & 1 & 0 \\
\hline burin & 0 & 1 \\
\hline uniface & 7 & 3 \\
\hline notch/uniface & 0 & 1 \\
\hline biface & 9 & 22 \\
\hline projectile point & 3 & 13 \\
\hline column total & $\mathbf{2 6}$ & $\mathbf{5 3}$ \\
\hline
\end{tabular}

biface is heavily burned (12/574). In addition, the fact that there are significantly more medium-grained burned materials, vs. fine- or coarse-grained, indicates a pattern of heat treating medium-grained materials for the production of tools. Heat treatment would have increased the knappability, and therefore, the possible tool use-life of medium-grained chert bifaces. This is important given that these medium-grained materials were the prevalent local material type, with fewer finegrained materials. It seems likely that both prepared cores and large flake blanks for biface production were heat treated.

Table 9-21. Artifact Type by Burning

Top value in cell represent artifact count, and bottom value represents adjusted residuals.

Significant $(p<0.05)$ positive values are shown in bold.

\begin{tabular}{|l|c|c|}
\hline \multirow{2}{*}{ Artifact Type } & \multicolumn{2}{|c|}{ Burning } \\
\cline { 2 - 3 } & Absent & Present \\
\hline \multirow{2}{*}{ cores } & 8 & 5 \\
& -1.1 & 1.1 \\
\hline \multirow{2}{*}{ debitage } & 3380 & 1120 \\
& $\mathbf{8 . 2}$ & -8.2 \\
\hline \multirow{2}{*}{ retouched tools } & 26 & 53 \\
& -8.4 & $\mathbf{8 . 4}$ \\
\hline
\end{tabular}

Chi-sq $=71.6, \mathrm{df}=2, \mathrm{p}=<0.01$

\section{Tool Use}

\section{Cores/Debitage}

None of the cores or cobble unifaces exhibits any obvious evidence of damage which could be attributed to use; however, 1.2 percent $(n=54)$ of the debitage exhibits edge damage which was observable under a $10 \mathrm{x}$ binocular scope (Table 9-22). Use-wear is primarily evident on core flakes $(n=44)$, with fewer biface flakes $(n=5)$, undetermined flake fragments, and blades. A single edge was most commonly selected for use on a flake, although two or three edges were occasionally used. The majority of the damaged edges are situated along the lateral edges of flakes (76.5 percent), with fewer being situated at the end (Table 9-23). Most of edges have straight outlines (68.1 percent), with less concave and convex outliers and one utilized projection. The latter reflects use as an expedient perforator.

Larger flakes were selected from the site's flake population for use. The mean length of whole utilized flakes is $32.6 \mathrm{~mm}(\mathrm{sd}=13.9, \mathrm{n}=24)$. Nonutilized flakes exhibit a smaller mean length of $18.9 \mathrm{~mm}(\mathrm{sd}=9.7$, $\mathrm{n}=939$ ). These larger flakes are easier to hold and manipulate by hand. They primarily consist of core flakes $(n=44)$, with fewer biface flakes $(n=5)$, undetermined flake fragments $(n=4)$, and a blade.

Edge angles range from 20 to 75 degrees; however, the lateral edges exhibit a slightly more acute mean edge angle ( 40.2 percent, $s d=12.18$ ) when compared with the flake ends (43.1 percent; $s d=16.3$ ). The utilized flakes have a complementary edge angle pattern to that present on the retouched tools. The retouched flakes (mean $=65.0$ percent, $s d=7.9$ ), notches (mean $=61.5$ percent, $s d=17.9$ ) and unifaces (mean $=62.2$ percent, $s d=11.2$ ) exhibit the steepest mean edge angles. In contrast, the projectile points (mean $=46.4$ percent, sd=6.9), utilized flakes (mean $=40.9$ percent, $\mathrm{sd}=13.1$ ), and late-stage bifaces (mean=38.5 percent, $\mathrm{sd}=6.9$ ) exhibit more-acute edge angles. This presumably reflects differing functional roles for these tool groups. Ethnographic information on arid hunter-gatherers indicates that more-acute edge angles are often associated with cutting activities, and obtuse angles with wood working or scraping activities (Gould et al. 1971). A higher-powered microscopic analysis 
Table 9-22. Debitage Type by Utilized Edge

\begin{tabular}{|l|c|c|c|c|}
\hline \multirow{2}{*}{ Debitage Type } & \multicolumn{4}{|c|}{ Number of Utilized } \\
\cline { 2 - 5 } & $\mathbf{0}$ & $\mathbf{1}$ & $\mathbf{2}$ & $\mathbf{3}$ \\
\hline angular debris & 474 & 0 & 0 & 0 \\
\hline core flake & 2101 & 36 & 7 & 1 \\
\hline blade & 3 & 1 & 0 & 0 \\
\hline biface flake & 383 & 3 & 2 & 0 \\
\hline uniface flake & 9 & 0 & 0 & 0 \\
\hline ct flake & 10 & 0 & 0 & 0 \\
\hline burin spall & 2 & 0 & 0 & 0 \\
\hline pot lid & 42 & 0 & 0 & 0 \\
\hline hs flake & 1 & 0 & 0 & 0 \\
\hline und. fragment & 1418 & 4 & 0 & 0 \\
\hline overstruck & 2 & 0 & 0 & 0 \\
\hline oc flake & 1 & 0 & 0 & 0 \\
\hline column total & $\mathbf{4 4 4 6}$ & $\mathbf{4 5}$ & $\mathbf{1 1}$ & $\mathbf{4}$ \\
\hline
\end{tabular}

Table 9-23. Location by Edge Outline for Use-damaged Debitage

\begin{tabular}{|l|c|c|c|c|}
\hline \multirow{2}{*}{ Location } & \multicolumn{4}{|c|}{ Edge Outline } \\
\cline { 2 - 5 } & Straight & Concave & Convex & Projection \\
\hline end & 9 & 2 & 4 & 1 \\
\hline lateral & 38 & 9 & 5 & 0 \\
\hline $\begin{array}{c}\text { column } \\
\text { total }\end{array}$ & 47 & $\mathbf{1 1}$ & $\mathbf{9}$ & $\mathbf{1}$ \\
\hline
\end{tabular}

(e.g. $40 \times 80$ ) needs to be conducted to further evaluate possible tool functions.

\section{Retouched Tools}

Three marginally retouched flakes exhibit obvious edge damage. Two of these have unidirectional scarring along the face of the retouched edge. The other has some rounding and slight bidirectional scarring along a unmodified edge which is opposite the retouched edge.
Obvious edge damage was identified on three notches. One of these exhibits unidirectional scarring, and another rounding and unidirectional scarring on the face of the retouched edges. The other has unidirectional scarring along an unmodified edge adjacent to the retouched notch.

The perforator has a broken tip and polish along one of the lateral edges. The burin exhibits possible usewear on both opposing burinated ends. One of these has micro-scarring and polish on the transverse edge, and some polish along one of the lateral edges. The other has two tiny microburins which originate from the transverse edge.

Only one uniface exhibits obvious edge damage. This consists of unidirectional scarring which extends up the surface of the retouched edge.

Four bifaces exhibit some form of evidence for usewear and/or hafting. Three of these are lanceolateshaped fragments consisting of late stage bifaces with square bases. The larger fragment (Figure 9-5; 41/1204) exhibits polish on both faces, with some minimal micro-scarring along the edge adjacent to the break. This polish presumably reflects hafting wear, and the micro-scarring is use wear. The two smaller fragments are corner pieces, and exhibit some micro-scarring along their edges. These artifacts probably represent hafted knives which broke during use. In contrast, one biface midsection (Figure 9-5; 15/1107) exhibits rounding on high points situated on both surfaces, and along both lateral retouched edges. This presumably represents hafting wear, and it is possible that the artifact is the remains of an adze which broke in the haft since both ends exhibit snap breaks. The bit end could have broken off as a result of end shock, and the opposite end due to weak hafting.

Ten of the projectile points exhibit snap breaks. Most of these are transverse breaks which appear to be due to end shock which removed the tips of the points (i.e., impact fractures). In some cases the corners or barbs of the points are also broken, and one point has tiny burination scars on both faces adjacent to the broken tip. Two other points exhibit oblique snaps. One of the these is probably an impact break (Figure 9-7; 37/953); however, two burination scars which originate from 
the broken end could be due to impact or reuse as a graver. The other obliquely fractured point was probably broken as a result of resharpening (Figure 9-6; 40/1036). Lastly, the large Marshall point fragment (Figure 9-7; 37/957) exhibits micro-scarring along one edge. The transverse snap break on this point is probably due to use as a hafted knife.

\section{Ground Stone}

The ground stone consists of a single broken one-hand mano fragment. The mano has a plano-convex crosssection (Figure 9-8; 1/152). Both surfaces are ground and pitted. The fragment is $43 \mathrm{~mm}$ in diameter and weighs $64.9 \mathrm{~g}$.

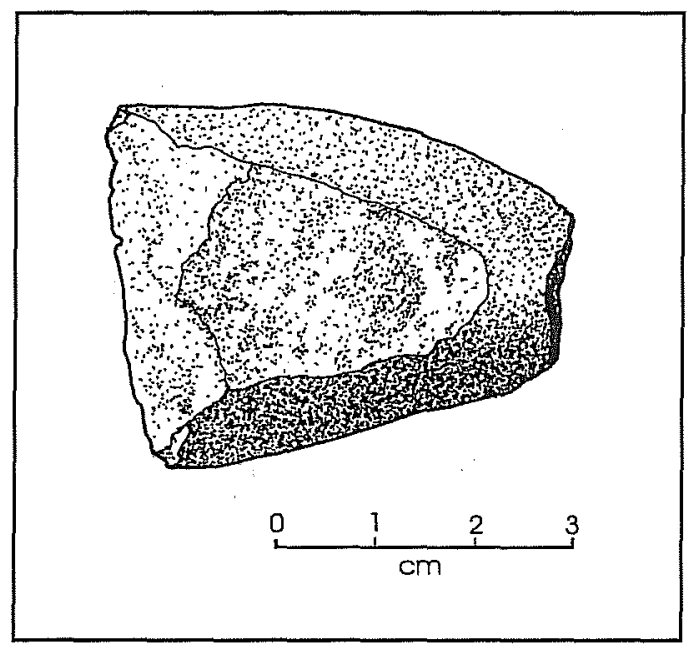

Figure 9-8. One-hand mano fragment.

\section{Regional Comparisons}

There are very few excavated prehistoric sites in Maverick County to which site $41 \mathrm{MV} 120$ can be compared. Limited testing has been conducted at 28 sites in the Dos Republicas Mine area (Uecker 1994; Uecker and Warren 1994). These sites are situated in streamside settings on terraces or the floodplain adjacent to Elm Creek. Two hundred fifteen pieces of debitage were the only artifacts recovered from 108 test pits excavated on these sites, with the majority ( 80 percent) of the material being present in the upper $20 \mathrm{~cm}$ of fill.
However, many of these sites are on an Early Holocene terrace (Nordt, Chapter 7) and may represent turbated palimpsests, although more detailed field investigations are necessary to make this determination. The Dos Republicas sites stand at a marked contrast to site 41MV120, which exhibits a greater vertical distribution and higher artifact densities. The Dos Republicas sites contain a low overall artifact density of 18.3 artifacts per cubic meter. This is similar to the one observed in Area 4 (with $0-18.0$ artifacts per $\mathrm{m}^{3}$ ) which contains the lowest artifact densities on site 41MV120, but contrasts with Area 1 (with 406.3-660.0 artifacts per $\mathrm{m}^{3}$ ) which contains the highest artifact densities on the site.

Too few artifacts were recovered from the test excavations conducted at the Dos Republicas sites to warrant a comparison of site assemblages. Therefore, three other sites were selected for a simple comparison of assemblage composition with site 41MV120: 41LK8 (Hall et al. 1986), 41LK31/32 (Scott 1982), and 41LK67 (Brown et al. 1982). These sites were excavated as part of the Choke Canyon Reservoir project, and are situated on terraces adjacent to the Frio River which drains into the Nueces River. All the sites are campsites containing chipped and ground-stone artifacts, burned rock, and snail and mussel shells. They have buried analytical units, and are located in areas with local terrace or lag gravels. Together they span a time range from Early-Middle Archaic (41LK31/32), Middle-Late Archaic (41LK8), and Late Archaic-Late Prehistoric (41LK67).

A comparison of artifact classes indicates a significant difference between the sites (Table 9-24; chi$\mathrm{sq}=88.1, \mathrm{df}=6, \mathrm{p}<0.01)$. Site $41 \mathrm{LK} 67$ contains more cores than expected, site 41LK31/32 more retouched tools, and sites 41MV120 and 41LK8 more flakes. Cores compose $0.2-1.0$ percent, and retouched tools from $0.4-1.3$ percent of the assemblages. Site $41 \mathrm{MV} 120$ contains the smallest percentage of cores for any of these sites. This can be contrasted with lithic procurement sites (41BX1088, 1090, 1091near the southern edge of the Edwards Plateau at Lackland Air Force Base which contain 13.7 percent cores and 4.8 percent retouched tools, emphasizing both core reduction and tool production activities (Houk et al. 1997). 
Table 9-24. Artifact Classes by Site

Top value in cell represent artifact count, and bottom value represents adjusted residuals.

Significant $(p<0.05)$ positive values are shown in bold.

\begin{tabular}{|c|c|c|c|}
\hline \multirow{2}{*}{ Site } & \multicolumn{3}{|c|}{ Artifact Classes } \\
\cline { 2 - 4 } & Cores & Flakes & $\begin{array}{c}\text { Retouched } \\
\text { Tools }\end{array}$ \\
\hline \multirow{2}{*}{$41 \mathrm{MV} 120$} & 15 & 7825 & 79 \\
& -5.6 & $\mathbf{2 . 4}$ & 1.5 \\
\hline \multirow{2}{*}{$41 \mathrm{LK} 31 / 32$} & 52 & 7611 & 102 \\
& 0.9 & -4.4 & $\mathbf{5 . 0}$ \\
\hline \multirow{2}{*}{$41 \mathrm{LK} 8$} & 20 & 4388 & 16 \\
& -1.4 & $\mathbf{3 . 9}$ & -3.9 \\
\hline \multirow{2}{*}{$41 \mathrm{LK} 67$} & 84 & 8171 & 49 \\
& $\mathbf{5 . 7}$ & -1.2 & -3.2 \\
\hline
\end{tabular}

Chi-sq $=88.1, \mathrm{df}=6, \mathrm{p}=<.01$

This differing emphasis between core reduction and tool production is more evident when comparing the presence/absence of cortex in the flake assemblages. There is a similar significant difference in the distribution of cortex across the sites (Table 9-25; chi$\mathrm{sq}=164.6, \mathrm{df}=3, \mathrm{p}<0.01$ ). Site $41 \mathrm{LK} 67$ contains more cortical flakes than expected, and sites 41 LK $31 / 32$ and

Table 9-25. Cortex by Site

Top value in cell represent artifact count, and bottom value represents adjusted residuals.

Significant $(p<0.05)$ positive values are shown in bold.

\begin{tabular}{|l|c|c|}
\hline \multirow{2}{*}{ Site } & \multicolumn{2}{|c|}{ Cortex } \\
\cline { 2 - 3 } & Present & Absent \\
\hline \multirow{2}{*}{$41 \mathrm{MV} 120$} & 194 & $\mathbf{7 2 9}$ \\
& -9.4 & $\mathbf{9 . 4}$ \\
\hline \multirow{2}{*}{$41 \mathrm{LK} 31 / 32$} & 964 & 2088 \\
& -4.8 & $\mathbf{4 . 8}$ \\
\hline \multirow{2}{*}{$41 \mathrm{LK} 8$} & 374 & 743 \\
& -1.1 & 1.1 \\
\hline \multirow{2}{*}{$41 \mathrm{LK} 67$} & 1651 & 2352 \\
& $\mathbf{1 1 . 1}$ & -11.1 \\
\hline
\end{tabular}

Chi-sq $=164.6, \mathrm{df}=3, \mathrm{p}=<0.01$
41MV120 more noncortical flakes. Site 41MV120 contains fewer flakes with cortex (21.0 percent) and site 41LK67 the most (41.2 percent). This latter figure is somewhat lower than that observed on lithic procurement sites (62.9 percent). The presence of more cores and cortical flakes on site 41LK67 presumably reflects a greater emphasis on core reduction vs. retouched tools and noncortical flakes at site 41LK31/ 32 which reflects an emphasis on tool production. A comparison of platform type by site supports this interpretation.

Information on platform type was not available from site 41LK8; however, a comparison of the remaining sites indicates a significant difference between the flake assemblages (Table 9-26; chi-sq=320.0, $\mathrm{df}=3, \mathrm{p}<0.01$ ). Site 41LK67 contains more cortical platforms than expected and site 41LK31/32 more faceted platforms. Cortical platforms comprise from 2.3-17.3 percent of the flake assemblages, with site $41 \mathrm{MV} 120$ being situated in the middle (12.5 percent). In comparison, lithic procurement sites exhibit 21.6 percent cortical platforms. The presence of high percentages of cortical platforms and cortex on site 41LK67 indicates that cobbles were reduced at the site; in contrast, the lower percentage of cortical platforms and cortex at sites $41 \mathrm{LK} 31 / 32$ and $41 \mathrm{MV} 120$ may reflect that more prepared cores were being reduced at these sites.

Table 9-26. Platform Type by Site

Top value in cell represent artifact count, and bottom value represents adjusted residuals.

Significant $(p<0.05)$ positive values are shown in bold.

\begin{tabular}{|c|c|c|}
\hline \multirow{2}{*}{ Site } & \multicolumn{2}{|c|}{ Platform Type } \\
\cline { 2 - 3 } & Cortical & Faceted \\
\hline \multirow{2}{*}{41 MV120 } & 221 & 1550 \\
& 0.8 & -0.8 \\
\hline \multirow{2}{*}{ 41LK31/32 } & 54 & 2313 \\
& -17.1 & $\mathbf{1 7 . 1}$ \\
\hline \multirow{2}{*}{ 41LK67 } & 705 & 3379 \\
& $\mathbf{1 4 . 9}$ & -14.9 \\
\hline
\end{tabular}

Chi $s q=320.0, \mathrm{df}=3, \mathrm{p}=<0.01$ 
In summary, site $41 \mathrm{MV} 120$ contrasts with sites 41LK67 and 41LK31/32 which emphasize core reduction and tool production activities, respectively. 41MV120 is situated between these two ends of the reduction continuum, reflecting more of a balance in core reduction and tool production. The lack of cortex and cortical platforms at $41 \mathrm{MV} 120$ is in part due to prepared cores and large flakes being brought to the site for reduction and tool production; however, there are still relatively fewer cores present when compared to the other sites. It seems possible that some of the cores which were worked at the site were subsequently removed and taken to other off-site locations. It may be that curated cores (e.g., bifacial and platform) were carried away by the site occupants, and expedient cores (e.g., platform and cobble unifaces) were discarded. It is also plausible that reduction loci containing cores were not adequately sampled at the site, but this seems unlikely given the total number of artifacts recovered from varying site contexts.

\section{Summary and Conclusions}

Excavations at 41MV120 have identified the presence of a stratified Late Archaic sequence. The assemblage is dominated by chert (e.g., a light tan/gray color), with lesser amounts of chalcedony, jasper, salt/pepper rhyolite, and other materials. The presence of water-worn cortex, in conjunction with comparisons of local gravel collections, indicate that these raw materials were primarily obtained from nearby local Rio Grande terrace sources. Medium- and coarse-grained lithic materials appear to have been used for core reduction, and fineand medium-grained materials for tool production.

It appears that prepared cores and large flake blanks were brought to the site for further reduction and tool production. At least some cobbles were also reduced at the site. The paucity of cores present in the site assemblage, however, indicates that these artifacts were removed from the site for further reduction at other localities. Several core reduction strategies were identified through the analysis of cores, debitage, and retouched tools. A prepared core-flake-tool trajectory was used to produce utilized flake and retouched tool blanks. A bifacial core-flake-tool trajectory was used to manufacture blanks for retouched flakes and notches. A large flake-tool trajectory reflects large flake blanks being used for the production of bifaces. Lastly, unretouched utilized flake blanks were also manufactured through a cobble uniface-flake trajectory. This involved two different tactics depending on raw material shape. Spheroid cobbles were reduced with several flakes being removed along a single end of the cobble, producing orange-rind flakes with cortex extending along part of the perimeter of the flake. In contrast, lenticular or cigar-shaped cobbles were reduced by removing single flakes with cortex around the total edge perimeter from end-to-end of the cobble.

The debitage reflects that core reduction and tool production/maintenance activities occurred at the site. This is represented by core flakes, core maintenance flakes, and a variety of tool flakes (i.e., biface, uniface, notching, and overstruck). Early- middle- and late-stage bifaces also attest to the production of these tools, and their discard during manufacturing and use-breakage. The projectile points have been heavily resharpened and were finally discarded at the site after breakage or exhaustion. Several Late Archaic point types are represented: Shumla, Desmuke, Langtry, Marcos, Montell, Marshall, and Ensor:

Heat treating was used as a technique to increase the knappability of medium-grained lithic materials. This may have taken place by heating prepared cores and large flake blanks prior to further reduction and tool production.

A low-power technique was employed to identify possible tool use. Retouched flakes, notches, and unifaces are characterized by steeper edge angles, vs. utilized flakes, bifaces, and projectile points which have moreacute edge angles. These differences may reflect variations in tool functions, with the former group representing scraping and wood-working activities, and the latter group cutting and piercing activities. A detailed microscopic analysis could be done to further evaluate these patterns. 


\section{Chapter 10: Fire-cracked Rock}

\section{David L. Nickels, Bradley J. Vierra, and Wulf Gose}

\section{Introduction}

Fire-cracked rock was recovered from 39 of the 43 excavation units at 41MV120. The collection was examined in the laboratory, and data on provenience, material type, and weight to the nearest one-tenth of a gram were recorded. All specimens were first classified by raw material type and weighed. A total of 827 fragments was analyzed, representing eight different rock types, and a combined weight of $30,903 \mathrm{~g}$. The raw data and proveniences of materials collected are presented in Appendix E. Level numbers used in this chapter are the original field designations, not the revised $10-\mathrm{cm}$ levels referred to in Chapter 8 (see Appendix $\mathrm{C}$ for conversions [level vs. level 2]).

\section{Results of the Analysis}

Fire-cracked rock was recovered from all areas of the site. They are the second most common artifacts represented, after chipped stone artifacts. The firecracked rock analysis was designed to collect information on raw material type and size range. This information is then used to contrast variations in burned rock composition across the site. Archaeomagnetic samples were also collected from selected rocks in the field. This study will aid in the identification of possible intact features, and determine the temperature at which these rocks were heated. This information will be used to help ascertain possible feature func- tion, and whether raw materials were selected for differing uses.

\section{Rock Type Frequency}

No raw materials either in the form of cobbles or in situ solid outcrops are present at the site. Sandstone outcrops occur locally, and cobbles are present in nearby gravel terraces. The prehistoric inhabitants of 41MV120 presumably visited these locations and obtained lithic materials which were taken back to the campsite.

The majority of the fire-cracked rock is composed of sandstone (39.5 percent), with chert (28.7 percent), limestone (18.5 percent), and rhyolite ( 8.0 percent) constituting other frequent types (Figure 10-1). The other rock types present in the assemblage occur at much lower frequencies, consisting of quartzite, chalcedony, silicified wood, and quartz.

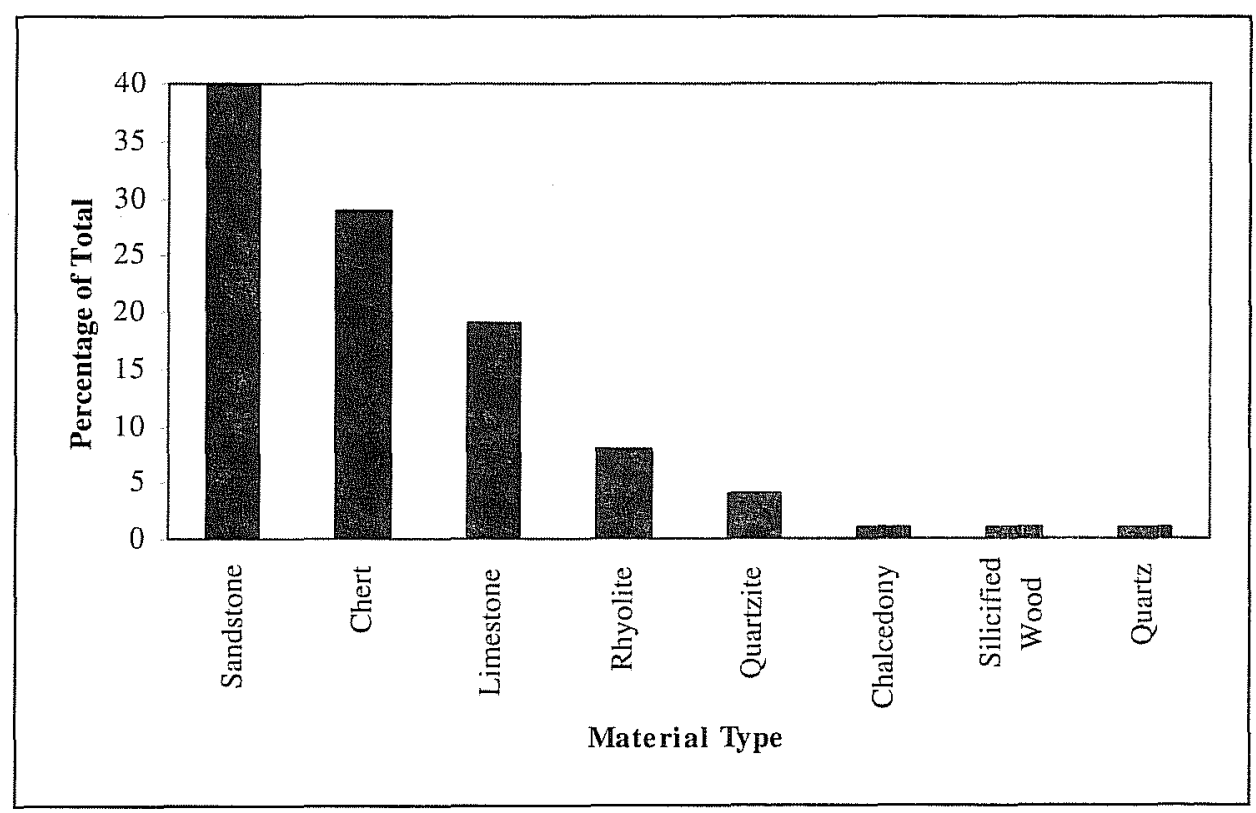

Figure 10-1. Fire-cracked rock frequencies. 
The frequencies in rock types found on the site were examined relative to the availability of raw materials outcropping nearby. As discussed in Chapter 9, a sample of 210 cobbles was collected from nearby Rio Grande gravels. Table 10-1 shows the relationship between raw material types collected off site and those recovered at $41 \mathrm{MV} 120$. Frequencies of chert, limestone, rhyolite, and "other" (i.e., quartzite, chalcedony, silicified wood, and quartz) cobbles were compared from on and off-site locations using a standard chisquare test with adjusted residuals. There is a significant difference in the raw material types present between these two locations (chi-sq=61.4, $\mathrm{df}=4$, $\mathrm{p}=<0.01$ ). There is more chert than expected in the Rio Grande gravels, and more limestone and quartzite present on the site; whereas, rhyolite and the other materials were not significantly different between the two areas. It appears that limestone and quartzite were preferentially selected from the local gravels for use in heating features at the site.

\section{Total Weights}

Although frequencies of material types are somewhat informative, variability in raw material properties ne-

\section{Table 10-1. Fire-cracked Rock Material Type by Location}

Top value in cell represent artifact count, and bottom value represents adjusted residuals.

Significant $(p<0.05)$ positive values are shown in bold.

\begin{tabular}{|l|c|c|}
\hline \multirow{2}{*}{ Material } & \multicolumn{2}{|c|}{ Location } \\
\cline { 2 - 3 } & Off Site & On Site \\
\hline \multirow{2}{*}{ chert } & 210 & 237 \\
& 7.4 & -7.4 \\
\hline \multirow{2}{*}{ limestone } & 30 & 153 \\
& -6.3 & $\mathbf{6 . 2}$ \\
\hline \multirow{2}{*}{ rhyolite } & 28 & 66 \\
& -1.3 & 1.3 \\
\hline \multirow{2}{*}{ quartzite } & 7 & 33 \\
& -2.5 & $\mathbf{2 . 5}$ \\
\hline \multirow{2}{*}{ other } & 6 & 11 \\
& -0.1 & 0.1 \\
\hline
\end{tabular}

Chi-sq $=61.4, \mathrm{df}=4, \mathrm{p}=<0.01$ gate quantity as a reliable predictor of usage. It is also recognized that variation in grain structure or texture cause different material types to fracture differently, thus comparing mean weights of the fractured remains can be misleading. Therefore the sum weight of materials relative to quantities may be a more accurate measure of usage intensity, as well as raw material volume and size. Figure 10-2 demonstrates that the relationship between frequency and weight is quite similar; however, sandstone is more highly represented by volume when compared to frequency.

\section{Mean Weights}

Figure 10-3 examines material types in respect to mean artifact weights as a general indicator of artifact size. Complementing the high frequency data for sandstone, cher,t and limestone presented in Figure 10-1, sandstone, chert, and limestone also make up the largest pieces of burned rock found at the site. Sandstone comprises not only the highest frequency and total volume, but is also represented by the largest pieces with a mean weight per piece of $53.4 \mathrm{~g}$. Limestone possesses the second highest mean weight per piece (30.9 g), followed by chert $(27.9 \mathrm{~g})$. Several different factors can affect the size of the remaining pieces of fire-cracked rock, including original raw material size, thermal properties of the rock, and temperatures to which the rock was subjected. Gravels probably entered the site as smaller items, and a more easily transportable raw material than sandstone. Sandstone might have been collected as larger fragments adjacent to bedrock outcrops or directly mined from the outcrops. Additionally, sandstone is less easily fractured when exposed to heat than are chert, limestone, and the other cobble materials.

\section{Intrasite Spatial Distribution}

As discussed above, sandstone, chert, limestone, and rhyolite make up 94.7 percent of the material recovered, while the remaining four raw material types comprise only 5.3 percent. Given that sandstone and cobble materials were obtained from differing sources, might they also not have been used for somewhat different 

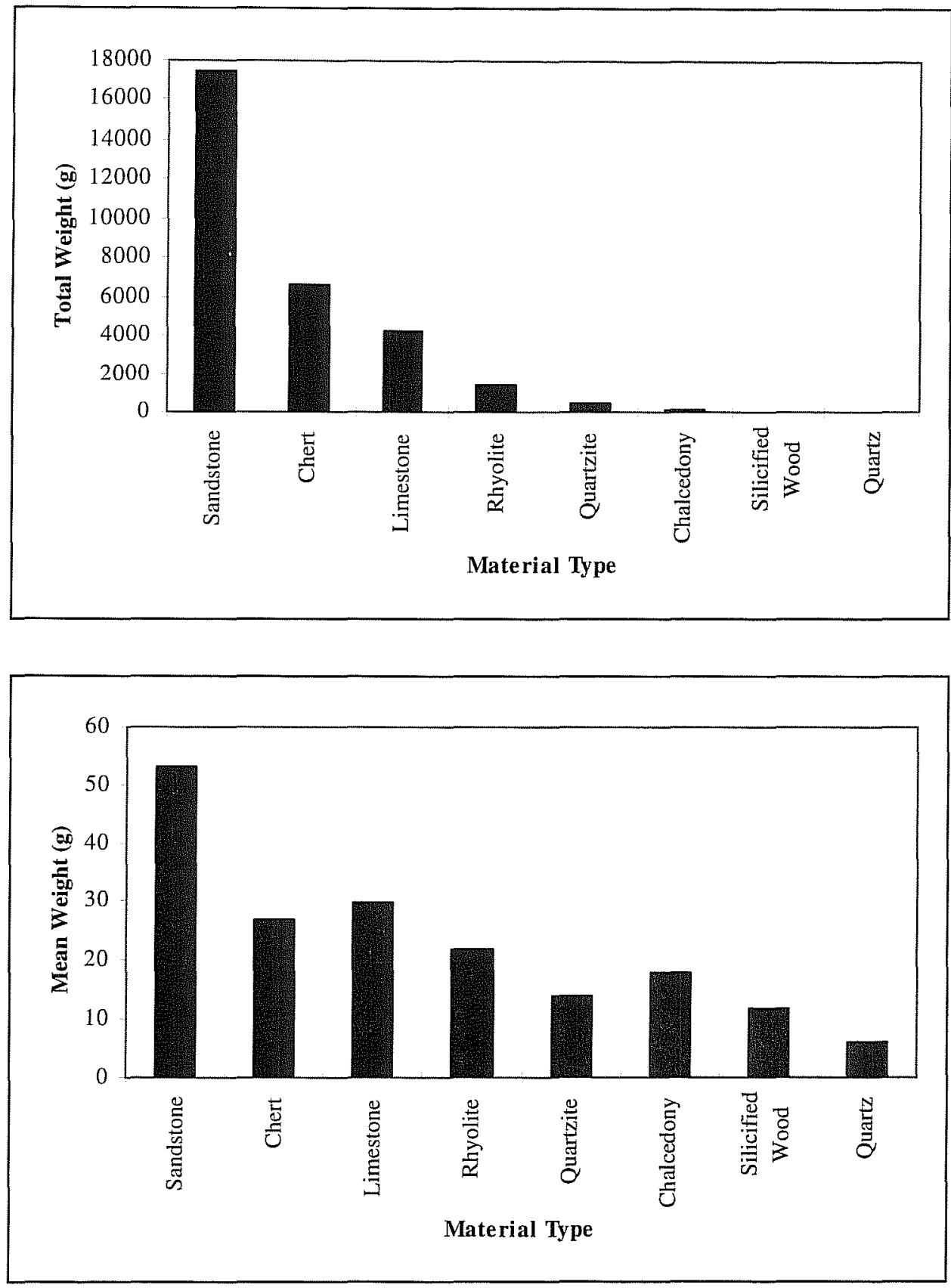

Figure 10-2. Fire-cracked rock weight totals.
Figure 10-3. Fire-cracked rock mean weights. functions? The distribution of the burned rock types is analuzed to determine if any differences are seen in the distribution of these materials across the site. How does the distribution of sandstone contrast with that for the other cobble materials?

Table 10-2 presents information on the distribution of fire-cracked rock material types by site area. There ia a significant differences in the distribution of raw materials by area (chi-sq $=2146.6, d f=15, p=<0.01$ ). Area 1 contains more chert, rhyolite, and quartzite than expected, Area 2 more limestone and rhyolite, Area 3 more sandstone, limestone, quartzite, and other materials, and Area 4 more sandstone. This pattern is graphically illustrated in Figure 10-4. There is a general increase in the relative percentage of sandstone from Area 1 to Area 4 across the site (i.e., east to west). In conjunction with this pattern, there is a general decline in chert from Area 1 to Area 4. It may be that the 
Table 10-2. Fire-cracked Rock Total Weight (g) by Site Area

Top value in cell represent artifact count, and bottom value represents adjusted residuals.

Significant $(\mathrm{p}<0.05)$ positive values are shown in bold.

\begin{tabular}{|c|c|c|c|c|c|c|}
\hline \multirow{3}{*}{ Area } & \multicolumn{7}{|c|}{ Material } \\
\cline { 2 - 7 } & Sandstone & Chert & Limestone & Rhyolite & Quartzite & Other \\
\hline \multirow{3}{*}{ Area 1 } & 4371 & 3219 & 1182 & 538 & 210 & 19 \\
& -21.6 & $\mathbf{3 2 . 4}$ & -10.6 & $\mathbf{4 . 1}$ & $\mathbf{2 . 5}$ & -4.3 \\
\hline \multirow{2}{*}{ Area 2 } & 3584 & 1402 & 1120 & 417 & 16 & 0 \\
& 0.9 & -3.4 & $\mathbf{4 . 5}$ & $\mathbf{6 . 3}$ & -11.7 & -6.2 \\
\hline \multirow{2}{*}{ Area 3 } & 3234 & 773 & 1004 & 181 & 225 & 80 \\
& $\mathbf{7 . 6}$ & -17.9 & $\mathbf{6 . 7}$ & -6.4 & $\mathbf{1 3 . 3}$ & $\mathbf{1 3 . 6}$ \\
\hline \multirow{2}{*}{ Area 4 } & 1680 & 42 & 346 & 32 & 7 & 0 \\
& $\mathbf{2 4 . 5}$ & -24 & 1.3 & -7.6 & -5.6 & -3.1 \\
\hline Total & 12869 & 5436 & 3652 & 1168 & 458 & 99 \\
\hline
\end{tabular}

Chi-sq $=2146.6, \mathrm{df}=15, \mathrm{p}=<0.01$

activities associated with the heating of chert were more spatially limited to the eastern side of the site near Elm Creek. This area of the site does contain relatively higher mussel shell densities, indicating that the burned rock may in part be associated with cooking mussels.

Chapter 8 presents information on the vertical distribution of fire-cracked rock within each of the respective block excavation areas. Multiple isolated peaks of burned rock by $10-\mathrm{cm}$ levels were identified, and the composition of these were determined. Fifteen of these burned rock concentrations were subjected to a chisquare analysis of a contingency table of material type by excavation unit level. There is a significant difference in the distribution of rock types by level across these units (Table 10-3; chi-sq= 7260.1, $\mathrm{df}=42, \mathrm{p}=<0.01$ ). Inspection of the adjusted residuals in specific levels with high densities of burned rock indicates that most of the concentrations contain relatively more sandstone $(\mathrm{n}=4)$, limestone $(\mathrm{n}=4)$, and chert $(n=4)$ than expected. Only one level is dominated by rhyolite. The majority of the levels dominated by sandstone contain more than $400 \mathrm{~g}$ of rock; whereas, most of the levels dominated by chert or limestone exhibit total weights of less than $400 \mathrm{~g}$. These patterns cross-cut the site areas, and are similar to those described in Chapter 8 where cobble materials were prevalent in low-density levels, and sandstone in high-density levels.

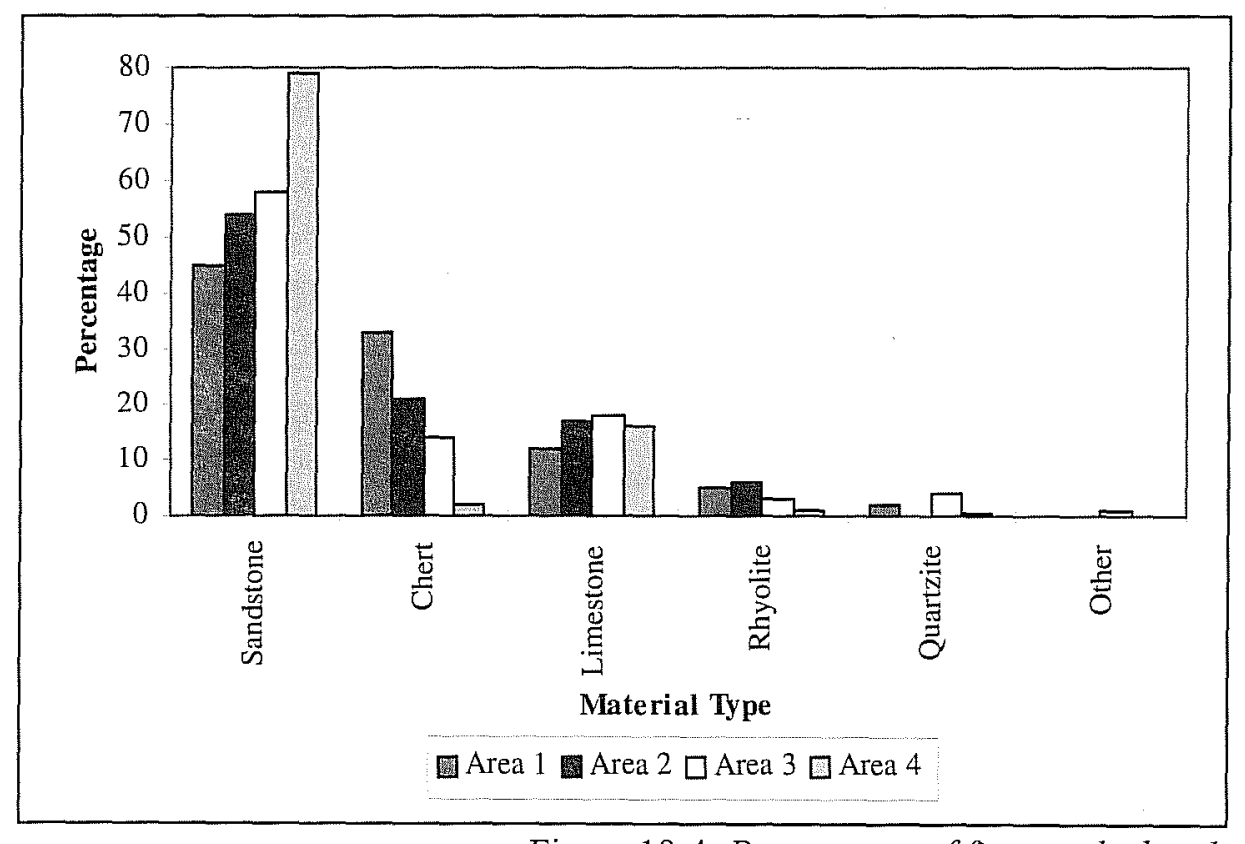

Figure 10-4. Percentages of fire-cracked rock. 
Table 10-3. Burned Rock Material Types by Higher Density Levels

Top value in cell represent artifact count, and bottom value represents adjusted residuals.

Significant $(p<0.05)$ positive values are shown in bold.

\begin{tabular}{|c|c|c|c|c|c|c|}
\hline \multirow{2}{*}{ Area } & \multirow{2}{*}{$\begin{array}{c}\text { Excavation } \\
\text { Unit }\end{array}$} & \multirow{2}{*}{ Level } & \multicolumn{4}{|c|}{ Material } \\
\hline & & & Sandstone & Limestone & Chert & Rhyolite \\
\hline \multirow[t]{2}{*}{1} & 1 & 11 & $\begin{array}{c}201 \\
-12.4 \\
\end{array}$ & $\begin{array}{r}195 \\
\mathbf{1 0 . 9}\end{array}$ & $\begin{array}{l}37 \\
-6.1\end{array}$ & $\begin{array}{r}133 \\
16.3\end{array}$ \\
\hline & 31 & 8 & $\begin{array}{c}271 \\
-17.1\end{array}$ & $\begin{array}{r}134 \\
-1.3\end{array}$ & $\begin{array}{l}406 \\
\mathbf{2 9 . 0}\end{array}$ & $\begin{array}{c}16 \\
-6.1\end{array}$ \\
\hline \multirow{5}{*}{2} & 7 & 11 & $\begin{array}{c}6 \\
-17.5 \\
\end{array}$ & $\begin{array}{c}0 \\
-7.0\end{array}$ & $\begin{array}{c}0 \\
-6.4\end{array}$ & $\begin{array}{l}212 \\
53.5\end{array}$ \\
\hline & \multirow[t]{2}{*}{16} & 2 & $\begin{array}{l}68 \\
1.0 \\
\end{array}$ & $\begin{array}{c}12 \\
-.17 \\
\end{array}$ & $\begin{array}{l}25 \\
2.4\end{array}$ & $\begin{array}{c}0 \\
-2.8 \\
\end{array}$ \\
\hline & & 4 & $\begin{array}{l}315 \\
4.0\end{array}$ & $\begin{array}{c}65 \\
-2.1\end{array}$ & $\begin{array}{l}79 \\
1.1\end{array}$ & $\begin{array}{c}0 \\
-6.1\end{array}$ \\
\hline & 20 & 4 & $\begin{array}{l}177 \\
-5.0\end{array}$ & $\begin{array}{c}0 \\
-9.3\end{array}$ & $\begin{array}{c}161 \\
\mathbf{1 5 . 4}\end{array}$ & $\begin{array}{l}35 \\
1.9\end{array}$ \\
\hline & 38 & 6 & $\begin{array}{l}500 \\
17.7\end{array}$ & $\begin{array}{c}15 \\
-9.3\end{array}$ & $\begin{array}{c}5 \\
-9.6\end{array}$ & $\begin{array}{c}0 \\
-6.5\end{array}$ \\
\hline \multirow{4}{*}{3} & 11 & 8 & $\begin{array}{l}170 \\
-6.3\end{array}$ & $\begin{array}{r}200 \\
18.2 \\
\end{array}$ & $\begin{array}{c}12 \\
-6.9\end{array}$ & $\begin{array}{c}0 \\
-5.5\end{array}$ \\
\hline & 22 & 7 & $\begin{array}{l}365 \\
3.1\end{array}$ & $\begin{array}{l}133 \\
4.0\end{array}$ & $\begin{array}{c}56 \\
-3.6\end{array}$ & $\begin{array}{c}0 \\
-6.8\end{array}$ \\
\hline & 24 & 6 & $\begin{array}{l}210 \\
1.7\end{array}$ & $\begin{array}{l}80 \\
3.2\end{array}$ & $\begin{array}{c}36 \\
-2.2\end{array}$ & $\begin{array}{c}0 \\
-5.1\end{array}$ \\
\hline & 26 & 8 & $\begin{array}{l}59 \\
-0.5\end{array}$ & $\begin{array}{c}0 \\
-4.8\end{array}$ & $\begin{array}{l}43 \\
7.5\end{array}$ & $\begin{array}{c}1 \\
-2.4\end{array}$ \\
\hline \multirow{4}{*}{4} & \multirow{2}{*}{39} & 10 & $\begin{array}{c}488 \\
18.4\end{array}$ & $\begin{array}{c}0 \\
-10.8\end{array}$ & $\begin{array}{c}7 \\
-9.0\end{array}$ & $\begin{array}{c}0 \\
-6.3\end{array}$ \\
\hline & & 11 & $\begin{array}{l}388 \\
14.5\end{array}$ & $\begin{array}{c}0 \\
-9.9\end{array}$ & $\begin{array}{l}27 \\
-5.2\end{array}$ & $\begin{array}{c}0 \\
-5.8\end{array}$ \\
\hline & \multirow{2}{*}{40} & 10 & $\begin{array}{c}64 \\
-12.9\end{array}$ & $\begin{array}{r}208 \\
25.3\end{array}$ & $\begin{array}{c}0 \\
-7.3\end{array}$ & $\begin{array}{c}8 \\
-2.8\end{array}$ \\
\hline & & 11 & $\begin{array}{r}210 \\
11.5\end{array}$ & $\begin{array}{c}0 \\
-7.0 \\
\end{array}$ & $\begin{array}{c}5 \\
-5.4 \\
\end{array}$ & $\begin{array}{c}0 \\
-4.1 \\
\end{array}$ \\
\hline
\end{tabular}

Chi-sq $=7260.1, \mathrm{df}=42, \mathrm{p}=<0.01$

Several intact or clustered burned rock features were identified on the site. These primarily consist of clusters of sandstone, including Feature 2 and Level 12 in Area 1, Level 6 in Area 2 (EU 38), and Feature 10 in BHT 10 (adjacent to Area 3). Feature 10 actually includes portions of two features. It is regrettable that the backhoe trench destroyed most of these two features since their structure appears somewhat different from the others. That is, Feature 10 is characterized by a layer of multiple burned rocks, rather than single pieces of clustered sandstone at the same level. The sandstone clusters probably represent simple hearths. The exact structure and composition of Feature 10 is undetermined; however, the same levels in adjacent excavation units contain mostly sandstone with less limestone and chert (EU 11, Level 7), and mostly lime- 
stone and sandstone with very little chert (EU 22, Level 8). The lack of intact features at 41MV120 makes the interpretation of possible burned rock function difficult. Could the sandstone materials have been primarily used in the construction of simple hearths, and the cobble materials as hearth elements, in processing features or as boiling stones?

The Choke Canyon archaeological sites provide some information on the range of burned rock feature construction which existed on Archaic and Late Prehistoric sites in South Texas. These sites are located in the vicinity of the Frio River, where outcrops of sandstone, tuff, gravel terraces are exposed. They also represent campsites that contain a variety of lithic artifacts, burned rock, and the remains of mussel and snail shells. A review of Black (1986) and Scott (1982) reveals several basic patterns in the construction of intact burned rock features. The majority of the features consist of circular clusters of burned rock ranging from $40-115 \mathrm{~cm}$ in diameter. Some of these appear to be lining shallow pits or perhaps ovens. Only a single feature was identified as an unlined burned pit filled with ash and a few pieces of burned sandstone (41MC29, Feature 3; Hall et al. 1986:136). Otherwise, the circular burned rock features can be arbitrarily divided into smaller and larger forms. The smaller diameter features (ca. 40-70 cm), consist of a single layer of burned rock, with little charcoal, mussel, or snail shell being present (e.g., 41LK210, Feature 1; 41MC24, Feature 1; 41MC75, Feature 1 [Hall et al. 1982:73, 177, 235]). In contrast, the larger diameter features $(\mathrm{ca} .100+\mathrm{cm}$ ) consist of a layer of rocks mixed with some mussel and snail shells, and underlain with a lens of charcoal (e.g., 41LK31/32, Feature 11 [Scott 1982:41]; 41LK128, Hearth 2; 41LK128, Hearth 17 [Hall et al. $1986: 43,45])$. Very little bone is present among any of the circular burned rock features. In addition, there are also scatters of burned rock which presumably reflect the disturbed remains of these features (e.g., 41LK51, Feature 5; 41LK53, Feature 2; 41MC96, Feature 1 [Hall et al. 1986:97, 108, 162]). Based on the illustrations, the smaller circular features $(n=9)$ tend to be composed of more sandstone or tuff, the larger circular features of mostly chert $(n=7)$, and the general scatters of a mixture of materials $(n=6)$. It is unclear how representative these features are of the actual variability that existed, or how much the local availability of materials is conditioning these patterns. Nonetheless, it indicates that an array of bedrock and cobble raw materials were used in the construction of circular burned rock features. At least some of these may represent simple hearths, and others shallow pit ovens (for cooking mussels, bulbs, tubers, and meats?). The variability exhibited by burned rock features at site 41MV120 appears be to limited to isolated clusters of sandstone, possibly larger features in BHT 10, and burned rock scatters of varying density across the site.

\section{Archaeomagnetic Sampling}

To gain contextual evidence on the burned rock features, a program of archaeomagnetic analysis was instituted. The form of analysis can provide independent evidence concerning feature integrity and disturbances.

\section{Methods}

CAR collected 44 core samples from 13 excavation units and one backhoe trench (Table 10-4). Fire cracked rocks from various features were drilled in place using an Echo E-Z Core rock drill, model D-2801, with a 1 -inch diamond-tipped bit. The angle and dip were recorded using a Brunton compass mounted on a goniometer. The elevation of each sample relative to the unit datum was also recorded. A plan-view map of the drilled rocks was annotated with the sample number. After each sample was scored and marked with a Sharpie to ensure proper alignment during the laboratory processing phase, they were separated from the parent rock and placed in individual labeled bags.

Twenty of the 44 samples were selected for analysis based on a review of their context and suitability for examination. These were submitted to Dr. Wulf Gose at the Paleomagnetic Laboratory, Department of Geological Sciences, The University of Texas at Austin. There the samples were cut down to 0.9 -inch lengths and labeled with Pelican ink. Next they were placed in a helium-cooled cryogenic magnetometer to record their natural remanent magnetization (NRM) signature. After this they were subjected to alternating field (AF) 
Table 10-4. Archaeomagnetic Samples from 41MV120

\begin{tabular}{|c|c|c|c|}
\hline Sample \# & Excavation Unit & Level & Remarks \\
\hline 1 & 1 & $100-105$ & submitted for analysis \\
\hline 2 & 1 & $100-105$ & \\
\hline 3 & 14 & 80 & \\
\hline 4 & 14 & 80 & submitted for analysis \\
\hline 5 & 10 & $60-65$ & \\
\hline 6 & 10 & $55-60$ & \\
\hline 7 & BHT 10 & $70-80$ & \\
\hline 8 & 13 & $70-80$ & \\
\hline 9 & 13 & $70-80$ & submitted for analysis \\
\hline 10 & 13 & $70-80$ & submitted for analysis \\
\hline 11 & 13 & $70-80$ & submitted for analysis \\
\hline 12 & 13 & $70-80$ & submitted for analysis \\
\hline 13 & 26 & $70-80$ & submitted for analysis \\
\hline 14 & 26 & $70-80$ & \\
\hline 15 & 13 & $100-110$ & \\
\hline 16 & 15 & $80-90$ & \\
\hline 17 & 40 & $100-110$ & \\
\hline 18 & 40 & $100-110$ & submitted for analysis \\
\hline 19 & 40 & $100-110$ & \\
\hline 20 & 40 & $100-110$ & submitted for analysis \\
\hline 21 & 40 & $110-120$ & \\
\hline 22 & 40 & $90-100$ & \\
\hline 23 & 38 & $50-60$ & submitted for analysis \\
\hline 24 & BHT 10 & $70-80$ & \\
\hline 25 & BHT 10 & $70-80$ & \\
\hline 26 & BHT 10 & $70-80$ & \\
\hline $27 \mathrm{~A}$ & BHT 10 & $80-90$ & submitted for analysis \\
\hline $27 \mathrm{~B}$ & BHT 10 & $80-90$ & submitted for analysis \\
\hline 28 & BHT 10 & $80-90$ & submitted for analysis \\
\hline 29 & BHT 10 & $80-90$ & submitted for analysis \\
\hline 30 & BHT 10 & $50-60$ & \\
\hline 32 & BHT 10 & $50-60$ & \\
\hline 33 & BHT 10 & $70-80$ & \\
\hline 34 & BHT 10 & $70-80$ & \\
\hline 35 & BHT 10 & $80-90$ & \\
\hline 36 & BHT 10 & $80-90$ & \\
\hline 37 & BHT 10 & $70-80$ & \\
\hline 38 & BHT 10 & $70-80$ & \\
\hline 39 & BHT 10 & $70-80$ & \\
\hline 41 & 43 & $110-120$ & submitted for analysis \\
\hline 42 & 43 & $110-120$ & submitted for analysis \\
\hline 43 & 36 & $110-120$ & submitted for analysis \\
\hline 44 & 34 & $110-120$ & submitted for analysis \\
\hline 45 & 33 & $110-120$ & \\
\hline 46 & 33 & $110-120$ & \\
\hline
\end{tabular}


demagnetization in increments of $50^{\circ} \mathrm{Am}^{2} / \mathrm{kg}$. After each demagnetization step, their magnetic signature was measured in the magnetometer and recorded in a computer database.

\section{Analysis of Heated Rocks}

When rocks originally form they adopt a magnetic signature pointing toward the current magnetic north. If collected and heated in a hearth or oven, their magnetic field is altered. As they cool, the rocks adopt a magnetic signature aligned with the magnetic north existing at the time of heating. If the rock is moved by natural processes or humans after it has cooled, then the magnetic alignment preserved in the rock will shift from the magnetic pole. In some cases a rock may be moved while it is cooling or it may have been heated more than once, and two or more magnetic alignments can be preserved in the rock. By using a series of measurements with a stepped demagnetization process, magnetic alignments can be measured. The demagnetization in the laboratory erases the magnetic signal preserved in the rock at the demagnetization level or below. Thus heating events can be identified.

Individual magnetic signals are measured, and the data are plotted on vector component diagrams and equal area stereographic projections (Figure 10-5). On the equal-area stereographic projections, declinations are measured along the perimeter of the circle, and inclinations decrease from $90^{\circ}$ at the center to $0^{\circ}$ at the perimeter. Positive declinations are shown as solid crosses on individual plots or solid circles on composite plots, and negative declinations are shown as open circles on both types of plots.

On the vector component diagram (Figure 10-6) the axes represent the intensity of magnetization calibrated in $\mathrm{Am}^{2} / \mathrm{kg}$. The crosses are the vector end points projected on an up-down horizontal plane, and the open squares are the vector end points projected on a northsouth-east-west plane. Samples whose vector plots demonstrate one general direction toward 100-percent demagnetization or "zero" suggest one heating event; more than one direction may indicate more than one heating event has occurred or that a single event failed to erase the original remanent magnetism of the rock.
Three or more co-linear points on a vector diagram suggest a change in magnetization vectors which, on an archaeological sample, most probably reflects a single heating event. For each sample, Gose plotted the discrete components of demagnetization, and the data was interpreted by Gose and CAR staff. The composite equal-area stereographic projections are presented in Figure 10-7 and the $\mathrm{Am}^{2} / \mathrm{kg}$ range follows the sample number. Individual sample plots are illustrated in Appendix F. However, the reader must realize that AF demagnetization is not directly equitable to thermal demagnetization. There is not a 1:1 correspondence between the two forms of demagnetization. Nevertheless, it is reasonable to assume that lower $\mathrm{Am}^{2} / \mathrm{kg}$ readings probably correspond to lower heating temperatures in these burned rock features, and high $\mathrm{Am}^{2} / \mathrm{kg}$ readings reflect higher heating temperatures.

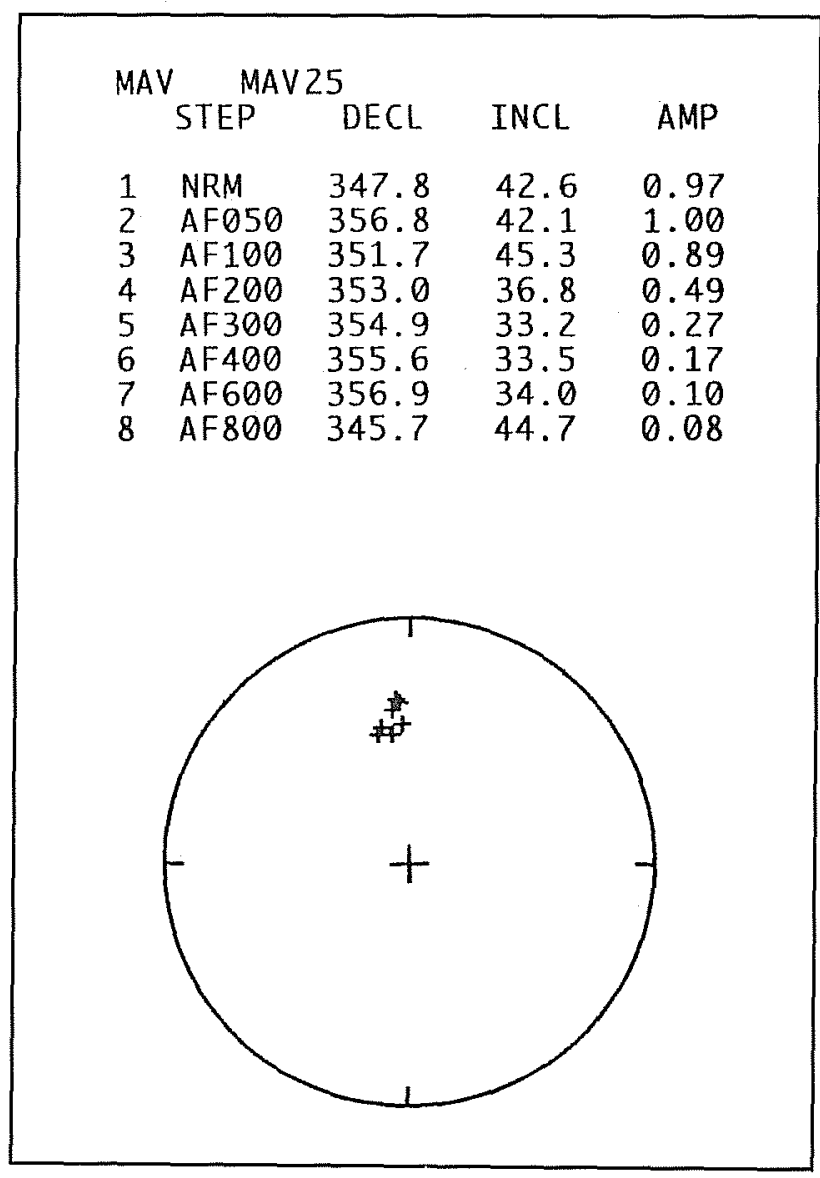

Figure 10-5. Archaeomagnetic heating events. 


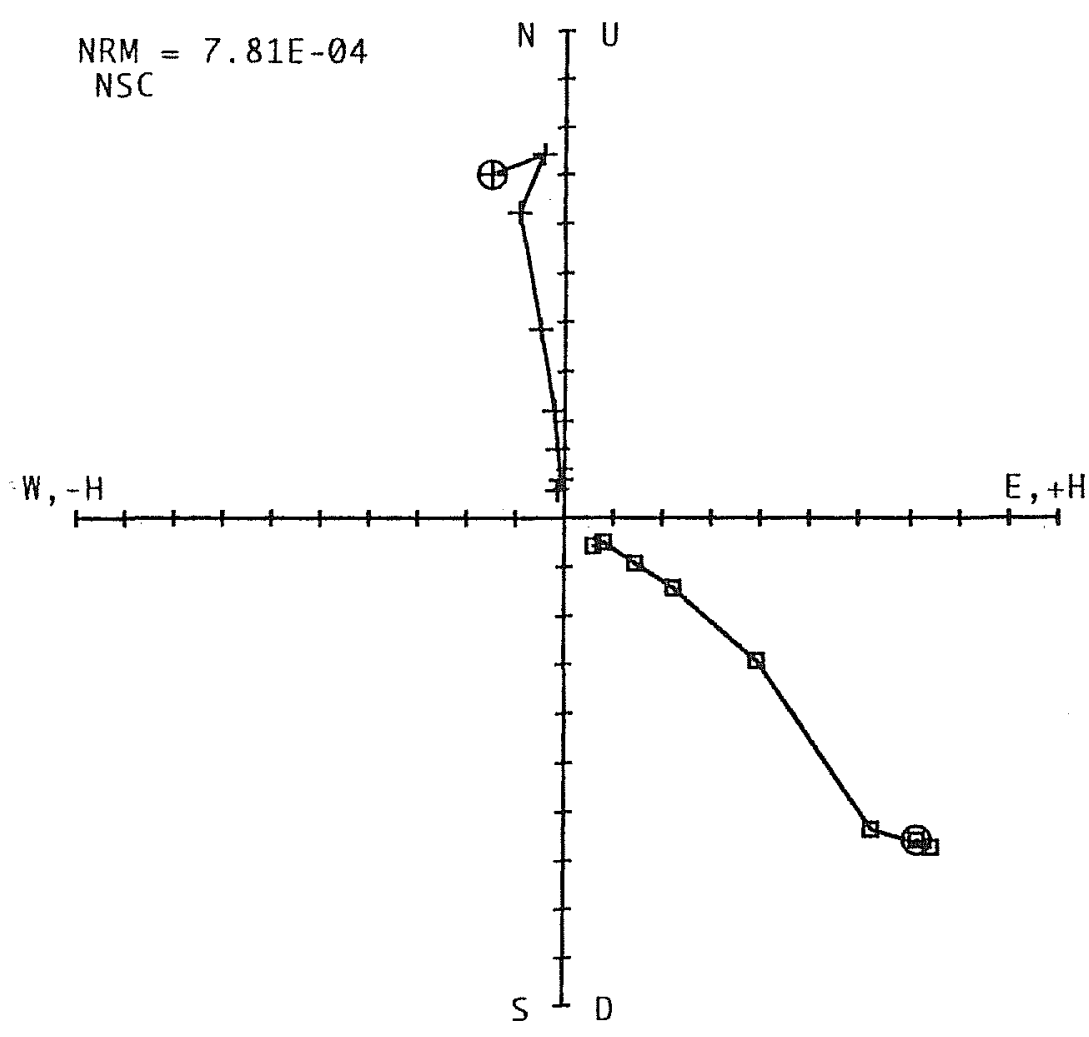

Figure 10-6. Vector component diagram representing intensity of magnetization.

\section{Heated Rocks at $41 \mathrm{MV} 120$}

Sample 1 was taken from a burned rock in EU 1, Level 1. Vector plots of this sample indicate two possible cultural heating events, the first to around $400 \mathrm{Am}^{2} / \mathrm{kg}$ and the second to around $200 \mathrm{Am}^{2} / \mathrm{kg}$. After it cooled the rock was moved and was not in situ when sampled. Under the supposition that this rock was part of a cultural feature, our interpretation is that it was reused in a cooking feature and then disturbed after its last cooling.

Sample 4 is fire-cracked rock in EU 13, Level 6. Patterns in the vector component diagram indicate this rock may have been culturally heated to around $100 \mathrm{Am}^{2} /$ $\mathrm{kg}$ and then moved after cooling. As stated previously, interpretations of data at lower temperatures are at best problematic; however, under the supposition that this sample was culturally heated, the data suggests that it may have been part of the periphery of a higher heat source, such as a hearth ring, before it cooled and was moved either by natural or cultural causes.

Samples 9-12 were taken from four fire-cracked rocks in feature in EU 13 between $70-80 \mathrm{~cm}$ bs. Data from Sample 9 suggest this rock was heated to between $100^{\circ}$ $\mathrm{Am}^{2} / \mathrm{kg}$ and $200^{\circ} \mathrm{Am}^{2} / \mathrm{kg}$ before being allowed to cool and then moved. Data from Sample 10 reveal no conclusive indicators of cultural heating, but do show that the rock has been moved. Sample 11 data suggest that this rock was heated to around $300 \mathrm{Am}^{2} / \mathrm{kg}$, but has been badly disturbed since it cooled; it has rotated and been turned over since being heated. The data obtained from Sample 12 may not be totally reliable, but may indicate that this rock was heated to around $200^{\circ}$ $\mathrm{Am}^{2} / \mathrm{kg}$. In any case, it has been badly disturbed since it cooled. Given the cultural context from which these samples were obtained, our interpretation is that they were part of an open hearth; however, at some point since they cooled they have been moved around by either natural or cultural causes.

Sample 14 is from Level 7 in EU 26. Vector plots for this sample indicate a possible low heating event to around $100^{\circ} \mathrm{Am}^{2} / \mathrm{kg}$; however, after it cooled the rock was disturbed either by natural or cultural causes. The high temperature component appears to be the natural remanent magnetic signal. Given the cultural context of this sample and its relationship to other nearby firecracked rock, we posit that it may have been peripheral to the main heat source, such as a rock forming part of an open hearth ring.

Samples 18 and 20 are from EU 40. Sample 18 was taken from a fire-cracked rock in Level 3; Sample 20 came from Level 4 . Vector plots for Sample 18 indicate it has been heated to around $40^{\circ} \mathrm{Am}^{2} / \mathrm{kg}$ since it 

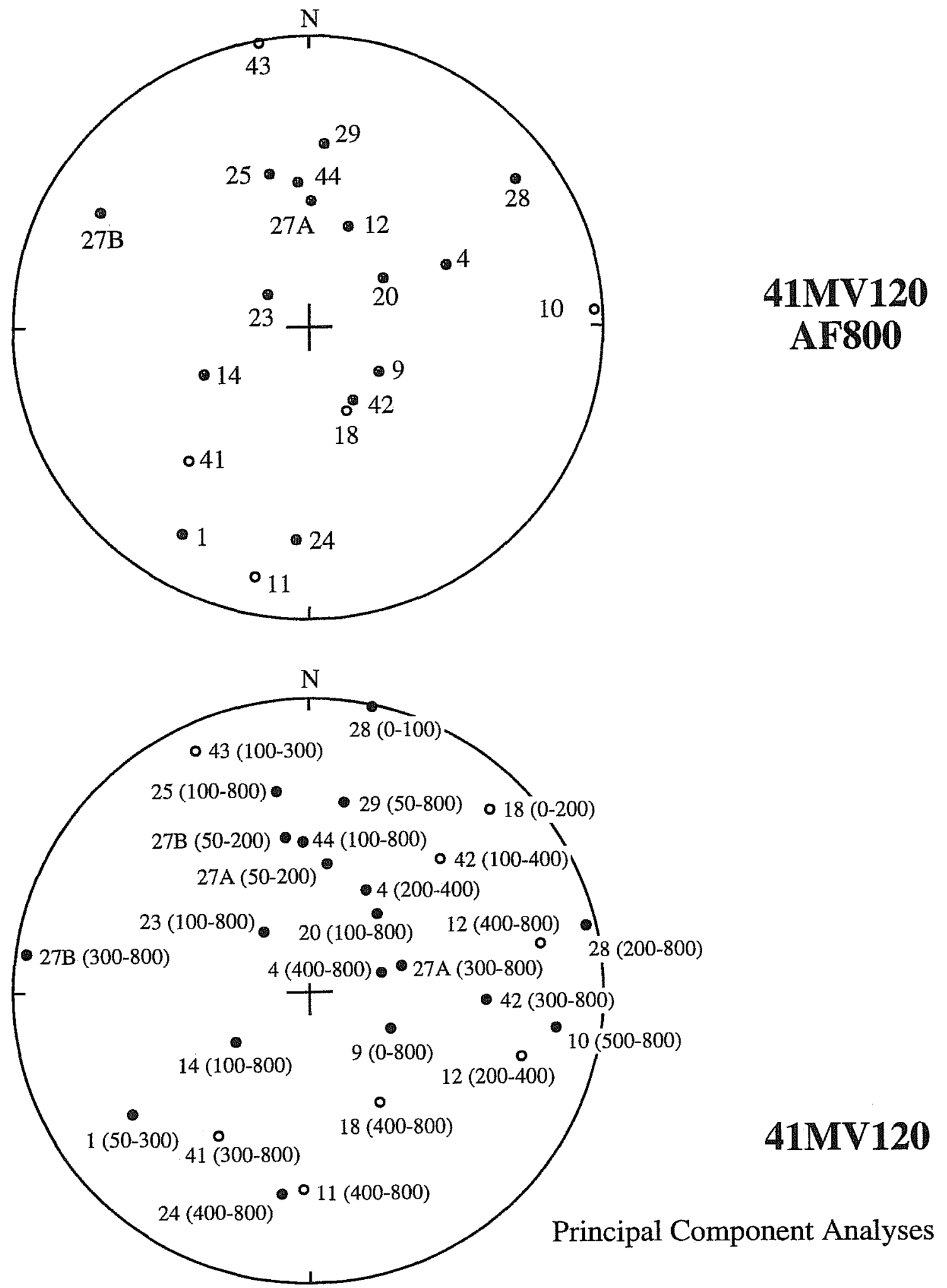

Figure 10-7. Archaeomagnetic heating for events for all site samples. 
was naturally formed; however, after it was heated and allowed to cool, it has rotated and flipped. The rock from which sample 20 was obtained may have been exposed to a low heat (ca. $100^{\circ} \mathrm{Am}^{2} / \mathrm{kg}$ ), and appears to have been slightly disturbed after it cooled. Under the supposition that these samples have been culturally altered, and given the context of the fire-cracked rock as one piece of a cooking feature, the data suggests that rock 18 may have been within or near the center of the feature but was later moved after it cooled, either by natural or cultural causes. Rock 20 may have been on the periphery or ring of the feature thus being exposed to less heat, but was only slightly moved after it cooled.

Sample 23 was taken from EU 38, Level 5. Vector plots for this sample suggest it may have been exposed to a low temperature (ca. $100^{\circ} \mathrm{Am}^{2} / \mathrm{kg}$ ), and has been slightly disturbed since it cooled. Assuming it is part of a hearth feature, our interpretation is that it was either directly exposed to a low temperature fire, or was part of the periphery of a hotter fire such as a hearth ring, was left to cool in place, and was later slightly disturbed after cooling, either by natural or cultural causes.

Six samples from 70-80 $\mathrm{cm}$ below the surface (bs) in BHT 10 were analyzed. Vector plots for samples 24 , $25,27 \mathrm{~A}, 27 \mathrm{~B}, 28$ and 29 suggest perhaps a very low temperature heating event ( $\mathrm{ca} .100^{\circ} \mathrm{Am}^{2} / \mathrm{kg}$ ) may have occurred in these rocks, however, Samples 24 and 28 have been disturbed while 25,27A and 29 appear to be in situ. Problematic to this interpretation for $27 \mathrm{~A}$ is that vector plots for sample $27 \mathrm{~B}$ which came from the same rock suggest it has been heated to ca. $200 \mathrm{Am}^{2} /$ $\mathrm{kg}$ and is not in situ, even though sample 27B behaves more like $27 \mathrm{~A}$ when heated to below $300 \mathrm{Am}^{2} / \mathrm{kg}$. Two explanations are feasible for the difference in magnetic signatures: either data recorded in the field during sampling was in error, or one of the samples was contaminated (subjected to a magnetic field) during transport to the lab. Under the supposition that these six samples are pieces of a cultural feature, our interpretation is that rocks 25,27 , and 29 were either directly exposed to a low temperature fire, or were part of the periphery of a hotter fire such as a hearth ring, were left to cool in place, and were not later disturbed. The same inter- pretation applies to rocks 24 and 28 except they were moved after cooling either by natural or cultural causes.

Samples 41-44 were taken from Level 11 in EUs 34, 36 , and 43 respectively. The vector plots for samples 41,42 , and 43 indicate that the natural remanent magnetization (NRM) of these rocks were altered at around $300^{\circ} \mathrm{Am}^{2} / \mathrm{kg}$, and they are not in situ. The rock from which sample 44 was taken was in situ and its NRM appears to have been altered at around $100^{\circ} \mathrm{Am}^{2} / \mathrm{kg}$. Given the archaeological context of these four samples, our interpretation is that all have been culturally heated: Samples 41, 42, and 43 were heated to around $300^{\circ}$ $\mathrm{Am}^{2} / \mathrm{kg}$ but have been moved either by natural or artificial means after they cooled; Sample 44 cooled in place but was heated to only around $100^{\circ} \mathrm{Am}^{2} / \mathrm{kg}$. If the supposition that all four samples are from the same cooking element because they are linked vertically and horizontally, then we can suggest that Samples 41-43 were within the hottest part of the cooking element, and Sample 44 may have been on the periphery of the fire which only reached lower temperatures. Rocks that show evidence of heating to temperatures in the higher temperature ranges are thought to be related to open hearth features used for plant processing (Gose 1990). In any case, rocks 41 through 43 were moved after they were removed from the heat and allowed to cool, but rock 44 cooled and did not move.

\section{Discussion}

Only Sample 1 demonstrated more than one heating event suggesting reuse. No samples demonstrated the newly recognized signature for boiling stones. An analysis of all heating events reveals that 11 samples were heated to lower temperatures $\left(100^{\circ} \mathrm{Am} 2 / \mathrm{kg}\right)$, seven to moderate temperatures $\left(100-300^{\circ} \mathrm{Am}^{2} / \mathrm{kg}\right)$, and two to higher temperatures $\left(400^{\circ} \mathrm{Am}^{2} / \mathrm{kg}\right)$. If the 11 lowtemperature events are not considered because of their questionable reliability, a near unimodal pattern emerges (Figure 10-8). Bimodal patterns observed in samples from Camp Pearl Wheat (Gose 1990) and Fort Bliss (Gose 1997) suggest heated rocks associated with plant processing features at lower temperatures and meat processing at higher temperatures. Although a bimodal pattern is not manifested at 41MV120, a larger 


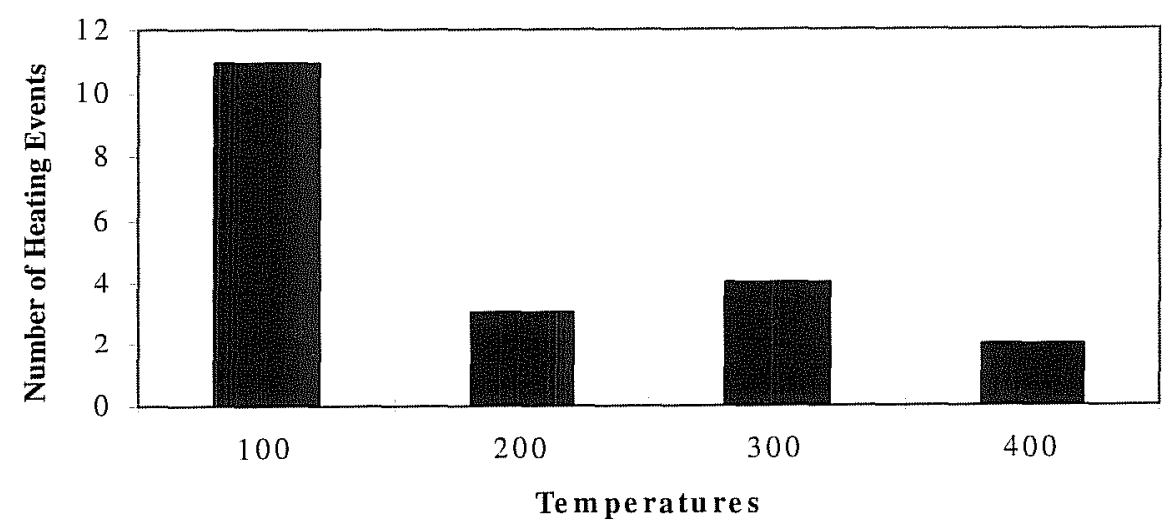

Figure 10-8. Maximum temperatures $\left({ }^{\circ} \mathrm{C}\right)$.

sample size from individual features along with chemical residue analysis could have provided better information.

Closer examination of the type of material sampled may offer clues to the food processing that occurred at 41MV120, but admittedly our sample size is too small from which to draw conclusive evidence. Table 10-5 demonstrates that 20 heating events occurred within the samples: 17 to sandstone, two to limestone, and one to chert. Assuming no bias in sampling methods, sandstone was clearly the material of choice for heating elements. Interestingly, 5 of 11 ( 45 percent) samples that were heated to lower temperatures were left to cool in place, but none of the nine moderate- to higher-heated rocks were left in place. Even with our limited sample size, the data raises questions as to why moderate-tohotter rocks were displaced and cooler rocks left in place. One possible explanation is that there was more than one method of processing. For example, the lower temperatures could represent open hearth features, and the moderateto-higher temperatures could represent ovens or stone boiling. Recent experiments with burned rock ovens have demonstrated that temperatures will easily exceed $400^{\circ} \mathrm{C}$ when abundant amounts of fuel are burned in large ovens (Nickels and Bousman 1988). This information could indicate that different types of features were in use.

\section{Conclusions}

The raw materials selected for thermal features at $41 \mathrm{MV} 120$ were available from local outcrops and gravel terraces. Most of the burned rock is composed of sandstone, with less limestone, chert, rhyolite, and other materials. The sandstone fragments tend to be larger than those of broken cobbles. The density of fire-cracked rock decreases from east to west across the site, with relatively more cobble materials toward the east, and sandstone to the west. The prevalence of burned cobbles in the eastern section of the site, in conjunction with mussels shells, may indicate that these

Table 10-5. Archaeomagnetic Materials and Heated Temperatures

\begin{tabular}{|c|c|c|c|c|}
\hline${ }^{\circ} \mathbf{C}$ & Sandstone & Limestone & Chert & Total \\
\hline 100 & $10(4)^{*}$ & 0 & $1(1)^{*}$ & $11(5)^{*}$ \\
\hline 200 & 2 & 1 & 0 & 3 \\
\hline 300 & 3 & 1 & 0 & 4 \\
\hline 400 & 2 & 0 & 0 & 2 \\
\hline Total & $17(4)^{*}$ & 2 & $1(1)^{*}$ & $20(5)^{*}$ \\
\hline
\end{tabular}

*Number in parenthesis is the number of in situ samples. 
cobbles were used in cooking activities. The firecracked rock at $41 \mathrm{MV} 120$ is distributed as isolated clusters of sandstone, as a layer of burned rock in Feature 10 , and mostly as varying densities of rock scatters. A review of the excavated intact thermal features from Choke Canyon Reservoir indicates that many were circular in form and measure about $40-115 \mathrm{~cm}$ in diameter. The smaller clusters tend to be made of mostly sandstone or tuff, and the larger features of cobbles. These smaller features could represent simple domestic hearths, and the larger features shallow ovens perhaps used for cooking mussels). The scatters of fire-cracked rock of mixed composition were identified as disturbed features.

The analysis of archaeomagnetic samples from site 41MV120 indicates that most of the rocks heated to low temperatures were found in situ. This includes four pieces of sandstone and one of chert. In contrast, all the rocks heated to moderate and higher temperature were recovered from disturbed contexts. These consist of mostly sandstone, with some limestone. It is unclear as to why no higher temperature features were recovered in situ, but this may be due to either maintenance activities, or post-occupational disturbances. More work needs to be conducted to further identify the structural variation in thermal features, and possible explanations for the use of differing raw material types in South Texas. 


\section{Chapter 11: Macrobotanical Remains}

\section{J. Philip Dering}

\section{Introduction and Laboratory Methods}

This chapter presents the results of archaeobotanical investigations of samples from 41MV120. One flotation sample and 43 macroplant samples were submitted to the Texas A\&M University (TAMU) Archaeobotanical Laboratory for examination. Flotation samples consist of archaeological sediment that has been floated in water to separate lighter charred plant remains from heavier material and from clays/ silts that can be suspended in water and rinsed out of the sample. The sediment sample was floated by CAR personnel, and the light fraction submitted to TAMU for analysis. The second type of sample in this analysis is termed a macroplant sample. This includes plant material that is collected from archaeological screens, collected in situ during excavation, or picked from archaeological sediments during laboratory analysis.

Standard archaeobotanical laboratory procedures were followed during analysis of the flotation sample. The single sample was sorted through a series of four nested geological screens, with mesh sizes ranging from $4 \mathrm{~mm}$ to $0.450 \mathrm{~mm}$. Each size grade, including the pan, was scanned for plant seeds/fruit under a binocular dissecting microscope at 8 magnifications. Carbonized wood remains from the 2-mm and 4-mm mesh sieves were separated for identification.

All charred seeds and fruit and nut fragments were counted. Identifications were made using reference collections at TAMU. Carbonized wood was treated in the same manner. In cases where a large amount of wood is encountered, a sample of 25 pieces from the 4-mm and 2-mm mesh sieves is examined; however, in this study carbonized wood was so rare that the 25 piece maximum was not often reached. All the charred material was counted in the flotation sample, and the density of charred plant material was expressed in parts per liter.
The anatomy of some woods is so similar that it is very difficult to identify to the genus level. In other cases, genera within a plant family are usually distinguishable, but some of the archaeological material is often too fragmented or deteriorated to allow identification to the genus level. For these reasons, I combine some taxa into wood types. All identifications in the "type" category represent identifications to the taxon level indicated by the name of the type. The following wood types or categories are used in this report:

Mesquite-Refers to honey mesquite (Prosopis glandulosa). The screwbean mesquite (Prosopis reptans) lacks a large woody stem or trunk, and what greatly reduced parts it has do not resemble either honey mesquite or the acacias.

Acacia-Refers to several plants of the genus, including huisache (Acacia farnesiana), blackbrush (Acacia rigidula), and whitethorn mescat (Acacia constricta). The material in the 41MV120 samples strongly favor huisache. Acacia wood can be distinguished from mesquite in pieces larger than $4 \mathrm{~mm}$ in cross-section. In the acacias, early-wood pores usually do not occur in groups of up to 10cells; whereas in mesquite, earlywood pores are in much smaller groups those of the acacias. In the acacias, late-wood pores occur in groups of one to five, and usually are arranged in single file (seriate) along the radius of the stem. In contrast, mesquite late-wood pores usually occur singly or in small groups, but are not seriate. In addition, late-wood parenchyma of mesquite is paratracheal, and usually occurs in almost continuous bands around the stem.

Arboreal Legume - Refers to woody members of the bean family (Fabaceae), including mesquite and several species of acacia. Depending on the size and condition of the piece of wood that is submitted for analysis, it is often difficult to separate the acacias from mesquite. 
Indeterminate Hardwood - Refers to any woody seed-bearing plant (i.e., not a cone-bearing tree such as pine, cypress, or juniper).

\section{Results and Discussion}

Over 350 wood or woody root fragments, $107.9 \mathrm{~g}$ of carbonized wood, and one uncharred nutshell fragment were identified in the flotation and macroplant samples. No charred seeds were recovered during this analysis. The taxa, counts, and weights identified in the study are listed Table 11-1. Level numbers used in this table are the original field designations, and not the revised $10-\mathrm{cm}$ levels referred to in Chapter 8 (see Appendix C for conversions [level vs. level 2]). The acacia wood compares very favorably to huisache (Acacia farnesiana). These trees are common components of open creek floodplains and the higher alluvial terraces located along the margins of creeks.

Two features contained carbonized wood. Acacia wood, probably huisache, was identified from Feature 8 . The fact that the wood represented a large stem suggests that Feature 8 may be a tree burn rather than material recovered from a hearth. The flotation sample from Feature 1 contained 127 pieces of charred mesquite wood, and 169 pieces of uncharred mesquite wood and root. No carbonized seeds were noted in the flotation sample, which had a charred plant part density of 20.3 parts/liter. The age of the carbonized plant material is questionable. Some of the wood is partly carbonized, that is, it has some visibly uncharred surfaces. Although charred material consists of 50-60 percent elemental carbon (McGinnes et al. 1974), in archaeological specimens the uncharred portions are almost always encased and preserved in the charred portions, and the material appears black. In addition, the uncharred wood in the flotation sample is a recent intrusion. Therefore, the charred material may be coeval with the feature, or it may be the result of a more recent burn that arrived via bioturbation. Also, I have seen root burns extending one meter into a profile.

A pecan orchard is located to the immediate north of the site; therefore, the single uncarbonized pecan shell recovered from EU 19 (Level 7) is probably modern. However, the archaeological record indicates that pe- can was distributed as far west as the Devils River (Ken Brown, personal communication 1996), and pecans were growing near the mouth of the Devils River until the 1954 flood (David Riskind, personal communication 1995). Although pecans were restricted to wellwatered or sheltered environments throughout the western limits of their range, there remains a possibility that pecan trees grew on the banks of Elm Creek at some time during the Holocene.

Huisache (Acacia farnesiana) and other acacias are also quite common in the region. Huisache grows in low terraces or swales on the open floodplains of drainages, and competes well in heavier soils. Although it is a dense wood, huisache produces secondary metabolites (i.e., chemicals which reduce insect predation and pathogen growth), that give off a strong odor, both before and after burning. As a result, its utility as a fuel wood may be limited. The huisache recorded in these samples may be the remains of a prehistoric tree burn.

Both prehistoric and historic records indicate that mesquite was distributed widely throughout southern and western Texas prior to the twentieth century. Mesquite wood charcoal is often recovered at archaeological sites in South Texas (Dering 1995, 1997; Holloway 1986), and it was utilized for fuel and food by Archaic populations as early as 8000 B.P. (Dering 1997). Reports of the "spread" of mesquite tend to overlook just how widespread mesquite was prior to the impact of recent ranching practices. Although extensive stands of mesquite were limited to erosional breaks, open woodlands along creeks, and rocky uplands (Johnston 1963), small groves or mottes of mesquite and solitary trees often grew in the uplands.

Mesquite is well documented by the Spanish explorers who passed through Maverick County during the sixteenth and seventeenth centuries. Fernando del Bosque encountered grasslands that he described as "fine pastures" containing "much mesquite" (Inglis 1964:46). In 1709 the Espinosa-Olivares-Aguirre expedition passed 30 miles southeast of Eagle Pass. The account notes the presence of mesquite groves on level ground and thickets along creeks (Inglis 1964:48). These descriptions characterize a savanna parkland (Archibold 1995:61). 
Table 11-1. Plant Remains Identified in the Samples

\begin{tabular}{|c|c|c|c|c|c|c|c|}
\hline Unit & Level & Lot & Feature & Plant Name & Part & Count & Weight (g) \\
\hline \multirow[t]{2}{*}{ BHT 7} & & 179 & & In determinable & Wood & 3 & 0.1 \\
\hline & & 197 & & Honey Mesquite & Wood & 3 & 0.1 \\
\hline \multirow[t]{3}{*}{ BHT 10} & & 256 & & Indeterminable & Wood & 3 & 0.1 \\
\hline & & 270 & & No Carbonized Remains & Not Applicable & & 0.0 \\
\hline & & 274 & & No Carbonized Remains & Soot/sediment & & 0.0 \\
\hline \multirow[t]{4}{*}{ BHT 12} & & 701 & & Arboreal legume & Wood & & 0.0 \\
\hline & & 702 & & Honey Mesquite & Wood & 3 & 0.1 \\
\hline & & 703 & & Honey Mesquite & Wood & 4 & 1.4 \\
\hline & & 704 & & Acacia & Wood & 10 & 0.5 \\
\hline EU 2 & 12 & 3 & & Honey Mesquite & Wood & 8 & 0.2 \\
\hline \multirow[t]{3}{*}{ EU 6} & 6 & 52 & & Acacia & Wood & 25 & 28.7 \\
\hline & 7 & 58 & 1 & Honey Mesquite & Nut & 7 & 4.2 \\
\hline & & $59^{1}$ & 1 & Honey Mesquite & Wood & 25 & 5.2 \\
\hline \multirow[t]{3}{*}{ EU 7} & 2 & 78 & & No Carbonized Remains & Not Applicable & & 0.0 \\
\hline & 12 & 88 & & Honey Mesquite & Wood & & 0.0 \\
\hline & 3 & 429 & & Honey Mesquite & Wood & 1 & 0.7 \\
\hline \multirow[t]{4}{*}{ EU 8} & 1 & 104 & & Honey Mesquite & Wood & 4 & 0.2 \\
\hline & 2 & 108 & & Indeterminable & Wood & 3 & 0.1 \\
\hline & & 109 & & Honey Mesquite & Wood & 11 & 0.1 \\
\hline & 3 & 115 & & Honey Mesquite & Wood & 11 & 0.4 \\
\hline EU 9 & 8 & 140 & & Honey Mesquite & Wood & 25 & 1.4 \\
\hline \multirow[t]{2}{*}{ EU 10} & 14 & 454 & & Honey Mesquite & Wood & 6 & 0.6 \\
\hline & 17 & 459 & & Honey Mesquite & Wood & 7 & 0.5 \\
\hline \multirow[t]{3}{*}{ EU 11} & 4 & 358 & & No Carbonized Remains & Not Applicable & & 0.0 \\
\hline & 5 & 363 & & Honey Mesquite & Wood & 21 & 2.2 \\
\hline & 17 & 661 & & In determinable & Wood & 5 & 0.1 \\
\hline \multirow[t]{3}{*}{ EU 13} & 8 & 765 & & Honey Mesquite & Wood & 25 & 2.3 \\
\hline & 9 & 772 & 6 & No Carbonized Remains & Not Applicable & & 0.0 \\
\hline & & 773 & 7 & No Carbonized Remains & Not Applicable & & 0.0 \\
\hline EU 15 & 9 & 1105 & & Honey Mesquite & Wood & 17 & 0.3 \\
\hline \multirow[t]{2}{*}{ EU 16} & 4 & 631 & & Indeterminable & Wood & 1 & 0.3 \\
\hline & 5 & 632 & & Honey Mesquite & Wood & 2 & 0.2 \\
\hline \multirow[t]{3}{*}{ EU 19} & 3 & 778 & & Indeterminable & Wood & 5 & 0.1 \\
\hline & 4 & 780 & & Acacia & Wood & 1 & 0.1 \\
\hline & 7 & 788 & & Pecan & Nut & 1 & 0.2 \\
\hline \multirow[t]{2}{*}{ EU 22} & 4 & 811 & & Honey Mesquite & Wood & 5 & 0.2 \\
\hline & 8 & 820 & & Indeterminate Hardwood & Wood & & 0.0 \\
\hline EU 33 & 12 & 1260 & & Arboreal legume & Wood & & 0.0 \\
\hline
\end{tabular}


Table 11-1. continued

\begin{tabular}{|c|c|c|r|l|l|r|r|}
\hline Unit & Level & Lot & Feature & \multicolumn{1}{|c|}{ Plant Name } & \multicolumn{1}{|c|}{ Part } & Count & Weight (g) \\
\hline EU 34 & 9 & 1280 & & Honey Mesquite & Wood & 23 & 0.2 \\
\hline EU 36 & 7 & 1304 & & Arboreal legume & Wood & & 0.0 \\
\hline \multirow{2}{*}{ EU 39 } & 2 & 1001 & 8 & Acacia & Wood & 25 & 28.7 \\
\cline { 2 - 8 } & 3 & 1002 & 8 & Acacia & Wood & 25 & 22.8 \\
\cline { 2 - 8 } & 6 & 1007 & & Indeterminable & Wood & 11 & 0.6 \\
\hline EU 40 & 1 & 1028 & & Honey Mesquite & Wood & 25 & 5.0 \\
\hline
\end{tabular}

${ }^{1}$ Lot 59 is a flotation sample with a sediment volume of 6.25 liters before flotation.

These brief descriptions illustrate the mix of woody species and grasslands typical of a savanna. Savannas are located in the tropics and subtropics that are best characterized as a tension zone between woody and grassland vegetation (Cole 1986). In southern Texas and northern Mexico, the conversion of a low tree and shrub savanna to a thicket and scrub community has been both rapid and recent, occurring within the last 100 years. Today most of the Rio Grande Plains can be characterized as a mesquite-thornscrub savanna parkland in which the woody vegetation has recently expanded due to a variety of causes, primarily overgrazing, suppression of fire, and variation in rainfall on a decadal scale (Archer 1995:83).

Overgrazing and the 1880 s drought have often been blamed for the destruction of the grasslands and the subsequent brush invasion of the late-nineteenth and early-twentieth centuries (Bray 1901; Cook 1908). Johnston (1963:464) was the first to criticize these assertions as oversimplification, and he emphasizes that the vegetation changed from "mesquite-prairie" to "mesquite brush." However, the impact of Anglo-European ranching and land use practices reached a peak in the early- to middle-twentieth century, and this occurred simultaneously with a rise in effective moisture between 1940 and 1980 .

Archer (1995) demonstrates that the rise in effective moisture, coupled with fire suppression, probably contributed more to the spread of brush than any other land management factor. The concept of the spread of mesquite shrub lands is itself an oversimplification of a complex vegetation succession process. Mesquite acts as a nurse tree that encourages the establishment of shrub clusters which serve to limit the recruitment of mesquite. Woody species include colima (Zanthoxylon fagara), prickly pear (Opuntia spp.), agarita (Berberis trifoliata), and lotebush (Ziziphus obtusifolia). Demise of grasslands in the region is primarily due to abiotic factors, such as the suppression of fire and variations in rainfall, rather than the tendency of grasslands to resist mesquite recruitment (Archer 1995).

\section{Conclusions}

The 43 macroplant samples and the single flotation sample yielded an assemblage dominated by mesquite wood. The presence of mesquite in the region, and the utilization of mesquite by the prehistoric human population, is documented in the archaeological record (Dering 1995; Holloway 1986). Mesquite mottes commonly occurred on alluvial landforms along creeks, and solitary trees on upland prairies (cf., Inglis 1964). Thus mesquite was probably a common component of the prehistoric landscape. Because of this fact it may be difficult to unequivocally demonstrate the anthropogenic origin of the mesquite wood recovered from $41 \mathrm{MV} 120$. Clearly however, mesquite was growing in the area of the site, and the tree was available for use as both a source of food and a source of fuel. 


\section{Chapter 12: Freshwater Mussel (Unionidae) Shell Remains}

\section{Robert G. Howells}

\section{Introduction}

Freshwater mussels (Family Unionidae) were utilized by Native Americans in Texas from northeastern Caddos to others along the Rio Grande (Neck 1982a). Harvest in Texas and elsewhere focused on shells (Chandler and Kumpe 1992; Lintz 1992; Murray 1982a), pearls (Kunz 1897), and meat (Neck 1982a; Parmalee and Klippel 1974). Large shell mounds in some parts of the country indicate extensive and longterm harvest of freshwater mussels (Kunz 1897). This chapter presents the results of the analysis of freshwater mussel remains recovered during archaeological excavations conducted at site $41 \mathrm{MV} 120$.

\section{Materials and Methods}

Excavations by CAR at site 41MV120 were performed using standard archaeological techniques, including sieving to obtain small specimens and fragments. Unioid remains were bagged separately for subsequent examination and identification. Each bag was labeled with excavation unit, level, and lot or bag number. Shell remains were recovered from both excavation units (EU) and backhoe trenches (BHT). Level numbers used in this chapter are the original field designations, and not the revised $10-\mathrm{cm}$ levels referred to in Chapters 8 (see Appendix $\mathrm{C}$ for conversions [level vs. level2]).

Identification of unionid shells and fragments followed Howells et al. (1996a). Terminology follows that currently given by the American Fisheries Society (Turgeon et al. 1988) and Williams et al. (1993). Previous reports of unionid fauna of the Rio Grande by Metcalf (1982), Neck (1982b), and Neck and Metcalf (1988) in addition to recent field surveys of freshwater mussel distribution in Texas by the Texas Parks and Wildlife Department (TPWD) Heart of the Hills Research Station (HOH) (Howells 1994, 1995, 1996a, 1996b) helped focus identification efforts on the unionid species most likely to be present in these samples (Table 12-1) and their ecological associations. Scientific name synonymy to allow comparison of current findings to previous reports of unionids at other archaeological sites in Texas is presented in Table 12-2. Structures most useful in identification of shell fragments included beaks, beak sculpture, lateral teeth, pseudocardinal teeth, and occasionally adductor muscle scars and complete or nearly complete valves (Figure 12-1). These structures were typically noted with the recorded identification of each species (Appendix G, Tables G-1 and G-2). Additionally, combinations of pseudocardinal teeth, lateral teeth, or beaks were collectively termed hinges. Weights ( $\mathrm{g}$ ) of each sample bag as determined by CAR are reported herein, except a single sample which contained three large pieces of fossil Exogyra shell; this sample was reweighed to subtract the weight of the fossil specimens. Weights are also summarized by level (Table 12-3). Several other possible fossil fragments which were too limited in number and weight to skew analyses were not differentiated from more-recent material. No efforts were made to enumerate the multitude of unidentifiable shell fragments due to their extremely brittle nature and inclination to readily break into multiple smaller fragments.

Valves which were intact, or nearly so, were also examined to determine the relative width of the most marginal growth-rest band in an effort to define possible season of harvest (Table 12-4). Additionally, shell remains were examined for signs of human manipulation. 
Table 12-1. Freshwater Mussels (Family Unionidae)

Reported in the Rio Grande Drainage by Howells et al. (1996b)

\section{Common name}

Tampico pearlymussel

Yellow sandshell

Washboard

Texas hornshell

Bleufer

Salina mucket

Southern mapleleaf

Rio Grande monkeyface

False spike

Giant floater

Lilliput

Texas lilliput

Tapered pondhorn

Pondhorn

Paper pondshell
Uniomerus declivis

Uniomerus tetralasmus

Utterbackia imbecillis

Questionable Records

Threeridge

Round pearlshell

Amblema plicata

Glebula rotundata
Cyrtonaias tampicoensis

Lampsilis teres

Megalonaias nervosa

Popenaias popei

Potamilus purpuratus

Potamilus salinasensis

Quadrula apiculata

Quadrula couchiana

Quincuncina mitchelli

Pyganodon grandis

Toxolasma parvus

Toxolasma texasensis

\section{Comments}

Endemic.

Introduced (Howells 1997b).

Disconaias in Turgeon et al. (1988)

and Williams et al. (1993).

possible introduction (Neck and Metcalf (1988).

Endemic.

Previously Anodonta.

Western lilliput (T. mearnsi) also from this system is held as a valid species by the American Fisheries Society (Turgeon et al. 1988) but could not be genetically distinguished from $T$. texasensis (Howells 1997a).

Previously Anodonta.

Though present in the Nueces River, reports from the Rio Grande are believed to be misidentified M. nervosa.

Original reports from the Rio Grande were misidentified C.tampicoensis; however, recent commercially harvested shells reportedly from the lower Rio Grande included this species. 
Table 12-2. Synonymy of Scientific Names of Freshwater Mussels (Unionidae) Associated with 41MV120 and Other Species Reported from the Rio Grande

Terminology follows Howells et al. (1996b), Turgeon et al. (1988), and Williams et al. (1993).

\section{Currently Accepted Name \\ Tampico pearlymussel \\ Cyrtonaias tampicoensis \\ Yellow sandshell \\ Lampsilis teres \\ Texas lilliput \\ Toxolasma texasensis \\ Giant floater \\ Pyganodon grandis \\ Paper pondshell \\ Utterbackia imbecillis \\ Salina mucket \\ Potamilus salinasensis}

Southern mapleleaf

Quadrula apiculata

\section{Synonymy}

Historically listed by some in the genus Lampsilis, and with species or subspecies of berlandierii, heermanii, and tecomatensis. Genetic analysis by TPWD failed to find significant differences among any Texas populations.

Frequently listed in the past as $L$. anodontoides or $L$. teres anodontoides.

Currently most authorities have not maintained subspecies and teres has been shown to have priority over anodontoides.

Members of this group were previously placed in the genus Carunculina. The three forms known from Texas waters (parvus, texasensis, mearnsi) were also often listed as subspecies of parvus. Genetic analysis by TPWD failed to find differences between texasensis and mearnsi (Howells 1997a) and Howells et al. (1996a) grouped mearnsi under texasensis.

Until 1990, both were placed in the genus Anodonta. Genetic work ultimately demonstrated this genus should be divided into three genera and most authorities now follow this reclassification.

Although the American Fisheries Society continues to include this species under Disconaias, Howells et al. (1996a) placed it in Potamilus. However, genetic confirmation as to which is most appropriate is lacking to date.

Originally under mapleleaf ( $Q$. quadrula), but now accepted as a valid species.

\section{Results And Discussion}

\section{Climatic and Zoogeographical Changes in the Rio Grande Valley}

During the late Cretaceous period, much of the current Rio Grande drainage basin was inundated by marine transgressions (Smith and Miller 1986). Wilkins (1992) reported a general climatic trend of warming and drying in the region since the last Wisconsinan glaciation ca. 18,000 B.P. Based on his study of mammalian fossils from the Central Rio Grande basin, Hulbert (1984) reconstructed a climatic history including 1) a wet period $9000-5000$ B.P. ( $>46 \mathrm{~cm}$ precipitation/yr); 2) a more-xeric period $5000-3000$ B.P. $(<31 \mathrm{~cm} / \mathrm{yr})$; and
3) a period $3000-400$ B.P. more similar to present conditions $(31-41 \mathrm{~cm} / \mathrm{yr})$. Similarly, Smith and Miller (1986) cited studies of fossil plants from the TransPecos which demonstrated a shift from woodlands to grasslands and deserts that occurred less than 11,500 B.P.

In their discussion of fish communities of the Rio Grande basin, Smith and Miller (1986) conclude that the development in North America of progressively more severe climates is evidenced by changes in plant and animal communities, including fishes. Metcalf (1982) found that at least six unionid species occurred as far upstream as New Mexico in the late Pleistocene, but noted that depauperization occurred throughout the Holocene suggesting Hulbert's (1984) conclusion that 

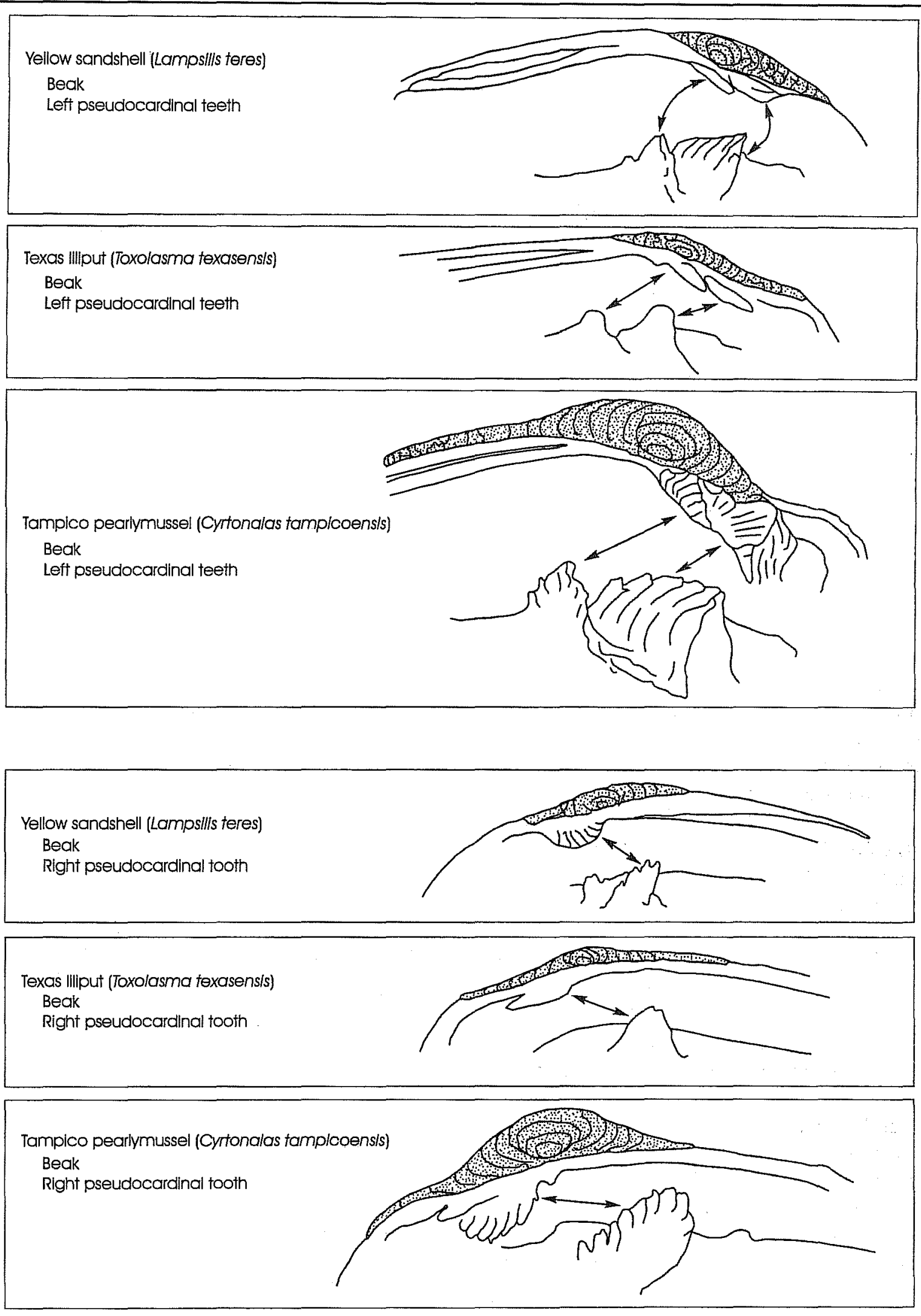

Figure 12-1. Unionid structures most useful in identification of shell fragments. 
$3000-400$ B.P. was more like the present should not be interpreted to mean exactly like the present. Within the past 150 years, human-related major changes have occurred over the Texas landscape with subsequent impacts on aquatic communities, with environmental impacts being especially severe since 1900 (Howells et al. 1996b; Miller 1961). Nonetheless, there are few reported human-related impacts on native unionid faunas in Texas reported prior to the Civil War. Although the freshwater mussel assemblage in the Rio Grande has apparently been in a natural state of decline for several thousand years due to climatic changes, the most significant changes occurred in the upstream basin and populations in the vicinity of 41MV120 should have been relatively stable at the time the site was occupied.

At least 15 species of freshwater mussels have been known to occur in the Rio Grande (Table 12-1). Another species, round pearlshell (Glebula rotundata), may also occur in the lower Rio Grande, and the report of an additional species, threeridge (Amblema plicata), appears to be a misidentification. Further, among these unionids, Neck and Metcalf (1988) suggested southern mapleleaf (Quadrula apiculata) may be an introduction. It did not occur in Metcalf's (1982) study of the fossil record and the current morphological form in the Rio Grande is most similar to populations from the Colorado and Brazos rivers and distinctly different from other populations in the Guadalupe, San Antonio, Frio, and Nueces rivers (TPWD, unpublished data). Bleufer (Potamilus purpuratus) likewise did not occur in the fossil record for the Rio Grande (Metcalf 1982), none of the previous individuals who were summarized by Neck and Metcalf (1988) as having worked on unionids from the Rio Grande identified bleufer from the system, and although old reports of it from the area were based upon misidentifications, this species has been found alive near Del Rio and also appears to be a recent introduction (Howells 1997a). Additionally, a figure in Chandler and Kumpe (1992) of a shell from the lower Rio Grande appears to be a bleufer with distinct engravings confirming human handling of this species in the area. Among the 13 taxa which could have occurred in the area at the time of the 41MV120 site, Metcalf (1982) found specimens of seven in deposits in the Rio Salado and Rio San Juan just downstream of the Elm Creek site.
Finally, unionid shells collected during a $\mathrm{HOH}$ fisheries survey of Elm Creek in 1992 included relatively recently dead valves of Tampico pearlymussel (Cyrtonaias tampicoensis) and yellow sandshell (Lampsilis teres) (Howells 1994). However, when this site was reexamined by $\mathrm{HOH}$ in 1996, a deep layer of silt had covered the creek bed and eliminated the local unionid fauna (Howells, in preparation).

\section{Freshwater Mussels Recovered at Site $41 \mathrm{MV120}$}

\section{General Species Composition}

In general, three species occurred throughout these samples: Tampico pearlymussel, yellow sandshell, and Texas lilliput (Toxolasma texasensis). All three were distributed among the various units and among levels, except in a few instances where few unionid remains were found or remains comprised only small, unidentifiable fragments.

Tampico pearlymussel was found to be the most abundant taxon by Neck and Metcalf (1988) in their study of the lower Rio Grande and in TPWD surveys (Howells 1993, 1994, 1995, 1996a, 1996b). Yellow sandshell was listed by Neck and Metcalf (1988) as common in the Rio Grande, associated with resacas, and second in abundance to Tampico pearlymussel. However, surveys by TPWD found this species only as long-dead or subfossil valves, except for recently dead shells from Elm Creek in 1992; no living specimens were located at sites from Brownsville upstream to Big Bend (Howells 1994, 1995, 1996a, 1996b).

Three species of lilliputs (Toxolasma spp.) recognized by Turgeon et al. (1988) occur in Texas (Williams et al. 1993): lilliput (T. parvus), Texas lilliput ( $T$. texasensis), and western lilliput (T. mearnsi). All three have been reported in the Rio Grande drainage. Electrophoretic genetic analysis has thus far failed to find genetic differences between Texas and western lilliputs, and the latter appears to only represent a South Texas form of the former (Howells 1997b). Neck and Metcalf (1988) reported only lilliput from the lower Rio Grande 
and collections by TPWD found only this species in Falcon Reservoir and Lake Casa Blanca. However, lilliput is typically a hermaphrodite with limited apparent sexual dimorphism, but Texas lilliput is diecious with well-defined sex differences in shell morphology. Specimens recovered from the 41MV120 site appeared to be Texas lilliput, except in a few instances where too little shell remained to allow confident identification.

Relatively few specimens with critical portions of shell were unidentifiable from 41MV120. One inflated, thin valve fragment with short lateral teeth (EU10, Level 8, Lot 349) did not correspond closely with other possible taxa and was likely a deformed individual, possibly yellow sandshell. A section of pseudocardinal teeth and a worn beak fragment (EU 13, Level 8, Lot 787) was atypical as well. A single pseudocardinal tooth fragment (EU 18, Level 2, Lot 1526) may have come from an unusually large yellow sandshell. A distal piece of a large lateral tooth (EU 23, Level 11, Lot 877) appeared to belong to bleufer, which is not believed to have been present in the area during the time period when the 41MV120 shells were harvested and deposited. Bleufer is a large, colorful species which is abundant in the Colorado River and other systems to the north and east. If this lateral tooth fragment was indeed from bleufer (too little remained for positive identification), it may have been transported to the area.

Among the species not found among the remains from the 41MV120 site were two anodontids, giant floater (Pyganodon grandis) and paper pondshell (Utterbackia imbecillis), but both species are often associated with lilliputs. Both have extremely fragile shells which often crack upon drying and therefore probably preserve rather poorly. However, none of the recovered hinge fragments displayed the lack of lateral and pseudocardinal teeth characteristic of both anodontids. Interestingly, Murray (1982a, 1982b) also failed to find either at similar sites on the Frio River drainage where both occur. He suggested possible selection against these species, perhaps associated with unpleasant flavor, as a possible explanation (Murray 1982b).

Additionally, Atlantic rangia (Rangia cuneata; Family Mactridae), which is an estuarine species often common at archaeological sites along coastal Texas, was not found among the 41MV120 samples. Shells of this species were found by TPWD in Elm Creek adjacent to the current excavation sites in 1992 (Howells 1994). However, shell deposits are frequently mined in coastal areas and used as fill material in construction of roads and boat ramps. Therefore, the Elm Creek Atlantic rangia found in 1992 were likely recently transported to the area.

Finally, four unionid species are endemic to the Rio Grande and a fifth occurred in the Rio Grande and as a second disjunct population in Central Texas (Howells et al. 1996b). All are currently extremely rare and several may be extinct (Howells et al. 1996a, b). None of these five species was found among the 41MV120 samples. This may suggest they were either selected against during harvest or were also rare at the time.

\section{Size of Recovered Unionid Specimens}

Among the three unionid species found at the 41MV120 site, Texas lilliput has been reported to reach $75 \mathrm{~mm}$ shell length, but is usually $25-45 \mathrm{~mm}$ (Howells et al. 1996b). However, both Tampico pearlymussel and yellow sandshell exceed $100 \mathrm{~mm}$ shell length and can become very solid, heavy, and thick in large adults (Howells et al. 1996b). The Texas lilliput remains recovered represented typical adults of the species, but with very few exceptions, both Tampico pearlymussel and yellow sandshell remains were those of larger juveniles and small adults. Very few valves or shell fragments of the latter two species were those of large adults (which would have been expected to preserve well had they been present). Although harvest may have selected against larger specimens which may have been tougher or less flavorful, material from other archaeological sites in Texas often contains larger specimens (TPWD, unpublished data). Texas lilliputs typically inhabit shallow waters. Juveniles and smaller specimens of many unionids are more actively mobile than larger adults with heavier shells. On the other hand, yellow sandshells are often very actively mobile at all sizes, and extremely active specimens appear more likely to occur in shallow waters. All but one of the limited number of fragments of larger specimens recovered were those of yellow sandshell. Collectively, this suggests inhabitants of the $41 \mathrm{MV} 120$ site were perhaps opportunistic 
harvesters who took only specimens readily available in shallow waters. These shell remains provide little evidence of major harvest efforts in deeper waters (e.g., 1-2 $\mathrm{m}$ ) where more abundant, larger specimens were likely to occur.

\section{Unionid Associations with Units}

A review of recovered material by unit and level provides an indication of the amount of unionid material deposited and the duration of deposition (Table 12-3). Among the various EUs excavated, EUs 8-11 contain the most shell by weight $(118.18-387.17 \mathrm{~g})$, with less in EUs 3-7 and 12 (49.93-97.754g), and the least in EUs 1, 2, 13, 14-20 (0.37-23.98g). Although mussel shells were not systematically collected from the backhoe trenches, BHT 8 did yield relatively more shell than the other trenches.

\section{Species Descriptions and Biology}

The following descriptive summaries were largely condensed from Howells et al. (1996b) and unpublished TPWD data.

\section{Tampico pearlymussel (Cyrtonaias tampicoensis)}

Synonymy: Placed in the genus Lampsilis in historical literature. Several subspecies listed by Strecker (1931), including berlandierii, have largely been ignored in recent literature and genetic analyses at $\mathrm{HOH}$ have failed to find significant differences between populations in Texas despite minor morphological differences.

Range: Originally distributed from the Brazos River drainage southwest to the Rio Grande and northeastern Mexico.

Size: Confirmed to $143 \mathrm{~mm}$ shell length in Texas (but probably slightly larger), with most adults about $100-120 \mathrm{~mm}$.

Shell description: Generally oval to subrectangular in shape; thick to very thick (in some adults);
Table 12-3. Total Weight (g), Number of Samples (Lots), and Number of Samples with Identifiable Freshwater Mussel (Unionidae) Valves or Fragments Found at 41MV120

\begin{tabular}{cccc}
\hline Unit & $\begin{array}{c}\text { Total } \\
\text { weight } \\
\text { (g) }\end{array}$ & $\begin{array}{c}\text { N } \\
\text { Samples }\end{array}$ & $\begin{array}{c}\text { N samples } \\
\text { with } \\
\text { identifiable } \\
\text { unionids }\end{array}$ \\
\hline EU 1 & 2.18 & 4 & 1 \\
EU 2 & 21.04 & 20 & 7 \\
EU 3 & 49.93 & 32 & 4 \\
EU 4 & 50.33 & 29 & 6 \\
EU 5 & 97.75 & 27 & 9 \\
EU 6 & 59.94 & 27 & 7 \\
EU 7 & 80.20 & 40 & 11 \\
EU 8 & 211.88 & 39 & 16 \\
EU 9 & 387.17 & 39 & 17 \\
EU 10 & 303.55 & 35 & 13 \\
EU 11 & 118.18 & 33 & 11 \\
EU 12 & 55.97 & 23 & 7 \\
EU 13 & 9.22 & 7 & 2 \\
EU 14 & 23.98 & 6 & 2 \\
EU 15 & 0.37 & 3 & 0 \\
EU 16 & 0.90 & 2 & 1 \\
EU 17 & 3.10 & 2 & 1 \\
EU 18 & 0.46 & 1 & 0 \\
EU 19 & 0.03 & 1 & 0 \\
EU 20 & 0.29 & 1 & 0 \\
BHT 7 & 3.89 & 4 & 2 \\
BHT 8 & 37.28 & 5 & 2 \\
BHT 9 & 0.19 & 1 & \\
BHT 10 & 1.51 & 2 & 1 \\
BHT 12 & 11.67 & 1 & \\
\hline
\end{tabular}


pseudocardinal teeth (two left, one right) heavier and more molar-like than those of yellow sandshell or Texas lilliput; lateral teeth (two left, one right) moderate in length and moderately thick and high; beaks elevated well above hinge line; disk without external sculpturing.

Spawning Season: Gravid females occur with eggs and glochidia throughout the year.

Habitat: Occurs on mud, sand, gravel, and occasionally cobble in small and large rivers and streams, adapts well to reservoirs; may occur in main-channel areas or backwaters and oxbows; recorded to depths over $13 \mathrm{~m}$, but most found less than $3 \mathrm{~m}$ and often occurs in very shallow areas where water levels are stable; juveniles and smaller adults are moderately active.

Comments: This species produces the famous "Concho River pearls" and sometimes produces gem-quality pearls more frequently than other native unionids. Interior nacre color is usually purple, but can be pink, orange, lavender, white, or bicolored; pearls occur in these same colors (Howells 1996c). Rio Grande populations are frequently relatively heavy-shelled but often with white or pastel nacres unlike others populations in the Colorado or Brazos drainages where nacre is often darker.

\section{Yellow sandshell (Lampsilis teres)}

Synonymy: Considered $L$. anodontoides or $L$. teres anodontoides in older literature; subspecies have largely been dropped by most authorities and teres has been shown to have priority over anodontoides.

Range: Occurs from the Rio Grande to the Red River in Texas and in all major drainage basins.

Size: Reported to $145 \mathrm{~mm}$ shell length in Texas; to $178 \mathrm{~mm}$ elsewhere.
Shell Description: Shell shape elongate-oblong, sexually dimorphic with males pointed posteriorly and females more truncate; relatively thin in juveniles but moderately thick in large adults, but never extremely thick; pseudocardinal teeth (two left, one right) compressed and often lamellar; lateral teeth (two left, one right) long but not extremely thick or high; beaks rise above hinge line but are not high; beak sculpture less heavy than in Texas lilliput; disk unsculptured and often glossy in living specimens.

Spawning Season: Females may carry eggs and glochidia throughout the year in Texas.

Habitat: Tolerates a variety of substrate types in large and small streams, rivers, lakes, and reservoirs; occurs in fast- or slow-flow conditions; often occurs in shallow waters; specimens of all sizes are extremely active and have been reported to follow flood waters onto inundated terrestrial areas; does not tolerate drought or dewatering well (active nature and occurrence in shallow waters often results in stranding losses; this could be responsible for it apparent decline in the area in recent decades when Rio Grande water levels have fluctuated dramatically).

Comments: This species was a popular source of material for buttons due to its pearly white nacre and evenly thick shell.

\section{Texas lilliput (Toxolasma texasensis)}

Synonymy: Placed in the genus Carunculina in older literature and previously considered a subspecies of lilliput (T. parvus) which also occurs in the Rio Grande; a third local species, western lilliput (T. mearnsi) has not been found to be genetically different from Texas lilliput (Howells 1997b) and was considered under Texas lilliput by Howells et al. (1996a).

Range: Occurs from the Rio Grande to the Red River in all major drainage basins in Texas. 
Size: Reported to $75 \mathrm{~mm}$ shell length in Texas, but usually only $25-45 \mathrm{~mm}$.

Shell Description: Small, sexually dimorphic, elliptical to slightly elongate and centrally pointed posteriorly in males, more oval and posteriorly truncate in females; thin to moderately thick; pseudocardinal teeth (two left, one right) thin, triangular, compressed; lateral teeth (two left, one right) thin, not high; beaks rise only slightly above the hinge line; beak sculpture heavier than in equalsized yellow sandshells; disk unsculptured but often with a rough epidermis.

Spawning Season: Although reported as a longterm brooder with a gap in reproductive activity in July and August, dissections by TPWD have found gravid females only in spring and early summer.

Habitat: Typical of still or low-flow waters of feeder creeks, small ponds, embayments, and oxbows and is only rarely found in main-stream river channels; occurs on mud and sand, but tolerates limited silt and organic debris deposition; nearly always in rather shallow waters; often locally abundant.

Comments: Specimens taken by TPWD in Falcon Reservoir on the Rio Grande and genetically identified as lilliput (T. parvus) were more inflated than Texas lilliput; even fragments from 41MV120 which were only identified as Toxolasma spp. did not appear inflated.

\section{Indicators of Human Manipulation of Specimens}

Among the 41MV120 specimens examined, one Tampico pearlymussel (EU 32, Level 10, Lot 1083) and one yellow sandshell (EU 33, Level 12, Lot 1258) displayed damage which suggested human manipulation of these valves. Both had V-shaped notches near the margin of the valve, with possible drill marks at the apex of the V. Larger predators like raccoons (Procyon lotor), which prey heavily on freshwater mussels, have been observed to bite smaller mussels across the beaks (Howells et al. 1996a) or to break away the margin of larger shells, often at the posterior margin where shells are thinnest (TPWD, unpublished data). Additionally, Chandler and Kumpe (1992) presented figures of yellow sandshells from the lower Rio Grande with drill holes in virtually the same marginal position as the current specimens. None of the thousands of recent or subfossil unionid shells examined during TPWD surveys have displayed the type of damage seen in the two $41 \mathrm{MV} 120$ specimens.

A noteworthy number of $41 \mathrm{MV} 120$ specimens was found to have fractured along marginal growth-rest lines one or more times producing roughly $\mathrm{C}$-shaped bands of shell disassociated from the original valve. Attempts to age modern unionids have included heating and ashing of shells (Neves and Moyer 1988; Sterrett and Saville 1974) to deliberately cause fracturing along growth-rest lines. Further, examination of subfossil valves collected by TPWD among natural shell deposits throughout Texas found this type of fragmentation largely lacking in specimens in the $\mathrm{HOH}$ collection (TPWD, unpublished data). The propensity of this type of disassociation of valve layers in the 41MV120 specimens may suggest they had been cooked or at least heated to force the animals to open (living unionids readily open when heated). This feature among the 41MV120 specimens ultimately served to confound subsequent attempts to assess seasonality for many valves in this collection.

\section{Seasonality}

Determining the season during which a bivalve mollusk was harvested based upon shell features can in turn provide a wealth of related information including the time of site habitation. Using Atlantic rangia, an estuarine species, Aten (1981) reported a method to determine month of harvest (plus or minus one month) based upon external growth-rest lines. Since this report, others have used his method on Atlantic rangia from other archaeological deposits (e.g., Carlson 1987; Rogers et al. 1991). However, others, including Weinstein and Whelan (1987) and Fullington (1995) have criticized the Aten technique. Zimmerman (1995) summarized reviews on this subject. 
Major problems with the Aten method voiced by Weinstein and Whelan (1987) included Aten's use of annual growth increments which were equal in size, differential growth rates among different specimens from the same area, and absence of annual growth/ year data from living specimens collected over time. Fullington (1995) considered Aten's methods invalid and cited inconsistency in incremental growth patterns in Atlantic rangia from Texas and that actual growth increments in relation to months of the year remained unknown.

A further problem reflects application of Aten's methods to freshwater mussels of a variety of species. Even ifAten's methods were valid for estuarine populations of Atlantic rangia, application to unionids in freshwater remains to be demonstrated. Shells of freshwater mussels also exhibit pronounced growth-rest bands or rings externally and the distance between these bands decreases progressively with an increase in shell size (Neves and Moyer 1988).

Neves and Moyer (1988) evaluated several techniques for aging unionids in western Virginia, and concluded that methods using external growth bands were often hampered by shell erosion, obscurity of bands, subjectively distinguishing annuli from other growth checks, and inability to distinguish closely positioned bands near the shell margin in older specimens. They concluded that population statistics derived from this method lacked both accuracy and precision, and were therefore fraught with problems.

Since TPWD began studies of unionids in Texas in 1992 , attempts to confirm age and define growth by monitoring measured and marked specimens, examination of external growth-rest lines, and sectioning shells remain the least successful area of species biology investigated (TPWD, unpublished data). Most unionids live far longer than do Atlantic rangia and many grow far larger. This often contributes to a large number of annuli and stress-related growth checks. Over their long lives, unionids often develop extensive shell erosion which further obscures patterns. Additionally, minor differences in micro-habitat, even in the same area, often result in dramatic differences in growth patterns. Growth-rest patterns are further confounded in Central and South Texas where mild winters may allow continued growth, or hot summer droughts may slow or stop growth. Finally, larger, adult unionids of many species may only grow a few tenths of a mm each year, making comparison of growth periods between checks difficult or impossible.

Nonetheless, unionids do show patterns of periods of rapid growth (usually late spring and summer) between periods of little or no growth (usually winter). Attempts to evaluate the width of the most marginal growth bands as a general guide to season of collection for 41MV120 specimens are presented in Table 12-4. Among all the unionid remains collected from this site, only 10 specimens appeared to have sufficiently intact margins to allow such evaluation. Among these were representatives of all three species. Specimens of all three species generally had marginal growth bands which appeared to be moderately broad to very broad (relative to expected size based on previous growth bands). One yellow sandshell had a rather narrow band and another was just beginning to approach a moderately broad band. This suggests most specimens were harvested during or at the end of rapid growth (probably late spring to late fall) with two taken earlier in the spring, but after growth had resumed. None of the specimens appeared to have been taken prior to resumption of growth in spring (i.e., this was probably not a winter fishery).

Again, it should be noted that the specimens with broad marginal bands which appeared to have been harvested in fall (after a long season of growth) may have experienced a mild winter with continued growth. Others which appeared to have been taken in spring may have experienced growth cessation during a summer drought with a subsequent growth spurt again in fall under more-favorable conditions.

\section{Conclusions}

1. Freshwater mussels (Unionidae) of three species were utilized by inhabitants of the $41 \mathrm{MV} 120$ archaeological site throughout the levels examined.

2. Species present included Tampico pearlymussel (Cyrtonaias tampicoensis), yellow sandshell 
Table 12-4. Possible Season of Harvest of Freshwater Mussel (Unionidae)

Valves and Fragments from 41MV 120

Based on Relative Width of the Most Marginal Growth Band

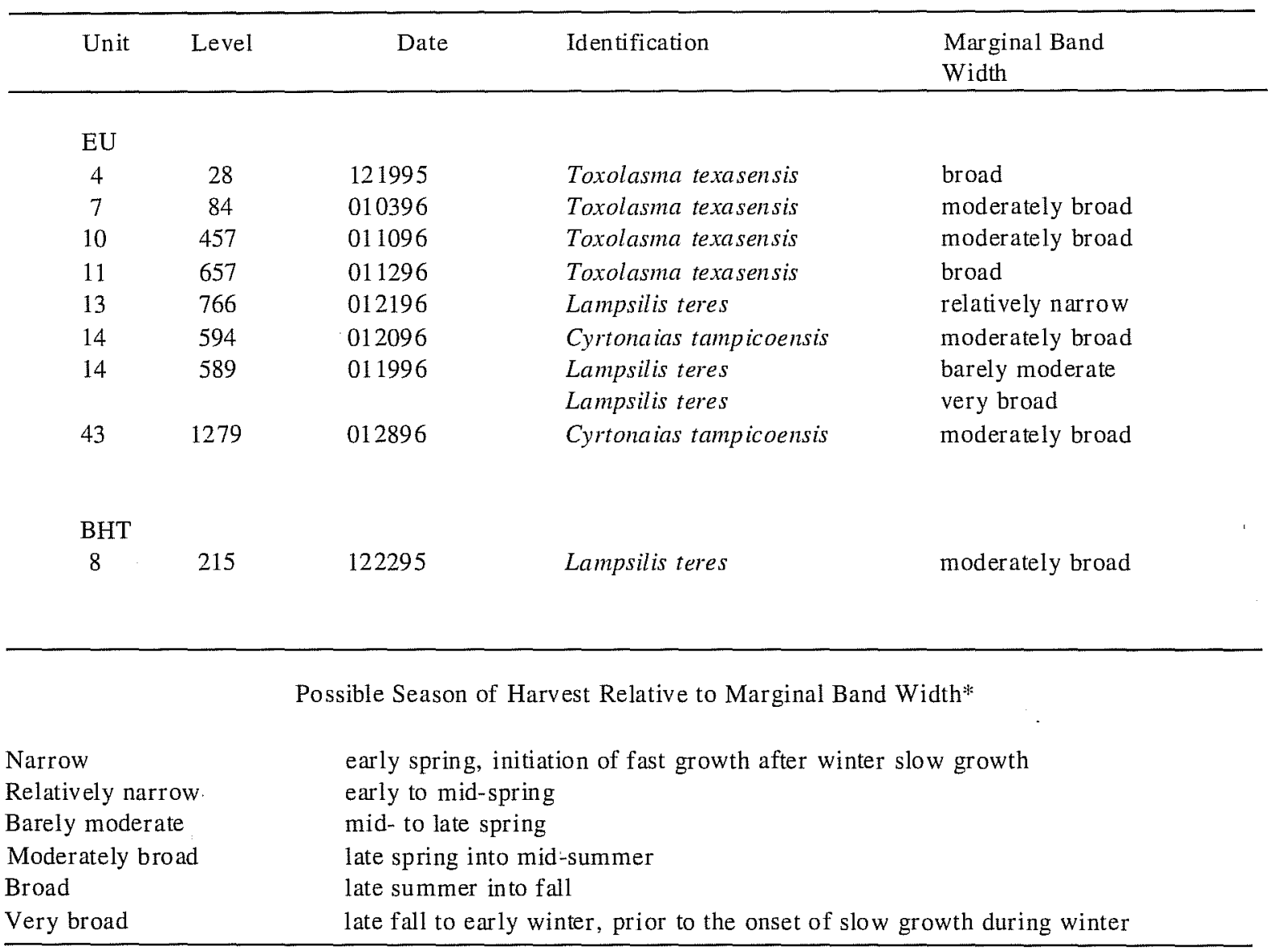

\footnotetext{
* Although use of marginal band width has been applied to Atlantic rangia (Rangia cuneata) populations in Tex as in an effort to define season of harvest, this method has been questioned by some. Further, even if valid, direct application to freshwater mussels has not been demonstrated. In fresh water situations, warm winters which allow continued growth, summer droughts which hinder growth, and micro-habitat differences between specimens can dramatically impact growth-rest marks in unionid shells. Caution should be applied to in terpretation of possible growth implications presented above.
} 
(Lampsilis teres), and Texas lilliput (Toxolasma texasensis).

3. Only uppermost and lowermost levels, which contained too little unionid material to accurately assess species present, failed to contain all three species.

4. Except for Texas lilliput which never grows large, specimens recovered were juveniles and small adults, with only a few fragments from larger individuals.

5. Based upon size of the specimens recovered and knowledge of their behavior and habitat preferences, inhabitants appear to have been opportunistic unionid harvesters in shallows and backwaters, and apparently did not mount major efforts to harvest larger adults in slightly deeper, main-channel waters.

6. Two valves displayed damage which may have been attributable to human manipulation. A number of valves showed fractures along growth-rest lines which may have been associated with heating.

7. Only 10 specimens, representing all three species, had intact valve margins which could allow speculation on season of harvest. Most of these showed moderate to broad marginal growth bands suggesting harvest from late spring through late fall (during or after periods of active growth).

8. Although other unionid species were and are present in the vicinity of the $41 \mathrm{MV} 120$ site, no confirmation of their remains was identified among these samples.

9. A portion of a lateral tooth may have been that of bleufer (Potamilus purpuratus), which is not believed to be native to the Rio Grande. This species is abundant in drainages to the north and northeast and may have been transported to the site if this identification is correct. 


\title{
Chapter 13: Gastropod Remains
}

\author{
Artie L. Metcalf
}

\section{Introduction}

The site is located near the $100^{\text {th }}$ meridian, often considered an ecotonal area between more eastern and more western types of biotas in Texas. This also applies to more eastern and more western subspecies of some kinds of land snails, treated below. Blair (1950) included Maverick County in the northwestern part of a Tamaulipan Biotic Province, which he recognized as including the region of Texas south of the Edwards Plateau. Goldman and Moore (1946) included a large part of northeastern Mexico in their Tamaulipas Biotic Province, including the area opposite Maverick County, in Mexico. These and other authors emphasize that the predominant native vegetation of the Tamaulipan Province is brushland. Regarding the Texas part of the province, Blair (1950:103) wrote "thorny brush is the predominant vegetation type"; for Mexico, Goldman and Moore (1946) similarly noted "the area is semi-arid and the vegetation is made up mainly of thorny shrubs and small trees with a liberal admixture of yuccas, agaves, and cacti."

The latter description seems to characterize well the native vegetation in the Eagle Pass area. Frye (1984), in his analysis of the vegetation types of Texas, showed the site, 41MV120, as located in "cropland," but the nearby, and presumably original, vegetation type around the small cropland areas was categorized as a "Ceniza-Blackbrush-Creosote bush Brush" association. This association is mapped as occurring as a narrow strip along the Rio Grande, from western Val Verde County southeastward to Zapata County. Again, brushland is emphasized.

The gastropod remains received and analyzed are from the archeological site 41MV120. They comprise 308 lots, individually numbered and bagged in small plastic bags. Each bag indicated excavation unit (EU) number, level, depth, type of screen used, lot number, a count of number of specimens in each lot, and their total weight. Level numbers used in this chapter are the original field designations, and not the revised 10 $\mathrm{cm}$ levels referred to in Chapters 8 (see Appendix C for conversions [level vs. level 2]). Appendix $\mathrm{H}$ provides information on the species identified for each specimen, except for fragments deemed unidentifiable. Each species is discussed in the following section.

\section{List of Species}

\section{Rabdotus alternatus, striped rabdotus}

The taxonomic history of the larger bulimulid snails of South Texas is complex. In earlier works the generic name Bulimulus was employed for these, with Rabdotus considered as a subgenus. Pratt (1969) elevated Rabdotus to a full genus. Pilsbry (1946:14 ff.) recognized a subspecies, Bulimulus alternatus mariae, as occurring in the Lower Rio Grande Valley and other parts of the Tamaulipan Biotic Province area of southernmost Texas. Northwestward from the area occupied by $B$. a. mariae along the Rio Grande Valley of Texas, Pilsbry (1946:16) recognized the species Bulimulus schiedeanus as occurring. Pratt (1974) restricted Bulimulus (his Rabdotus) schiedeanus to populations far to the south in Mexico, and employed the available name, Rabdotus alternatus hesperius for populations in Texas formerly ascribed to schiedeanus.

Thereupon, Fullington and Pratt (1974:15, Figure 5) recognized two subspecies of $R$. alternatus in Texas. The populations of southeasternmost Texas, ascribed by Pilsbry (1946) to the subspecies $B$. a. mariae, were reassigned to the nominal subspecies, $R$. a. alternatus, whereas more northwestern populations were retained in $R$. a. hesperius, as in Pratt (1974), noted above. The result of all this complex assigning and reassigning is to place Maverick County in an area where the 
two subspecies, $R$. a. alternatus, (formerly mariae) and $R$. a. hesperius might be expected to intergrade.

Indeed, specimens from site 41MV120 do include shells that could easily be assigned to one subspecies or the other, as well as many that are intermediate. The more southeastern $R$. a. mariae is referred to as "mariae" in some places, below, for convenience. The mariae form is characterized by having brown to gray, ragged stripes that descend to varying distances from the apical area, in some cases to the bottom of the shell. The aperture is tan to chocolate-brown in color, and often bears a thickened tooth on the columellar wall. In $R$. $a$. hesperius, on the other hand, the mottled or ragged stripes are replaced by widely spaced yellowish-tan streaks, narrow and of uniform width, which parallel the growth lines. The aperture is white to light tan in color, and a columellar tooth is lacking. At 41MV120, shells of the hesperius type were common, but both forms, as well as intergrades, were present at various levels. Thus, there was no readily discernible evidence that one form or another was consistently associated with certain levels. Perhaps larger samples might reveal some recognizable trends.

\section{Rabdotus dealbatus, whitewashed rabdotus}

This is, by far, the most widespread species of Rabdotus in the United States, occurring from Alabama, Tennessee, and Kentucky, to the east, to New Mexico, in the west, and from Kansas and Missouri southward into northern Mexico. Over this broad area, and especially to the west, several different subspecies have been recognized. In Texas, as mapped by Fullington and Pratt (1974:Figure 6) and by Hubricht (1985: Maps 355 and 356 ), the nominal subspecies, $R$. $d$. dealbatus, is more southern and eastern in distribution, and $R$. d. ragsdalei is more western, with a broad zone of intergradation in an area on both sides of the $100^{\text {th }}$ meridian. This zone includes Maverick County.

The subspecies $R$. $d$. ragsdalei differs from the nominal subspecies mainly in having well-developed ribs that parallel the growth lines and, in many cases, a more slender shell. Ribs are variously developed in specimens from the present site. Shells of some speci- mens are especially slender, even for the ragsdalei subspecies. In general, specimens seem closer to $R$. $d$. ragsdalei. Neck (1995) assigned Rabdotus dealbatus from site 41UV60, in southwestern Uvalde County, to R. d. ragsdalei.

\section{Succinea luteola, Mexican ambersnail}

Succinea luteola is a widespread species of the southern United States and adjacent Mexico. Pilsbry (1948:830) interpreted its type locality as being at Galveston, Texas. Hubricht (1985:Map 123) mapped it as occurring from the Florida Panhandle to West Texas. It has also been recorded in New Mexico and Arizona. Hubricht (1985:Map 123) showed it as widespread in southern Texas, especially in the Rio Grande Valley, where it has been found as far west as El Paso County.

Hubricht (1961) described an additional species in this genus, Succinea solastra, with type locality "near" the Bentsen-Rio Grande Valley State Park, Hidalgo County. In 1985 (Map 130) Hubricht mapped it from seven counties in the southern "peninsula" of Texas, including Val Verde and Dimmit counties, to the west and east, respectively, of Maverick County.

Shells of snails in the genus Succinea are notoriously difficult to identify to species, and this is true of $S$. luteola and $S$. solastra. The distinguishing criteria between these two species were based mainly on soft anatomy in Hubricht's description of $S$. solastra. Shells of solastra were characterized as being smaller at maturity than those of luteola, but this is not borne out by actual values given by Hubricht (1961:30) for solastra and by Pilsbry (1948:828) for luteola. Neither do the illustrations provided by these two authors show any clearly recognizable differences in shell morphology. Although Hubricht asserted that solastra had a more acute spire, this is not observable (by me, at least) in the illustrations. Obviously, the tendency, noted by Hubricht, for shells of solastra to be dirt-covered, in contrast to those of luteola, is not helpful to the archaeologist, nor is a purported difference in translucency of shells of much help either. 
It was anticipated that shells from the present locality might prove to be easily separable into two groups, appertaining to $S$. luteola and $S$. solastra. Although a few shells tended more to the supposed morphology of solastra, most fit comfortably within the taxonomic confines of luteola, where I have assigned them all. From a paleoecological point of view, distinguishing between the two species may be of little importance. Hubricht, in his original description of $S$. solastra, noted (1961:31) that it was "frequently found associated with Succinea luteola." Many of the paratypes of solastra were collected inside highway culverts, where snails were in dormancy, and attached to inner sides of the culverts. Succinea luteola also attaches, when dormant, to various surfaces, including small trees and shrubs, where I have collected it in the lower Rio Grande Valley. The overall pattern seems to suggest that $S$. luteola is the more common species in the Rio Grande Valley, which accords with the assignment made here of succineid materials from site $41 \mathrm{MV} 120$ to this species.

\section{Linisa texasiana, Texas liptooth}

For over a century (1878-1986) this species was assigned to the genus Polygyra. Its more recent taxonomic history has been less stable. It was placed in the genus Daedalochila by Richardson (1986) and, in a revision of the family Polygyridae, Emberton (1995:90) reassigned it to the genus Linisa.

As with the two species of Rabdotus, discussed above, some authors have recognized eastern and western subspecies of $L$. texasiana in Texas. Cheatum and Fullington (1971:Figures 3 and 4) mapped the nominal subspecies, $L$. texasiana texasiana, as occurring widely in eastern Texas. They assigned populations from the Edwards Plateau region in central Texas variously to both the nominal subspecies and to $L$. texasiana texasensis. They mapped the latter subspecies as occurring from Maverick County, northwestward, in the Rio Grande Valley, as well as in the Pecos River region, and in the Trans-Pecos westward to Brewster and Reeves counties.

Hubricht (1985:Map 373) mapped this taxon as a species only, not as two subspecies. This may be the bet- ter approach as distinctions between the two subspecies are subtle. Linisa t. texasensis has a smoother, slightly more depressed shell, and a "somewhat" wider umbilicus than the nominal subspecies according to Pilsbry (1940:619). Like Cheatum and Fullington, Pilsbry (1940:618 ff.) assigned specimens from Maverick and nearby counties to both subspecies, while noting that "it is a variable species." Cheatum and Fullington (1971:13) suggest a clinal gradation from one subspecies to the other across Texas. This seems to accord well with the situation at 41MV120, where fossil specimens seem more or less intermediate between the more heavily ribbed shells seen in $L$. $t$. texasiana and the weakly ribbed, almost smooth shells seen in extreme examples of L.t. texasensis.

The three species Rabdotus alternatus, Rabdotus dealbatus, and Linisa texasiana all share a history of problematic taxonomic allocations in regard to how many subspecies, if any, should be recognized, and what the distributional patterns of such subspecies would be. In all three cases, the area bordering the $100^{\text {th }}$ meridian, including Maverick County and site $41 \mathrm{MV} 120$, is in a zone of intermediacy between two subspecies. Perhaps this is related, in some ways, to differing ecological conditions encountered, east to west, such as those that were utilized in setting up the biotic provinces discussed above, especially as regards a more eastern Tamaulipan and more western Chihuahuan province, of pertinence here. Since the area studied here is in this zone of intermediacy, in regard to subspecific allocations, it seems judicious merely to utilize the species names without attempting to make subspecific distinctions. This approach is generally followed hereafter, including Appendix $\mathrm{H}$.

\section{Discussion}

The two most salient aspects of the 41MV120 gastropod assemblage are: 1) the absence of smaller gastropods (i.e., less than $5 \mathrm{~mm}$ in greatest dimension), and 2) the absence of aquatic gastropods. Typically, a natural fossil assemblage will contain more smaller than larger specimens (less than vs. more than $5 \mathrm{~mm}$ in greatest dimension). Since $1 / 8$-inch mesh sieves were employed in processing about half ( 48 percent) of the lots 
considered here, at least some smaller shells should have been retained if they were present.

A typical situation involving a natural assemblage is provided in a report prepared by Raymond W. Neck (1995) for a site (41UV60) in stream-deposited alluvial sediments located in southwestern Uvalde County, some $75 \mathrm{~km}$ northeast of the Eagle Pass area. At that site three species of aquatic gastropods and one fingernail clam were reported, together with 16 species of land snails.

Of the 16 species of land snails, eight have adults exceeding one centimeter in either length or diameter of shell, and are not shaped so as to pass through a $1 / 8$-inch screen. These include Helicina orbiculata, a succineid, Glyphyalinia umbilicata, Rabdotus alternatus, $R$. dealbatus, $R$. mooreanus, Thysanophora hornii, and Polygyra texasiana. In four species, trials indicate that the largest specimens do not pass through the 1/8-inch mesh: Strobilops texasiana, Helicodiscus singleyanus, Hawaiia miniscula, and Pupoides albilabris. However, $P$. albilabris is a slender, cylindrical snail, and will pass through such mesh if oriented with smaller dimension vertical. Four species are small enough to pass easily through $1 / 8$-inch mesh: Gastrocopta pellucida, G. procera, G. contracta, and Deroceras sp. (fossil slug plates). Of the aquatic species reported by Neck, mature specimens of three species would not pass through 1/8-inch mesh: Physella virgata, Planorbella trivolvis, and a Pisidium fingernail clam. Specimens of the fourth species, an Amnicola, could pass through such mesh.

It should be emphasized that Neck employed hand-picking, and also used screens with mesh as small as .0234 inch, so that the recovery of even the smallest snails would be expected; however, if 41MV120 represented a natural assemblage, it seems likely that there should have been present at least some smaller species and juveniles of larger species in the size range of 3-7 mm, even with the $1 / 8$-inch mesh screen used. Of course, it is quite possible that some of the species reported by Neck did not occur at 41MV120; however, four of the species reported by him are represented there by larger shells. It is difficult to envision a natural assemblage in which there would not be present some juveniles of these four spe- cies in the size range of 3-7 mm; but these are lacking. This suggests that the 41MV120 gastropod assemblage was not deposited by natural formation processes, but was brought to the campsite by humans. Larger individuals are also represented at the Mariposa site in nearby Zavala County, where Montgomery (1978:102-103) interprets their presence to human activities.

In contrast to the lack of aquatic snails at the site, shells of aquatic mussels (bivalves) have been recovered (Chapter 12). It seems that both gastropods and the bivalves can be considered artifacts, in the sense of having been transported to the site by its inhabitants for some useful purpose or purposes. Mussels are often associated with archaeological sites. Flesh likely was used for food, although Parmalee and Klippel (1974) found it not to be very rich, calorie-wise. Shells probably were used in producing various utilitarian and ornamental objects, as discussed by Pearce and Jackson (1933:120) in connection with an archaeological site in nearby Val Verde County, Texas. Mussels still inhabit nearby streams, the Rio Grande and Elm Creek, where also, presumably, ancient inhabitants of the site could have collected them. The absence of aquatic gastropods seems to indicate that these, on the other hand, were not being brought to, and utilized at the campsite as were mussels (see Chapter 12).

In contrast to the above, land snails seem to have been gathered and brought to camp. They may have been found and collected at any time of year, but perhaps it was especially easy to collect them at times when snails were dormant and attached to various plants. This is often termed estivation, but it appears that in the relatively warm climate of the Tamaulipan Biotic Province, above-ground dormancy may occur during dry periods at other times of the year than in summer. I have observed succineids attached to trunks and branches of small trees in the region in mid-winter, and have seen specimens of Rabdotus alternatus attached to plants in the Eagle Pass area in early spring.

Rabdotus alternatus is, no doubt, the most commonly observed land snail in the site area, both by present and, presumably, by ancient inhabitants, because of its large size, and its tendency, when dormant, to attach to various structures up to a meter or more above ground. Hubricht wrote $(1960: 68)$ of this species that 
"one has but to drive along the highway to locate colonies." He termed it a "semiarboreal" species. Pilsbry noted (1946:17) that $R$. alternatus may be seen "sealed to large cactus, mesquite, coarse grass and shrubs, and on fence posts and telephone poles, even to the very top in the full glare of the hot sun." The flat leaves of agaves and yuccas also provide good places for attachment by this species during dormancy. Pilsbry (1946:12) also found Rabdotus dealbatus ragsdalei, together with Linisa texasiana, "hidden under the dead reversed leaves which thatch the trunks of yuccas." Thus, all four species of land snails present in the 41MV120 assemblage are known to attach to plants, at least at some times when in dormancy.

Possible ways in which land snails may have been utilized by native people in South Texas have been summarized by Clark (1973). He suggested that they might 1) have been collected for protein-rich food; 2) have been collected for ornaments; 3 ) have been carried inadvertently to campsites, attached to vegetation; or 4) "represent a natural population . . . attracted by decomposing midden refuse" (Clark 1973). Of course, there could be some combination of these factors, as well. It has been pointed out by Hester and Hill (1975a:38) that, after being boiled, bodies of snails are easily extracted from the shell, leaving it intact. Such empty shells could, conceivably, have been utilized, subsequently, as ornaments. The shells at site 41MV120 are unburned, indicating that if they were cooked, they would have been boiled rather than placed directly in the fire or ashes (also see Montgomery 1978:102-103).

There has been considerable discussion, pro and con, about the food-use hypothesis, especially whether bulimulid snails (Rabdotus) were eaten by Native Americans in southern Texas. This has been discussed in papers by Allen and Cheatum (1961:295), Clark (1973:24; 1976:13, 14), Hester and Hill $(1975: 37,38)$, Mueggenborg (1994:58), Schuetz (1961:203), and Suhm (1957:51). Mueggenborg (1994:58) cites further papers indicating ethnohistoric evidences for the use of snails as food by hunter-gatherers in South Texas, and biochemical evidences of high protein levels in Rabdotus. Protein as a dietary component may have been salubrious, and was a factor not considered by Parmalee and Klippel (1974) in their study of caloric content (only) in freshwater mussels. Supplemental protein might have been especially welcomed if there were times when site $41 \mathrm{MV} 120$ occupants were restricted to a diet preponderantly of carbohydrates for whatever reason (seasonal or climatic factors? lack of success in hunting?). There have been some reservations concerning the food-use hypothesis, since snail radulae have not been reported in human coprolites preserved in rock shelters in Texas (Clark 1976:14). However, it seems possible that radulae were simply extracted during food preparation or after cooking (boiling?), or that they were expectorated. The hypothesis, listed above, suggesting that some shells found at campsites, like the present one, might have represented snails looking for edible debris, both during or after camp occupation, does not seem applicable to this assemblage. Such visitors should have included some small snails, either small species or juveniles of larger species. As noted, snails of this size are generally not included in the 41MV120 assemblage. Similarly, vegetation carried to camp likely would have had snails of diverse sizes attached. Perhaps the ornament-collection hypothesis is least vulnerable of those listed by Clark (1973), since necklaces of Rabdotus shells have actually been found in rock shelters in the region (see below). Nevertheless, the large numbers of shells reported from some campsites make the food-hypothesis difficult to reject. Presence of such large numbers of Rabdotus dealbatus shells in rock shelters in Texas led Allen and Cheatum $(1961: 293,295)$ to contend that these snails were likely used as food.

One might speculate that $41 \mathrm{MV} 120$ campsite inhabitants could have gone out with some kind of container, and picked snails off of plants much as they might have picked berries or the tunas (fruits of Opuntia cacti). Such a scenario is suggested, since it might have included picking off even the relatively small Succinea luteola and Linisa texasiana, possibly incidental to collecting the larger, meatier Rabdotus. What Succinea and Linisa might have been used for is not clear. There is not much flesh in such snails, but possibly it was a gourmet delicacy, or perhaps even a few small snails were welcomed during times of food shortage. Clark (1976:14) quotes from a Relación of Cabeza de Vaca suggesting that food shortages in the region may have driven people to eat even less palatable food than small snails. It is possible, also, that these small snails might have been used in making ornaments such as neck- 
(1933:29, 118, Figure 4, Pl XXVII) a necklace consisting of 21 shells of Rabdotus alternatus hesperius obtained from a rock shelter in Val Verde County, not far to the northwest of 41MV120.

In addition to intact shells, many fragments of Rabdotus alternatus occur in the $41 \mathrm{MV} 120$ assemblage. If snails were being boiled and used for food, perhaps in some specimens it was difficult to extract the bodies, so shells had to be broken. However, it is less conjectural merely to suppose that trampling by prehistoric occupants and archaeological excavations would have resulted in breakage of many shells.

\section{Summary}

In summary, it seems most likely that the presence of shells of four species of land snails at site 41MV120 is attributable to their having been brought to the campsite by humans, who used them as a source of food and possibly ornaments. Thus, the shells comprise an artificial, rather than a natural assemblage. Lacking the greater species diversity (including presence of smaller species), which might be found in a natural assemblage, I suggest that the selective tastes of the ancient snailgatherers hamper efforts to visualize paleoecological conditions; however, the four species occurring in the fossil assemblage still occur in the immediate area today. This suggests that conditions typical of the northwestern part of the Tamaulipan Biotic Province, today, may also have prevailed at the time when the fossil fauna was still a living one. This interpretation accords well with that of Neck (1995) derived from his study of mollusks in a section of alluvial sediments (41UV60) in Uvalde County, Texas, involving almost four times as many species as were found at 41MV120. Neck (1995) concluded that "snail species of this area have been the same for at least 3000 years." This exceeds the ages, indicated above for site $41 \mathrm{MV} 120$, by a millennium, increasing confidence that the paleoecological conditions and biota in the area of Eagle Pass were probably not greatly different from those observed at present, at least within areas that have not been greatly affected by human modifications of the past few centuries. 


\section{Chapter 14: Faunal Remains}

\section{Barbara A. Meissner}

Only 15 bones were recovered from the 41MV120, of which only four could be identified to any taxonomic level lower than Class. These were all of the genus Rana, the true frogs, of which $R$. catesbeiana (the bullfrog) and $R$. pipiens (the leopard frog) are the most common in the area today (Stebbins 1985). As is common in buried remains of even adult amphibians (Olsen 1968:63), only the diaphyses of the long bones were present.

Table 14-1 is a provenienced list of the recovered bone. This includes information on excavation unit, level number of specimens, taxon, and notes. Level numbers used in this table are the original field designations, and not the revised 10-cm levels referred to in Chapter 8 (see Appendix C for conversions [level vs. level 2]).

The absence of recovered bone in this site may be attributed to several factors, including absence of bone deposition and bone preservation variables, such as cultural taphonomic processes and diagenesis. The near absence of bone may be largely due to the lack of bone deposition at the site in the first place. Ethnographic descriptions of Native American subsistence practices in the sixteenth and seventeenth centuries indicate that, at times, bones of both land animals and fish were pounded into a fine meal and eaten (Cabeza de Vaca 1961[1871]:103). Little bone would be expected in a site at which this custom was practiced. If the site was used largely as a camp while processing vegetal resources and/or hunting very small animals such as mice and minnows, one would again not expect a great deal of bone deposition, as the latter were often eaten whole (Sobolik 1991:110).

Bone preservation is another factor to be considered in understanding the small count of vertebrate remains recovered from this site. Cultural practices such as smashing the bone into small pieces to be boiled for bone grease extraction could seriously impact the ability of the bone to survive long periods of burial. Small

Table 14-1. Faunal Remains Taxa

\begin{tabular}{|c|c|c|r|l|l|}
\hline Unit & Level & \# & Wt. (g) & \multicolumn{1}{|c|}{ Taxon } & \multicolumn{1}{|c|}{ Notes } \\
\hline \multirow{2}{*}{8} & 1 & 1 & .04 & Vertebrata & Little weathering \\
\cline { 3 - 7 } & & 1 & .08 & Mammalia & Little weathering \\
\hline 10 & 2 & 1 & .08 & Vertebrata & Pitted \\
\hline 11 & 1 & 1 & .55 & Mammalia & Possible chop mark on one end; pitted \\
\cline { 2 - 7 } & 2 & 2 & 1.04 & Mammalia & Badly pitted \\
\cline { 2 - 6 } & 11 & 4 & .06 & Rana sp. & $\begin{array}{l}\text { Femur, humerus and 2 unidentified long bone } \\
\text { fragments; bone is not weathered. }\end{array}$ \\
\hline 14 & 1 & 1 & .06 & Mammalia & \\
\hline 16 & 3 & 1 & .62 & Mammalia & $\begin{array}{l}\text { Possible chop marks on both ends; 1 end has slight } \\
\text { smoke discoloration; surface is slightly pitted. }\end{array}$ \\
\hline 19 & 3 & 1 & .37 & Vertebrata & Pitted \\
\hline 20 & 2 & 1 & 1.26 & Mammalia & $\begin{array}{l}\text { May be part of the maxilla of a medium-sized } \\
\text { mammal; slightly pitted. }\end{array}$ \\
\hline 29 & 9 & 1 & .05 & Vertebrata & Slight weathering. \\
\hline
\end{tabular}


bone fragments tend to preserve less well than larger ones (Von Endt and Ortner 1984).

No detailed examination of the diagenetic processes commonly encountered in archaeological sites in South Texas is currently available, however, Chaplin (1971:16-18) suggests that at least four properties of the depositional matrix affect skeletal tissue preservation: $\mathrm{pH}$, aeration, water regime, and bacterial and fungal action. In general, acidic soils inhibit bacterial action but will dissolve the mineral component of bone, depending to a large extent on the amount of water percolating through the matrix (Lyman 1994:421); however, in a well-aerated basic matrix the organic component decays more rapidly, exposing the mineral component to leaching (Lyman 1994:442).

Most of the bone recovered from this project shows a slight to severe pitting of the surface consistent with chemical weathering of the bone (Lyman 1994:442). Only two small pieces show distinct signs of weathering caused by exposure on the surface. Some of the bone shows little weathering of any kind, but all of the bone except the frog bone (Rana sp.) is extremely fragmented. Two pieces show some evidence of having been chopped, but their small size makes it impossible to be certain. At least three of the bones show some evidence along at least one broken surface of having been broken while the bone was still fresh.

Open campsites in South Texas often have few vertebrate faunal remains (Hester 1995:439), although this is not always the case (see Black 1986); however, sites with poor bone preservation usually have a much higher bone count than was seen in this site. In other words, while identification of bone may be impossible, making it "analytically absent" (Lyman and O'Brien 1987), even very poor conditions for bone preservation should leave more badly fragmented and unidentifiable bone than was seen in this site. In conclusion, though the poor condition of bone in open campsites is a common phenomenon in South Texas, cultural processes must be considered an important factor in the near-absence of bone from site 41MV120. 


\section{Chapter 15: Historic Artifacts}

\section{Anne A. Fox}

\section{Introduction}

All historic artifacts recovered from the excavations at site 41MV120 can be dated to the twentieth century. No surface artifacts were collected. Of the 79 total artifacts analyzed, the majority (51) are bottle glass which are common in post- 1900 historic deposits. Table $15-1$ presents an inventory of the artifacts by provenience. Level numbers used in this table are the original field designations, and not the revised $10-\mathrm{cm}$ levels referred to in Chapters 8 (see Appendix $\mathrm{C}$ for conversions [Level vs. Level2]).

\section{Historic Artifacts from $41 \mathrm{MV} 120$}

\section{Glass Containers}

Of the 51 glass container fragments recovered, 31 (63 percent) are from modern brown glass beer bottles. The others were clear and bright green bottle fragments. No diagnostic fragments were recovered except for the rim of one beer bottle.

\section{Ceramics}

Two sherds of common whiteware were recovered, both from EU 11. They appear to be from the same vessel, although one was from Level 1 and the other from Level 5. This particular ceramic variety has been in use since the late-nineteenth century and continues to be available today.

\section{Thin Metal}

Fragments of thin rusted metal generally represent tin cans, which are nearly always present on sites of this period. The three fragments from this collection are too small to identify further.

\section{Nails}

All the nails recovered are wire nails which would have been made after the late-nineteenth century. One complete six-inch nail was found, the rest were fragments of much smaller nails.

\section{Wire}

One fragment of wire with a maximum diameter of $1 / 8$-inch and about three inches long came from EU 23, Level 1.

\section{Cartridges}

Three metallic rifle cartridges were excavated, two are .22 caliber short and one is .22 caliber long. They came from various levels in EUs 16, 23, and 25. 
Table 15-1. Historic Artifacts

\begin{tabular}{|c|c|c|c|c|}
\hline EU & Level & Lot \# & Description & Count \\
\hline \multirow[t]{2}{*}{4} & 11 & 26 & brown glass & 1 \\
\hline & 12 & 34 & clear glass & 1 \\
\hline \multirow[t]{2}{*}{6} & 9 & 66 & brown glass & 1 \\
\hline & 10 & 69 & brown glass & 1 \\
\hline \multirow[t]{2}{*}{7} & 3 & 80 & brown glass & 2 \\
\hline & 6 & 85 & brown glass & 1 \\
\hline \multirow[t]{2}{*}{8} & 1 & 102 & brown/clear glass & 2 \\
\hline & 5 & 309 & brown glass & 1 \\
\hline \multirow[t]{5}{*}{9} & \multirow[t]{2}{*}{1} & 127 & plastic & 1 \\
\hline & & 127 & brown glass & 1 \\
\hline & \multirow[t]{3}{*}{2} & 130 & brown glass & 1 \\
\hline & & 130 & plastic & 1 \\
\hline & & 131 & wire & 7 \\
\hline \multirow[t]{4}{*}{11} & \multirow[t]{2}{*}{1} & 351 & white ware & 1 \\
\hline & & 351 & brown/green glass & 3 \\
\hline & 2 & 353 & tin $\operatorname{can}(?)$ & 2 \\
\hline & 5 & 362 & white ware & 1 \\
\hline \multirow[t]{2}{*}{16} & 1 & 626 & 22 cal. short casing & 1 \\
\hline & 5 & 639 & brown glass & 1 \\
\hline \multirow[t]{2}{*}{19} & 3 & 777 & clear glass & 1 \\
\hline & 9 & 790 & plastic & 2 \\
\hline \multirow[t]{3}{*}{20} & 1 & 676 & brown glass & 1 \\
\hline & 2 & 697 & brown/green glass & 2 \\
\hline & 3 & 684 & brown glass & 2 \\
\hline \multirow[t]{2}{*}{21} & 2 & 1228 & brown/green & 2 \\
\hline & 3 & 1241 & brown glass & 1 \\
\hline \multirow[t]{5}{*}{22} & surface & 801 & brown glass & 2 \\
\hline & 1 & 802 & $\begin{array}{l}\text { brown/clear/green } \\
\text { glass }\end{array}$ & 11 \\
\hline & & 803 & wire & 1 \\
\hline & & 804 & brown/clear glass & 2 \\
\hline & 3 & 806 & brown glass & 1 \\
\hline \multirow[t]{3}{*}{23} & 1 & 728 & wire & 1 \\
\hline & 3 & 735 & $22 \mathrm{cal}$. short casing & 1 \\
\hline & 6 & 738 & clear glass & 1 \\
\hline 25 & 4 & 1276 & $22 \mathrm{cal} .1$ ong casing & 1 \\
\hline 26 & 4 & 611 & clear glass & 7 \\
\hline \multirow[t]{2}{*}{30} & 5 & 538 & wire & 4 \\
\hline & 7 & 539 & tin can & 1 \\
\hline 36 & 8 & 1303 & clear glass & 1 \\
\hline \multirow[t]{2}{*}{37} & 2 & 973 & brown glass & 1 \\
\hline & 5 & 1401 & brown glass & 1 \\
\hline \multirow[t]{2}{*}{38} & \multirow[t]{2}{*}{2} & 1126 & clear glass & 1 \\
\hline & & 1126 & wire & 1 \\
\hline
\end{tabular}




\section{Chapter 16: Site Structure}

\section{Bradley J. Vierra}

Excavations reveal that site $41 \mathrm{MV} 120$ was periodically inundated by Rio Grande flood waters, and that a series of stratified layers was preserved within the deposits. Chapter 8 describes the intricacies of the site stratigraphic sequence, and Chapters $9-15$ provide a descriptive baseline for the various material classes recovered from the site. This chapter addresses the issue of site structure; that is, the spatial distribution and relationship between the various features and material classes on the site. Information derived from the previous discussions is used to provide a synthetic perspective of long-term site organization and use.

The chapter begins with a summary of site geomorphology, including depositional context and stratigraphic sequence. This discussion is followed by a review of the chronological information, which describes the temporal relationship between the site deposits. The subsequent sections involve studies of varying scales in site structure. This begins with a general comparison of artifact density by block excavation areas. Then the scale shifts to individual excavation levels, and the implications of site organization on material class density and composition. The final section identifies specific sediment packages of Analytical Units (AUs) which could represent limited periods of site occupation; a compositional analysis is then conducted of the defined AUs.

\section{Site Geomorphology}

The stratigraphic sequence at $41 \mathrm{MV} 120$ is the result of the shifting position of the Rio Grande channel relative to the site area (Chapter 7). Underlying point-bar deposits reflect the presence of the Rio Grande channel in the immediate area of the site ca. 6000-3000 B.P. During the site occupation (ca. 2200-1200 B.P.), the ancient confluence of the Rio Grande and Elm Creek moved about one kilometer to the south. By about 1000 B.P., the river channel was down cutting and therefore depositing very little sediment across the site. Instead, the surface is characterized by relative stability, with little evidence of human occupation.

Nordt's study (Chapter 7) of the alluvial stratigraphy at the site identified the presence of floodplain and underlying point-bar deposits (or facies). The floodplain facies could be separated into three lithofacies (See Figure 7-6 for a graphic illustration of backhoe trench profiles with defined lithologies). Unit 2-f1 directly overlies the point-bar facies. It represents the rapid deposition of overbank deposits over the site area from ca. 2200-2000 B.P. There is a high potential for the preservation of archaeological materials in this lithofacies, due to the rapid buildup of sediments. In contrast, Unit 2-f2 exhibits a much reduced sedimentation rate (ca. $2000-1900$ B.P.). This rate is about 10 times less than that exhibited by Unit 2-f1, with the subsequent formation of the Abl paleosol. The lower rate of deposition for this lithofacies indicates that it has a lower potential for preservation. In addition, the deposit is much thinner, and there is a greater likelihood of mixing archaeological materials. Aggradation increases during the formation of Unit 2-f3 (ca. 1900 1200 B.P.), but at a rate five times less than that exhibited by Unit 2-fl. This increase in sediment deposition may be due to the movement of the channel nearer to site, or increased channel discharge and flood frequency. The deposits thicken to the west in Area 4, which contain a higher potential for preservation.

Periods of increased occupational intensity were identified through the stratigraphic profile by analyzing the abundance and distribution of debitage and charcoal. Unit 2-fl witnesses the highest levels of occupational intensity in Area 1. Artifact density increases from 120 $70 \mathrm{~cm}$, and then decreases in Units 2-f2 and 2-f3. A similar pattern is exhibited in Area 2 where Unit 2-f1 also exhibits the highest levels of occupational intensity, then decreases in the upper levels. This pattern contrasts with that observed for Area 3. In Area 3 there 
is a more even distribution of archaeological materials through the sequence, but with the highest levels of occupational intensity being represented in the lower part of Unit 2-f3. The few remains present in Area 4 are mostly present in Unit 2-f3. Overall, occupational intensity declines over time at the site, in conjunction with decreasing flooding. Areas 1 and 2 witnessed intense early occupations (ca. 2200-2000 B.P.), and Areas 3 and 4 more intense later occupations (ca. 1900-1200 B.P.).

\section{Site Chronology}

The occupational history represented at 41MV120 is complicated given the evidence for multiple occupations and activity areas across the site. Nonetheless, radiocarbon dates and diagnostic projectile points indicate that these occupations were primarily limited to the Late Archaic period.

Table 16-1 provides information on the radiocarbon dates obtained from the site. The archaeological date range is from approximately $1240-3200$ B.P. These dates span the length of the Late Archaic period, which Hester (1995:441) defines from ca. 2400-1300 B.P. A variety of Late Archaic point types have also been defined for South Texas, including Shumla, Marcos, Montell, Ensor, Frio, Ellis, Fairland, Frio, Catan, and Matamoros (Hester 1995:441-442). Shumla, Desmuke, Langtry, Marcos, Montell, Marshall, and
Ensor point types were recovered from the excavations at 41MV120. The Shumla points are consistently found in the lower levels of these excavations. Three of the five Shumla points are present in Unit 2-f1, with one of these being directly associated with a date of $2200 \pm 50$ B.P. Desmuke and Langtry points were also recovered from Unit 2-f1 in Area 1. In contrast, the remaining point types were found in the middle and upper levels of the excavations. Marshall and Montell points are present in the upper portion of Unit 2-f1 in Area 2, and Marcos and Ensor points in Unit 2-f2 in Areas 1 and 4, respectively. Both these latter point types are associated with a buried Ab1 horizon which dates to ca. 1900 B.P. Ensor points are also present in Unit 2f3 in Areas 3 and 4. Hester (1978:42-43) reports finding Ensor and Montell types overlying Marcos and Shumla types at site 41ZV10. The stratigraphic sequence at 41MV120 indicates a relative chronological placement from early to late of Shumla/Desmuke (lower 2-f1), Langtry/Montel1/Marshall (upper 2-f1), Marcos/ Ensor (2-f2), and Ensor (2-f3). Langtry and Marshall point types date to the middle Archaic in the Lower Pecos region (Turpin 1991); however, they overlie Shumla and Desmuke types at 41MV120. It is unclear as to whether this represents some form of disturbance, the scavenging and reuse of the artifacts, or a later date for these point types

The stratigraphic sequence defined in Area 1 provides the only consistent set of radiocarbon dates for the site. These dates consist of 1240, 1970, and 2200 B.P., and

Table 16-1. Radiocarbon Dates from 41MV120

\begin{tabular}{|c|c|l|l|l|}
\hline Provenience & $\begin{array}{c}\text { Level/ } \\
\text { depth }\end{array}$ & Date B.P. & Laboratory \# & \multicolumn{1}{|c|}{ Material } \\
\hline 2 & 4 & $1460 \pm 50$ & Beta-82289 & wood charcoal \\
\hline 3 & 6 & $1240 \pm 50$ & Beta-82290 & wood charcoal \\
\hline 6 & 5 & $760 \pm 50$ & Beta-104966 & mesquite charcoal \\
\hline 7 & 9 & $3200 \pm 50$ & NSRL-3531 & mesquite charcoal \\
\hline 15 & 9 & $1970 \pm 50$ & NSRL-3534 & mesquite charcoal \\
\hline 22 & 8 & $3050 \pm 50$ & NSRL-3533 & mesquite charcoal \\
\hline 33 & 12 & $2200 \pm 50$ & NSRL-3535 & mesquite charcoal \\
\hline 39 & 7 & $540 \pm 40$ & Beta-104967 & acacia charcoal \\
\hline BHT 12 & $150 \mathrm{~cm}$ & $1940 \pm 40$ & NSRL-3532 & legume charcoal \\
\hline
\end{tabular}


accurately reflect the date range as defined by Hester (1995) for the Late Archaic. The two ca. 3000 B.P. dates in Areas 2 and 3 are significantly older than the others on the site (i.e., greater than two sigma). Both dates are stratigraphically located above younger deposits. For example, the 3200 B.P. date from Area 2 is situated in the $\mathrm{Bw} 2$ horizon above the $\mathrm{Bcb} 1$ horizon which is dated to 2200 B.P. This latter date is consistent with the dated sequence in Area 1. The 3050 B.P. date from Area 3 is also located in the Bw2 horizon, but one situated above the $\mathrm{Ab} 1$ paleosol. Two separate dates of ca. 1900 B.P. have been obtained from this paleosol in the eastern and western sections of the site. Therefore, these ca. 3000 B.P. dates are not consistent with the stratigraphic and radiocarbon evidence as exhibited across the site.

These older samples might reflect bioturbation, with the small pieces of charcoal having originated in the lower point-bar deposits. The sample from Area 2 is situated adjacent to these deposits; however, the sample from Area 3 is located in the same level as the main occupation in the block. An alternative explanation is that these samples represent the "old wood problem" with ancient dead wood being used as fuel at the site. Schiffer (1986:21) has dated specimens of mesquite from modern surface collections and dead wood from standing trees in southern Arizona to ca. $970 \pm 430$ B.P. and $1007 \pm 153$ B.P., respectively. It could be that the ca. 3000 B.P. dates are derived from a similar old fuel population since both are present in the same horizon, but do not correlate with the rest of the stratigraphic and radiocarbon evidence. Nonetheless, isolated char- coal fragments from alluvial soils are not a reliable source for dating cultural deposits. They are easily affected by a variety of taphonomic processes, and are more likely to be moved through the soil profile than charcoal recovered from intact features.

An additional charcoal sample was submitted for AMS dating to clarify the old wood problem. A small piece of unidentifiable wood charcoal from EU 11 (Level 11 ) in Area 3 was selected. This sample is located in the unit adjacent to that with a $3050 \pm 50$ B.P. date; however, it is situated about three levels lower at the contact between the silty soils and the underlying point bar sands. The sample yielded a date of $2940 \pm 50$ B.P. (NSRL-3998), and is statistically the same as the 3050 B.P. date. This may indicate that the ca. 3000 B.P. wood charcoal on the site is associated with the top of the point bar deposits. It could be that the wood in EU 22 (Level 8 ) is actually disturbed, and was ultimately derived from a lower context.

\section{Excavation Blocks and Isolated Units}

The previous sections have provided the background for site depositional context, and temporal placement of the site deposits. This section begins the study of site structure through the general analysis of artifact distribution by block excavation area. Table 16-2 presents information on the distribution and density of lithic artifacts by block excavation area (1-4), and isolated

Table 16-2. Distribution and Density of Lithic Artifacts

\begin{tabular}{|c|c|c|c|c|c|c|c|c|}
\hline $\begin{array}{l}\text { Prov- } \\
\text { enience }\end{array}$ & Cores & Debitage & $\begin{array}{l}\text { Ret. } \\
\text { Tools }\end{array}$ & $\begin{array}{l}\text { Ground } \\
\text { stone }\end{array}$ & $\begin{array}{c}\mathrm{m}^{3} \\
\text { excavated }\end{array}$ & $\begin{array}{l}\text { Artifacts } \\
\text { per } \mathrm{m}^{3}\end{array}$ & $\begin{array}{c}\text { Cores } \\
\text { per } \mathrm{m}^{3}\end{array}$ & $\begin{array}{c}\text { Ret. Tools } \\
\text { per } \mathbf{m}^{3}\end{array}$ \\
\hline Area 1 & 4 & 4538 & 25 & 1 & 8.40 & 551.9 & 0.27 & 2.86 \\
\hline Area 2 & 3 & 1825 & 19 & 0 & 9.30 & 210.3 & 0.41 & 2.76 \\
\hline Area 3 & 5 & 1288 & 19 & 0 & 6.70 & 195.2 & 0.80 & 2.17 \\
\hline Area 4 & 0 & 35 & 4 & 0 & 4.45 & 8.6 & 0.00 & 0.67 \\
\hline IU 2 & 0 & 152 & 0 & 0 & 1.20 & 126.7 & 0.00 & 0.00 \\
\hline IU 4 & 0 & 86 & 0 & 0 & 1.20 & 71.7 & 0.00 & 0.00 \\
\hline IU 6 & 0 & 128 & 1 & 0 & 1.20 & 107.5 & 0.00 & 0.83 \\
\hline IU 8 & 0 & 531 & 3 & 0 & 1.20 & 445.0 & 0.00 & 2.50 \\
\hline IU 10 & 1 & 466 & 7 & 0 & 1.20 & 395.0 & 0.83 & 5.83 \\
\hline
\end{tabular}


units (IUs) $(2,4,6,8$, and 10). Lithic artifact densities vary across the site in respect to the mean number of artifacts per cubic meter excavated. These densities can be divided into high (395.0-551.9), medium (195.2-210.3) and low (8.6-126.7) concentrations. The highest artifact concentrations are present in Area 1 and IUs 8 and 10. Medium artifact densities are represented in Areas 2 and 3, and low artifact densities in Area 4 and IUs 2 and 4 . The highest artifact densities are present at the eastern end of the site adjacent to Elm Creek, and the lowest at the western end of the site.

Not only does lithic artifact density decline from east to west, but other material classes decline as well (Table 16-3). For example, the maximum weight per level of burned rock and mussel shell decreases across the site, with Areas 2 and 3 exhibiting similar maximum weights. There are relatively few snail remains represented on the site, but these also decrease from east to west, with Areas 1 and 2 being the most similar.

This general pattern would seem to reflect that the occupation of 41MV120 was primarily oriented toward Elm Creek; however, Area 4 does contain relatively more recent deposits with much less cultural material. Nonetheless, the high artifact densities represented at the eastern section of the site indicate that buried cultural deposits may extend further toward Elm Creek. This is represented by a continuation of this large surface scatter to adjacent sites 41MV107 and 41MV109 which are located on the eastern side of the creek.

The mean site lithic artifact density per cubic meter is 275.0; however, there are subtle variations in artifact density within the block excavation areas. Artifact densities in Area 1 range from 406.3-750.0 artifacts per cubic meter with the highest densities in three contigu- ous EUs $(32,33$, and 36), and EU 12. In Area 2 the artifact densities range from 142.2-368.0 artifacts per cubic meter. Three contiguous EUs located in the northwest corner of the block $(18,20,21)$ contain the highest densities in this area. Artifact densities in Area 3 range from 134.3-263.3 artifacts per cubic meter. The EUs with the highest artifact densities are situated at the east end (11 and 22) and northwest corner of the block (25 and 26). EUs 11 and 22 are located to the immediate south of the Feature 10, a charcoal and burned rock lens exposed in BHT 10. These units are situated to the west of IU 8 which also contains a high artifact density of 445.0. Lastly, Area 4 contains very few artifacts with individual grid densities ranging from only $0.0-18.0$ per cubic meter.

If we look at lithic artifact density solely by EU, then these densities appear to be distributed into four groups: 1) 0-49, 2) 50-299, 3) 300-499, and 4) 500+. Most of the EUs contain low artifact densities of less than $300(n=26)$; whereas, only eight contain densities of $300-499$, and six have densities of 500 . All six of the 500 or higher density EUs are located in Area 1, with five of the 300-499 group also being present in Area 1, a single EU in Area 2, and both IUs 8 and 10. Area 4 contains all six of the lowest density EUs.

There are too few cores to make any meaningful statement about artifact densities, but they occur in areas with artifact densities ranging from 134.3-489.2. Table 16-4 provides information on debitage type by area and isolated unit on the site. The data on IUs 8 and 10 , as well as 2 and 4 , have been combined to increase the sample sizes of these adjacent units. Area 4 was excluded from the analysis because of its small sample size. A chi-square test of the contingency table indicates that there is significant difference between these areas in respect to the distribution of debitage types

Table 16-3. Artifact Distribution by Area

\begin{tabular}{|c|c|c|c|c|}
\hline Area & $\begin{array}{c}\text { Lithic Artifact } \\
\text { Density per } \mathbf{~ m}^{3}\end{array}$ & $\begin{array}{c}\text { Maximum B urned Rock } \\
\text { per level (g) }\end{array}$ & $\begin{array}{c}\text { Maximum Mussel Shell } \\
\text { per level (g) }\end{array}$ & $\begin{array}{c}\text { Maximum Snail Shell } \\
\text { per level (g) }\end{array}$ \\
\hline 1 & 551.9 & 954.5 & 106.7 & 10.0 \\
\hline 2 & 199.2 & 625.7 & 17.7 & 10.5 \\
\hline 3 & 107.5 & 734.8 & 21.6 & 7.7 \\
\hline 4 & 0.8 & 495.3 & 5.2 & 1.3 \\
\hline
\end{tabular}


Table 16-4. Debitage Type by Area and Isolated Unit

Top value in cell represent artifact count and bottom value represents adjusted residuals.

Significant $(p=\leq .05)$ positive values are shown in bold.

\begin{tabular}{|l|c|c|c|c|c|}
\hline \multirow{2}{*}{ Debitage Type } & \multicolumn{5}{|c|}{ Area and Isolated Unit } \\
\cline { 2 - 6 } & $\mathbf{1}$ & $\mathbf{2}$ & $\mathbf{3}$ & IU 2/4 & IU 8/10 \\
\hline angular debris & 495 & 140 & 173 & 54 & 259 \\
& -5.0 & -7.1 & 1.0 & $\mathbf{4 . 7}$ & $\mathbf{1 3 . 5}$ \\
\hline core flake & 1932 & 691 & 562 & 55 & 206 \\
& $\mathbf{7 . 5}$ & -0.9 & $\mathbf{3 . 9}$ & -5.0 & -12.4 \\
\hline biface flake & 372 & 151 & 130 & 17 & 77 \\
& -0.7 & -0.2 & $\mathbf{2 . 4}$ & -0.7 & -0.8 \\
\hline und. fragment & 1685 & 833 & 391 & 110 & 440 \\
& -3.6 & $\mathbf{6 . 6}$ & -6.8 & $\mathbf{2 . 3}$ & $\mathbf{3 . 6}$ \\
\hline other & 54 & 10 & 32 & 2 & 14 \\
& -0.6 & -3.1 & $\mathbf{4 . 3}$ & -0.6 & 0.4 \\
\hline
\end{tabular}

Chi-square $=419.8, \mathrm{df}=16, \mathrm{p}=<0.01$

(chi-sq=419.88, $\mathrm{df}=16, \mathrm{p}=<0.01$ ). There is relatively more angular debris than expected in IUs 8 and 10 , and 2 and 4, and more core flakes in Areas 1 and 3. Area 3 also contains more biface flakes and "other" flakes than expected, and Area 2 more undetermined flake fragments. The "other" flakes in Area 3 primarily reflect pot lids (associated with Feature 10?), and most of the undetermined flake fragments in Area 2 are probably broken biface flakes.

There are also some differences in retouched tool density across the site. Retouched tool artifact densities for individual EUs can be divided into three groups: 1) $0.0-1.7(n=18), 2) 2.5-3.7(n=18)$, and 3) $4.1-6.7$ $(n=6)$. The units with the highest densities of retouched tools are present in Area 1 (EU 1, 12), Area 2 (EU $16,21,37)$ and in $I U 10$, with artifact densities from 142.5-652.0. Overall, retouched tool densities are highest in Area 1 (1.7-6.0) and $\Pi U 10$ (5.8), somewhat lower in Areas $2(0.0-6.7)$ and $3(0.0-3.3)$, and the lowest in Area 4 (0.0-2.5) and IUs $2(0.0), 4(0.0)$, and $8(2.5)$. This pattern is similar to the general artifact density pattern exhibited across the site.

Figure 16-1 illustrates the distribution of projectile point types across the site. Shumla points have the widest distribution, being present in Areas 1, 2, and 3. The Ensor points are primarily located on the western end of the site in Areas 3 and 4 . In contrast, the Langtry, Desmuke, and Marcos are only present in Area 1, and the Montell, Marshall, and untyped stemmed point in Area 2. No projectile points were recovered from IUs $2,4,6,8$ or 10 . It is noteworthy that $I U 10$ contains relatively more retouched tools, but these do not include projectile points.

\section{Excavation Levels}

The study of individual block excavation areas was able to identify variations in the distribution of artifact classes across the site. Most notable of these, was a general decrease in artifact density from east to west. In this section the focus changes towards the vertical distribution of material classes by excavation level. The vertical distribution of lithic artifacts at $41 \mathrm{MV} 120$ is apparently constrained by the presence of an underlying point bar deposit situated in the central area of the site.

Table 16-5 presents information on the distribution of material classes through the stratigraphic profile, denoting which zones exhibit the highest occupational intensity. These zones are defined as the upper (1-4), middle (6-8), and lower (8-12) levels of the block excavations. Artifact densities are greatest in the lower 


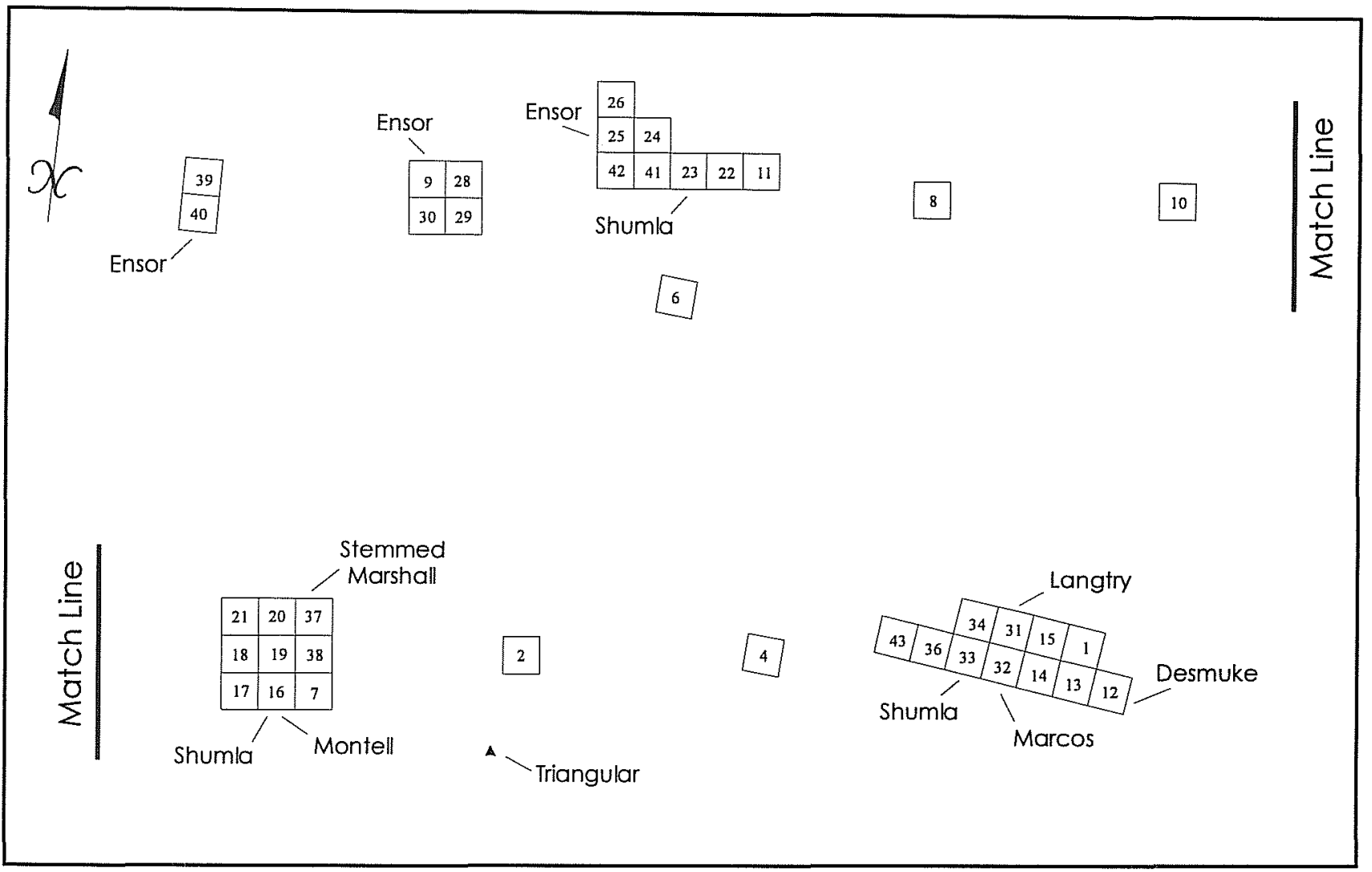

Figure 16-1. Schematic distribution of projectile point types across site $41 M V 120$.

cavations. Artifact densities are greatest in the lower portions of the sequence in Areas 1 (Levels 9-11) and 4 (Levels 10-12); whereas, it is the middle levels of Areas 2 (Levels 4-6) and 3 (Levels 6-8) which contain the highest densities. This pattern is in part conditioned by the apex of the point bar being situated underneath Area 2. The sides of the point bar then slope down towards the east and west.

The internal spatial organization of activities at $41 \mathrm{MV} 120$ are most clearly represented by the hearths and surrounding artifact distributions identified in
Area 1. As described in Chapter 8, nearly intact hearth features were identified in Levels 8 and 12. A study of the adjacent artifact distributions identified a consistent pattern in the location of campsite activities. Using hearths as the central focus of the campsite it was observed that some mussel shell, snail shells, a projectile point and a mano were found in the immediate area of the hearths (e.g., drop zones). These reflect the location where food processing, consumption, and tool maintenance activities occurred. Moving several meters out from the hearth there are concentrations of mussel shells, snail shells, and burned rock

Table 16-5. Vertical Distribution of Material Classes by Area and Stratigraphic Location of High Occupational Intensity Levels

\begin{tabular}{|c|c|c|c|c|}
\hline Area & Lithic Artifacts & Fire-Cracked Rock & Mussel Shell & Snail Shell \\
\hline 1 & lower & lower & lower & lower \\
\hline 2 & middle & middle & upper & middle-upper \\
\hline 3 & middle & middle & middle & lower \\
\hline 4 & upper & upper & lower & middle \\
\hline
\end{tabular}


which may reflect discard piles and the remains of processing features. Lastly, the lithic reduction locus is located furthest from the hearth. This activity produces a large amount of debris, and its distant location is probably designed so as not to interfere with the activities being conducted in the immediate vicinity of the hearth. The fact that this organizational module is present in the lower and upper levels of the site indicates a long-term redundant pattern in site reuse.

How does the organization of site activities as identified in Area 1 compare across the site? Although intact hearth features are rare, we can study the relationship between various artifact classes as a measure of intrasite organization. Scatter plots can be used to identify low/high artifact density within the 345 excavated $10-\mathrm{cm}$ levels across the site. Based on the organizational modules discussed above, we might expect to find isolated burned rock clusters (hearths, processing features, or dumps), isolated mussel and snail shell clusters (drop zones), mussel and snail shell mixed with burned rock (dumps or disturbed deposits), isolated lithic reduction loci, and a mixture of lithic reduction and burned rock materials (dumps or disturbed deposits). All of these will be characterized by differing artifact densities.

Figure 16-2 is a scatter plot of the number of lithic artifacts and total weight of burned rock by individual levels. As can be seen, the majority of the levels contain low densities of both lithic artifacts and burned rock. That is, fewer than 50 lithic artifacts, and less than about $200 \mathrm{~g}$ of burned rock. The remainder of the distribution is characterized by levels with high densities of lithic artifacts, but few burned rocks, and high densities of burned rock, but few lithic artifacts.

In the case of the low overall artifact density, this would presumably be the result of low occupational intensity. That is, short term site occupation, and/or limited activity use. Instances of high artifact density are probably related to high occupational intensity, including longer term occupation and/or the spatial segregation of activities. The single level which exhibits both high

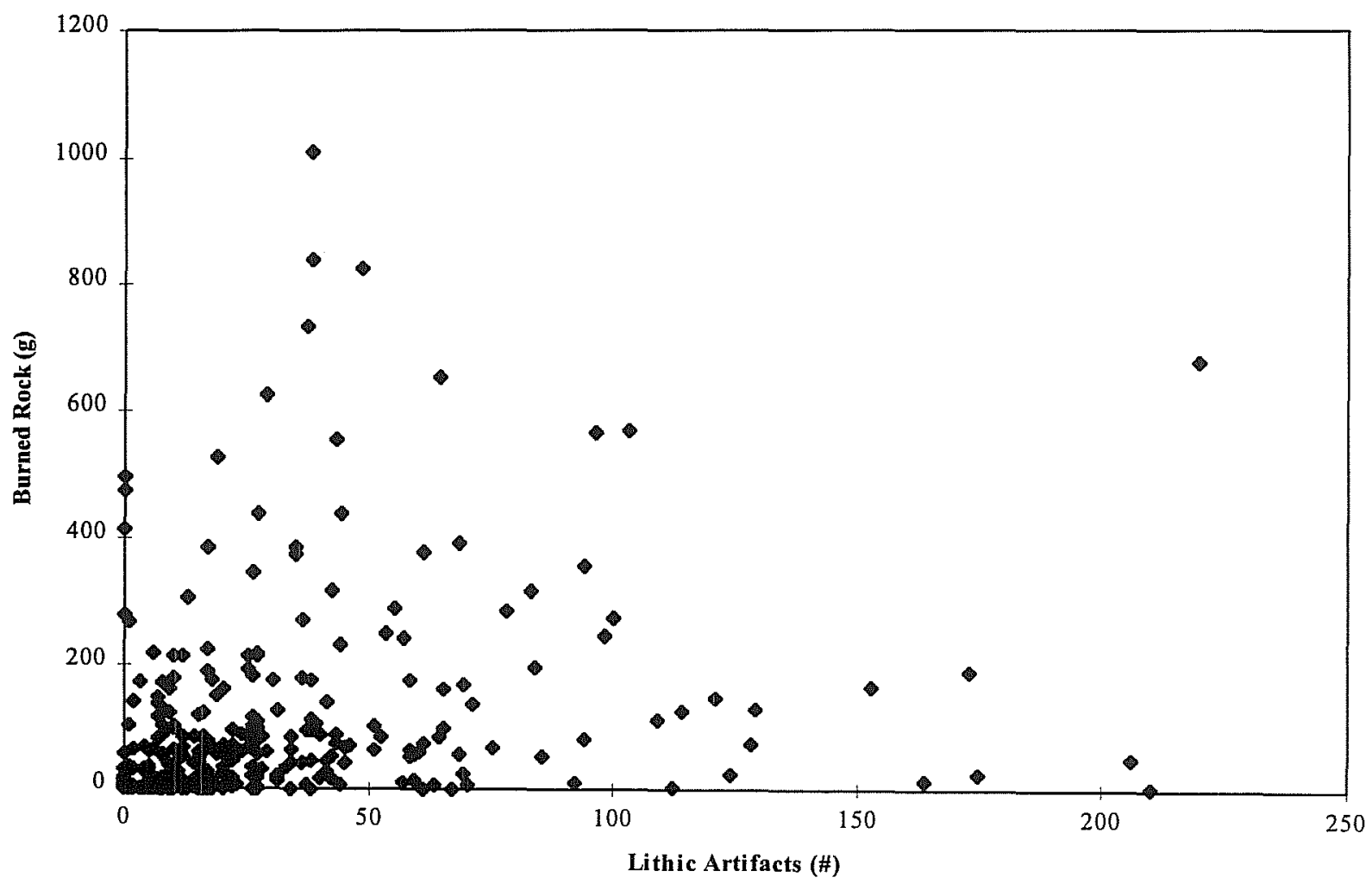

Figure 16-2. Scatter plot of number of lithic artifacts by burned rock weight $(g)$ for individual levels. 
A compositional analysis of the low vs. high lithic artifact density levels may help clarify the differing activities represented. Levels with less than 50 artifacts were classified as low density, and those with 50 or more artifacts as high density.

A chi-square test of a contingency table of debitage type by low/high density indicates that there is a significant difference in the distribution (Table 16-6; chi$s q=25.1, d f=4, p=<0.01)$. These differences are limited to the presence of more angular debris than expected in the low density levels, and more undetermined flake fragments in the high density levels. Analyses performed in Chapter 9 indicate that many of the undetermined flake fragments are probably broken biface thinning flakes. These loci probably reflect high intensity activity locations for lithic reduction, including tool production. Repeated use of these loci may also have had a trampling-effect on artifacts, increasing the number of broken flakes. The presence of more angular debris in the low density areas reflects a greater emphasis on core reduction activities, or that some of this debris may actually represent small burned fragments of siliceous rocks.

An analysis of the material composition of low vs. high density burned rock levels also indicates a significant difference in the distribution (Table 16-7; chi-sq=120.3, $\mathrm{df}=7, \mathrm{p} \leq 0.01$ ). Low density levels contain less than $200 \mathrm{~g}$ of burned rock, and high density levels more than or equal to $200 \mathrm{~g}$. There appears to be more sandstone than expected in the high-density levels, and more rhyolite, chert, quartzite and chalcedony than expected in the low density levels. These lithic materials are available from separate local sources. That is, the sandstone from bedrock outcrops and the other materials from terrace gravels. The differences in material type and source location would presumably indicate that these materials were also selected for separate functions. Sandstone could have been used for hearth elements, but the cobbles could have served as hearth elements, in processing features, or as boiling stones; however, there is no evidence of intact processing features on the site (e.g., cobble-lined pits). It is therefore unclear as to what the original structure of these features might have been, but it seems likely that they were used to cook mussels and other foods.

A scatter plot of mussel shell by burned rock weight was drawn to study the relationship between these artifact groups (Figure 16-3). Mussel shells are generally present in levels with low densities of burned rock (i.e., less than about $200 \mathrm{~g}$ ). Overall, there is no linear relationship between mussel shell and burned rock weight. The presence of relatively more mussel shell in low-density burned rock levels may support the sug-

Table 16-6. Lithic Artifact Density by Debitage Type

Top value in cell represent artifact count and bottom value represents adjusted residuals.

Significant $(\mathrm{p}=\leq .05)$ positive values are shown in bold.

\begin{tabular}{|l|c|c|}
\hline \multirow{2}{*}{ Debitage Ty pe } & \multicolumn{2}{|c|}{ Lithic Artifact Density } \\
\cline { 2 - 3 } & $<\mathbf{5 0}$ & $\geq \mathbf{5 0}$ \\
\hline \multirow{2}{*}{ angular debris } & 668 & 494 \\
& $\mathbf{4 . 9}$ & -4.9 \\
\hline \multirow{2}{*}{ core flake } & 1753 & 1731 \\
& -0.8 & 0.8 \\
\hline \multirow{2}{*}{ biface flake } & 378 & 376 \\
& -0.4 & 0.4 \\
\hline \multirow{2}{*}{ undetermined fragment } & 1737 & 1785 \\
& -2.3 & 2.3 \\
\hline \multirow{2}{*}{ other } & 56 & 59 \\
& -0.5 & 0.5 \\
\hline
\end{tabular}

Chi-square $=25.1, \mathrm{df}=4, \mathrm{p} \leq 0.01$ 
Table 16-7. Burned Rock Density by Material Type

Top value in cell represent artifact count and bottom value represents adjusted residuals.

Significant $(\mathrm{p}=\leq .05)$ positive values are shown in bold.

\begin{tabular}{|l|c|c|}
\hline \multirow{2}{*}{ Material Ty pe } & \multicolumn{2}{|c|}{ Burned Rock Density (g) } \\
\cline { 2 - 3 } & $<\mathbf{2 0 0}$ & $\mathbf{2 0 0}$ \\
\hline \multirow{2}{*}{ rhyolite } & $\mathbf{8 8 5}$ & 2335 \\
& $\mathbf{5 . 0}$ & -5.0 \\
\hline \multirow{2}{*}{ sandstone } & 7085 & 24508 \\
& -8.8 & $\mathbf{8 . 8}$ \\
\hline \multirow{2}{*}{ limestone } & 2116 & 6806 \\
& -0.4 & 0.4 \\
\hline \multirow{2}{*}{ chalcedony } & 75 & 151 \\
& $\mathbf{3 . 3}$ & $\mathbf{- 3 . 3}$ \\
\hline \multirow{2}{*}{ chert } & 3512 & 10084 \\
& $\mathbf{6 . 1}$ & -6.1 \\
\hline \multirow{2}{*}{ silicified wood } & 19 & 70 \\
& -0.6 & 0.6 \\
\hline \multirow{2}{*}{ quartzite } & 335 & 810 \\
& 4.3 & -4.3 \\
\hline \multirow{2}{*}{ quartz } & 20 & 41 \\
& 1.6 & -1.6 \\
\hline
\end{tabular}

Chi-square $=120.3, \mathrm{df}=7, \mathrm{p} \leq 0.01$

gestion that cobbles were in part used for cooking mussels, with the remnants of this activity being discarded in the same location. This location appears to have been separated from the high-density burned rock hearth areas.

The distribution of mussel and snail shells can be divided into three groups (Figure 16-4). The first group consists of those levels with low-high densities of mussel shell and low densities of snail shells (i.e., less than $2 \mathrm{~g}$ ). The second group is composed of levels with high densities of snail shells and low densities of mussel shells (i.e., less than $100 \mathrm{~g}$ ). The third group consists of a series of levels characterized by a linear relationship between mussel shell and snail shell weight. There are relatively few snails present on the site, but they generally occur in conjunction with mussel shells. It is unclear as to whether the snails are of a cultural or natural origin. They are biased towards larger individuals (Chapter 13), and they are found in similar areas as the mussels. Yet, surface food debris might have also attracted these snails.
Although mussel and snail remains have been preserved throughout the site, there is a general lack of animal bone represented. Fifteen bones were recovered from the site, and only four could be identified (see Chapter 14). At least two undetermined mammal bone fragments exhibit possible chopping marks. Given the preservation of mussel, snail, and macrobotanical remains, it seems unlikely that the paucity of animal bone is related to preservation. It may be that mussels and snails provided most of the animal protein consumed at the site, being supplemented with some small-medium game or fish. Small game and fish are sometimes pulverized prior to consumption, thereby leaving little archaeological evidence of their existence (e.g., see Campbell and Campbell 1981:19). In addition, mesquite and acacia pods might have also been available as a food item, given the presence of wood charcoal. 


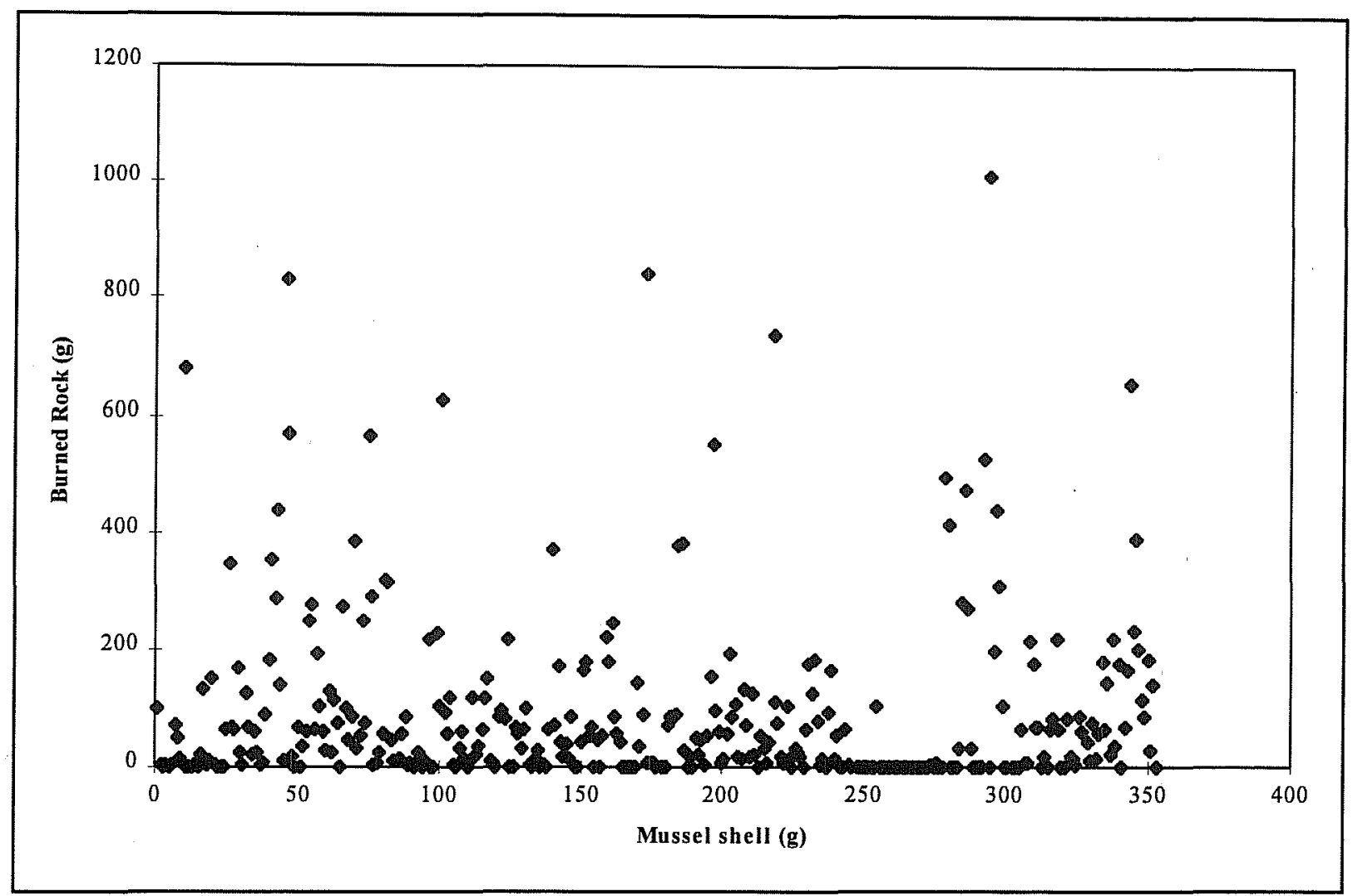

Figure 16-3. Scatter plot of mussel shell weight (g) by burned rock weight ( $g$ ) for individual levels.

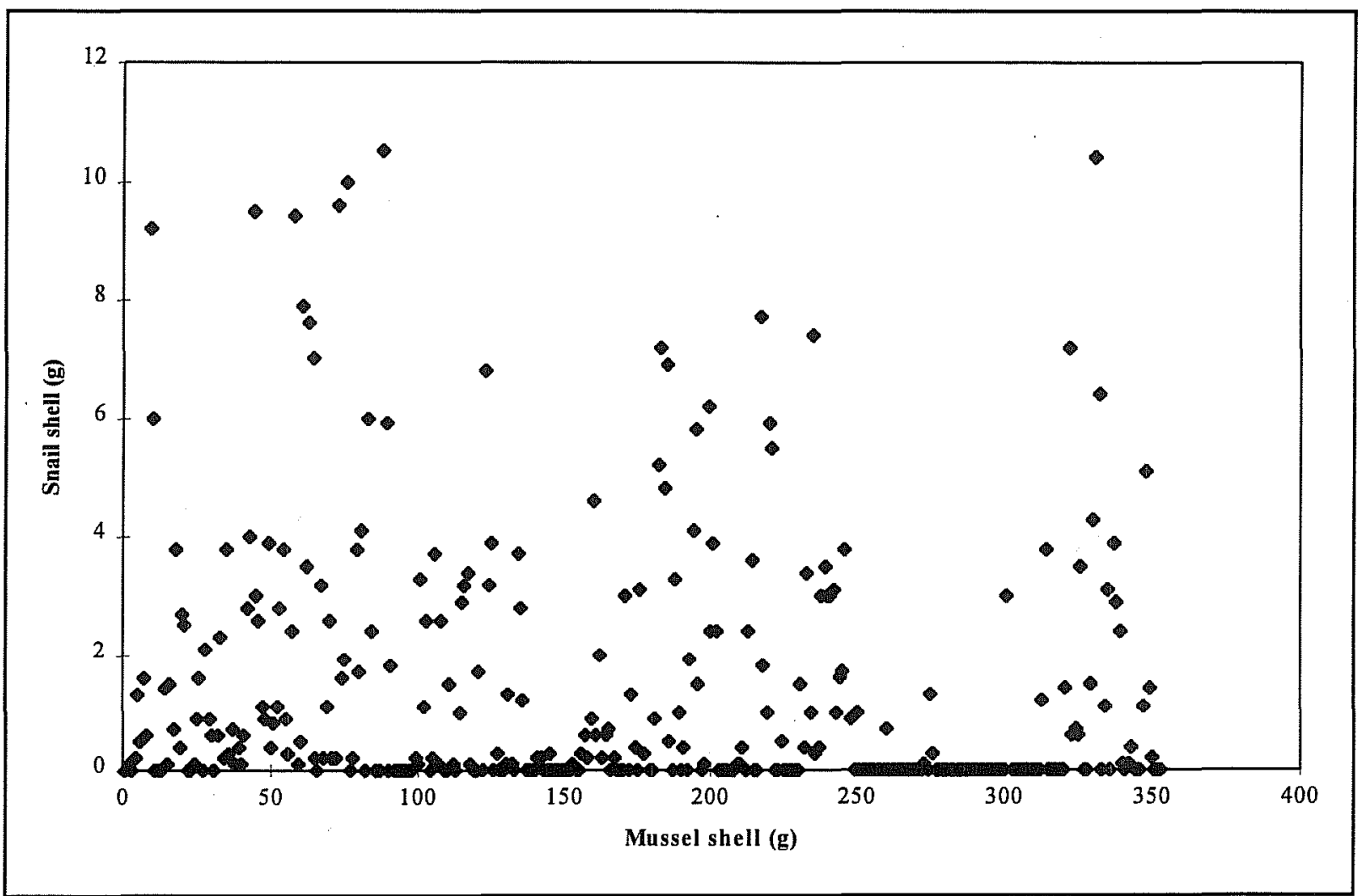

Figure 16-4. Scatter plot of snail shell weight (g) by mussel shell weight (g) for individual levels. 


\section{Sediment Packages}

The previous sections provided a baseline summary of varying artifact density and assemblage composition for the block excavations and isolated units; however, these data either represent the cumulative sum of all the occupational horizons represented, or a single level within these respective proveniences. The various vertical segments of the site which contributed to these assemblages need to be isolated and individually described. This information can then be used to identify the occupational sequence and long-term pattern of site reuse. Vertically distributed occupational Analytical Units (AUs) can be defined by changing artifact density and mean debitage weight through the stratigraphic sequence. Once isolated, these AUs can be separately analyzed to study variations in assemblage composition and long-term site use. Field methods at 41MV120 included the excavation of both 5- and 10-cm arbitrary levels. For analytical purposes, sets of levels excavated in 5-cm increments were lumped together to form a consistent $10-\mathrm{cm}$ sequence for each $\mathrm{EU}$. Information on the correspondence between the original level numbers (level), and the lumped $10-\mathrm{cm}$ level numbers (Level 2) are provided in Appendix C. The lumped 10$\mathrm{cm}$ excavation levels are discussed in this section.

\section{Size Sorting}

Site 41MV120 is situated near the ancient confluence of the Elm Creek and the Rio Grande. Given this depositional context, it seems important to identify any evidence of artifact size sorting which might affect our study of the vertical distribution of artifacts. Size sorting, and the vertical movement artifacts through the soil horizon, is especially a problem in sandy deposits (e.g., see Gifford-Gonzalez et al.1985; Stevenson 1991; Villa 1982). Information on mean debitage weight per level is used to determine if there is any evidence of size sorting which might affect our attempt to isolate stratigraphic site AUs, and study variations in interassemblage composition.

Figure 16-5 illustrates the distribution of mean debitage weight by $10-\mathrm{cm}$ levels for Area 1 . As can be seen, there is subtle rhythmic pattern of larger and smaller mean artifact size which varies by level at $20-\mathrm{cm}$ increments (i.e., Levels 6-7, 8-9, 10-11, and 12-13). The larger retouched tools exhibit a similar distribution as that of the smaller debitage (Figure 16-6). Although this pattern appears to indicate an overall lack of size sorting in respect to a general decrease in artifact size from upper to lower levels, it does show a repeated pattern. This pattern becomes clearer once it is plotted against lithic artifact density, and compared with information on site sediments and chronology (Figure 16-7).

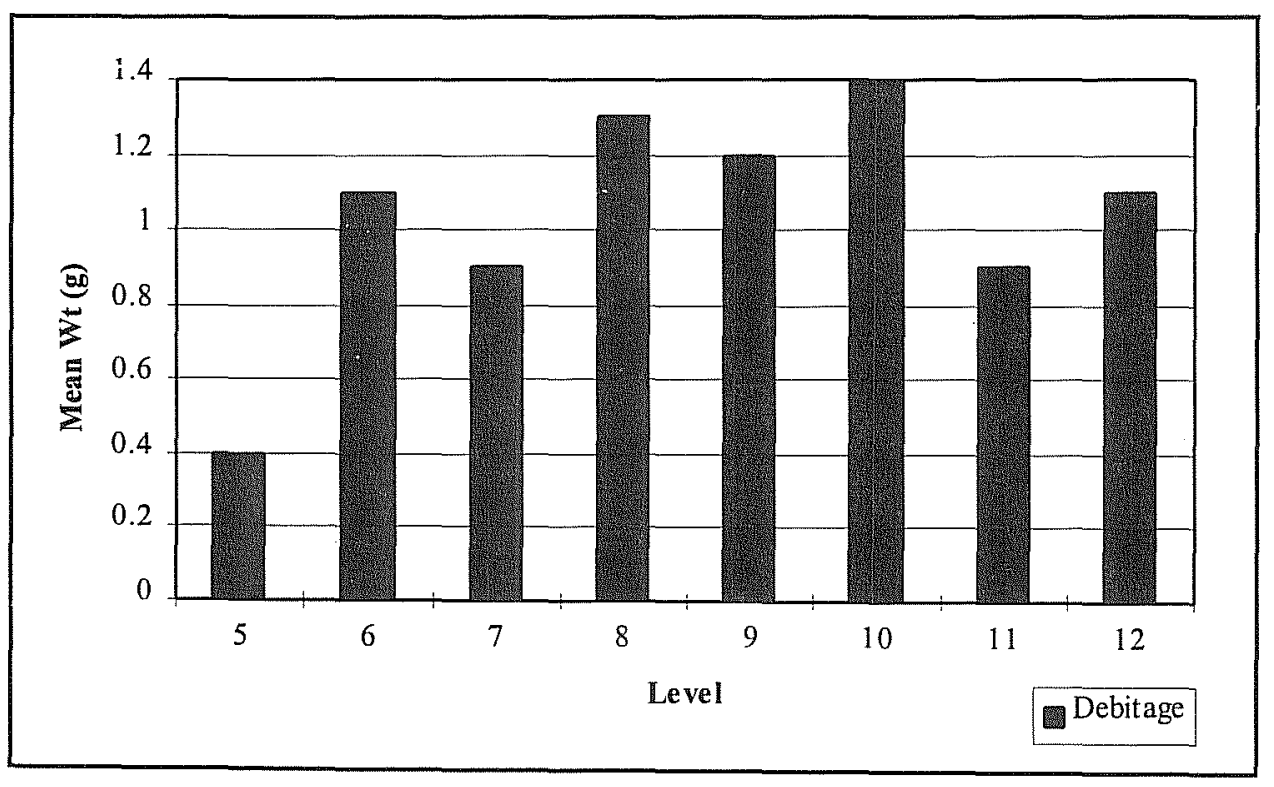

Figure 16-5. Mean debitage weight (g) by level for Area 1. 


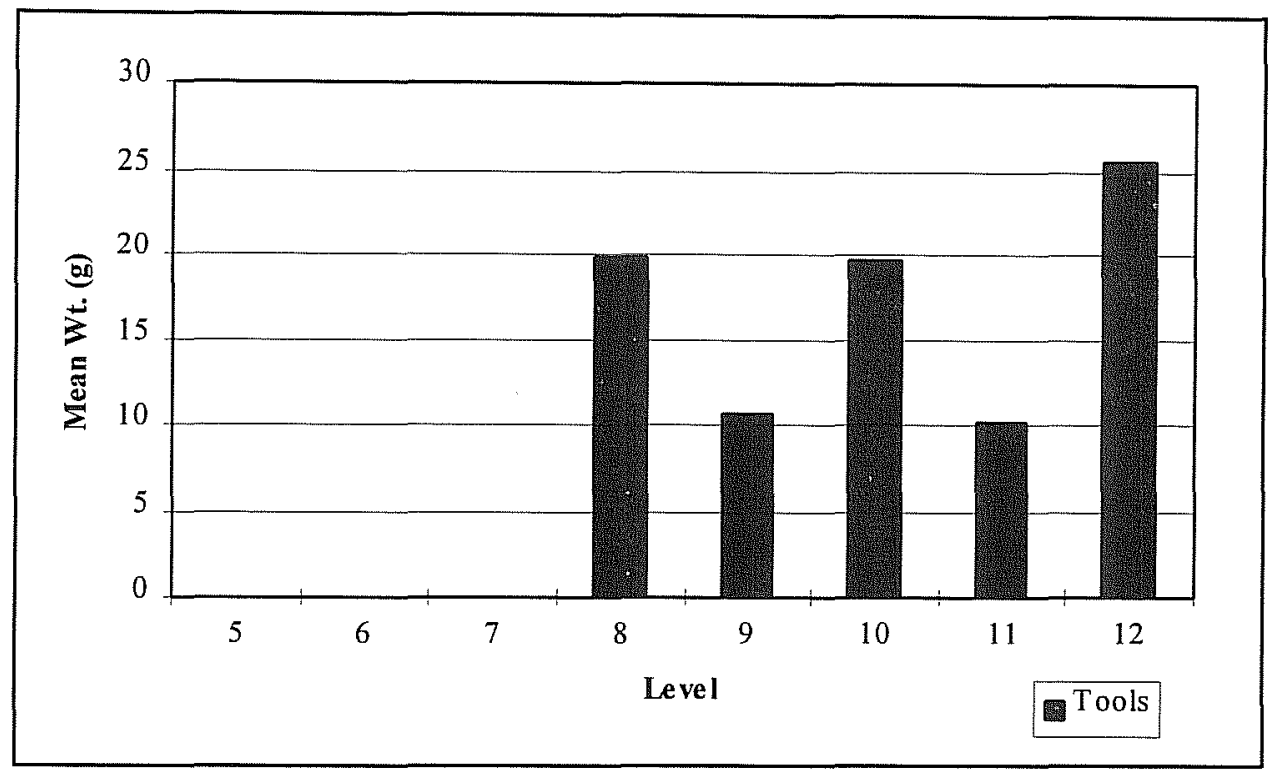

Figure 16-6. Mean retouched tool weight $(g)$ by level for Area 1.

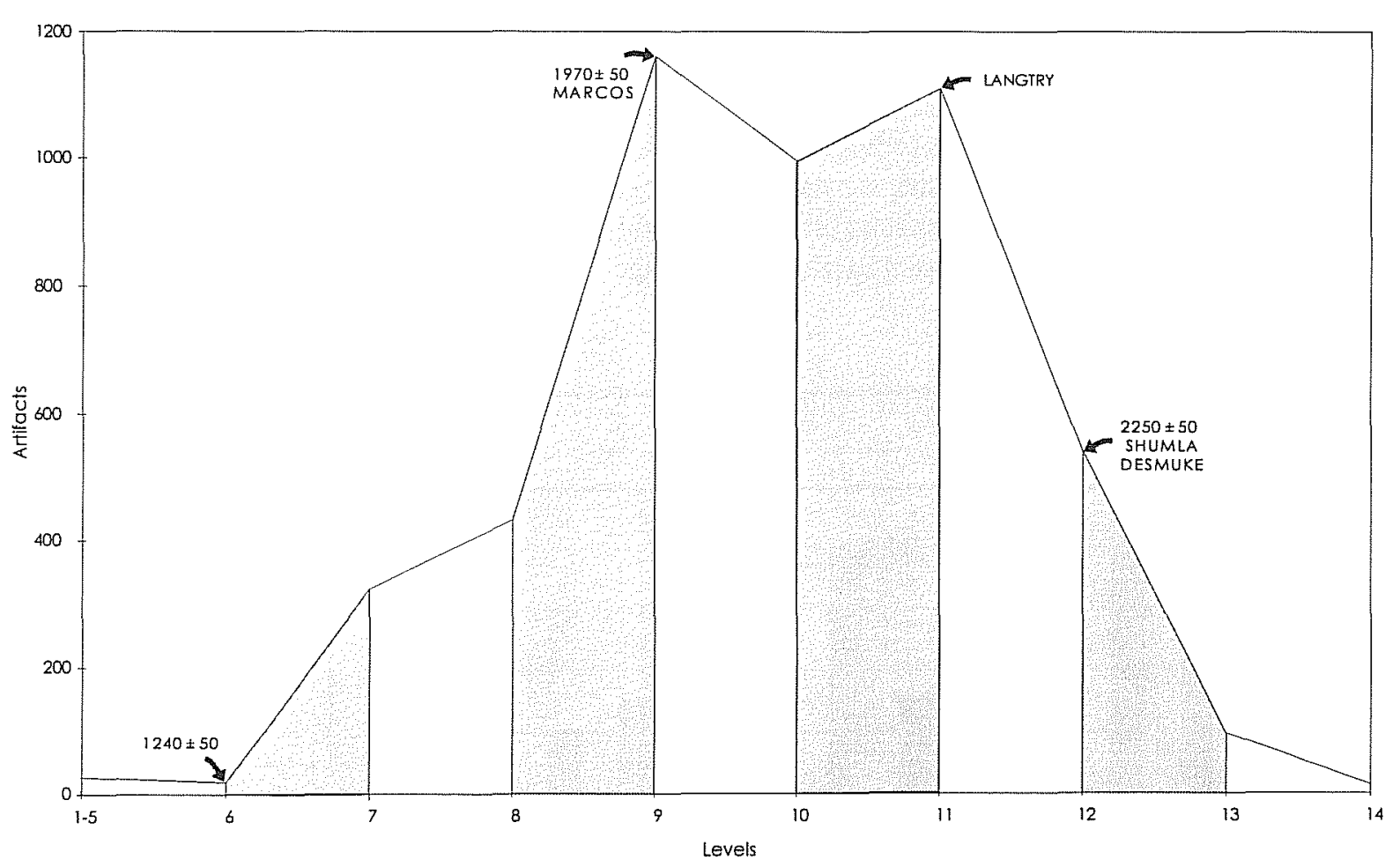

Figure 16-7. Lithic artifact frequencies by $A U$ (shaded area) for Area 1. 
Levels 12-13 are associated with the occupational surface identified in Level 12. This surface is dated to $2200 \pm 50$ B.P. and contains Shumla and Desmuke projectile points. Levels 10-11 correlate with increased lithic artifact density and a Langtry projectile point. These lower levels (10-13) are present in floodplain unit 2-f1 as defined by Nordt (Chapter 7). Levels $8-9$ are associated with the occupational surface identified in Level 8 and a buried $\mathrm{Ab} 1$ paleosol. A Marcos projectile point was recovered from Level 9, which also yielded a radiocarbon date of $1970 \pm 50$ B.P. Upper Levels 6-7 are associated with the mussel shell lens exposed in EU 3, Level 6 by TxDOT. This lens yielded a charcoal date of $1240 \pm 50$ B.P. Levels $6-7$ are situated within the most recent floodplain unit 2-f3. It appears that a series of four separate sediment packages can be defined, three of which are associated with occupational surfaces and features. Levels containing the larger mean debitage sizes appear to correlate with occupational surfaces. Together, these data provide a coherent and consistently dated sequence.

Area 2 exhibits a similar rhythmic pattern in $20-\mathrm{cm}$ couplets in the upper six levels (Figure 16-8); however, mean debitage size declines from Level 7-12. This latter pattern appears to represent vertical size sorting of artifacts, and corresponds with the presence of an underlying sand deposit that may have been sterile originally. Smaller pieces of debitage were presumably moving down the soil profile through the point bar deposit.
Four sediment packages can also be identified within the Area 2 stratigraphic profile (Figure 16-9). That is, Levels 1-2, 3-4, 5-6 and 7-12. The lower AU corresponds to the bottom of floodplain unit 2-f1 and the upper part of the point bar (Unit 2-p). A Shumla and Montell were recovered from Levels 10 and 7, respectively. Levels 5-6 are associated with high artifact density, a possible in situ burned rock, and a Marshall point which is also situated in Unit 2-f2. Artifact density decreases in Levels 3-4 and Levels 1-2 which are present in Unit 2-f3. A charcoal sample from nearby TxDOT EU 2, Level 4 yielded a date of $1460 \pm 50$ B.P. Although no clear occupational surfaces or features were defined in Area 2, the sediment packages do correspond with changes in artifact density and site sediments.

Area 3 is characterized by a different pattern than those witnessed in Areas 1 and 2 (Figure 16-10). Mean debitage size is somewhat larger in this area, and the rhythmic pattern varies from 20 - to 40 -cm increments from the lower to upper levels. The sequence is bounded by large mean weights at the top and bottom, with no evidence of generalized size sorting from larger- to smallersized artifacts through the profile. Nonetheless, four sediment packages can also be identified in the Area 3 stratigraphic sequence (Figure 16-11). These consist of Levels $1-4,5-7,8-9$, and 10-11. Level 12 presumably represents the severed portion of another package.

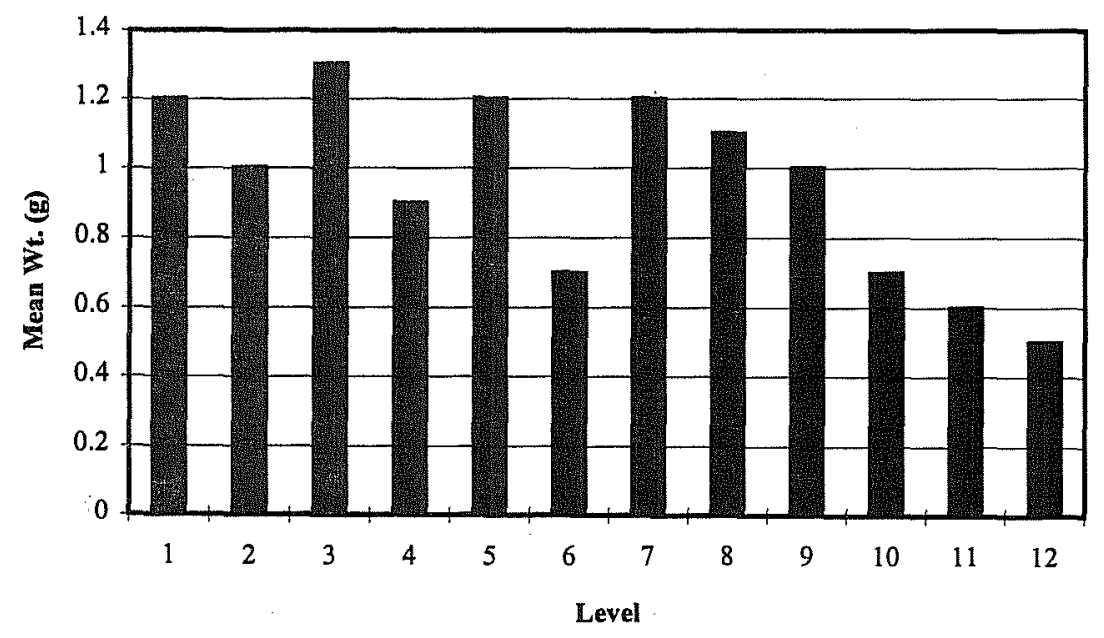

Figure 16-8. Mean debitage weight $(g)$ by level for Area 2. 


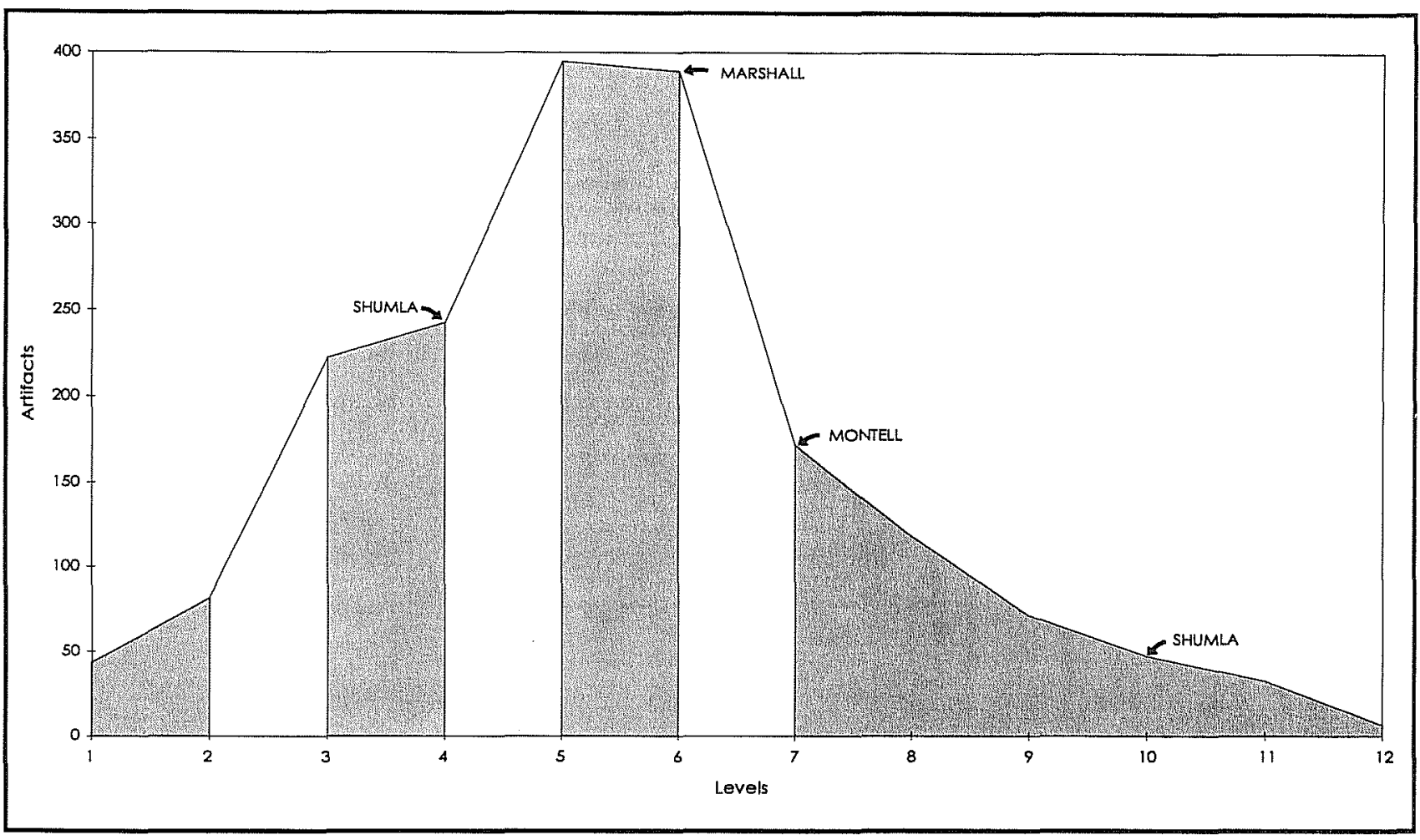

Figure 16-9. Lithic artifact frequencies by AU (shaded area) for Area 2.

Lower Levels 10-11 are present in floodplain unit 2-f1, and Levels 8-9 with Unit 2-f2 (i.e., Ab1 paleosol). A Shumla point was recovered from Level 11. Levels 5-7 exhibit high artifact densities which peak in Level 7 and form the lower portions of Unit 2-f3. Feature 10 consists of two partially intact thermal features which are associated with Levels 6-7, and an Ensor point was also recovered from Level 7. Artifact density decreases in upper Levels 1-4 which are situated in Unit 2-f3.

There are too few artifacts present in Area 4 to make any meaningful statements about size sorting and the distribution of these artifacts through the stratigraphic profile.

The results of this analysis indicate that the lower levels of Area 2 are the only ones which exhibit a consistent pattern of size sorting, with declining mean debitage weights through the lower section of the sequence. Nonetheless, rhythmic patterns of varying artifact size are also represented in the site deposits. These patterns are displayed in 20-cm intervals within Areas 1 and 2, and in 20-40-cm intervals in Area 3. These appear to represent "sediment packages" which can used as AUs to study variations in the vertical distribution of the various material classes at the site.

\section{Site Analytical Units and Block Excavation Assemblages}

\section{Lithic Artifacts}

The site occupational sequences can be divided into four AUs for Areas 1-3. These are numbered 1-4 from upper to lower levels. The results of the lithic analysis of all the EUs are used to contrast inter-assemblage composition for the various AUs within their respective areas. This information is, however, limited to debitage material and artifact type categories, which are discussed in respect to material selection, production/ maintenance, and tool-use activities. 


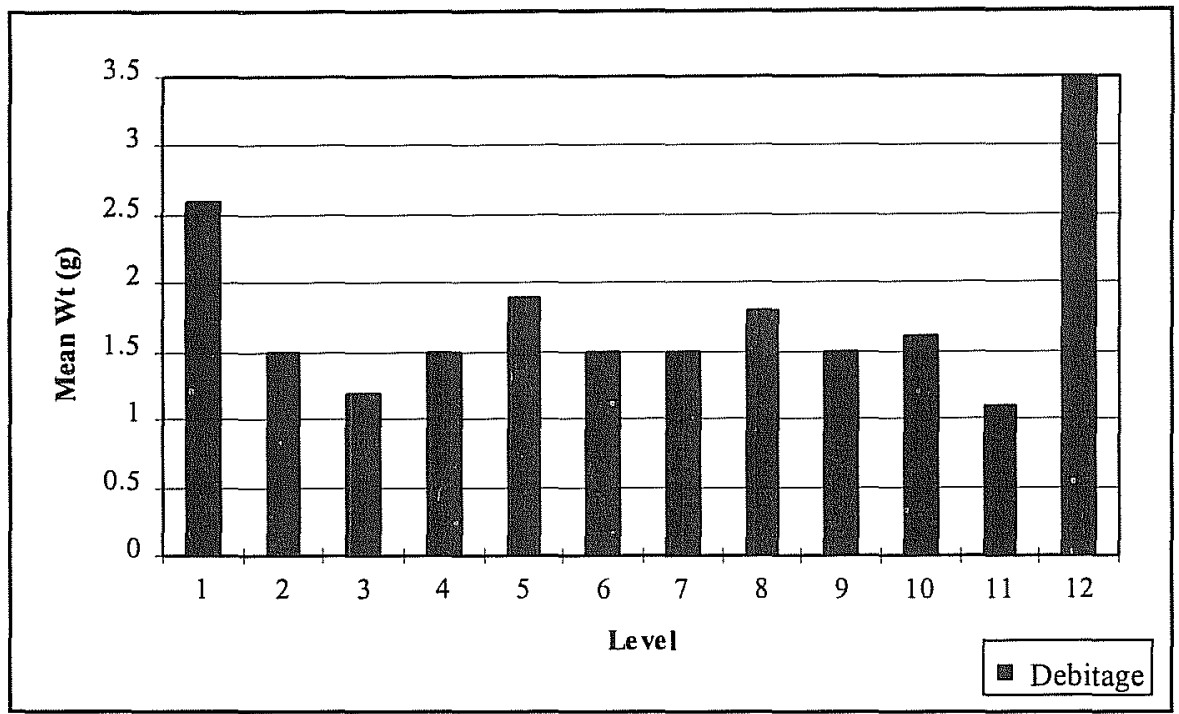

Figure 16-10. Mean debitage weight $(g)$ by level for Area 3.

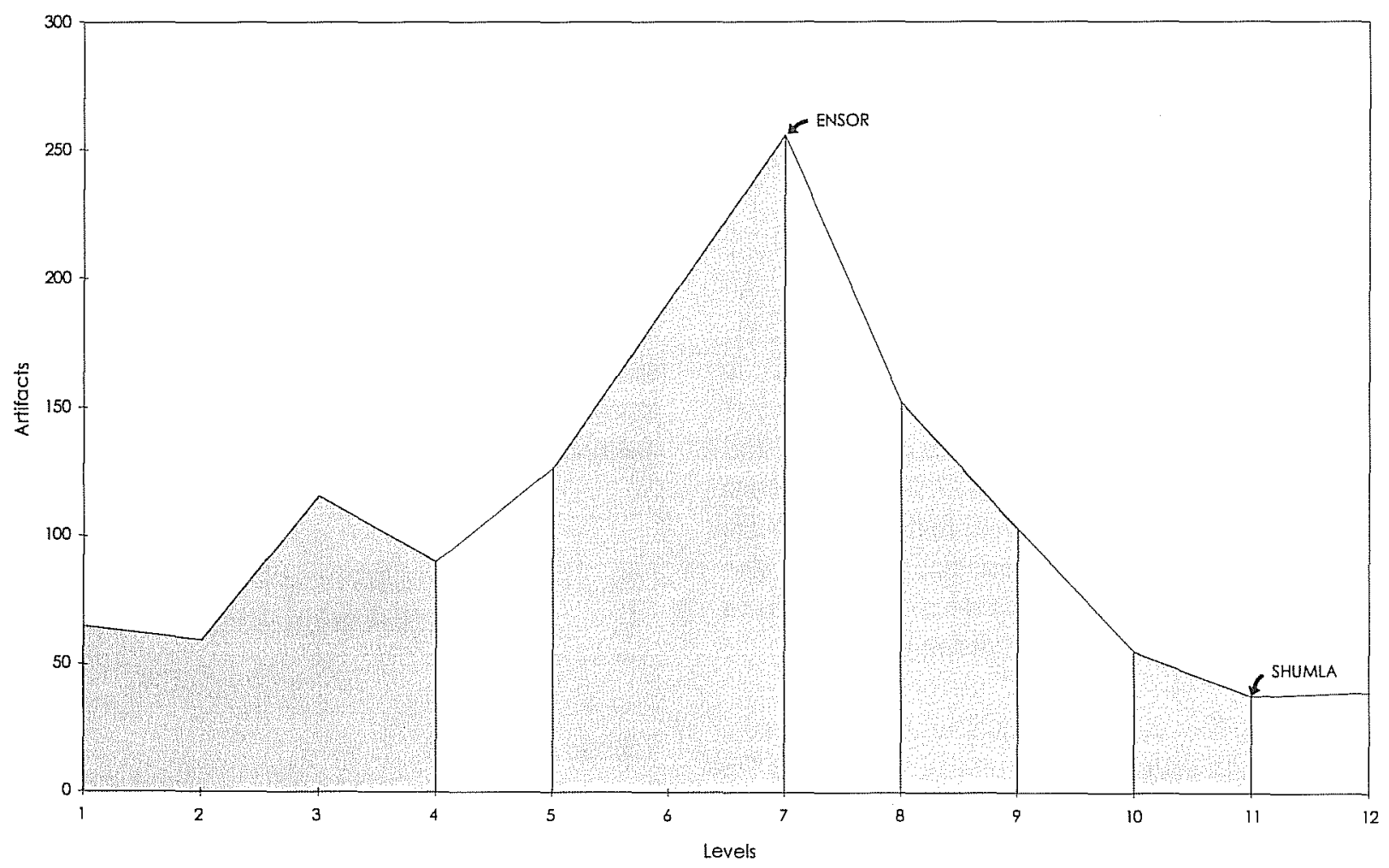

Figure 16-11. Lithic artifact frequencies by $A U$ (shaded area) for Area 3.

\section{Material Selection}

As stated in Chapter 9, the majority of the debitage on the site is composed of chert, with much less jasper, chalcedony, salt/pepper rhyolite, and other materials.
Information on Area 1 debitage material type by AUs is presented in Table 16-8. A chi-square test of the contingency table indicates a significant difference in the distribution of material types across the area AUs (chi-sq=53.5, $\mathrm{df}=12, \mathrm{p} \leq 0.01$ ). AUs 1 and 2 contain more "other" materials than expected (e.g., quartz and 
Table 16-8. Material Type by Area 1 Analytical Units

Top value in cell represents artifact count, and bottom value represents adjusted residuals.

Significant $(\mathrm{p}=\leq .05)$ positive values are shown in bold.

\begin{tabular}{|l|c|c|c|c|}
\hline \multirow{2}{*}{ Material Type } & \multicolumn{4}{|c|}{ Analy tical Unit } \\
\cline { 2 - 5 } & 1 & 2 & 3 & 4 \\
\hline \multirow{2}{*}{ salt/pepper rhy olite } & 6 & 26 & 31 & 27 \\
& 0.2 & -1.9 & -1.4 & 4.7 \\
\hline \multirow{2}{*}{ chalcedony } & 5 & 47 & 60 & 20 \\
& -1.1 & -0.7 & 0.8 & 0.6 \\
\hline \multirow{2}{*}{ jasper } & 10 & 59 & 35 & 14 \\
\hline \multirow{2}{*}{ chert } & 1.1 & 2.6 & -2.7 & -0.5 \\
\hline \multirow{2}{*}{ other } & 240 & 1553 & 1716 & 529 \\
& -1.1 & -1.0 & 2.6 & -1.7 \\
\hline
\end{tabular}

Chi-square $=53.5, \mathrm{df}=12, \mathrm{p} \leq 0.01$

rhyolite), and AU 2 more jasper. Both AUs 1 and 2 appear to contain relatively more jasper (3.5-3.7 percent) when compared to the lower units (1.9-2.4 percent). AU 3 does, however, contain more chert, and AU 4 more salt/pepper rhyolite than expected. A chert core and rhyolite cobble uniface are present in AU1, and a single chert core in AUs 2 and 3 . All the retouched tools from these AUs are also made of chert, with the exception of a single chalcedony biface from AU 3.
Table 16-9 presents the information on debitage material type by $\mathrm{AU}$ for Area 2. Given the paucity of jasper within this area, all seven pieces of this material were included within the "other" category. There is a significant difference in the distribution of material types by unit (chi-sq=23.7, df=9, $\mathrm{p} \leq 0.01$ ). AU 1 contains more chalcedony than expected, and AU 4 more salt/ pepper rhyolite. Otherwise, all the cores and retouched tools recovered from Area 2 are made of chert. The

Table 16-9. Material Type by Area 2 Analytical Units

Top value in cell represents artifact count, and bottom value represents adjusted residuals.

Significant $(\mathrm{p}=\leq .05)$ positive values are shown in bold.

\begin{tabular}{|l|c|c|c|c|}
\hline \multirow{2}{*}{ Material Type } & \multicolumn{4}{|c|}{ Analytical Un it } \\
\cline { 2 - 5 } & $\mathbf{1}$ & $\mathbf{2}$ & $\mathbf{3}$ & $\mathbf{4}$ \\
\hline salt/pepper & 6 & 17 & 35 & 35 \\
rhyolite & -0.1 & -1.6 & -1.0 & $\mathbf{2 . 9}$ \\
\hline \multirow{2}{*}{ chalcedony } & 12 & 15 & 46 & 28 \\
& $\mathbf{2 . 1}$ & -2.5 & 0.6 & 0.6 \\
\hline \multirow{2}{*}{ chert } & 101 & 414 & 687 & 384 \\
& -1.8 & 1.9 & 1.1 & -2.1 \\
\hline \multirow{2}{*}{ other } & 5 & 17 & 14 & 10 \\
& 1.1 & 1.8 & -1.7 & -0.5 \\
\hline
\end{tabular}

Chi-square $=23.3, \mathrm{df}=9, \mathrm{p} \leq 0.01$ 
presence of relatively more salt/pepper rhyolite in AU 4 corresponds with that observed in Area 1. Although there is no significant difference in the relative presence of "other" materials between the levels, AUs 1 and 2 do contain more of these rarer types than the lower units $(3.7-4.0$ percent vs. 1.8-2.2 percent, respectively). These types consist of rhyolite, limestone, and jasper. This pattern also corresponds with that exhibited in Area 1. These similarities may reflect the roughly contemporaneous nature of the deposits as reflected in the site stratigraphy. That is, AUs 1 and 2 are present in floodplain unit 2-f3, and AU 4 in floodplain unit 2-f1.

The distribution of debitage material types by component for Area 3 is given in Table 16-10. This area also exhibits a significant difference in the distribution of material type by $\mathrm{AU}$ (chi-sq=31.0, df=9, $\mathrm{p}=<0.01$ ). $\mathrm{AU}$ 2 contains more salt/pepper rhyolite than expected, and AUs 3 and 4 more chalcedony. Although there is no significant difference in the distribution of chert, the upper AUs contain relatively more chert than the lower AUs (84.9-85.6 percent vs. 75.5-79.8 percent). All the cores recovered from $\mathrm{AU} 1$, and the single core from AU 4 are made of chert; whereas, the cobble uniface from AU 2 is made of salt/pepper rhyolite. With the exception of a single chalcedony biface present in the $\mathrm{AU} 3$, all the remaining retouched tools are made of chert.
In summary, the AUs from Areas 1-3 are dominated by artifacts made of chert. There are, however, some subtle differences in the distribution of the remaining material types. For example, there is relatively more jasper present in the upper AUs of Area 1 than in other areas on the site. The upper AUs in Areas 1 and 2 also have more "other" materials, and the lower AUs more salt/pepper rhyolite than expected. In contrast, the upper AUs of Area 3 contains more salt/pepper rhyolite and chert, and the lower AUs more chalcedony. These differences seem to be the greatest between the upper and lower two AUs across the site.

\section{Production/Maintenance}

\section{Cores}

Very few cores are present in any of the areas on the site. Nonetheless, of the 13 cores and cobble unifaces recovered from these AUs, eight are found within AU 1 in Areas 1-3. Obviously, the presence of cores is highly biased toward the uppermost AU.

\section{Debitage}

Core flakes and undetermined flake fragments dominate all the analytical assemblages, ranging from $37.0-58.8$

Table 16-10. Material Type by Area 3 Analytical Units

Top value in cell represents artifact count, and bottom value represents adjusted residuals.

Significant $(\mathrm{p}=\leq .05)$ positive values are shown in bold.

\begin{tabular}{|l|c|c|c|c|}
\hline \multirow{2}{*}{ Material Ty pe } & \multicolumn{4}{|c|}{ Analytical Unit } \\
\cline { 2 - 5 } & 1 & 2 & 3 & 4 \\
\hline \multirow{2}{*}{ salt/pepper rhyolite } & 9 & 34 & 12 & 2 \\
& -1.7 & 2.1 & 0.1 & -1.4 \\
\hline \multirow{2}{*}{ chalcedony } & 25 & 35 & 39 & 16 \\
& -1.0 & -3.5 & 3.8 & 2.3 \\
\hline \multirow{2}{*}{ chert } & 273 & 485 & 191 & 83 \\
& 1.5 & 1.9 & -3.4 & -0.8 \\
\hline \multirow{2}{*}{ other } & 12 & 17 & 11 & 3 \\
& 0.4 & -0.8 & 0.9 & -0.3 \\
\hline
\end{tabular}

Chi-square $=31.0, \mathrm{df}=9, \mathrm{p} \leq 0.01$ 
percent and 23.7-49.1 percent, respectively. The assemblages generally reflect a mixture of core reduction and tool production/maintenance, with the latter primarily including the production of bifaces, with some limited evidence for uniface production. There are, however, some subtle differences in the composition of the debitage assemblages when comparing AUs within the different areas. In Area 1 there are significant differences in the distribution of debitage type by component (Table 16-11; chi-sq=69.1, df=12, $\mathrm{p}=<0.01$ ). AU 2 contains more angular debris and "other" debitage types than expected (e.g., pot lids), AU 3 more core flakes, and AU 4 more undetermined flake fragments. Some of the angular debris in AU 2 could represent small burned fragments from chert cobbles, as indicated in the presence of pot lids, and Feature 5. Nonetheless, there is more angular debris in the upper vs. the lower AUs (11.6-15.0 percent vs. 7.8-8.1 percent). Lastly, AU 4 contains more undetermined flake fragments than expected. These small fragments may be the by-product of biface production/maintenance. Area 2 exhibits a somewhat similar pattern to Area 1 . There is a significant difference in the distribution of debitage types by AU (Table 16-12; chi-sq=39.5, $\mathrm{df}=12, \mathrm{p}=<0.01$ ).

AU 1 contains more angular debris than expected, and AU 3 more undetermined flake fragments; however, it appears that AUs 3 and 4 actually contain relatively more undetermined fragments (46.8-49.1 percent), than the upper two AUs (38.7-40.5 percent); whereas, the upper two AUs contain somewhat more angular debris (8.9-17.7 percent vs. 4.9-8.5 percent). This presumably reflects an increase in core reduction in the upper AUs, and biface production/maintenance in the lower AUs.

Area 3 also exhibits a significant difference in the distribution of debitage types by AU (Table 16-13; chi$\mathrm{sq}=33.2, \mathrm{df}=12, \mathrm{p}=<0.01)$; however, in this area there are more core flakes than expected in AU 1, more undetermined flake fragments in AU 2, and more biface flakes and angular debris in AU 3. The pattern here also reflects an increasing emphasis on biface production from upper to lower levels. Overall, the upper three AUs contain relatively more angular than the lowest $\mathrm{AU}$ (12.2-17.8 percent vs. 8.7 percent), and the lower two AUs more biface flakes (14.4-14.6 percent) than the upper two AUs (7.5-8.9 percent). AU 8 also contains more pot lids than the other units, which is probably related to the presence of Feature 10.

The composition of the debitage assemblages for all the AUs is quite similar; however, as was the case with the material types, there are some subtle differences. In this case, there is a pattern reflecting a slight emphasis on core reduction in the upper AUs, and tool production/maintenance in the lower AUs.

Table 16-11. Debitage Type by Area 1 Analytical Units

Top value in cell represents artifact count, and bottom value represents adjusted residuals.

Significant $(\mathrm{p}=\leq .05)$ positive values are shown in bold.

\begin{tabular}{|l|c|c|c|c|}
\hline \multirow{2}{*}{ Debitage Type } & \multicolumn{4}{|c|}{ Analytical Unit } \\
\cline { 2 - 5 } & $\mathbf{1}$ & $\mathbf{2}$ & $\mathbf{3}$ & $\mathbf{4}$ \\
\hline \multirow{2}{*}{ angular debris } & 31 & 257 & 150 & 46 \\
& 0.3 & $\mathbf{6 . 9}$ & -5.2 & -2.6 \\
\hline \multirow{2}{*}{ core flake } & 108 & 674 & 849 & 244 \\
& -0.7 & -3.2 & 3.9 & -0.6 \\
\hline \multirow{2}{*}{ biface flake } & 28 & 121 & 162 & 50 \\
& 1.4 & -2.1 & 1.2 & 0.3 \\
\hline \multirow{2}{*}{ und. fragment } & 100 & 630 & 671 & 247 \\
& 0.0 & -0.5 & -1.2 & 2.4 \\
\hline \multirow{2}{*}{ other } & 1 & 28 & 20 & 4 \\
& -1.3 & $\mathbf{2 . 1}$ & -0.6 & -1.3 \\
\hline
\end{tabular}

Chi-square $=69.1, \mathrm{df}=12, \mathrm{p} \leq 0.01$ 
Table 16-12. Debitage Type by Area 2 Analytical Units

Top value in cell represents artifact count, and bottom value represents adjusted residuals.

Significant $(\mathrm{p}=\mathrm{V} .05)$ positive values are shown in bold.

\begin{tabular}{|l|c|c|c|c|}
\hline \multirow{2}{*}{ Debitage Type } & \multicolumn{4}{|c|}{ Analytical Unit } \\
\cline { 2 - 5 } & $\mathbf{1}$ & $\mathbf{2}$ & $\mathbf{3}$ & $\mathbf{4}$ \\
\hline \multirow{2}{*}{ angular debris } & 22 & 41 & 38 & 39 \\
& $\mathbf{4 . 4}$ & 1.1 & -3.9 & 0.8 \\
\hline \multirow{2}{*}{ core flake } & 46 & 187 & 289 & 169 \\
& -0.2 & 1.3 & -0.7 & -0.4 \\
\hline \multirow{2}{*}{ biface flake } & 8 & 42 & 69 & 32 \\
& -0.8 & 0.7 & 0.7 & -1.1 \\
\hline \multirow{2}{*}{ und. fragment } & 48 & 187 & 384 & 214 \\
& -1.6 & -2.6 & 2.6 & 0.6 \\
\hline \multirow{2}{*}{ other } & 0 & 5 & 2 & 3 \\
& -0.9 & 1.8 & -1.5 & 0.4 \\
\hline
\end{tabular}

Chi-square $=39.5, \mathrm{df}=12, \mathrm{p} \leq 0.01$

Table 16-13. Debitage Type by Area 3 Analytical Units

Top value in cell represents artifact count, and bottom value represents adjusted residuals. Significant $(\mathrm{p}=\leq .05)$ positive values are shown in bold.

\begin{tabular}{|l|c|c|c|c|}
\hline \multirow{2}{*}{ Debitage Type } & \multicolumn{4}{|c|}{ Analytical Unit } \\
\cline { 2 - 5 } & $\mathbf{1}$ & $\mathbf{2}$ & $\mathbf{3}$ & $\mathbf{4}$ \\
\hline \multirow{2}{*}{ angular debris } & 39 & 75 & 45 & 9 \\
& -0.8 & -0.3 & $\mathbf{2 . 3}$ & -1.5 \\
\hline \multirow{2}{*}{ core flake } & 162 & 230 & 107 & 40 \\
& $\mathbf{3 . 2}$ & -1.9 & -0.3 & -1.0 \\
\hline \multirow{2}{*}{ biface flake } & 24 & 51 & 37 & 15 \\
& -1.8 & -1.3 & $\mathbf{2 . 6}$ & 1.5 \\
\hline \multirow{2}{*}{ und. fragment } & 85 & 201 & 60 & 36 \\
& -1.8 & $\mathbf{3 . 2}$ & -2.7 & 0.9 \\
\hline \multirow{2}{*}{ other } & 9 & 14 & 4 & 4 \\
& 0.4 & -0.1 & -1.0 & 0.9 \\
\hline
\end{tabular}

Chi-square $=33.2, \mathrm{df}=12, \mathrm{p} \leq 0.01$

\section{Retouched tools}

The presence of retouched tools seems to vary by area rather than $\mathrm{AU}$ across the site. There is a lower percentage of retouched tools per chipped stone artifacts in the Area 1 AUs (ca. 0.5 percent), with relatively more present in Area 2 (ca. 1.0 percent), and the most present in the Area 3 (ca. 1.4 percent). AU 1 in Area 2, and AUs 1 and 4 in Area 3 contain the highest percentage of retouched tools per chipped stone artifacts (Table 16-14). If the production and discard of retouched tools is constant, then this relative increase in retouched tools per chipped stone artifacts may reflect lower lithic artifact densities in these areas of the site (i.e., less lithic 
Table 16-14. Percentage of Retouched Tools per Chipped Stone Artifacts

Top value in cell represents count, and bottom value represents percentage.

\begin{tabular}{|c|c|c|c|c|}
\hline \multirow{2}{*}{ Area } & \multicolumn{4}{|c|}{ Analytical Unit } \\
\cline { 2 - 5 } & $\mathbf{1}$ & $\mathbf{2}$ & $\mathbf{3}$ & $\mathbf{4}$ \\
\hline \multirow{2}{*}{1} & 1 & 5 & 13 & 4 \\
& 0.3 & 0.2 & 0.7 & 0.6 \\
\hline \multirow{2}{*}{2} & 3 & 6 & 6 & 4 \\
& 2.4 & 1.2 & 0.1 & 0.8 \\
\hline \multirow{2}{*}{3} & 8 & 6 & 3 & 3 \\
& 2.5 & 1.0 & 1.1 & 2.8 \\
\hline
\end{tabular}

reduction and less debitage). For example, there are only 35 pieces of debitage and 4 retouched tools recovered from Area 4 . This yields a high 9.7 percent retouched tools per chipped stone artifacts.

Projectile points are sensitive indicators for temporal change. In Area 1, a Shumla and Desmuke point were recovered from $A U$ 1, a Langtry point from $A U$ 2, and an Marcos point from AU 3. In Area 2, a possible Shumla is present in Level 10 of AU 1, a Montell in Level 7 of AU 1, a Marshall in AU 2, and a Shumla in AU 3. In Area 3 a Shumla point was recovered from $A U 1$, and an Ensor from AU 3. Shumla points are almost exclusively found in the lower AUs of the Areas 1-3 (i.e., floodplain unit 2-f1). The point from Area 1 is associated with a date of 2200 B.P. In contrast, the Marcos and Ensor points in Areas 1, 0, and 4 appear to be associated with a buried $\mathrm{Ab} 1$ paleosol which dates ca. 1900 B.P. As previously mentioned, the projectile point sequence at the site from early to late is Shumla/ Desmuke (lower 2-f1), Langtry/Marshall/Montell (upper 2-f1), Marcos/Ensor (2-f2), and Ensor (2-f3). The relationship between point types, floodplain facies, and radiocarbon dates is shown in Table 6-15.

\section{Tool Use}

As was the case with the retouched tools, the distribution of utilized flakes also seems to vary more by area than AU. The percentage of utilized flakes is only 0.9 percent in Area 1 units, vs. 1.4 percent and 1.7 percent in Areas 2 and 3. As Table 16-16 reveals, there are relatively more utilized flakes in AU 2 of Area 2, and
AUs 1 and 3 of Area 3. It may also be true that if the use of flakes is constant, then the decreasing densities of debitage may be artificially increasing the percentage of used flakes. For example, 2.8 percent of the debitage from Area 4 exhibits evidence of use (i.e., 1 of 35). Again, the percentage of retouched tools and utilized flakes seems to covary with chipped stone artifact density. Besides the utilized debitage, the other obvious indication of tool use is the presence of a onehand mano fragment associated with the occupational surface in AU 2 of Area 1.

\section{Fire-cracked Rock}

Figures 16-12-16-14 indicate that the majority of the fire-cracked is situated in the mid-level AUs, with much less in the top and bottom AUs. That is, AUs 2 and 3 in Areas 1 and 2, and AU 2 in Area 3 contain most of the burned rock. The top of AU 4 in Area 1 does, however, contain relatively more burned rock than the other bottom AUs, but this is due to the presence of several possible hearths in Level 12.

Comparisons among the AUs in Areas 1-3 shows that there is very little difference in the composition of firecracked rock by AU (Table 16-17). Individual area contingency tables do, however, have too many cells with expected frequencies of less than 5 to run a chi-square test. Nonetheless, there are some subtle patterns. For example, sandstone decreases and chert increases in prevalence from the lower to upper AUs in Area 1. In Areas 2 and 3, limestone and sandstone decrease from lower to upper AUs, respectively. 
Table 16-15. Correlation of Area Analytical Units with Point Types, Floodplain Facies, and Radiocarbon Dates

\begin{tabular}{|c|c|c|c|c|}
\hline \multirow{2}{*}{$\mathbf{A U}$} & \multicolumn{4}{|c|}{ Area } \\
\hline & 1 & 2 & 3 & 4 \\
\hline \multicolumn{5}{|c|}{ Projectile Point Types } \\
\hline 4 & & & & Ensor \\
\hline 3 & Marcos & Shumla & Ensor & \\
\hline 2 & Langtry & Marshall, Montell & & \\
\hline 1 & Shumla, Desmuke & Shumla & Shumla & Enosr \\
\hline \multicolumn{5}{|c|}{ Flooplain Facies } \\
\hline 4 & $2-f 3$ & $2-f 32$ & $2-f 32$ & $2-\mathrm{f} 32$ \\
\hline 3 & $2-f 2$ & $2-f 32$ & $2-f 32$ & $2-f 32$ \\
\hline 2 & 2-f1 & 2-f1 & $2-\mathrm{f} 2$ & $2-\mathrm{f} 32$ \\
\hline 1 & 2-f1 & $2-\mathrm{f} 1$ & 2-f1 & $2-f 2$ \\
\hline \multicolumn{5}{|c|}{ Radiocarbon Dates, B.P. } \\
\hline 4 & $1240 \pm 50$ & & & \\
\hline 3 & $1970 \pm 50$ & $1460 \pm 50$ & & \\
\hline \multicolumn{5}{|l|}{2} \\
\hline 1 & $2200 \pm 50$ & $3200 \pm 50$ & $2940 \pm 50$ & $1940 \pm 40$ \\
\hline
\end{tabular}

Table 16-16. Percentage of Utilized Flakes per Debitage

Top value in cell represents count, and bottom value represents percentage.

\begin{tabular}{|c|c|c|c|c|}
\hline \multirow{2}{*}{ Area } & \multicolumn{4}{|c|}{ Analytical Unit } \\
\cline { 2 - 5 } & $\mathbf{1}$ & $\mathbf{2}$ & $\mathbf{3}$ & $\mathbf{4}$ \\
\hline 1 & 2 & 7 & 6 & 4 \\
& 1.4 & 1.0 & 0.6 & 1.3 \\
\hline 2 & 1 & 6 & 5 & 3 \\
& 0.9 & 2.1 & 1.2 & 1.0 \\
\hline 3 & 7 & 6 & 6 & 0 \\
& 2.2 & 1.3 & 2.6 & 0.0 \\
\hline
\end{tabular}

Most of the burned rock is composed of sandstone $(40.0$ percent), with less chert (29.2 percent), limestone (18.6 percent), and "other" materials (12.3 percent). In Area 1 most of the burned rock is composed of sandstone and chert; whereas, Areas 2 and 3 contain more sandstone. There are some significant differences in the distribution of burned rock material types by area (Table 16-18; chi-sq=22.7, df=6, $\mathrm{p}=<0.01$ ). Area 1 contains more chert than expected, Area 2 more sandstone, and Area 3 more "other" materials (e.g., rhyolite and quartzite). There is also somewhat more limestone in Areas 2 and 3 (19.9-22.5), vs. Area 1 (14.8 percent). Analyses of fire-crack rock composition by area in Chapter 10 also noted a general decrease in the presence of chert and an increase in sandstone from east to west across the site.

In summary, the general trend is for slight differences in the composition of burned rock from lower to upper AUs, and more significant variations between the three block excavation areas on the site. 


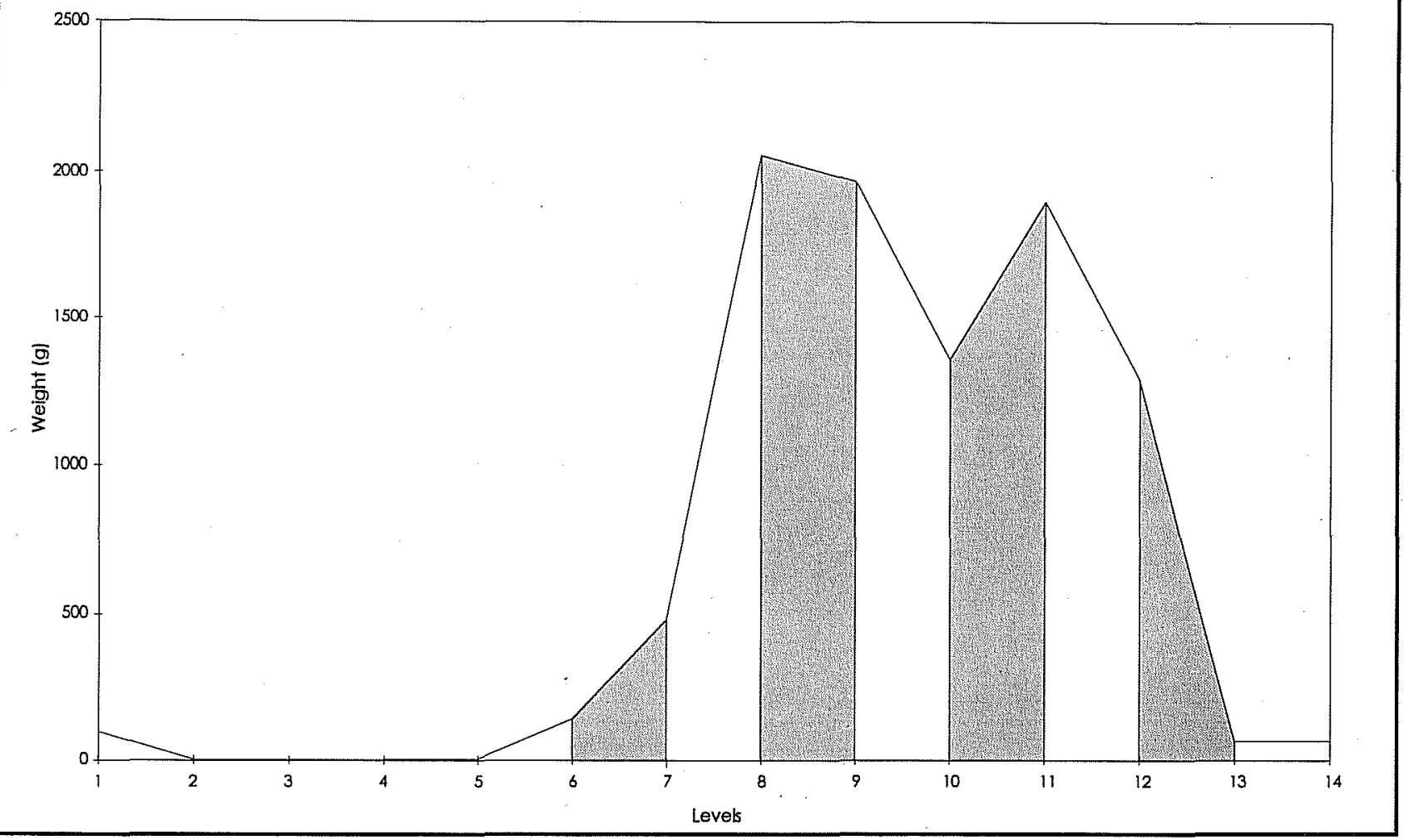

Figure 16-12. Fire-cracked rock weight (g) by $A U$ (shaded area) for Area 1.

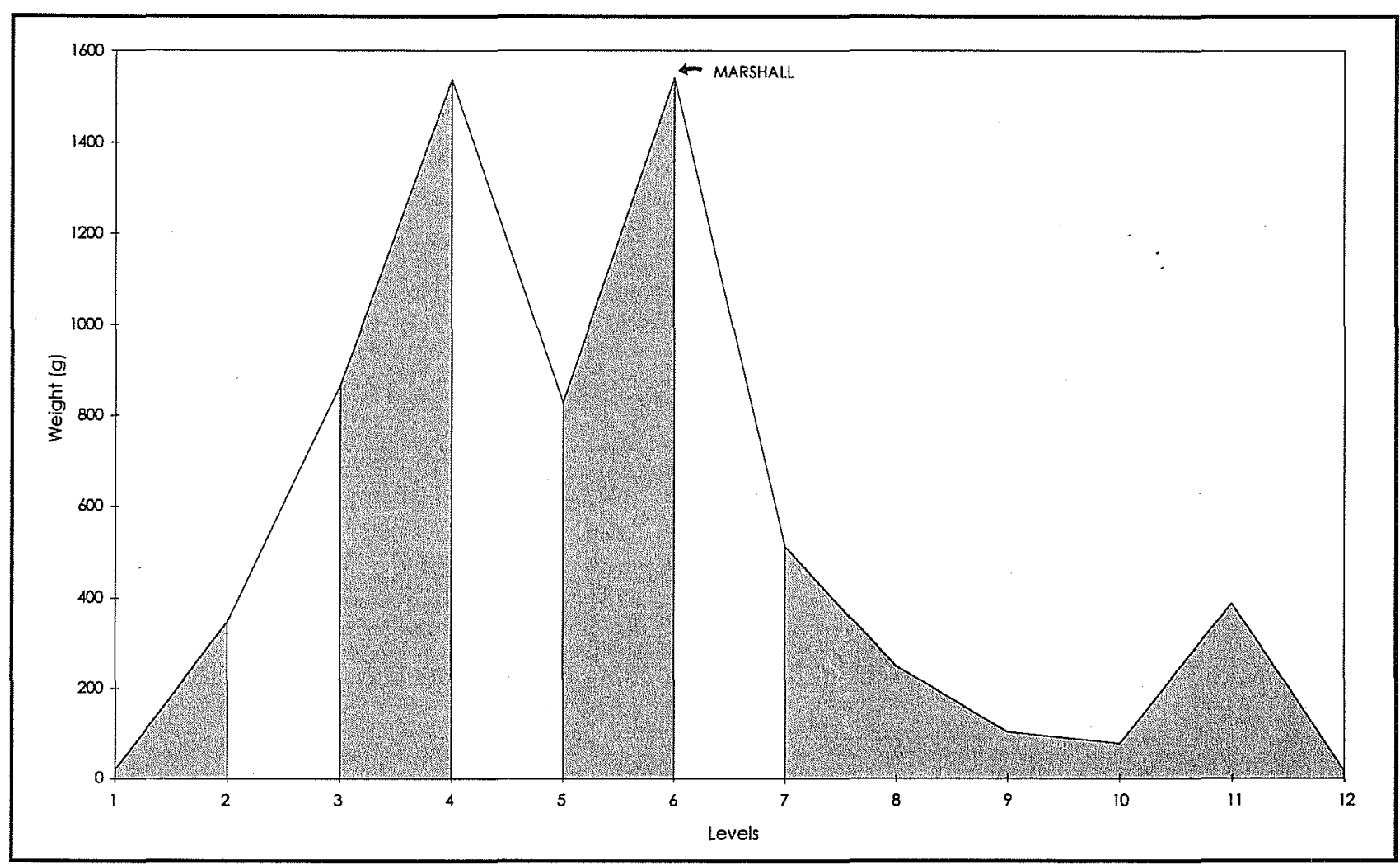

Figure 16-13. Fire-cracked rock weight (g)by $A U$ (shaded area) for Area 2. 


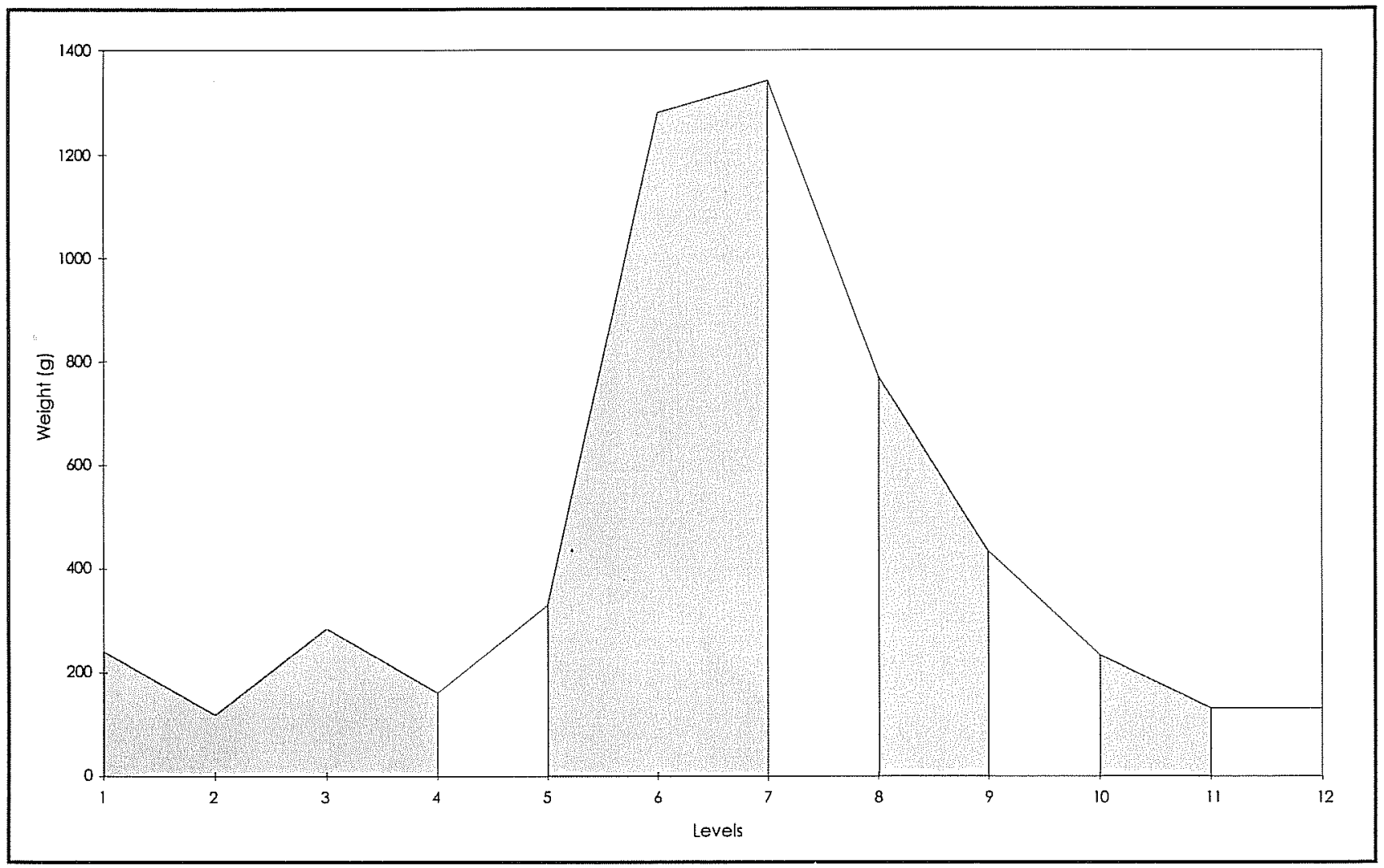

Figure 16-14. Fire-cracked rock weight (g) by $A U$ (shaded area) for Area 3.

Table 16-17. Burned Rock Material Types by Area and Analytical Unit

\begin{tabular}{|c|c|c|c|c|c|}
\hline \multirow{2}{*}{ Area } & \multirow{2}{*}{$\begin{array}{c}\text { Material } \\
\text { Type }\end{array}$} & \multicolumn{4}{|c|}{ Analytical Unit } \\
\hline & & 1 & 2 & 3 & 4 \\
\hline \multirow{4}{*}{1} & sandstone & 10 & 38 & 31 & 13 \\
\hline & limestone & 6 & 11 & 11 & 8 \\
\hline & chert & 14 & 38 & 28 & 8 \\
\hline & other & 2 & 16 & 9 & 0 \\
\hline \multirow{4}{*}{2} & sandstone & 6 & 22 & 29 & 22 \\
\hline & limestone & 2 & 9 & 11 & 16 \\
\hline & chert & 2 & 15 & 10 & 13 \\
\hline & other & 2 & 1 & 3 & 6 \\
\hline \multirow{4}{*}{3} & sandstone & 12 & 29 & 19 & 10 \\
\hline & limestone & 7 & 19 & 9 & 3 \\
\hline & chert & 16 & 16 & 11 & 5 \\
\hline & other & 10 & 16 & 7 & 2 \\
\hline
\end{tabular}


Table 16-18. Burned Rock Material Types by Area

Top value in cell represents artifact count, and bottom value represents adjusted residuals. Significant $(\mathrm{p}=\leq .05)$ positive values are shown in bold.

\begin{tabular}{|c|c|c|c|}
\hline \multirow{2}{*}{ Material Type } & \multicolumn{3}{|c|}{ Area } \\
\cline { 2 - 4 } & $\mathbf{1}$ & $\mathbf{2}$ & $\mathbf{3}$ \\
\hline \multirow{2}{*}{ sandstone } & 92 & 79 & 70 \\
& -0.9 & $\mathbf{2 . 1}$ & -1.1 \\
\hline \multirow{2}{*}{ limestone } & 36 & 38 & 38 \\
& -2.0 & 1.5 & 0.6 \\
\hline \multirow{2}{*}{ chert } & 88 & 40 & 48 \\
& $\mathbf{3 . 1}$ & -1.9 & -1.5 \\
\hline \multirow{2}{*}{ other } & 27 & 12 & 35 \\
& -0.7 & -2.4 & $\mathbf{3 . 1}$ \\
\hline
\end{tabular}

Chi-square $=22.7, \mathrm{df}=6, \mathrm{p}=<0.01$

\section{Mussel Shell}

The distribution of mussel shell remains by AUs is similar to that exhibited by the lithic artifacts and burned rock (Figures 16-15-16-17). That is, AUs 2 and 3 in Areas 1 and 2, and AU 2 in Area 3 contain the highest levels of occupational intensity, including most of the mussel shells. The only deviation from this pattern is a slight reduction in mussel shell within AU 2 of Area 2.

Three species of freshwater shellfish were identified at the site, consisting of yellow sandshell, Texas lilliput, and Tampico pearlymussel (Chapter 12). Table 16-19 presents information on the number of specimens per species by $\mathrm{AU}$ and area. The sample sizes for Areas 2 and 3 are quite small $(n=14$ and $n=8$, respectively); however, the sample size is much larger for Area 1 $(n=114)$, and it does exhibit some patterning by AU. A contingency table for Area 1 would still contain too many cells with an expected frequency of less than 5 to run a chi-square test. Nonetheless, all the AUs are dominated by yellow sandshell. In contrast, lilliputs are most prevalent in the upper and lower units, and Tampico pearlymussel in the middle two units.

Therefore, during periods of lower occupational intensity there are relatively more lilliputs represented, and during periods of higher occupational intensity there are more Tampico pearlymussels present; however, it is more likely that this pattern reflects changes in river ecology. That is, during periods of site flooding there are more lilliputs represented, and with surface stability more pearlymussels. Lilliputs are more active and would have colonized small pools along an oxbow, whereas, the pearlymussels favor more stable habitats (Howells, personal communication 1997).

\section{Summary}

Site 41MV120 was subjected to repeated flooding episodes during its occupation from ca. $2200-1200$ B.P. A series of stratified layers was preserved as a result of this process. The general trend represented by these deposits is for a long-term decline in site occupational intensity in conjunction with decreasing flooding. It appears that Areas 1 and 2 witnessed more intense early occupations (ca. 2200-2000 B.P.), in contrast to Areas 3 and 4 which exhibit more intense later occupations (ca. 1900-1200 B.P.). The deposits in Area 1 do provide a consistent dated sequence for the site. In addition, a buried $\mathrm{Ab} 1$ paleosol was dated to ca.1900 B.P. in both the eastern and western sections of the site. The two ca. 3000 B.P. dates obtained from Areas 2 and 3 do not correlate with the site stratigraphy and the remaining radiocarbon dates. They may, therefore, reflect ancient charcoal that has been bioturbated, or possibly the use of "old wood" for fuel. 


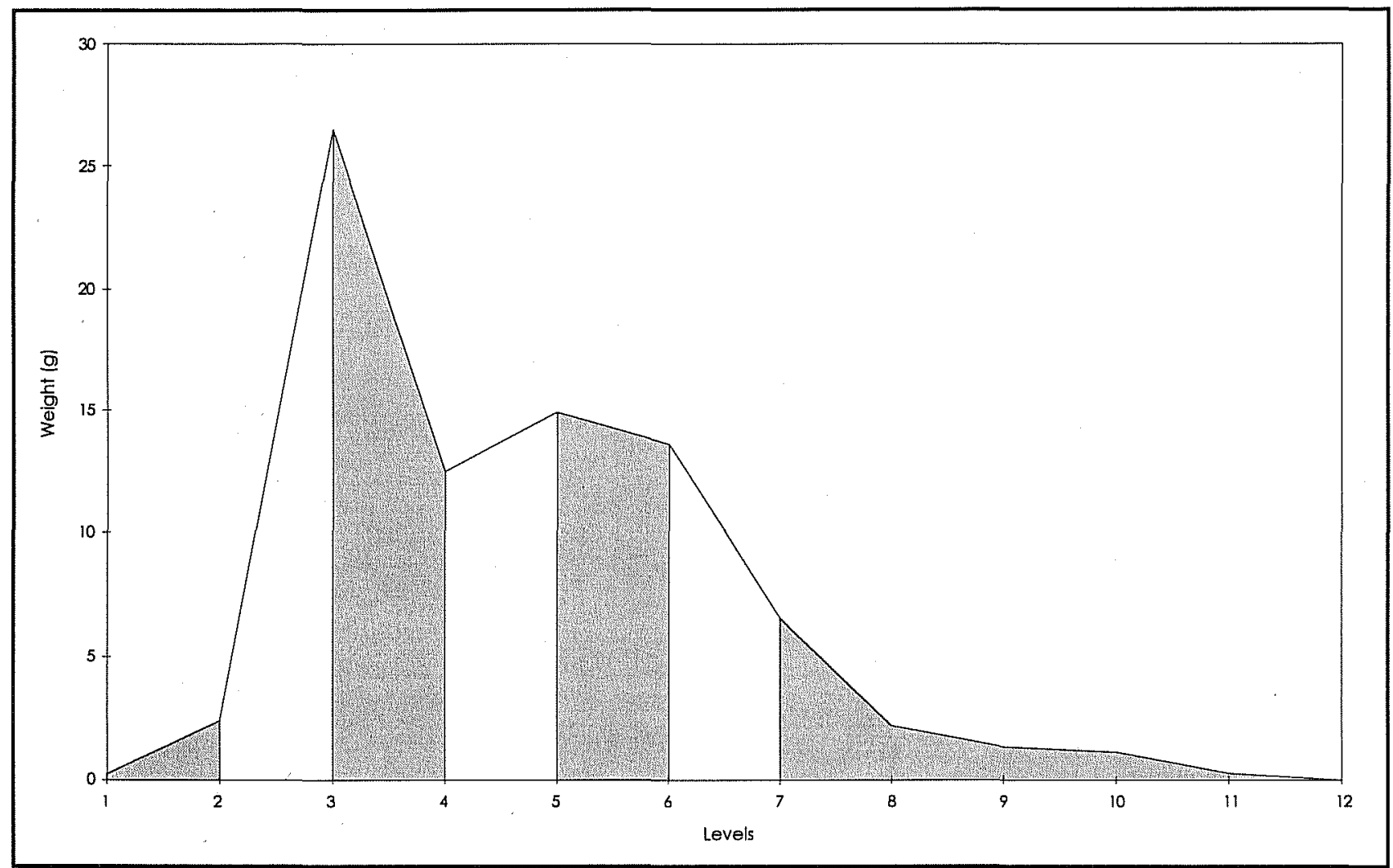

Figure 16-15. Mussel shell, weight (g) by $A U$ (shaded area) for Area 1.

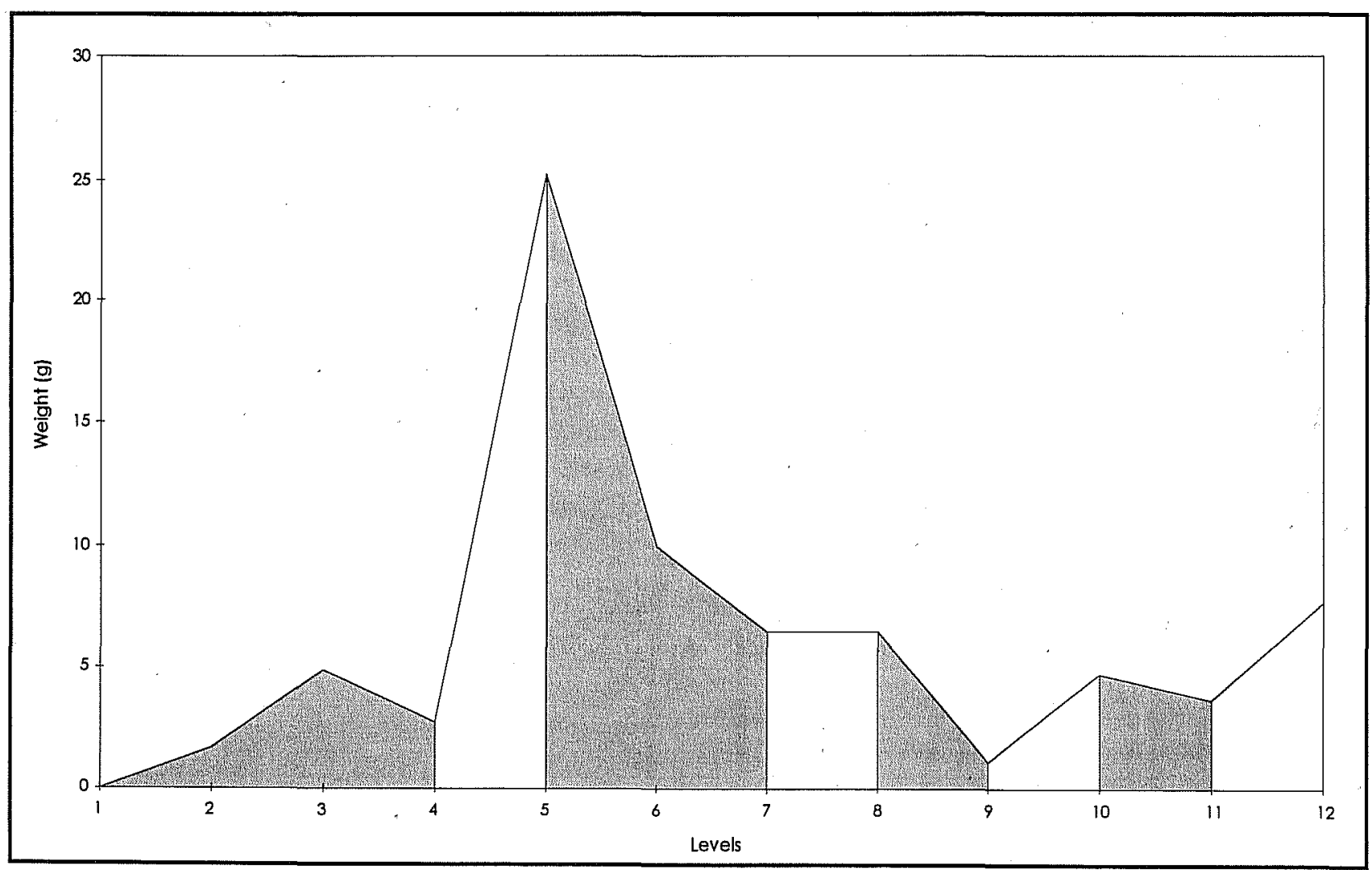

Figure 16-16. Mussel shell weight (g) by AU (shaded area) for Area 2. 


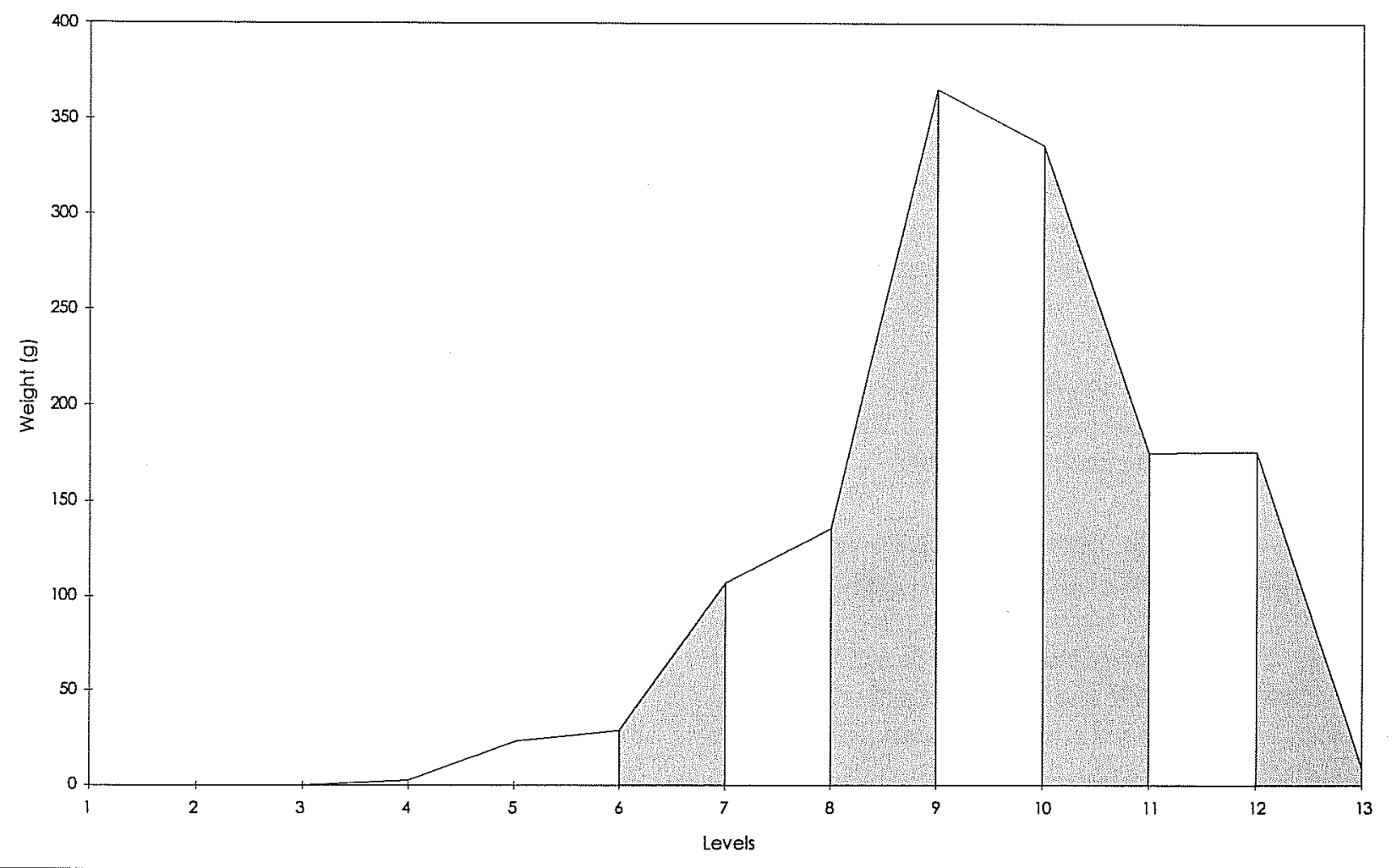

Figure 16-17. Mussel shell weight (g) by AU (shaded area) for Area 3.

Table 16-19. Number of Specimens per Mussel Species by Analytical Unit and Area

Top value in cell represents artifact count, and bottom value column percentage within area.

\begin{tabular}{|c|c|c|c|c|c|}
\hline \multirow{2}{*}{ Area } & \multirow{2}{*}{$\begin{array}{l}\text { Material } \\
\text { Type }\end{array}$} & \multicolumn{4}{|c|}{ Analytical Unit } \\
\hline & & 1 & 2 & 3 & 4 \\
\hline \multirow{3}{*}{1} & sandshell & $\begin{array}{c}7 \\
53.8\end{array}$ & $\begin{array}{c}27 \\
57.4\end{array}$ & $\begin{array}{c}24 \\
55.8\end{array}$ & $\begin{array}{c}7 \\
63.6\end{array}$ \\
\hline & lilliput & $\begin{array}{c}6 \\
46.2 \\
\end{array}$ & $\begin{array}{c}5 \\
10.6 \\
\end{array}$ & $\begin{array}{c}0 \\
0.0\end{array}$ & $\begin{array}{c}3 \\
27.2 \\
\end{array}$ \\
\hline & $\begin{array}{l}\text { pearlymussel } \\
\text { shell }\end{array}$ & $\begin{array}{c}0 \\
0.0\end{array}$ & $\begin{array}{c}15 \\
31.9\end{array}$ & $\begin{array}{c}19 \\
44.1\end{array}$ & $\begin{array}{c}1 \\
9.0\end{array}$ \\
\hline \multirow{3}{*}{2} & sandshell & $\begin{array}{c}0 \\
0.0\end{array}$ & $\begin{array}{c}4 \\
30.7\end{array}$ & $\begin{array}{c}2 \\
66.6\end{array}$ & $\begin{array}{c}2 \\
100.0\end{array}$ \\
\hline & lilliput & $\begin{array}{c}0 \\
0.0\end{array}$ & $\begin{array}{c}6 \\
46.1\end{array}$ & $\begin{array}{c}1 \\
33.3\end{array}$ & $\begin{array}{c}0 \\
0.0\end{array}$ \\
\hline & $\begin{array}{l}\text { pearlymussel } \\
\text { shell }\end{array}$ & $\begin{array}{c}0 \\
0.0\end{array}$ & $\begin{array}{c}3 \\
23.0\end{array}$ & $\begin{array}{c}0 \\
0.0\end{array}$ & $\begin{array}{c}0 \\
0.0\end{array}$ \\
\hline \multirow{3}{*}{3} & sandshell & $\begin{array}{c}2 \\
100.0\end{array}$ & $\begin{array}{c}0 \\
0.0\end{array}$ & $\begin{array}{c}1 \\
100.0\end{array}$ & $\begin{array}{c}1 \\
100.0\end{array}$ \\
\hline & lilliput & $\begin{array}{c}0 \\
0.0\end{array}$ & $\begin{array}{c}1 \\
25.0\end{array}$ & $\begin{array}{c}0 \\
0.0\end{array}$ & $\begin{array}{c}0 \\
0.0\end{array}$ \\
\hline & $\begin{array}{l}\text { pearly mussel } \\
\text { shell }\end{array}$ & $\begin{array}{c}0 \\
0.0\end{array}$ & $\begin{array}{c}3 \\
75.0\end{array}$ & $\begin{array}{c}0 \\
0.0\end{array}$ & $\begin{array}{c}0 \\
0.0\end{array}$ \\
\hline
\end{tabular}


Artifact and material class densities generally decline across the site from east to west. That is, densities are greatest near Elm Creek. This could reflect that site activities were focused towards the creek, with the greatest amount of occupational intensity occurring in this area. On the other hand, this pattern has been affected by the deposition of floodplain unit 2-f 3 over the eastern portion of the site. This unit is more recent in age, and contains much less cultural material. It is thicker in this area of the site, and presumably covers deeper and older aged deposits which might contain evidence of a more intense occupations.

Artifact and material class densities also vary greatly by level across the site. Compositional analyses identified several patterns when comparing low-vs. highdensity levels. Low-density levels either reflect short-term occupation and/or limited activity use, and high density levels long-term occupation and/or the spatial segregation of activities. Although lithic artifact composition among the various levels is quite similar, the lower-density levels may exhibit a slight emphasis on core reduction, and the high-density levels on tool production/maintenance. In contrast, there is a distinct difference in the composition of burned rock by level. Lower-density levels contain relatively more cobble materials, and higher-density levels more sandstone. Presumably, cobbles and sandstone materials were selected for separate functions of features. The fact that they occur in varying densities might also reflect differences in the construction and maintenance of these features. For example, the sandstone might be used in domestic hearths, and the cobbles in hearth elements, processing features, or as boiling stones. The mussel shell remains are generally associated with the low density burned rock scatters. These primarily contain cobble materials which might reflect their use for cooking mussels.

Analysis of site sediment packages indicates that these assemblages generally reflect a long-term redundant pattern in site use. All the AUs on the site are similar in assemblage composition, with only a few significant differences. The most striking among these is the distinction between the upper and lower AUs, and between Areas 1-2 and Area 3. For example, the upper AUs in Area 1 contain relatively more jasper than any other areas on the site; but the upper AUs in both Ar- eas 1 and 2 contain more jasper than the lower AUs. Areas 1 and 2 also contain relatively more "other" materials in the upper AUs, and more salt/pepper rhyolite in the lower. This contrasts with Area 3 which contains more salt/pepper rhyolite and chert in the upper AUs, and more chalcedony in the lower. In addition, the upper AUs of all the areas exhibit a slight emphasis on core reduction, and the lower AUs on tool production/maintenance. On the other hand, there is no significant difference in the composition of burned rock by $\mathrm{AU}$ within the respective areas of the site; but there are some tendencies for the amount of sandstone to decrease from the lower to upper levels. Comparisons between areas shows the most differences, with relatively more burned chert in Area 1, more burned sandstone in Area 2, and "other" burned materials in Area 3 (e.g., rhyolite and quartzite). Sample sizes were only large enough to study species composition for shellfish by AU in Area 1. Nonetheless, all the AUs are dominated by yellow sandshell; however, the upper and lower units contain more lilliputs, and the middle AUs more Tampico pearlymussel shell.

In summary, the overall pattern across the site appears to be one of long-term redundant site reuse. There are some subtle differences, but these are limited to contrasts between upper and lower AUs, and the similarities between Areas 1 and 2. Changes in projectile point types throughout the site sequence reflects some modifications to local hunter-gatherer strategies over time. Areas 1 and 2 exhibit the heaviest evidence of occupation during the early part of the site sequence (ca. 2200 1900 B.P.), and Areas 3 and 4 during the later part of the sequence (ca. 1900-1200 B.P.). 


\section{Chapter 17: Evaluation of Research Issues}

\section{Bradley J. Vierra}

An in-depth discussion of the research design was presented in Chapter 5. As stated, only two regional historic contexts have been published by the Texas Historic Commission for eastern Texas (Kenmotsu and Perttula 1993; Mercado-Allinger 1996), and a third is currently being prepared on South Texas. Nonetheless, three specific research contexts were presented to guide the data recovery program at site $41 \mathrm{MV} 120$. These contexts consist of site formation processes, climate and environment, and subsistence and adaptation. They were further subdivided into a series of specific topics. The context of site formation processes involves aspects of site geomorphology, paleotopography, chronology, and site occupational history.

The climate and environment context reviews the geomorphological and archaeological evidence for past environmental conditions. The subsistence and adaptation context includes issues involving subsistence and seasonality, technology (i.e., thermal features and stone tool technology), site structure, site function, and regional land use. An explicit set of research questions has been formulated based on these contexts and research topics.

These questions are presented and discussed in this chapter. Site 41MV120 provides the researcher with a rare opportunity to study a stratified sequence in this poorly documented region of Texas. As will be seen, these data provide some productive insights into the nature of prehistoric hunter-gatherer strategies in South Texas.

\section{Site Formation Processes}

Geomorphology

What was the nature of the prehistoric landscape in the vicinity of the site when it was occupied?
Since its first occupation, $41 \mathrm{MV} 120$ has always been located to the immediate west of Elm Creek; however, the main channel of the Rio Grande has shifted its course over the last several thousand years. The confluence of the river and creek was situated in the area of the site between about 6000-3000 B.P. (Channel 1). This is evidenced by the presence of point-bar deposits underlying the alluvial silts. During the occupation of $41 \mathrm{MV} 120$ the channel had shifted its location to about one kilometer further south (Channel 2; 2200-1200 B.P.). By the end of the occupation, the river began downcutting and/or flooding decreased. At any rate, very little sediment was deposited across the site at this time.

Are the site's overbank sediments associated with EIm Creek or the Rio Grande?

Sediment analyses indicate that the overbank deposits at 41MV120 are associated with multiple flooding episodes of the Rio Grande. These sediments more closely resemble alluvial river deposits than the sediments from Elm Creek based on differences in texture, color, and carbonate content. Flooding from the Rio Grande is coeval with the site occupation. By the end of the occupation, there was very little sediment deposited over the site. Instead, the surface of the site is characterized by relative stability, as evidenced in the presence of mesquite and acacia stumps dating ca. 500-700 B.P.

What is the depositional sequence and the nature of these aggrading deposits? What are the implications for understanding local sedimentation rates, and their effect on the burial of past human occupations?

The stratigraphic sequence at $41 \mathrm{MV} 120$ is the result of the shifting position of the Rio Grande channel relative to the site area. Nordt's study (Chapter 7) of the alluvial stratigraphy at the site identified the presence of floodplain and underlying point-bar deposits (or facies). The floodplain facies could be separated into three 
lithofacies. Unit 2-f1 directly overlies the point-bar facies. It represents the rapid deposition of overbank deposits over the site area from ca. 2200-2000 B.P. There is a high potential for the preservation of archaeological materials in this lithofacie, due to the rapid build-up of sediments. In contrast, Unit 2-f2 exhibits a much reduced sedimentation rate (ca. 2000-1900 B.P.). This rate is about nine times less than that exhibited by Unit 2-f1, with the subsequent formation of the Ab1 paleosol. The lower rate of deposition for this lithofacie indicates that it has a lower potential for preservation. In addition, the deposit is much thinner and there is a greater likelihood of mixing archaeological materials. Aggradation increases during the formation of Unit 2f3 (ca. 1900-1200 B.P.), but at a rate three times less than that exhibited by Unit 2-f1. This increase in sediment deposition may be due to the movement of the channel nearer to site, or increased channel discharge and flood frequency. The deposits thicken to the west in Area 4, which contain a higher potential for preservation.

\section{To what extent has bioturbation or other recent ac- tivities affected the integrity of the deposits?}

The effects of bioturbation were observed across the site during the excavations. This included both macro (e.g., rodent), and micro (e.g., insect) disturbance. The upper $40 \mathrm{~cm}$ of fill was generally disturbed by recent activities, with most of the historic artifacts being recovered in these upper levels. Rodent burrows and insect nests were noted to a depth of about one meter below the surface in some isolated locations (e.g., Area 3). A modern pecan shell was recovered at about 60 $70 \mathrm{~cm}$ below the surface in Area 2. Nordt also notes the presence of moderate to high micro-biological activity in his petrographic analysis of site sediments.

\section{Paleotopography}

What evidence is there for buried occupational surfaces? Can these be identified through studies of site stratigraphy in conjunction with the distribution of artifacts and features?
Nordt (Chapter 7) identified a buried Ab1 soil horizon in Areas 1, 3, and 4. This soil represents a short period of development within floodplain Unit 2-f2. It is dated to ca. 1900 B.P. at either end of the site in Areas 1 and 4. In Area 1 the Ab1 soil horizon is associated with Analytical Unit (AU) 2 . An occupational surface was identified at the top of this analytical unit, with a Marcos point and a radiocarbon date obtained from the bottom of the unit. A piece of mesquite charcoal yielded a date of $1970 \pm 50$ B.P. The $A b 1$ soil horizon was also exposed in the BHT 10 profile. Archaeomagnetic sample \#29 was identified as being in situ, and is situated on top of the buried paleosol, below Feature 10 . Since Feature 10 appears to be associated with AU 2 in adjacent block excavation Area 3, it would appear that AU 3 may be situated on this buried Ab1 horizon. In Area 4, a charcoal stained lens denotes the presence of this paleosol. An Ensor point was recovered from this lens, with a mesquite charcoal date of $1940 \pm 50$ B.P.

The archeomagnetic analysis of 20 burned rock samples was able to determine that four of these rocks had not moved since being heated, and two had only moved slightly (Chapter 10). These in situ rocks indicate the presence of intact features, and possible occupational surfaces. In Area 1, two in situ rocks were part of several clusters of burned sandstone found in Level 12 at the western end of the block. This level is situated at the top of AU 4, and exhibits some internal structure in relation to the spatial distribution of possible activity areas. Shumla and Desmuke projectile points were recovered from this level, and a piece of mesquite charcoal yielded a date of $2200 \pm 50$ B.P. As previously mentioned, a second possible occupational surface was identified in Level 8 (AU 2). Although a single sample from this cluster of burned rock failed to indicate that it was in situ, the presence of this tight circular cluster seems to indicate that the feature has not been substantially disturbed. The distribution of possible activity areas in this level is similar to that observed in lower Level 12.

Only a single burned rock was identified as being in situ in Area 2. This piece of burned sandstone is located in Level 6 at the bottom of AU 3.Neither obvious features nor distinctive patterning in the material classes were present across this level. A Marshall projectile point 
was, however, recovered from this level. As already mentioned, three in situ burned rocks were identified in the profile of BHT 10. Two of these are associated with separate clusters, but were defined as Feature 10 . They appear to be associated with peak occupational intensity Levels 6-7 in AU 2 of Area 3. An Ensor point was recovered from Leve1 7. The third burned rock in BHT 10 was located on the buried $\mathrm{Ab} 1$ paleosol at same level as AU 3 in adjacent Area 3.

No in situ rocks were identified in Area 4; however, as noted above, a buried Ab1 horizon was associated with a charcoal-stained lens which contained an Ensor point, and a radiocarbon date of $1940 \pm 50$ B.P.

\section{Can surfaces be distinguished from stratigraphic "zones"? Do these surfaces or zones extend across the site, or are they limited to specific areas within the site?}

Studies of the horizontal and vertical distribution of material classes across the site revealed distinctive patterning. For example, material class density generally decreases from east to west. The highest concentrations are present in Area 1, medium concentrations in Areas 2 and 3, and the lowest densities in Area 4. This general pattern indicates that the occupation at site $41 \mathrm{MV} 120$ was primarily oriented toward Elm Creek; however, Area 4 does contain relatively more recent deposits which have much less cultural material Nonetheless, the high artifact densities present at the eastern end of the site indicate that buried cultural deposits may extend further toward Elm Creek. This is represented by a continuation of this large surface scatter to adjacent sites $41 \mathrm{MV} 107$ and 41MV109 which are located on the opposite side of the creek.

Studies of material class density and mean debitage size were able to identify a series of "sediment packages" (or analytical units) across the site. In Areas 1 and 2 , these packages are vertically distinguished in 20-cm intervals; whereas, Areas 3 exhibits a range in package size from $20-40 \mathrm{~cm}$ in thickness. These AUs directly correspond with variations in floodplain lithofacies, paleosols, occupational intensity, and the presence of features and occupational surfaces. Occupational surfaces in Area 1 are directly associated with the top of these AUs which contain larger mean arti- fact sizes. It is unclear as to whether this pattern of larger to smaller mean artifact size is an indication of alluvial sorting, or post-depositional downward movement of smaller sized items. Overall, Areas 1 and 2 witnessed more intense early occupations (ca. 22001900 B.P.), and Area 3 (and 4) more intense later occupations (ca. 1900-1200 B.P.).

\section{Chronology}

What absolute temporal span does the radiocarbon evidence indicate for the site stratigraphic sequence?

Nine charcoal samples were submitted for radiocarbon dating by the test excavations and data recovery programs at site 41MV120 (Table 8-5). Most of these consist of small pieces of wood charcoal (mesquite and acacia) which were dispersed through the site sediments. Using isolated pieces of charcoal to date archeological deposits is an ambiguous technique. Smiley (1985:7172) provides a list of radiocarbon-dateable materials which he considers to have the highest to lowest potential for accurately dating archeological contexts:

1. Annual subsistence materials (e.g., cultigens or charred seeds).

2. Samples from structural logs retaining outer rings.

3. Sticks, twigs, or small branches.

4. Large cross-sectional pieces from beams or fuel that lacks outside rings.

5. Scattered charcoal from undisturbed contexts (e.g., hearth fill).

6. Scattered charcoal from excavated strata.

7. Unprovenienced charcoal samples.

Only two samples submitted for radiocarbon dating were collected from clearly intact contexts. These were obtained from Feature 1 (mussel shell lens) in Area 1, and the charcoal-stained lens in Area 4; however, the absence of intact features which contained charcoal precluded the possibility of using materials derived from these preferred contexts. Small pieces of charcoal such as these, require the use of the Accelerator Mass Spectrometer technique for dating; whereas, the larger chunks submitted from burned stumps were analyzed using conventional radiocarbon methods. 
Nonetheless, given these limitations, Area 1 does contain a consistent dated sequence: $1240 \pm 50$ B.P. (Feature 1; Level 6), $1970 \pm 50$ B.P. (Level 9), and 2200 \pm 50 B.P. (Level 12). Intact or relatively intact features were identified in Levels 8 and 12. A study of the distribution of artifacts around these features produced a similar organizational pattern. All of this information indicates that Area 1 is probably not heavily disturbed, with the dated pieces of charcoal being in relative stratigraphic sequence.

Two charcoal samples were analyzed from Area 2. One of these was submitted by TxDOT during the test excavations of adjacent EU 2. This sample provided a date of $1460 \pm 50 \llbracket$ from Level 4 . A second sample was submitted from EU 22, Level 9, within Area 2. This sample yielded a date much older date of $3200 \pm 50$ B.P. The 1460 B.P. date appears to correspond with the sequence defined in Area 1; however, the 3200 B.P. is significantly older than the 2200 B.P. date from the bottom of Area 1. In Area 3, a burned mesquite stump in adjacent EU 6 (Level 5) provided a date of $760 \pm 50$ B.P. This date is associated with a period of occupational decline at the site. An isolated piece of charcoal recovered from Level 8 in EU 22 yielded a date of $3050 \pm 50$ B.P. Levels 7 and 8 in Area 3 contain the greatest evidence of occupation, with adjacent Feature 10 in BHT 12 also being situated in the same levels. The ca. 3000 B.P. date is similar to the one identified in Area 2, but is also much older than the 2200 B.P. from Area 1.

Two radiocarbon samples were also submitted from Area 4. The upper sample was obtained from a buried acacia tree stump in EU 39 (Level 7). It yielded a date of $540 \pm 40$ B.P. A piece of charcoal from a charcoal stained lens in BHT 12 (Level 11) provided a date of $1940 \pm 40$ B.P. As in Area 3, the tree stump is associated with a period of surface stability dating to the period of post-occupational site abandonment. The 1940 B.P. date is consistent with the upper portion of the sequences identified in Areas 1. Both ca. 1900 B.P. dates are associated with a buried paleosol which was identified in Areas 1, 3 and 4. Most of the radiocarbon dates fit the 1240-2200 B.P. range defined in Area 1; however, the two ca. 3000 B.P. dates stand out as outliers when compared to the others. These older dates could be the result of several different formational pro- cesses. First, they could simply represent an older occupation at the site. Secondly, the charcoal could have been derived from the underlying point-bar deposits which are speculated to date to this earlier period (see Chapter 7). Lastly, they could be the by-product of the "old wood problem," with ancient dead wood being used a fuel at the site.

There is no clear evidence of an earlier occupation situated directly on top of the sand bar. The 3200 B.P. date from Area 2 is located just above the underlying sand deposits; however, the artifacts present in the lower levels of the area are size sorted vertically, and were presumably derived from the overlying silty deposits. On the other hand, the source of the burned charcoal could have been the point-bar deposits since they rise up to about the same level in an adjacent unit. It seems less likely that the charcoal in Level 8 of Area 3 was derived from point-bar deposits, because it is situated at the same level as an intact feature identified in nearby BHT 10, and that the sand deposits in this block area are situated at a much lower elevation. Nonetheless, the ca. 3000 B.P. dates are older than the range associated with the Late Archaic projectile points present on the site (see Hester 1995).

An alternative explanation is that the dates represent "old wood." That is, dead wood obtained from surrounding landscape (e.g., terrace or floodplain) which was scavenged and subsequently used as firewood. Schiffer (1986:21) has dated specimens of mesquite from modern surface collections and dead wood from standing trees in southern Arizona. The surface collections yielded a pooled date of $970 \pm 430$ B.P. $(n=23)$, and the dead branches of $1007 \pm 153$ B.P. $(n=30)$. It could be that the ca. 3000 B.P. dates are derived from a similar old wood population. This old wood might have been present as standing dead wood, or more likely, as surface dead wood in nearby terraces.

\section{What are the implications of this information for understanding site sedimentation rates?}

Three floodplain lithofacies were defined at the site (Chapter 7). Unit 2-f1 directly overlies the point-bar deposits. It represents the rapid deposition of overbank deposits from ca. 2200-1900 B.P. These deposits are present in Areas 1-3, but are deeply buried in Area 4. 
In contrast, Unit 2-f2 exhibits a much reduced sedimentation rate (ca. 2000-1900 B.P.), which is nine times less than that exhibited by Unit 2-f1. The formation of the $\mathrm{Ab} 1$ paleosol occurred during this period of increased surface stability; however, Unit 2-f2 is thinner than the other lithiofacies, and therefore more likely to exhibit the mixing of archaeological materials. Aggradation increases during the formation of Unit 2- $\mathrm{f}$ (ca. $1900-1200$ B.P.), but at a rate three times less than that exhibited by Unit 2-f1. These deposits thicken to the west in Area 4 where the paleosol is buried at a much greater depth.

\section{How do the relative dates of the projectile points compare with the radiocarbon dates?}

The majority of the projectile points recovered from the excavations at $41 \mathrm{MV} 120$ can be classified as Late Archaic. The relative age of two undiagnostic points from the upper levels of the site could not, however, be determined (i.e., the stemmed and triangular point forms). Shumla points $(n=5)$ are the most prevalent point type identified at the site, being situated in the lower levels of Areas 1-3.

The greatest diversity of point types was observed in the western section of the site in Areas 1 and 2. Four different point types were identified in Area 1. Shumla and Desmuke types were recovered from Level 12, a Langtry from Level 11, and a Marcos from Level 9. Levels 11 and 12 are situated within floodplain Unit 2$\mathrm{fl}$, and Level 9 is associated with the buried Abl paleosol. Radiocarbon dates were obtained for Levels 12 and 9: $2200 \pm 50$ B.P. and 1970 \pm 50 B.P., respectively. Three point types were identified in Area 2: a Shumla point was found in Level 10, a Montell in Level 7, a Marshall in Level 6, and a Shumla in Level 4. Levels 6-10 are included within the floodplain Unit 2-p (point bar) and Unit 2-f1 sediments; whereas, Level 4 is part of Unit 2-f3.

In contrast to Areas 1 and 2, only two points types were identified in the eastern section of the site in Areas 3 and 4. A Shumla point was recovered from Level 11, and an Ensor from Level 7 in Area 3. Level 11 is situated within floodplain Unit 2-f1, and Level 7 at the bottom of Unit 2-f2. Two Ensor points were also identified in Area 4, Levels 2 and 12. The point from Level
12 was situated within a charcoal-stained lens of the Ab1 paleosol which was dated to $1940 \pm 50$ B.P. The other point is located in floodplain Unit 2-f3.

Most of the Shumla points, and the Desmuke, Langtry, Montell, and Marshall points are all situated within the older floodplain Unit 2-f1 (ca. 2200-1900 B.P.); whereas, the Marcos and Ensor points are associated with the Ab1 paleosol (ca. 1900 B.P.), and the remaining Ensor points are present in Unit 2-f3 (ca. 19001200 B.P.). The general site stratigraphic sequence consists of Shumla/Desmuke, Langtry/Montell/Marshall, Marcos/Ensor, and Ensor. This sequence is somewhat different that the one described by Hester (1978) at site 41ZV10, where Ensor and Montell types were found in deposits overlying Shumla and Marcos types. Langtry and Marshall point types date to the middle Archaic in the Lower Pecos region (Turpin 1991); however, they overlie Shumla and Desmuke types at $41 \mathrm{MV} 120$. It is unclear as to whether this represents some form of disturbance, the scavenging and reuse of the artifacts, or a later date for these point types. Otherwise, the remaining point types date to the Late Archaic (ca. 2500-1150 B.P.) as defined by Hester (1995).

\section{Climate and Environment}

What does the geomorphological data indicate about the past environmental setting at 41MV120?

As previously discussed, the results of the geomorphological study of the site area indicates that the coarse of the Rio Grande has changed several times during the middle and late Holocene. The relocation of the channel had significant effects on the local depositional sequence represented at the site. From approximately 6000-3000 B.P. the channel was situated in the immediate area of the site, depositing the point-bar sands which form the basal site unit. The river subsequently shifted course to south, with the confluence of the Rio Grande and Elm Creek moving about one kilometer away. During the site occupation (ca. 2200-1200 B.P.), the area was periodically inundated by floodwaters, depositing a series of alluvial sediments, and covering some developing A horizons. The amount of flood waters covering the site was reduced by ca. 1000 B.P., either due to the downcutting of the Rio Grande or to decreased river flow and 
flooding. The presence of the buried tree stumps in the upper levels of the site are a testimony to the stability of the surface during this later time period (ca. 500-700 B.P.).

It therefore appears that the period of predominant site occupation corresponds with the episodic floodings of the Rio Grande, and the general site abandonment with the down-cutting and decreased flooding of the river. It is unclear as to whether there is a direct cause-andeffect relationship between flooding and site occupation. For example, the Rio Grande drainage basin includes areas from Southern Colorado, New Mexico, and West Texas.

Flooding in this portion of the river may not simply reflect local rainfall patterns, but are also related to increased moisture, snow pack, and rainfall in any of the areas drained by the river. It is difficult to assess what this period of flooding may actually represent in respect to local climatic and environmental conditions. That is, could local increases in moisture and terrestrial resource productivity be acting as a magnet for Late Archaic populations? Or is it simply an increase in resource productivity within the floodplain as a result of flooding and the deposition of nutrient rich soils? Floodwaters could also strand fish and shellfish providing a short-term resource windfall.

The downcutting episode represented at the time of general site abandonment is also documented across Oklahoma and Texas at ca. 1000 B.P. (Hall 1990). It is currently undetermined whether this activity was in response to warmer or cooler climates. What effect the relocation of the river channel and subsequent downcutting had on the local environment is unclear, and whether the abandonment of the site was a response to changes in local and/or regional climatic conditions.

\section{Is there any archeological evidence which provides information for reconstructing the prehistoric site environment? Do the macrobotanical, shellfish, snails, and faunal remains provide data on the local paleoenvironment?}

There is very little archaeological data with which to address any issues concerning the paleoenvironmental reconstruction of the area. Nonetheless, the various plant and animals species present at the site are similar to those found in the area today. All the species are represented throughout the various levels across the site. Only the shellfish in Area 1 exhibit some vertical patterning in their distribution.

Two woody species were identified during the analysis of macrobotanical remains (Chapter 11). These are mesquite and acacia (huisache) wood. Mesquite wood charcoal is dated from ca.3000-1900 B.P. Both acacia and mesquite burned stumps are also dated at 540 and 760 B.P., respectively. The absence of acacia charcoal in the archaeological deposits may be the result of cultural selection, since acacia wood gives off a strong odor. As any Texan knows, mesquite grill tastes better than acacia grill. Both species occur in open floodplain and drainage system environmental settings.

Three species of freshwater shellfish were identified (Chapter 12). These consist of Tampico pearlymussel, yellow sandshell, and Texas lilliput. The Tampico pearlymussel is typically found in the main river channel or along backwaters and oxbows. It primarily lives in shallow areas which contain mud, sand, or gravel substrates. The yellow sandshell prefers either the fastor slow-flowing waters of river or stream channels, residing in a variety of sediment substrates. The Texas lilliput lives in the mud and sand of still or low-flowing creeks and oxbows. All three species can be observed in similar habitats of the region today. Area 1 is the excavation block which contains a sufficiently largesized sample to study changes in the number of specimens per species through the sequence. Yellow sandshell dominates all the AUs; however, there are relatively more lilliputs in the lower and upper AUs, and more Tampico pearlymussels in the middle AUs. It is likely that this pattern reflects changes in river ecology. That is, during periods of site flooding there are more lilliputs represented, and with surface stability more pearlymussels. Lilliputs are more active and would have colonized small pools along an oxbow; whereas, the pearlymussels favor more stable habitats (Howells, personal communication, 1997)

Four species of terrestrial snails were identified (Chapter 13): striped rabdotus, whitewashed rabdotus, Mexican ambersnail, and Texas liptooth. No aquatic species were observed, even though the site sediments are in 
part of alluvial origin. Nonetheless, all four species are present in the area today.

Very few faunal remains were recovered during the excavation of site 41MV120. Most of these consist of unidentifiable fragments. Some of these are mammal bones, but four others were identified as frog bones. These latter elements reflect the proximity of the site to a streamside setting.

\section{How do the archaeological remains compare with the results of the stable carbon isotope analysis?}

Soil samples from three separate coring locations were submitted for stable carbon isotope analysis (Chapter 7). These cores were situated on the Rio Grande floodplain, $\mathrm{T} 1$ terrace and Elm Creek. $\mathrm{C}_{4}$ plants are warm season grasses with ${ }^{13} \mathrm{C}$ values of approximately $-13 \%$, whereas $\mathrm{C}_{3}$ plants consist of cool season grasses, trees, and shrubs with ${ }^{13} \mathrm{C}$ values of $-27 \%$ (Boutton 1991b). Together they reflect a long-term sequence representing a cool early Holocene dominated by $\mathrm{C}_{3}$ plants, a warm middle Holocene dominated by $\mathrm{C}_{4}$ plants, and a late Holocene characterized by an intermediate climate and a mixture of $\mathrm{C}_{3}$ and $\mathrm{C}_{4}$ species. Soil samples analyzed from the site exhibit this intermediate Late Holocene pattern.

\section{Subsistence and Adaptation}

\section{Subsistence and Seasonality}

What resources were being exploited at the site, and during which season(s) was the site occupied? Do the macrobotanical, shellfish, snail, and faunal remains provide information on subsistence and possible season of collection?

Site $41 \mathrm{MV} 120$ represents a single location on the landscape which was occupied by prehistoric hunter-gatherer groups during their annual rounds. There is very little direct information on which subsistence foods were procured by the prehistoric inhabitants of the site. Nonetheless, it seems likely that several aquatic and terrestrial plant and animal species were consumed at the site. On the other hand, we can only speculate on the possible season of occupation.

The presence of macrobotanical remains is limited to isolated pieces of mesquite charcoal at the site. Burned mesquite and acacia stumps are also present in the upper levels. Mesquite wood was being used as a fuel. On the other hand, there is no direct evidence for the use of pods or seeds at the site. This is understandable given the lack of intact features and the absence of flotation samples from which these remains might be recovered and identified. Nonetheless, mature mesquite pods are primarily available during the summer (Vora 1990b); however, green pods can be eaten earlier, and dried pods may still be attached to trees or present on the ground surface during the fall. During droughts they can be present well into the winter. The single mano fragment recovered from the site could have been used to mill mesquite and acacia seeds, but the season of use in undetermined.

Shellfish were available in riverine and stream settings. The smaller size of the individuals indicate that many are juveniles, which tend to be more mobile than adults and live in shallow waters. The absence of the larger and deeper-water adults indicates that the most accessible individuals were probably being collected. Only a few shells are whole and exhibit intact outer rings. These specimens are characterized by a wide outside growth band which could indicate that specimens were collected during the nutrient-rich growing season from spring to fall.

Relatively few terrestrial snails are present on the site. Although their distribution generally coincides with that of mussels across the site, it is unclear as to whether they were collected and consumed by the site inhabitants or were simply attracted to the site food debris. The fact that the snails are biased towards larger individuals may indicate that they were being collected and consumed at the site. At any rate, they would have comprised only a minor portion of the diet.

Very few faunal remains were recovered during the excavations, primarily consisting of undetermined fragments. Some are identified as mammal, with several exhibiting chopping marks (Chapter 14). Tiny bone fragments were also identified during the petrographic analy- 
sis of a soil sample from Feature 10 (Chapter 7). Otherwise, the only identifiable remains are unburned long bones from a frog in Level 7 of Area 3.

\section{Technology}

Burned pit features or fire-cracked rock clusters could reflect domestic hearths, roasting pits, and/or discard piles. What are the structure and contents of these features, and what are the implications of this information for understanding food processing, and consumption activities at the site?

Very few intact features were identified during the excavations at 41MV120. The results of the archaeomagnetic analysis indicates that only four of the 20 rocks analyzed had not moved since being heated, and two had only moved slightly. Three of the in situ rocks were discovered in the south profile of BHT 10 . They represent the remnants of three separate features which are situated at a depth of approximately $70-80 \mathrm{~cm}$. A single burned rock was identified as being in situ from clusters of two, seven, and eight rocks, respectively. In each of the latter two clusters, an additional burned rock was also identified as not being in situ. Given that most of the features were removed during the excavation of BHT 10, it is difficult to determine what their original structure might have been. Nonetheless, the clusters with 7-8 rocks might represent only a small portion of much larger original features.

The only other burned rock sample identified as being in situ is one of a cluster of five burned pieces of sandstone exposed in Level 12 at the western end of Area 1. Twelve pieces of burned sandstone were exposed in the portion of the block excavation. The analysis of three samples from two other locations in this level determined that they were not in situ. Nonetheless, the burned rock appears to be part of a larger occupational surface identified in this level. A cluster of 10 burned pieces of sandstone was also identified in Level 8; however, the four samples taken from this feature (5) had moved since being burned. One of these rocks had not moved as much as the others, and together they formed a tight cluster indicating that the feature had retained some structure.
The two slightly moved burned rock samples are present in Areas 2 and 4. A single burned piece of sandstone has moved slightly in Level 6 of Area 2. It is situated within a level which contains a high density of burned sandstone. The other sample is from Level 11 in Area 4 , being one of three isolated pieces of sandstone identified in the level. One other piece was analyzed and determined that it had substantially moved since being heated.

Otherwise, most of the burned rock is distributed in varying densities across the site, although density generally declines from east to west. The burned rock is primarily composed of sandstone, with less chert, limestone, rhyolite, and other materials. The sandstone is available from local bedrock outcrops, and the remaining materials as cobbles in terrace gravels. The composition of the terrace cobble materials does vary significantly from those represented at the site. That is, significantly more limestone and quartzite are represented in the site assemblage than would occur naturally in the gravel deposits. Therefore, the prehistoric site occupants were preferentially selecting these materials for use, although at lower quantities than the more ubiquitous cherts.

Several discernable archaeological patterns appear to segregate sandstone vs. cobble materials at the site. First, the composition of the burned rock covaries by density and level. That is, levels with less than $200 \mathrm{~g}$ of burned rock contain significantly more chert and limestone, while levels with greater than $200 \mathrm{~g}$ contain more sandstone. Second, a selective analysis of relatively higher density peaks within each area indicates that either sandstone, limestone, or chert tend to dominate the rock in these selected levels. Again, limestone and chert dominate in levels with less than $400 \mathrm{~g}$ of burned rock, and the sandstone in levels with more than $400 \mathrm{~g}$. Third, not only does the amount of burned rock decline from east to west across the site, but there is an inverse relationship between chert and sandstone. Chert is found in the highest densities in the eastern areas of the site, and sandstone in the western areas of the site; whereas, the amount of limestone present stays relatively constant. Lastly, the results of the archaeomagnetic analysis reveals that the in situ samples were primarily heated at lower temperatures, and the disturbed samples to higher temperatures. Since the analyzed samples are mainly composed 
of sandstone, it is undetermined how chert and limestone materials fit into this dichotomy. Overall, it would appear that sandstone was, at least in part, being differentially selected over cobble materials for use in thermal features.

It is possible that the sandstone was primarily used as peripheral elements in domestic hearths, but it is unclear for what feature(s) the cobbles were being used. They might have simply been used for the construction of simple open hearths which were used for cooking mussels and other foods. It seems unlikely that they were used for small ovens, since no such features were identified during the excavations; however, various sized cobble-lined features were identified in the excavations at Choke Canyon Reservoir. These features were often associated with mussel remains, with some snail shells and a few bone fragments (Hall et al. 1982; Hall et al. 1986; Scott 1982). The presence of relatively more burned chert cobbles in the eastern area of the site does correspond with the presence of higher densities of mussel shell. Occupational surfaces in Area 1 also indicate a spatial relationship between mussel shell and burned rock concentrations. Nonetheless, ovens are not needed to simply cook mussels. Pierce's (1984) review of ethnographic data from California Native American groups shows that roots, tubers, and fish were generally baked in pit ovens; whereas, mussels and mammal meat were more commonly roasted in open hearths. Given the absence of any intact cobble features and the presence of varying densities of burned rock, it seems likely that small cobble-lined hearths were used to cook mussels and other foods. This type of feature construction would have been more susceptible to disturbance than shallow cobblelined ovens. In addition, some of the cobbles might also have been used for stone boiling.

\section{How did South Texas foragers balance tool design requirements for a generalized foraging strategy within the limitations of regional lithic resource avail- ability? Does the stone tool technology at the site re- flect a "retooling tactic" whereby exhausted tools were simply replaced, or a "gearing up tactic" whereby a suite of tools were produced for use elsewhere?}

Recent research efforts have focused on the effects of biotic resource structure and lithic raw material availability on tool design and the organization of stone tool technology. These perspectives can be referred to as foraging strategy vs. economizing behavior models (e.g., Andrefsky 1994; Bamforth 1986; Binford 1980; Kelly 1983; Odell 1996). Although these arguments are often framed in respect to tool use-life, other researchers have used tool replacement rates as a means of evaluating the effects of varying foraging strategies on hunter-gatherer technology (e.g., Kuhn 1989; Vierra 1995). For example, a "retooling tactic" is predicted for residentially mobile groups who reside in environments which exhibit continuous tool use/maintenance schedules, with tools being replaced as they become exhausted. In contrast, a "gearing up tactic" is predicted for logistically organized groups who reside in environments characterized by short periods of intense resource procurement, whereby a suite of tools is produced during periods of downtime in anticipation of future use. The former tactic is characterized by the use of a few generalized tools, and the latter by a greater variety of specialized tools.

The Late Archaic environment of the South Texas brush country was probably similar to today, being a savanna dissected by riparian zones; however, wooded thickets have greatly expanded during historic times. Information on resource structure, the archaeological record, and ethnohistorical documents paint a picture of generalized foragers who were residentially mobile, with seasonal mobility being primarily conditioned by the abundance and distribution of plant resources. Residences were often situated near riparian habitats. Food tended to be consumed on a daily basis, with little or no dependence on storage (see Chapters 2, 3, and 4; Black 1989c; Hester 1980, 1981, 1995). Regional lithic resources are restricted to gravels along various drainages (e.g., Nueces River and Rio Grande), and surface Uvalde lag gravels in upland settings. Given the nature of this evidence we might expect the use of a retooling tactic, with tools being maintained and used on a continual basis, and then subsequently replaced and discarded upon exhaustion. This situation can be contrasted with that exhibited by the Late Archaic in the Texas Panhandle, which has been characterized as reflecting a logistically organized foraging strategy based on the exploitation of bison (Boyd et al. 1990). This Late Archaic technology may therefore be characterized by a gearing-up tactic. The Late Prehistoric (Toyah horizon) in South Texas also involved the hunting of bison, but other species like deer, antelope and small game were important as well (Black 1986, 1989c; Highley 1986; Montgomery 1978; Hall et al. 
1986; Hester 1995; Hester and Hill 1975). Does the assemblage from site 41MV120 reflect a tactic involving the production of tools which were simply used to replace exhausted ones, or is there a dominance of production by-products with most of the tools having been removed from the site?

The majority of the raw materials reduced at site 41MV120 are cherts obtained from local terrace gravels. It appears that prepared cores and large flake blanks were produced at terrace procurement sites, and then brought back to $41 \mathrm{MV} 120$ for further reduction and tool production. Some cobbles were also brought to the site; however, the paucity of cores at 41MV120 may reflect that they were removed from the site for further reduction at some other location. Fine- to medium-grained raw materials were selected for the production of retouched tools with longer use-lifes, and medium- to coarse-grained materials for the production of expedient unretouched flakes. Several differing core reduction strategies were identified through the analysis of core, debitage, and retouched tools. A prepared core-flake-tool trajectory was used to produce utilized flakes and retouched tool blanks. A bifacial core-flake-tool trajectory was involved in manufacturing blanks for retouched flakes and notches. A large flake-tool trajectory reflects that large flake blanks were used for the production of bifaces. Lastly, unretouched utilized flakes were also manufactured through a cobble uniface-flake trajectory. The debitage types reflect evidence of core reduction and tool production/maintenance. These include core flakes, core maintenance flakes, biface flakes, uniface flakes, notching flakes, and overstruck flakes. The presence of early-, middle, and late-stage bifaces attests to the production of these tools and eventual discard primarily due to manufacturing, but some use-breakage. The projectile points are heavily resharpened, and discarded after breakage and exhaustion. There are few late-stage bifaces represented, presumably reflecting the removal of finished bifaces and projectile points from the site for use during the remainder of their annual rounds.

The technology at site 41MV120 appears to reflect aspects of both retooling and gearing up tactics. Indications of a gearing-up tactic include the presence of prepared cores and large flake blanks which were brought to site from the procurement location. This reflects an increased investment in the production of cores and tools beyond that needed to simply replace exhausted tools. In addition, the removal of most cores from the site also reflects the production of these items in greater quantities than what was simply needed to replenish exhausted cores. In contrast, the evidence for retooling consists of the production of bifaces (including point preforms) which were used to replace exhausted projectile points (and bifaces). The removal of cores from the site, however, is probably not related to a gearing up tactic in anticipation of the bulk acquisition of resources, but strategic planning in anticipation of moving into lithic resource poor areas. This interpretation is supported by the fact that the assemblage at site 41MV120 is characterized by a flake and not a blade technology which is often associated with logistically organized bison hunters (e.g., Quigg 1997).

\section{Besides foraging strategy, lithic raw material avail- ability can also have an important effect on stone tool technology. Given the limited nature of lithic resource availability in South Texas, are there indi- cations that the prehistoric inhabitants were using resharpening and beveling techniques to increase tool use-life and thereby reduce tool replacement costs?}

Arguments concerned with the effect of lithic raw material availability on stone tool technology are often framed in respect to curated vs. expedient components of lithic technology (sensu Binford 1977, 1979). That is, the cost-benefit analysis of procurement/production costs compared maintenance/replacement costs provides the following predictions: 1) a greater emphasis on the curated component of the technology in lithic resource poor areas, and 2) a greater emphasis on the expedient aspect of the technology in lithic resource rich areas (Andrefsky 1994; Bamforth 1986). The question is, at what point is it more cost-effective to replace a tool vs. resharpen it and extend its use-life? Procurement costs are an important factor in tool production costs. With reduced procurement costs, we can expect greater replacement rates, and the use of more expedient tools with shorter use-lives. In contrast, with increased procurement costs, we can expect lower replacement rates, and the use of more curated tools with longer tool use-lives. 
An important aspect of bifacial technologies is the ability to increase tool use-life through resharpening (Kelly 1988). Given the cost-benefit assumptions underlying the resource scarcity economizing model, we can expect that: 1) in lithic resource rich areas tool designs should reflect decreased tool replacement costs and therefore lower intensities of tool resharpening and beveling; and 2) in lithic resource poor areas tool designs should reflect greater tool replacement costs, and therefore increasing intensities of resharpening and beveling in order to increase tool use-life (Sollberger 1971; Wiant and Hassen 1985).

The projectile points at site $41 \mathrm{MV} 120$ are heavily resharpened and exhibit beveling. They appear to have been discarded after extreme tool exhaustion. This supports the contention that tool use-life is in part affected by lithic resource availability. In this case, attempts to increase tool use-life was a means of reducing tool procurement/production costs due to low regional lithic resource availability. The large amounts of debitage at the site not only reflects the importance of tool production, but the expedient production of flakes due to the lower cost of using local materials. This expedient component of the technology would presumably be less evident in other areas of the region where lithic materials are not as readily available (e.g., Bamforth 1986).

Is there evidence that local materials were heattreated increase their quality for knapping, and to increase tool use-life?

As Hester and Collins (1974) have pointed out, heattreated chert was commonly used for the production of projectile points in South Texas. Heat-treatment makes the stone less grainy, smoother in texture, more brittle, and therefore easier to flake (Whittaker 1994:72). Shott (1986) suggests that tool use-life is a proxy measure of manufacturing costs. That is, you should expect an increase in manufacturing costs with increasing tool use-life. This can be reflected in the increased costs of producing highly curated formal tools (e.g., bifaces) vs. expedient flake tools (e.g., utilized flakes). In this case, heat-treatment is adding a manufacturing cost which is, however, offset by the increased knappability of the material, and therefore increased tool use-life through resharpening. This tactic can be used to re- duce overall tool replacement costs given a lack of lithic raw materials.

The lithic assemblage at 41MV120 is dominated by the use of local, medium-grained cherts. Analyses indicate that there are significantly more medium-grained materials which have been subjected to heat-treatment than fine- or coarse-grained (Chapter 9). This presumably reflects that fine-grained materials do not require it, and heating coarse-grained materials would not increase their knappability. More importantly, there are significantly more retouched tools exhibiting evidence of heat treating than debitage. Again, the added cost of heat-treating is offset by increased tool use-life for the retouched tools vs. debitage. Indeed, biface flakes exhibit significantly more evidence of light heating and core flakes of no heating. This also corresponds with the fact that higher-quality fine- to medium-grained materials were preferentially selected for the production of retouched tools, and medium- to coarse-grained materials for core reduction.

\section{Site Structure}

What is the horizontal and vertical extent of artifact and feature distribution across the site? What are the implications of these spatial relationships for defining site organization, the use of space, activity areas, and discard zones?

Excavations at site $41 \mathrm{MV} 120$ indicate that artifacts and features extend for a distance of at least $200 \mathrm{~m}$ east-west along the road right-of-way, and up to 1.20 $\mathrm{m}$ in depth. As previously noted, there is a general decline in artifact density from east to west. The mean site lithic-artifact density is 275.0 artifacts per cubic $\mathrm{m}$. Area 1 exhibits the highest density (551.9), Areas 2 and 3 intermediate densities (210.3 and 195.2, respectively), and Area 4 the lowest density (8.6); however, IUs 2 (126.7) and 4 (71.7) contain lower densities than surrounding Areas 1 and 2, whereas, IUs 8 and 10 contain higher densities than surrounding Areas 2 and 3. The general pattern from east to west is high density, low density, medium density, high density, medium density, and low density. These patterns reflect several site formation processes. 
First, the presence of higher densities in the vicinity of Elm Creek may indicate that this area of the site acted as a focus for campsite activities. Second, since the excavation blocks represent the cumulative sum of multiple occupations, these densities are affected by varying site organization and sampling intensity. Third, the underlying point bar deposits rise up in the center of the site in Area 2, and slope down toward the east and west. This geomorphic feature acts to compress the deposits containing archaeological materials in Area 2. Lastly, the floodplain stratigraphic sequence varies somewhat across the site, with Unit 2-f3 being thicker at the east end of the site. This unit is more recent in age, and contains much less cultural material. In addition, it may be obscuring deeper deposits which might contain older occupations.

Artifact and material class density does vary by site stratigraphic context. As previously mentioned, the floodplain stratigraphic sequence on the site has been divided into three lithofacies (Chapter 7). Lower Unit 2-f1 dates to ca. 2200-2000 B.P. and contains the most intense occupations in Areas 1 and 2. Unit 2-f2 is represented by a short period of surface stability, and the presence of the buried Ab1 horizon in Areas 1, 3, and 4 (ca. 2000-1900 B.P.). Unit 2-f3 witnessed an increased rate of sediment deposition over Unit 2-f2, and is characterized by an intense occupation in Area 3 (ca. 19001200). Although Unit 2-f3 is thicker in Area 4, it contains very little cultural material. This sequence corresponds with the distribution of projectile point types across the site. That is, Shumla, Desmuke, Langtry, Marshall, and Montell types were recovered from Unit 2-f1 in Areas 1 and 2, Marcos and Ensor types from Unit 2-f2 in Areas 1 and 4, and Ensor from Unit 2-f3 from Areas 3 and 4.

The compositional analysis of artifact and material classes was able to identify differences between low and high density levels across the site. These patterns provide some insight into organization and use of space, and activity areas on the site. Low-density levels reflect short-term occupation and/or limited activity use, and high-density levels long-term occupation and/or the spatial segregation of activities. Although lithic artifact composition among the various levels is quite similar, the lower-density levels may exhibit a slight emphasis on core reduction, and the high-density lev- els on tool production/maintenance. In contrast, there is a distinct difference in the composition of fire-cracked rock by level. Lower-density levels contain relatively more cobble materials, and higher-density levels more sandstone. These differences presumably reflect variations in the function, construction, and maintenance of thermal features. Several isolated clusters of sandstone were identified during the excavation, some of which contained in situ rocks. These features may represent domestic hearths with the sandstone outlining the periphery of the feature. It is, however, unclear as to the exact structure and function of the burned cobble materials. No intact cobble-lined pit features were encountered during the excavations. The fact that these materials are primarily represented in low-density scatters may indicate that they were used for lining shallow, open hearths and for stone boiling. The mussel shell remains are generally associated with these lowerdensity burned rock scatters. This probably reflects that cobble materials were being used for cooking mussels.

The internal spatial organization of activities at the site are most clearly represented by the hearths and surrounding artifact distributions identified in Area 1. Nearly intact hearth features were identified in Levels 8 and 12 . A study of the artifact distributions identified a consistent pattern in the location of possible activity areas. Using hearths as the central focus of the campsite, it was observed that some mussel shell, snail shells, a projectile point, and a mano were found in the immediate area of the hearths. These reflect the locations where food processing, consumption, and tool maintenance activities might have occurred. Several meters from the hearth are concentrations of mussel shell and burned rock which could reflect discard piles, and the remains of cooking features. Lastly, the lithic reduction locus is located furthest from the hearth. The fact that this organizational module is present in the lower and upper levels of the area indicates a long-term redundant pattern of site reuse. No other clear spatial patterning was identified on the remainder of the site; however, there were very few intact features with which to study these spatial relationships. A single in situ burned rock in Area 4 (Level 6) was not associated with any distinctive patterning, but the $2-\mathrm{x}-3-\mathrm{m}$ area might have been too small (or the area too disturbed) to detect the full extent of the spatial module. In Area 3, the units with the highest artifact densities are located in Level 7 to the immediate south of Feature 10 (BHT 10). The block excavation 
sampled a portion of this activity area with the highest concentration on the eastern end of the block, and the lowest along the western periphery of the block.

Studies of the vertical distribution of artifact and material class density, and mean debitage size identified the presence of multiple "sediment packages" in Areas $1-3$. These packages (AUs), were situated at $20-\mathrm{cm}$ intervals in Areas 1 and 2, and $20-40 \mathrm{~cm}$ intervals in Area 3. In Area 1, the tops of AUs 2 and 4 correspond with the presence of the occupational surfaces in Levels 8 and 12 . Slightly larger pieces of debitage compose the upper portion of the AUs, and smaller-sized debitage the lower portion of the AUs. It is unclear as to whether this pattern reflects trampling and/or the downward movement of smaller items. All the AUs across the site are similar in assemblage composition, with only a few significant differences. These differences are primarily characterized by a distinction between upper and lower AUs, and between Areas 1-2 and Area 3. For example, the upper AUs exhibit a slight emphasis on core reduction and the lower AUs on tool production/maintenance. In Area 1-2 the upper AUs contain relatively more jasper and "other" materials, and the lower AUs more salt/pepper rhyolite. In contrast, Area 3 contains more salt/pepper rhyolite and chert in the upper AUs, and more chalcedony in the lower. There are no significant differences in the composition of burned rock within any specific area, although there is a tendency for sandstone to decrease from the lower to upper AUs. Burned rock composition does appear to vary more between areas, with relatively more chert in Area 1, sandstone in Area 2, and "other" materials (e.g., rhyolite and quartzite) in Area 3. Sample sizes were large enough to study variations in the distribution of shellfish by AU in Area 1. Although yellow sandshell dominates all the AUs, there are more lilliputs in the upper and lower AUs, and more Tampico pearlymussel shell in the middleAUs.

Overall, the site stratigraphic sequence reflects a longterm redundant pattern of site use from ca. 2200-1200 B.P. There are some limited differences between the upper and lower AUs, but they are general similar across the site. Areas 1-2 are also more similar than Area 3 (and 4), however, this relates to the presence of a relatively more intense early occupation in Areas 1-2, and late occupations in Areas 3-4. Therefore, most of the evidence for the earlier occupations is situated on the eastern side of the site nearer to Elm Creek, and the later occupations on the western side of the site.

\section{Site Function}

The information gathered from the previous studies of subsistence, seasonality, technology, and site structure can be used to make interpretations of possible site function(s).

\section{Does 41MV120 represent a residential or logistical campsite?}

A residential site is where the family resides. It is the terminal focus for subsistence activities, being surrounded by a foraging area within which individuals conduct their daily foraging activities. In contrast, a logistical site is the location where a segment of the group conducts task-specific activities. Once these activities are completed, the products procured at this location are generally carried back to the residential site for processing, distribution, and consumption by the site occupants. In some cases they might be cached in the field for future use (Binford 1980).

41MV120 appears to represent a residential site because a variety of domestic activities took place there. These include lithic reduction, tool production/maintenance, food processing, and consumption. Although there is very little ground stone represented at the site, a review of the Maverick County site data indicates that ground stone is found at both riverine and streamside site settings (Chapter 4 ). In addition, mussel, medium to small game, and presumably plant resources were processed and consumed at the site. This range in activities implies a division of labor as might be expected to occur at a residential site.

Second, there is at least some variation represented in the construction of thermal features. Sandstone could have been used for domestic hearths, and cobbles for lining of open hearths which were used for mussels and other foods. 
Third, the site is linked to a logistical site location where lithic raw materials were initially procured, and reduced before being brought back to the residential site for further reduction and tool production. Lastly, these cores and finished tools were subsequently carried away and used at other locations during the remainder of the group's annual rounds.

\section{When was the site occupied, what was the structure of the occupying group(s), and how long was the site occupied?}

There is very little data with which to discern the possible season of occupation(s) represented at the site. There does appear to be long-term redundant pattern of site use through time. Direct evidence for season of occupation is provided by the shellfish. Only 10 specimens contained a sufficient amount of their outer rings to speculate about possible season of collection (Chapter 12). All these exhibit wide growth rings, reflecting a warm season of collection (spring-fall). Other indirect information is based on the assumption that the ground stone would have been used to mill mesquite and acacia seeds (supported by the presence of mesquite charcoal). If so, these are primarily available during the summer (and possibly as dried pods into the fall and winter). Therefore, it can only be tentatively suggested that the site was occupied during the warm season, possibly during the summer.

If 41MV120 represents a residential site, then the occupying group would have consisted of one or more families. The occupational surfaces identified in Levels 8 and 12 of Area 1 do provide some limited information on possible site organization. If we assume that these represent a campsite module, then a large enough area of the site would need to be excavated to identify how many modules are actually present. Once multiple modules were identified, their contemporaneity would need to be determined before any arguments could be made concerning possible occupying group size (e.g., see Vierra 1985). On the other hand, there are no large bulk-processing features on the site, or refuse middens which might be imply larger groups and longer periods of occupation. Instead, the site contains small domestic hearths, and varying densities of burned rocks reflecting a smaller group and shorter period of occupation. A scenario could be suggested whereby $41 \mathrm{MV} 120$ represents a short-term occupied residential site. Late Archaic groups periodically returned to the site to produce cores and tools from materials obtained in nearby terraces. Easily accessible aquatic and terrestrial resources were procured and consumed in sufficient quantities to sustain a small group while residing in this location. The site may have been occupied during the summer, after which they continued they annual rounds with a newly refurbished tool kit.

\section{Regional Land Use}

\section{What role did site $41 \mathrm{MV} 120$ play in respect to South Texas hunter-gatherer settlement patterns?}

As Hester (1981:126) points out, seasonal mobility is conditioned by the abundance and distribution of key resources (also see Binford 1980; Kelly 1983). In areas with "high density" or concentrated resources we might expect reduced residential mobility, increased site differentiation, and possibly territorality. In contrast, groups residing in areas with "low density" or dispersed resources would be characterized by increased residential mobility, and less site differentiation over a broader portion of the landscape. Stated another way, this dichotomy is similar to what Binford (1980) refers to as logistically vs. residentially organized foraging systems. It is the latter organization which was probably more representative of the South Texas savanna environment(Hester 1981), probably one characterized as serial foraging (sensu Binford 1980).

There are currently three models of South Texas huntergatherer mobility strategies. All agree that these foragers were highly mobile, exploiting a variety of seasonally available plant and animal species. However, they disagree on the specific organization of these foraging systems. Hester $(1976,1981)$ suggests that large base camps were occupied in resource-rich riparian settings, with periodic logistical forays onto adjacent uplands. Shafer and Baxter (1975) consider that this seasonal pattern of movement between riparian and upland resource areas was conditioned by the availability of water. That is, prehistoric groups would make residential moves to uplands areas during the wet season, and return to lowland riverine areas during the dry season. Lastly, Lynn et al. 
(1977) agree with Hester that riverine habitats are the most productive; however, they argue that the seasonal transhumance pattern was characterized by a series of residential moves oriented along these stream and river channels.

How do the data from site 41MV120 fit these three models? Let us assume that the tentative interpretation of site function at $41 \mathrm{MV} 120$ is correct; that is, the site represents a short-term residential site which was occupied during the summer, primarily for the production of cores and tools to be used during their annual rounds. Local riverine and terrestrial resources were exploited while residing at the campsite. Forays were made to nearby gravel sources to obtain raw materials which were initially reduced at that location. If so, then this contradicts aspects of all three models. Contra Hester, the site would represent a short-term campsite linked to a nearby logistical procurement site, and not a long-term base camp. Although an extensive surface scatter covers portions of both sides of Elm Creek, this pattern may be due to repeated short-term occupations, and not a group aggregation site(s). In contrast to Shafer and Baxter, it would appear that this riverine setting was occupied during the summer rainy season (assuming a similar climatic regime as today), but the movement onto the lithic resource poor uplands is implied by the evidence for gearing up (i.e., cores), and the replacement of worn out tools. Lastly, this shortterm residential site could also fit the linear riverine pattern, but gearing up activities would seem unnecessary for movements along riverine settings with abundant lithic resources.

So, from where did the prehistoric occupants of site 41MV120 come, and where did they go? The distribution of nonlocal lithic raw materials have often been used to study regional hunter-gatherer mobility patterns (Shackley 1990; Vierra 1993, 1994). As argued by Binford (1979:266), "raw materials are generally procured as elements of an embedded strategy and are obtained in anticipation of future needs." If we assume these materials were incidentally collected by a group during their seasonal rounds, then the distribution of these materials could provide insights into the size of their annual ranges. Although this technique has provided productive avenues for research in the American Southwest, this was primarily due to the fact that distinctive obsidian and chert sources are situated at isolated points on the landscape; however, this does not appear to be the case in Central and South Texas. It is extremely difficult to discern particular source areas due to the ubiquitous nature of the primary chert sources. Attempts at discriminating between different possible sources using ultraviolet light have met with limited or no success (Hillman 1992; Hoffman et al. 1991). In addition, the problem is exacerbated by the presence of secondary sources which increase the regional distribution of these materials. As pointed out in Chapter 9, many of the chert subtypes identified in the Rio Grande gravels could also be found in the upland Uvalde Gravels. Both contain cherts which appear to have originated from the Edwards Formation. Curated tools with long use lives are sensitive indicators of regional mobility patterns. Although the projectile points from 41MV120 are heavily resharpened, and were presumably carried over long distances, they still resemble materials that can be obtained in many parts of Central and South Texas.

Regional studies of the distribution of nonlocal material types in American Southwest have provided some preliminary indications of the size of Archaic annual ranges and overall territories. On the Colorado Plateau these ranges are approximately $100 \mathrm{~km}$ (60 miles) in diameter; whereas, seasonal movements between the Sonoran Desert and upland Mogollon highlands included distances of about $220 \mathrm{~km}$ (135 miles) (Vierra 1993c). The distance between seasonal summer basin and fall mountain resource areas is much shorter on the plateau than in the more homogenous Sonoran desert of southern Arizona. As pointed out by Wills (1988:57), the resource structure on the plateau is therefore more conducive to seasonal logistic strategy, and in the southern deserts to more of a residentially organized strategy.

During Protohistoric times, hunter-gatherer groups in South Texas were moving up to about $160 \mathrm{~km}$ (100 miles) during their annual rounds (Campbell 1983). This figure is intermediate to the ones defined for the Colorado Plateau and Sonoran Desert. A review of the distribution of projectile points provides some insights into the areas possible traversed by the prehistoric occupants of site $41 \mathrm{MV} 120$. As previously mentioned, several Late Archaic projectile point types were identified at the site. Shumla and Desmuke were present in the lower section of floodplain Unit 2-f1; Langtry, 
Marshall, and Montell in the upper section of Unit 2-f1; Marcos and Ensor in Unit 2-f2; and Ensor in Unit 2-f3. These point types have also been identified on 31 sites in Maverick County (Chapter 4).

Figure 17-1 illustrates the number of sites recorded in Maverick County for each point type. As can be seen, the types fall into three groups similar to those identified in the stratigraphic sequence at site 41MV120: Shumla/ Desmuke, Langtry/Montell/Marshall, and Marcos/ Ensor. One could speculate as to whether this implies a pattern of increasing site use of the area through time during the Late Archaic, which are associated with the use of different point types. If we review Prewitt's (1995) recent review of the distribution of Texas point types by county, we also find shifting long-term patterns in the regional distribution of these types (i.e., for counties with $>10$ points for each type).

For example, Shumla, Desmuke, and Langtry types are generally distributed along a northwest-southeast axis of the Rio Grande valley and adjacent areas (Figure 17-2). Marshall and Montell types reflect a change in orientation towards a northeast-southwest pattern including the Rio Grande Valley, savanna uplands, and the Balcones Escarpment. Marcos types reflect a pattern similar to that of the Marshall and Montell; however, the distribution of Ensor points indicates an increase in the overall size of this region, encompassing both of the previous areas. One can only speculate

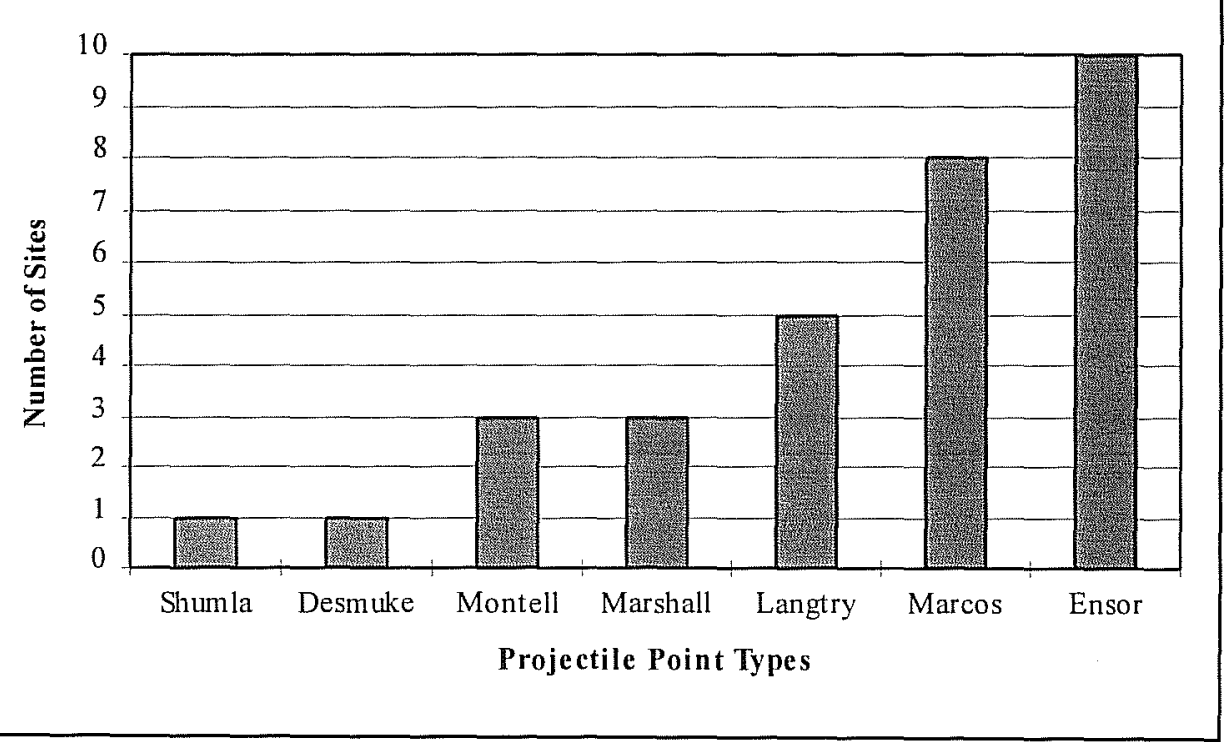

on what these preliminary patterns might reflect. Nonetheless, it is worth considering whether they are providing us with insights into long-term changes in the location and size of the territories being traversed by Late Archaic groups. For example, is there a long-term shift in the location and general direction of overall territories through time, and how far are groups ranging during their seasonal rounds? Do they range as far as the escarpment and plateau to the north, or the mountains of northeast Mexico to the south? These questions are beyond the scope of this report, but certainly need to be addressed by future research.
Figure 17-1. Projectile point-dated sites in Maverick County. 


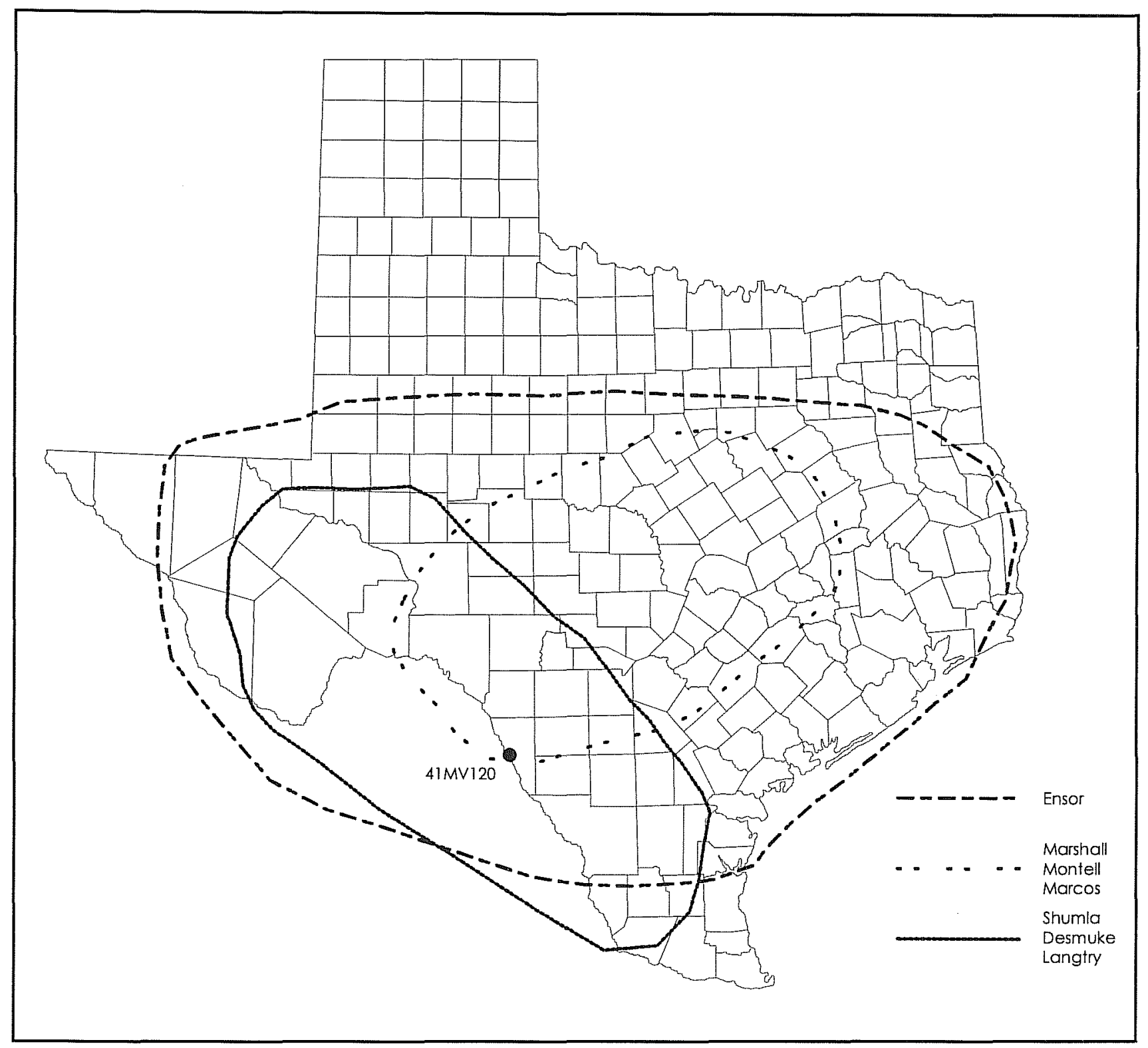

Figure 17-2. Regional distributions of projectile point types. 


\title{
Chapter 18: Recommendations for Future Research
}

\author{
Bradley J. Vierra and C. Britt Bousman
}

\section{Introduction}

Little is known of the prehistoric archaeological record of South Texas. Excavations at 41MV120 have provided some fruitful insights into the nature of Late Archaic gisements in river valley settings. Nonetheless, several suggestions can be made concerning productive directions for future research. This involves aspects of both the local geomorphology and specific intrasite analyses. One outcome of our geomorphic study is that several predictions can be made concerning possible site distributions, preservation and visibility in the area. In addition, there are several supplemental studies which were not conducted at 41MV120, but which would have provided more detailed information on site formation processes and the archaeological record.

\section{Geomorphology}

The implications of the geological investigations at 41MV120 for future highway construction projects is clear: alluvial sediments in the Rio Grande and its tributary valleys have an enormous potential for encountering well preserved and in situ archaeological sites. These alluvial deposits can be extensive in the main and side valleys. Initial assessment of geological and soils maps can provide a preliminary indication of the potential for buried sites. More detailed work accompanied with radiocarbon chronological control will help confirm the reliability of the chronological information produced by this current project (i.e., Late Holocene deposits in the upper few meters of the Rio Grande valley and Early to Middle Holocene deposits in the tributary Elm Creek valley). Irrespectively of the confirmation of this pattern to the larger region, it is obvious that the alluvial valley fills have a high potential for buried archaeological sites.
The limited work at site 41MV120 strongly suggests that the prehistoric landscape was highly dynamic and prehistoric inhabitants of this region adapted to this landscape and manipulated its resources to their advantage. Geoarchaeological studies in the region must continue to obtain systematic information on the nature of this changing landscape and the manners in which prehistoric inhabitants used the available biotic and abiotic resources. Associated with this endeavor is the objective of obtaining a more comprehensive understanding of the geological depositional systems in South Texas.

Within the state, South Texas remains one of the most poorly understood areas in terms of depositional systems and Late Quaternary geological records. The limited information collected by this project regarding the nature and timing of alluvial deposition in this segment of the Rio Grande and its tributary, Elm Creek, demonstrate that each alluvial system could have deposits of distinctly different ages and that the archaeological potential and thus possible impacts for each area are very different as well. More regional work, based on careful examination of existing geological and soils literature and new field efforts aimed at defining the chronology and nature of deposition, erosion, and soil formation, should be focused on constructing the geological record for South Texas. This is a regional problem that must be approached from a regional perspective.

The results of this project show that detailed geological studies of archaeological sites can provide critical information regarding the interpretation of the vertical and horizontal distribution of features and artifacts at sites. Even though this project can be regarded as a successful effort, in the future more careful integration between the geological record and the archaeological record should be attempted. For example, a textural analysis of sediments could have been linked 
directly to the analysis of artifact size that so effectively allowed the segregation of assemblages into analytical units. Also, the use of micromorphology of sediment samples provides a window into formational processes that is not available with other forms of analysis. At 41MV120 various forms of turbation acted to vertically smear the original archaeological occupations; however, by carefully and thoughtfully analyzing the geological and archaeological evidence these disturbances could be recognize and, at least to a degree, controlled. Additionally, the reconstruction of paleo-landscapes provides a environmental context for different occupations at different times. This information, along with good chronological control, provides a view into the identification and formation of palimpsest assemblages or well-stratified assemblages. Also, the reconstruction of site settings through the continued identification of sediment and soil stratigraphy provides distinct clues for understanding the nature of prehistoric resource (biotic and abiotic) exploitation patterns that is critical toward understanding the archaeological remains recovered on such projects.

Specific recommendations for future research includes: 1) a regional approach to geoarchaeological studies; 2) preliminary assessment of any project area by a careful inspection and assessment of geological and soils maps; 3) continued detailed recording of sediment and soil stratigraphic units that are directly linked to archaeological materials, when possible and appropriate; 4) systematic use of radiocarbon dating throughout the sediment profile in order to obtain good chronological control so that absolute chronologies for sediment deposition and soil formation, and deposition rates can be developed; and 5) detailed sediment analysis that includes texture, organic carbon, carbonate, magnetic susceptibility, and micromorphology. These provide the basic data necessary for developing detailed soil/stratigraphic sequences and for understanding formation processes. These analytical techniques need to be linked directly with archaeological samples.

\section{Site Specific Analyses}

A series of column samples was taken from several of the backhoe trenches for sediment analyses; however, it would also be productive to collect soil samples for several other analyses. Although pollen preservation is extremely bad in South Texas (Bryant and Holloway 1985:60), the analysis of phytolith silicates could provide an alternative source of information on paleoenvironmental conditions. Robinson's $(1979,1982)$ work has already shown the potential of this research strategy, but no one else has followed up on his initial studies. Soil samples could also be fine-screened for the recovery of small snails. The archaeological record at 41MV120 appears to be biased toward larger individuals; however, the identification of smaller species and individuals might help clarify issues concerned with natural vs. cultural selection, and paleoenvironment (e.g., Neck 1995). Soil collected for flotation samples would increase the likelihood of recovering macrobotanical remains. In addition, the samples could be scanned for the presence of fish otoliths and microdebitage. Lastly, magnetic susceptibility analyses could aid in the identification of buried paleosols and ancient surfaces. This might have been especially informative at site $41 \mathrm{MV} 120$ for identifying any correspondence between the results of the susceptibility study and the presence of the buried A horizons, sediment packages, and high density artifact zones. Would the magnetic analysis have identified the presence of the sediment packages, or only the buried A horizons?

Intrasite studies concerned with the description of stratified deposits often plot the vertical distribution of artifact frequency by level; however, the use of mean debitage weight, in conjunction with artifact frequency by level, proved to be a productive approach for identifying sediment packages. Future studies which are involved in the identification of vertically separated occupational zones should use this method. It would be informative to see if similar rhythmic patterns composed of large and small mean artifact sizes can be identified at other gisements.

It was disappointing that so few intact features were encountered at site 41MV120. Future data-recovery programs should emphasize the identification and excavation of intact features. Flotation samples could provide critical information on site subsistence, seasonality, and chronology. In addition, thermal features can be used as a focal point for site structure studies. Based on the results of the excavations at 41MV120, block excavations should be at least six meters in 
diameter: That is, the distance between hearth and lithic reduction locus as identified on these possible campsite modules.

The identification and excavation of thermal features would also contribute to our understanding of the possible function of burned rock material types. Is there a functional difference in the use of sandstone vs. cobble raw materials? That is, is sandstone primarily used as a simple border for domestic hearths, and cobbles for lining open hearths and pit ovens? A review of studies which have determined the thermal properties of the varying rock types should be done, and the implications of these data for material use and feature function evaluated (e.g., see Pierce 1984). Obviously, sandstone and the various cobble materials (e.g., chert, limestone, rhyolite, and quartzite) exhibit differing thermal properties. More work also needs to be conducted on the pattern of material type and heating temperature. For example, are sandstones generally heated at lower temperatures than the cobble materials?

The study of the chipped stone tool technology at site 41MV120 indicated that the assemblage is geared toward the production of cores, bifaces, and projectile points for use during annual rounds. Prepared cores and large flake blanks were produced at a nearby terrace procurement site, then transported to $41 \mathrm{MV} 120$ for further reduction. We need to locate and collect information on these procurement sites which presumably contain evidence for the initial stages of core reduction and large flake blank production. In addition, it would be important to determine whether there is any evidence for the heat treatment of lithic materials at these field locations.

Several different models for hunter-gatherer settlement organization have been proposed for South Texas. What we need is information on site structure, site function, and scale of mobility to address these arguments. How were prehistoric groups integrating riparian and upland savanna resource areas into their annual rounds, and how far did they traverse during their annual movements? These are indeed difficult questions to answer. Given the regional distribution of primary and secondary chert sources across the region, can we identify any diagnostic lithic sources which could be used to tract mobility patterns? Are there any distinctive sources in northeastern Mexico which might be used to identify movements between these areas? What about differences in the materials used to produce projectile points over time, are there broad temporal changes in material selection which could be indicative of shifts in regional mobility? Obviously much more work needs to be done in order to address the question of huntergatherer mobility and settlement organization in South Texas. 


\section{References Cited}

Acklen, J. M., M. Harlan, S. Lent, and J. Moore

1983 Supplemental Inventory of 53 Prehistoric Sites for the Ute Mountain Land Exchange. Archeological Report No. 6. Public Service Company of New Mexico, Albuquerque.

Allen, D. C., and E. P. Cheatum

1961 Ecological Implications of Fresh-water and Land Gastropods in Texas Archeological Studies. Bulletin of the Texas Archeological Society 31:291-316.

Andrefsky, W., Jr.

1994 Raw-Material Availability and the Organization of Technology. American Antiquity 59:21-34.

Arbingast, S. A., L. G. Kennamer, R. H. Ryan, A. Lo, D. L. Karney, C. P. Zlatkovic, M. E. Bonine, and R. G. Steele

1973 Atlas of Texas. Bureau of Business Research, The University of Texas at Austin.

Archer, S.

1995 Tree-grass Dynamics in a Prosopis-thorn Scrub Savannah Parkland: Reconstructing the Past and Predicting the Future. Ecoscience 2(1):84-99.

Archibold, O. W.

1995 Ecology of World Vegetation. Chapman and Hall, London.

Aten, L. E.

1981 Determining Seasonality of Rangia Cuneata from Gulf Coast Shell Middens. Bulletin of the Texas Archeological Society 52:179-200.

Bamforth, D.

1986 Technological Efficiency and Tool Curation. American Antiquity 51:38-50.

Barnes, V. E.

1976 Geologic Atlas of Texas: Crystal City-Eagle Pass Sheet. Bureau of Economic Geology, The University of Texas at Austin.

Bartram, L. E., E. M. Knoll, and H. T. Bunn

1991 Variability in Camp Structure and Bone Food Refuse Patterning at Kua San Hunter-Gatherer Camps. In The Interpretation of Archaeological Spatial Patterning, edited by E. M. Kroll and T. D. Price, pp. 77-148. Plenum, New York.

Binford, L. R.

1973 Interassemblage Variability: The Mousterian and the 'Functional Argument.' In The Explanation of Cultural Change: Models in Prehistory, edited by C. Renfrew, pp. 227-254. Duckworth, London.

1977 Forty-Seven Trips. In Stone Tools as Cultural Markers, edited by R. Wright, pp. 24-36. Australian Institute of Aboriginal Studies, Canberra, Australia. 
1978 Dimensional Analysis of Behavior and Site Structure: Learning from an Eskimo Hunting Stand. American Antiquity 43:330-361.

1979 Organization and Formation Processes: Looking at Curated Technologies. Journal of Anthropological Research 35:255-273.

1980 Willow Smoke and Dogs' Tails: Hunter-Gatherer Settlement Systems and Archaeological Site Formation. American Antiquity 45:4-20.

Black, S. L.

1986 The Clemente and Herminia Hinojosa Site, 41JW8, A Toyah Horizon Campsite in Southern Texas. Special Report, No. 18. Center for Archaeological Research, The University of Texas at San Antonio.

1989a South Texas Plains. In From the Gulf Coast to the Rio Grande: Human Adaptation in Central, South, and Lower Pecos Texas, edited by T. R. Hester, S. L. Black, D. G. Steele, B. W. Olive, A. A. Fox, K. J. Reinhard, and L. C. Bement, pp. 39-62. Research Series No. 33. Arkansas Archaeological Survey, Fayetteville.

1989b Environmental Setting. In From the Gulf to the Rio Grande: Human Adaptation in Central, South, and Lower Pecos Texas, edited by T. R. Hester, S. L. Black, D. G. Steele, B. W. Olive, A. A. Fox, K. J. Reinhard, and L. C. Bement, pp. 5-16. Research Series No. 33. Arkansas Archeological Survey, Fayetteville.

1989c Central Texas Plateau Prairie. In From the Gulf Coast to the Rio Grande: Human Adaptation in Central, South, and Lower Pecos Texas, edited by T. R. Hester, S. L. Black, D. G. Steele, B. W. Olive, A. A. Fox, K. J. Reinhard, and L. C. Bement, pp. 17-38. Research Series No. 33. Arkansas Archaeological Survey, Fayetteville.

Blair, W. F.

1950 The Biotic Provinces of Texas. Texas Journal of Science 2:93-117.

Bleed, $\mathrm{P}$.

1986 The Optimal Design of Hunting Weapons: Maintainability or Reliability. American Antiquity 51: 737-747.

Bordes, F.

1981 Typologie de Paléolithque Ancien et Moyen. Centre National de la Rescherche Scientifique, Paris.

Bousman, C. B.

1991 Holocene Paleoecology and Later Stone Age Hunter-Gatherer Adaptations in the South African Interior Plateau. Ph.D. dissertation. Southern Methodist University, Dallas.

1992 Preliminary Oxygen Isotope Evidence for Late Pleistocene-Early Holocene Climatic Changes. Current Research in the Pleistocene 9:78-80.

1993 Hunter-Gatherer Adaptations, Economic Risk and Tool Design. Lithic Technology 18:59-86.

1997 Paleoenvironmental Change in Central Texas: The Palynological Evidence. Plains Anthropologist. In press.

Boutton, T. W.

1991a Stable Carbon Isotope Ratios of Natural Materials: I. Sample Preparation and Mass Spectrometric Analysis. In Carbon Isotope Techniques, edited by D. C. Coleman and B. Fry, pp. 155-171. Academic, San Diego, 
$1991 b$ Stable Carbon Isotope Ratios of Natural Materials: II. Atmospheric, Terrestrial, Marine, and Freshwater Environments. In Carbon Isotope Techniques, edited by D. C. Coleman and B. Fry, pp. 173-185. Academic, San Diego.

Boutton, T. W., A. T. Harrison, and B. N. Smith

1980 Distribution of Biomass of Species Differing in Photosynthetic Pathway Along an Altitudinal Transect in Southeastern Wyoming Grassland. Oecologia 45:287-298.

Boyd, D. B., S. A. Tomka, R. C. Fields, and E. R. Prewitt

1990 Research Design and Data Recovery Plan for Phase III Cultural Resources Investigations at Justiceburg, Reservoir. Prewitt, Austin.

Boyd, D. K., J. Peck, S. A. Tomka, and K. W. Kibler

1993 Data Recovery at Justiceburg Reservoir (Lake Alan Henry), Garza and Kent Counties, Texas: Phase III, Season 2. Report of Investigations, Number 88. Prewitt, Austin.

Bray, W. L.

1901 The Ecological Relations of the Vegetation of Western Texas. Botanical Gazette 32:99-123.

Brewer, R.

1976 Fabric and Mineral Analysis of Soils. Second edition. Robert E. Krieger, New York.

Brown, K. M.

1979 An Archaeological Reconnaissance of the Proposed Eagle Pass Municipal Airport Site, Maverick County, Texas. Archaeological Survey Report, No. 87. Center for Archaeological Research, The University of Texas at San Antonio.

Brown, K. M., D. R. Potter, G. D. Hall, and S. L. Black

1982 Excavations at 4lLK67, A Prehistoric Site in the Choke Canyon Reservoir, South Texas. Choke Canyon Series, No. 7. Center for Archaeological Research, The University of Texas at San Antonio.

Brune, G.

1981 Springs of Texas. Branch-Smith, Fort Worth.

Bryant, V. M., Jr.

1977 A 16,000 year Pollen Record of Vegetational Change in Central Texas. Palynology 1:143-156.

Bryant, V. M., Jr., and R. G. Holloway

1985 A Late Quaternary Paleoenvironmental Record of Texas: An Overview of the Pollen Evidence. In Pollen Records of Late Quaternary North American Sediments, edited by V. M. Bryant, Jr., and R. G. Holloway, pp. 39-70. American Association of Stratigraphic Palynologists, Dallas.

Bryant, V. M., Jr., and D. H. Riskind

1980 The Paleoenvironmental Record for Northeastern Mexico: A Review of the Pollen Evidence. In Papers on the Prehistory of Northeastern Mexico and Adjacent Texas, edited by J. F. Epstein, T. R. Hester, and C. Graves, pp. 7-31. Special Report, No. 9. Center for Archaeological Research, The University of Texas at San Antonio. 
Byrd, C. L.

1971 Origin and History of the Uvalde Gravel of Central Texas. Baylor Geological Studies Bulletin 20. Baylor University, Waco, Texas.

Cabeza de Vaca, A. N.

1961[1871] Relation of Nuñez Cabeza de Vaca. Translated by B. Smith. Readex Microprint.

Callahan, E.

1979 The Basics of Biface Knapping in the Eastern Fluted Point Tradition: A Manual for Flintknappers and Lithic Analysts. Archaeology of Eastern North America 7:1-180.

Campbell, T. N.

1975 The Payaya Indians of Southern Texas. Special Publications No. 1. The Southern Texas Archaeological Association, San Antonio.

1979 Ethnohistoric Notes on the Indian Groups Associated with Three Spanish Missions at Guerrero, Coahuila. Archaeology and History of the San Juan Bautista Mission Area, Coahuila and Texas, No. 3. Center for Archaeological Research, The University of Texas at San Antonio.

1983 Coahuiltecans and Their Neighbors. In Handbook of North American Indians (Vol. 10), edited by A. Ortiz, pp. 343-358. Smithsonian Institution, Washington D.C.

1988 The Indians of Southern Texas and Northeastern Mexico: Selected Writings of Thomas Nolan Campbell. Texas Archeological Research Laboratory, The University of Texas at Austin.

Campbell, T. N., and T. J. Campbell

1981 Historic Indian Groups of the Choke Canyon Reservoir and Surrounding Area, Southern Texas. Choke Canyon Series, No. 1. Center for Archeological Research, The University of Texas at San Antonio.

1985 Indian Groups Associated with Spanish Missions of the San Antonio Missions National Historical Park. Special Report, No. 16. Center for Archaeological Research, The University of Texas at San Antonio.

Caran, S.

1993 Geoarcheology. In Expanded Archeological Assessments at the Proposed Site for the New International Bridge at Eagle Pass, Maverick County, Texas, edited by M. Davis and J. Jones, pp. A1-A7. Archeology Series 21. Hicks, Austin.

Carlson, D. L.

1987 Rangia Cuneata as a Seasonal Indicator for Coastal Archeological Sites. Bulletin of the Texas Archeological Society 58:201-214.

Chandler, C. K., and D. Kumpe

1992 Decorated Freshwater Mussels Shell Artifacts from the Lower Rio Grande River of South Texas. $L a$ Tierra 10(3):8-14.

1994 Folsom Points from Deep South and Southwest Texas. La Tierra 21(3):6-9.

Chaplin, R. E.

1971 The Study of Animal Bones from Archaeological Sites. Seminar, London. 
Chapman, R. C., and J. A. Schutt

1977 Methodology of Lithic Analysis. In Archeological Investigations in Cochiti Reservoir; New Mexico (Vol. 2), Excavation and Analysis, 1975 Season, edited by R. Chapman and J. Biella, pp. 83-96. Office of Contract Archeology, The University of New Mexico at Albuquerque.

Cheatum, E. P., and R. W. Fullington

1971 Aquatic and Land Mollusca of Texas: The Recent and Pleistocene Members of the Gastropod Family Polygyridae in Texas. Bulletin 1, Part 2. Dallas Museum of Natural History, Dallas.

1973 The Aquatic and Land Mollusca of Texas: The Recent and Pleistocene Members of the Papillate and Urocoptidae (Gastropoda) in Texas. Bulletin 1, Part 2. Dallas Museum of Natural History, Dallas.

Cheek, C. S., S. Bearden, W. Young, and C. B. Bousman

1980 Archeological Investigations at the Graham Site, 34AT90: 1975, 1977, and 1978. Research Report 23. Archeological Research Associates, Tulsa.

Christenson, A. L.

1987 The Prehistoric Tool Kit. In Prehistoric Stone Technology on Northern Black Mesa, Arizona, by W. Parry and A. Christenson, pp. 43-94. Occasional Paper No. 12. Center for Archaeological Investigations, Southern Illinois University, Carbondale.

Clark, J. W.

1973 The Problem of the Land Snail Genus Rabdotus in Texas Archeological Sites. The Nautilus 87:24.

1976 Alvar Núnez and the Snail Rabdotus in Texas. The Nautilus 90:13-14.

Clark, D. L.

1968 Analytical Archaeology. Methuen, London.

Cole, M. M.

1986 The Savannas: Biogeography and Geobotany. Academic, New York.

Cole, D. R., and H. C. Monger

1994 Influence of Atmospheric $\mathrm{CO}_{2}$ on the Decline of $\mathrm{C}_{4}$ Plants During the Last Deglaciation. Nature 368: 533-536.

Collins, M. B.

1995 Forty Years of Archeology in Central Texas. Bulletin of the Texas Archeological Society 66:361-400.

Collins, M. B., B. Ellis, and C. Dodt-Ellis

1990 Excavations at the Camp Pearl Wheat Site (41KR243): An Eariy Archaic Campsite on Town Creek, Kerr County, Texas. Studies in Archeology 6. Texas Archeological Research Laboratory, The University of Texas at Austin.

Collins, M. B., C. B. Bousman, P. Goldberg, J. Guy, P. Takac, T. Stafford, Jr., and V. Holliday

1993 The Paleoindian Sequence at the Wilson-Leonard Site, Texas. Current Research in the Pleistocene 10:10-12. 
Cook, O. F.

1908 Change of Vegetation on the South Texas Prairies. Circular 14. U.S. Department of Agriculture, Bureau of Plant Industries, Washington, D.C.

Crabtree, D. E.

1972 An Introduction to Flintworking. Occasional Papers of the Idaho State University Museum, No. 28. Pocatello, Idaho.

Davis, M. W., and J. T. Jones

1993 Mechanically Assisted Subsurface Evaluation of Prehistoric Site 41MV104, Maverick County, Texas. Archaeology Series 20. Hicks, Austin.

1993 Expanded Archaeological Assessments at the Proposed Site for the New International Bridge at Eagle Pass, Maverick County, Texas. Archaeology Series 21. Hicks, Austin.

Davis, R. B., and D. J. Schmidler

1994 The Mammals of Texas. Texas Parks and Wildlife, Austin.

Dering, J. P.

1995 Modern and Contact-Period Vegetation in the Area of the Jonas Terrace Site of Northern Medina County. In Past Cultures and Climates at Jonas Terrace 41ME29, by L. Johnson, pp. 293-300. Report 40. Office of the State Archeologist, Austin.

1997 Formation Processes and the Plant Economy at Burned Rock Middens. The View from a Rockshelter. Manuscript on file. Center for Environmental Archaeology, Texas A\&M University, College Station.

Dillehay, T. D.

1974 Late Quaternary Bison Population Changes on the Southern Plains. Plains Anthropologist 19:180-196.

Durst, J. J.

1995 An Archaeological Assessment of 5.0 Acres for the Eagle Pass Hospital District, Maverick County, Texas. Letter Report, No. 111. Center for Archaeological Research, The University of Texas at San Antonio.

Eaton, J. D., and F. Valdez, Jr.

1978 An Archaeological Survey of Areas to be Developed at the Municipal Sewage Treatment Plant, Eagle Pass, Texas. Manuscript on file. Center for Archaeological Research, The University of Texas at San Antonio.

Emberton, K. C.

1995 When Shells Do Not Tell: 145 Million Years of Evolution in North America's Polygyrid Land Snails, with a Revision and Conservation Priorities. Malacologia 37:69-109.

Espey, Huston and Associates

1980 Site Survey Forms for sites 41MV75 through 41MV80. Photocopies on file. Center for Archaeological Research, The University of Texas at San Antonio.

1981 A Cultural Resource Survey and Assessment of the Maverick County Coal Project. Unpublished report on file. Texas Historical Commission, Austin. 
Evans, G.

1961 Notes on Terraces of the Rio Grande, Falcon-Zapata Area, Texas. Bulletin of the Texas Archeological Society 32:33-45.

Ferring, C.

1986 Rates of Fluvial Sedimentation: Implications for Archaeological Variability. Geoarchaeology 1:259-274.

Folk, R. L.

1980 Petrology of Sedimentary Rocks. Hemphill, Austin.

Frkuska, A. J., E. C. Frkuska, D. Brown, and T. R. Hester

1977 Archaeological Test Excavations at 41MV57: The SECO Mines Project, Maverick County, Texas. Archaeological Survey Report, No. 28. Center for Archaeological Research, The University of Texas at San Antonio.

Frye, R. G.

1984 The Vegetation Types of Texas Including Cropland. Texas Parks and Wildlife Department, Austin.

Fullington, R. W.

1995 Seasonality and Texas Rangia. In Archeological Test Excavations at Four Shell Midden Sites in the Wallisville Lake Project Area, Chambers and Liberty Counties, edited by B. Ensor, pp. C3-C61. GeoMarine, Plano, Texas.

Fullington, R. W., and W. L. Pratt, Jr.

1974 The Aquatic and Land Mollusca of Texas, The Helicinidae, Carychiidae, Achatinidae, Bradybaenidae, Bulimulidae, Cionellidae, Haplotrematidae, Helicidae, Oreohelicidae, Spiraxidae, Streptaxidae, Strobilopsidae, Thysanophoridae, Valloniidae (Gastropoda) in Texas. Bulletin 1(3):48. The Dallas Museum of Natural History, Dallas.

GEEM.

1975 Epipaléolitique-Mésolithique: L'outillage du Fonds Commun. Bulletin de la Société Préhistorique Française 72:319-332.

Gargett, R., and B. Hayden

1991 Site Structure, Kinship, and Sharing in Aboriginal Australia: Implications for Archaeology. In The Interpretation of Archaeological Spatial Patterning, edited by E. M. Kroll and T. D. Price, pp. 11-32. Plenum, New York.

Garner, E.

1997 Natural Deposits of the River Terraces in the Vicinity of 41WB206. In Campfires and Ghost Towns on the Rio Grande: The Archeology and History of the Laredo-Colombia Solidarity International Bridge Site, Nuevo Leon, Mexico and Webb County, Texas, edited by A. McGraw. Texas Department of Transportation, Austin.

Gifford-Gonzalez, D. P., D. B. Damrosch, D. R. Damrosh, J. Pryor, and R. L. Thunen

1985 The Third Dimension in Site Structure: An Experiment in Trampling and Vertical Dispersal. American Antiquity 50:803-824. 
Goldman, E. A., and R. T. Moore.

1946 The Biotic Provinces of Mexico. Journal of Mammalogy 26:347-360.

Goode, G. T.

1991 Late Prehistoric Burned Rock Middens in Central Texas. In The Burned Rock Middens of Texas: An Archeological Symposium. Studies in Archeology, No. 13. Texas Archeological Research Laboratory, The University of Texas at Austin.

Goodyear, A. C.

1979 A Hypothesis for the Use of Cryptocrystalline Raw Materials Among Paleoindian Groups of North America. Research Manuscript Series, No. 156. Institute of Archaeology and Anthropology, University of South Carolina, Columbia.

Gose, W. A.

1990 Data from Archeomagnetic Analysis. In Excavations at the Camp Pearl Wheat Site (41KR243): An Early Archaic Campsite on Town Creek, Kerr County, Texas, edited by M. R. Collins, B. Ellis, and C. Dodt-Ellis, pp. 115-124, Studies in Archeology 6. Texas Archeological Research Laboratory, The University of Texas at Austin.

1994 Archeomagnetism. In Archaic and Late Prehistoric Human Ecology in the Middle Onion Creek Valley, Hays County, Texas, edited by R. A. Ricklis and M. B. Collins. Studies in Archeology 9. Texas Archeological Research Laboratory, The University of Texas at Austin.

1997 Archaeomagnetic Analysis of Burned Rocks from Fort Bliss. In Fire-cracked Rock Use and Reuse in the Hueco Bolson, Fort Bliss, Texas, edited by C. L. Tennis and J. M. Hunziker, pp. 123-148. Archaeological Survey Report, No. 257. Center for Archaeological Research, The University of Texas at San Antonio.

Gould, R. A., D. A. Koster, and A. H. Sontz

1971 The Lithic Assemblage of the Western Desert Aborigines of Australia. American Antiquity 36(2):149-169.

Gross, K. J., and D. L. Nickels

1994 An Archaeological Survey of 6.4 Acres for the Eagle Pass Independent School District. Letter Report, No. 108. Center for Archaeological Research, The University of Texas at San Antonio.

Haberman, S. J.

1973 The Analysis of Residuals in Cross-Classified Table. Biometrics 29:205-220.

Hall, G. D., S. L. Black, and C. Graves

1982 Archaeological Investigations at Choke Canyon Reservoir, South Texas: The Phase I Findings. Choke Canyon Series, No. 5. Center for Archaeological Research, The University of Texas at San Antonio.

Hall, G. D., T. R. Hester, and S. L. Black

1986 The Prehistoric Sites at Choke Canyon Reservoir; Southern Texas: Results of Phase II Archaeological Investigations. Choke Canyon Series, No. 10. Center for Archaeological Research, The University of Texas at San Antonio. 
Hall, S. A.

1990 Channel Trenching and Climatic Change in the Southern U. S. Great Plains. Geology 18:342-345.

Hallmark, C. T., L. T. West, L. P. Wilding, and L. R. Drees

1986 Characterization Data for Selected Texas Soils. Texas Agriculture Experiment Station Miscellaneous Publication 1583. Texas A\&M University, College Station.

Hayden, B., and W. K. Hutchings

1989 Whither the Billet Flake? In Experiments in Lithic Technology, edited by D. Amick and R. Mauldin, pp. 235-258. BAR International Series No. 528. Oxford, England.

Hester, T. R.

1976 Hunters and Gatherers of the Rio Grande Plain and the Lower Coast of Texas. Center for Archaeological Research, The University of Texas at San Antonio

1978 Background to the Archaeology of the Chaparrosa Ranch, Southern Texas. Volume I: Studies in the Archaeology of Chaparrosa Ranch. Special Report, No. 6. Center for Archaeological Research, The University of Texas at San Antonio.

1980 Digging into South Texas Prehistory. Corona, San Antonio.

1981 Tradition and Diversity Among the Prehistoric Hunters and Gatherers of Southern Texas. Plains Anthropologist 26:119-128.

1995 The Prehistory of South Texas. Bulletin of the Texas Archeological Society 66:427-459.

Hester, T. R., and M. B. Collins

1974 Evidence of Heat Treating of Southern Texas Projectile Points. Bulletin of the Texas Archeological Society 45:119-224.

Hester, T. R., and T. C. Hill, Jr.

1975a Eating Land Snails in Prehistoric Southern Texas: Ethnohistoric and Experimental Data. The Nautilus 89:37-38.

1975 Some Aspects of Late Prehistoric and Protohistoric Archaeology in Southern Texas. Special Report, No. 1. Center for Archaeological Research, The University of Texas at San Antonio.

Hietala, H. (editor)

1984 Intrasite Spatial Analysis in Archaeology. Cambridge University Press, Cambridge.

Highley, C. L.

1986 Archaeological Investigations at 41LK201, Choke Canyon Reservoir; Southern Texas. Choke Canyon Series, Vol. 11. Center for Archaeological Research, The University of Texas at San Antonio.

1995 Chipped Stones. In Archeological Investigations at the Loma Sandia Site (41LK28): A Prehistoric Cemetery and Campsite in Live Oak County, Texas, by A. J. Taylor and C. L. Highly, pp. 405-484. Studies in Archeology, No. 20. Texas Archeological Research Laboratory, The University of Texas at Austin.

Hillman, M. J.

1992 Evaluation of Visible and Ultraviolet-excited Attributes of some Texas and Macroscopically Similar New Mexico Cherts. Master's thesis, Department of Anthropology. Eastern New Mexico University, Portales. 
Hoffman, J. L., L. C. Todd, and M. B. Collins

1991 Identification of Central Texas Edwards Chert at the Folsom and Lindenmeier Sites. Plains Anthropologist 36:297-308.

Holloway, R. G.

1986 Macrobotanical Analysis of Phase II Materials from the Choke Canyon Reservoir Area, Texas. In Prehistoric Sites at Choke Canyon Reservoir, Southern Texas: Results of Phase II Archaeological Investigations, by G. D. Hall, T. R. Hester, and S. L. Black, pp. 437-451. Choke Canyon Series, No. 10. Center for Archaeological Research, The University of Texas at San Antonio.

Holloway, R. G., and V. M. Bryant, Jr.

1984 Picea glauca Pollen from Late Glacial Deposits of Central Texas. Palynology 8:21-32.

Holloway, R. G., L. M. Raab, and R. Stuckenrath

1987 Pollen Analysis of Late-Holocene Sediments from a Central Texas Bog. The Texas Journal of Science 39:71-79.

Houk, B. A., C. B. Bousman, and D. L. Nickels

1997 Analysis and Research Issues. In Phase II Archaeological Testing at Lackland Air Force Base, San Antonio, Texas, by B. Houk and D. Nickels, pp. 105-146. Archaeological Survey Report, No. 248. Center for Archaeological Research, The University of Texas at San Antonio.

Howells, R. G.

1993 Preliminary Survey of Freshwater Mussel Harvest in Texas. Management Data Series 100. Texas Parks and Wildlife Department, Austin.

1994 Preliminary Distributional Studies of Freshwater Bivalves in Texas. Management Data Series 105. Progress report for 1992. Texas Parks and Wildlife Department, Austin.

1995 Distributional Studies of Freshwater Bivalves in Texas. Management Data Series 118. Progress report for 1993. Texas Parks and Wildlife Department, Austin.

1996a Distributional Studies of Freshwater Bivalves in Texas. Management Data Series 120. Progress report for 1994. Texas Parks and Wildlife Department, Austin.

1996b Distributional Studies of Freshwater Bivalves in Texas. Management Data Series 125. Progress report for 1995. Texas Parks and Wildlife Department, Austin.

1996c Tampico Pearlymussel (Cyrtonaias tampicoensis): Shades of the Old West. American Conchologist 24(2):24-26.

1997a Range Extension for Bleufer Potamilus Purpuratus (Bivalvia: Unionidae). The Texas Journal of Science 49(1). In press.

1997b Taxonomic Status of Western Lilliput (Toxolasma mearnsi). Triannual Unionid Report (11):32.

1997c Distributional Studies of Freshwater Bivalves in Texas. Management Data Series. Progress report for 1996. Texas Parks and Wildlife Department, Austin. In preparation.

Howells, R. G., R. W. Neck, and H. D. Murray

1996a Freshwater Mussels of Texas. Texas Parks and Wildlife, Inland Fisheries Division, Austin. 
Howells, R. G., C. M. Mather, and J. A. M. Bergmann

1996b Conservation Status of Selected Freshwater Mussels in Texas. Symposium on the Conservation and Management of Freshwater Mussels II: Initiatives for the Future. In press.

Hubbard, R. A., and D. E. Fox

1990 An Archeological Reconnaissance of Sewerage System Improvements Proposed by the City of Eagle Pass, Maverick County, Texas, State Revolving Fund Project No. 2427-001. Texas Water Development Board, Austin.

Hubbs, C., R. J. Edwards, and G. P. Garrett

1991 An Annotated Checklist of the Freshwater Fishes of Texas, with Keys to the Identification of Species. The Texas Journal of Science 43(4):1-56.

Hubricht, L.

1960 The Genus Bulimulus in Southern Texas. The Nautilus 74:68-70.

1961 Eight New Species of Land Snails from the Southern United States. The Nautilus 75:26-33; 60-64.

1985 The Distributions of the Native Land Mollusks of the Eastern United States. Fieldiana: Zoology, New Series 24.

Huebner, J. A.

1991a Late Prehistoric Bison Populations in Central and Southern Texas. Plains Anthropologist 36(137): 343-358.

1991b Cactus for Dinner Again!: Isotopic Analysis of Late Archaic Diet. In The Lower Pecos Region of Texas. In Papers on Lower Pecos Prehistory, edited by S. A. Turpin, pp. 175-190. Studies in Archeology No. 8. Texas Archeological Research Laboratory, The University of Texas at Austin.

Hulbert, R. C. Jr.

1984 Late Pleistocene and Holocene Leprid Faunas from Texas: Their Composition, Distribution and Climatic Implications. The Southwestern Naturalist 29(2):197-210.

Humphrey, J. D., and C. R. Ferring

1994 Stable Isotopic Evidence for Late Pleistocene to Holocene Climate Change, North-Central Texas. Quaternary Research 41:200-213.

Inglis, J. M.

1964 A History of Vegetation on the Rio Grande Plain. Bulletin 45. Texas Parks and Wildlife Department, Austin.

Jackson, M. F., and G. D. Hall

1976 Eagle Pass Main Arroyo Development Project: Assessment of Its Impact on the Archaeological Resources. Photocopy on file. Center for Archaeological Research, The University of Texas at San Antonio.

Johnson, J. K.

1979 Archaic Biface Manufacture: Production Failures, A Chronicle of the Misbegotten. Lithic Technology $8(2): 25-35$. 
Johnson, L., Jr.

1995 Past Cultures and Climates at Jones Terrace, 41 ME29, Medina County, Texas. Office of the State Archeologist Report No. 40. Texas Department of Transportation and Texas Historical Commission, Austin.

Johnson, L., Jr., and G. T. Goode

1994 A New Try at Dating and Characterizing Holocene Climates, as Well as Archaeological Periods, on the Eastern Edwards Plateau. Bulletin of the Texas Archeological Society 65:1-51.

Johnston, M. C.

1963 Past and Present Grasslands of Southern Texas and Northeastern Mexico. Ecology 44:456-466.

Keeley, L. H.

1991 Tool Use and Spatial Patterning: Complications and Solutions. In The Interpretation of Archaeological Spatial Patterning, edited by E. M. Kroll and T. D. Price, pp. 257--268. Plenum, New York.

Kelly, R. L.

1983 Hunter-Gatherer Mobility Strategies. Journal of Anthropological Research 39:277-306.

1988 Three Sides of a Biface. American Antiquity 53:717-734.

1995 The Foraging Spectrum. Smithsonian Press, Washington, D.C.

Kenmotsu, N. A., and T. K. Perttula

1993 Archaeology in the Eastern Planning Region, Texas: A Planning Document. Cultural Resources Management Report 3. Department of Antiquities Protection, Texas Historical Commission, Austin.

Kroll, E. M., and T. D. Price (editors)

1991 The Interpretation of Archaeological Spatial Patterning. Plenum, New York.

Kuhn, S. L.

1989 Hunter-gatherer Foraging Organization and Strategies of Artifact Replacement and Discard. In Experiments in Lithic Technology, edited by D. Amick and R. Mauldin, pp. 33-47. BAR International Series 528 , Oxford, England.

Kunz, G. F.

1897 Fresh-water Pearls and Pearl Fisheries of the United States. Bulletin of the U.S. Fish Commission $17: 373-426$.

Lee, D. S., C. R. Gilbert, C. H. Hocutt, R. E. Jenkins, P. E. McAllister, and J. R. Stauffer, Jr.

1980 Atlas of North American Freshwater Fishes. North Carolina Biological Survey Publication 1980-12. North Carolina State Museum of Natural Sciences, Raleigh.

Lintz, C.

1992 Late Prehistoric Decorated Freshwater Mussel Shells from West Central Texas: Examples of Portable Art from O. H. Ivie Reservoir. La Tierra 10(3):19-23. 
Lord, K. J.

1984 The Zooarchaeology of Hinds Cave (41VV456). Unpublished Ph.D. dissertation. The University of Texas at Austin.

Lyman, R. L.

1994 Vertebrate Taphonomy. Cambridge University Press, Cambridge.

Lyman, R. L., and M. J. O’Brien

1987 Plow-zone Zooarchaeology: Fragmentation and Identifiability. Journal of Field Archaeology 14:493-498.

Lynn, W. M., D. E. Fox, and N. O'Malley

1977 Cultural Resource Survey of Choke Canyon Reservoir. Texas Historical Commission, Austin.

Machette, M. N.

1985 Calcic Soils of the Southwestern United States. In Soils and Quaternary Geology of the Southwestern United States, edited by D. L. Weide, pp.1-21. Special Paper 203. Geological Society of America . Boulder.

Marks, M. E.

1976 Glossary. In Prehistory and Paleoenvironments in the Central Negev, Israel (Vol. 1), edited by A. Marks, pp. 371-382. Reports of Investigation No. 2. Institute for the Study of Earth and Man, Southern Methodist University, Dallas.

McGinnes, E. A., Jr. P. S. Szopa, and J. E. Phelps

1974 Some Structural Changes Observed in the Transformation of Wood into Charcoal. Wood and Fiber 3:77-83.

McGraw, A. J.

1995 Borderlands Archaeology on the Rio Grande, Prehistoric Cultural Deposits of the Dolores and Darwin Terraces at the Laredo-Colombia Solidarity International Bridge Site, Nuevo Leon, Mexico and Webb County, Texas. Texas Department of Transportation, Austin.

McGraw, A. J., B. J. Van Note, and C. J. Jones

1987 Archaeology of the Brasada: A Cultural Resource Assessment of the Chevron Resources Company Property in Northeastern Duval County, Texas. Archaeological Survey Report, No. 113. Center for Archaeological Research, The University of Texas at San Antonio.

McKinney, W. W.

1981 Early Holocene Adaptations in Central and Southwestern Texas: The Problem of the Paleo-IndianArchaic Transition. Bulletin of the Texas Archeological Society 52:91-120.

Mercado-Allinger, P. A., N. A. Kenmotsu and T. K. Perttula

1996 Archeology in the Central and Southern Planning Region, Texas: A Planning Document. Special Report 35. Office of the State Archeologist, Austin. 
Metcalf, A. L.

1982 Fossil Unionacean Bivalves from Three Tributaries of the Rio Grande. In Proceedings of the Symposium on Recent Benthological Investigations in Texas and Adjacent States, edited by J. Davis, pp. 43-59. Texas Academy of Science, Austin.

Miller, R. R.

1961 Man and the Changing Fish Fauna of the American Southwest. Paper of the Michigan Academy of Sciences, Arts, and Letters XLVI:365-404.

Montgomery, J. L.

1978 The Mariposa Site: A Late Prehistoric Site on the Rio Grande Plain of Texas. Special Report, No. 6. Center for Archaeological Research, The University of Texas at San Antonio.

Mueggenborg, H. E.

1994 Excavations at the Blue Hole Site, Uvalde County, Texas, 1990. Bulletin of the Texas Archeological Society 62:1-74.

Murray, H. D.

1982a Unionids from Indian Sites in McMullen and Live Oak Counties, Texas. Bulletin of the American Malacological Union 1981:10-11.

1982b An Analysis of Unionids (Freshwater Mussels) Recovered in Phase I Archaeological Investigations at Choke Canyon Reservoir. In Archaeological Investigations at Choke Canyon Reservoir, South Texas: The Phase I Findings, edited by G. D. Hall, S. L. Black, and C. Graves, pp. 541-555. Choke Canyon Series, Vol. 5. Center for Archaeological Research, The University of Texas at San Antonio.

Neck, R. W.

1995 Land Snails and Environmental Reconstruction of 41UV60. In The Anthon Site 41UV60 A Prehistoric Encampment in Southern Uvalde County, Texas, edited by G. T. Goode, pp.1-23. Texas Department of Transportation, Austin, Texas.

1982a A Review of Interactions Between Humans and Freshwater Mussels in Texas. In Proceedings of the Symposium on Recent Benthological Investigations in Texas and Adjacent States, edited by J. Davis, pp. 169-182. Texas Academy of Science, Austin.

1982b Preliminary Analysis of Ecological Zoogeography of the Freshwater Mussels of Texas. In Proceedings of the Symposium on Recent Benthological Investigations in Texas and Adjacent States, edited by J. Davis, pp. 33-42. Texas Academy of Science, Austin.

Neck, R. W., and A. L. Metcalf

1988 Freshwater Bivalves of the Lower Rio Grande. The Texas Journal of Science 40:259-268.

Neves, R. J., and S. N. Moyer

1988 Evaluation of Techniques for Age Determination in Freshwater Mussels (Unionidae). American Malacological Bulletin 6(2):179-188.

Newcomb, W. W., Jr.

1961 The Indians of Texas. University of Texas Press, Austin.

1993 Historic Indians of Central Texas. Bulletin of the Texas Archeological Society 64:164. 
Nickels, D. L. and C. B. Bousman

1998 Test Excavations at the Culebra Creek Site, 41BX126, Bexar County, Texas. Archaeological Survey Report, No. 265. Center for Archaeological Research, The University of Texas at San Antonio.

Nordt, L. C., T. W. Boutton, C. T. Hallmark, and M. R. Waters

1994 Late Quaternary Vegetation and Climatic Changes in Central Texas Based on the Isotopic Composition of Organic Carbon. Quaternary Research 41:109-120.

Norwine, J.

1995 The Regional Climate of South Texas: Patterns and Trends. In The Changing Climate of Texas: Predictability and Implications for the Future, edited by J. Norwine, J. Giardino, G. North, and J. Valdes, pp. 138-155. Texas A\&M University, College Station.

Nunley, J. P.

1975a Site forms on file at Texas Archeological Research Laboratory.

1975b Report of Archaeological Survey Activities, 1975. In Archaeology and Ethnohistory of the Gateway Area, Middle Rio Grande of Texas. Report of the 1975 Investigations. Unpublished manuscript assembled by R. E. W. Adams and submitted to the National Endowment for the Humanities by the University of Texas at San Antonio, December, 1975, pp. 40-47. Photocopy on file. Center for Archaeological Research, The University of Texas at San Antonio.

O'Connell, J. F.

1987 Alyawara Site Structure and its Archaeological Implications. American Antiquity 52:74-108.

O’Connell, J. F., K. Hawkes, and N. B. Jones

1991 Distribution of Refuse-Producing Activities at Hadza Residential Base Camps: Implications for Analyses of Archaeological Site Structure. In The Interpretation of Archaeological Spatial Patterning, edited by E. M. Kroll and T. D. Price, pp. 61-76. Plenum, New York.

Odell, G. H.

1996 Economizing Behavior and the Concept of "Curation." In Stone Tools Theoretical Insights into Human Prehistory, edited by G. Odell, pp. 51-80. Plenum, New York.

Office of State Climatology

1987 The Climates of Texas Counties. The University of Texas at Austin.

Olsen, S. J.

1968 Fish, Amphibian and Reptile Remains from Archaeological Sites, Part I: Southeastern and Southwestern United States. Peabody Museum, Harvard University, Cambridge.

O’Neill, P. L.

1991 Evaluation of Cultural Resources Affected by City of Eagle Pass Wastewater System Improvements. Mariah, Austin

Parmalee, P. W., and W. E. Klippel

1974 Freshwater Mussels as a Prehistoric Food Source. American Antiquity 39:421-434. 
Patton, P. C., and D. S. Dibble

1982 Archeologic and Geomorphic Evidence for the Paleohydrologic Record of the Pecos River in West Texas. American Journal of Science 282:97-121.

Pearce, J. E., and A. T. Jackson

1933 A Prehistoric Rock Shelter in Val Verde County, Texas. The University of Texas Bulletin 3327:1-143.

Pierce, C.

1984 Analysis of Cooking Stones from a Late Period Chumash Village. Paper Presented at the 45th Annual Meeting of the Society for American Archaeology, Portland.

Pilsbry, H. A.

1940 Land Mollusca of North America (North of Mexico). The Academy of Natural Sciences of Philadelphia, Monograph 3, Vol. I, Part 2.

1946 Land Mollusca of North America (North of Mexico). The Academy of Natural Sciences of Philadelphia, Monograph 3, Vol. II, Part 1.

1948 Land Mollusca of North America (North of Mexico). The Academy of Natural Sciences of Philadelphia, Monograph 3, Vol. II, Part 2.

Potter, D. R., S. L. Black, and K. Jolly

1995 Archeology Along the Wurzbach Parkway: Module I Introduction, Conceptual Framework, and Contexts of Archeological Investigations in Bexar County, South Central Texas. Studies in Archeology, No. 18. Texas Archeological Research Laboratory, The University of Texas at Austin.

Potter, D. R.

1990 Archaeological Survey of Property for the Proposed Eagle Pass International Bridge, Maverick County, Texas. Archaeological Survey Report, No. 200. Center for Archaeological Research, The University of Texas at San Antonio.

Pratt, W. L.

1969 A Preliminary Revision of the Land Snail Genus Rabdotus in Texas. Annual Reports, The American Malacological Union, 1969:47-49.

1974 A Revision of the Mainland Species of the Bulimulid Snail Genus Rabdotus. Bulletin, The American Malacological Union, 1974:24-25.

Prentiss, W. C., and E. J. Romansky

1989 Experimental Evaluation of Sullivan and Rosen's Debitage Typology. In Experiments in Lithic Technology, edited by D. Amick and R. Mauldin, pp. 89-100. BAR International Series No. 528. Oxford, England.

Prewitt, E. R.

1981 Cultural Chronology in Central Texas. Bulletin of the Texas Archeological Society 52:65-90.

1985 From Circleville to Toyah: Comments on Central Texas Chronology. Bulletin of the Texas Archeological Society 54:201-238.

1995 Distribution of Typed Projectile Points in Texas. Bulletin of the Texas Archeological Society 66:83-173. 
Quigg, J. M.

1997 The Sanders Site (41HF128): A Single Event Late Archaic Camp/Bison Processing Site, Hansford County, Texas. Technical Report No. 19751. Mariah, Austin.

Rappole, J. H., and G. W. Blacklock

1994 Birds of Texas: A Field Guide. Texas A\&M University Press, College Station.

Reynolds, H. T.

1984 Analysis of Nominal Data. Quantitative Applications in the Social Sciences No. 7. Sage University Press, Beverly Hills.

Richardson, L.

1986 Polygyracea: Catalog of Species (Parts 1, Polygyridae; 2, Corillidae; 3, Sagdidae). Tryonia 13:1-139, $1-40,1-39$.

Ricklis, R. A., and R. R. Gunter

1986 Archaeological Investigations at the Means Site (41NU184), Nueces County, Texas. La Tierra 13: $15-32$.

Robinson, R. L.

1979 Biosilica and Climatic Change at 41GD21 and 41GD21A. In Archaeological Investigations of Two Prehistoric Sites on the Coleto Creek Drainage, Goliad County, Texas. Archaeological Survey Report, No. 69. Center for Archaeological Research, The University of Texas at San Antonio.

1982 Biosilica Analysis of Three Prehistoric Archaeological Sites in the Choke Canyon Reservoir, Live Oak County, Texas: Preliminary Summary of Climatic Implications. In Archaeological Investigations at Choke Canyon Reservoir; South Texas: The Phase I Findings, edited by G. D. Hall, S. L. Black and, C. Graves, pp. 597-610. Choke Canyon Series, Vol. 5. Center for Archaeological Research, The University of Texas at San Antonio.

Rogers, R., W. Glander, P. McCoy, and M. Nash.

1991 National Register Testing at Site 41OR58:Sabine River; Orange County, Texas. Espey, Huston and Associates, Austin.

Salinas, M.

1990 Indians of the Rio Grande Delta: Their Role in the History of Southern Texas and Northeastern Mexico. University of Texas Press, Austin.

Schiffer, M. B.

1986 Radiocarbon Dating and the "Old Wood" Problem: The Case of the Hohokam Chronology. Journal of Archaeological Science 13:13-30.

Schuetz, M. K.

1961 An Analysis of Val Verde Cave Material: Part II. Bulletin of the Texas Archeological Society, 31:167205. 
Scott, R. F.

1982 Prehistoric Investigations (Part I). In Excavations at Sites $41 L K 31 / 32$ and $41 L K 202$ in the Choke Canyon Reservoir, South Texas, by R. Scott and D. Fox, pp. 1-90. Choke Canyon Series No. 8. Center for Archaeological Research, The University of Texas at San Antonio.

\section{SDHPT}

1988 Archaeological Site Data Form for 41MV100. Copy on file. Center for Archaeological Research, The University of Texas at San Antonio.

Shackley, M. S.

1990 Early Hunter-Gatherer Procurement Ranges in the Southwest: Evidence from Obsidian Geochemistry and Lithic Technology. Ph.D. dissertation. Department of Anthropology, Arizona State University, Tempe.

Shafer, H. J.

1970 Notes on Uniface Retouch Technology. American Antiquity 35(4):480-487

Shafer, H. J., and E. P. Baxter

1975 An Archeological Survey of the Lignite Project Atascosa and McMullen Counties, Texas. Anthropology Laboratory Report 7. Texas A\&M University, College Station.

Shafer, H. J., and V. M. Bryant, Jr.

1977 Archeological and Botanical Studies of Hinds Cave, Val Verde County, Texas. Special Series 1. Anthropological Laboratory, Texas A\&M University, College Station.

Shaffer, B. S.

1992 Quarter-inch Screening: Understanding Biases in Recovery of Vertebrate Faunal Remains. American Antiquity 57:129-136.

Sheets, $\mathrm{P}$.

1973 Edge Abrasion During Biface Manufacture. American Antiquity 38(2):215-218.

Shelford, V.

1963 The Ecology of North America. University of Illinois Press, Chicago.

Shott, M. J.

1986 On Tool-class Use Lives and the Formation of Archaeological Assemblages. American Antiquity 54: 9-30.

Smiley, F. E.

1985 The Chronometrics of Early Agricultural Sites in Northeastern Arizona: Approaches to the Interpretation of Radiocarbon Dates. Ph.D. dissertation. Department of Anthropology, University of Michigan, Ann Arbor.

Smith, M. L., and R. R. Miller

1986 The Evolution of the Rio Grande Basin as Inferred from its Fish Fauna. In The Zoogeography of North American Fishes, edited by C. Nocutt and E. Wiley, pp. 457-485. John Wiley \& Sons, New York. 
Sobolik, K. D.

1991 Prehistoric Diet and Subsistence in the Lower Pecos As Reflected in Coprolites from Baker Cave, Val Verde County, Texas. Studies in Archeology No. 7. Texas Archeological Research Laboratory, The University of Texas at Austin.

Soil Stratigraphic Code

1983 North American Stratigraphic Code. American Association of Petroleum Geologists Bulletin 67:841-875.

Soil Survey Division Staff

1993 Soil Survey Manual. U.S. Department of Agriculture Handbook Number 18. U. S. Government Printing Press, Washington, D.C.

Sollberger, J. B.

1971 A Technological Study of Beveled Knives. Plains Anthropologist 16:209-218.

Spurling, B., and B. Hayden

1984 Ethnoarchaeology and Intrasite Spatial Analysis: A Case Study of the Australian Western Desert. In Intrasite Spatial Analysis in Archaeology, edited by H. Hietala, pp. 224-241. Cambridge University Press, Cambridge, England.

Stahle, D. W., and M. K. Cleaveland

1993 Southern Oscillation Extremes Reconstructed from Tree Rings of the Sierra Madre Occidental and Southern Great Plains. Journal of Climate 6(1):129-140.

Stebbins, R. C.

1985 A Field Guide to Western Reptiles and Amphibians. Houghton-Mifflin, Boston.

Steele, D. G., and C. Assad Hunter

1986 Analysis of Vertebrate Faunal Remains from 41MC222 and 41MC296, McMullen County, Texas. In Prehistoric Sites at Choke Canyon Reservoir, Southern Texas: Results of Phase II Archaeological Investigations, by G. D. Hall, T. R. Hester, and S. L. Black, pp. 452-494. Choke Canyon Series, Vol. 10. Center for Archaeological Research, University of Texas at San Antonio.

Sterrett, S. S., and L. D. Saville

1974 A Technique to Separate the Annual Layers of a Naiad Shell (Mollusca, Bivalvia, Unionacea) for Analysis by Neutron Activation. Bulletin of the American Malacological Union 1974:55-57.

Stevens, J. W., and D. Arriaga

1977 Soil Survey of Maverick County, Texas. United States Department of Agriculture, Soil Conservation Service, Washington D.C.

Stevenson, M. G.

1991 Beyond the Formation of Hearth-Associated Artifact Assemblages. In The Interpretation of Archaeological Spatial Patterning, edited by E. M. Kroll and T. D. Price, pp. 269-299. Plenum, New York. 
Story, D. A.

1985 Adaptive Strategies of Archaic Cultures of the West Gulf Coastal Plain. In Prehistoric Food Production in North America, edited by R. I. Ford, pp.19-56. Anthropological Papers No. 75. Museum of Anthropology, University of Michigan, Ann Arbor:

Strecker, J.

1931 The Distribution of Naiads or Pearly Fresh-water Mussels of Texas. Bulletin 2, Baylor University Museum, Waco, Texas.

Suhm, D. A.

1957 Excavations at the Smith Rockshelter, Travis County, Texas. The Texas Journal of Science 9:1-58.

Sullivan, A. P., and K. C. Rosen

1985 Debitage Analysis and Archaeological Interpretation. American Antiquity 50(4):755-799.

Takac, P.

1995 Archeomagnetic Studies. In Archeological Investigations at the Wilson-Leonard Site, edited by M. B. Collins. Texas Archeological Research Laboratory, The University of Texas at Austin. In review.

Taylor, A. J., and C. L. Highley

1995 Archaeological Investigations at the Loma Sandia Site (41LK28). A Prehistoric Cemetery in Live Oak County, Texas (Vol. 1). Studies in Archeology 20. Texas Archeological Research Laboratory, Austin.

Terri, J. A., and L. G. Stowe

1976 Climatic Patterns and the Distribution of $\mathrm{C}_{4}$ Grasses in North America. Oecologia 23:1-12.

Texas Game, Fish, and Oyster Commission

1945 Principal Game Birds and Mammals of Texas. Texas Game, Fish, and Oyster Commission, Austin.

Texas Department of Transportation

1995 Archaeological Site Data Forms for 41MV112 through 41MV120. On file. Center for Archaeological Research, The University of Texas at San Antonio.

Tharp, B. C.

1944 The Mesa Region of Texas: An Ecological Study. Proceedings and Transactions of the Texas Academy of Sciences 27:81-91.

Thoms, A. V.

1989 The Northern Roots of Hunter-Gatherer Intensification: Camas and the Pacific Northwest. Ph. D. dissertation, Department of Anthropology. Washington State University, Pullman.

Titmus, G. L.

1985 Some Aspects of Stone Tool Notching. In Stone Tool Analysis, edited by M. Plew, J. Woods, and M. Pavesic, pp. 243-264. University of New Mexico Press, Albuquerque. 
Tomka, S. A.

1989 Differentiating Lithic Reduction Techniques. In Experiments in Lithic Technology, edited by D. Amick and R. Mauldin, pp. 137-162. BAR International Series No. 528. Oxford, England.

Toomey, R. S., III, M. D. Blum, and S. Valastro

1993 Late Quaternary Climates and Environments of the Edwards Plateau, Texas. Global and Planetary Change 7:299-320.

Treece, A. C., and J. T. Jones

1995 Letter Report for an Archaeological Survey of Two Parcels of Land for the City of Eagle Pass, Maverick County, Texas. Hicks, Austin.

Treece, A. C., C. Lintz, W. N. Trierweiler, J. M. Quigg, and K. A. Miller

1993 Cultural Resource Investigations in the O. H. Ivie Reservoir; Concho, Coleman, and Runnels Counties, Texas: Volume IV: Data Recovery from Ceramic Sites. Technical Report No. 346-IV. Mariah, Austin.

Turgeon, D. D., A. E. Bogan, E. V. Coan, W. K. Emerson, W. G. Lyons, W. L. Pratt, C. F. E. Roper, A. Scheltema, F. G. Thompson, and J. D. Williams

1988 Common and Scientific Names of Aquatic Invertebrates of the United States and Canada: Mollusks. American Fisheries Society Special Publication 16. Bethesda, Maryland.

Turner, E. S., and T. R. Hester

1993 A Field Guide to Stone Artifacts of Texas Indians. Second edition. Texas Monthly Field Guide Series. Gulf, Houston.

Turpin, S. A.

1995 The Lower Pecos Region of Texas and Northern Mexico. Bulletin of the Texas Archeological Society $66: 541-560$.

Turpin, S.A. (editor)

1991 Papers on the Lower Pecos Prehistory. Studies in Archeology 8. Texas Archeological Research Laboratory, Austin.

Uecker, H. G.

1994 The Dos Republicas Project: Phase II Archaeological Investigations at a Proposed Coal Strip Mine, Maverick County, Texas. Archaeological Survey Report, No. 215. Center for Archaeological Research, The University of Texas at San Antonio.

Uecker, H. G., and J. E. Warren

1994 The Dos Republicas Project: Cultural Resources Survey of a Proposed Mining Project in Maverick County, Texas. Report No. 342. Archaeology Consultants, George West, Texas.

University of Texas at San Antonio, The

1975 Site Survey Records for 41MV3 through 41MV36, 41MV38 through 41MV45, 41MV50 through 41MV52, 41MV58, 41MV59, 41MV61 through 41MV72. Photocopies on file. Center for Archaeological Research, The University of Texas at San Antonio. 
1981 Site Survey Records for 41MV81 through 41MV99. Photocopies on file. Center for Archaeological Research, The University of Texas at San Antonio.

Van Davender, T. R.

1990 Late Quaternary Vegetation and Climate of the Chihuahuan Desert, United States and Mexico. In Packrat Middens, edited by J. Bettencourt, T. Van Davender, and P. Martin, pp. 104-133. University of Arizona Press, Tucson.

Vierra, B. J.

1985 Hunter-Gatherer Settlement System: To Reoccupy or not to Reoccupy, That is the Question. Unpublished Master's thesis. Department of Anthropology, University of New Mexico, Albuquerque.

1993a Explaining Long-term Changes in Lithic Procurement and Reduction Strategies. In Across the Colorado Plateau: Anthropological Studies for the Transwestern Pipeline Expansion Project, Volume XVII: Architectural Studies, Lithic Analyses, and Ancillary Studies, edited by B. Vierra, T. Burchett, K. Brown, M. Brown, P. Kay, and C. Phagan, pp. 139-381. Office of Contract Archeology, University of New Mexico, Albuquerque.

1993b Technological Variation and Subsistence Strategies: Explaining Changes in Stone Tool Technology. Paper presented at the Fifth Occasional Anasazi Conference, Farmington, New Mexico.

1993c Archaic Hunter-Gatherer Mobility Patterns in the American Southwest. In Across the Colorado Plateau: Anthropological Studies for the Transwestern Pipeline Expansion Project, Volume XIV: Excavation and Interpretation of Aceramic and Archaic Sites, by T. Burchett, B. Vierra, and K. Brown, pp. 385-398. Office of Contract Archeology, University of New Mexico, Albuquerque.

1994 Archaic Hunter-Gatherer Mobility Strategies in Northwestern New Mexico. In Archaic Hunter-Gatherer Archaeology in the American Southwest, edited by B. Vierra, pp. 121-154. Contributions in Anthropology 13(1). Eastern New Mexico University, Portales.

1995 Subsistence and Stone Tool Technology: An Old World Perspective. Anthropological Research Papers No. 47. Department of Anthropology, Arizona State University, Tempe.

Villa, P.

1982 Conjoinable Pieces and Site Formation Processes. American Antiquity 47(2): 276-290.

Von Endt, D. W., and D. J. Ortner

1984 Experimental Effects of Bone Size and Temperature on Bone Diagenesis. Journal of Archaeological Science 11:247-253.

Vora, R. S.

1990a Plant Communities of the Santa Ana National Wildlife Refuge, Texas. The Texas Journal of Science 42(2):115-128

1990b Plant Phenology in the Lower Rio Grande Valley, Texas. The Texas Journal of Science 42(2): 137-142.

Ward, C. G.

1995a Interim Report of Significance Testing at 41MV107 and 41MV120 Along FM1589, Maverick County, Texas. Texas Department of Transportation, Austin.

1995b Archeological Resources Survey Report for FM Road 1589. Texas Department of Transportation, Austin. 
Weinstein, R. A., and J. P. Whelan, Jr.

1987 Archaeological Testing at Three Sites in the Wallisville Lake Project Area, Trinity River Delta, Chambers County, Texas. Coastal Environments, Baton Rouge.

Whittaker, J. C.

1994 Flintknapping: Making and Understanding Stone Tools. University of Texas Press, Austin.

Wiant, M. D., and H. Hassen

1985 The Role of Lithic Resource Availability and Accessibility in the Organization of Technology. In Lithic Resource Procurement: Proceedings from the Second Conference on Prehistoric Chert Exploitation, edited by S. Vehic, pp. 101-104. Center for Archaeological Investigations Occasional Paper 4. Southern Illinois University, Carbondale.

Wilkins, K. T.

1992 Mammalian Paleofaunas of Central Texas from the Late Wisconsinan Glacial Period to the Latest Holocene. The Texas Journal of Science 44:263-281.

Williams, J. D., M. L. Warren, Jr., K. S. Cummings, J. L. Harris, and R. J. Neves.

1993 Conservation Status of Freshwater Mussels of the United States and Canada. Fisheries 18(9):6-22.

Wills, W. H.

1988 Prehistoric Agriculture in the American Southwest. School of American Research, Santa Fe.

Yellen, J. E.

1977 Archaeological Approaches to the Present: Models for Reconstructing the Past. Academic, New York.

Zimmerman, L. S.

1995 Sites 41CH70, 41CH252, and 41LB4. In Archeological Test Excavations at Four Shell Midden Sites in the Wallisville Lake Project Area, Chambers and Liberty Counties, Texas, edited by B. Ensor, pp. B3-B13. Geo-Marine, Plano, Texas. 


\section{Appendix A: Maverick County Site Data}

\section{Key to Abbreviations}

Site type:

$\mathrm{LS}=$ lithic scatter

Lith-proc. $=$ lithic procurement site

LS-eph $=$ ephemeral lithic scatter

LS-h.d. $=$ high-density lithic scatter

\section{Mat. Recovered:}

$\mathrm{LS}=$ lithic tools and debris

$\mathrm{BR}=$ burned rock scatter

\section{Features:}

$\mathrm{BR}-$ midden $=$ burned rock midden

BR-conc. = burned rock concentration not referred to as a midden in text hearth $=$ intact hearth 


\begin{tabular}{|c|c|c|c|c|c|c|c|c|c|c|}
\hline Site & Setting & $\begin{array}{l}\text { Elev. } \\
(\mathrm{m})\end{array}$ & Site Size & Site Type & Mat. Recovered & Features & Gr. stone & $\begin{array}{l}\text { Diagnostics: } \\
\text { Temp. Affil. }\end{array}$ & Investigations & Sources \\
\hline $41 \mathrm{MV} 3$ & $\begin{array}{c}\text { Rio Grande } \\
\text { T2 } \\
\end{array}$ & & $20 \times 100 \mathrm{~m}$ & LS & $\mathrm{LS}, \mathrm{BR}$, mussel & hearths & & & $\begin{array}{r}\text { subsurface } \\
<50 \mathrm{cmbs} \\
\end{array}$ & $\begin{array}{l}\text { Nunley } 1975 \\
\text { UTSA site forms }\end{array}$ \\
\hline $41 \mathrm{MV} 4$ & $\begin{array}{c}\text { Cueras Creek } \\
\text { ridge } \\
\end{array}$ & & $600 \times ? \mathrm{~m}$ & LS-quarry? & LS, & & & & surface survey & $\begin{array}{l}\text { Nunley } 1975 \\
\text { UTSA site forms }\end{array}$ \\
\hline 41MV5 & $\begin{array}{c}\text { Rio Grande } \\
\text { T1 } \\
\end{array}$ & & $25 \mathrm{~m}^{2}$ & LS & $\begin{array}{c}\begin{array}{c}\text { LS, BR, mussel, } \\
\text { snail }\end{array} \\
\end{array}$ & hearths & & & surface survey & $\begin{array}{l}\text { Nunley } 1975 \\
\text { UTSA site forms }\end{array}$ \\
\hline 41MV6 & $\begin{array}{c}\text { Cueras Creek } \\
\text { ridge } \\
\end{array}$ & & $300 \times ? \mathrm{~m}$ & LS & LS, BR & & & & surface survey & $\begin{array}{l}\text { Nunley } 1975 \\
\text { UTSA site forms }\end{array}$ \\
\hline $41 \mathrm{MV} 7$ & $?$ & & & LS-quarry? & LS & & & & surface survey & $\begin{array}{l}\text { Nunley } 1975 \\
\text { UTSA site for ms }\end{array}$ \\
\hline $41 \mathrm{MV} 8$ & $\begin{array}{c}\text { Cueras Creek } \\
\text { terrace }\end{array}$ & & & LS & LS, BR & & & & surface survey & $\begin{array}{l}\text { Nunley } 1975 \\
\text { UTSA site forms }\end{array}$ \\
\hline 41MV9 & $\begin{array}{c}\text { Cueras Creek } \\
\text { terrace }\end{array}$ & & & LS & LS, BR, snail & & & & surface survey & $\begin{array}{l}\text { Nunley } 1975 \\
\text { UTSA site for ms }\end{array}$ \\
\hline $41 \mathrm{MV} 10$ & $\begin{array}{c}\text { Cueras Creek } \\
\text { terrace } \\
\end{array}$ & & & $\mathrm{LS}$ & LS, BR & & & . & surface survey & $\begin{array}{l}\text { Nunley } 1975 \\
\text { UTSA site forms } \\
\end{array}$ \\
\hline $41 \mathrm{MV} 11$ & $\begin{array}{c}\text { Cueras Creek } \\
\text { ridge } \\
\end{array}$ & & & LS & LS, BR & & & & surface survey & $\begin{array}{l}\text { Nunley } 1975 \\
\text { UTSA site forms }\end{array}$ \\
\hline $41 \mathrm{MV} 12$ & $\begin{array}{c}\text { Cueras Creek } \\
\text { bluff }\end{array}$ & 216 & & LS & LS, BR, snail & hearths & & & surface survey & $\begin{array}{c}\text { Nunley } 1975 \\
\text { UTSA site for ms }\end{array}$ \\
\hline $41 \mathrm{MV} 13$ & ridge & 207 & $30 \times 10 \mathrm{~m}$ & LS-quarry? & $\begin{array}{c}\begin{array}{c}\text { LS, BR, mussel, } \\
\text { snail }\end{array} \\
\end{array}$ & & & & surface survey & $\begin{array}{c}\text { Nunley } 1975 \\
\text { UTSA site forms }\end{array}$ \\
\hline 41MV14 & $\begin{array}{c}\text { Cueras Creek } \\
\text { terrace }\end{array}$ & 201 & & LS & LS, BR, snail & & & & surface survey & $\begin{array}{c}\text { Nunley } 1975 \\
\text { UTSA site forms } \\
\end{array}$ \\
\hline $41 \mathrm{MV} 15$ & $\begin{array}{c}\text { Rio Grande } \\
\text { T2 } \\
\end{array}$ & & & LS & $\begin{array}{l}\text { LS, BR, mussel, } \\
\text { snail }\end{array}$ & $\begin{array}{l}\text { mussel- } \\
\text { conc. }\end{array}$ & & & $\begin{array}{l}\text { subsurface } \\
<150 \mathrm{cmbs}\end{array}$ & $\begin{array}{c}\text { Nunley } 1975 \\
\text { UTSA site for ms }\end{array}$ \\
\hline $41 \mathrm{MV} 16$ & $\begin{array}{c}\text { Rio Grande } \\
\mathrm{T} 2 \\
\end{array}$ & & $30 \mathrm{~m}^{2}$ & LS-quarry? & LS, BR, snail & hearths & & & surface survey & $\begin{array}{c}\text { Nunley } 1975 \\
\text { UTSA site forms }\end{array}$ \\
\hline $41 \mathrm{MV} 17$ & $\begin{array}{c}\text { Rio Grande } \\
\text { T2 } \\
\end{array}$ & 216 & & LS & LS, BR & & & & surface survey & $\begin{array}{c}\text { Nunley } 1975 \\
\text { UTSA site forms } \\
\end{array}$ \\
\hline $41 \mathrm{MV} 18$ & $\begin{array}{c}\text { Rio Grande } \\
\text { T2 } \\
\end{array}$ & 183 & & LS, burial & $\begin{array}{c}\text { LS, BR, mussel, } \\
\text { snail }\end{array}$ & $\begin{array}{l}\text { burial, } \\
\text { hearth }\end{array}$ & & & $\begin{array}{l}\text { subsurface } \\
<100 \mathrm{cmbs}\end{array}$ & $\begin{array}{c}\text { Nunley } 1975 \\
\text { UTSA site forms }\end{array}$ \\
\hline 41MV19 & ridge & 213 & & LS-quarry? & LS, BR & & & & surface survey & $\begin{array}{c}\text { Nunley } 1975 \\
\text { UTSA site forms } \\
\end{array}$ \\
\hline $41 \mathrm{MV} 21$ & arroyo bank & & & LS & LS, snail & hearths & & & surface survey & $\begin{array}{c}\text { Nunley } 1975 \\
\text { UTSA site forms }\end{array}$ \\
\hline
\end{tabular}




\begin{tabular}{|c|c|c|c|c|c|c|c|c|c|c|}
\hline Site & Setting & $\begin{array}{c}\text { Elev. } \\
(\mathbf{m})\end{array}$ & Site Size & Site Type & Mat. Recovered & Features & Gr. stone & $\begin{array}{l}\text { Diagnostics: } \\
\text { Temp. Affil. }\end{array}$ & Investigations & Sources \\
\hline 41MV22 & $\begin{array}{l}\text { Rio Grande } \\
\text { T2 } \\
\end{array}$ & 201 & & LS-quarry? & LS, BR & hearths & & & exposed gravels & $\begin{array}{c}\text { Nunley } 1975 \\
\text { UTSA site for ms } \\
\end{array}$ \\
\hline $41 \mathrm{MV} 23$ & arroyo bank & 198 & & LS & $\begin{array}{c}\text { LS, BR, mussel, } \\
\text { snail }\end{array}$ & hearths & & & surface survey & $\begin{array}{c}\text { Nunley } 1975 \\
\text { UTSA site for ms }\end{array}$ \\
\hline 41MV24 & $\begin{array}{c}\text { Rio Grande } \\
\mathrm{T} 2 \\
\end{array}$ & & & histor ic & & & & & surface survey & $\begin{array}{c}\text { Nunley } 1975 \\
\text { UTSA site for ms } \\
\end{array}$ \\
\hline $41 \mathrm{MV} 25$ & gravel ridge & & & LS-quarry? & LS, BR, snail & & & & surface survey & $\begin{array}{c}\text { Nunley } 1975 \\
\text { UTSA site forms } \\
\end{array}$ \\
\hline $41 \mathrm{MV} 26$ & $\begin{array}{c}\begin{array}{c}\text { unknown creek } \\
\text { knoll }\end{array} \\
\end{array}$ & & $300 \mathrm{~m}^{2}$ & LS-quarry & LS & & & & surface survey & $\begin{array}{l}\text { Nunley } 1975 \\
\text { UTSA site forms }\end{array}$ \\
\hline $41 \mathrm{MV} 27$ & \begin{tabular}{|c|} 
Rio Grande \\
T2 \\
\end{tabular} & & $25 \mathrm{~m}^{2}$ & LS & LS, BR & & & Archaic? & $\begin{array}{r}\text { subsurface } \\
<25 \mathrm{cmbs} \\
\end{array}$ & $\begin{array}{c}\text { Nunley } 1975 \\
\text { UTSA site forms }\end{array}$ \\
\hline 41MV28 & $\begin{array}{c}\text { Cueras Creek } \\
\text { ridge }\end{array}$ & & & LS & LS, BR & & & & surface survey & $\begin{array}{l}\text { Nunley } 1975 \\
\text { UTSA site forms }\end{array}$ \\
\hline 41MV29 & $\begin{array}{c}\text { Cueras Creek } \\
\text { terrace }\end{array}$ & & & LS & LS, BR, snail & & & & surface survey & $\begin{array}{c}\text { Nunley } 1975 \\
\text { UTSA site forms } \\
\end{array}$ \\
\hline 41MV30 & $\begin{array}{c}\text { Rio Grande } \\
\text { T2 } \\
\end{array}$ & & & LS & LS & & & & surface survey & $\begin{array}{c}\text { Nunley } 1975 \\
\text { UTSA site forms } \\
\end{array}$ \\
\hline $41 \mathrm{MV} 31$ & $\begin{array}{c}\text { Rio Grande } \\
\text { T2 } \\
\end{array}$ & & & LS & LS & hearth & & & $\begin{array}{l}\text { subsurface } \\
<100 \mathrm{cmbs} \\
\end{array}$ & $\begin{array}{l}\text { Nunley } 1975 \\
\text { UTSA site forms } \\
\end{array}$ \\
\hline $41 \mathrm{MV} 32$ & gravel ridge & & & LS-quarry & LS & & & & surface survey & $\begin{array}{c}\text { Nunley } 1975 \\
\text { UTSA site forms } \\
\end{array}$ \\
\hline $41 \mathrm{MV} 33$ & $\begin{array}{c}\text { Rio Gr ande } \\
\text { T2 }\end{array}$ & & $300 \mathrm{~m}^{2}$ & LS & LS, BR & & & Archaic? & surface survey & $\begin{array}{c}\text { Nunley } 1975 \\
\text { UTSA site forms } \\
\end{array}$ \\
\hline $41 \mathrm{MV} 34$ & $\begin{array}{c}\text { Rio Grande } \\
\text { T2 }\end{array}$ & & $200 \mathrm{~m}^{2}$ & LS & LS, BR & BR-conc. & & & surface survey & $\begin{array}{c}\text { Nunley } 1975 \\
\text { UTSA site forms }\end{array}$ \\
\hline 41MV35 & ridge & & & LS-quarry & LS & & & & surface survey & $\begin{array}{l}\text { Nunley } 1975 \\
\text { UTSA site forms } \\
\end{array}$ \\
\hline $41 \mathrm{MV} 36$ & $\begin{array}{c}\text { Rio Grande } \\
\text { T2 } \\
\end{array}$ & & & histor ic & & & & & surface survey & $\begin{array}{c}\text { Nunley } 1975 \\
\text { UTSA site forms } \\
\end{array}$ \\
\hline 41MV38 & $\begin{array}{c}\text { Elm Creek } \\
\text { T0 } \\
\end{array}$ & & & LS & LS & & & & surface survey & Nunley 1975 \\
\hline 41 MV39 & $\begin{array}{c}\text { Elm Creek } \\
\text { ridge }\end{array}$ & & & LS-quarry & LS & & & & surface survey & Nunley 1975 \\
\hline $41 \mathrm{MV} 40$ & $\begin{array}{c}\text { unknown creek } \\
\text { terrace }\end{array}$ & & $50 \mathrm{~m}^{2}$ & LS & LS, BR & & & & surface survey & $\begin{array}{l}\text { Nunley } 1975 \\
\text { UTSA site for ms }\end{array}$ \\
\hline
\end{tabular}




\begin{tabular}{|c|c|c|c|c|c|c|c|c|c|c|}
\hline Site & Setting & $\begin{array}{l}\text { Elev. } \\
(\mathrm{m})\end{array}$ & Site Size & Site Type & Mat. Recovered & Features & Gr. stone & $\begin{array}{l}\text { Diagnostics: } \\
\text { Temp. Affil. }\end{array}$ & Investigations & Sources \\
\hline $41 \mathrm{MV} 41$ & $\begin{array}{c}\text { Rio Grande } \\
\text { T2 } \\
\end{array}$ & & & LS, burial & $\begin{array}{c}\text { LS, BR, mussel, } \\
\text { snail }\end{array}$ & burial & & & $\begin{array}{l}\text { subsurface } \\
<100 \mathrm{cmbs}\end{array}$ & $\begin{array}{c}\text { Nunley } 1975 \\
\text { UTSA site forms }\end{array}$ \\
\hline $41 \mathrm{MV} 42$ & $\begin{array}{c}\text { Rio Grande } \\
\text { T2 } \\
\end{array}$ & & & burial & $\mathrm{BR}$, mussel & burial & & & surface survey & $\begin{array}{l}\text { Nunley } 1975 \\
\text { UTSA site forms }\end{array}$ \\
\hline $41 \mathrm{MV} 43$ & $\begin{array}{c}\text { Indio Creek } \\
\text { bank }\end{array}$ & & $150 \times 300 \mathrm{~m}$ & LS & LS, mussel & hearths & & & surface survey & $\begin{array}{c}\text { Nunley } 1975 \\
\text { UTSA site forms } \\
\end{array}$ \\
\hline $41 \mathrm{MV} 44$ & flpn & & & LS & LS, BR & & & & surface survey & $\begin{array}{c}\text { Nunley } 1975 \\
\text { UTSA site forms } \\
\end{array}$ \\
\hline 41MV45 & $\begin{array}{c}\begin{array}{c}\text { Cueras Creek } \\
\text { knoll }\end{array} \\
\end{array}$ & & & LS-quarry & LS & & & & surface survey & $\begin{array}{c}\text { Nunley } 1975 \\
\text { UTSA site forms } \\
\end{array}$ \\
\hline 41 MV50 & $\begin{array}{c}\text { Rio Grande } \\
\mathrm{T} 2 \\
\end{array}$ & & & LS & LS, BR, mussel & & & & $\begin{array}{l}\text { subsurface } \\
<150 \mathrm{cmbs}\end{array}$ & $\begin{array}{c}\text { Nunley } 1975 \\
\text { UTSA site forms } \\
\end{array}$ \\
\hline 41MV51 & $\begin{array}{c}\text { Rio Grande } \\
\text { T2 } \\
\end{array}$ & & & LS & $\begin{array}{c}\text { LS, BR, mussel, } \\
\text { snail } \\
\end{array}$ & hearths & & & surface survey & $\begin{array}{l}\text { Nunley } 1975 \\
\text { UTSA site forms } \\
\end{array}$ \\
\hline 41MV52 & $\begin{array}{c}\text { Rio Grande } \\
\text { T2 } \\
\end{array}$ & & & LS & $\begin{array}{c}\text { LS, BR, mussel, } \\
\text { snail }\end{array}$ & hearths & & & $\begin{array}{l}\text { subsurface } \\
<200 \text { cmbs }\end{array}$ & $\begin{array}{c}\text { Nunley } 1975 \\
\text { UTSA site forms } \\
\end{array}$ \\
\hline 41 MV53 & arroyo bank & & $4 \mathrm{~m}^{2}$ & LS & LS & & & & surface survey & $\begin{array}{c}\text { Jackson \& Hall } \\
1976 \\
\end{array}$ \\
\hline 41MV54 & tributary bank & & $20 \times 20 \mathrm{~m}$ & LS & LS & & & & surface survey & $\begin{array}{c}\text { Jackson \& Hall } \\
1976 \\
\end{array}$ \\
\hline 41MV55 & arroyo bank & & $20 \times 30 \mathrm{~m}$ & LS & LS & & & Angostura: L. Paleo & surface survey & $\begin{array}{c}\text { Jackson \& Hall } \\
1976 \\
\end{array}$ \\
\hline $41 M V 56$ & arroyo bank & & $50 \mathrm{~m}^{2}$ & LS & LS, BR & hearths & & & surface survey & $\begin{array}{c}\text { Jackson \& Hall } \\
1976 \\
\end{array}$ \\
\hline 41MV57 & $\begin{array}{c}\text { floodplain } \\
\& \text { low terrace } \\
\end{array}$ & & $305 \times 76 \mathrm{~m}$ & LS & LS, BR & & & & $\begin{array}{c}\text { surf. survey \& test } \\
\text { units } \\
\end{array}$ & Frkuska et al. 1977 \\
\hline $41 M V 58$ & $\begin{array}{c}\text { Rio Grande } \\
\text { T2 }\end{array}$ & & & LS & LS, BR & & & & surface survey & $\begin{array}{c}\text { Nunley } 1975 \\
\text { UTSA site for ms }\end{array}$ \\
\hline 41MV59 & $\begin{array}{c}\text { Rio Grande } \\
\mathrm{T} 2 \\
\end{array}$ & & & LS-quarry? & LS & & & & exposed gravels & $\begin{array}{c}\text { Nunley } 1975 \\
\text { UTSA site forms } \\
\end{array}$ \\
\hline 41MV61 & $\begin{array}{c}\text { Rio Grande } \\
\mathrm{T} 2 \\
\end{array}$ & & & LS & LS, BR, snail & & & & surface survey & $\begin{array}{l}\text { Nunley } 1975 \\
\text { UTSA site forms } \\
\end{array}$ \\
\hline 41MV62 & $\begin{array}{c}\text { Rio Grande } \\
\text { T2 } \\
\end{array}$ & & & LS & $\begin{array}{c}\text { LS, BR, mussel, } \\
\text { snail }\end{array}$ & hearths & & & surface survey & $\begin{array}{c}\text { Nunley } 1975 \\
\text { UTSA site forms }\end{array}$ \\
\hline $41 M V 63$ & $\begin{array}{c}\text { Rio Grande } \\
\text { T2 } \\
\end{array}$ & & & LS & $\begin{array}{l}\text { LS, BR, mussel, } \\
\text { snail, an. bone }\end{array}$ & hearths & & & surface survey & $\begin{array}{c}\text { Nunley } 1975 \\
\text { UTSA site forms } \\
\end{array}$ \\
\hline
\end{tabular}




\begin{tabular}{|c|c|c|c|c|c|c|c|c|c|c|}
\hline Site & Setting & $\begin{array}{l}\text { Elev. } \\
\text { (m) }\end{array}$ & Site Size & Site Type & Mat. Recovered & Features & Gr. stone & $\begin{array}{l}\text { Diagnostics: } \\
\text { Temp. Affil. }\end{array}$ & Investigations & Sources \\
\hline 41MV64 & $\begin{array}{c}\text { Rio Grande } \\
\text { T2 }\end{array}$ & & & LS, burial & $\begin{array}{c}\begin{array}{c}\text { LS, BR, mussel, } \\
\text { snail, }\end{array} \\
\end{array}$ & $\begin{array}{c}\text { hearths, } \\
\text { burial }\end{array}$ & & & $\begin{array}{r}\text { subsurface } \\
<50 \mathrm{cmbs} \\
\end{array}$ & $\begin{array}{c}\text { Nunley } 1975 \\
\text { UTSA site forms } \\
\end{array}$ \\
\hline 41MV65 & $\begin{array}{c}\text { Rio Grande } \\
\text { T2 } \\
\end{array}$ & & & LS & $\begin{array}{c}\text { LS, BR, mussel, } \\
\text { snail }\end{array}$ & hearths & & & surface survey & $\begin{array}{c}\text { Nunley } 1975 \\
\text { UTSA site forms } \\
\end{array}$ \\
\hline $41 \mathrm{MV} 66$ & $\begin{array}{c}\text { Rio Grande } \\
\text { T2 }\end{array}$ & & & LS & LS & & & & surface survey & $\begin{array}{c}\text { Nunley } 1975 \\
\text { UTSA site forms }\end{array}$ \\
\hline $41 \mathrm{MV} 67$ & $\begin{array}{l}\text { Rio Grande } \\
\text { T2 }\end{array}$ & & & LS & LS, mussel & $\begin{array}{l}\text { mussel- } \\
\text { conc. }\end{array}$ & & & $\begin{array}{l}\text { subsurface } \\
<100 \mathrm{cmbs}\end{array}$ & $\begin{array}{c}\text { Nunley } 1975 \\
\text { UTSA site forms }\end{array}$ \\
\hline 41MV68 & gravel ridge & & & LS-quarry? & LS & & & & surface survey & $\begin{array}{c}\text { Nunley } 1975 \\
\text { UTSA site forms }\end{array}$ \\
\hline $41 \mathrm{MV} 69$ & gravel ridge & & & LS-quarry? & LS & & & & surface survey & $\begin{array}{c}\text { Nunley } 1975 \\
\text { UTSA site forms }\end{array}$ \\
\hline $41 \mathrm{MV} 70$ & $\begin{array}{l}\text { Rio Grande } \\
\text { T2 }\end{array}$ & & & LS-quarry? & LS & & & & eroded gravels & $\begin{array}{c}\text { Nunley } 1975 \\
\text { UTSA site forms }\end{array}$ \\
\hline $41 \mathrm{MV} 71$ & mesa rim & 274 & $30 \times 50 \mathrm{~m}$ & LS & $\begin{array}{l}\mathrm{LS}, \mathrm{BR}, \text { Uvalde } \\
\text { gravels }\end{array}$ & & mano & & surface survey & Brown 1979 \\
\hline $41 \mathrm{MV} 71 ?$ & $\begin{array}{c}\text { Cueras Creek } \\
\text { bank }\end{array}$ & & & LS & LS, BR & & & & surface survey & $\begin{array}{c}\text { Nunley } 1975 \\
\text { UTSA site forms }\end{array}$ \\
\hline $41 \mathrm{MV} 72$ & mesa rim & 267 & $15 \times 20 \mathrm{~m}$ & LS & $\begin{array}{l}\text { LS, Uvalde } \\
\text { gravels }\end{array}$ & & & & surface survey & Brown 1979 \\
\hline $41 \mathrm{MV} 72 ?$ & $\begin{array}{c}\text { Cueras Creek } \\
\text { terrace }\end{array}$ & & & LS & LS, BR & & & & surface survey & $\begin{array}{c}\text { Nunley } 1975 \\
\text { UTSA site forms } \\
\end{array}$ \\
\hline $41 \mathrm{MV} 73$ & mesa top & 270 & $120 \times ? \mathrm{~m}$ & LS & $\begin{array}{c}\text { LS, Uvalde } \\
\text { gravels }\end{array}$ & & & & surface survey & Brown 1979 \\
\hline $41 \mathrm{MV} 75$ & $\begin{array}{c}\text { Rio Grande } \\
\text { terrace }\end{array}$ & 238 & $50 \mathrm{~m}$ diam. & LS & LS & & & & surface survey & $\begin{array}{c}\text { Nunley } 1975 \\
\text { UT SA site forms }\end{array}$ \\
\hline $41 \mathrm{MV} 76$ & $\begin{array}{c}\text { Rio Grande } \\
\text { terrace }\end{array}$ & 232 & $50 \times 50 \mathrm{~m}$ & LS & $\begin{array}{c}\text { LS, BR, hist. } \\
\text { scatter }\end{array}$ & & & prehistoric \& historic & surface survey & $\begin{array}{c}\text { Nunley } 1975 \\
\text { UTSA site forms } \\
\end{array}$ \\
\hline 41MV77 & $\begin{array}{c}\text { Rio Grande } \\
\text { terrace }\end{array}$ & 234 & $200 \times 50 \mathrm{~m}$ & LS & $\begin{array}{c}\text { LS, mussel, BR, } \\
\text { bone }\end{array}$ & hearth & & & $\begin{array}{c}\text { surface survey } \\
\text { hearth at } 75 \mathrm{cmbs}- \\
\text { erosional cut }\end{array}$ & $\begin{array}{l}\text { Nunley } 1975 \\
\text { UTSA site forms }\end{array}$ \\
\hline 41MV78 & $\begin{array}{c}\text { Rio Grande } \\
\text { ter race }\end{array}$ & 238 & $200 \times 100 \mathrm{~m}$ & LS & LS & & & & surface survey & $\begin{array}{c}\text { Nunley } 1975 \\
\text { UTSA site forms } \\
\end{array}$ \\
\hline 41MV79 & $\begin{array}{c}\text { Rio Grande } \\
\text { terrace }\end{array}$ & 235 & $50 \mathrm{~m}$ diam. & LS & LS, BR & & & & surface survey & $\begin{array}{c}\text { Nunley } 1975 \\
\text { UTSA site forms } \\
\end{array}$ \\
\hline
\end{tabular}




\begin{tabular}{|c|c|c|c|c|c|c|c|c|c|c|}
\hline Site & Setting & $\begin{array}{l}\text { Elev. } \\
(\mathrm{m})\end{array}$ & Site Size & Site Type & Mat. Recovered & Features & Gr. stone & $\begin{array}{l}\text { Diagnostics: } \\
\text { Temp. Affil. }\end{array}$ & Investigations & Sources \\
\hline 41MV80 & $\begin{array}{c}\text { Rio Grande } \\
\text { terrace }\end{array}$ & 235 & $75 \mathrm{~m}$ diam. & LS & LS, BR, mussel & BR-conc. & & & $\begin{array}{c}\begin{array}{c}\text { surface survey } \\
<20 \mathrm{cmbs}\end{array} \\
\end{array}$ & $\begin{array}{c}\text { Nunley } 1975 \\
\text { UTSA site forms } \\
\end{array}$ \\
\hline 41MV81 & $\begin{array}{l}\text { Sala do Creek } \\
\text { terrace }\end{array}$ & 224 & $250 \times 50 \mathrm{~m}$ & LS & LS, mussel, BR & $\begin{array}{c}\text { mussel } \\
\text { shell-conc. }\end{array}$ & & $\begin{array}{c}\text { Gower: Lt. Archaic } \\
\text { undeter mined: E. \& L. } \\
\text { Archaic } \\
\end{array}$ & surface survey & UTSA site forms \\
\hline 41MV82 & $\begin{array}{l}\text { Salado Creek } \\
\text { terrace slope }\end{array}$ & 223 & $50 \times 50 \mathrm{~m}$ & LS & LS, mussel & & & $\begin{array}{c}\text { Catan:L. Archaic- } \\
\text { L. Prehistoric } \\
\end{array}$ & surface survey & UTSA site forms \\
\hline $41 M V 83$ & $\begin{array}{c}\text { Salado Creek } \\
\text { T0 }\end{array}$ & 216 & $8 \times 12 \mathrm{~m}$ & LS & LS, BR, mussel & hearth & & $\begin{array}{c}\text { Ensor-like: Transitional } \\
\text { Archaic }\end{array}$ & surface survey & UTSA site forms \\
\hline 41MV84 & $\begin{array}{c}\text { Elm Creek } \\
\text { terrace }\end{array}$ & 238 & $11 \times 12 \mathrm{~m}$ & LS & LS, BR & hearth & & & surface survey & UTSA site forms \\
\hline $41 M V 85$ & $\begin{array}{c}\text { Elm Creek } \\
\text { terrace }\end{array}$ & 232 & $60 \times 12 \mathrm{~m}$ & LS & LS, BR & & & \begin{tabular}{|c} 
Kinney, undetermined: M. \\
Archaic \& L. Prehist. \\
\end{tabular} & surface survey & UTSA site forms \\
\hline 41MV86 & $\begin{array}{c}\text { Elm Creek } \\
\text { ter race }\end{array}$ & 232 & $30 \times 30 \mathrm{~m}$ & LS & LS, mussel & & & $\begin{array}{l}\text { Marcos, Matamoros: } \\
\text { L. Archiac-L. Prehist. } \\
\end{array}$ & surface survey & UTSA site forms \\
\hline 41MV87 & $\begin{array}{c}\text { Elm Creek } \\
\text { terrace }\end{array}$ & 230 & $20 \times 20 \mathrm{~m}$ & LS & LS & & & $\begin{array}{l}\text { Matamor os, undetermined: } \\
\text { L. Archiac-L. Prehist. }\end{array}$ & surface survey & UTSA site forms \\
\hline $41 \mathrm{MV} 88$ & $\begin{array}{l}\text { Elm Creek } \\
\text { terrace slope }\end{array}$ & 230 & $20 \times 20 \mathrm{~m}$ & LS & LS, BR, mussel & & & $\begin{array}{l}\text { arrow pt.(Bonham?): } \\
\text { L. Prehit. }\end{array}$ & surface survey & $\begin{array}{c}\text { UTSA site } \\
\text { forms; Bonham ID } \\
\text { questionable }\end{array}$ \\
\hline $41 M V 89$ & $\begin{array}{c}\text { Mula Creek } \\
\text { terrace }\end{array}$ & 238 & $40 \times 5 \mathrm{~m}$ & LS & LS, BR, mussel & & & Matamoros: L. Archaic & surface survey & UTSA site forms \\
\hline $41 \mathrm{MV} 90$ & $\begin{array}{c}\text { Mula Creek } \\
\text { terrace }\end{array}$ & 238 & $80 \times 50 \mathrm{~m}$ & LS & LS & & & & surface survey & UTSA site forms \\
\hline 41MV91 & $\begin{array}{c}\text { Elm Creek } \\
\text { terrace }\end{array}$ & 229 & $30 \times 40 \mathrm{~m}$ & LS & $\begin{array}{c}\mathrm{LS}, \mathrm{BR} \text {, mussel, } \\
\text { snail }\end{array}$ & & mano & & surface survey & UTSA site forms \\
\hline 41MV92 & $\begin{array}{c}\text { Mula Creek } \\
\text { terrace }\end{array}$ & 232 & $50 \times 30 \mathrm{~m}$ & LS & LS & & & & surface survey & UTSA site forms \\
\hline $41 \mathrm{MV} 93$ & $\begin{array}{c}\text { Mula Creek } \\
\text { terrace }\end{array}$ & 232 & $100 \times 40 \mathrm{~m}$ & LS & LS, BR, snail & & & & surface survey & UTSA site forms \\
\hline $41 \mathrm{MV} 94$ & $\begin{array}{l}\text { Mula Creek } \\
\text { terrace slope }\end{array}$ & 230 & $70 \times 10 \mathrm{~m}$ & LS & LS, BR & hearth & & $\begin{array}{c}\text { Ensor: } \\
\text { Transitional Archaic } \\
\end{array}$ & surface survey & UTSA site forms \\
\hline $41 \mathrm{MV} 95$ & $\begin{array}{c}\text { Palo Blanco Cr. } \\
\text { terrace }\end{array}$ & 227 & $30 \times 30 \mathrm{~m}$ & LS & LS, BR, mussel & & & $\begin{array}{c}\text { Gower, Catan, } \\
\text { Matamor os: E. Archaic \& } \\
\text { L. Archaic - L. Prehist. }\end{array}$ & surface survey & UTSA site forms \\
\hline $41 \mathrm{MV} 96$ & $\begin{array}{c}\text { Palo Blanco } \mathrm{Cr} . \\
\text { terrace }\end{array}$ & 226 & $20 \times 30 \mathrm{~m}$ & LS & $\mathrm{LS}, \mathrm{BR}$ & & & $\begin{array}{c}\text { undetermined point: } \\
\text { Late Archaic } \\
\end{array}$ & surface survey & UTSA site forms \\
\hline
\end{tabular}




\begin{tabular}{|c|c|c|c|c|c|c|c|c|c|c|}
\hline Site & Setting & $\begin{array}{l}\text { Elev. } \\
\text { (m) }\end{array}$ & Site Size & Site Type & Mat. Recovered & Features & Gr. stone & $\begin{array}{c}\text { Diagnostics: } \\
\text { Temp. Affil. } \\
\end{array}$ & Investigations & Sources \\
\hline $41 \mathrm{MV} 97$ & $\begin{array}{c}\text { Palo Blanco Cr. } \\
\text { terrace }\end{array}$ & 224 & $20 \times 40 \mathrm{~m}$ & LS & LS, BR & & & $\begin{array}{c}\text { Marcos, Matamoros, } \\
\text { Edgewood: L. Archaic- } \\
\text { L. Prehist. }\end{array}$ & surface survey & UTSA site forms \\
\hline 41MV98 & $\begin{array}{r}\text { Palo Blanco } \mathrm{Cr} \text {. } \\
\text { upland terrace }\end{array}$ & 229 & $25 \times 20 \mathrm{~m}$ & LS & LS & & & & surface survey & UTSA site forms \\
\hline 41MV99 & $\begin{array}{l}\text { Buck Hollow } \\
\text { Creek terrace }\end{array}$ & 224 & $5 \mathrm{~m}^{2}$ & LS & LS & & & Marcos: L. Archaic & surface survey & UTSA site forms \\
\hline $41 \mathrm{MV} 100$ & ridge top & 268 & $1000 \times 80 \mathrm{~m}$ & LS-quarry & LS & & & & surface survey & UTSA site for $\mathrm{ms}$ \\
\hline 41MV101 & rige top & 268 & $?$ & LS-quarry & LS & & & & surface survey & UTSA site for ms \\
\hline $41 \mathrm{MV} 103$ & $\begin{array}{c}\text { Rio Grande } \\
\text { terrace }\end{array}$ & 217 & $1400 \times 60 \mathrm{~m}$ & LS & LS, BR, mussel & & yes & $\begin{array}{c}\text { prehistor ic and } \\
\text { historic } 1920 \text { 's-30's }\end{array}$ & $\begin{array}{l}\text { surface survey, } \\
\text { backhoe trench }\end{array}$ & \begin{tabular}{|c|} 
Hubbard \& Fox \\
1990, O'Neill 1991 \\
\end{tabular} \\
\hline 41MV104 & terrace-tributary & 216 & $500 \times 300 \mathrm{~m}$ & LS & LS, BR & & yes & $\begin{array}{l}\text { undeter mined } \\
\text { point } s / \text { Archaic? }\end{array}$ & $\begin{array}{l}\text { surface survey, } \\
\text { backhoe trench }\end{array}$ & \begin{tabular}{|c|} 
Hubbard \& Fox \\
1990,Davis \& \\
Jones 1993 \\
\end{tabular} \\
\hline 41MV105 & upland slope & 218 & $700 \times 700 \mathrm{~m}$ & LS & LS, BR & & yes & & surface survey & $\begin{array}{c}\text { Hubbard \& Fox } \\
1990 \\
\end{array}$ \\
\hline 41MV106 & $\begin{array}{l}\text { Rio Grande } \\
\text { T0 \& terrace }\end{array}$ & 217 & $1200 \times 400 \mathrm{~m}$ & LS & LS, BR, mussel & $\begin{array}{c}\text { hearths } \\
\text { (stratified } \\
\text { deposits) }\end{array}$ & yes & $\begin{array}{c}\text { Gower (reworked): } \\
\text { L. Archaic (radioc arbon } \\
\text { date } 1600 \mathrm{BP} \text { ) } \\
\end{array}$ & $\begin{array}{c}\text { surface survey, } \\
\text { shovel \& backhoe } \\
\text { testing }\end{array}$ & $\begin{array}{c}\text { Hubbard \& Fox } \\
1990, \text { O'Neill } 1991\end{array}$ \\
\hline 41MV107 & $\begin{array}{c}\text { Elm Creek } \\
\text { terrace }\end{array}$ & 222 & $1200 \times 100 \mathrm{~m}$ & LS & LS, BR, mussel & & & & surface survey & $\begin{array}{c}\text { Hubbard \& Fox } \\
1990\end{array}$ \\
\hline 41MV108 & $\begin{array}{l}\text { Rio Grande } \\
\text { terrace edge }\end{array}$ & 220 & $500 \times 350 \mathrm{~m}$ & LS & LS, BR, mussel & & yes & & surface survey & $\begin{array}{c}\text { Hubbard \& Fox } \\
1990\end{array}$ \\
\hline 41MV109 & $\begin{array}{c}\text { Elm Creek } \\
\text { upland }\end{array}$ & 235 & $2100 \times 1000 \mathrm{~m}$ & LS & LS, BR, mussel & hearths & & $\begin{array}{c}\text { historic } 1880 \text { 's-1920's } \\
\text { \& prehistoric }\end{array}$ & surface survey & $\begin{array}{c}\text { Hubbard \& Fox } \\
1990 \\
\end{array}$ \\
\hline $41 \mathrm{MV} 111$ & upland slope & 230 & $400 \times 400 \mathrm{~m}$ & LS & LS, BR & & & & surface survey & $\begin{array}{c}\text { Hubbard \& Fox } \\
1990 \\
\end{array}$ \\
\hline 41MV112 & upland terrace & 258 & $160 \times 18 \mathrm{~m}$ & LS-quarry & $\begin{array}{c}\text { LS, Uvalde } \\
\text { gravels }\end{array}$ & & & & surface survey & TXDOT-site forms \\
\hline $41 \mathrm{MV} 113$ & upland ridge & 261 & $460 \times 20 \mathrm{~m}$ & LS-quarry & $\begin{array}{c}\text { LS, Uvslde } \\
\text { gravels }\end{array}$ & & & & surface survey & TXDOT-site forms \\
\hline 41MV114 & upland ridge & 270 & $120 \times 40 \mathrm{~m}$ & LS-quarry & $\begin{array}{c}\text { LS, Uvalde } \\
\text { gravels }\end{array}$ & & & & surface survey & TXDOT-site forms \\
\hline 41MV115 & upland ridge & 270 & $230 \times 50 \mathrm{~m}$ & LS-quarry & $\begin{array}{l}\text { LS, Uvalde } \\
\text { gravels }\end{array}$ & & & & surface survey & TXDOT-site forms \\
\hline
\end{tabular}




\begin{tabular}{|c|c|c|c|c|c|c|c|c|c|c|}
\hline Site & Setting & $\begin{array}{l}\text { Elev. } \\
(\mathrm{m})\end{array}$ & Site Size & Site Type & Mat. Recovered & Features & Gr. stone & $\begin{array}{l}\text { Diagnostics: } \\
\text { Temp. Affil. }\end{array}$ & Investigations & Sources \\
\hline $41 \mathrm{MV} 116$ & upland ridge & 264 & $320 \times 50 \mathrm{~m}$ & LS-quarry & $\begin{array}{l}\text { LS, Uvalde } \\
\text { gravels }\end{array}$ & & & & surface survey & TXDOT-site forms \\
\hline $41 \mathrm{MV} 117$ & ridge & 258 & $100 \times 50 \mathrm{~m}$ & LS-quarry & $\begin{array}{l}\text { LS, Uvalde } \\
\text { gravels }\end{array}$ & & & & surface survey & TXDOT-site forms \\
\hline $41 \mathrm{MV} 118$ & upland ridge & 265 & $210 \times 50 \mathrm{~m}$ & LS-quarry & $\begin{array}{c}\text { LS, Uvalde } \\
\text { gravels }\end{array}$ & & & & surface survey & TXDOT-site forms \\
\hline 41MV119 & $\begin{array}{c}\text { upland ridge } \\
\text { slope }\end{array}$ & 270 & $40 \times 50 \mathrm{~m}$ & LS-quarry & $\begin{array}{c}\text { LS, Uvalde } \\
\text { gravels }\end{array}$ & & & & surface survey & TXDOT-site forms \\
\hline $41 \mathrm{MV} 120$ & $\begin{array}{c}\text { Rio Grande T0 } \\
\& \\
\text { Elm Cr. terrace } \\
\end{array}$ & 223 & $500 \times 800 \mathrm{~m}$ & LS & LS, BR, mussel & & & & $\begin{array}{l}\text { surface survey \& } \\
\text { shovel tests }\end{array}$ & TXDOT-site forms \\
\hline $41 \mathrm{MV} 121$ & $x_{-1}=-1$ & $?$ & $?$ & LS & LS, BR & & & $\begin{array}{c}\text { Triangular points: } \\
\text { E. Archaic? } \\
\end{array}$ & & \\
\hline $41 \mathrm{MV} 122$ & $?$ & $?$ & $?$ & LS & LS & hearths & & Almagre: M. Archaic & & \\
\hline $41 \mathrm{MV} 123$ & $?$ & $?$ & $?$ & LS & LS, BR & hearths & & $\begin{array}{c}\text { Bel1/Andice, Ler ma-like, } \\
\text { Langtry, Scallorn, } \\
\text { Triangular \& large } \\
\text { stemmed dart pts.: } \\
\text { Paleo-M. Archaic, } \\
\text { L. Prehist } \\
\end{array}$ & & \\
\hline $41 \mathrm{MV} 124$ & $?$ & $?$ & $?$ & LS & LS, BR & hearths & & Clearfork tool: Archaic & & \\
\hline $41 \mathrm{MV} 125$ & $?$ & $?$ & $?$ & LS & LS, BR & $\begin{array}{l}\text { lithic } \\
\text { reduction }\end{array}$ & & $\begin{array}{c}\text { Angostura-like, Triangular } \\
\text { dart pt., Clearfork tool: } \\
\text { L. Paleo-M. Archaic } \\
\end{array}$ & & \\
\hline 41MV126 & $?$ & $?$ & $?$ & LS & LS, BR & $\begin{array}{c}\text { poss. BR } \\
\text { midden }\end{array}$ & & & material $200 \mathrm{cmbs}$ & \\
\hline 41MV131 & $\begin{array}{l}\text { Elm Creek } \\
\text { fossil T0 }\end{array}$ & 236 & $6000 \mathrm{~m}^{2}$ & LS & LS, BR & & & & $\begin{array}{c}\text { surface suvey, } \\
\text { shovel \& backhoe } \\
\text { testing < } 20 \mathrm{cmbs}\end{array}$ & \begin{tabular}{|c|} 
Denney 1981, \\
Uecker \& Warren \\
1994 \\
\end{tabular} \\
\hline $41 \mathrm{MV} 132$ & $\begin{array}{l}\text { tributar y } \\
\text { fossil T0 }\end{array}$ & 236 & $3000 \mathrm{~m}^{2}$ & LS & LS, BR & & & & $\begin{array}{l}\text { surface suvey, } \\
\text { shovel \& backhoe } \\
\text { testing < } 40 \mathrm{cmbs}\end{array}$ & \begin{tabular}{|c|} 
Denney 1981 \\
Uecker \& Warren \\
1994
\end{tabular} \\
\hline $41 \mathrm{MV} 133$ & upland flat & 250 & $220 \times 70 \mathrm{~m}$ & LS & LS, BR & & metate & $\begin{array}{c}\text { Lerma-like, Triangular, } \\
\text { Early Barbed: } \\
\text { Paleo-M. Archaic } \\
\end{array}$ & $\begin{array}{c}\begin{array}{c}\text { surface suvey \& test } \\
\text { probes }\end{array} \\
\end{array}$ & Denney 1981 \\
\hline 41MV134 & upland flat & 253 & & LS & LS & & & & $\begin{array}{c}\text { surface suvey \& test } \\
\text { probes }\end{array}$ & Denney 1981 \\
\hline
\end{tabular}




\begin{tabular}{|c|c|c|c|c|c|c|c|c|c|c|}
\hline Site & Setting & $\begin{array}{c}\text { Elev. } \\
(\mathbf{m})\end{array}$ & Site Size & Site Type & Mat. Recovered & Features & Gr. stone & $\begin{array}{l}\text { Diagnostics: } \\
\text { Temp. Affil. }\end{array}$ & Investigations & Sources \\
\hline 41MV135 & $\begin{array}{l}\text { tributary fossil } \\
\text { T0/upland }\end{array}$ & 239 & $3000 \mathrm{~m}^{2}$ & LS & LS, BR & & & & $\begin{array}{c}\text { surface suvey, } \\
\text { shovel \& backhoe } \\
\text { testing }<20 \mathrm{cmbs}\end{array}$ & $\begin{array}{c}\text { Denney } 1981, \\
\text { Uecker \& Warren } \\
1994\end{array}$ \\
\hline $41 \mathrm{MV} 136$ & $\begin{array}{l}\text { tributary fossil } \\
\text { T0/upland }\end{array}$ & 238 & $2200 \mathrm{~m}^{2}$ & LS & $\mathrm{LS}, \mathrm{BR}$, mussel & hearths & yes & $\begin{array}{c}\text { Montell, Abasolo, Marcos: } \\
\text { M.-L. Archaic }\end{array}$ & $\begin{array}{c}\text { surface suvey, } \\
\text { shovel \& backhoe } \\
\text { testing }<30 \mathrm{cmbs}\end{array}$ & $\begin{array}{c}\text { Denney 1981, } \\
\text { Uecker \& Warren } \\
1994 \\
\end{array}$ \\
\hline 41MV137 & $\begin{array}{l}\text { tributary fossi1 } \\
\text { To/upland }\end{array}$ & 244 & $1800 \mathrm{~m}^{2}$ & LS & LS, BR & $\begin{array}{l}\text { poss. } \\
\text { midden }\end{array}$ & & & $\begin{array}{c}\text { surface suvey, } \\
\text { shovel \& backhoe } \\
\text { testing }<30 \mathrm{cmbs}\end{array}$ & $\begin{array}{c}\text { Denney } 1981, \\
\text { Uecker \& Warren } \\
1994 \\
\end{array}$ \\
\hline 41MV138 & $\begin{array}{l}\text { tributary fossi } 1 \\
\text { T0/upland }\end{array}$ & 244 & $3000 \mathrm{~m}^{2}$ & LS & LS, BR & hearth & & & $\begin{array}{c}\text { surface suvey, } \\
\text { shovel \& backhoe } \\
\text { testing }<30 \mathrm{cmbs}\end{array}$ & $\begin{array}{c}\text { Denney 1981, } \\
\text { Uecker \& Warren } \\
1994 \\
\end{array}$ \\
\hline 41MV139 & $\begin{array}{l}\text { tributary fossil } \\
\text { To/upland }\end{array}$ & 250 & & LS & LS, BR & hearths & & & $\begin{array}{c}\begin{array}{c}\text { surface suvey \& test } \\
\text { probes }\end{array} \\
\end{array}$ & Denney 1981 \\
\hline $41 \mathrm{MV} 140$ & $\begin{array}{l}\text { tributary } \\
\text { fossil T0 } \\
\end{array}$ & 250 & & LS & LS, BR & & & Ensor: Terminal Archaic & $\begin{array}{c}\text { surface suvey \& te st } \\
\text { probes }\end{array}$ & Denney 1981 \\
\hline $41 \mathrm{MV} 141$ & $\begin{array}{l}\text { tributary fossil } \\
\text { T0/upland }\end{array}$ & 250 & $2800 \mathrm{~m}^{2}$ & LS & LS, BR & hearths & & prehistoric \& historic & $\begin{array}{c}\text { surface suvey \& test } \\
\text { probes }\end{array}$ & $\begin{array}{c}\text { Denney 1981, } \\
\text { Uecker \& Warren } \\
1994\end{array}$ \\
\hline $41 \mathrm{MV} 142$ & high ter. & 236 & $50 \times 30 \mathrm{~m}$ & LS & LS & & & & \begin{tabular}{|c} 
surface suvey \& test \\
probes
\end{tabular} & Denney 1981 \\
\hline $41 \mathrm{MV} 143$ & $\begin{array}{l}\text { Elm Creek } \\
\text { high terrace }\end{array}$ & 242 & $6600 \mathrm{~m}^{2}$ & LS & LS & & & & $\begin{array}{c}\text { surface suvey, } \\
\text { shovel \& backhoe } \\
\text { testing }\end{array}$ & $\begin{array}{c}\text { Denney 1981, } \\
\text { Uecker \& Warren } \\
1994 \\
\end{array}$ \\
\hline $41 \mathrm{MV} 144$ & $\begin{array}{l}\text { Elm Creek } \\
\text { old terrace }\end{array}$ & 236 & $135 \times 90 \mathrm{~m}$ & LS & LS, BR & & & & $\begin{array}{c}\text { surface suvey \& test } \\
\text { probes }<10 \mathrm{cmbs}\end{array}$ & Denney 1981 \\
\hline 41MV145 & $\begin{array}{l}\text { Elm Creek } \\
\text { fossil T0 }\end{array}$ & 233 & $7200 \mathrm{~m}^{2}$ & LS & LS, BR & & & Clearfork tool: M. Archaic & $\begin{array}{l}\text { surface suvey, } \\
\text { shovel \& backhoe } \\
\text { testing }<30 \mathrm{cmbs}\end{array}$ & \begin{tabular}{|c|} 
Denney 1981, \\
Uecker \& Warren \\
1994 \\
\end{tabular} \\
\hline $41 \mathrm{MV} 146$ & $\begin{array}{l}\text { Elm Creek } \\
\text { fossil T0 }\end{array}$ & 235 & $4500 \mathrm{~m}^{2}$ & LS & LS, BR & & & & $\begin{array}{c}\text { surface suvey, } \\
\text { shovel \& backhoe } \\
\text { testing }\end{array}$ & $\begin{array}{c}\text { Denney 1981, } \\
\text { Uecker \& Warren } \\
1994\end{array}$ \\
\hline 41MV147 & upland slope & 248 & & Lith.-proc. & LS & & & & $\begin{array}{c}\text { surface suvey \& test } \\
\text { probes }\end{array}$ & Denney 1981 \\
\hline $41 \mathrm{MV} 148$ & upl and slope & 248 & & Lith.-proc. & LS & & & $\begin{array}{l}\text { undetermined point: } \\
\text { Archaic }\end{array}$ & $\begin{array}{c}\text { surface suvey \& te st } \\
\text { probes }\end{array}$ & Denney 1981 \\
\hline
\end{tabular}




\begin{tabular}{|c|c|c|c|c|c|c|c|c|c|c|}
\hline Site & Setting & $\begin{array}{l}\text { Elev. } \\
\text { (m) }\end{array}$ & Site Size & Site Type & Mat. Recovered & Features & Gr. stone & $\begin{array}{l}\text { Diagnostics: } \\
\text { Temp. Affil. }\end{array}$ & Investigations & Sources \\
\hline $41 \mathrm{MV} 149$ & upland slope & 242 & & Lith. -proc. & LS, BR & & & & \begin{tabular}{|c|} 
surface suvey \& test \\
probes
\end{tabular} & Denney 1981 \\
\hline 41MV150 & $\begin{array}{l}\text { tributary } \\
\text { fossil T0 } \\
\end{array}$ & 244 & $200 \times ? \mathrm{~m}$ & LS & LS, BR & hearth & & & \begin{tabular}{|c|} 
surface suvey $\&$ test \\
probes $<30 \mathrm{cmbs}$
\end{tabular} & Denney 1981 \\
\hline $41 \mathrm{MV} 151$ & upland slope & 250 & & Lith. -proc. & LS & & & & \begin{tabular}{|c|}
$\begin{array}{c}\text { surface suvey \& test } \\
\text { probes }\end{array}$ \\
\end{tabular} & Denney 1981 \\
\hline $41 \mathrm{MV} 152$ & $\begin{array}{l}\text { tributary } \\
\text { fossil T0 }\end{array}$ & 239 & & LS & LS, BR & & & & \begin{tabular}{|c|}
$\begin{array}{c}\text { surface suvey \& test } \\
\text { probes }\end{array}$ \\
\end{tabular} & Denney 1981 \\
\hline $41 \mathrm{MV} 153$ & $\begin{array}{l}\text { tributary } \\
\text { fossil T0 }\end{array}$ & 245 & & LS & LS, BR & & & & $\begin{array}{c}\text { surface suvey \& test } \\
\text { probes }\end{array}$ & Denney 1981 \\
\hline 41MV154 & $\begin{array}{l}\text { tributary } \\
\text { fossil T0 }\end{array}$ & 242 & & LS & LS & & & & $\begin{array}{c}\text { surface suvey \& test } \\
\text { probes }\end{array}$ & Denney 1981 \\
\hline $41 \mathrm{MV} 155$ & upland slope & 250 & $1000 \mathrm{~m}^{2}$ & LS & LS & & & & \begin{tabular}{|c|} 
surface suvey, \\
shovel \& backhoe \\
testing
\end{tabular} & $\begin{array}{c}\text { Denney 1981, } \\
\text { Uecker \& Warren } \\
1994\end{array}$ \\
\hline 41MV156 & upl and ridge & 250 & & Lith-proc. & $\begin{array}{c}\text { LS, Uvalde } \\
\text { gravels }\end{array}$ & & & & \begin{tabular}{|c|}
$\begin{array}{c}\text { surface suvey \& test } \\
\text { probes }\end{array}$ \\
\end{tabular} & Denney 1981 \\
\hline 41MV157 & $\begin{array}{l}\text { Elm Creek } \\
\text { fossil T0 }\end{array}$ & 240 & $22500 \mathrm{~m}^{2}$ & LS & LS, BR & $\begin{array}{c}\text { BR-conc., } \\
\text { hearths }\end{array}$ & & $\begin{array}{c}\text { Frio, Bulverde, Abasolo: } \\
\text { M.-L. Archaic }\end{array}$ & \begin{tabular}{|c|} 
surface suvey, \\
shovel \& backhoe \\
testing $<40 \mathrm{cmbs}$ \\
\end{tabular} & $\begin{array}{c}\text { Denney } 1981, \\
\text { Uecker \& Warren } \\
1994 \\
\end{array}$ \\
\hline 41MV158 & $\begin{array}{c}\text { tributary fossil } \\
\text { T0/uplands }\end{array}$ & 242 & & LS & LS, BR & $\begin{array}{c}\text { BR-conc., } \\
\text { hearths } \\
\end{array}$ & yes & $\begin{array}{l}\text { Castroville, Guadalupe } \\
\text { tool: L.-Archaic }\end{array}$ & \begin{tabular}{|c|} 
surface suvey \& test \\
probes
\end{tabular} & Denney 1981 \\
\hline 41MV159 & $\begin{array}{l}\text { tributary fossil } \\
\text { T0/upland slope }\end{array}$ & 244 & & LS & LS, BR & $\begin{array}{c}\text { BR-conc., } \\
\text { hearths } \\
\end{array}$ & & Marshall-like: Archaic & \begin{tabular}{|c|}
$\begin{array}{c}\text { surface suvey \& te st } \\
\text { probes }\end{array}$ \\
\end{tabular} & Denney 1981 \\
\hline $41 \mathrm{MV} 160$ & $\begin{array}{l}\text { tributary fossil } \\
\text { T0/upland }\end{array}$ & 244 & $6400 \mathrm{~m}^{2}$ & LS & LS, BR & $\begin{array}{l}\text { BR-conc., } \\
\text { midden }\end{array}$ & & $\begin{array}{l}\text { Ensor, Frio: } \\
\text { M.-L. Archaic }\end{array}$ & $\begin{array}{l}\text { surface suvey, } \\
\text { shovel \& backhoe } \\
\text { testing }<60 \mathrm{cmbs}\end{array}$ & \begin{tabular}{|c|} 
Denney 1981, \\
Uecker 1994, \\
Uecker \& Warren \\
1994 \\
\end{tabular} \\
\hline 41MV161 & $\begin{array}{l}\text { tributary fossil } \\
\text { T0/upland slope }\end{array}$ & 246 & $6000 \mathrm{~m}^{2}$ & LS & LS, BR & $\begin{array}{c}\text { BR-midden } \\
\text { (5ocmbs) } \\
\text { hearths }\end{array}$ & & $\begin{array}{l}\text { Alamagre Large Stemmed, } \\
\text { Marcos: M.-L. Archaic }\end{array}$ & $\begin{array}{l}\text { surface suvey, } \\
\text { shovel \& backhoe } \\
\text { testing }<60 \mathrm{cmbs}\end{array}$ & \begin{tabular}{|c|} 
Denney 1981, \\
Uecker 1994, \\
Uecker \& Warren \\
1994 \\
\end{tabular} \\
\hline 41MV162 & upland slope & 244 & & LS & LS, BR & & & & \begin{tabular}{|c|}
$\begin{array}{c}\text { surface suvey \& test } \\
\text { probes }\end{array}$ \\
\end{tabular} & Denney 1981 \\
\hline $41 \mathrm{MV} 163$ & $\begin{array}{l}\text { tributary } \\
\text { fossil T0 } \\
\end{array}$ & 238 & & LS & LS, BR & & yes & & $\begin{array}{c}\text { surface suvey \& test } \\
\text { probes }\end{array}$ & Denney 1981 \\
\hline
\end{tabular}




\begin{tabular}{|c|c|c|c|c|c|c|c|c|c|c|}
\hline Site & Setting & $\begin{array}{l}\text { Elev. } \\
(\mathbf{m})\end{array}$ & Site Size & Site Type & Mat. Recovered & Features & Gr. stone & $\begin{array}{l}\text { Diagnostics: } \\
\text { Temp. Affil. }\end{array}$ & Investigations & Sources \\
\hline $41 \mathrm{MV} 164$ & $\begin{array}{l}\text { Elm Creek } \\
\text { fossil T0 }\end{array}$ & 237 & $22500 \mathrm{~m}^{2}$ & LS & LS, BR & $\begin{array}{l}\text { poss. BR- } \\
\text { midden }\end{array}$ & metate & $\begin{array}{l}\text { Frio, Ensor-like, Scallorn, } \\
\text { Clearfork tool: } \\
\text { L. Archaic - L.Prehist. }\end{array}$ & $\begin{array}{l}\text { surface suvey, } \\
\text { shovel \& backhoe } \\
\text { testing }<40 \mathrm{cmbs}\end{array}$ & \begin{tabular}{|c|} 
Denney 1981, \\
Uecker 1994, \\
Uecker \& Warren \\
1994
\end{tabular} \\
\hline 41MV165 & $\begin{array}{l}\text { Elm Creek } \\
\text { fossil T0 }\end{array}$ & 237 & $3600 \mathrm{~m}^{2}$ & LS & LS, BR & $\begin{array}{c}\text { BR-conc., } \\
\text { hearths }\end{array}$ & & La Jita: E. Archaic & $\begin{array}{c}\text { surface suvey, } \\
\text { shovel \& backhoe } \\
\text { testing }\end{array}$ & \begin{tabular}{|c|} 
Denney 1981, \\
Uecker \& War ren \\
1994 \\
\end{tabular} \\
\hline 41MV166 & $\begin{array}{l}\text { Elm Creek } \\
\text { fossil T0 }\end{array}$ & 237 & $3600 \mathrm{~m}^{2}$ & Lith. -proc. & LS, BR & & & Marcos: L. Archaic & $\begin{array}{c}\text { surface suvey, } \\
\text { shovel \& backhoe } \\
\text { testing }<20 \mathrm{cmbs}\end{array}$ & \begin{tabular}{|c} 
Denney 1981, \\
Uecker \& War ren \\
1994 \\
\end{tabular} \\
\hline $41 \mathrm{MV} 167$ & upland slope & 243 & & LS & LS, BR & hearths & yes & $\begin{array}{l}\text { Frio, Langtry-like, undet. } \\
\text { L. Archaic points: } \\
\text { M.-L. Archaic }\end{array}$ & $\begin{array}{c}\text { surface suvey \& test } \\
\text { probes }\end{array}$ & Denney 1981 \\
\hline $41 \mathrm{MV} 168$ & upland slope & 249 & $14400 \mathrm{~m}^{2}$ & Lith. -proc. & LS & & & Bulverde: E. Archaic & $\begin{array}{c}\text { surface suvey, } \\
\text { shovel \& backhoe } \\
\text { testing }\end{array}$ & $\begin{array}{c}\text { Denney 1981, } \\
\text { Uecker \& War ren } \\
1994 \\
\end{array}$ \\
\hline $41 \mathrm{MV} 169$ & upland slope & 249 & & LS & LS, BR & & & & $\begin{array}{c}\text { surface suvey \& test } \\
\text { probes }\end{array}$ & Denney 1981 \\
\hline $41 \mathrm{MV} 170$ & upland ridge & 253 & $3900 \mathrm{~m}^{2}$ & Lith.-proc. & $\begin{array}{l}\text { LS, BR, Uvalde } \\
\text { gravels }\end{array}$ & & & & $\begin{array}{c}\text { surface suvey, } \\
\text { shovel \& backhoe } \\
\text { testing }\end{array}$ & \begin{tabular}{|c|} 
Denney 1981, \\
Uecker \& Warren \\
1994 \\
\end{tabular} \\
\hline $41 \mathrm{MV} 173$ & $\begin{array}{c}\text { Elm Creek } \\
\text { T0 }\end{array}$ & 235 & $1800 \mathrm{~m}^{2}$ & LS & LS, BR & & & Lerma-like: E. Archaic & $\begin{array}{c}\text { surface survey, } \\
\text { shovel, backhoe } \\
\text { testing }\end{array}$ & $\begin{array}{c}\text { Uecker 1994, } \\
\text { Uecker \& Warren } \\
1994 \\
\end{array}$ \\
\hline 41MV174 & $\begin{array}{c}\text { Elm Creek } \\
\text { T0 }\end{array}$ & 230 & & LS & LS--? & & & & $\begin{array}{c}\text { surface survey, } \\
\text { shovel, backhoe } \\
\text { testing }\end{array}$ & Uecker 1994 \\
\hline $41 \mathrm{MV} 175$ & $\begin{array}{c}\text { Elm Creek } \\
\text { T0 }\end{array}$ & 230 & & LS & LS--? & & & & $\begin{array}{l}\text { surface survey, } \\
\text { shovel, backhoe } \\
\text { testing }\end{array}$ & Uecker 1994 \\
\hline $41 \mathrm{MV} 176$ & $\begin{array}{c}\text { Elm Creek } \\
\text { T0 }\end{array}$ & 230 & & LS & LS--? & & & & $\begin{array}{c}\text { surface survey, } \\
\text { shovel, backhoe } \\
\text { testing }\end{array}$ & Uecker 1994 \\
\hline 41MV177 & $\begin{array}{c}\text { Elm Creek } \\
\text { T0 }\end{array}$ & 230 & & LS & LS--? & & & $\begin{array}{l}\text { Guadalupe tool: } \\
\text { E. Archaic }\end{array}$ & $\begin{array}{l}\text { surface survey, } \\
\text { shovel, backhoe } \\
\text { testing }\end{array}$ & Uecker 1994 \\
\hline
\end{tabular}




\begin{tabular}{|c|c|c|c|c|c|c|c|c|c|c|}
\hline Site & Setting & $\begin{array}{l}\text { Elev. } \\
\text { (m) }\end{array}$ & Site Size & Site Type & Mat. Recovered & Features & Gr. stone & $\begin{array}{l}\text { Diagnostics: } \\
\text { Temp. Affil. }\end{array}$ & Investigations & Sources \\
\hline 41MV178 & $\begin{array}{l}\text { Elm Creek } \\
\text { T0 }\end{array}$ & 230 & & LS & LS--? & & mano & $\begin{array}{l}\text { Desmuke, Edgewood, } \\
\text { Langtry: M.-L. Archaic }\end{array}$ & $\begin{array}{l}\text { surface survey, } \\
\text { shovel, backhoe } \\
\text { testing }\end{array}$ & Uecker 1994 \\
\hline 41MV179 & $\begin{array}{l}\text { Elm Creek } \\
\text { T0 }\end{array}$ & 230 & & LS & LS--? & & & & $\begin{array}{c}\text { surface survey, } \\
\text { shovel, backhoe } \\
\text { testing }\end{array}$ & Uecker 1994 \\
\hline 41MV180 & $\begin{array}{c}\text { Elm Creek } \\
\text { T0 }\end{array}$ & & & LS & LS- -? & & & $\begin{array}{l}\text { Edgewood, Frio: } \\
\text { L. Archaic }\end{array}$ & $\begin{array}{c}\text { surface survey, } \\
\text { shovel, backhoe } \\
\text { testing }\end{array}$ & Uecker 1994 \\
\hline 41MV181 & $\begin{array}{l}\text { Elm Creek } \\
\text { upland terrace }\end{array}$ & 250 & & LS & LS--? & & & $\begin{array}{l}\text { Abasolo, Figueroa, } \\
\text { Palmillas, Zavala: } \\
\text { E. Archaic-L. Prehist. }\end{array}$ & $\begin{array}{c}\text { surface survey, } \\
\text { shovel, backhoe } \\
\text { testing }\end{array}$ & Uecker 1994 \\
\hline 41MV182 & $\begin{array}{c}\text { Elm Creek } \\
\text { T0 }\end{array}$ & 230 & $4000 \mathrm{~m}^{2}$ & LS & $\begin{array}{c}\text { LS, BR, engr aved } \\
\text { stone }\end{array}$ & hearths & manos & \begin{tabular}{|c|} 
Abasolo, Ensor, Figueroa, \\
Martindale, Pandale, \\
Zavala: \\
E. Archaic-L. Prehist. \\
\end{tabular} & $\begin{array}{l}\text { surface survey, } \\
\text { shovel, backhoe } \\
\text { testing }\end{array}$ & $\begin{array}{c}\text { Uecker 1994, } \\
\text { Uecker \& Warren } \\
1994\end{array}$ \\
\hline $41 \mathrm{MV} 183$ & $\begin{array}{l}\text { Elm Creek } \\
\text { T0 }\end{array}$ & 230 & $1800 \mathrm{~m}^{2}$ & LS & LS, BR & & & $\begin{array}{l}\text { unidentified point: } \\
\text { M.-L. Archaic }\end{array}$ & $\begin{array}{c}\text { surface survey, } \\
\text { shovel, backhoe } \\
\text { testing }\end{array}$ & $\begin{array}{c}\text { Uecker 1994, } \\
\text { Uecker \& Warren } \\
1994 \\
\end{array}$ \\
\hline 41MV184 & $\begin{array}{l}\text { Elm Creek } \\
\text { T0 }\end{array}$ & 230 & $12000 \mathrm{~m}^{2}$ & LS & $\begin{array}{l}\text { LS, BR, mussel, } \\
\text { snail, bone }\end{array}$ & & & $\begin{array}{l}\text { poss. Bulverde barb: } \\
\text { E. Archaic? }\end{array}$ & $\begin{array}{l}\text { surface survey, } \\
\text { shovel, backhoe } \\
\text { testing }\end{array}$ & $\begin{array}{c}\text { Uecker 1994, } \\
\text { Uecker \& Warren } \\
1994\end{array}$ \\
\hline 41MV185 & $\begin{array}{l}\text { Elm Creek } \\
\text { To }\end{array}$ & 230 & $10 \times 40 \mathrm{~m}$ & LS & $\begin{array}{c}\text { LS, BR, mussel, } \\
\text { snail }\end{array}$ & BR-midden & & $\begin{array}{l}\text { Castroville, Conejo, } \\
\text { Edgewood, Marshall, } \\
\text { Matamoros, Pandale, } \\
\text { arrow pt. preform: } \\
\text { E. Archaic-L. Prehist. }\end{array}$ & $\begin{array}{l}\text { surface survey, } \\
\text { shovel, backhoe } \\
\text { testing, }<50 \mathrm{cmbs}\end{array}$ & $\begin{array}{c}\text { Uecker 1994, } \\
\text { Uecker \& Warren } \\
1994\end{array}$ \\
\hline 41MV186 & $\begin{array}{l}\text { Elm Creek } \\
\text { fossil T0 }\end{array}$ & 230 & $30 \times 15 m$ & LS & LS, BR & hearths & & $\begin{array}{l}\text { Angostura, Langtry, } \\
\text { Paisano, arrow pt. } \\
\text { preforms: L. Paleo \& } \\
\text { M. Archaic-L. Prehist. }\end{array}$ & $\begin{array}{l}\text { surface survey, } \\
\text { shovel, backhoe } \\
\text { testing }<20 \mathrm{cmbs}\end{array}$ & $\begin{array}{c}\text { Uecker 1994, } \\
\text { Uecker \& Warren } \\
1994\end{array}$ \\
\hline 41MV187 & $\begin{array}{l}\text { Elm Creek } \\
\text { terrace }\end{array}$ & 230 & $80 \times 15 m$ & LS & $\begin{array}{l}\text { LS, BR, mussel, } \\
\text { snail }\end{array}$ & $\begin{array}{c}\text { BR-conc., } \\
\text { hearths }\end{array}$ & & $\begin{array}{c}\text { Edgewood, Perdiz, } \\
\text { Figuer oa(Zavala), } \\
\text { Fairland, Sc allorn, arrow } \\
\text { pt. preforms: } \\
\text { Trans. Archaic-L. Prehist. }\end{array}$ & $\begin{array}{l}\text { surface survey, } \\
\text { shovel, backhoe } \\
\text { testing, }<40 \mathrm{cmbs}\end{array}$ & $\begin{array}{c}\text { Uecker 1994, } \\
\text { Uecker \& Warren } \\
1994\end{array}$ \\
\hline
\end{tabular}




\begin{tabular}{|c|c|c|c|c|c|c|c|c|c|c|}
\hline Site & Setting & $\begin{array}{l}\text { Elev. } \\
(\mathrm{m})\end{array}$ & Site Size & Site Type & Mat. Recovered & Features & Gr. stone & $\begin{array}{l}\text { Diagnostics: } \\
\text { Temp. Affil. }\end{array}$ & Investigations & Sources \\
\hline 41MV188 & $\begin{array}{l}\text { Elm Creek } \\
\text { T0 }\end{array}$ & 230 & $6500 \mathrm{~m}^{2}$ & LS & LS, BR & & & $\begin{array}{l}\text { Ensor, Montell, Palmillas, } \\
\text { Shumla: M.-L. Archaic }\end{array}$ & $\begin{array}{l}\text { surface survey, } \\
\text { shovel, backhoe } \\
\text { testing }<20 \mathrm{cmbs}\end{array}$ & $\begin{array}{c}\text { Uecker 1994, } \\
\text { Uecker \& Warren } \\
1994 \\
\end{array}$ \\
\hline $41 \mathrm{MV} 189$ & $\begin{array}{l}\text { Elm Creek } \\
\text { To }\end{array}$ & 230 & $15 \times 50 \mathrm{~m}$ & LS & $\begin{array}{l}\text { LS, BR, mussel, } \\
\text { snail }\end{array}$ & hearth & & $\begin{array}{c}\text { Bell, Figueroa, Frio, } \\
\text { Langtry, Marcos, } \\
\text { Pedernales, Ensor, } \\
\text { Matamoros: E.-L. Archaic }\end{array}$ & $\begin{array}{l}\text { surface survey, } \\
\text { shovel, backhoe } \\
\text { testing, }<20 \mathrm{cmbs}\end{array}$ & $\begin{array}{c}\text { Uecker 1994, } \\
\text { Uecker \& Warren } \\
1994\end{array}$ \\
\hline $41 \mathrm{MV} 190$ & $\begin{array}{l}\text { Elm Creek } \\
\text { T0 }\end{array}$ & 230 & $20000 \mathrm{~m}^{2}$ & LS & $\begin{array}{l}\text { LS, BR, mussel, } \\
\text { red ochre }\end{array}$ & & $\operatorname{mano}$ & $\begin{array}{c}\text { Frio, Marcos, Pandora, } \\
\text { Tortugas, Ensor, Marshall- } \\
\text { like: M.-L. Archaic } \\
\end{array}$ & $\begin{array}{l}\text { surface survey, } \\
\text { shovel, backhoe } \\
\text { testing }<50 \mathrm{cmbs}\end{array}$ & $\begin{array}{c}\text { Uecker 1994, } \\
\text { Uecker \& Warren } \\
1994 \\
\end{array}$ \\
\hline 41MV 191 & $\begin{array}{l}\text { Elm Creek } \\
\text { T0 }\end{array}$ & 230 & & & & & & $\begin{array}{l}\text { arrow pt. distal tip \& } \\
\text { preform: L. Prehist. }\end{array}$ & $\begin{array}{l}\text { surface survey, } \\
\text { shovel, backhoe } \\
\text { testing }\end{array}$ & Uecker 1994 \\
\hline 41MV192 & $\begin{array}{l}\text { Elm Creek } \\
\text { T0 }\end{array}$ & 230 & & & & & & $\begin{array}{l}\text { Perdiz, Scallorn, Toyah- } \\
\text { like: L.-Prehist. }\end{array}$ & $\begin{array}{c}\text { surface survey, } \\
\text { shovel, backhoe } \\
\text { testing }\end{array}$ & Uecker 1994 \\
\hline 41MV 193 & $\begin{array}{l}\text { Elm Creek } \\
\text { T0 }\end{array}$ & 230 & $800 \times 400 \mathrm{~m}$ & LS & LS, mussel, snail & hearths & & $\begin{array}{l}\text { Almagre, Bulverde, Ellis, } \\
\text { Peder nales, Fresno, } \\
\text { Fairland, Frio, Conejo, } \\
\text { Ensor, Fi gueroa, Pandale, } \\
\text { Montell, Sabinal, Scallorn, } \\
\text { Zavala: } \\
\text { E. Archaic-L. Prehist. } \\
\end{array}$ & $\begin{array}{l}\text { surface survey, } \\
\text { shovel, backhoe } \\
\text { testing }<40 \mathrm{cmbs}\end{array}$ & $\begin{array}{c}\text { Uecker 1994, } \\
\text { Uecker \& Warren } \\
1994\end{array}$ \\
\hline 41MV194 & $\begin{array}{c}\text { Elm Creek } \\
\text { T0 }\end{array}$ & 230 & $3900 \mathrm{~m}^{2}$ & LS & LS, BR & & & & $\begin{array}{c}\text { surface survey, } \\
\text { shovel, backhoe } \\
\text { testing }\end{array}$ & $\begin{array}{c}\text { Uecker 1994, } \\
\text { Uecker \& Warren } \\
1994 \\
\end{array}$ \\
\hline 41MV195 & $\begin{array}{c}\text { Elm Creek } \\
\text { T0 }\end{array}$ & 230 & $400 \mathrm{~m}^{2}$ & LS & $\begin{array}{l}\text { LS, BR, mussel, } \\
\text { snail, red ochre }\end{array}$ & & & & $\begin{array}{l}\text { surface survey, } \\
\text { shovel, backhoe } \\
\text { testing }<20 \mathrm{cmbs}\end{array}$ & $\begin{array}{c}\text { Uecker 1994, } \\
\text { Uecker \& Warren } \\
1994\end{array}$ \\
\hline 41MV196 & $\begin{array}{c}\text { Elm Creek } \\
\text { T0 }\end{array}$ & 230 & & LS & LS & & & $\begin{array}{l}\text { Darl, Carrizo, Pandora, } \\
\text { Scallorn: } \\
\text { M. Archaic-L.-Prehist. }\end{array}$ & $\begin{array}{c}\text { surface survey, } \\
\text { shovel, backhoe } \\
\text { testing }\end{array}$ & Uecker 1994 \\
\hline 41MV197 & $\begin{array}{c}\text { Elm Creek } \\
\text { T0 }\end{array}$ & 230 & & LS & LS...? & & & Pandale E. Archaic & $\begin{array}{c}\text { surface survey, } \\
\text { shovel, backhoe } \\
\text { testing }\end{array}$ & Uecker 1994 \\
\hline 41MV198 & $\begin{array}{l}\text { Elm Creek } \\
\text { T0 }\end{array}$ & 230 & & LS & LS...? & & & $\begin{array}{c}\text { Almagre Large-stemmed?: } \\
\text { M. Archaic }\end{array}$ & $\begin{array}{l}\text { surface survey, } \\
\text { shovel, backhoe } \\
\text { testing }\end{array}$ & Uecker 1994 \\
\hline
\end{tabular}




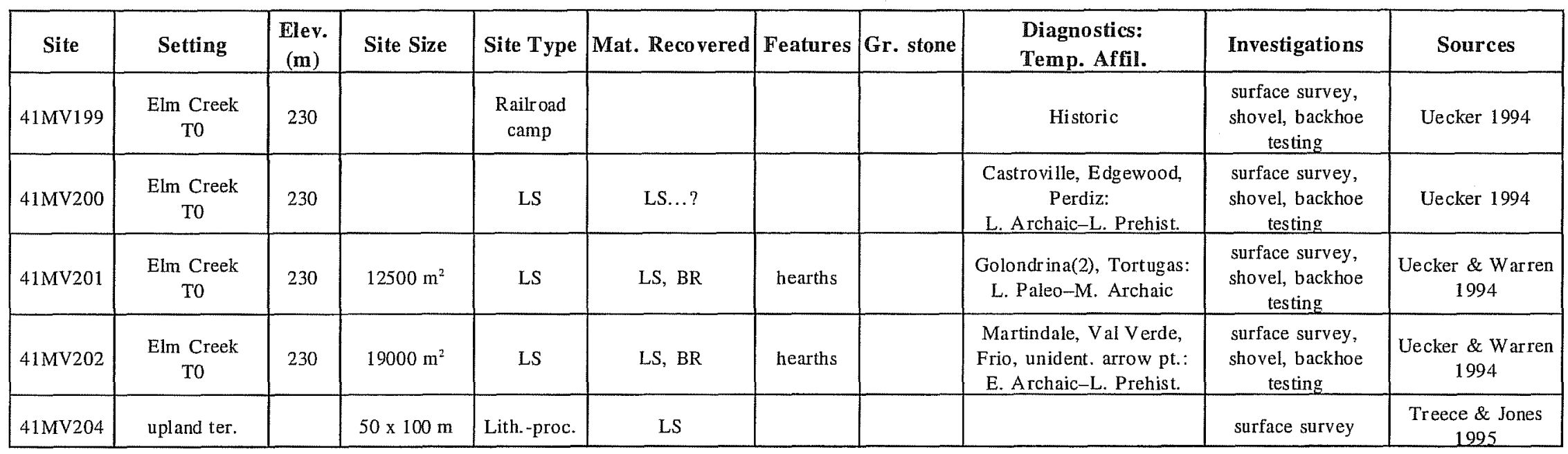




\section{Appendix B: Geomorphological Data}

\section{Lee C. Nordt}

Part 1: Alluvial Stratigraphic Description

Part 2: Soil Micromorphic Descriptions

Part 3: Soil Stratigraphic Characterization Data 


\section{Part 1: Alluvial Stratigraphic Descriptions}

\section{BHT 7}

Area 1; Rio Grande T1 flood terrace; calcareous throughout; highway wall; elevation $733 \mathrm{ft}, 33 \mathrm{ft}$ above Rio Grande channel.

Ap1 (fill) $\quad$ 0-25 cm; Historic; dark grayish brown (10YR 4/2) silt loam; massive; very hard; few biocasts; abrupt wavy.

Ap2 (fill) 25-39 cm; very dark grayish brown (10YR 3/2) silty clay loam; moderate medium subangular blocky; very hard; many biocasts; clear smooth.

Bw1 39-48 cm; Unit 2-f; dark grayish brown (10YR 4/2) silty clay loam; weak coarse angular blocky; extremely hard; many biocasts; gradual smooth.

Bw2 48-59 cm; dark grayish brown (10YR 4/2) silt loam; moderate medium subangular blocky; very hard; many biocasts; clear smooth.

Bw3 59-76 cm; dark grayish brown (10YR 3.5/2) silty loam; moderate medium subangular blocky; very hard; many biocasts; gradual smooth; charcoal ${ }^{14} \mathrm{C}$ age of $1240 \pm 60$ B.P. from a depth of 50-60 cm extrapolated from EU 1.

Ab1 76-89 cm; brown (10YR 4.5/3) silty clay loam; moderate medium subangular blocky; very hard; common biocasts; gradual smooth; charcoal ${ }^{14} \mathrm{C}$ age of $1970 \pm 50$ yr B.P. (CAMS 37203 ) from a depth of 80-90 cm extrapolated from Area 1, TU33.

Bwb1 89-110 cm; grayish brown (10YR 4.5/2) silt loam; weak coarse subangular blocky; very hard; common biocasts; gradual smooth.

BCb1 110-120 cm; brown (10YR 5/3) silt loam; weak medium subangular blocky; very hard; few biocasts; charcoal ${ }^{14} \mathrm{C}$ age of $2200 \pm 50$ B.P. (CAMS 37204) from a depth of $110-120 \mathrm{~cm}$ extrapolated from TU33.

\section{BHT 8}

Areas 1-2; Rio Grande T1 flood terrace; calcareous throughout; fence wall; elevation $735 \mathrm{ft}, 35 \mathrm{ft}$ above Rio Grande channel.

Ap (fill) $\quad$ 0-25 cm; Historic; dark grayish brown (10YR 3.5/2) silt loam; moderate medium subangular blocky; very hard; $2 \%$ matrix-supported pebbles, angular, $<1 \mathrm{~cm}$ diameter; clear wavy.

A

25-40 cm; Unit 2-f; very dark grayish brown (10YR 3/2) silty clay loam; moderate medium subangular blocky; very hard; many biocasts; gradual smooth; charcoal ${ }^{14} \mathrm{C}$ age of $1460 \pm 50$ from a depth of $30-40 \mathrm{~cm}$ extrapolated from $\mathrm{EU} 2$. 
Bw1 40-49 cm; dark grayish brown (10YR 4/2) silt loam; moderate medium subangular blocky; very hard; many biocasts; gradual smooth.

Bw2 49-64 cm; dark grayish brown (10YR 4/2) silty clay loam; moderate medium subangular blocky; very hard; common biocasts; gradual smooth.

Ab1 64-76 cm; very dark grayish brown (10YR 3/2) silty clay loam; moderate fine prismatic; very hard; common biocasts; gradual smooth.

Bw1b1 76-86 cm; dark grayish brown (10YR 4/2) silty clay loam; moderate fine prismatic; very hard; common biocasts; clear smooth.

Bw2b1 86-106 cm; brown (10YR 4/2.5) silty clay loam; moderate medium subangular blocky; hard; common biocasts; gradual smooth.

Bw3b1 106-125 cm; dark yellowish brown (10YR 4/4.5) silt loam; moderate medium subangular blocky; hard; common biocasts; gradual smooth.

Bw4bl 125-149 cm; brown (10YR 5/3) silt loam; weak medium subangular blocky; hard; common biocasts; gradual smooth.

BCb1 149-164 cm; brown (10YR 5/3) silt loam; weak medium subangular blocky; hard; few biocasts; gradual smooth.

\section{BHT 9}

Area 2; Rio Grande T1 flood terrace; calcareous throughout; fence wall; elevation $735 \mathrm{ft}, 35 \mathrm{ft}$ above Rio Grande channel.

Ap1 (fill) 0-11 cm; Historic; dark grayish brown (10YR 3.5/2) silt loam; moderate medium subangular blocky; very hard; common biocasts; small pieces of plastic; abrupt wavy.

Ap2 (fill) 11-21 cm; very dark grayish brown (10YR 3/2) silty clay loam; moderate medium subangular blocky; very hard; common biocasts; $2 \%$ matrix supported pebbles, angular, $0.5 \mathrm{~cm}$ diameter; abrupt wavy.

A1

21-39 cm; Unit 2-f; dark grayish brown (10YR 3.5/2) silty clay loam; moderate medium subangular blocky; very hard; many biocasts; gradual smooth.

A2

39-49 cm; dark grayish brown (10YR 4/2) silt loam; moderate medium subangular blocky; very hard; common biocasts; gradual smooth.

Bw1 49-63 cm; dark grayish brown (10YR 4/2) silt loam; moderate medium subangular blocky; very hard; common biocasts; gradual smooth; charcoal C-14 age of $3200 \pm 50$ B.P. (CAMS 37206) from a depth of 80-90 cm extrapolated from TU7 (rejected). 
Bw2 63-88 cm; dark grayish brown (10YR 4/2) silt loam; moderate medium subangular blocky; hard; common biocasts; gradual smooth.

Bw3 88-108 cm; brown (10YR 5/2.5) silt loam; weak coarse subangular blocky; hard; few biocasts; gradual smooth.

BC 108-149 cm; Unit 2-p; brown (10YR 5/3) loam; weak coarse subangular blocky; slightly hard; common biocasts; gradual smooth.

C 149-164 cm; pale brown (10YR 6/3) loam; weak coarse subangular blocky; slightly hard; few biocasts.

\section{BHT 10}

Area 3; Rio Grande T1 flood terrace; calcareous throughout; fence wall; elevation $735 \mathrm{ft}, 35 \mathrm{ft}$ above Rio Grande channel.

Ap(fill) $\quad 0-17 \mathrm{~cm}$; Historic; pale brown (10YR 6/3) silt loam.

A $\quad 17-40 \mathrm{~cm}$; Unit 2-f; brown (10YR 4/3) silty clay loam.

Bw1 40-64 cm; brown (10YR 5/3) silt loam; charcoal C-14 age of 760 450 B.P. (Beta 104966) from a depth of $50 \mathrm{~cm}$ in $\mathrm{EU} 6$; probably related to the $\mathrm{T} 1$ flood terrace surface.

Bw2 64-76 cm; pale brown (10YR 6/3) silt loam; charcoal C-14 age of $3050 \pm 50$ B.P. (CAMS 37207) from a depth of $71 \mathrm{~cm}$ (rejected).

Ab1 76-88 cm; brown (10YR 5/3) silty clay loam.

Bw1b1 88-104 cm; pale brown (10YR 6/3) silt loam.

Bw2b1 104-127 cm; pale brown (10YR 6/3) silt loam.

BCbl $\quad 127-137 \mathrm{~cm}$; very pale brown (10YR 7/3) very fine sandy loam.

\section{BHT 12}

Area 4; Rio Grande T1 flood terrace; calcareous throughout; fence wall; elevation $735 \mathrm{ft}, 35 \mathrm{ft}$ above Rio Grande channel.

Ap(fill) $\quad$ 0-50 cm; Historic; yellowish brown (10YR 5/4) silt loam.

A $\quad 50-65 \mathrm{~cm}$; Unit 2-f; light yellowish brown (10YR 5/4) silty clay loam; charcoal ${ }^{14} \mathrm{C}$ age of $540 \pm 40$ B.P.(Beta 104967) from a depth of $70 \mathrm{~cm}$ in EU 40 ; probably related to the $\mathrm{T} 1$ flood terrace surface. 
Bw $\quad 65-75 \mathrm{~cm}$; light yellowish brown (10YR 6/4) silt loam.

Bw2 $75-85 \mathrm{~cm}$; light yellowish brown (10YR 5/4) silty clay loam.

Bw3 85-105 cm; light yellowish brown (10YR 6/4) silt loam.

Bw4 105-115 cm; light yellowish brown (10YR 5/4) silty clay loam.

Bw5 115-140 cm; light yellowish brown (10YR 6/4) silt loam.

Ab1 140-152 cm; brown (10YR 4/3) silty clay loam; charcoal ${ }^{14}$ Cage of $1940 \pm 40$ B.P. (CAMS 37202 ) from a depth of $150-155 \mathrm{~cm}$.

BCb1 152-175 cm; Unit 2-p; very pale brown (10YR 7/3) very fine sandy loam.

\section{EP-1}

Rio Grande TO floodplain; calcareous throughout; elevation $713 \mathrm{ft}, 13 \mathrm{ft}$ above Rio Grande channel; drill rig description.

Ap 0-35 cm; Unit 3-f; grayish brown (10YR 5/2) silt loam; weak fine subangular blocky; friable; gradual.

C1 35-53 cm; brown (10YR 5/3) and pale brown (6/3) very fine sandy loam; single grained; abrupt.

$\mathrm{C} 2$ 53-176 cm; interbedded (8-15 cm thick each) brown (10YR 5/3) very fine sandy loam, single grained and dark grayish brown (10YR 4/2) silty clay loam, massive, firm; clear.

C3 176-295 cm; brown (10YR 5/3) silt loam; weak fine subangular blocky; very friable; clear.

295-343 cm; brown (10YR 5/3) silt loam; weak medium platy; very friable; abrupt.

C5 343-382 cm; dark grayish brown (10YR 3.5/2) silt loam; massive; firm; 10\% gray (10YR 5/1) pockets; abrupt.

C6 382-408 cm; Unit 3-p; brown (10YR 5/3) and pale brown (6/3) loamy fine sand; single grained; abrupt.

C7 408-575 cm; brown (10YR 5/3) silt loam; massive; firm; faintly laminated; $15 \%$ charcoal fragments; charcoal C-14 age of $1170 \pm 60$ yr B.P. (CAMS 37205) from a depth of $518 \mathrm{~cm}$.

C8 575-710 cm; very pale brown (10YR 7/3) sand; single grained.

C9 710-870; very pale brown (10YR 7/3) sand; water saturated (compressed). 
Rio Grande T1 flood terrace; calcareous throughout; elevation $732 \mathrm{ft}, 32 \mathrm{ft}$ above Rio Grande channel; drill rig description.

Ap $\quad$ 0-33 cm; Unit 2-f; dark grayish brown (10YR 3.5/2) silt loam; weak coarse angular blocky; very firm; few fine charcoal fragments; gradual.

A

Bw1

Bw2

$\mathrm{C} 1$

$\mathrm{C} 2$

C3

$\mathrm{C} 4$

C1b1

$\mathrm{C} 2 \mathrm{~b} 1$
33-71 cm; dark grayish brown (10YR 3.5/2) silty clay loam; weak medium angular blocky; very firm; few brown (10YR 5/3) biocasts; gradual.

71-117 cm; dark grayish brown (10YR 4/2) silty clay loam; weak coarse angular blocky; very firm; few brown (10YR 5/3) biocasts; gradual.

117-150 cm; grayish brown (10YR 5/2) silt loam; faintly laminated; friable; clear.

150-231 cm; brown (10YR 5/3) silt loam, faintly laminated; friable; gradual.

231-419 cm; brown (10YR 5.5/3) loam; single grained; gradual.

419-586 cm; pale brown (10YR 6/3) very fine sandy loam; single grained; gradual.

$586-763 \mathrm{~cm}$; interbedded (10 $\mathrm{cm}$ thick each) brown (10YR 5/3) very fine sandy loam, fri able and light olive brown (2.5Y 5/3) silt loam, very firm; abrupt.

763-1040 cm; Unit 1-p; interbedded (10 cm thick each) brown (7.5YR 4/3, 5/3), light olive brown (2.5Y 5/3) silty clay, very firm and light olive brown (2.5Y 5/4) fine sandy loam, friable; $2 \%$ matrix supported pebbles, subrounded, $0.3-1 \mathrm{~cm}$ diameter; abrupt; bulk humate ${ }^{14} \mathrm{C}$ age of $6010 \pm 60$ B.P. (Beta 104968) from a depth of $878 \mathrm{~cm}$.

1040-1161 cm; Unit 1-c; light olive brown (2.5Y 5/4) loam; 60\% mostly grain supported pebbles, subrounded, poorly sorted, mostly quartzite, chert, and some limestone, $0.5-3 \mathrm{~cm}$ diameter.

\section{EP-3}

Elm Creek T2/T1 terrace escarpment; elevation $760 \mathrm{ft}, 18 \mathrm{ft}$ above the Elm Creek channel; drill rig.

A

$\mathrm{Bt}$
0-33 cm; Unit 1-s; very dark grayish brown (10YR 3/2) sandy clay loam; weak medium angular blocky; very firm; $2 \%$ pale brown (10YR 6/3) biocasts; few charcoal fragments; weakly calcareous; gradual.

$33-56 \mathrm{~cm}$; dark grayish brown (2.5Y 4/2) and light olive brown (2.5Y 5/3) clay loam; weak coarse angular blocky; very firm; $1 \%$ very dark grayish brown (10YR 3/2) biocasts; calcareous; gradual. 
Btk 56-93 cm; light olive brown (2.5Y 5/3) clay loam; $10 \%$ dark grayish brown $(2.5 \mathrm{Y} 4 / 2) ; 3 \%$ very dark grayish brown (10YR 3/2) biocasts; weak coarse angular blocky; very firm; $2 \%$ calcium carbonate filaments; calcareous; gradual.

Bky1 93-124 cm; light olive brown (2.5Y 5/4) clay loam; 5\% grayish brown (2.5Y 5/2); weak coarse angular blocky; very firm; $1 \%$ very dark grayish brown (10YR $3 / 2)$ biocasts; $2 \%$ calcium carbonate filaments; $5 \%$ gypsum crystals, $2-3 \mathrm{~mm}$ diameter; calcareous; gradual.

Bky2 124-194 cm; olive yellow (2.5Y 6/6) clay loam; 35\% gray (2.5Y 5/1); weak coarse angular blocky; very firm; $1 \%$ very dark grayish brown (10YR 3/2) biocasts; $3 \%$ calcium carbonate nodules, $1 \mathrm{~cm}$ diameter; $5 \%$ gypsum crystals, 2-3 mm diameter; calcareous; gradual.

Bky3 194-245 cm; olive yellow (2.5Y 6/6) clay loam; $40 \%$ gray $(2.5 \mathrm{Y} 6 / 1)$; weak coarse angular blocky; very firm; $1 \%$ very dark grayish brown (10YR $3 / 2$ ) biocasts; $10 \%$ calcium carbonate nodules, $1 \mathrm{~cm}$ diameter; $3 \%$ gypsum crystals, $2-3 \mathrm{~mm}$ diameter; $1 \%$ iron manganese stains; calcareous; abrupt.

C

245-278 cm; Unit 1-p; olive yellow (2.5Y 6/6) loamy fine sand; $15 \%$ gray (2.5Y 6/1); single grained; few clay clasts; noncalcareous; abrupt.

$\mathrm{Ck}$

278-332 cm; light yellowish brown (2.5Y 6/4) and olive yellow (2.5Y 6/6) loam; massive; very firm; $20 \%$ calcium carbonate nodules, $1 \mathrm{~cm}$ diamater and coalescing; calcareous; abrupt; bulk humate ${ }^{14} \mathrm{C}$ age of $7540 \pm 60$ B.P. (Beta 104969) from a depth of $306 \mathrm{~cm}$.

C1 $332-370 \mathrm{~cm}$; yellow (2.5Y 7/6) loamy fine sand; $5 \%$ light gray (2.5Y 7/1); single grained; $1 \%$ matrix supported pebbles (siliceous), subrounded, $1 \mathrm{~cm}$ diameter; abrupt.

C2 370-416 cm; Unit 1-c; yellow (2.5Y 7/6) sandy clay loam; massive; very firm; $2 \%$ calcium carbonate nodules, $1 \mathrm{~cm}$ diameter; few shale clasts; $40 \%$ iron/manganese pebbles, $0.2-1 \mathrm{~cm}$ diameter, angular; $5 \%$ matrix supported pebbles (mostly siliceous), subrounded to angular, $0.5-1 \mathrm{~cm}$ diameter; noncalcareous matrix; abrupt.

Cr1 416-507 cm; bedrock; gray (5Y 5/1) laminated shale; $15 \%$ light yellowish brown (2.5Y 6/4); very firm; noncalcareous; abrupt.

Cr2 507-567 cm; very dark gray (2.5Y 3/1), light yellowish brown (2.5Y 6/4), and olive yellow (2.5Y 6/6) interbedded ( $10 \mathrm{~cm}$ thick each) shale; very firm; few fine charcoal fragments.

\section{EP-4}

Elm Creek T1 flood terrace; elevation $750 \mathrm{ft}, 10 \mathrm{ft}$ above the Elm Creek channel; drill rig description.

A

Bt
0-19 cm; Unit 1-f; very dark gray (10YR 3/1) sandy clay loam; moderate medium subangular blocky; very firm; moderately calcareous; clear.

19-76 cm; light olive brown (2.5Y 5/3) sandy clay loam; moderate medium angular blocky; very firm; common distinct very dark gray (10YR 3/1) patchy clay films; noncalcareous; gradual. 
Btk

76-97 cm; dark yellowish brown (10YR 4/4) sandy clay loam; weak coarse angular blocky; very firm; common distinct patchy very dark gray (10YR $3 / 1$ ) clay films; $4 \%$ calcium carbonate filaments; 3\% matrix supported pebbles, $0.5-1 \mathrm{~cm}$ diameter, siliceous and iron oxide; calcareous; clear.

Bk 97-113 cm; Unit 1-p; light olive brown $(2.5 Y$ 5/3, 5/4) sandy clay loam; moderate medium subangular blocky; very firm; $5 \%$ calcium carbonate nodules, $0.3-1 \mathrm{~cm}$ diameter; $4 \%$ matrix supported pebbles, $0.2-8 \mathrm{~cm}$ diameter, subrounded, siliceous and iron oxide; calcareous; abrupt.

Ck 113-155 cm; Unit 1-c; brown (10YR 5/3) sandy clay loam; massive; very firm; $1 \%$ calcium carbonate nodules, $1 \mathrm{~cm}$ diameter; $70 \%$ grain supported pebbles, subrounded, moderately well sorted, 0.5-4 cm diameter, mostly siliceous; abrupt.

Cr1 155-210 cm; bedrock; light yellowish brown $(2.5 \mathrm{Y} 6 / 3,6 / 4)$ weakly consolidated sandstone; very firm; distinct bedding planes and laminations; carbonate filaments along bedding planes; calcareous; abrupt.

Cr2 210-220 cm; very dark gray (10YR 3/1) bedded shale; very firm; calcareous.

\section{EP-5}

Rio Grande T1 flood terrace; elevation $735 \mathrm{ft}, 35 \mathrm{ft}$ above the Rio Grande channel; drill rig description.

Ap 0-21 cm; Unit 2-f; dark grayish brown (10YR 4/2) silt loam; weak medium subangular blocky; hard; gradual.

Bw1 21-60 cm; brown (10YR 4/3) silt loam; weak coarse subangular blocky; slightly hard; gradual.

Bw2 60-101 cm; brown (10YR 5/3) silt loam; weak coarse subangular blocky; slightly hard; gradual.

Bw3 101-242 cm; brown (10YR 5/3) silt loam; weak coarse subangular blocky; slightly hard; faintly laminated; gradual.

C1 242-372 cm; Unit 2-c; brown (10YR 5/3) very fine sandy loam; single grained; clear.

C2 372-671 cm; interbedded (20 cm thick each) brown (10YR 5/3) very fine sandy loam, single grained and brown (10YR 4/3) silt loam, massive; firm; clear.

C3 671-798 cm; pale brown (10YR 6/3) loamy fine sand; single grained; clear.

C4 798-986 cm; brown (10YR 5/3) silt loam; massive; friable; gradual.

C5 986-1160 cm; pale brown (10YR 6/3) fine sandy loam; single grained. 


\section{Part 2: Soil Micromorphic Descriptions}

\begin{tabular}{|c|c|}
\hline \multicolumn{2}{|r|}{ EP-1 } \\
\hline $\begin{array}{l}\text { C2 Horizon; Unit 3-f; } \\
53-176 \mathrm{~cm} \text {. }\end{array}$ & $\begin{array}{l}\text { plasmic fabric: crystic } \\
\text { related distribution: vughy porphyroskelic } \\
\text { skeleton grains: mostly silt to fine sand-size quartz, subrounded, well sorted; few } \\
\text { sand-size carbonate clasts; trace amounts of silt-size amphiboles and mica; few fine to } \\
\text { medium sand-size cracking clay clasts; } 2 \% \text { silt to fine sand-size charcoal fragments, } \\
\text { subrounded to angular } \\
\text { pedological features: few snail fragments; few roots; common vughs, few channels } \\
\text { and chambers; few aggrotubules } \\
\text { cultural materials: none }\end{array}$ \\
\hline $\begin{array}{l}\text { C6 Horizon; Unit 3-p; } \\
382-408 \mathrm{~cm}\end{array}$ & $\begin{array}{l}\text { plasmic fabric: argillasepic } \\
\text { related distribution: porphyr oskelic } \\
\text { skeleton grains: mostly silt-size quartz, subrounded, well sorted; } 10 \% \text { silt to fine } \\
\text { sand-size charcoal, horizontally laminated } \\
\text { pedological features: common planes, and few vughs, channels and chambers; few } \\
\text { ir on depletion zones, vertically and horizontally oriented; some soft sediment } \\
\text { defor mation } \\
\text { cultural materials: none }\end{array}$ \\
\hline $\begin{array}{l}\text { C7 Horizon; Unit 3-p; } \\
408-575 \mathrm{~cm}\end{array}$ & $\begin{array}{l}\text { plasmic fabric: crystic } \\
\text { related distribution: porphyroskelic to agglomeroplasmic } \\
\text { skeleton grains: mostly silt size quartz, subrounded, well sorted; few silt-size mica; } \\
\text { trace amounts of amphiboles; } 10 \% \text { silt-size charcoal, angular to subrounded } \\
\text { pedological features: common vughs; many aggrotubules, few granotubules; many } \\
\text { compound packing voids } \\
\text { cultural materials: none }\end{array}$ \\
\hline \multicolumn{2}{|r|}{ EP-2 } \\
\hline $\begin{array}{l}\text { C1b1 Horizon (fine-grained } \\
\text { stratum); Unit 1-p; } \\
763-1040 \mathrm{~cm}\end{array}$ & $\begin{array}{l}\text { plasmic fabric: crystic } \\
\text { related distribution: porphyr oskelic } \\
\text { skeleton grains: mostly silt-size quartz, subrounded, well sorted; few silt-size } \\
\text { amphiboles; common fine sand-size to pebble size cracking clay clasts, distinct } \\
\text { cracking clay laminations; } 10 \% \text { silt-size char coal fragments, angular to subrounded } \\
\text { pedological features: } 3 \% \text { fine to me dium sand-size gypsum crystals, euhedral; trace } \\
\text { amounts of silt-size calcans in vughs; common vughs, few channels and chambers; } \\
\text { common iron oxide stains; few horizontally and vertically iron depletion zones } \\
\text { cultural material: none }\end{array}$ \\
\hline $\begin{array}{l}\text { C1b1 Horizon (coarse- } \\
\text { grained stratum); } \\
\text { Unit 1-p; 763-1040 cm }\end{array}$ & $\begin{array}{l}\text { plasmic fabric: crystic } \\
\text { related distribution: vughy porphyroskelic } \\
\text { skele ton grains: mostly silt to fine sand-size quartz, subrounded, well sorted; common } \\
\text { fine to medium-size carbonate clasts, horizontally laminated; few silt-size amphiboles; } \\
\text { few fine to medium sand-size feldspars; few fine to medium sand-size chert; trace } \\
\text { amounts of mica; } 3 \% \text { silt to fine sand-size charcoal fragments, angular to subrounded } \\
\text { pedological features: many simple packing voids; common horizontally oriented } \\
\text { vughs; few embedded grain argillans } \\
\text { cultural materials: none }\end{array}$ \\
\hline
\end{tabular}




\begin{tabular}{|c|c|}
\hline \multicolumn{2}{|r|}{ EP-3 } \\
\hline $\begin{array}{l}\text { Bky2 Horizon; Unit 1-s; } \\
1242-194 \mathrm{~cm}\end{array}$ & $\begin{array}{l}\text { plasmic fabric: crystic } \\
\text { related distribution: porphyr oskelic } \\
\text { skele ton grains: mostly fine to medium sand-size quartz and chert; few fine to medium } \\
\text { sand-size feldspars; common fine to medium sand-size cracking clay clasts } \\
\text { pedological features: } 10 \% \text { fine to medium sand-size gypsum crystals mostly along } \\
\text { channels, lenticular; } 10 \% \text { fine to medium sand-size carbonate nodules and calcans } \\
\text { mostly in vughs; few roots; common vughs, few channels, chambers, and plains; } \\
\text { common aggrotubules; few iron stains and fine iron masses } \\
\text { cultural materials: none }\end{array}$ \\
\hline $\begin{array}{l}\text { C1 Horizon; Unit 1-p; } \\
332-370 \mathrm{~cm}\end{array}$ & $\begin{array}{l}\text { plasmic fabric: silasepic } \\
\text { related distribution: granular } \\
\text { skele ton grains: mostly fine to medium sand-size chert and quart, subrounded, } \\
\text { moderately well sorted; few fine to medium sand-size feldspars; common cracking } \\
\text { clay clasts, fine to coarse sand-size; few fine dispersed masses of detrital carbonate; } \\
2 \% \text { silt to medium sand-size charcoal, angular to subrounded } \\
\text { pedological features: few vughs; few faint Horizontal laminations; few free-grain } \\
\text { argillans; few fine ir on stains and masses } \\
\text { cultural materials: none }\end{array}$ \\
\hline \multicolumn{2}{|r|}{ BHT 8} \\
\hline $\begin{array}{l}\text { Ap Horizon; road fill; } 0-25 \\
\text { cm }\end{array}$ & $\begin{array}{l}\text { plasmic fabric: crystic } \\
\text { related distribution: porphyroskelic to agglomeroplasmic } \\
\text { skeleton grains: mostly silt to medium sand-size quartz, subrounded, poorly sorted; } \\
\text { common fine-sand to pebble-size car bonate clasts, angular, poorly sorted; few silt to } \\
\text { fine sand-size feldspars; few fine to medium sand-size chert; trace amounts of silt-size } \\
\text { zircons and amphiboles; two pebble-size olivine phenocrysts and one pebble-size } \\
\text { rhyolite clast; } 5 \% \text { silt to fine sand-size charcoal fragments, subrounded to angular } \\
\text { pedological features: few roots; many vughs, common channels and chambers; many } \\
\text { aggr otubules, few striotubules; mostly compound packing voids; two fine sand-size } \\
\text { wood fragments } \\
\text { cultural materials: none }\end{array}$ \\
\hline $\begin{array}{l}\text { A Horizon; Unit 2-f; } 25-40 \\
\text { cm }\end{array}$ & $\begin{array}{l}\text { plasmic fabric: crystic } \\
\text { related distribution: vughy porphyroskelic } \\
\text { skeleton grains: mostly silt to fine sand-size quartz, moderately sorted; few silt to fine } \\
\text { sand-size amphiboles and feldspars; few fine sand-size carbonate clasts; trace amounts } \\
\text { of silt-sized mica and zircon; few fine sand-size cracking clay clasts } \\
\text { pedological features: few snail fragments; few roots; many vughs, channels, and } \\
\text { chambers; many aggrotubules, few granotubules and striotubules; few compound } \\
\text { packing voids; } \\
\text { cultural materials: } 5 \% \text { silt to very fine sand-size charcoal fragments, mostly angular; } \\
\text { one bone fragment, } 0.5 \mathrm{~mm} \text { diameter }\end{array}$ \\
\hline $\begin{array}{l}\text { Bw1 Horizon; Unit 2-f; } \\
40-49 \mathrm{~cm}\end{array}$ & $\begin{array}{l}\text { plasmic fabric: crystic } \\
\text { related distribution: vughy porphyr oskelic } \\
\text { skele ton grains: mostly silt to fine sand-size quartz, moderately well sorted; few silt to } \\
\text { fine sand-size amphiboles; few silt to sand-size feldspars, amphiboles, and mica; few } \\
\text { fine sand-size carbonate clasts; trace amounts of silt-sized zircon; few fine to medium } \\
\text { sand-size cracking clay clasts; few faint Horizontal laminated cracking clay clasts; } 3 \% \\
\text { silt to very fine sand-size charcoal fragments, subangular to angular } \\
\text { pedological features: few snail fragments; few roots; common aggrotubules, few } \\
\text { granotubules and striotubules; common compound packing voids } \\
\text { cultural materials: none }\end{array}$ \\
\hline
\end{tabular}




\begin{tabular}{|c|c|}
\hline $\begin{array}{l}\text { Bw2 Horizon; Unit 2-f; } \\
49-64 \mathrm{~cm}\end{array}$ & $\begin{array}{l}\text { plasmic fabric: crystic } \\
\text { related distribution: vughy porphyroskelic } \\
\text { skele ton grains: mostly silt to fine sand-size quartz, moderately well sorted; common } \\
\text { fine sand-size carbonate clasts, subrounded; few silt to fine sand-size amphiboles, } \\
\text { feldspars, and micas; trace amounts of silt-sized zircon; few distinct cracking clay } \\
\text { clasts, silt to fine sand-size; } 5 \% \text { silt to fine sand-size charcoal fragments, subrounded } \\
\text { to angular. } \\
\text { pedological features: few fine calcans in vughs; few snail fragments; few roots; } \\
\text { common vughs, channels and chambers; common aggrotubules, few granotubules and } \\
\text { striotubules; common compound packing voids } \\
\text { cultural materials: none }\end{array}$ \\
\hline $\begin{array}{l}\text { Ab1 Horizon; Unit 2-f; } \\
64-76 \mathrm{~cm}\end{array}$ & $\begin{array}{l}\text { plasmic fabric: crystic } \\
\text { related distribution: porphyr oskelic } \\
\text { skele ton grains: mostly silt to fine sand-size quartz, moderately well sorted; common } \\
\text { fine sand-size carbonate clasts, subrounded; few silt to fine sand-size amphiboles and } \\
\text { micas; two medium to coarse sand-size igneous rock fragments; few distinct cracking } \\
\text { clay clasts, fine sand-size } \\
\text { pedological features: common snail fragments; few roots; common vughs, channels } \\
\text { and chambers; common aggr otubules and granotubules, few striotubules; common } \\
\text { compound packing voids } \\
\text { cultural materials(?): } 7 \% \text { silt to fine sand-size charcoal fragments, mostly angular }\end{array}$ \\
\hline $\begin{array}{l}\text { Bw1b1 Horizon; Unit 2-f; } \\
76-86 \mathrm{~cm}\end{array}$ & $\begin{array}{l}\text { plasmic fabric: crystic } \\
\text { related distribution: vughy porphyroskelic } \\
\text { skeleton grains: mostly silt to fine sand-size quartz, moderately well sorted; common } \\
\text { fine sand-size carbonate clasts, subrounded; few silt-size amphiboles, micas, and } \\
\text { feldspars; few distinct cracking clay clasts, fine sand-size } \\
\text { pedological features: } 1 \% \text { silt to fine sand-size gypsum crystals in vughs; common snail } \\
\text { fragments; few roots; many vughs, channels and chambers; common aggrotubules and } \\
\text { few granotubules, striotubules; common compound packing voids } \\
\text { cultural materials: } 5 \% \text { silt-size charcoal fragments, mostly angular; two fine to } \\
\text { medium-sand size bone fragments }\end{array}$ \\
\hline $\begin{array}{l}\text { Bw2b1 Horizon; Unit 2-f; } \\
86-108 \mathrm{~cm}\end{array}$ & $\begin{array}{l}\text { plasmic fabric: crystic } \\
\text { related distribution: vughy porphyroskelic } \\
\text { skele ton grains: mostly silt to fine sand-size quartz, moderately well sorted; common } \\
\text { fine sand-size carbonate clasts, subrounded; few silt-size amphiboles, micas, and } \\
\text { feldspars; } 3 \% \text { silt-size charcoal fragments, subrounded to angular } \\
\text { pedological features: } 2 \% \text { silt to fine sand-size gypsum crystals in vughs; few snail } \\
\text { fragments; few roots; many vughs, channels and chambers; common aggrotubules, } \\
\text { and few granotubules, striotubules; common compound packing voids } \\
\text { cultural materials: none }\end{array}$ \\
\hline $\begin{array}{l}\text { Bw3b1 Horizon; Unit 2-f; } \\
86-108 \mathrm{~cm}\end{array}$ & $\begin{array}{l}\text { plasmic fabric: crystic } \\
\text { related distribution: vughy porphyr oskelic } \\
\text { skeleton grains: mostly silt to fine sand-size quartz, moderately well sorted; common } \\
\text { fine sand-size carbonate clasts, subrounded; few silt-size amphiboles, micas, and } \\
\text { feldspars; common distinct cracking clay clasts, fine sand-size; } 3 \% \text { silt-size charcoal } \\
\text { fragments, subrounded to angular } \\
\text { pedological features: few snail fragments; few roots; many vughs, common channels } \\
\text { and chambers; common aggrotubules and gr anotubules, common striotubules; } \\
\text { common compound packing voids } \\
\text { cultural materials: none }\end{array}$ \\
\hline
\end{tabular}




\begin{tabular}{|c|c|}
\hline $\begin{array}{l}\text { Bw4b1 Horizon; Unit 2-f; } \\
125-149 \mathrm{~cm}\end{array}$ & $\begin{array}{l}\text { plasmic fabric: crystic } \\
\text { related distribution: vughy porphyroskelic } \\
\text { skele ton grains: mostly silt to fine sand-size quartz, moderately well sorted; few } \\
\text { silt-size amphiboles, micas, and feldspars; common fine sand-size carbonate clasts, } \\
\text { subrounded; common distinct cracking clay clasts, fine sand-size; } 3 \% \text { silt to fine } \\
\text { sand-size charcoal fragments, subrounded to angular } \\
\text { pedological features: } 1 \% \text { silt-size calcans in vughs; few snail fragments; few roots; } \\
\text { many vughs, common channels and chambers; common aggrotubules, few } \\
\text { striotubules; common compound packing voids } \\
\text { cultural materials: none }\end{array}$ \\
\hline $\begin{array}{l}\text { BCb4 Horizon; Unit 2-f; } \\
149-164 \mathrm{~cm}\end{array}$ & $\begin{array}{l}\text { plasmic fabric: crystic } \\
\text { related distribution: vughy porphyroskelic } \\
\text { skeleton grains: mostly silt to fine sand-size quartz, moderately well sorted; common } \\
\text { fine sand-size carbonate clasts, subrounded; few silt-size amphiboles, micas, and } \\
\text { feldspars; few distinct cracking clay clasts, fine sand-size; } 1 \% \text { silt to fine sand-size } \\
\text { charcoal fragments, mostly subrounded } \\
\text { pedological features: } 1 \% \text { silt-size calcans in vughs; few snail fragments; few roots; } \\
\text { many vughs, common channels and chambers; common aggr otubules, few } \\
\text { granotubules and striotubules; common compound packing voids } \\
\text { cultural materials: none }\end{array}$ \\
\hline \multicolumn{2}{|r|}{ BHT 9} \\
\hline $\begin{array}{l}\text { Ap2 Horizon; fill; } \\
11-21 \mathrm{~cm}\end{array}$ & $\begin{array}{l}\text { plasmic fabric: crystic } \\
\text { related distribution: porphyroskelic to agglomeroplasmic } \\
\text { skele ton grains: mostly silt to medium sand-size quartz, poorly sorted; common fine to } \\
\text { coarse sand-size carbonate clasts, subrounded to angular, poorly sorted; few silt-size } \\
\text { micas; few silt to fine-sand size zircon and amphiboles; one piece of rhyolite ( } 1.5 \mathrm{~mm} \\
\text { diameter) and one piece of trachyte ( } 3.5 \mathrm{~mm} \text { diameter); few cracking clay clasts, fine } \\
\text { sand-size; } 4 \% \text { silt to fine sand-size charcoal fragments, mostly subrounded } \\
\text { pedological features: few snail fragments; few roots; common vughs, channels and } \\
\text { chambers; many aggrotubules; common compound packing voids } \\
\text { cultural materials: none }\end{array}$ \\
\hline $\begin{array}{l}\text { A1 Horizon; Unit 2-f; 21-39 } \\
\text { cm }\end{array}$ & $\begin{array}{l}\text { plasmic fabric: crystic } \\
\text { related distribution: porphyr oskelic to agglomeroplasmic } \\
\text { skele ton grains: mostly silt to medium sand-size quartz, moderately sorted; common } \\
\text { fine sand-size carbonate clasts, subrounded to angular, poorly sorted; three angular } \\
\text { limestone fragments, } 1 \text { to } 2 \mathrm{~mm} \text { diameter; few fine to coarse sand-size feldspars; trace } \\
\text { amounts of silt to very fine sand-size zircon, amphibole, chert; few distinct cracking } \\
\text { clay clasts, silt to coarse-sand size; } 2 \% \text { silt to fine sand-size charcoal fragments, } \\
\text { angular to subrounded } \\
\text { pedological features: common snail fragments; few roots; many vughs, common } \\
\text { channels, and chambers; many aggrotubules; few striotubules; common compound } \\
\text { packing voids } \\
\text { cultural materials: none }\end{array}$ \\
\hline $\begin{array}{l}\text { A2 Horizon; Unit 2-f; 39-49 } \\
\mathrm{cm}\end{array}$ & $\begin{array}{l}\text { plasmic fabric: crystic } \\
\text { related distribution: porphyr oskelic } \\
\text { skele ton grains: mostly silt to fine sand-size quartz, moderately sorted; common silt to } \\
\text { fine sand-size carbonate clasts, subrounded; few silt to fine sand-size feldspars, and } \\
\text { amphiboles; trace amounts of silt to very fine sand-size zircon and mica; common } \\
\text { distinct cracking clay clasts, fine to very coarse sand-size } \\
\text { pedological features: few snail fragments; few roots; many vughs, channels, and } \\
\text { chambers; common aggrotubules, few granotubules; common compound packing voids } \\
\text { cultural materials: 7\% silt to fine sand-size charcoal fragments, mostly subrounded; } \\
\text { one medium sand-size bone fragment }\end{array}$ \\
\hline
\end{tabular}




\begin{tabular}{|c|c|}
\hline $\begin{array}{l}\text { Bw1 Horizon; Unit 2-f; } \\
49-63 \mathrm{~cm}\end{array}$ & $\begin{array}{l}\text { plasmic fabric: crystic } \\
\text { related distribution: porphyr oskelic } \\
\text { skele ton grains: mostly silt to fine sand-size quartz, moderately sorted; common silt to } \\
\text { fine sand-size carbonate clasts, subrounded; few silt to fine sand-size feldspars, } \\
\text { amphiboles; few silt-size micas; trace amounts of very fine sand-size zircon; common } \\
\text { distinct cracking clay clasts, fine to very coarse sand-size; } 6 \% \text { silt to fine sand-size } \\
\text { charcoal fragments, subrounded to angular } \\
\text { pedological features: few snail fragments; few roots; many vughs, common chambers; } \\
\text { common aggrotubules, few granotubules; few compound packing voids } \\
\text { cultural materials: none }\end{array}$ \\
\hline $\begin{array}{l}\text { Bw2 Horizon; Unit 2-f; } \\
63-88 \mathrm{~cm}\end{array}$ & $\begin{array}{l}\text { plasmic fabric: crystic } \\
\text { related distribution: porphyr oskelic } \\
\text { skeleton grains: mostly silt to fine sand-size quartz, moderately sorted; common fine } \\
\text { to medium sand-size carbonate clasts, subrounded; few silt to fine sand-size feldspars, } \\
\text { amphiboles; few silt-size micas; trace amounts of very fine sand-size zircon; three } \\
\text { igneous rock fragments, } 2.5 \text { to } 3.5 \mathrm{~mm} \text { diameter; few faint cracking clay clasts, fine } \\
\text { to very coarse sand-size; } 4 \% \text { silt-size charcoal fragments, mostly subrounded } \\
\text { pedological features: few snail fragments; few roots; many vughs, common chambers; } \\
\text { common aggrotubules, granotubules; few compound packing voids } \\
\text { cultural materials: none }\end{array}$ \\
\hline $\begin{array}{l}\text { Bw3 Horizon; Unit 2-f; } \\
88-108 \mathrm{~cm}\end{array}$ & $\begin{array}{l}\text { plasmic fabric: crystic } \\
\text { related distribution: porphyr oskelic } \\
\text { skeleton gr ains: mostly silt to fine sand-size quartz, moderately sorted; common fine } \\
\text { to medium sand-size carbonate clasts, subrounded; few silt to fine sand-size feldspars, } \\
\text { and amphiboles; few silt-size micas; trace amounts of very fine sand-size zircon; few } \\
\text { cracking clay clasts, fine to very coarse sand-size; 3\% silt-size charcoal fragments, } \\
\text { mostly subrounded } \\
\text { pedological features: common vughs, common chambers; few aggrotubules, } \\
\text { granotubules; few compound packing voids } \\
\text { cultural materials: none }\end{array}$ \\
\hline $\begin{array}{l}\text { BC Horizon; Unit 2-p; } \\
108-149 \mathrm{~cm}\end{array}$ & $\begin{array}{l}\text { plasmic fabric: crystic to silasepic fabric } \\
\text { related distribution: vughy porphyr oskelic to granular } \\
\text { skele ton grains: mostly silt to fine sand-size quartz, moderately sorted; many fine to } \\
\text { medium sand-size carbonate clasts, subrounded; few silt to fine sand-size feldspars, } \\
\text { amphiboles; few silt-size micas; trace amounts of very fine sand-size zircon; few faint } \\
\text { cracking clay clasts, fine to medium sand-size; } 3 \% \text { silt to fine sand-size charcoal } \\
\text { fragments, subrounded to angular } \\
\text { pedological features: one fine sand-size carbonate nodule in matrix; common vughs, } \\
\text { few chambers; few granotubules } \\
\text { cultural materials: none }\end{array}$ \\
\hline $\begin{array}{l}\text { C Horizon; Unit 2-p; } \\
149-164 \mathrm{~cm}\end{array}$ & $\begin{array}{l}\text { plasmic fabric: crystic to silasepic fabric } \\
\text { related distribution: vughy porphyr oskelic to granular } \\
\text { skeleton grains: mostly silt to medium sand-size quartz, moderately sorted; many fine } \\
\text { to medium sand-size carbonate clasts, subrounded; few silt to fine sand-size feldspars, } \\
\text { amphiboles; few silt-size micas; trace amounts of very fine sand-size zircon; very few } \\
\text { cracking clay clasts, fine to medium sand-size; } 4 \% \text { silt to fine sand-size charcoal } \\
\text { fragments, subrounded to angular } \\
\text { pedological features: few vughs, channels; many simple packing voids } \\
\text { cultural materials: none }\end{array}$ \\
\hline
\end{tabular}




\begin{tabular}{|c|c|}
\hline \multicolumn{2}{|r|}{ ВHT 10} \\
\hline $\begin{array}{l}\text { Bw2 Horizon; Unit 2-f; } \\
64-76 \mathrm{~cm}\end{array}$ & $\begin{array}{l}\text { plasmic fabric: crystic } \\
\text { related distribution: vughy porphyroskelic } \\
\text { skeleton grains: mostly silt to fine sand-size quartz, moderately sorted; common silt to } \\
\text { fine sand-size carbonate clasts, subrounded; trace amounts of silt to very fine } \\
\text { sand-size, mica, feldspars, and amphiboles; common distinct cracking clay clasts, fine } \\
\text { to medium sand-size } \\
\text { pedological features: few snails; few roots; many vughs, channels, and chambers; } \\
\text { many aggrotubules, few granotubules and striotubules } \\
\text { cultural materials: three fine sand-size cherts; } 5 \% \text { silt to fine sand-size charcoal } \\
\text { fragments, mostly angular. }\end{array}$ \\
\hline \multicolumn{2}{|r|}{ BHT 12} \\
\hline $\begin{array}{l}\text { Ab1 Horizon (upper } \\
\text { hearth); Unit 2-f; 140-152 } \\
\text { cm }\end{array}$ & $\begin{array}{l}\text { plasmic fabric: crystic } \\
\text { related distribution: vughy porphyroskelic } \\
\text { skele ton grains: mostly silt size quartz, subrounded, moderately sorted; } 2 \% \text { fine to } \\
\text { medium sand-size carbonates, subrounded; trace amounts of micas, amphiboles, and } \\
\text { feldspars; many medium sand to pebble-size cracking clay clasts } \\
\text { pedological features: } 1 \% \text { silt to very fine sand-size gypsum crystals in vughs; } 1 \% \text { fine } \\
\text { silt-size carbonate needles in vughs; few snails; few roots; many vughs, common } \\
\text { channels and chambers; many aggrotubules } \\
\text { cultural materials: } 10 \% \text { silt to medium sand-size charcoal fragments, mostly angular; } \\
\text { ashy }\end{array}$ \\
\hline $\begin{array}{l}\text { Ab1 Horizon (lower } \\
\text { hearth); Unit 2-f; 140-152 } \\
\text { cm }\end{array}$ & $\begin{array}{l}\text { plasmic fabric: crystic } \\
\text { related distribution: vughy porphyroskelic } \\
\text { skeleton grains: mostly silt size quartz, subrounded, moderately sorted; } 2 \% \text { fine to } \\
\text { medium sand-size carbonates, subrounded; trace amounts of micas, amphiboles, and } \\
\text { feldspars; many medium sand to pebble-size cracking clay clasts } \\
\text { pedological features: } 1 \% \text { silt to very fine sand-size gypsum crystals in vughs; } 1 \% \text { fine } \\
\text { silt-size carbonate needles in vughs; few snails; few roots; many vughs, common } \\
\text { channels and chambers; many aggrotubules } \\
\text { cultural materials: } 5 \% \text { silt to medium sand-size charcoal fragments, mostly angular; } \\
\text { ashy }\end{array}$ \\
\hline
\end{tabular}


EP-1

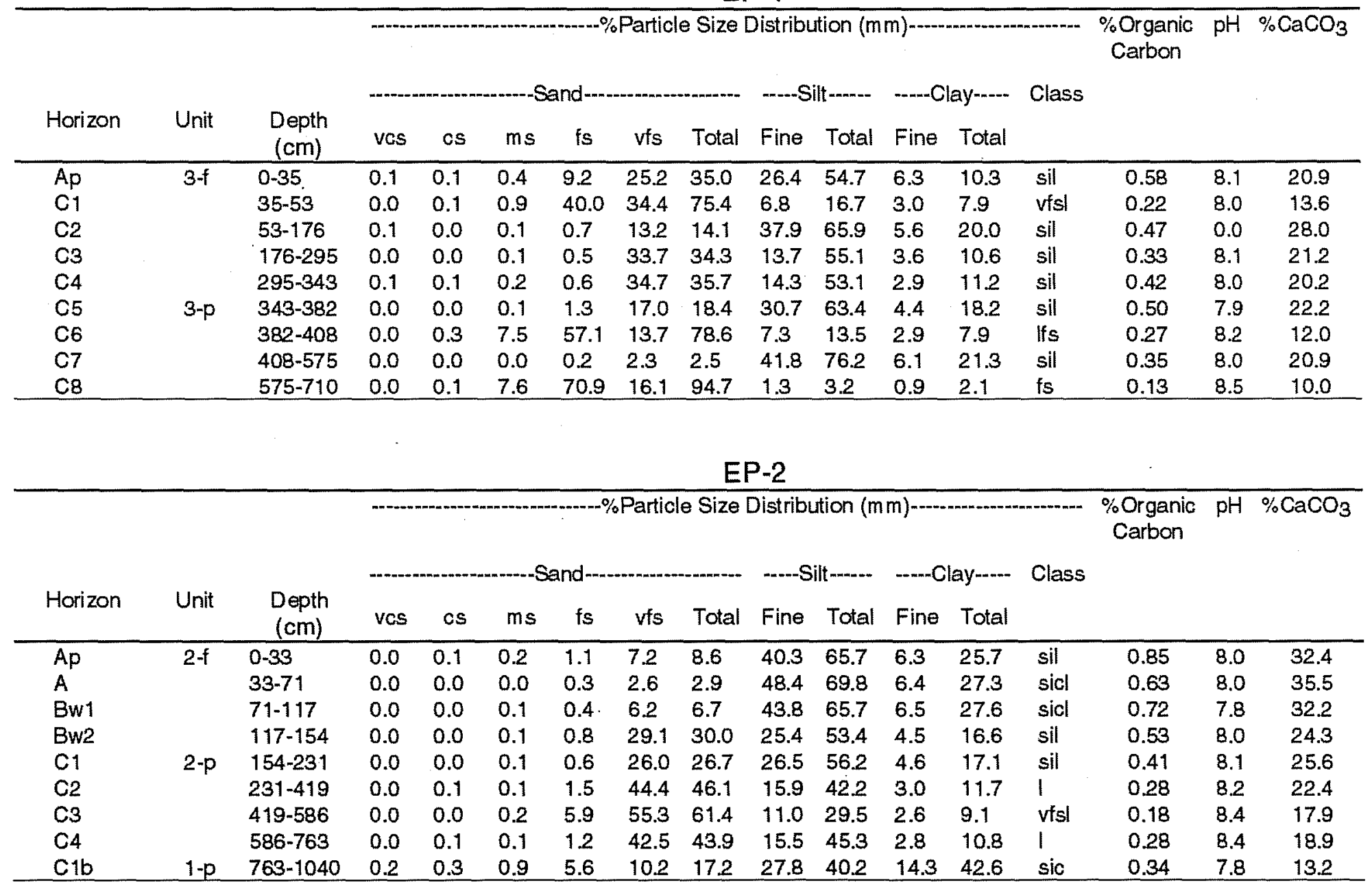




\section{EP-3}

$\%$ Particle Size Distribution ( $\mathrm{mm}$ )

$\%$ Organic $\mathrm{pH} \% \mathrm{CaCO}_{3} \% \mathrm{CaSO}_{4}$ Carbon

\begin{tabular}{|c|c|c|c|c|c|c|c|c|c|c|c|c|c|c|c|c|c|}
\hline \multirow[b]{2}{*}{ Horizon } & \multirow[b]{2}{*}{ Unit } & \multirow[b]{2}{*}{$\begin{array}{c}\text { Depth } \\
\text { (cm) }\end{array}$} & \multicolumn{6}{|c|}{-Sand } & \multicolumn{2}{|c|}{----Silt -......- } & \multicolumn{2}{|c|}{-.-.-Clay--..- } & \multirow[t]{2}{*}{ Class } & & & & \\
\hline & & & vas & cs & $\mathrm{ms}$ & is & $v f s$ & Total & Fine & Total & Fine & Total & & & & & \\
\hline$A$ & $1-s$ & $0-33$ & 0.5 & 1.6 & 9.5 & 31.2 & 15.3 & 58.1 & 10.5 & 17.4 & 10.3 & 24.5 & $\mathrm{scl}$ & 1.29 & 7.9 & 9.1 & \\
\hline $\mathrm{Bt}$ & & $33-56$ & 0.3 & 1.1 & 5.2 & 18.2 & 12.9 & 37.7 & 16.7 & 24.8 & 16.8 & 37.5 & $\mathrm{cl}$ & 0.52 & 7.7 & 20.0 & \\
\hline Btk & & $56-93$ & 0.1 & 0.8 & 4.6 & 16.2 & 12.0 & 33.7 & 22.3 & 32.2 & 19.3 & 34.1 & $\mathrm{cl}$ & 0.42 & 7.8 & 22.2 & \\
\hline Bky 1 & & $93-124$ & 0.1 & 0.5 & 2.6 & 11.6 & 10.9 & 25.7 & 19.9 & 33.7 & 22.4 & 40.7 & $\mathrm{c}$ & 0.24 & 7.6 & 16.4 & 15.7 \\
\hline Bky2 & & $124-194$ & 0.3 & 0.4 & 2.9 & 11.6 & 10.4 & 25.6 & 23.3 & 35.1 & 21.6 & 39.3 & $\mathrm{cl}$ & 0.14 & 7.7 & 17.1 & 7.0 \\
\hline Bky3 & & $194-245$ & 0.0 & 0.1 & 0.8 & 4.9 & 22.7 & 28.5 & 23.9 & 36.4 & 16.5 & 35.1 & $\mathrm{cl}$ & 0.05 & 7.7 & 20.6 & 4.2 \\
\hline $\mathrm{C}$ & $1-p$ & $245-278$ & 0.1 & 0.9 & 22.9 & 48.8 & 9.3 & 82.0 & 5.1 & 7.2 & 5.3 & 10.8 & Ifs & 0.05 & 8.2 & 0.8 & \\
\hline Ck & & $278-332$ & 1.5 & 1.3 & 2.1 & 20.1 & 14.4 & 39.4 & 28.5 & 37.1 & 9.3 & 23.5 & 1 & 0.02 & 7.9 & 32.1 & \\
\hline $\mathrm{C}_{1}$ & & $332-370$ & 0.0 & 0.0 & 2.3 & 75.9 & 10.3 & 88.5 & 2.4 & 3.9 & 3.6 & 7.6 & Ifs & 0.06 & 8.4 & 0.0 & \\
\hline $\mathrm{Cr} 1$ & bedrock & $401-487$ & 0.4 & 0.5 & 0.2 & 0.4 & 1.5 & 3.0 & 42.4 & 53.0 & 5.5 & 44.0 & sic & 0.22 & 7.2 & 0.7 & \\
\hline
\end{tabular}

EP-4

\begin{tabular}{|c|c|c|c|c|c|c|c|c|c|c|c|c|c|c|c|c|}
\hline \multirow[b]{3}{*}{ Horizon } & \multirow[b]{3}{*}{ Unit } & \multirow[b]{3}{*}{$\begin{array}{c}\text { Depth } \\
(\mathrm{cm})\end{array}$} & \multicolumn{11}{|c|}{ - $\%$ Particle Size Distribution $(\mathrm{mm})$} & \multirow[t]{3}{*}{$\begin{array}{c}\% \text { Organic } \\
\text { Carbon }\end{array}$} & \multirow[t]{3}{*}{$\mathrm{pH}$} & \multirow[t]{3}{*}{$\% \mathrm{CaCO}_{3}$} \\
\hline & & & \multicolumn{6}{|c|}{ 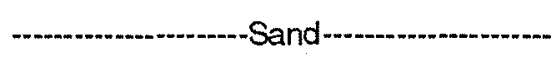 } & \multicolumn{2}{|c|}{-.---Silt -.....-- } & \multicolumn{2}{|c|}{-...-.-Clay-..... } & \multirow[t]{2}{*}{ Class } & & & \\
\hline & & & ves & cs & $\mathrm{ms}$ & fs & vis & Total & Fine & Total & Fine & Total & & & & \\
\hline A & $1-f$ & $0-19$ & 0.4 & 1.2 & 6.5 & 26.3 & 19.6 & 54.0 & 11.2 & 21.0 & 12.1 & 25.0 & $\mathrm{scl}$ & 1.65 & 7.4 & 2.0 \\
\hline $\mathrm{Bt}$ & & $19-76$ & 0.4 & 1.0 & 5.0 & 23.6 & 22.5 & 52.5 & 10.5 & 20.5 & 15.3 & 27.0 & $\mathrm{scl}$ & 0.54 & 7.8 & 2.9 \\
\hline Btk & & $76-97$ & 1.7 & 1.4 & 5.0 & 24.2 & 22.8 & 55.1 & 11.9 & 21.6 & 12.1 & 23.3 & $\mathrm{scl}$ & 0.34 & 8.0 & 8.1 \\
\hline $\mathrm{Bk}$ & $1-p$ & $97-113$ & 2.0 & 1.6 & 6.1 & 23.0 & 22.0 & 54.7 & 14.8 & 24.7 & 10.9 & 20.6 & $\mathrm{sol}$ & 0.34 & 8.1 & 14.2 \\
\hline
\end{tabular}


BHT-8

\begin{tabular}{|c|c|c|c|c|c|c|c|c|c|c|c|c|c|c|c|c|}
\hline \multirow[b]{3}{*}{ Horizon } & \multirow[b]{3}{*}{ Unit } & \multirow[b]{3}{*}{$\begin{array}{l}\text { Depth } \\
(\mathrm{cm})\end{array}$} & \multirow{2}{*}{\multicolumn{6}{|c|}{ Sand }} & \multirow{2}{*}{\multicolumn{2}{|c|}{----Silt ----.- }} & \multirow{2}{*}{\multicolumn{2}{|c|}{--.--Clay-.... }} & \multirow{3}{*}{ Class } & \multirow[t]{3}{*}{$\begin{array}{c}\text { \%Organic } \\
\text { Carbon }\end{array}$} & \multirow[t]{3}{*}{$\mathrm{pH}$} & \multirow[t]{3}{*}{$\% \mathrm{CaCO}_{3}$} \\
\hline & & & & & & & & & & & & & & & & \\
\hline & & & ves & cs & $\mathrm{ms}$ & fs & vis & Total & Fine & Total & Fine & Total & & & & \\
\hline $\mathrm{Ap}$ & fill & $0-25$ & 0.5 & 0.5 & 1.3 & 3.5 & 11.1 & 16.9 & 37.1 & 58.4 & 5.1 & 24.7 & sil & 1.27 & 7.6 & 26.6 \\
\hline A & $2-f$ & $25-40$ & 0.2 & 0.2 & 0.4 & 1.6 & 10.0 & 12.4 & 39.0 & 59.6 & 7.4 & 28.0 & sicl & 1.19 & 7.7 & 27.6 \\
\hline Bw1 & & $40-49$ & 0.1 & 0.1 & 0.3 & 1.1 & 15.6 & 17.2 & 32.3 & 59.8 & 6.0 & 23.0 & sil & 0.85 & 7.8 & 26.7 \\
\hline Bw2 & & $49-64$ & 0.1 & 0.1 & 0.2 & 0.8 & 9.8 & 11.0 & 35.7 & 61.1 & 8.6 & 27.9 & sicl & 0.70 & 7.7 & 30.0 \\
\hline Ab1 & & $64-76$ & 0.1 & 0.1 & 0.3 & 0.8 & 7.2 & 8.5 & 40.8 & 61.6 & 10.1 & 29.9 & sicl & 0.89 & 7.7 & 30.7 \\
\hline Bw1b1 & & $76-86$ & 0.0 & 0.1 & 0.3 & 0.7 & 6.5 & 7.6 & 41.8 & 61.4 & 9.5 & 31.0 & sicl & 0.82 & 7.8 & 33.8 \\
\hline Bw2b1 & & $86-106$ & 0.0 & 0.1 & 0.3 & 0.8 & 7.7 & 8.9 & 42.1 & 60.3 & 9.2 & 30.8 & sicl & 0.79 & 7.8 & 31.8 \\
\hline Bw3b1 & & $106-125$ & 0.1 & 0.1 & 0.2 & 0.9 & 11.4 & 12.7 & 39.3 & 60.9 & B.0 & 26.4 & sil & 0.56 & 7.9 & 28.9 \\
\hline Bw4b1 & & $125-149$ & 0.0 & 0.1 & 0.1 & 0.5 & 15.8 & 16.5 & 35.5 & 65.0 & 8.0 & 18.5 & sil & 0.50 & 8.0 & 30.0 \\
\hline $\mathrm{BCb} 1$ & & $149-164$ & 0.0 & 0.0 & 0.1 & 0.4 & 20.4 & 20.9 & 26.0 & 58.6 & 7.0 & 20.5 & sil & 0.38 & 8.1 & 28.8 \\
\hline
\end{tabular}

BHT-9

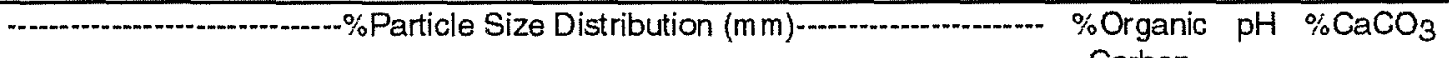
Carbon

\begin{tabular}{|c|c|c|c|c|c|c|c|c|c|c|c|c|c|c|c|c|}
\hline \multirow[b]{2}{*}{ Horizon } & \multirow[b]{2}{*}{ Unit } & \multirow[b]{2}{*}{$\begin{array}{l}\text { Depth } \\
(\mathrm{cm})\end{array}$} & \multicolumn{6}{|c|}{ - Sand - } & \multicolumn{2}{|c|}{-..---Silt-...-- } & \multicolumn{2}{|c|}{-.-.-.Clay-..-- } & \multirow[t]{2}{*}{ Class } & & & \\
\hline & & & vos & cs & ms & fs & vis & Total & Fine & Total & Fine & Total & & & & \\
\hline Ap1 & fill & $0-9$ & 0.7 & 0.6 & 1.5 & 4.3 & 16.6 & 23.7 & 29.5 & 54.1 & 4.6 & 22.2 & sil & 1.31 & 7.6 & 26.1 \\
\hline Ap2 & & $9-21$ & 0.4 & 0.5 & 1.3 & 3.7 & 14.5 & 20.4 & 31.2 & 52.4 & 8.0 & 27.2 & $\mathrm{cl}$ & 1.18 & 7.8 & 27.3 \\
\hline A1 & $2-f$ & $21-39$ & 0.1 & 0.2 & 0.4 & 1.2 & 10.6 & 12.5 & 35.2 & 57.3 & 9.2 & 30.2 & sicl & 0.99 & 7.9 & 28.4 \\
\hline $\mathrm{A} 2$ & & $39-49$ & 0.1 & 0.1 & 0.2 & 1.0 & $1 \mathrm{~B} .3$ & 19.7 & 32.6 & 55.2 & 8.4 & 25.1 & sil & 0.78 & 8.0 & 28.7 \\
\hline Bw1 & & $49-63$ & 0.1 & 0.2 & 0.3 & 1.2 & 19.8 & 21.6 & 32.2 & 54.8 & 8.6 & 23.6 & sil & 0.65 & 8.0 & 28.8 \\
\hline Bw2 & & $63-88$ & 0.0 & 0.0 & 0.1 & 1.0 & 22.2 & 23.3 & 26.0 & 56.3 & 6.0 & 20.4 & sil & 0.57 & 8.1 & 27.2 \\
\hline Bw3 & & $88-108$ & 0.0 & 0.0 & 0.1 & 0.9 & 30.4 & 31.4 & 20.3 & 52.5 & 4.9 & 16.1 & sil & 0.37 & B.1 & 27.0 \\
\hline $\mathrm{BCb}$ & $2-p$ & $108-149$ & 0.0 & 0.0 & 0.1 & 0.9 & 38.8 & 39.8 & 15.5 & 48.6 & 3.6 & 11.6 & 1 & 0.40 & 8.2 & 24.2 \\
\hline C & & $149-164$ & 0.0 & 0.0 & 0.1 & 0.8 & 48.9 & 49.8 & 10.4 & 42.1 & 2.6 & 8.1 & 1 & 0.29 & B. 3 & 20.5 \\
\hline
\end{tabular}


Appendix C: Site Artifact Data 


\begin{tabular}{|c|c|c|c|c|c|c|c|c|c|}
\hline Area & $\mathbf{E U}$ & Level & Level 2 & Cores & Debitage & Tools & FCR & Mussel & Snail \\
\hline 1 & 1 & 1.2 & 1 & 2 & 7 & 0 & 97.8 & 0 & 0 \\
\hline 1 & 1 & 3 & 2 & 0 & 2 & 0 & 3.2 & 0.1 & 0.1 \\
\hline 1 & 1 & 4 & 3 & 0 & 4 & 0 & 0 & 0 & 0 \\
\hline 1 & 1 & 5 & 4 & 0 & 5 & 0 & 4.6 & 1.3 & 0.2 \\
\hline 1 & 1 & 6 & 5 & 0 & 2 & 0 & 0.4 & 20.4 & 1.3 \\
\hline 1 & 1 & 7 & 6 & 0 & 10 & 0 & 2.8 & 9.9 & 0.5 \\
\hline 1 & 1 & 8 & 7 & 0 & 46 & 0 & 69.2 & 15.7 & 1.6 \\
\hline 1 & 1 & 9 & 8 & 0 & 206 & 0 & 48.6 & 9.5 & 0.6 \\
\hline 1 & 1 & 10 & 9 & 0 & 164 & 0 & 12.5 & 36 & 9.2 \\
\hline 1 & 1 & 11,12 & 10 & 0 & 215 & 5 & 678.8 & 11.30 & 6.00 \\
\hline 1 & 1 & 13,14 & 11 & 0 & 17 & 0 & 0 & 0 & 0 \\
\hline 1 & 1 & 15,16 & 12 & 0 & 0 & 0 & 0 & 0 & 0 \\
\hline 1 & 12 & 1,2 & 5 & 0 & 0 & 0 & 0 & 0 & 0 \\
\hline 1 & 12 & 3,4 & 6 & 0 & 4 & 0 & 4.6 & 8 & 1.4 \\
\hline 1 & 12 & 5,6 & 7 & 0 & 6 & 0 & 0 & 16.6 & 0.1 \\
\hline 1 & 12 & 7,8 & 8 & 0 & 26 & 1 & 21.7 & 2.5 & 1.5 \\
\hline 1 & 12 & 9 & 9 & 0 & 129 & 0 & 131.6 & 19.7 & 0.7 \\
\hline 1 & 12 & 10 & 10 & 0 & 207 & 3 & 3.5 & 66 & 3.8 \\
\hline 1 & 12 & 11 & 11 & 0 & 91 & 1 & 11 & 5.6 & 0.4 \\
\hline 1 & 12 & 12 & 12 & 0 & 120 & 1 & 147.8 & 9.9 & 2.7 \\
\hline 1 & 12 & 13 & 13 & 0 & 63 & 0 & 5.3 & 1.2 & 2.5 \\
\hline 1 & 12 & 14 & 14 & 0 & 0 & 0 & 0.00 & 0.1 & 0 \\
\hline 1 & 13 & 1,2 & 5 & 0 & 1 & 0 & 0 & 1.5 & 0 \\
\hline 1 & 13 & 3 & 6 & 0 & 3 & 1 & 0 & 0.9 & 0.1 \\
\hline 1 & 13 & 4 & 7 & 0 & 21 & 0 & 62.1 & 12.3 & 0.9 \\
\hline 1 & 13 & 5 & 8 & 0 & 26 & 0 & 345.9 & 7.3 & 1.6 \\
\hline 1 & 13 & 6 & 9 & 1 & 74 & 0 & 65.9 & 28 & 0 \\
\hline 1 & 13 & 7 & 10 & 0 & 33 & 1 & 62.7 & 22.5 & 2.1 \\
\hline 1 & 13 & 8 & 11 & 0 & 153 & 0 & 167.6 & 71.5 & 0.9 \\
\hline 1 & 13 & 9 & 12 & 0 & 19 & 1 & 23.4 & 5.1 & 0.6 \\
\hline 1 & 14 & 1,2 & 5 & 0 & 1 & 0 & 4.3 & 0.1 & 0 \\
\hline 1 & 14 & 3,4 & 6 & 0 & 9 & 0 & 124.5 & 9.4 & 0.6 \\
\hline 1 & 14 & 5,6 & 7 & 0 & 18 & 0 & 68.3 & 30.2 & 2.3 \\
\hline 1 & 14 & 7 & 8 & 0 & 15 & 0 & 22.3 & 49.2 & 0.2 \\
\hline 1 & 14 & 8 & 9 & 0 & 60 & 0 & 60.1 & 43.3 & 3.8 \\
\hline 1 & 14 & 9 & 10 & 0 & 175 & 0 & 23.8 & 97.6 & 0.3 \\
\hline 1 & 14 & 10 & 11 & 0 & 21 & 1 & 4 & 40.5 & 0.7 \\
\hline 1 & 14 & 11 & 12 & 0 & 44 & 0 & 6.5 & 18.8 & 0.1 \\
\hline 1 & 15 & 7 & 7 & 0 & 43 & 0 & 87 & 0.6 & 0.4 \\
\hline 1 & 15 & 8 & 8 & 0 & 10 & 0 & 179.6 & 8.8 & 0.1 \\
\hline 1 & 15 & 9 & 9 & 0 & 94 & 0 & 355.6 & 11.1 & 0.6 \\
\hline 1 & 15 & 10 & 10 & 0 & 78 & 0 & 285.2 & 51.8 & 2.8 \\
\hline 1 & 15 & 11 & 11 & 1 & 42 & 1 & 438.8 & 3.5 & 4 \\
\hline
\end{tabular}




\begin{tabular}{|c|c|c|c|c|c|c|c|c|c|}
\hline Area & $\mathbf{E U}$ & Level & Level 2 & Cores & Debitage & Tools & FCR & Mussel & Snail \\
\hline 1 & 15 & 12 & 12 & 0 & 70 & 1 & 137.4 & 106.7 & 9.5 \\
\hline 1 & 31 & 7 & 7 & 0 & 16 & 0 & 8.9 & 8.9 & 3 \\
\hline 1 & 31 & 8 & 8 & 0 & 48 & 0 & 826.7 & 7 & 2.6 \\
\hline 1 & 31 & 9 & 9 & 0 & 103 & 0 & 568.4 & 8 & 1.1 \\
\hline 1 & 31 & 10 & 10 & 0 & 42 & 0 & 17.8 & 17.4 & 0.9 \\
\hline 1 & 31 & 11 & 11 & 0 & 60 & 1 & 0.9 & 3.1 & 3.9 \\
\hline 1 & 31 & 12 & 12 & 0 & 45 & 0 & 67.9 & 0.5 & 0.4 \\
\hline 1 & 31 & 13 & 13 & 0 & 9 & 0 & 0 & 1 & 0.8 \\
\hline 1 & 31 & 14 & 14 & 0 & 1 & 0 & 35.5 & 20 & 1.1 \\
\hline 1 & 32 & 7 & 7 & 0 & 15 & 0 & 58.5 & 1.4 & 2.8 \\
\hline 1 & 32 & 8 & 8 & 0 & 53 & 0 & 249.2 & 9.2 & 3.8 \\
\hline 1 & 32 & 9 & 9 & 0 & 98 & 2 & 275.6 & 38.2 & 0.9 \\
\hline 1 & 32 & 10 & 10 & 0 & 58 & 0 & 62.8 & 34.5 & 0.3 \\
\hline 1 & 32 & 11 & 11 & 0 & 173 & 0 & 189.8 & 7.7 & 2.4 \\
\hline 1 & 32 & 12 & 12 & 0 & 51 & 0 & 101.3 & 2.2 & 9.4 \\
\hline 1 & 33 & 7 & 7 & 0 & 29 & 0 & 59.9 & 14.1 & 0.1 \\
\hline 1 & 33 & 8 & 8 & 0 & 41 & 0 & 26.7 & 7.6 & 0.5 \\
\hline 1 & 33 & 9 & 9 & 0 & 114 & 0 & 125.8 & 58.7 & 7.9 \\
\hline 1 & 33 & 10 & 10 & 0 & 69 & 0 & 23.8 & 7.3 & 3.5 \\
\hline 1 & 33 & 11 & 11 & 0 & 109 & 0 & 111.6 & 16.2 & 7.6 \\
\hline 1 & 33 & 12 & 12 & 0 & 42 & 1 & 73.9 & 25.2 & 7 \\
\hline 1 & 34 & 7 & 7 & 0 & 20 & 0 & 1.4 & 1.1 & 0.2 \\
\hline 1 & 34 & 8 & 8 & 0 & 35 & 1 & 271.7 & 8 & 0 \\
\hline 1 & 34 & 9 & 9 & 0 & 65 & 0 & 100.4 & 50.6 & 3.2 \\
\hline 1 & 34 & 10 & 10 & 0 & 38 & 0 & 46.7 & 4.5 & 0.2 \\
\hline 1 & 34 & 11 & 11 & 0 & 64 & 0 & 83.3 & 0.2 & 1.1 \\
\hline 1 & 34 & 12 & 12 & 0 & 35 & 0 & 385.7 & 3.8 & 2.6 \\
\hline 1 & 36 & 7 & 7 & 0 & 28 & 0 & 33.4 & 5.9 & 0.2 \\
\hline 1 & 36 & 8 & 8 & 0 & 58 & 0 & 54.3 & 19.5 & 0.2 \\
\hline 1 & 36 & 9 & 9 & 0 & 98 & 0 & 248.6 & 58.1 & 9.6 \\
\hline 1 & 36 & 10 & 10 & 0 & 60 & 1 & 74.9 & 20.2 & 1.6 \\
\hline 1 & 36 & 11 & 11 & 0 & 96 & 0 & 566.3 & 23.4 & 1.9 \\
\hline 1 & 36 & 12 & 12 & 0 & 55 & 0 & 290.8 & 2.3 & 10 \\
\hline 1 & 43 & 7 & 7 & 0 & 112 & 0 & 4.3 & 0 & 0 \\
\hline 1 & 43 & 8 & 8 & 0 & 70 & 0 & 6.8 & 7.2 & 0.2 \\
\hline 1 & 43 & 9 & 9 & 0 & 123 & 1 & 23.6 & 14.5 & 3.8 \\
\hline 1 & 43 & 10 & 10 & 0 & 68 & 0 & 56.7 & 3.8 & 1.7 \\
\hline 1 & 43 & 11 & 11 & 0 & 83 & 0 & 317.8 & 3.1 & 4.1 \\
\hline 1 & 43 & 12 & 12 & 0 & 42 & 0 & 316.3 & 1.8 & 0 \\
\hline 1 & 43 & 13 & 13 & 0 & 22 & 0 & 46.3 & 5.9 & 6 \\
\hline 1 & 43 & 14 & 14 & 0 & 11 & 0 & 11.9 & 0.5 & 2.4 \\
\hline 2 & 7 & 1 & 1 & 0 & 16 & 0 & 13.7 & 0.2 & 0 \\
\hline 2 & 7 & 2 & 2 & 0 & 0 & 0 & 55.3 & 0.1 & 0 \\
\hline
\end{tabular}




\begin{tabular}{|c|c|c|c|c|c|c|c|c|c|}
\hline Area & $\mathbf{E U}$ & Level & Level 2 & Cores & Debitage & Tools & FCR & Mussel & Snail \\
\hline 2 & 7 & 3 & 3 & 1 & 51 & 0 & 83.2 & 3.2 & 10.5 \\
\hline 2 & 7 & 4 & 4 & 0 & 21 & 0 & 5.3 & 0.7 & 5.9 \\
\hline 2 & 7 & 5 & 5 & 0 & 37 & 0 & 5.7 & 5.6 & 0 \\
\hline 2 & 7 & 6 & 6 & 0 & 67 & 0 & 0.7 & 1.1 & 1.8 \\
\hline 2 & 7 & 7 & 7 & 0 & 12 & 0 & 6.5 & 0 & 0 \\
\hline 2 & 7 & 8,9 & 8 & 0 & 9 & 0 & 24.1 & 0 & 0 \\
\hline 2 & 7 & 10,11 & 9 & 0 & 8 & 0 & 0.9 & 0.9 & 0 \\
\hline 2 & 7 & 12,13 & 10 & 0 & 9. & 0 & 9.3 & 0.7 & 0 \\
\hline 2 & 7 & 14,15 & 11 & 0 & 6 & 0 & 217.3 & 0 & 0 \\
\hline 2 & 7 & 16,17 & 12 & 0 & 2 & 0 & 0 & 0 & 0 \\
\hline 2 & 16 & 1 & 1 & 0 & 13 & 0 & 0 & 0 & 0 \\
\hline 2 & 16 & 2 & 2 & 0 & 17 & 0 & 225.1 & 0.3 & 0.2 \\
\hline 2 & 16 & 3,4 & 3 & 0 & 26 & 0 & 103.4 & 1.8 & 0.1 \\
\hline 2 & 16 & 5 & 4 & 0 & 27 & 2 & 625.7 & 0.6 & 3.3 \\
\hline 2 & 16 & 6 & 5 & 0 & 26 & 0 & 92.2 & 0 & 1.1 \\
\hline 2 & 16 & 7 & 6 & 0 & 25 & 2 & 55.3 & 0.2 & 2.6 \\
\hline 2 & 16 & 8 & 7 & 0 & 6 & 1 & 116.1 & 0 & 0 \\
\hline 2 & 16 & 9 & 8 & 0 & 12 & 0 & 3.3 & 0 & 0.2 \\
\hline 2 & 16 & 10 & 9 & 0 & 5 & 0 & 0 & 0 & 3.7 \\
\hline 2 & 16 & 11 & 10 & 0 & 4 & 0 & 31.9 & 0 & 0.1 \\
\hline 2 & 16 & 12 & 11 & 0 & 5 & 0 & 58.5 & 0 & 2.6 \\
\hline 2 & 16 & 13 & 12 & 0 & 0 & 0 & 13.9 & 0 & 0 \\
\hline 2 & 17 & 1 & 1 & 0 & 4 & 0 & 0 & 0 & 0 \\
\hline 2 & 17 & 2 & 2 & 0 & 6 & 2 & 10.5 & 0 & 1.5 \\
\hline 2 & 17 & 3 & 3 & 0 & 26 & 0 & 116.4 & 0.4 & 0.1 \\
\hline 2 & 17 & 4 & 4 & 0 & 31 & 0 & 19.7 & 4.4 & 0 \\
\hline 2 & 17 & 5 & 5 & 0 & 20 & 0 & 36.8 & 0 & 1 \\
\hline 2 & 17 & 6 & 6 & 0 & 21 & 0 & 63.1 & 0 & 2.9 \\
\hline 2 & 17 & 7 & 7 & 0 & 15 & 0 & 118.5 & 0.1 & 3.2 \\
\hline 2 & 17 & 8 & 8 & 0 & 7 & 0 & 149.2 & 0 & 3.4 \\
\hline 2 & 17 & 9 & 9 & 0 & 10 & 0 & 9.8 & 0 & 0.1 \\
\hline 2 & 17 & 10 & 10 & 0 & 7 & 0 & 7.7 & 0.1 & 0 \\
\hline 2 & 17 & 11 & 11 & 0 & 10 & 0 & 0 & 0 & 0 \\
\hline 2 & 18 & 1 & 3 & 1 & 13 & 0 & 85.4 & 0 & 1.7 \\
\hline 2 & 18 & 2 & 4 & 0 & 36 & 1 & 94.3 & 1.8 & 0 \\
\hline 2 & 18 & 3 & 5 & 0 & 94 & 0 & 80.3 & 2.1 & 6.8 \\
\hline 2 & 18 & 4 & 6 & 0 & 27 & 0 & 217 & 0.2 & 3.2 \\
\hline 2 & 18 & 5 & 7 & 0 & 12 & 0 & 0 & 0.8 & 3.9 \\
\hline 2 & 19 & 1,2 & 2 & 0 & 8 & 1 & 0 & 0 & 0 \\
\hline 2 & 19 & 3 & 3 & 0 & 20 & 0 & 68.6 & 0 & 0.3 \\
\hline 2 & 19 & 4 & 4 & 0 & 19 & 0 & 56.2 & 0 & 0 \\
\hline 2 & 19 & 5 & 5 & 0 & 33 & 0 & 33.6 & 0 & 0 \\
\hline 2 & 19 & 6 & 6 & 0 & 22 & 1 & 64.1 & 0 & 0.1 \\
\hline
\end{tabular}




\begin{tabular}{|c|c|c|c|c|c|c|c|c|c|}
\hline Area & EU & Level & Level 2 & Cores & Debitage & Tools & FCR & Mussel & Snail \\
\hline 2 & 19 & 7 & 7 & 0 & 27 & 0 & 97.5 & 0.3 & 1.3 \\
\hline 2 & 19 & 8 & 8 & 0 & 16 & 0 & 2.9 & 0 & 0.1 \\
\hline 2 & 19 & 9 & 9 & 0 & 16 & 0 & 1 & 0 & 0 \\
\hline 2 & 19 & 10 & 10 & 0 & 7 & 0 & 15.3 & 0 & 3.7 \\
\hline 2 & 19 & 11 & 11 & 0 & 4 & 0 & 28.1 & 0.2 & 2.8 \\
\hline 2 & 19 & 12 & 12 & 0 & 1 & 0 & 0 & 0 & 1.2 \\
\hline 2 & 20 & 1 & 1 & 0 & 11 & 0 & 4.3 & 0 & 0 \\
\hline 2 & 20 & 2 & 2 & 0 & 7 & 0 & 0 & 0.7 & 0 \\
\hline 2 & 20 & 3 & 3 & 0 & 21 & 0 & 62.9 & 0.7 & 0 \\
\hline 2 & 20 & 4 & 4 & 0 & 35 & 0 & 372.4 & 0 & 0 \\
\hline 2 & 20 & 5 & 5 & 0 & 46 & 0 & 70.3 & 0.2 & 0.2 \\
\hline 2 & 20 & 6 & 6 & 0 & 69 & 0 & 170.8 & 4.8 & 0.2 \\
\hline 2 & 20 & 7 & 7 & 1 & 33 & 0 & 40.9 & 2 & 0 \\
\hline 2 & 20 & 8 & 8 & 0 & 40 & 0 & 16.5 & 0 & 0 \\
\hline 2 & 20 & 9 & 9 & 0 & 9 & 0 & 38.9 & 0.2 & 0.3 \\
\hline 2 & 20 & 10 & 10 & 0 & 5 & 1 & 13.1 & 0 & 0 \\
\hline 2 & 20 & 11 & 11 & 0 & 8 & 0 & 86.7 & 0 & 0 \\
\hline 2 & 20 & 12 & 12 & 0 & 5 & 0 & 0 & 0 & 0 \\
\hline 2 & 21 & 1 & 2 & 0 & 0 & 0 & 0 & 0 & 0 \\
\hline 2 & 21 & 2 & 3 & 0 & 36 & 0 & 42.8 & 1.6 & 0 \\
\hline 2 & 21 & 3 & 4 & 0 & 9 & 0 & 162.3 & 0.3 & 0 \\
\hline 2 & 21 & 4 & 5 & 0 & 58 & 0 & 178.1 & 1.6 & 0 \\
\hline 2 & 21 & 5 & 6 & 0 & 85 & 0 & 52.3 & 0 & 0.1 \\
\hline 2 & 21 & 6 & 7 & 0 & 25 & 0 & 68 & 0.8 & 0 \\
\hline 2 & 21 & 7 & 8 & 0 & 17 & 0 & 0 & 0.2 & 0 \\
\hline 2 & 21 & 8 & 9 & 0 & 11 & 0 & 47.6 & 0.2 & 0.3 \\
\hline 2 & 21 & 9 & 10 & 0 & 12 & 0 & 0 & 0.2 & 0.6 \\
\hline 2 & 37 & 2 & 1.2 & 0 & 42 & 0 & 53.1 & 1.3 & 0.2 \\
\hline 2 & 37 & 3 & 3 & 0 & 26 & 1 & 220.2 & 21 & 0.9 \\
\hline 2 & 37 & 4 & 4 & 0 & 38 & 0 & 177.9 & 2.7 & 4.6 \\
\hline 2 & 37 & 5 & 5 & 0 & 56 & 1 & 243.3 & 3.3 & 0.6 \\
\hline 2 & 37 & 6 & 6 & 0 & 34 & 0 & 84.3 & 0.9 & 2 \\
\hline 2 & 37 & 7 & 7 & 0 & 20 & 0 & 56.3 & 1.9 & 0.2 \\
\hline 2 & 37 & 8 & 8 & 0 & 14 & 1 & 43.8 & 0 & 0.6 \\
\hline 2 & 37 & 9 & 9 & 0 & 6 & 1 & 0 & 0 & 0.7 \\
\hline 2 & 37 & 10 & 10 & 0 & 4 & 0 & 0 & 0.1 & 0 \\
\hline 2 & 37 & 11 & 11 & 0 & 2 & 0 & 0 & 0 & 0.2 \\
\hline 2 & 37 & 12 & 12 & 0 & 0 & 0 & 0 & 0 & 0 \\
\hline 2 & 38 & 1 & 2 & 0 & 0 & 0 & 0 & 0 & 0 \\
\hline 2 & 38 & 2 & 3 & 0 & 2 & 0 & 140 & 1.2 & 0 \\
\hline 2 & 38 & 3 & 4 & 0 & 25 & 1 & 33.8 & 2 & 3 \\
\hline 2 & 38 & 4 & 5 & 0 & 25 & 0 & 88.5 & 2.2 & 0 \\
\hline 2 & 38 & 5 & 6 & 0 & 37 & 1 & 839.1 & 6.4 & 1.3 \\
\hline
\end{tabular}




\begin{tabular}{|c|c|c|c|c|c|c|c|c|c|}
\hline Area & $\mathbf{E U}$ & Level & Level 2 & Cores & Debitage & Tools & FCR & Mussel & Snail \\
\hline 2 & 38 & 6 & 7 & 0 & 23 & 0 & 7.6 & 0.5 & 0.4 \\
\hline 2 & 38 & 7 & 8 & 0 & 5 & 0 & 7 & 2 & 0 \\
\hline 2 & 38 & 8 & 9 & 0 & 7 & 0 & 6.2 & 0 & 3.1 \\
\hline 2 & 38 & 9 & 10 & 0 & 1 & 0 & 0 & 0 & 0.3 \\
\hline 3 & 11 & 1 & 1 & 0 & 33 & 1 & 0 & 0 & 0 \\
\hline 3 & 11 & 2 & 2 & 0 & 25 & 1 & 0 & 0.5 & 0 \\
\hline 3 & 11 & 3,4 & 3 & 0 & 21 & 1 & 69.4 & 1.6 & 0.9 \\
\hline 3 & 11 & 5,6 & 4 & 0 & 25 & 0 & 85 & 0 & 5.2 \\
\hline 3 & 11 & 7,8 & 5 & 0 & 28 & 0 & 85.8 & 0.6 & 7.2 \\
\hline 3 & 11 & 9,1 & 6 & 0 & 40 & 0 & 89.6 & 0.9 & 4.8 \\
\hline 3 & 11 & 11,12 & 7 & 0 & 61 & 0 & 377.4 & 0.3 & 6.9 \\
\hline 3 & 11 & 13,14 & 8 & 0 & 17 & 0 & 383.8 & 3.5 & 0.5 \\
\hline 3 & 11 & 15 & 9 & 0 & 11 & 0 & 28.3 & 0.1 & 0 \\
\hline 3 & 11 & 16 & 10 & 0 & 7 & 0 & 0 & 0.2 & 3.3 \\
\hline 3 & 11 & 17 & 11 & 0 & 8 & 0 & 19.3 & 0.1 & 1 \\
\hline 3 & 11 & 18 & 12 & 0 & 4 & 0 & 0 & 0 & 0 \\
\hline 3 & 22 & 1 & 1 & 1 & 14 & 0 & 49 & 0 & 0.4 \\
\hline 3 & 22 & 2 & 2 & 0 & 19 & 2 & 21.2 & 0.5 & 0 \\
\hline 3 & 22 & 3 & 3 & 0 & 41 & 0 & 45.9 & 1.3 & 1.9 \\
\hline 3 & 22 & 4 & 4 & 0 & 14 & 0 & 3.6 & 0.7 & 4.1 \\
\hline 3 & 22 & 5 & 5 & 0 & 22 & 0 & 52.8 & 21.6 & 5.8 \\
\hline 3 & 22 & 6 & 6 & 0 & 17 & 2 & 152.3 & 1.3 & 1.5 \\
\hline 3 & 22 & 7 & 7 & 0 & 43 & 0 & 553.3 & 0.9 & 0 \\
\hline 3 & 22 & 8 & 8 & 0 & 38 & 0 & 94.7 & 0.7 & 0.1 \\
\hline 3 & 22 & 9 & 9 & 0 & 23 & 1 & 58.8 & 0.3 & 6.2 \\
\hline 3 & 22 & 10 & 10 & 0 & 6 & 1 & 8.1 & 0.2 & 2.4 \\
\hline 3 & 22 & 11 & 11 & 0 & 12 & 0 & 15.4 & 0 & 3.9 \\
\hline 3 & 22 & 12 & 12 & 0 & 8 & 0 & 57.5 & 0 & 2.4 \\
\hline 3 & 23 & 1 & 1 & 1 & 16 & 0 & 192 & 0 & 0 \\
\hline 3 & 23 & 2 & 2 & 0 & 11 & 1 & 85.2 & 0.6 & 0 \\
\hline 3 & 23 & 3 & 3 & 1 & 38 & 0 & 106.1 & 2 & 0 \\
\hline 3 & 23 & 4 & 4 & 0 & 22 & 0 & 16.1 & 1.9 & 0 \\
\hline 3 & 23 & 5 & 5 & 0 & 14 & 0 & 15.6 & 2.4 & 0 \\
\hline 3 & 23 & 6 & 6 & 0 & 8 & 0 & 129.9 & 0.3 & 0 \\
\hline 3 & 23 & 7 & 7 & 0 & 20 & 0 & 70.9 & 3.5 & 0.1 \\
\hline 3 & 23 & 8 & 8 & 0 & 16 & 0 & 17.5 & 1.1 & 0.1 \\
\hline 3 & 23 & 9 & 9 & 0 & 16 & 0 & 124.9 & 0.4 & 0.4 \\
\hline 3 & 23 & 10 & 10 & 0 & 9 & 0 & 21.7 & 0 & 0 \\
\hline 3 & 23 & 11 & 11 & 0 & 1 & 1 & 0 & 3 & 2.4 \\
\hline 3 & 23 & 12 & 12 & 0 & 8 & 0 & 54.1 & 0.2 & 3.6 \\
\hline 3 & 24 & 1 & 3 & 0 & 4 & 1 & 32 & 0 & 0 \\
\hline 3 & 24 & 2 & 4 & 0 & 6 & 0 & 8 & 0 & 0 \\
\hline 3 & 24 & 3 & 5 & 0 & 14 & 0 & 41.4 & 0.1 & 7.7 \\
\hline
\end{tabular}




\begin{tabular}{|c|c|c|c|c|c|c|c|c|c|}
\hline Area & $\mathbb{E} \mathbf{U}$ & Level & Level 2 & Cores & Debitage & Tools & FCR & Mussel & Snail \\
\hline 3 & 24 & 4 & 6 & 0 & 37 & 0 & 734.8 & 3.9 & 1.8 \\
\hline 3 & 24 & 5 & 7 & 0 & 27 & 0 & 110.6 & 0 & 1 \\
\hline 3 & 24 & 6 & 8 & 0 & 27 & 0 & 75.9 & 0.2 & 5.9 \\
\hline 3 & 24 & 7 & 9 & 0 & 10 & 0 & 17.6 & 0.1 & 5.5 \\
\hline 3 & 24 & 8 & 10 & 0 & 7 & 0 & 7.5 & 0 & 0 \\
\hline 3 & 25 & 5 & 5 & 0 & 10 & 0 & 103.3 & 0 & 0 \\
\hline 3 & 25 & 6 & 6 & 0 & 31 & 0 & 15 & 0 & 0.5 \\
\hline 3 & 25 & 7 & 7 & 0 & 37 & 1 & 0 & 1 & 0 \\
\hline 3 & 26 & 1 & 3 & 0 & 10 & 0 & 30.1 & 0 & 0 \\
\hline 3 & 26 & 2,3 & 4 & 0 & 15 & 1 & 26.3 & 0 & 0 \\
\hline 3 & 26 & 4 & 5 & 0 & 26 & 1 & 18.4 & 0 & 0 \\
\hline 3 & 26 & 5 & 6 & 0 & 27 & 0 & 1.2 & 1.5 & 0 \\
\hline 3 & 26 & 6 & 7 & 0 & 21 & 0 & 63.6 & 0.3 & 0 \\
\hline 3 & 26 & 7 & 8 & 0 & 18 & 0 & 174.9 & 0.4 & 1.5 \\
\hline 3 & 26 & 8 & 9 & 0 & 30 & 1 & 125.3 & 0.1 & 0.4 \\
\hline 3 & 26 & 9 & 10 & 1 & 25 & 0 & 182 & 1.5 & 3.4 \\
\hline 3 & 26 & 10 & 11 & 0 & 17 & 0 & 78.5 & 0.4 & 1 \\
\hline 3 & 26 & 11 & 12 & 0 & 20 & 0 & 2.6 & 7.5 & 7.4 \\
\hline 3 & 41 & 4 & 4 & 1 & 5 & 0 & 15.7 & 0 & 0.3 \\
\hline 3 & 41 & 5 & 5 & 0 & 4 & 0 & 0 & 0.5 & 0.4 \\
\hline 3 & 41 & 6 & 6 & 0 & 21 & 1 & 93.7 & 1.7 & 3 \\
\hline 3 & 41 & 7 & 7 & 1 & 19 & 0 & 161.7 & 0.4 & 3.5 \\
\hline 3 & 41 & 8 & 8 & 0 & 18 & 0 & 14.6 & 0.5 & 3 \\
\hline 3 & 41 & 9 & 9 & 0 & 11 & 1 & 54.6 & 0 & 3 \\
\hline 3 & 41 & 10 & 10 & 0 & 12 & 0 & 0 & 2.7 & 3.1 \\
\hline 3 & 42 & 5 & 5 & 0 & 8 & 0 & 0 & 0.1 & 1 \\
\hline 3 & 42 & 6 & 6 & 0 & 10 & 0 & 62.1 & 0.3 & 1.6 \\
\hline 3 & 42 & 7 & 7 & 0 & 26 & 1 & 3.8 & 0 & 1.7 \\
\hline 3 & 42 & 8 & 8 & 0 & 18 & 0 & 0 & 0 & 3.8 \\
\hline 4 & 9 & 1 & 1 & 0 & 3 & 0 & 0 & 0 & 0.9 \\
\hline 4 & 9 & 2 & 2 & 0 & 4 & 1 & 0 & 0.4 & 0 \\
\hline 4 & 9 & 3,4 & 3 & 0 & 3 & 2 & 0 & 0.9 & 1 \\
\hline 4 & 9 & 5,6 & 4 & 0 & 0 & 0 & 0 & 0.1 & 0 \\
\hline 4 & 9 & 7,8 & 5 & 0 & 0 & 0 & 0 & 0 & 0 \\
\hline 4 & 9 & 9,1 & 6 & 0 & 0 & 0 & 1.1 & 0 & 0 \\
\hline 4 & 9 & 11 & 7 & 0 & 0 & 0 & 0 & 0 & 0 \\
\hline 4 & 9 & 12 & 8 & 0 & 1 & 0 & 101.7 & 0 & 0 \\
\hline 4 & 28 & 1 & 1 & 0 & 6 & 0 & 0 & 0 & 0 \\
\hline 4 & 28 & 2 & 2 & 0 & 1 & 0 & 0 & 0 & 0 \\
\hline 4 & 28 & 3,4 & 3 & 0 & 1 & 0 & 0 & 0 & 0 \\
\hline 4 & 28 & 5,6 & 4 & 0 & 0 & 0 & 0 & 0 & 0 \\
\hline 4 & 28 & 7,8 & 5 & 0 & 0 & 0 & 0 & 0 & 0.7 \\
\hline 4 & 29 & 1 & 1 & 0 & 3 & 0 & 0 & 0 & 0 \\
\hline
\end{tabular}




\begin{tabular}{|c|c|c|c|c|c|c|c|c|c|}
\hline Area & $\mathbf{E U}$ & Level & Level 2 & Cores & Debitage & Tools & FCR & Mussel & Snail \\
\hline 4 & 29 & 2 & 2 & 0 & 2 & 0 & 0 & 0 & 0 \\
\hline 4 & 29 & 3,4 & 3 & 0 & 0 & 0 & 0 & 0 & 0 \\
\hline 4 & 29 & 5,6 & 4 & 0 & 4 & 1 & 0 & 0 & 0 \\
\hline 4 & 29 & 7,8 & 5 & 0 & 0 & 0 & 0 & 0 & 0 \\
\hline 4 & 29 & 9,1 & 6 & 0 & 0 & 0 & 0 & 0 & 0 \\
\hline 4 & 29 & 11,12 & 7 & 0 & 0 & 0 & 0 & 0 & 0 \\
\hline 4 & 29 & 13,14 & 8 & 0 & 0 & 0 & 0 & 0 & 0 \\
\hline 4 & 30 & 1 & 1 & 0 & 0 & 0 & 0 & 0 & 0 \\
\hline 4 & 30 & 2 & 2 & 0 & 0 & 0 & 0 & 0 & 0 \\
\hline 4 & 30 & 3,4 & 3 & 0 & 2 & 0 & 0 & 0 & 0 \\
\hline 4 & 30 & 5,6 & 4 & 0 & 0 & 0 & 0 & 0 & 0 \\
\hline 4 & 30 & 7,8 & 5 & 0 & 2 & 0 & 0 & 0 & 0.1 \\
\hline 4 & 30 & 9,1 & 6 & 0 & 0 & 0 & 2.4 & 0 & 0 \\
\hline 4 & 30 & 11,12 & 7 & 0 & 0 & 0 & 0 & 0 & 1.3 \\
\hline 4 & 30 & 13,14 & 8 & 0 & 0 & 0 & 5.8 & 0 & 0.3 \\
\hline 4 & 39 & 1 & 8 & 0 & 0 & 0 & 0 & 0 & 0 \\
\hline 4 & 39 & 2 & 9 & 0 & 0 & 0 & 0 & 0 & 0 \\
\hline 4 & 39 & 3 & 10 & 0 & 0 & 0 & 495.3 & 0.2 & 0 \\
\hline 4 & 39 & 4 & 11 & 0 & 0 & 0 & 414.5 & 0 & 0 \\
\hline 4 & 39 & 5 & 12 & 0 & 0 & 0 & 0 & 5.2 & 0 \\
\hline 4 & 39 & 6 & 13 & 0 & 0 & 0 & 0 & 0 & 0 \\
\hline 4 & 40 & 1 & 8 & 0 & 0 & 0 & 0 & 0 & 0 \\
\hline 4 & 40 & 2 & 9 & 0 & 0 & 0 & 32.1 & 0 & 0 \\
\hline 4 & 40 & 3 & 10 & 0 & 0 & 0 & 280.2 & 0 & 0 \\
\hline 4 & 40 & 4 & 11 & 0 & 0 & 0 & 474.1 & 0 & 0 \\
\hline 4 & 40 & 5 & 12 & 0 & 0 & 1 & 267.6 & 0.5 & 0 \\
\hline 4 & 40 & 6 & 13 & 0 & 2 & 0 & 32.4 & 0 & 0 \\
\hline IU & 2 & 1 & 1 & 0 & 1 & 0 & 0 & 0 & 0 \\
\hline $\mathrm{IU}$ & 2 & 2 & 2 & 0 & 6 & 0 & 0 & 0 & 0 \\
\hline $\mathrm{IU}$ & 2 & 3 & 3 & 0 & 4 & 0 & 0 & 0 & 0 \\
\hline IU & 2 & 4 & 4 & 1 & 18 & 0 & 525.9 & 0 & 0 \\
\hline $\mathrm{IU}$ & 2 & 5 & 5 & 0 & 38 & 0 & 1009.9 & 0 & 0 \\
\hline IU & 2 & 6 & 6 & 0 & 20 & 0 & 0 & 0 & 0 \\
\hline $\mathrm{IU}$ & 2 & 7 & 7 & 0 & 25 & 0 & 194.1 & 0 & 0 \\
\hline $\mathrm{IU}$ & 2 & 8 & 8 & 0 & 27 & 0 & 438.6 & 0 & 0 \\
\hline IU & 2 & 9 & 9 & 0 & 13 & 0 & 308 & 0 & 0 \\
\hline $\mathrm{IU}$ & 2 & 10 & 10 & 0 & 8 & 0 & 102.4 & 0 & 0 \\
\hline $\mathrm{IU}$ & 2 & 11 & 11 & 0 & 10 & 0 & 0 & 0 & 0 \\
\hline $\mathrm{IU}$ & 2 & 12 & 12 & 0 & 12 & 0 & 0 & 0.3 & 3 \\
\hline $\mathrm{IU}$ & 4 & 1 & 1 & 0 & 2 & 0 & 0 & 0 & 0 \\
\hline $\mathrm{IU}$ & 4 & 2 & 2 & 0 & 2 & 0 & 0 & 0 & 0 \\
\hline $\mathrm{IU}$ & 4 & 3 & 3 & 0 & 3 & 0 & 0 & 0 & 0 \\
\hline IU & 4 & 4 & 4 & 0 & 20 & 0 & 65 & 0 & 0 \\
\hline
\end{tabular}




\begin{tabular}{|c|c|c|c|c|c|c|c|c|c|}
\hline Area & $\mathbf{E U}$ & Level & Level 2 & Cores & Debitage & Tools & FCR & Mussel & Snail \\
\hline IU & 4 & 5 & 5 & 0 & 12 & 0 & 8.2 & 0 & 0 \\
\hline IU & 4 & 6 & 6 & 0 & 5 & 0 & 6.7 & 0 & 0 \\
\hline IU & 4 & 7 & 7 & 0 & 12 & 0 & 213.9 & 0 & 0 \\
\hline IU & 4 & 8 & 8 & 0 & 3 & 0 & 173.7 & 0 & 0 \\
\hline $\mathrm{IU}$ & 4 & 9 & 9 & 0 & 12 & 0 & 68.4 & 0 & 0 \\
\hline $\mathrm{IU}$ & 4 & 10 & 10 & 0 & 4 & 0 & 68.7 & 0 & 0 \\
\hline IU & 4 & 11 & 11 & 0 & 15 & 0 & 0 & 9.1 & 1.2 \\
\hline IU & 4 & 12 & 12 & 0 & 0 & 0 & 19.1 & 0.8 & 3.8 \\
\hline IU & 6 & 1 & 1 & 0 & 6 & 0 & 64.8 & 0 & 0 \\
\hline $\mathrm{IU}$ & 6 & 2 & 2 & 0 & 7 & 0 & 79.7 & 0.1 & 0 \\
\hline $\mathrm{IU}$ & 6 & 3 & 3 & 0 & 10 & 0 & 214.4 & 1.5 & 0 \\
\hline $\mathrm{IU}$ & 6 & 4 & 4 & 0 & 2 & 0 & 62.6 & 0 & 0 \\
\hline IU & 6 & 5 & 5 & 0 & 2 & 0 & 0 & 1.1 & 0 \\
\hline $\mathrm{IU}$ & 6 & 6 & 6 & 0 & 18 & 0 & 0 & 10.9 & 1.4 \\
\hline $\mathrm{IU}$ & 6 & 7 & 7 & 0 & 16 & 0 & 82.8 & 0.4 & 7.2 \\
\hline IU & 6 & 8 & 8 & 0 & 6 & 0 & 18.3 & 0.5 & 0.6 \\
\hline $\mathrm{IU}$ & 6 & 9 & 9 & 0 & 12 & 0 & 14.6 & 2.4 & 0.7 \\
\hline $\mathrm{IU}$ & 6 & 10 & 10 & 0 & 17 & 1 & 1.8 & 2.5 & 0.6 \\
\hline $\mathrm{IU}$ & 6 & 11 & 11 & 0 & 16 & 0 & 86.2 & 1.8 & 3.5 \\
\hline IU & 6 & 12 & 12 & 0 & 16 & 0 & 60.6 & 0.2 & 0 \\
\hline IU & 8 & 1 & 1 & 0 & 44 & 1 & 42.3 & 1.3 & 1.5 \\
\hline IU & 8 & 2 & 2 & 0 & 57 & 0 & 10 & 4.8 & 4.3 \\
\hline IU & 8 & 3 & 3 & 0 & 128 & 0 & 75.3 & 12.2 & 10.4 \\
\hline IU & 8 & 4 & 4 & 0 & 59 & 0 & 13.5 & 3.2 & 6.4 \\
\hline IU & 8 & 5 & 5 & 0 & 58 & 1 & 56.6 & 0.8 & 0 \\
\hline $\mathrm{IU}$ & 8 & 6 & 6 & 0 & 30 & 0 & 175.5 & 3.5 & 1.1 \\
\hline IU & 8 & 7 & 7 & 0 & 51 & 0 & 62.6 & 0.3 & 3.1 \\
\hline IU & 8 & 8.9 & 8 & 0 & 41 & 0 & 140.8 & 8.4 & 0 \\
\hline $\mathrm{IU}$ & 8 & 10,11 & 9 & 0 & 25 & 1 & 19.5 & 0.6 & 3.9 \\
\hline $\mathrm{IU}$ & 8 & 12,13 & 10 & 0 & 25 & 0 & 215.6 & 0 & 2.9 \\
\hline IU & 8 & 14,15 & 11 & 0 & 5 & 0 & 35.7 & 0 & 2.4 \\
\hline IU & 8 & 16. 17 & 12 & 0 & 8 & 0 & 172.2 & 0 & 0.1 \\
\hline IU & 10 & 1 & 1 & 0 & 24 & 1 & 65.8 & 0.6 & 0.1 \\
\hline $\mathrm{IU}$ & 10 & 2 & 2 & 0 & 64 & 1 & 161.3 & 4 & 0.4 \\
\hline IU & 10 & 3,4 & 3 & 1 & 63 & 0 & 653.9 & 3.9 & 0 \\
\hline IU & 10 & 5,6 & 4 & 0 & 44 & 0 & 231.7 & 1.3 & 0 \\
\hline $\mathrm{IU}$ & 10 & 7,8 & 5 & 0 & 65 & 3 & 391 & 2.8 & 0 \\
\hline IU & 10 & 9,10 & 6 & 0 & 84 & 0 & 198.9 & 0.1 & 1.1 \\
\hline IU & 10 & 11,12 & 7 & 0 & 38 & 0 & 113 & 0.2 & 5.1 \\
\hline IU & 10 & 13,14 & 8 & 0 & 24 & 0 & 86.5 & 0.3 & 1.4 \\
\hline $\mathrm{IU}$ & 10 & 15,16 & 9 & 0 & 35 & 1 & 181.5 & 0.9 & 0.2 \\
\hline IU & 10 & 17,18 & 10 & 0 & 17 & 0 & 29 & 3.6 & 0 \\
\hline IU & 10 & 19,20 & 11 & 0 & 6 & 1 & 138.7 & 0.4 & 0 \\
\hline $\mathrm{IU}$ & 10 & 21,22 & 12 & 0 & 2 & 0 & 1.2 & 0 & 0 \\
\hline
\end{tabular}




\section{Appendix D: Carbon-14 Data}

Results of the standard and AMS analysis of radiocarbon samples as provided by Beta Analytic (Part 1) and INSTARR (Part 2) are presented in this appendix. 


\section{Part 1: Beta Analytic Results}

\section{CALIBRATION OF RADIOCARBON AGE TO CALENDAR YEARS}

(Variables: est. C13/C12 $=-25 \cdot 0:$ lab. mult $=1$ )

Laboratory Number: Beta-82290

$\begin{array}{rl}\text { Conventional radiocarbon age } * & 1240+/-60 \text { BP } \\ \text { Calibrated results: } & \text { cal AD } 665 \text { to } 960\end{array}$

(2 sigma, 95\% probability)

$\mathrm{C} 13 / \mathrm{Cl} 2$ ratio cstimated

Intercept data:

Intercept of radiocarbon age with calibration curve:

cal AD 785

1 sigma calibrated results: (68\% probability)

cal AD 695 to 880

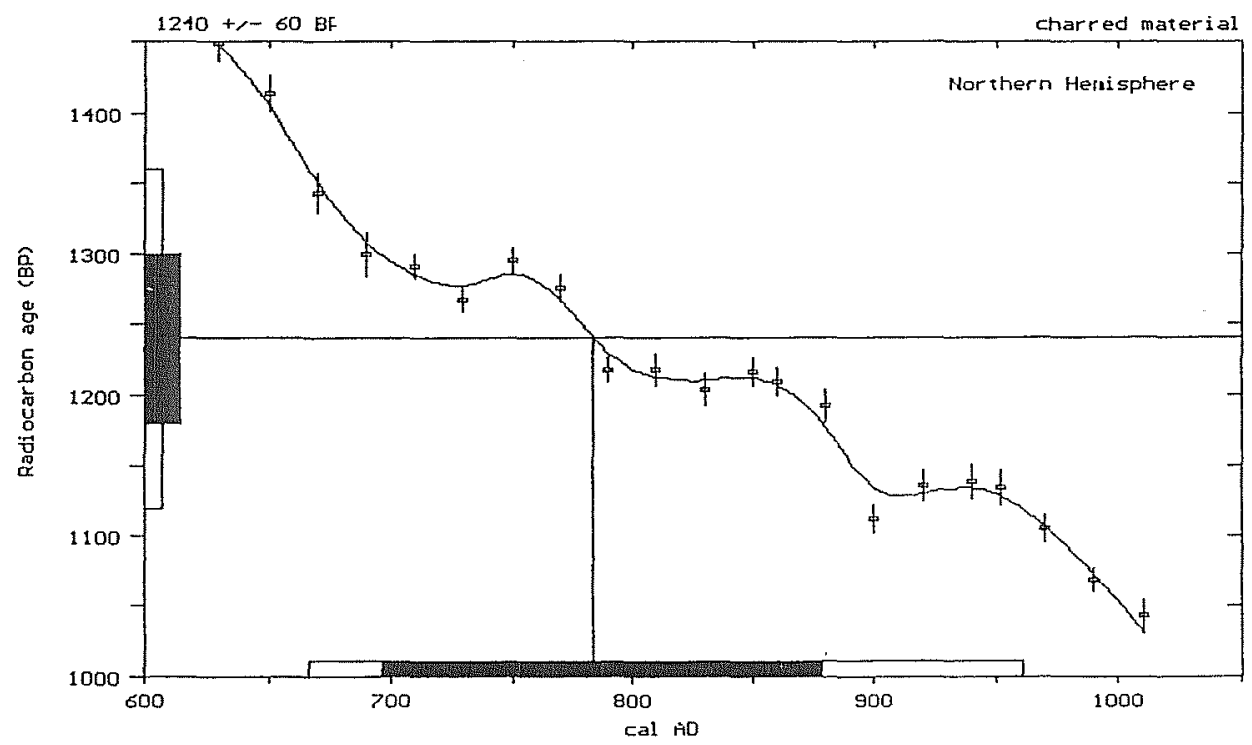

References:

Pretoria Calibration Curve for Short Lived Samples

Fogel, I. C. Fuls, A. Virser, E and Becker, B. 1993, Radiocarbon 35(1). p73-56

A Simplified Approach to Calibrating Cl $\$$ Dates

Talma, A. S. and Vogel, J. C., I993, Radiocarbon 35(2), p317-322

Callbration - 1993

Stuiver, M., Long, A., Kra, R S. and Devine, J. M., 1993. Radiocarbon 35(I)

\section{Beta Analytic Radiocarbon Dating Laboratory}

4985 S.W. 74th Court, Miami, Florida 33155 Tel: (305)667-5167 * Fax: (305)386-0964 E-mail: beta@analytic.win.net 


\section{CALIBRATION OF RADIOCARBON AGE TO CALENDAR YEARS}

(Variables:estimated $\mathrm{C} 13 / \mathrm{C} 12=-25: \mathrm{lab}$ mult $=1$ )

Laboratory Number: Beta-82289

Conventional radiocarbon age ${ }^{\star}: \quad 1460+/-50 \mathrm{BP}$

Calibrated results:

cal AD 535 to 665

( 2 sigma, $95 \%$ probability)

* C13/C12 ratio estimated

Intercept data:

Intercept of radiocarbon age with calibration curve:

cal AD 620

1 sigma calibrated results: $\quad$ cal $\mathrm{AD} 575$ to 650 (68\% probability)

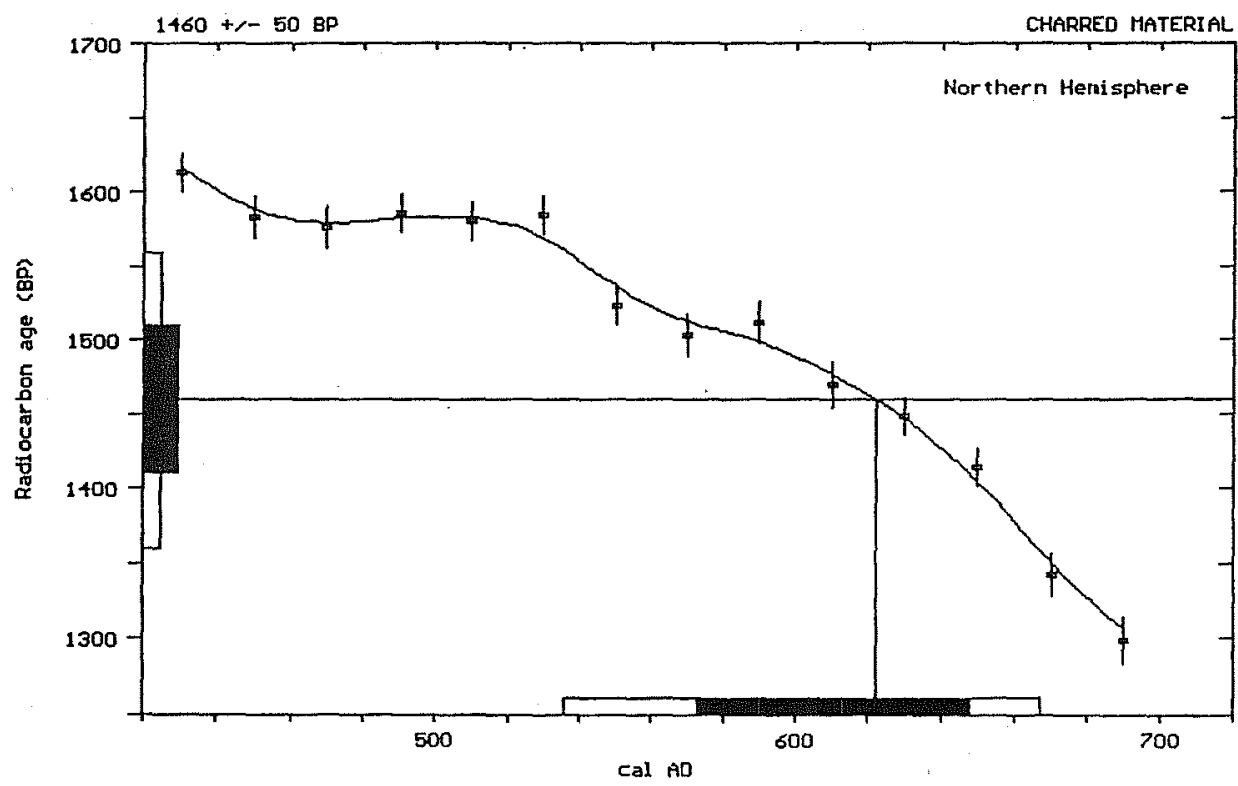

References:

Pretoria Calibration Curve for Short Lived Samples

Vogel, J. C., Fuls, A., Visser, E, and Becker, B. 1993, Radiocarbon 35(I), 73.86

A Simplified Approach to Calibrating CI 1 Dates

Talma, A. S. and Vogel, J. C.. 1993, Radiocarb in 35(2), p317.322

Calibration - 1993

Stuiver, M., Long, A., Kra, R. S. and Devine, J. M., 1993, Radiocarbon 35(I)

\section{Beta Analytic Radiocarbon Dating Laboratory}

4985 S.W. 74th Court, Miami, Florida 33155 Tel: (305)667.5167 Fax: (305)386-0964 E-mail: beta@analytic.win.net 
(Variables:estimated $\mathrm{C} 13 / \mathrm{C} 12=-25: \mathrm{lab}$ mult. $=1$ )

Laboratory Number: Beta-104966

Conventional radiocarbon age*: $\quad \mathbf{7 6 0} \pm 50 \mathrm{BP}$

Calibrated results:

(2 sigma, $95 \%$ probability)

cal AD 1205 to 1300

* $\mathrm{C} 13 / \mathrm{C} 12$ ratio estimated

Intercept data:

Intercept of radiocarbon age

with calibration curve:

cal AD 1275

1 sigma calibrated results: $\quad$ cal AD 1245 to 1290

(68\% probability)

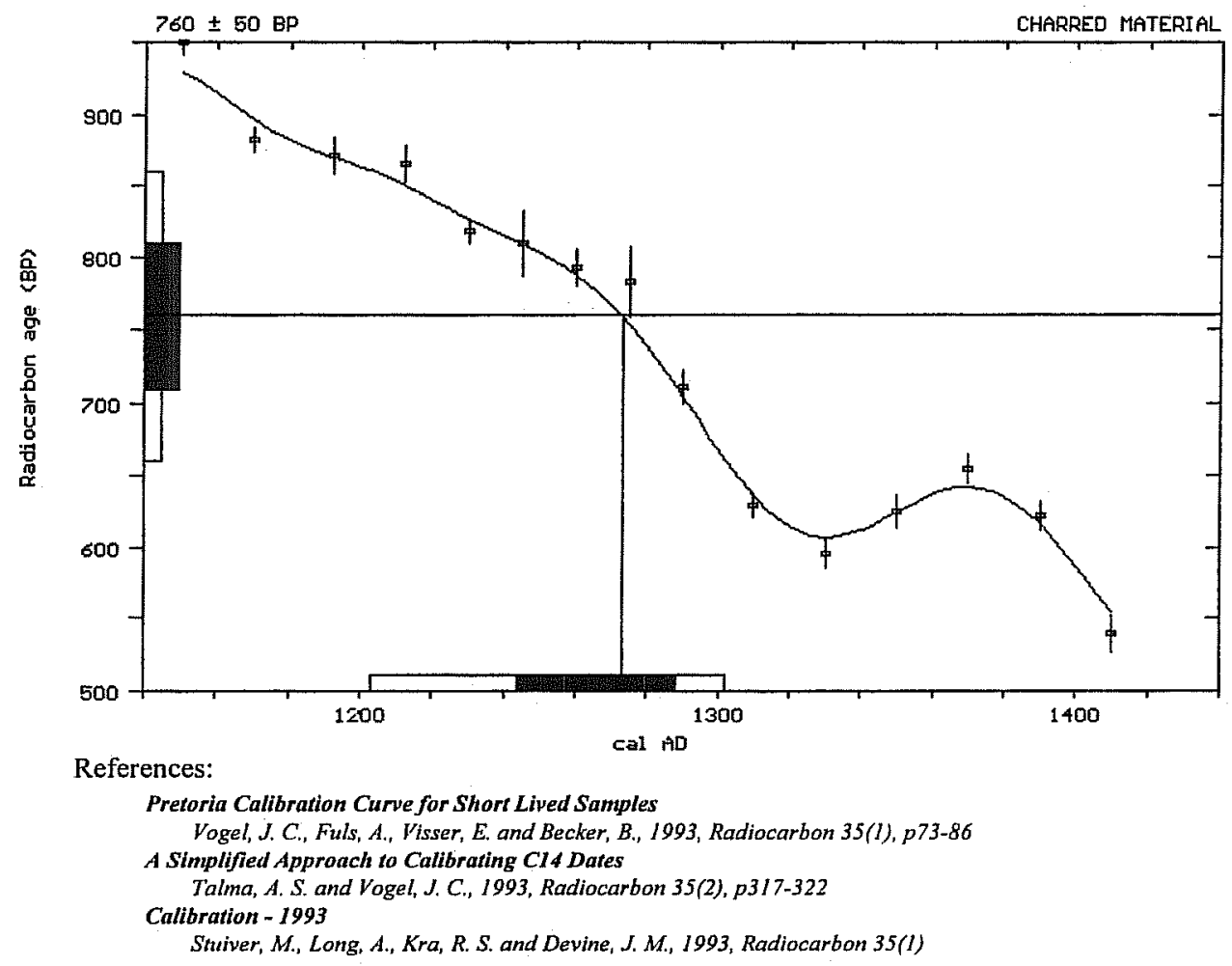

Beta Analytic Radiocarbon Dating Laboratory

4985 S.W. 74th Court, Miami, Florida 33155 m Tel: (305)667-5167 m Fax: (305)663-0964 E-mail: beta@)radiocarbon.com 


\section{CALIBRATION OF RADIOCARBON AGE TO CALENDAR YEARS}

(Variables:estimated $\mathrm{C} 13 / \mathrm{C} 12=-25: 1 \mathrm{ab}$ mult. $=1$ )

Laboratory Number: Beta-104967

Conventional radiocarbon age*: $\quad 540 \pm 40 \mathrm{BP}$

Calibrated results: cal AD 1315 to 1345 and

(2 sigma, 95\% probability) cal AD 1390 to 1440

* C13/C12 ratio estimated

Intercept data:

Intercept of radiocarbon age with calibration curve:

cal AD 1415

1 sigma calibrated results: $\quad$ cal AD 1400 to 1425

(68\% probability)

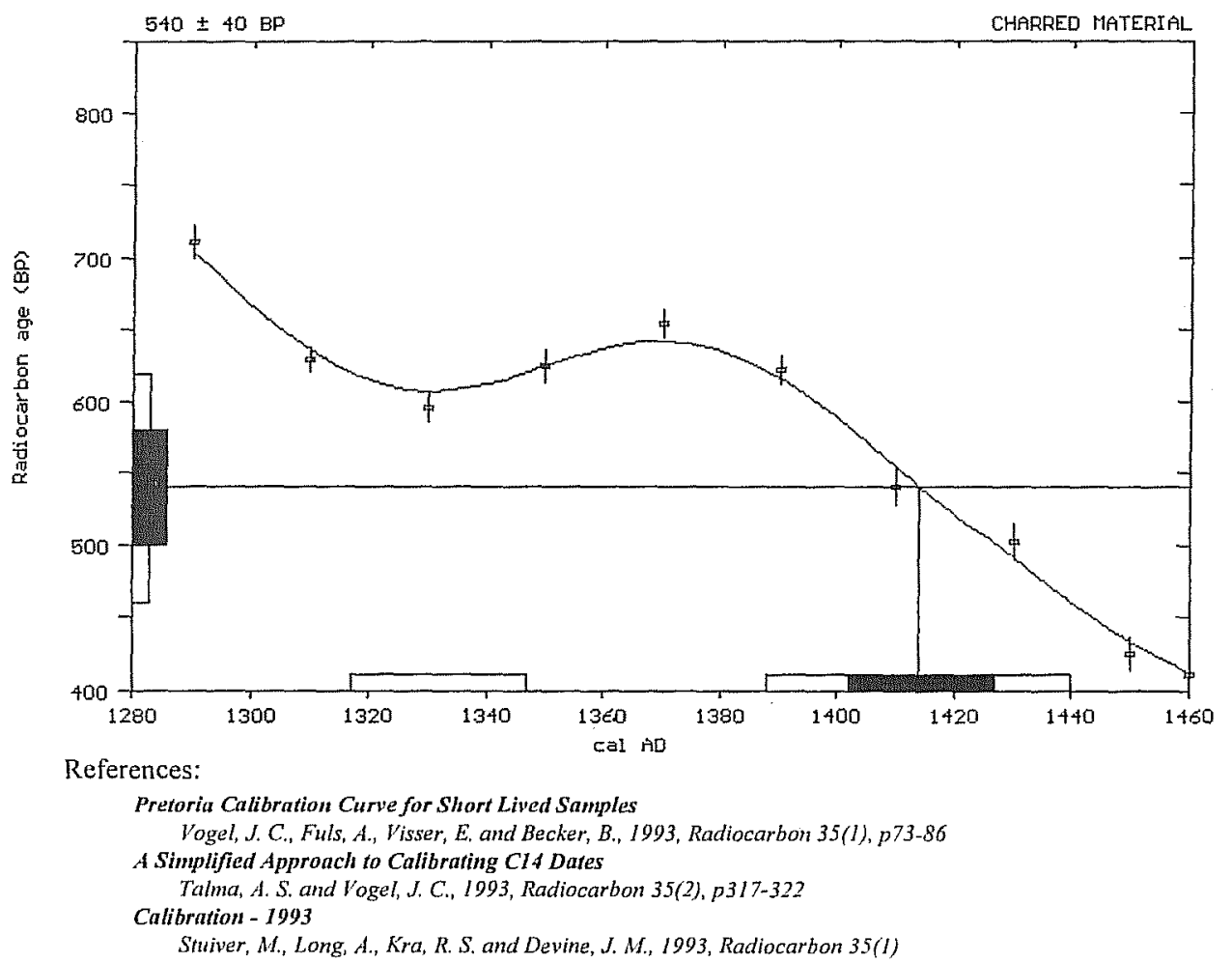

Beta Analytic Radiocarbon Dating Laboratory

4985 S.W. 74th Court, Miami, Florida 33155 m Tel: (305)667-5167 aㅣ Fax: (305)663-0964 E-mail: beta@radiocarbon.com 


\section{(Variables:C13/C12=-21:lab mult. $=1$ )}

Laboratory Number: Beta-104968

\section{Conventional radiocarbon age: $\quad 6010 \pm 60 \mathrm{BP}$}

Calibrated results:

( 2 sigma, $95 \%$ probability)

cal BC 5050 to 4780

Intercept data:

Intercept of radiocarbon age with calibration curve:

cal BC 4915

1 sigma calibrated results: (68\% probability)

cal BC 4950 to 4825

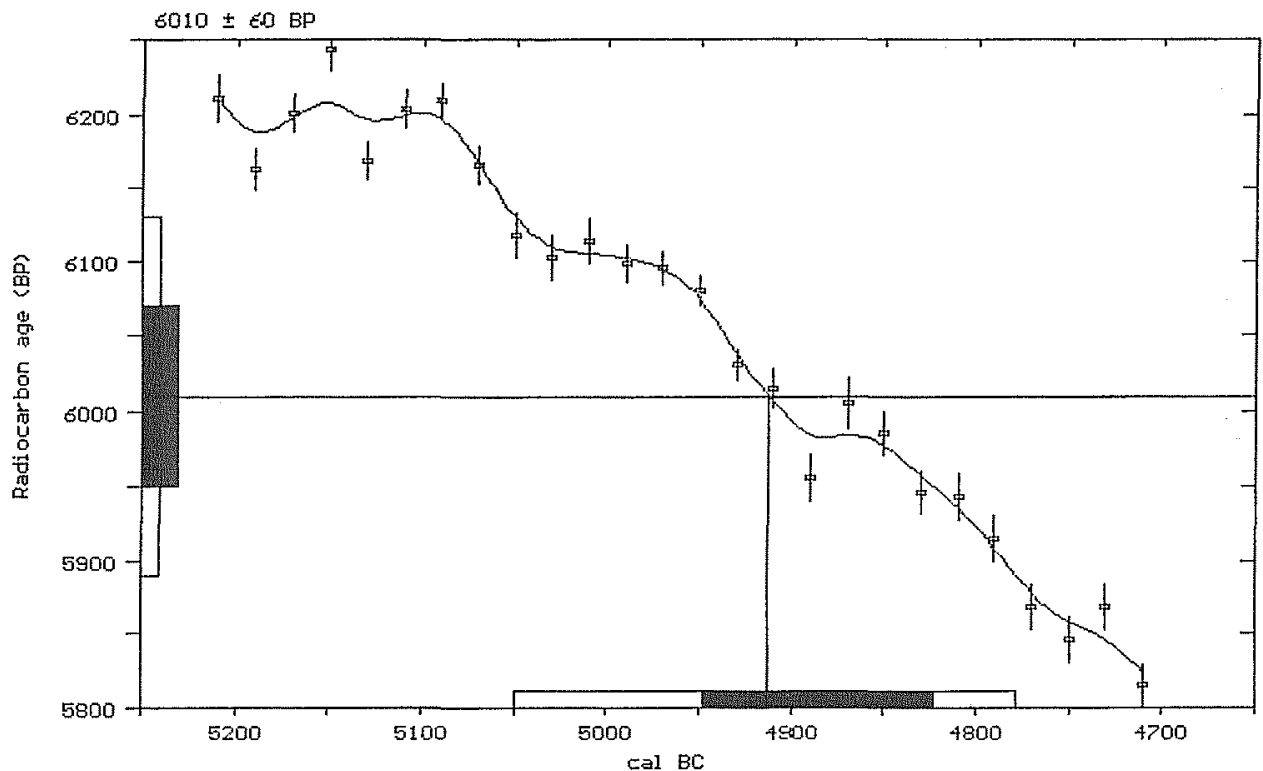

References:

Pretoria Calibration Curve for Short Lived Samples

Vogel, J. C., Fuls, A, Visser, E. and Becker, B., I993, Radiocarbon 35(1), p73-86

A Simplified Approach to Calibrating C14 Dates

Talma, A. S. and Vogel, J. C., 1993, Radiocarbon 35(2), p317.322

Calibration - 1993

Stuiver, M., Long, A., Kra, R. S. and Devine, J. M., 1993, Radiocarbon 35(1)

\section{Beta Analytic Radiocarbon Dating Laboratory}

4985 S.W. 74th Court, Miami, Florida 33155 m Tel: (305)667-5167 国 Fax: (305)663-0964 国 E-mail: beta@radiocarbon.com 
(Variables: $\mathrm{C} 13 / \mathrm{C} 12=-20.9: \mathrm{lab}$ mult. $=1$ )

Laboratory Number: Beta-104969

Conventional radiocarbon age:

Calibrated results:

(2 sigma, 95\% probability)

Intercept data:

Intercept of radiocarbon age with calibration curve:

1 sigma calibrated results: (68\% probability)
$7540 \pm 60 \mathrm{BP}$

cal BC 6450 to 6205

cal BC 6385

cal BC 6420 to 6350 and cal BC 6290 to 6255

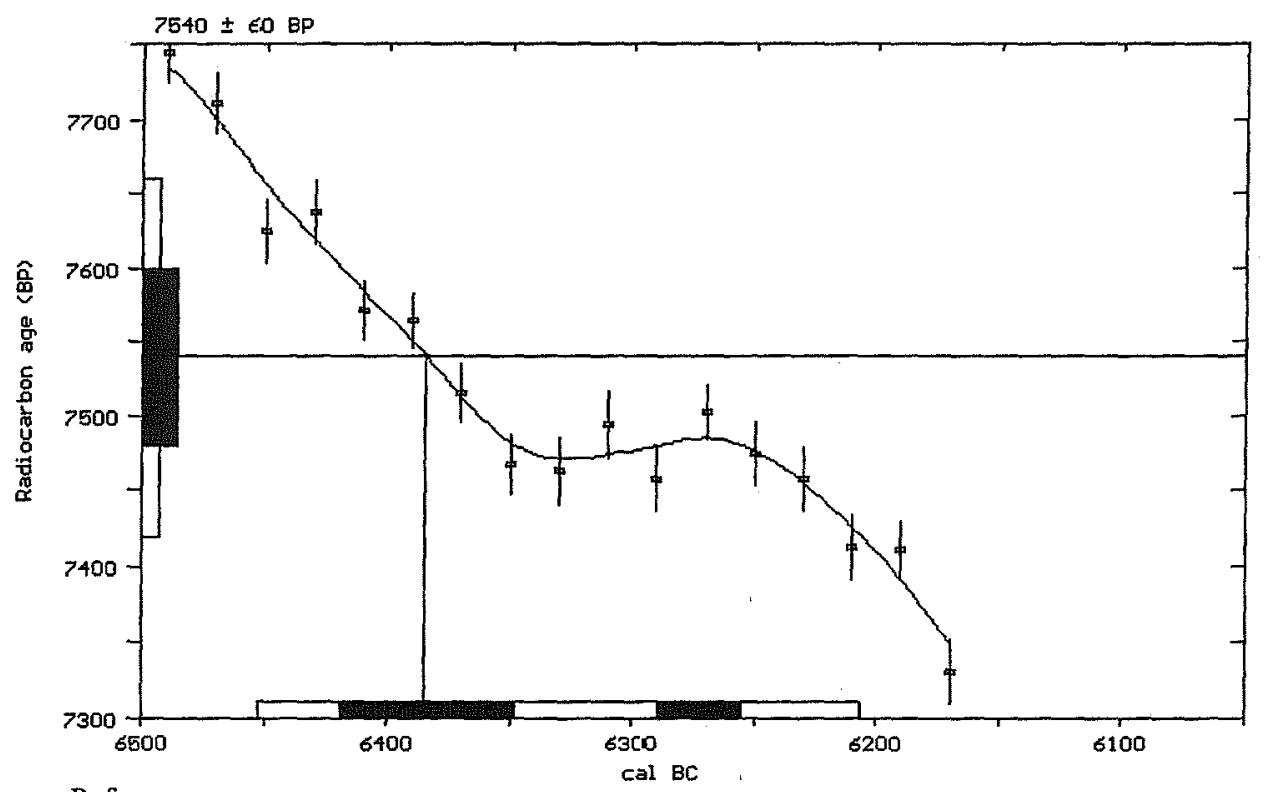

References:

Pretoria Calibration Curve for Short Lived Samples

Vogel, J. C., Fuls, A., Visser, E. and Becker, B., 1993, Radiocarbon 35(1), p73.86

A Simplified Approach to Calibrating C14 Dates

Talma, A. S. and Vogel, J. C., 1993, Radiocarbon 35(2), p317-322

Calibration - 1993

Stuiver, M., Long, A., Kra, R. S. and Devine, J. M., 1993, Radiocarbon 35(1)

\section{Beta Analytic Radiocarbon Dating Laboratory}

4985 S.W. 74th Court, Miami, Florida 33155 . Tel: (305)667-5167 Fax: (305)663-0964 E-mail: beta@radiocarbon.com 


\section{Part 2: INSTARR Results}

All dated fractions were standard acid-based treated charcoal.

\begin{tabular}{|c|c|c|c|c|c|c|c|}
\hline \multirow{2}{*}{$\begin{array}{c}\text { NSRL } \\
\text { sample \# }\end{array}$} & \multirow{2}{*}{$\begin{array}{l}\text { Proven- } \\
\text { ience }\end{array}$} & \multicolumn{2}{|c|}{ Depth } & \multirow{2}{*}{$\begin{array}{l}\text { mg C } \\
\text { Dated }\end{array}$} & \multirow[b]{2}{*}{ Fraction Modern } & \multirow{2}{*}{$\begin{array}{l}\delta^{1{ }^{3}} \mathbf{C} \\
(\% o)\end{array}$} & \multirow[b]{2}{*}{${ }^{14}$ C Age } \\
\hline & & Level & $\begin{array}{l}\text { cm below } \\
\text { surface }\end{array}$ & & & & \\
\hline 3531 & EU 7 & 9 & 80 & 1.12 & $0.6718 \pm 0.0040$ & -23.5 & $3,200 \pm 50$ \\
\hline 3532 & BHT 12 & - & 150 & 1.4 & $0.7850 \pm 0.0036$ & -25.0 & $1,940 \pm 40$ \\
\hline 3533 & EU 22 & 8 & 70 & 1.27 & $0.6838 \pm 0.0040$ & -25.0 & $3,050 \pm 50$ \\
\hline 3534 & EU 15 & 9 & 90 & 1.61 & $0.7822 \pm 0.0046$ & -24.0 & $1,970 \pm 50$ \\
\hline 3535 & EU 33 & 12 & 120 & 1.29 & $0.7603 \pm 0.0045$ & -26.4 & $2,200 \pm 50$ \\
\hline 3536 & EP-1 & - & 518 & 1.10 & $0.8648 \pm 0.0058$ & -28.0 & $1,170 \pm 60$ \\
\hline 3998 & EU 11 & 11 & 110 & 1.89 & $0.6931 \pm 0.0042$ & -23.5 & $2,940 \pm 50$ \\
\hline
\end{tabular}




\section{Appendix $\mathbb{E}:$ Lithic Analysis Methodls}

\section{Bradley J. Vierra}

\section{Cores and Core Tools}

Material type was recorded for all lithic artifacts. Artifact condition was monitored as whole or fragment. Measurements for cores, tested materials, cobble unifaces, and cobble bifaces were slightly different than those for the other artifacts. Length was measured in mm along the axis through the major flaking surface. Width was measured perpendicular to the length, and thickness was measured as the remaining dimension. In contrast, the length of hammerstones and anvils was measured in $\mathrm{mm}$ along the longest axis, the width was measured perpendicular to length, and thickness was the smallest dimension of the artifact. Each artifact was weighed to the nearest tenth of a gram with an Ohaus electronic beam. Weight was the only measurement recorded for core fragments.

Several core types were recorded based on platform orientation and core shape. These consist of singledirectional cores, bidirectional cores, multidirectional cores, bipolar cores, and core fragments. In addition, these core type were subdivided into specific subtypes. The single-directional cores are single-face, multifaced, prismatic or pyramidal cores with flakes removed from a single striking platform. Bidirectional cores are change-of-orientation, discoidal, bifacial, opposed same face, opposed different face, and ninety degree cores with flakes removed from two separate striking platforms. Multidirectional cores are globular, opposed/ ninety degrees, and opposed same/different face cores, with flakes being removed from three or more platforms. Bipolar cores exhibit battering, crushing and/ or negative or positive bulbs of percussion at one or both opposing ends of the core. Core fragments are broken cores.

Number of platforms, platform type, and platform preparation were recorded. Number of platforms was coded as zero for non-cores and core fragments; whereas, bipolar cores were arbitrarily assigned a single platform. Platform type was cortical, single-faceted, multifaceted, cortical/single-faceted and undetermined/ nonapplicable (i.e., core fragments or non-cores). Platform preparation, either on the platform or along the platform edge, was recorded as none, abraded, ground, abraded/ground, and undetermined/nonapplicable (i.e., core fragments and non-cores).

Cortex type was recorded as nodular, tabular, waterworn, and undetermined. Nodule or tabular cortex is the natural weathered surface of a nodule or tabularshaped rock; whereas, waterworn cortex is the rolled surface created through water transport of a rock. The percentage of the cortical or unflaked surface was measured for whole artifacts as less than 25 percent, 25-50 percent, 51-75 percent, more than 75 percent, and undetermined for fragments. The reason for discard was monitored for cores, tested materials, cobble unifaces and cobble bifaces. This consisted of broken (material flaw), broken (culturally induced facture), extensive hinging/stepping, exhausted, still usable, extensive battering, burned, undetermined, and nonapplicable (e.g., hammerstones). The presence or absence of burning was recorded. This could be represented by the presence of discoloration, pot lids, and/or crackling.

The number of damaged loci was also recorded; however, no cores exhibited damaged edges or surfaces.

\section{Debitage}

Material type was recorded for each piece. The condition of the artifact was recorded as either whole, proximal, midsection, distal, lateral or undetermined (e.g., flakes smaller than about $10 \mathrm{~mm}$ ). All pieces of angular debris were considered to be whole. Measurements were taken on all whole flakes. Length was defined as the distance along the proximal-distal axis of a flake (i.e., perpendicular to the platform) and was measured in mm using a sliding digital caliper. Weight was recorded for all debitage items to the nearest tenth of a 
gram using an Ohaus digital scale. Weight was the only measurement recorded for angular debris and flake fragments.

The type of platform was recorded for all flakes as absent, cortical single-faceted, dihedral, multifaceted, crushed, collapsed, battered, and nonapplicable (for angular debris). A cortical platform is unprepared and situated on cortex. A single-faceted platform consists of a single flake scar; whereas, a dihedral platform consists of two flake scars and a multifaceted platform as three or more flake scars. A crushed platform is one in which the proximal end of the flake is covered with step fractures, indicative of crushing along the edge of the core platform. A collapsed platform is identified on whole flakes that lack a clear platform and any traces of crushing. A battered platform is a cortical platform that is covered with battering and impact marks, which may be indicative of a hammerstone spall.

Cortex type was monitored using the same attributes as for the cores. The placement of the cortex was recorded on whole flakes only. It was monitored as absent, on the platform only, on the dorsal surface only, on the platform and partially on the dorsal surface, orange rind (i.e., along the platform and lateral edge), on the platform and totally covering the dorsal surface. The presence or absence of burning was recorded. In addition, type of burning was also noted. Heavy burning was defined by the presence of discoloration, crackling, and potlids. Light burning was defined by a greasy feel, and a glossy shine.

The presence or absence of edge damage was recorded as a possible indication of artifact use. This was done with a Wolf binocular microscope at a magnification of $10 \mathrm{x}$. Damage was recorded if it was consistent along the edge margin. All damaged edges were given a sequential number for each artifact. The location (end, lateral, or projection), edge angle, and edge outline (straight, concave, convex, or projection) were noted for each edge. The edge angle of all the damaged edges was recorded to the nearest five degrees. This measurement is equivalent to the "spine plane angle" (Tringham et al. 1974), which measures the intersection of the dorsal and ventral surfaces of the edge. If the angle varied along the edge, then a mean edge angle or the angle that characterized the majority of the edge was recorded. A "shurikan" edge-angle template was used for this analysis. The template consists of a circular disk with angles cut into its side at five-degree increments from 20 to 90 degrees. The edge to be measured is placed within a notch until the angle that fits most accurately is found. This device was developed by Kaoru Akoshima and is quite accurate and efficient.

\section{Retouched Tools}

Material type, condition, cortex type, cortex placement, and burning were recorded for retouched tools using the same attributes as those monitored for the debitage. Measurements were taken in mm for whole tools. Length was measured along the proximal-distal axis. Width was measured at a 90-degree angle to the proximal-distal axis. Thickness was the greatest measurement once the proximal-distal axis was rotated 90 degrees. The proximal end is the same as that defined for flakes on informal retouched tools, and the possible hafted end on formal tools (e.g., bifaces, projectile points and scrapers). Weight was measured to the nearest tenth of a gram. Tool fragments were only weighed.

The number of separate retouched edges was monitored on each tool. Each edge was given a sequential number. Only one edge was recorded on tools exhibiting a continuously retouched edge (e.g., scrapers, bifaces, drills, and projectile points). It is the marginally retouched flakes that most often exhibit separate retouched edges. Retouch type was recorded as unidirectional ventral (inverse), unidirectional dorsal (obverse), alternating (continuous inverse and obverse retouch along the same edge), bidirectional (both faces), burination, backed, and use-wear. The use-wear attribute was monitored when a retouched flake exhibited separate retouched and utilized edges. Perforators with inverse retouch along one edge and obverse retouch along the opposite edge were classified as exhibiting alternating retouch. Edge outline was coded in the same manner as it was for the debitage, with the addition of straight/concave, straight/convex, concave/ convex, and undetermined (e.g., point fragments). Edge outlines and edge angles were monitored on the blades of bifaces and projectile points, and the retouched edges on scrapers. Edge angles were measured using the same technique as for the debitage. The presence or absence 
of obvious edge damage that might attributed to use was recorded.

A separate analysis was conducted on the projectile points. Twelve metrical and qualitative measurements were taken of these artifacts: material type, condition, overall length, blade length, neck width, stem length, stem width, thickness, weight, haft type, blade shape and base shape. Material type, condition and weight are the same as monitored for the retouched tool. Figure E-4 illustrates the conventions used for the metrical attributes. The hafting type was described as side-notched, corner-notched, stemmed, contracting stemmed, lanceolate, fluted, basal-notch, sidenotched/basal-notch, other, or undetermined. The shape of the blade was coded as straight (angled), parallel, convex, serrated, concave, irregular, other or undetermined. The shape of the base was described as straight, concave, notched, convex, other, or undetermined.

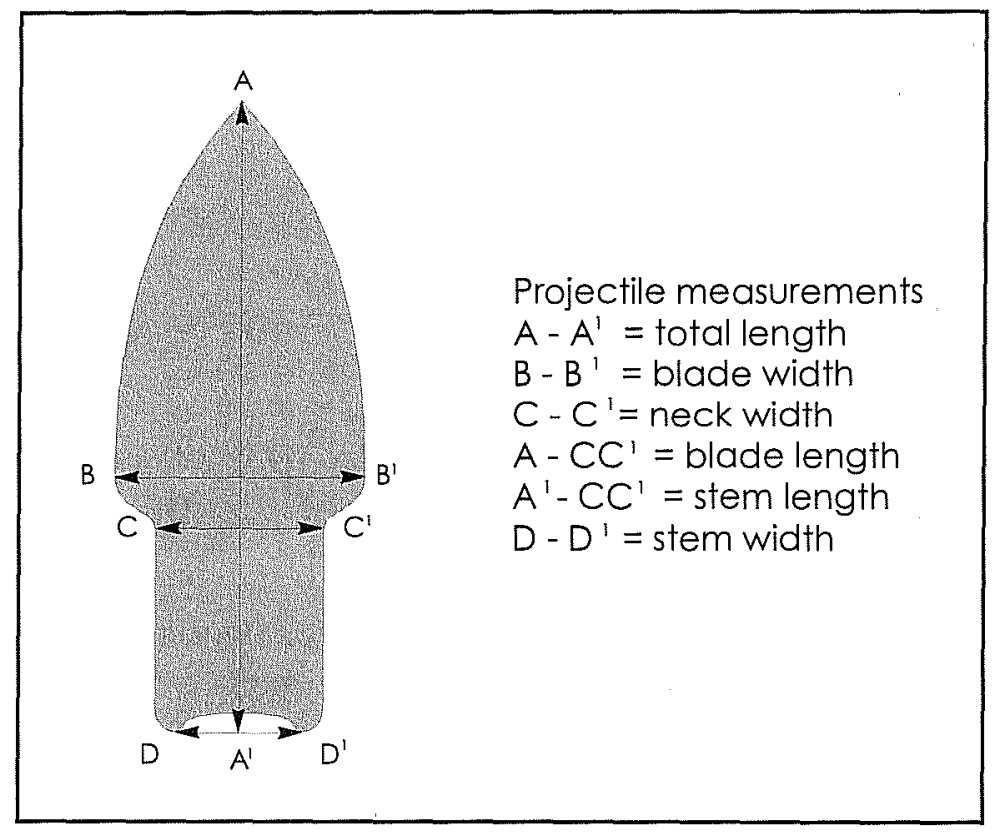

Figure E-4. Conventions used for metrical attributes of retouched tools.

\section{Ground-stone Tools}

Only one ground stone artifact was recovered, and this particular item was simply described.

\section{Reference Cited}

Tringham, R.., G. O'Dell, B. Voytek, and A. Whitman

1974 Experimentation in the formation of edge damage: a new approach to lithic analysis. Journal of Field Archaeology 1:171-196. 
Appendix F: Archaeomagnetic Data

Wulf Gose 


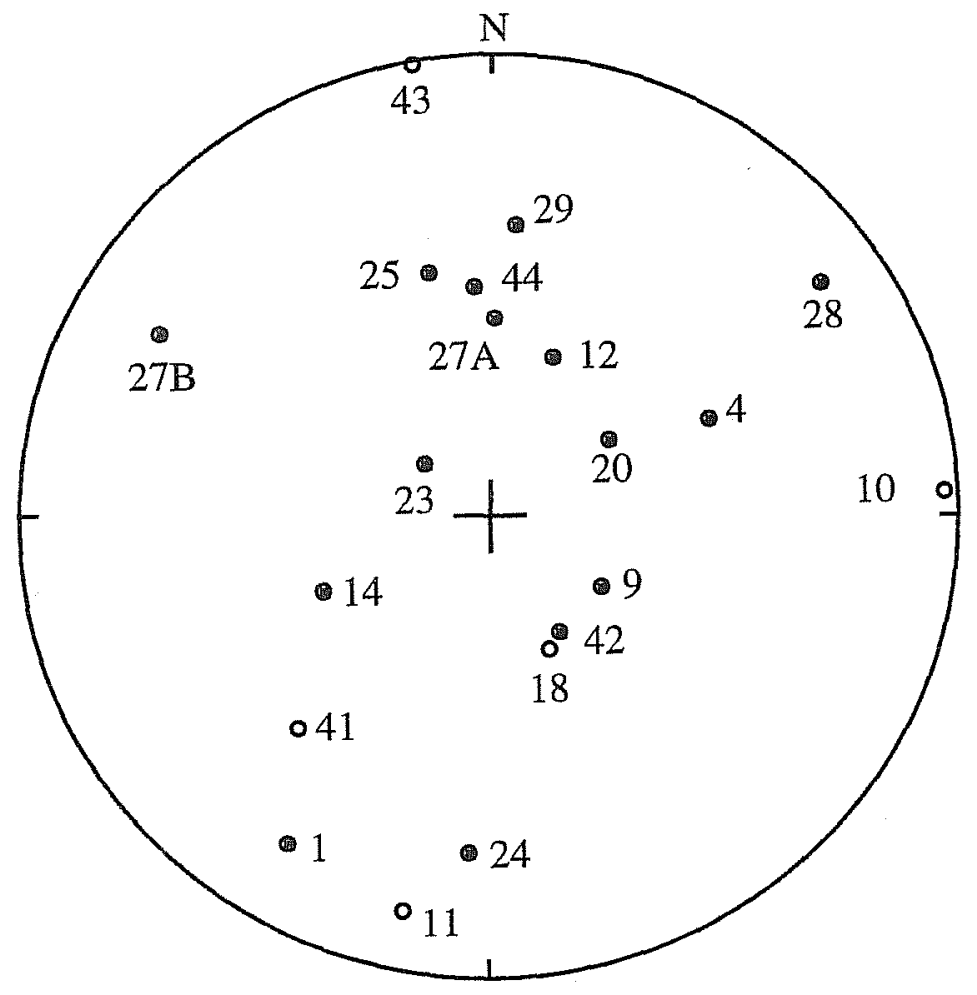

\section{MV120 $\mathrm{AF} 800$}

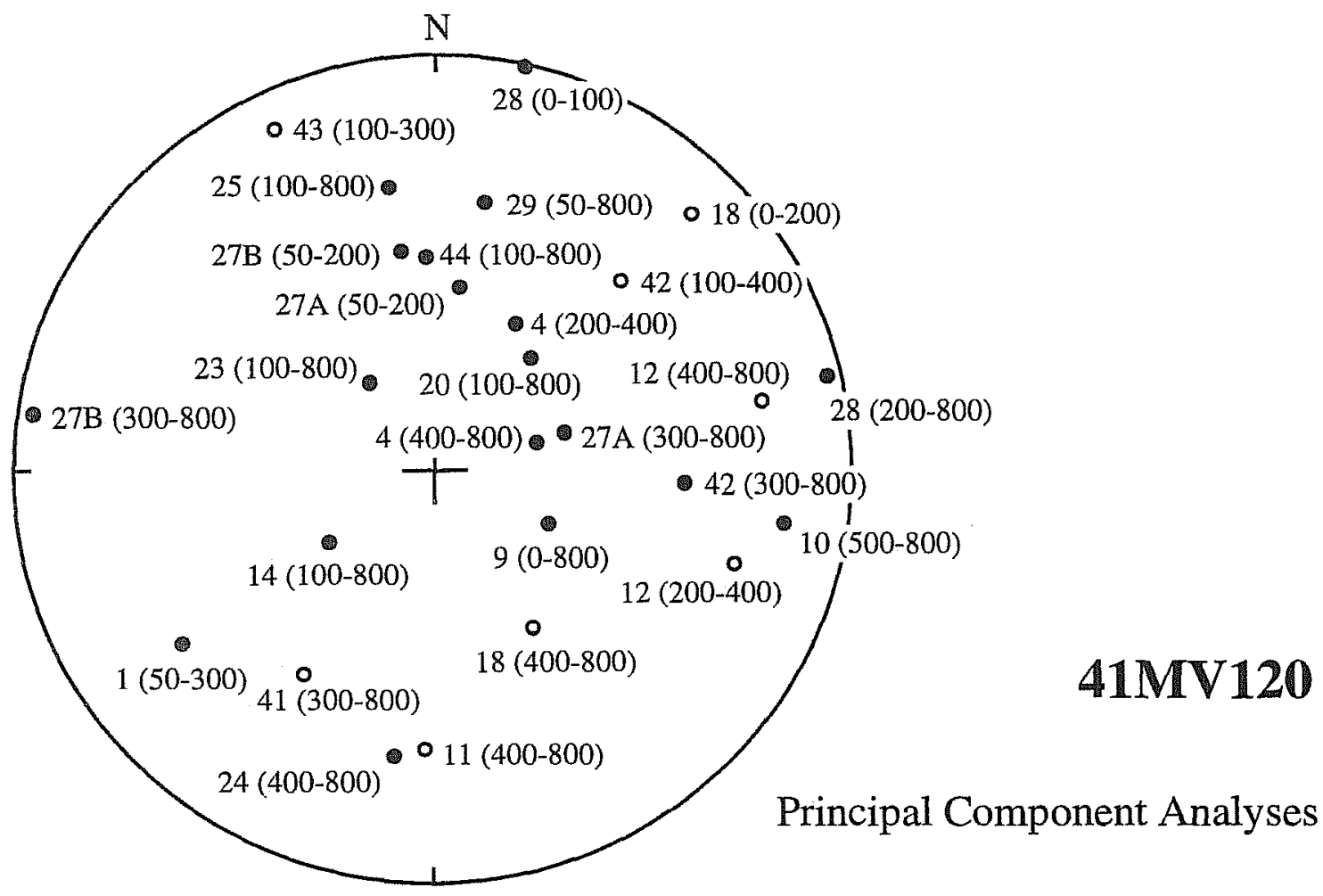




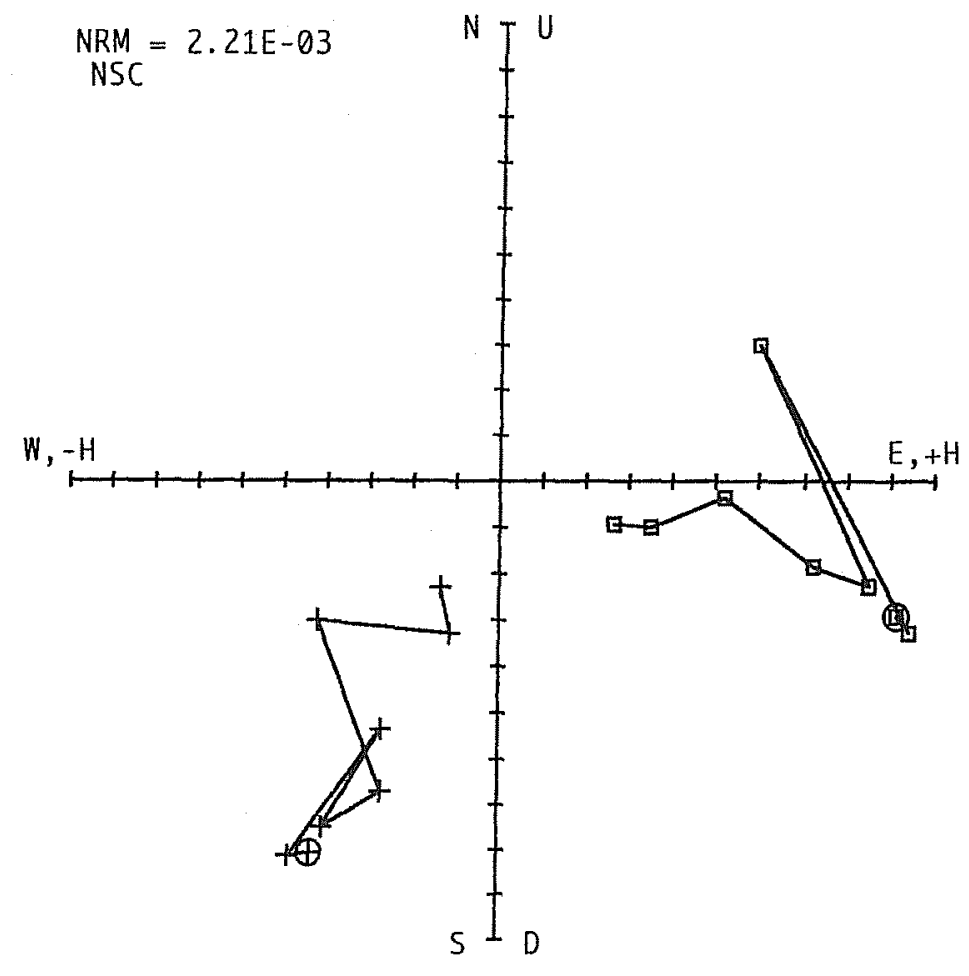

\begin{tabular}{lllrl}
\multicolumn{3}{c}{ MAV MAV1 } & & \\
& STEP & DECL & INCL & AMP \\
& & & & \\
1 & NRM & 208.3 & 17.6 & 0.96 \\
2 & AF050 & 210.7 & 19.0 & 1.00 \\
3 & AF100 & 206.9 & -26.3 & 0.67 \\
4 & AF200 & 208.5 & 15.0 & 0.88 \\
5 & AF300 & 202.1 & 14.5 & 0.75 \\
6 & AF400 & 235.0 & 4.0 & 0.52 \\
7 & AF600 & 199.4 & 15.8 & 0.36 \\
8 & AF800 & 211.4 & 18.9 & 0.28
\end{tabular}

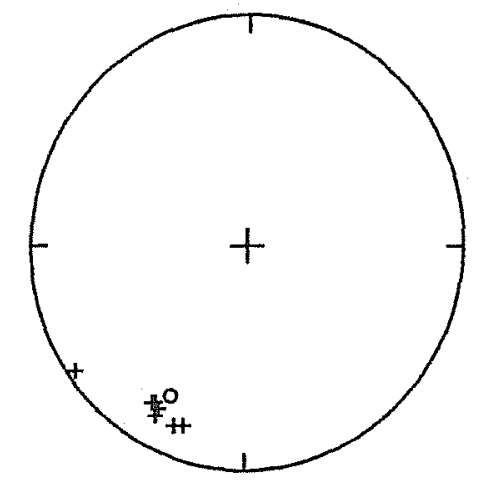

INTENSITY VS. DEMA GNETIZATION

1

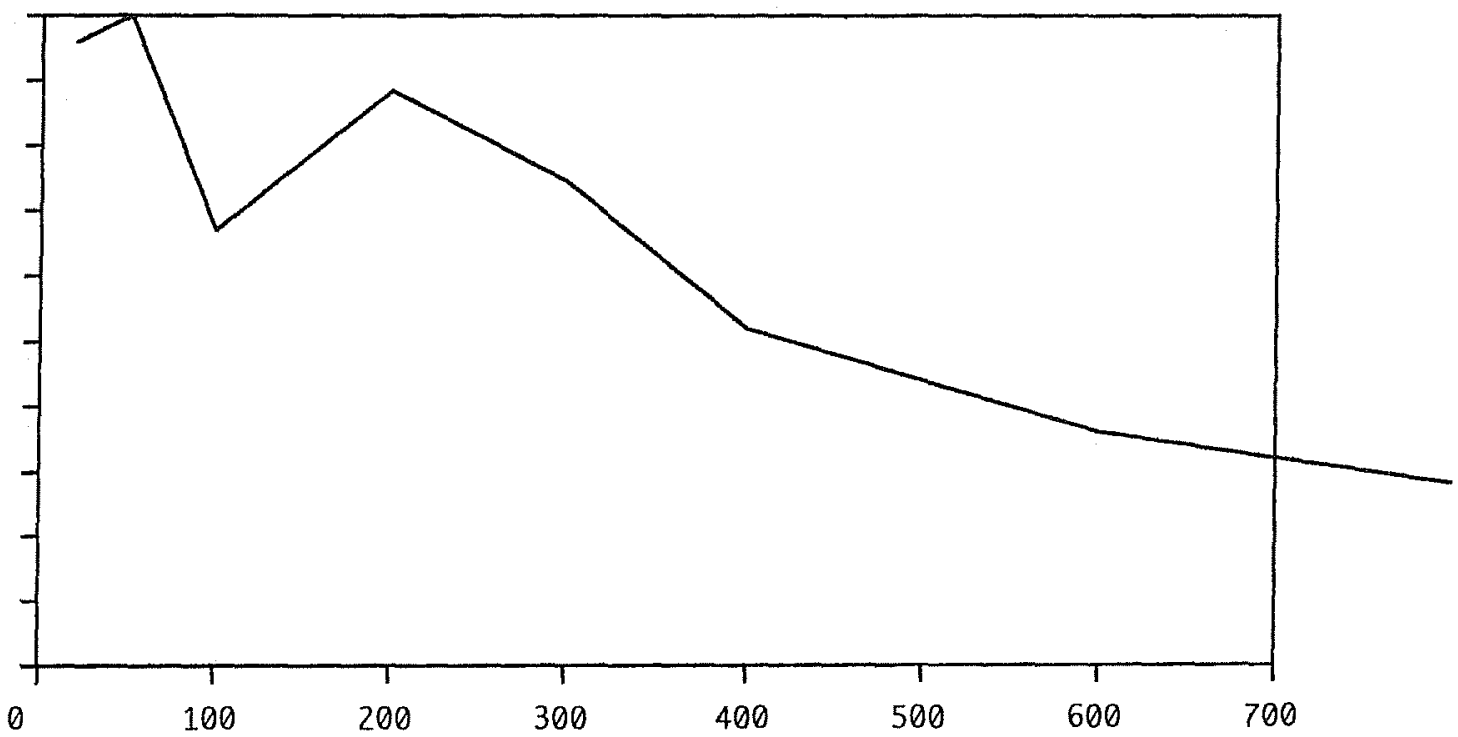



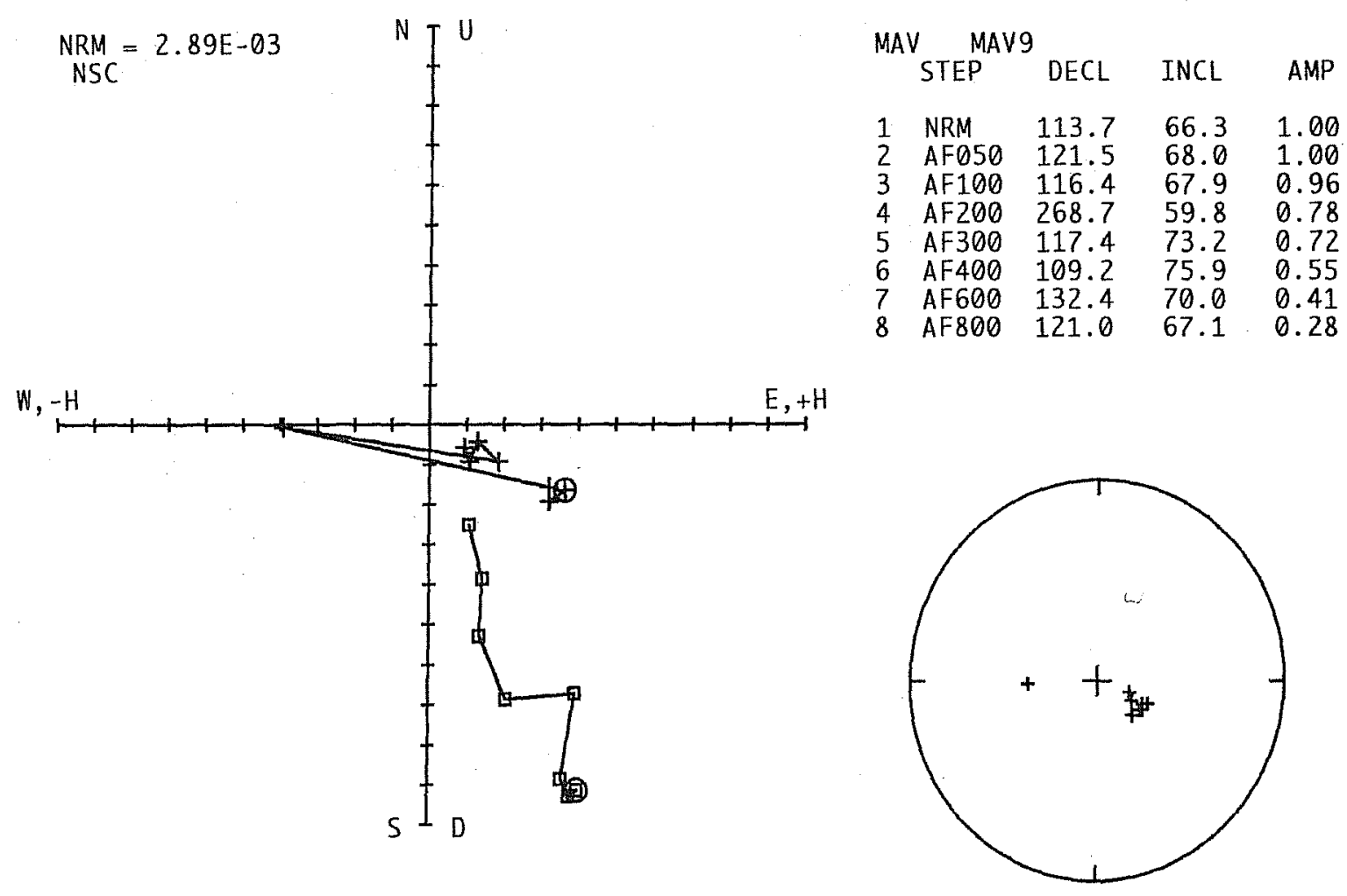

INTENSITY VS. DEMA GNETIZATION

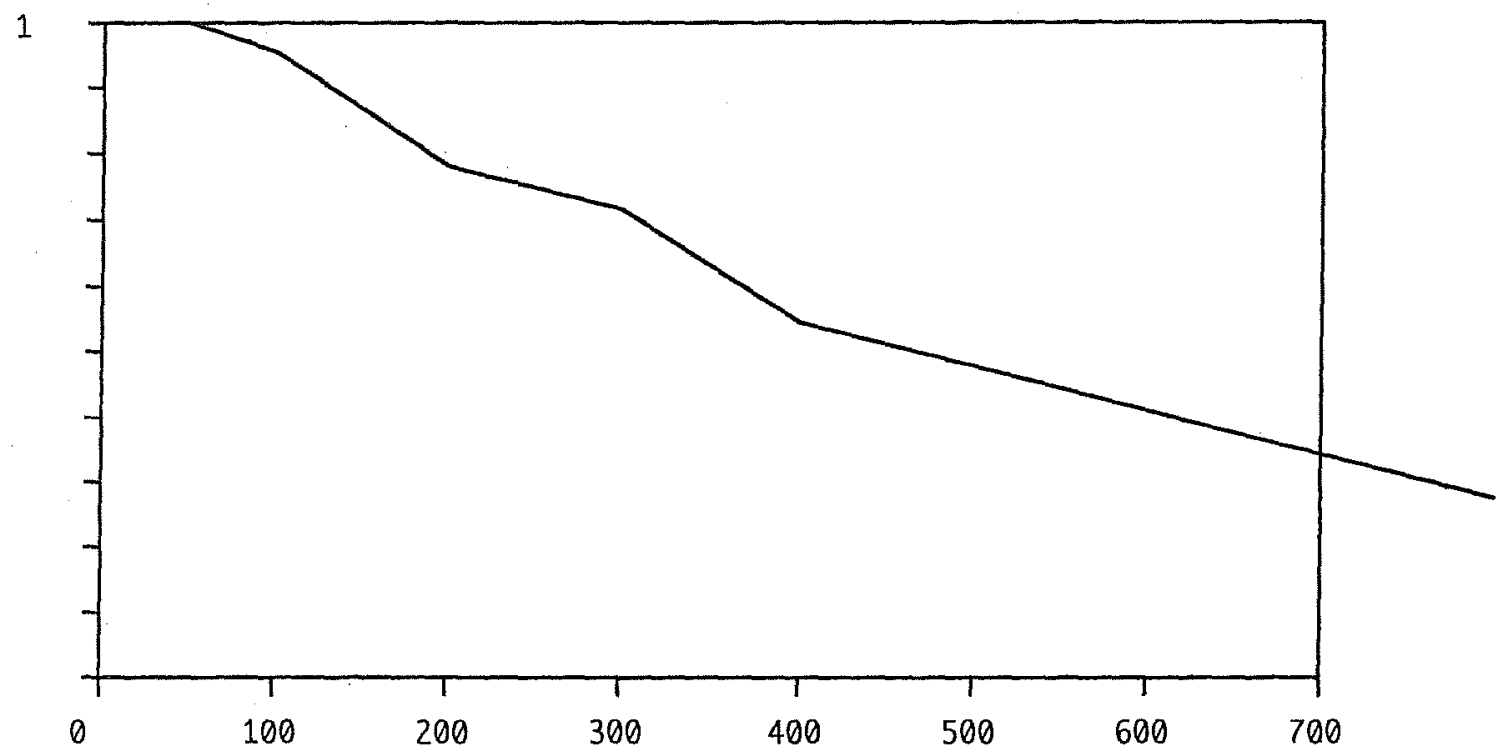




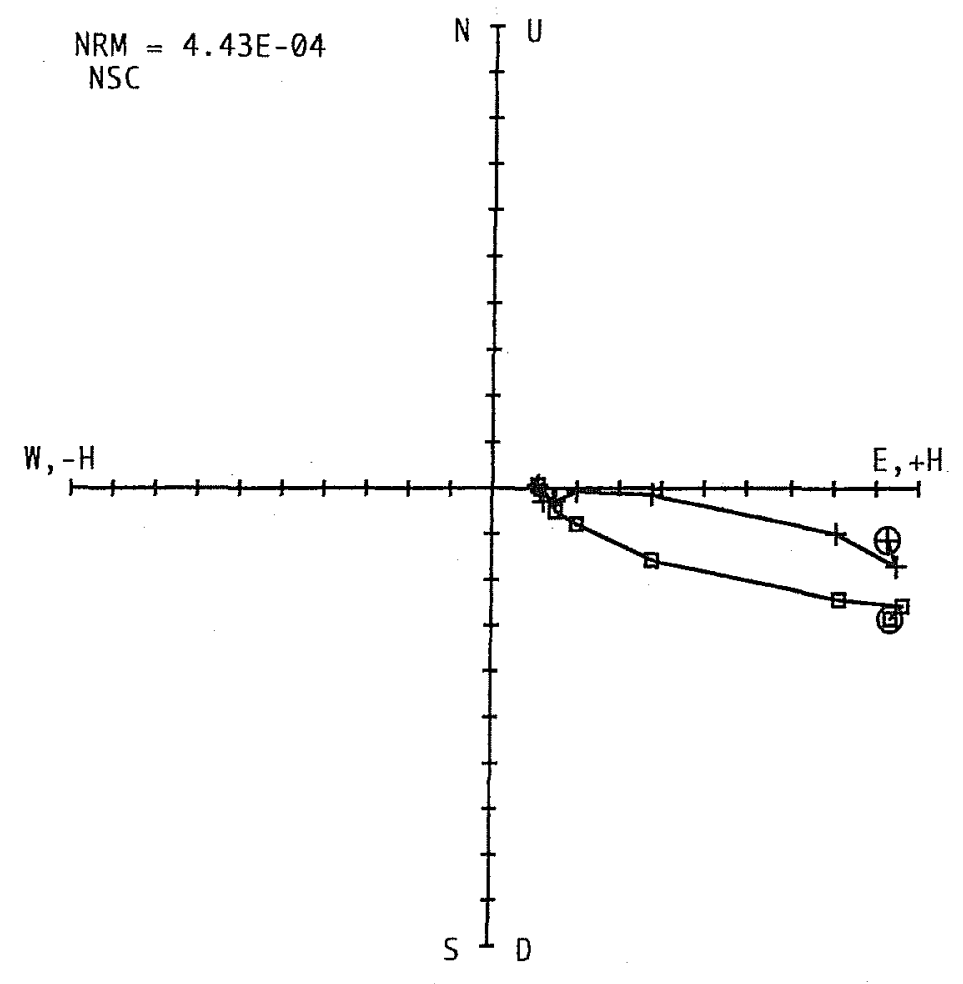

\begin{tabular}{llrrr}
\multicolumn{5}{c}{ MAV MAV10 } \\
STEP & DECL & INCL & AMP \\
& & & & \\
1 & NRM & 96.9 & 16.9 & 0.98 \\
2 & AF050 & 100.2 & 14.9 & 1.00 \\
3 & AF100 & 96.9 & 16.4 & 0.85 \\
4 & AF200 & 92.3 & 22.7 & 0.41 \\
5 & AF300 & 92.2 & 22.1 & 0.21 \\
6 & AF400 & 100.5 & 17.5 & 0.16 \\
7 & AF600 & 104.6 & 5.7 & 0.13 \\
8 & AF800 & 87.1 & -3.5 & 0.11
\end{tabular}

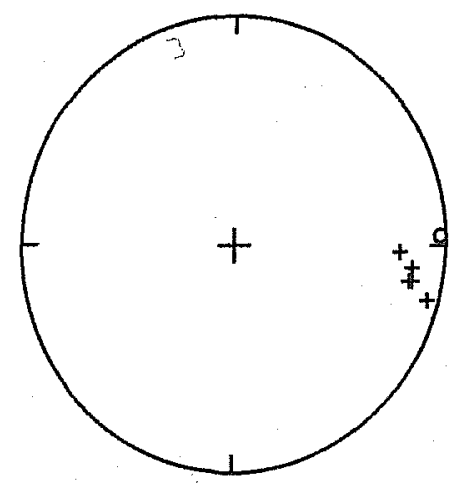

INTENSITY VS. DEMAGNETIZATION

1

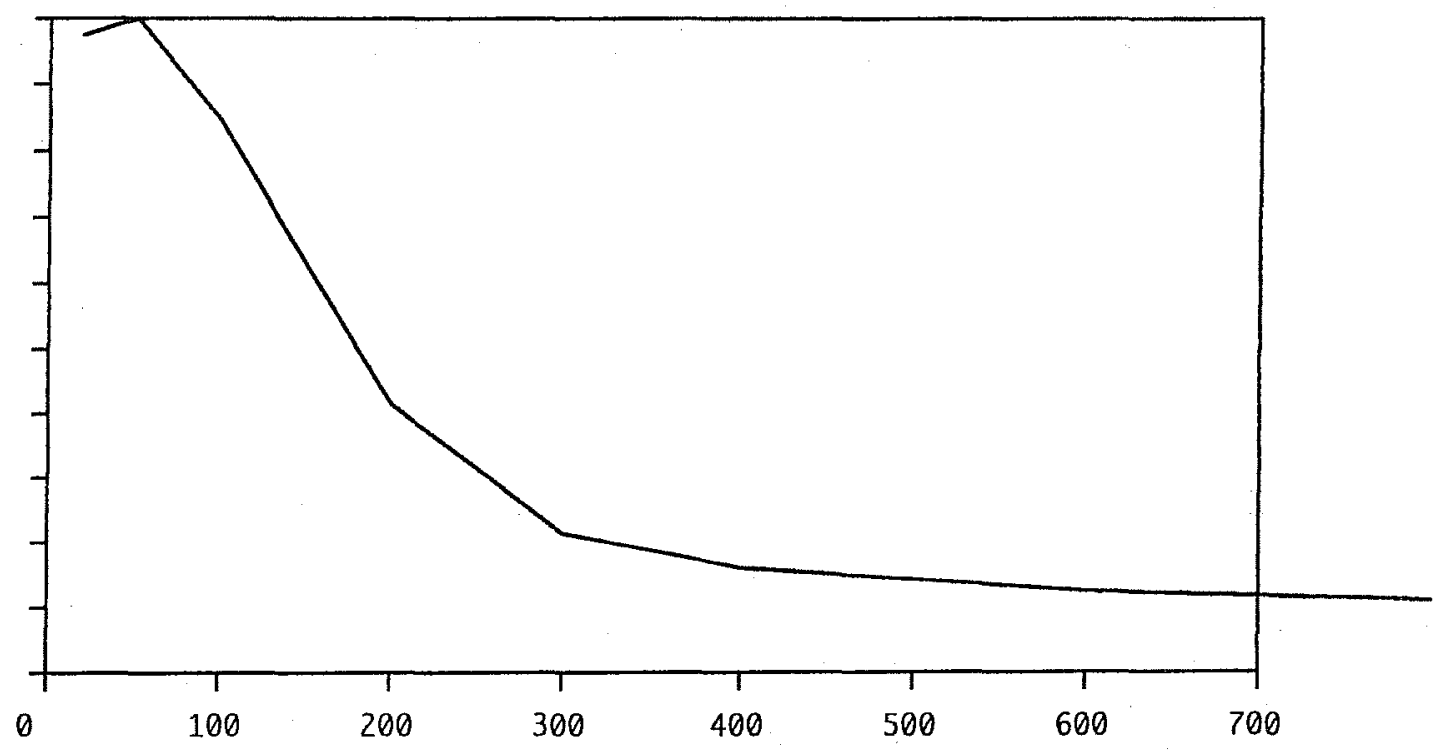




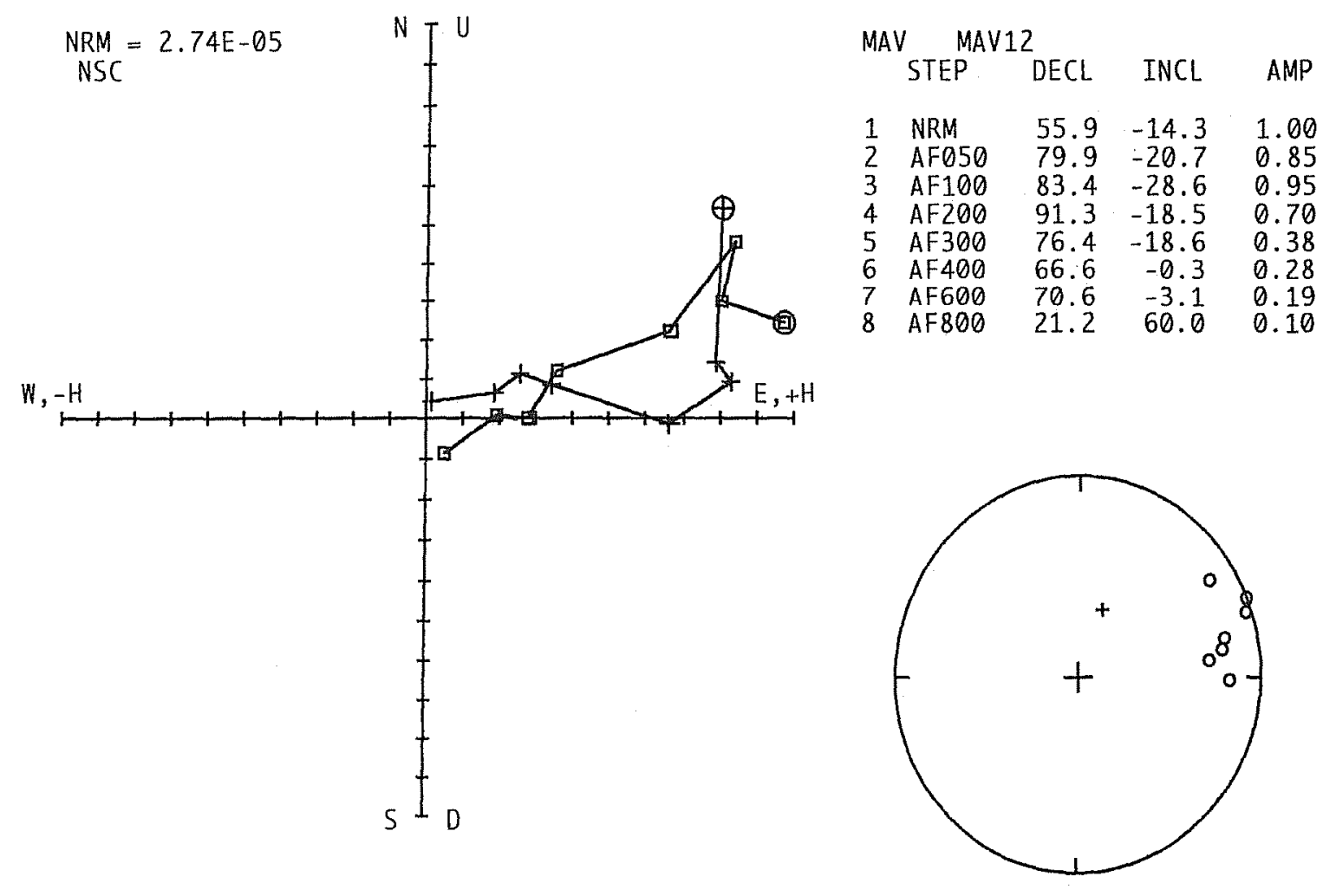

MAV MAV12

$\begin{array}{lllll}1 & N R M & 55.9 & -14.3 & 1.00\end{array}$

$\begin{array}{lllll}2 & \text { AF050 } & 79.9 & -20.7 & 0.85\end{array}$

$\begin{array}{lllll}3 & \text { AF100 } & 83.4 & -28.6 & 0.95\end{array}$

$\begin{array}{lllll}4 & \text { AF } 200 & 91.3 & -18.5 & 0.70\end{array}$

$\begin{array}{lllll}5 & \text { AF300 } & 76.4 & -18.6 & 0.38\end{array}$

$\begin{array}{lllll}6 & \text { AF400 } & 66.6 & -0.3 & 0.28\end{array}$

$\begin{array}{lllll}7 & \text { AF } 600 & 70.6 & -3.1 & 0.19 \\ 8 & \text { AF } 800 & 21.2 & 60.0 & 0.10\end{array}$

INTENSITY VS. DEMA GNETIZATION

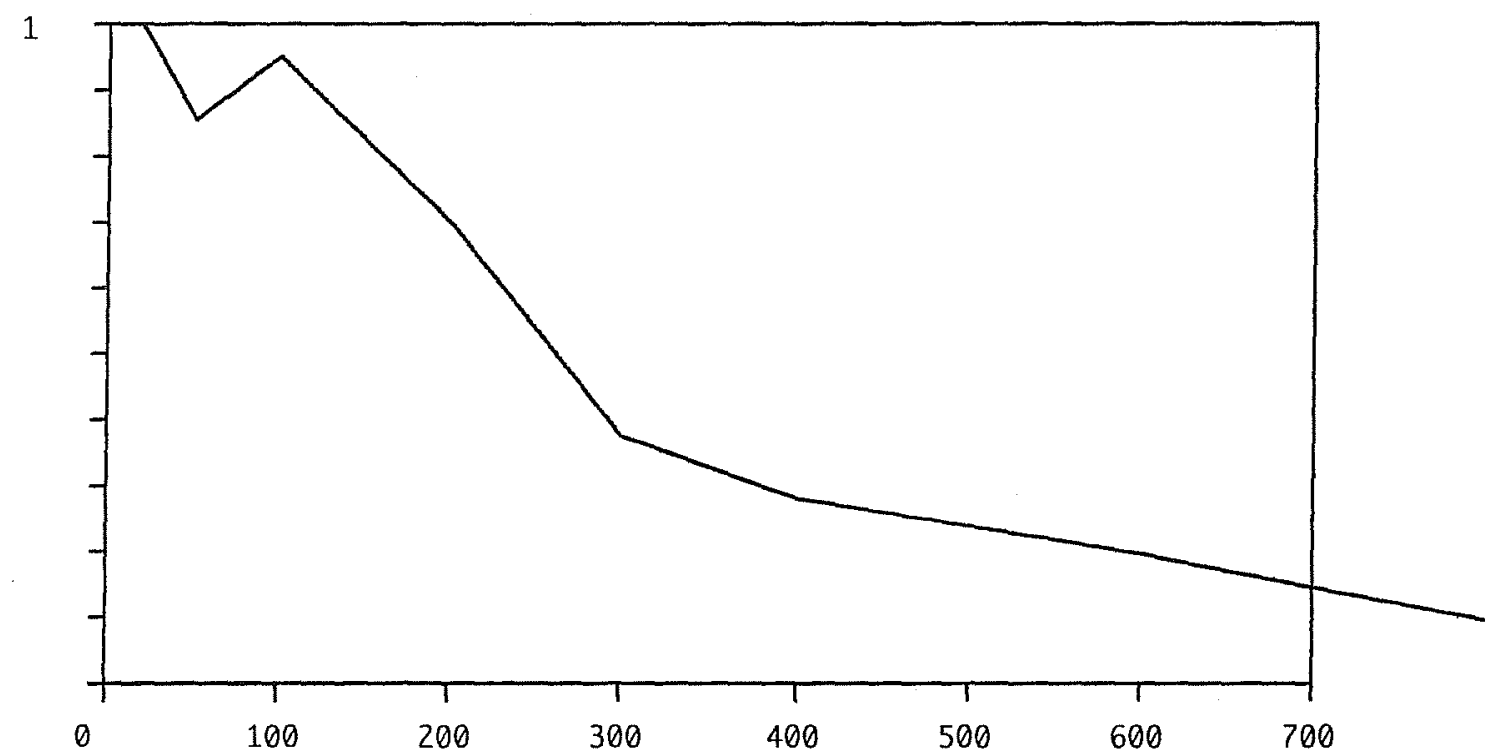




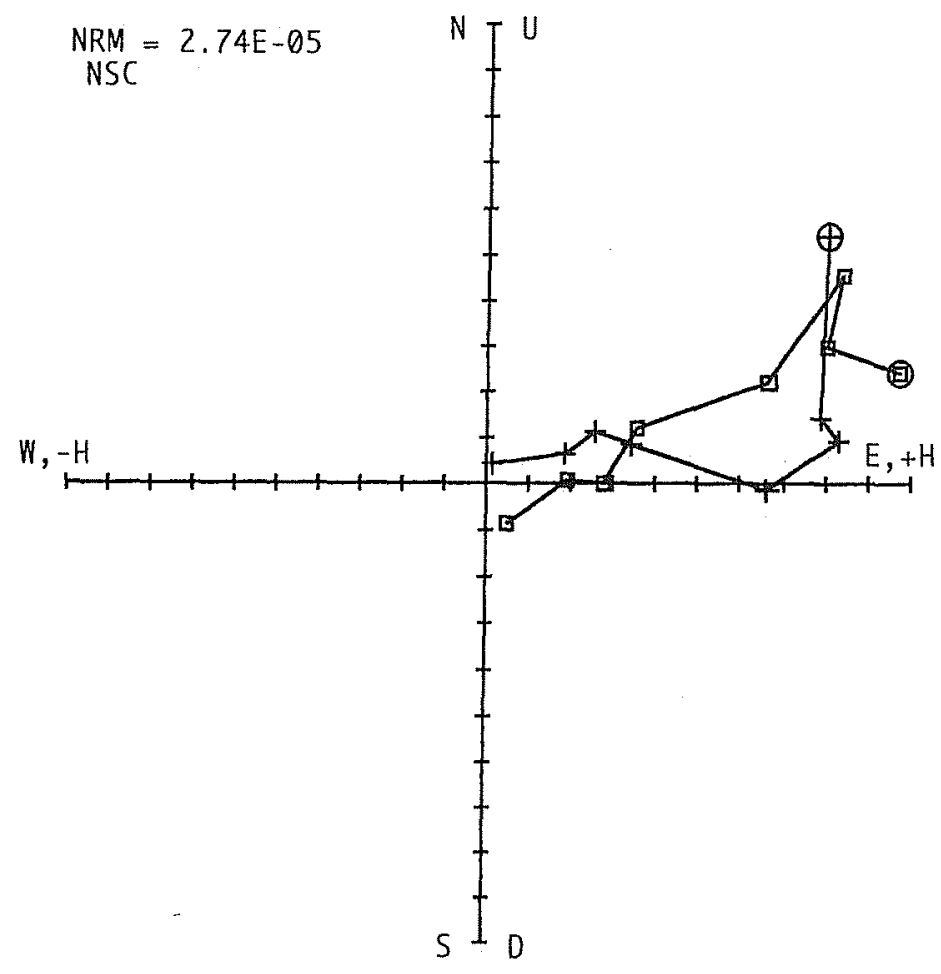

\begin{tabular}{|c|c|c|c|c|}
\hline & MAV & & & \\
\hline & STEP & $\mathrm{DECL}$ & INCL & AMP \\
\hline & NRM & 55.9 & -14.3 & 1.00 \\
\hline & AF050 & 79.9 & -20.7 & 0.85 \\
\hline & AF100 & 83.4 & -28.6 & 0.95 \\
\hline & AF200 & 91.3 & -18.5 & 0.70 \\
\hline & $A F 300$ & 76.4 & -18.6 & 0.38 \\
\hline & AF400 & 66.6 & -0.3 & 0.28 \\
\hline & AF600 & 70.6 & -3.1 & 0.19 \\
\hline 8 & AF 800 & 21.2 & 60.0 & 0.10 \\
\hline
\end{tabular}

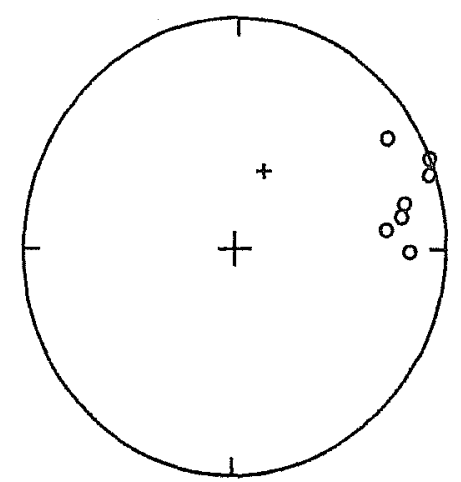

INTENSITY VS. DEMA GNETIZATION

1

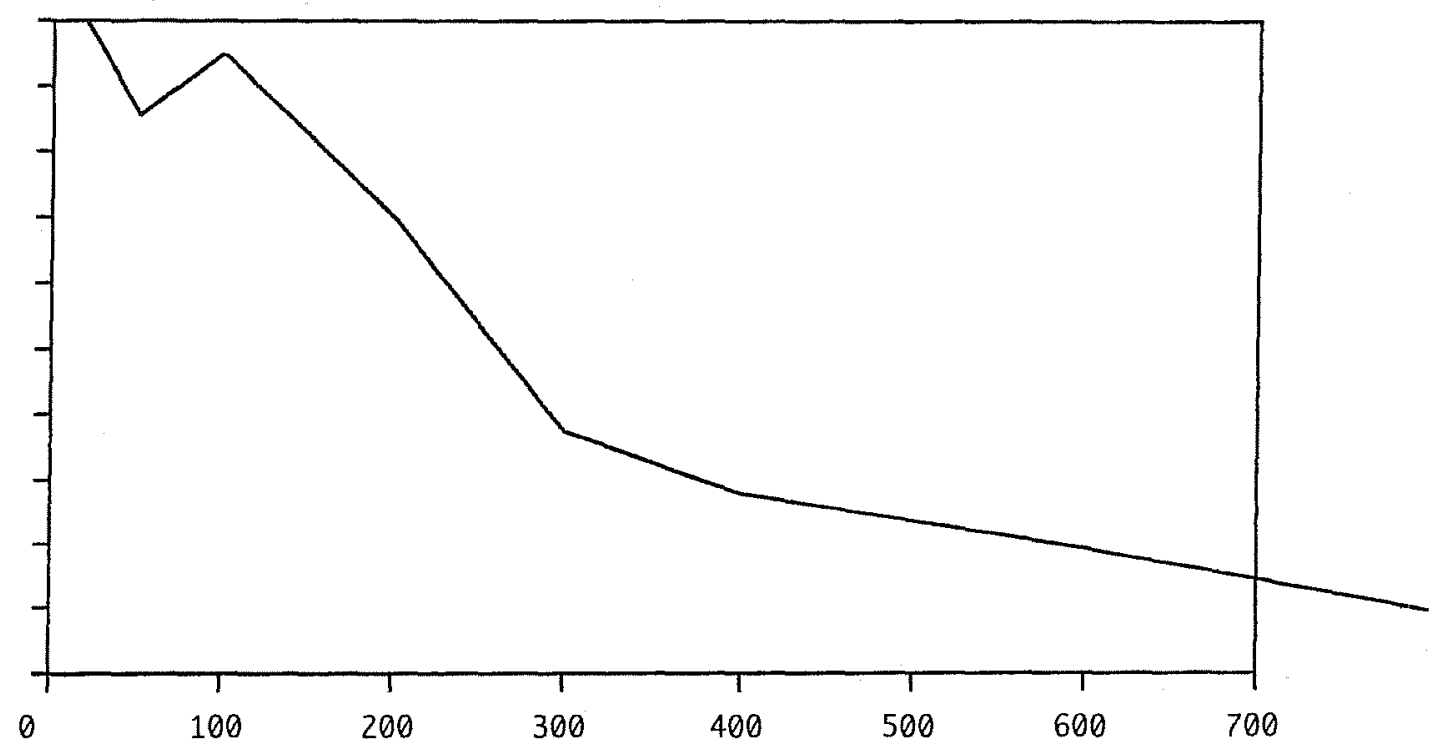




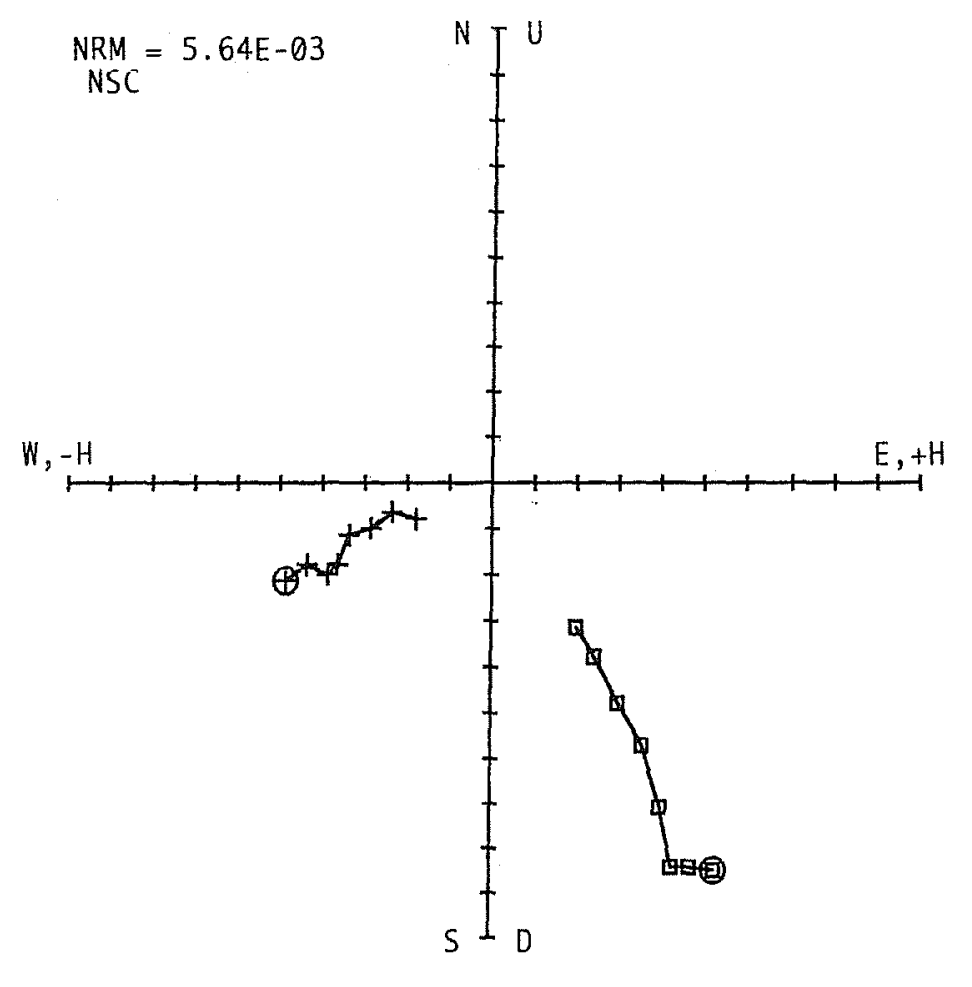

\begin{tabular}{lllll}
\multicolumn{5}{l}{ MAV MAV14 } \\
\multicolumn{1}{c}{ STEP } & DECL & INCL & AMP \\
& & & & \\
1 & NRM & 246.2 & 58.2 & 1.00 \\
2 & AF050 & 247.9 & 60.6 & 0.97 \\
3 & AF100 & 242.8 & 62.9 & 0.95 \\
4 & AF200 & 244.2 & 60.3 & 0.81 \\
5 & AF300 & 250.9 & 57.9 & 0.67 \\
6 & AF400 & 250.5 & 57.7 & 0.56 \\
7 & AF600 & 254.4 & 57.3 & 0.45 \\
8 & AF800 & 246.0 & 57.9 & 0.37
\end{tabular}

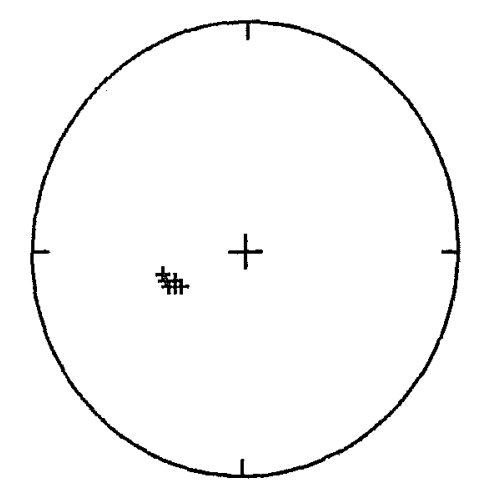

INTENSITY VS. DEMA GNETIZATION

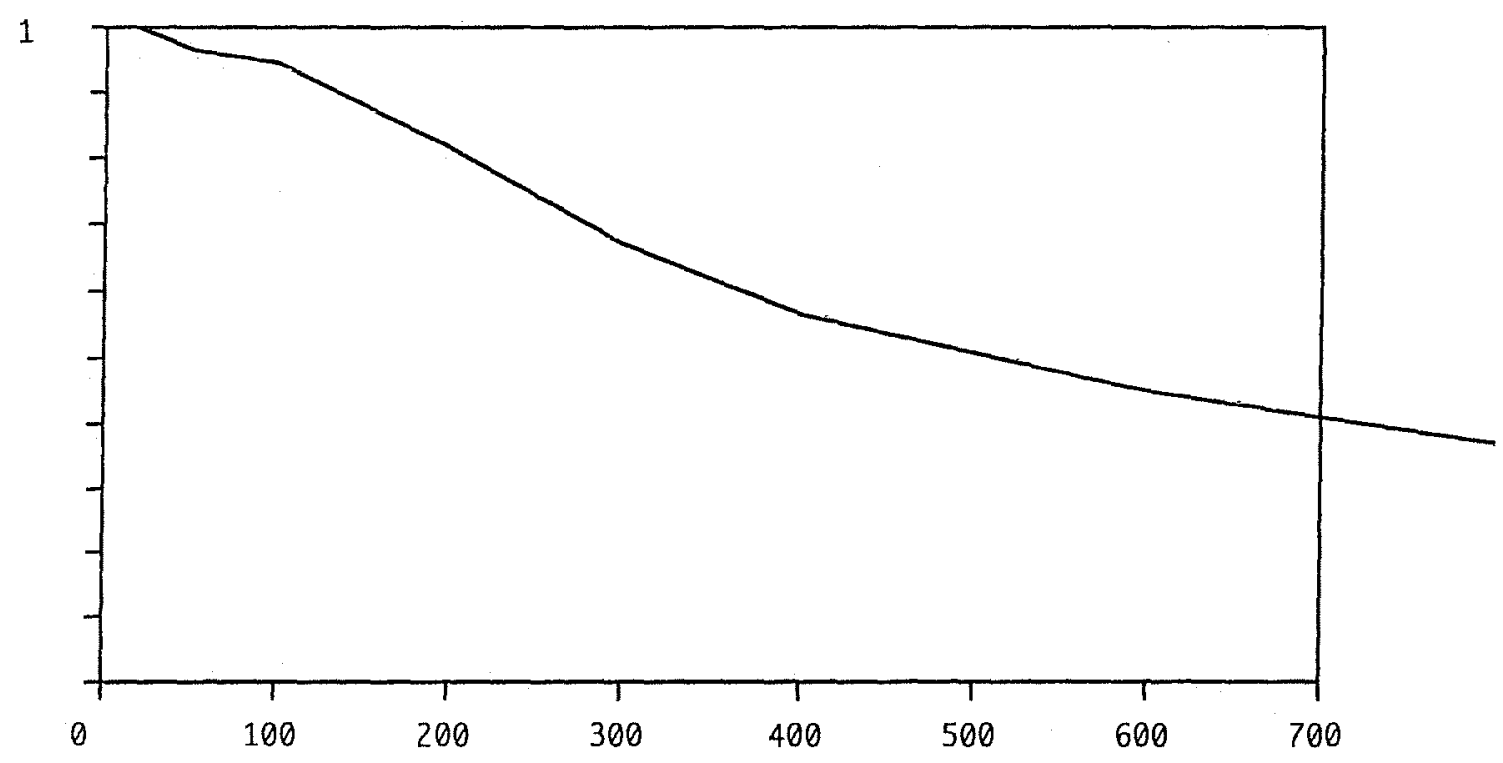



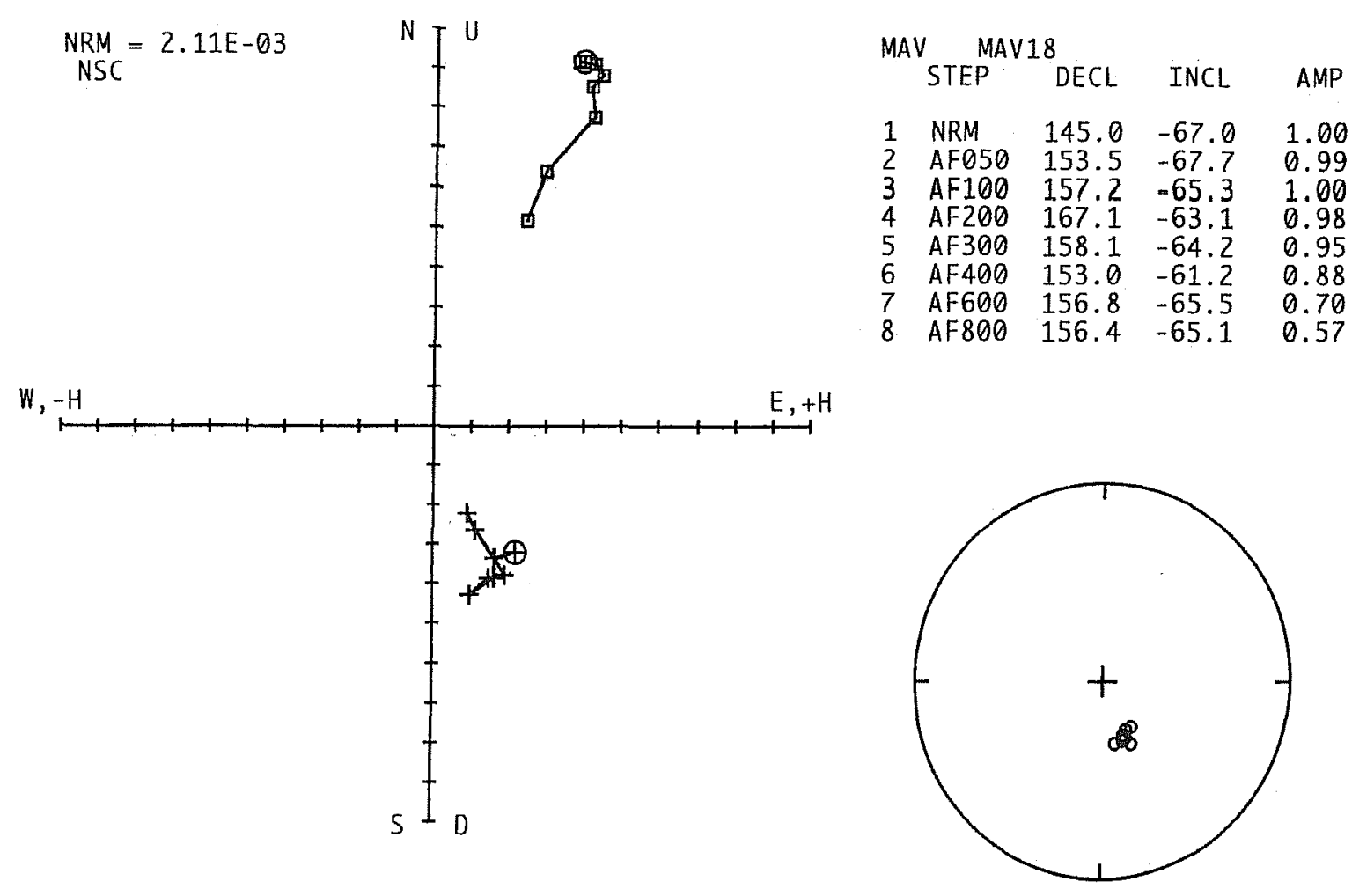

INTENSITY VS. DEMA GNETIZATION

1

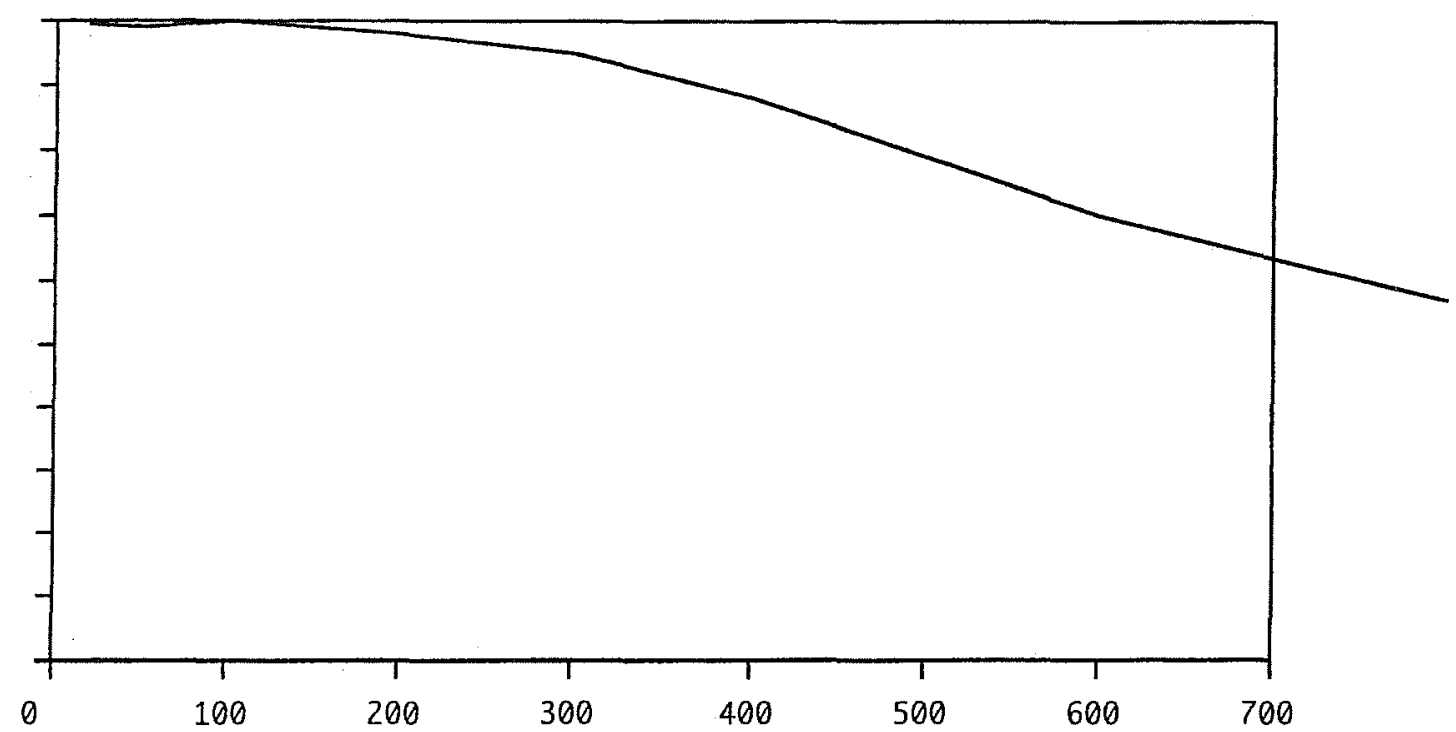




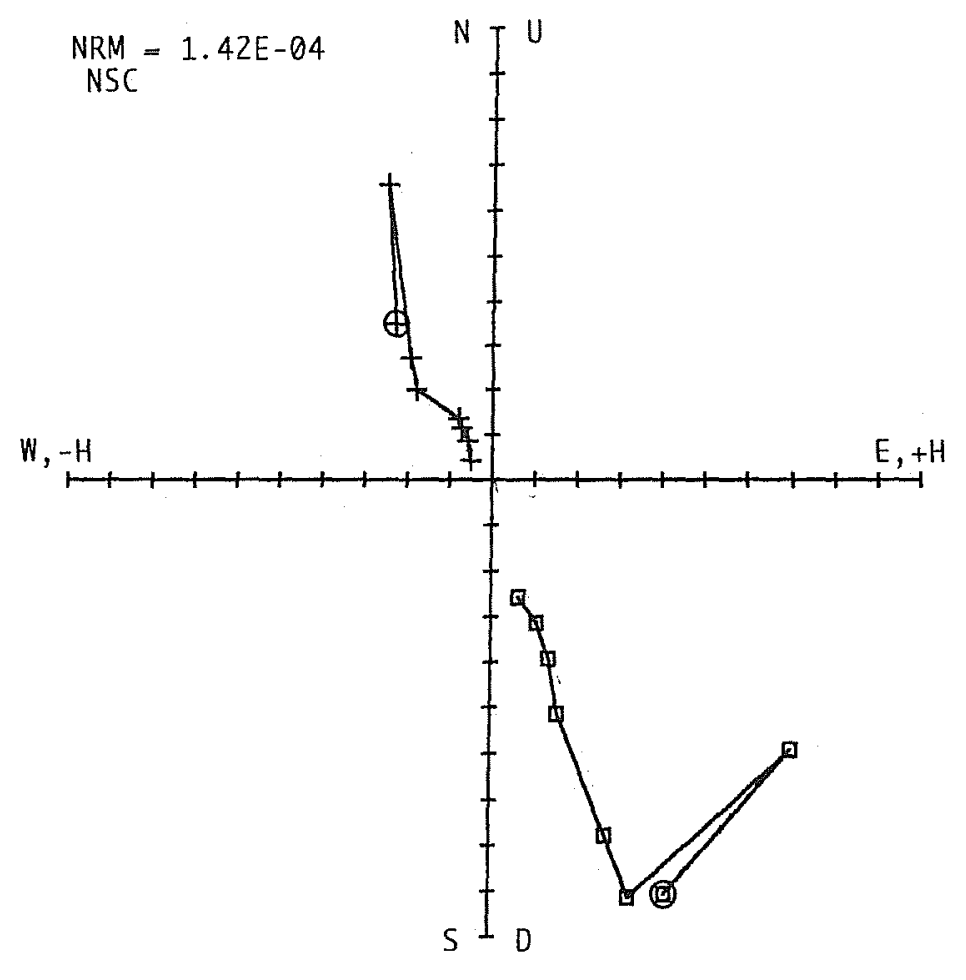

\begin{tabular}{lllll}
\multicolumn{5}{l}{ MAV MAV23 } \\
STEP & DECL & INCL & AMP \\
& & & & \\
1 & NRM & 327.0 & 65.4 & 1.00 \\
2 & AF050 & 338.9 & 40.0 & 0.92 \\
3 & AF100 & 324.9 & 70.2 & 0.97 \\
4 & AF200 & 318.5 & 70.8 & 0.83 \\
5 & AF300 & 329.5 & 72.9 & 0.53 \\
6 & AF400 & 328.2 & 70.9 & 0.42 \\
7 & AF600 & 325.5 & 71.9 & 0.33 \\
8 & AF800 & 308.4 & 75.5 & 0.27
\end{tabular}

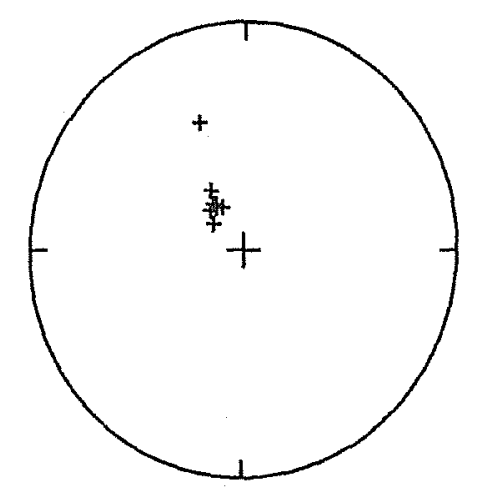

INTENSITY VS. DEMA GNETIZATION

1

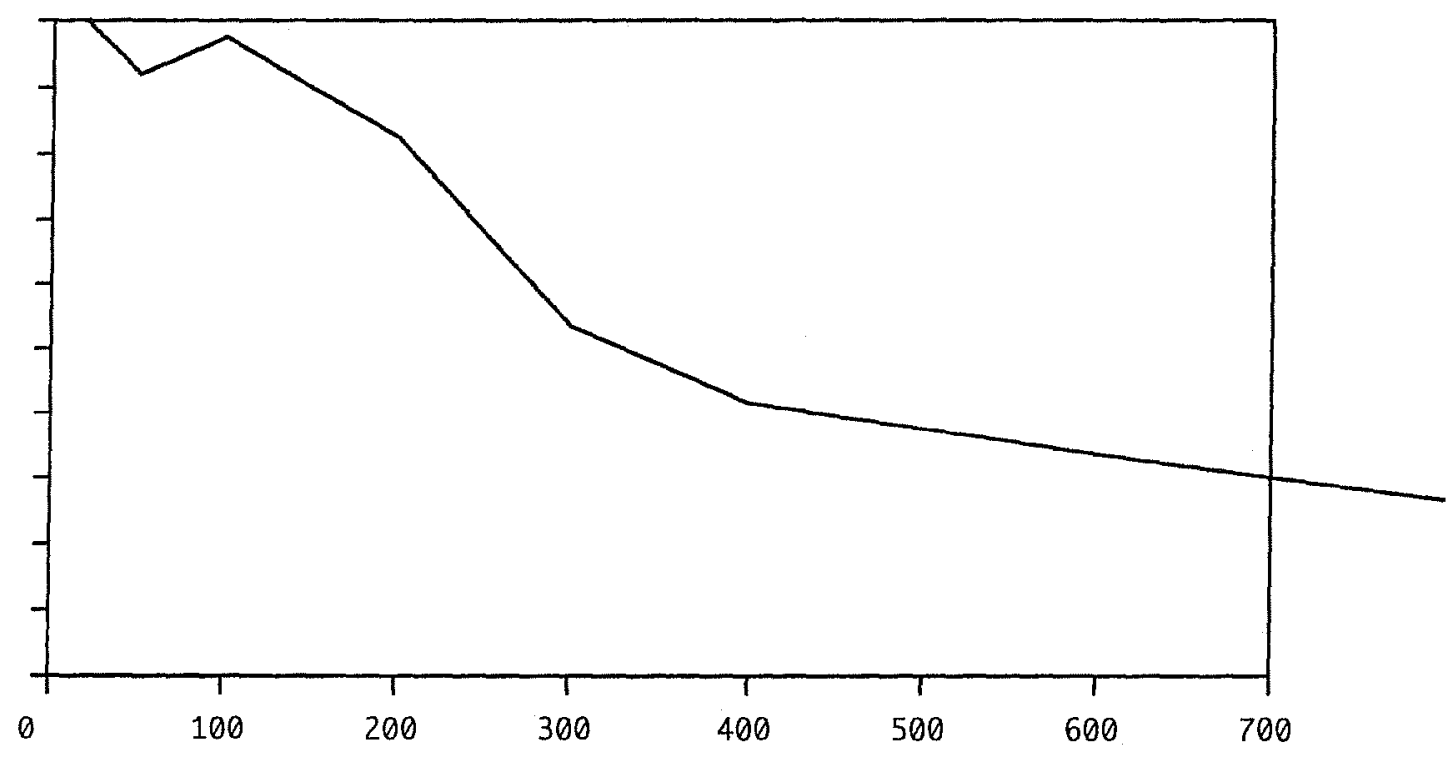



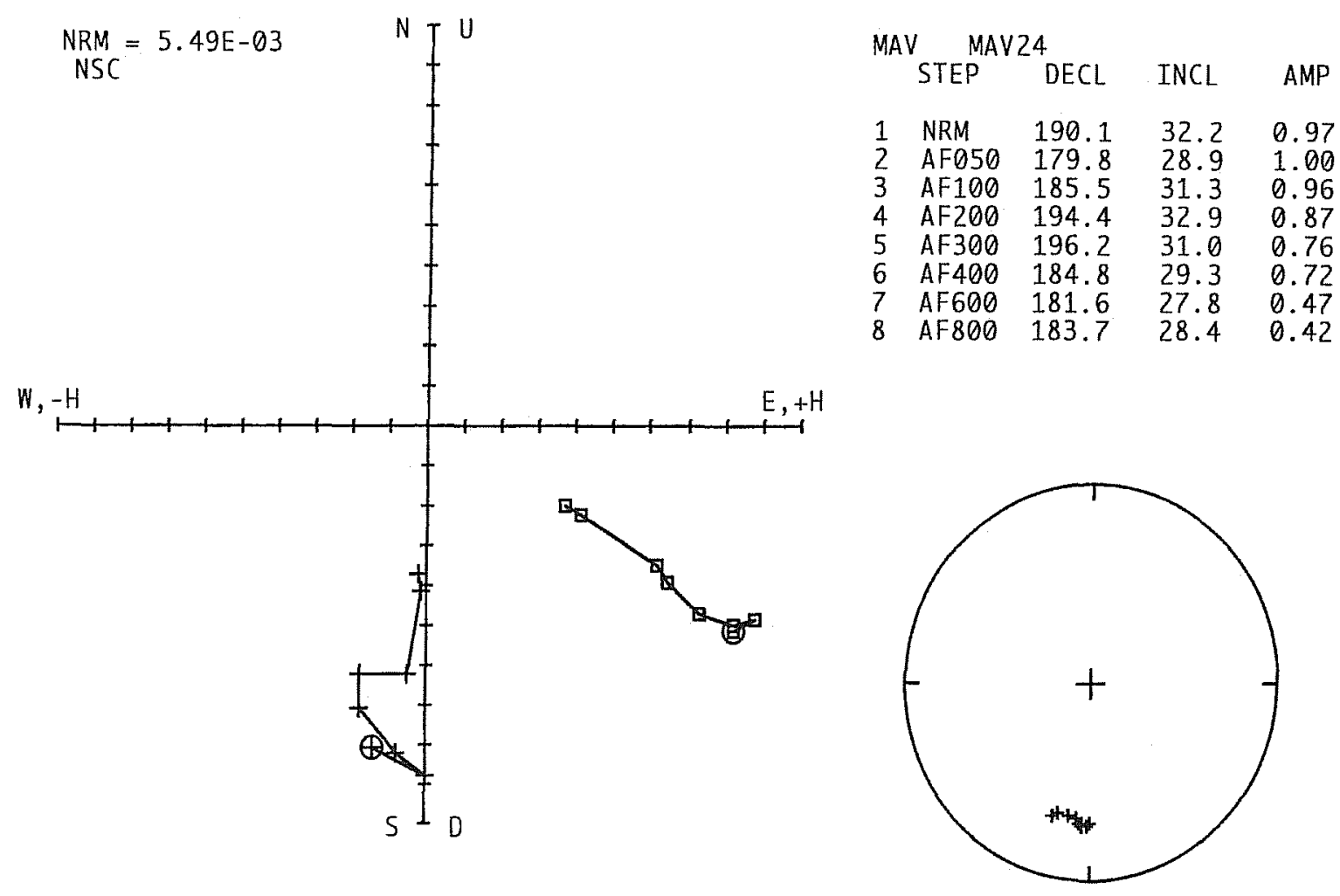

INTENSITY VS. DEMA GNETIZATION

1

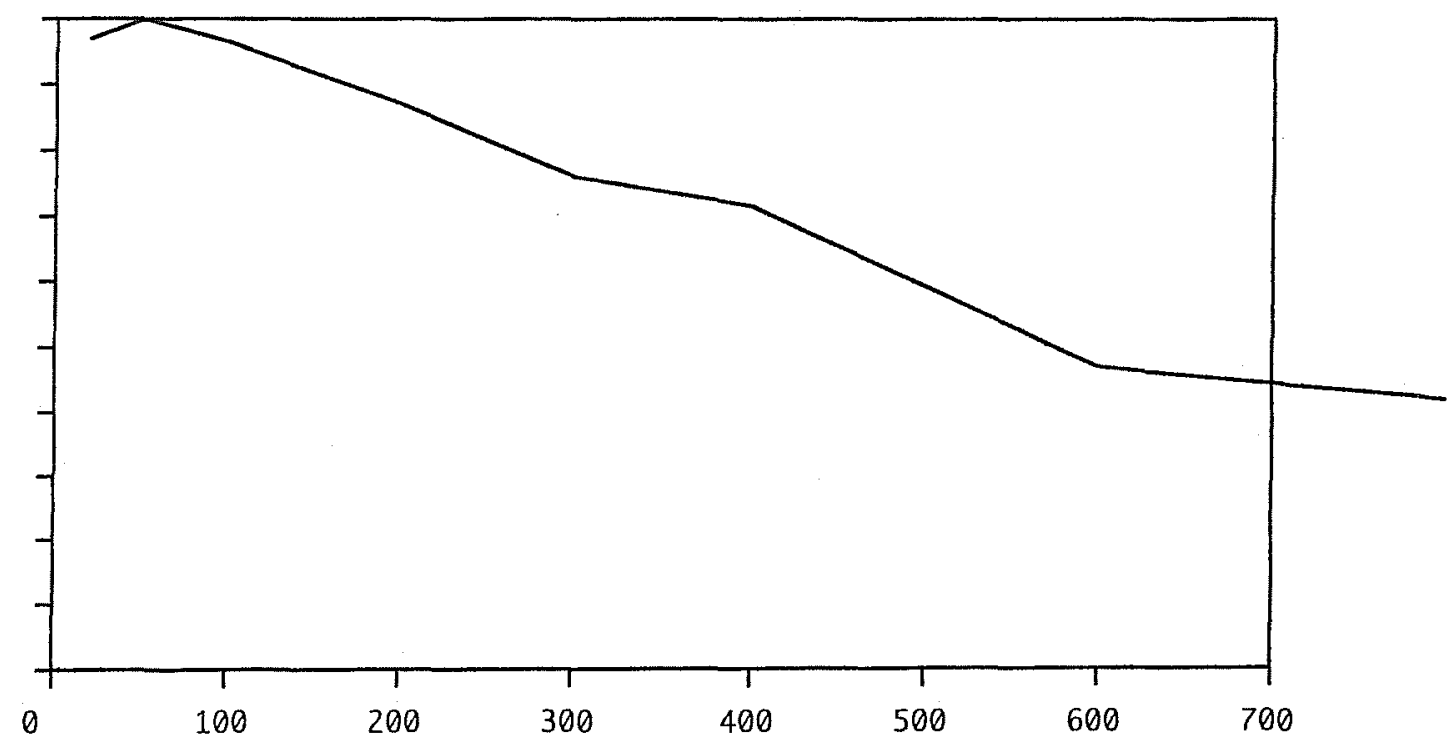



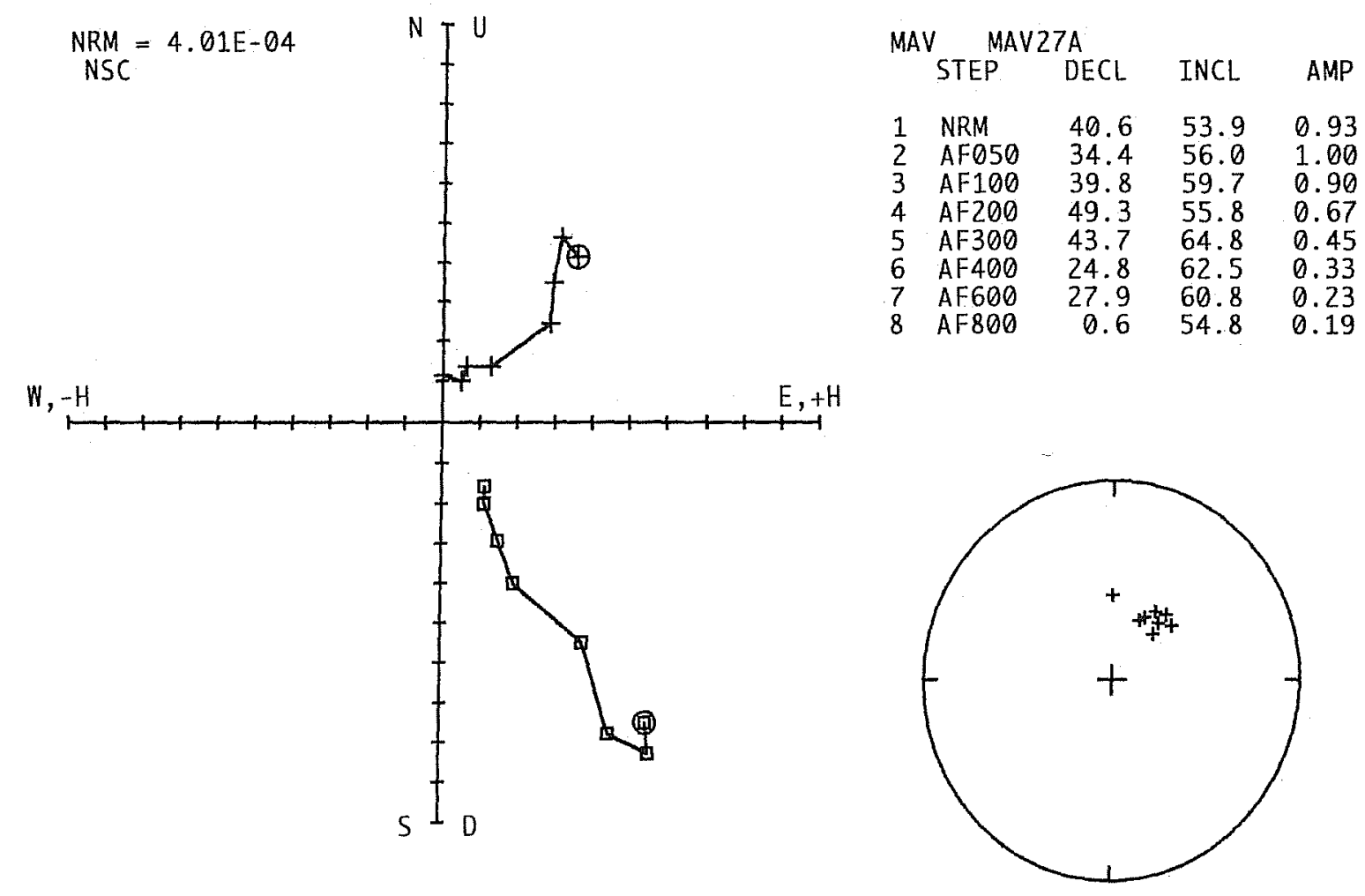

INTENSITY VS. DEMA GNETIZATION

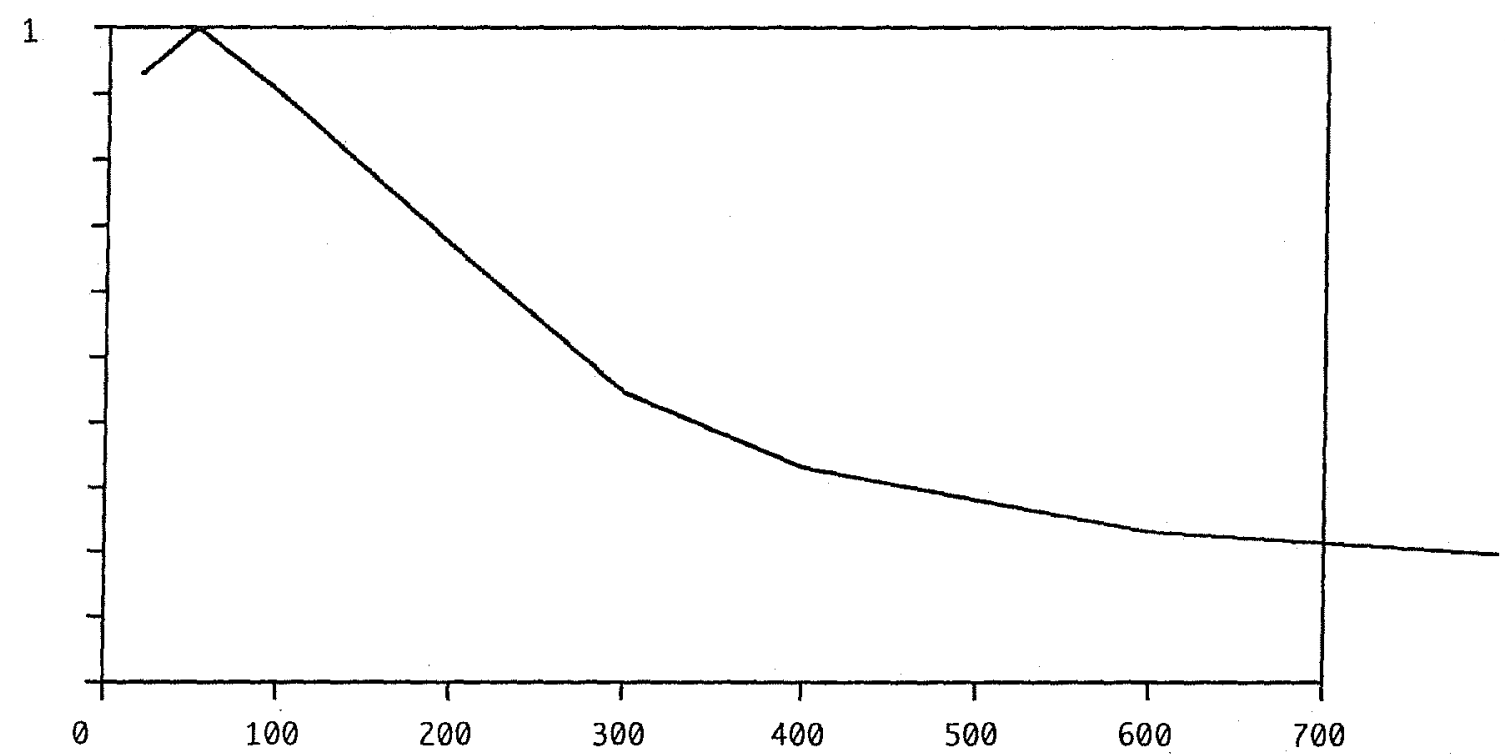




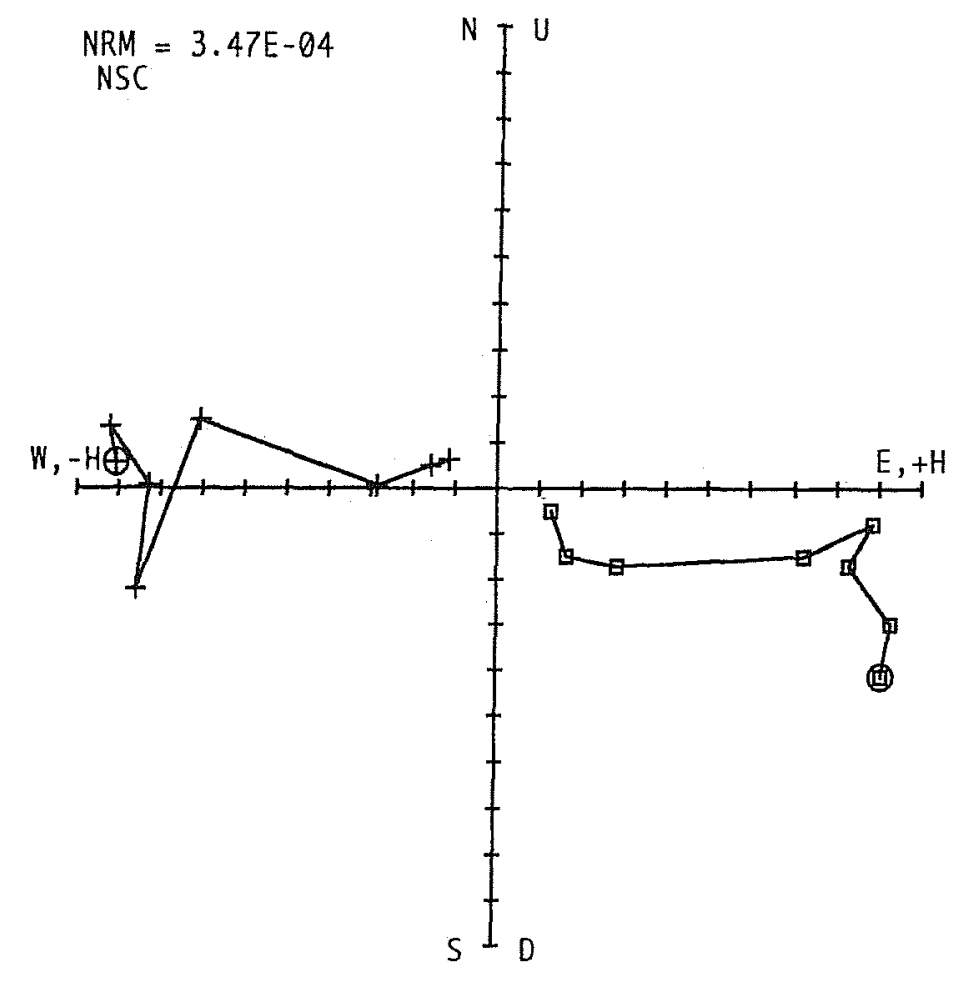

\begin{tabular}{lllrl}
\multicolumn{6}{c}{ MAV } & \multicolumn{1}{l}{ MAV27B } \\
& STEP & DECL & INCL & AMP \\
& & & \\
1 & NRM & 273.5 & 24.6 & 1.00 \\
2 & AF050 & 278.3 & 18.0 & 0.98 \\
3 & AF100 & 270.4 & 11.5 & 0.85 \\
4 & AF200 & 255.5 & 5.1 & 0.89 \\
5 & AF300 & 282.2 & 11.7 & 0.74 \\
6 & AF400 & 271.8 & 31.3 & 0.33 \\
7 & AF600 & 288.8 & 43.0 & 0.22 \\
8 & AF800 & 299.3 & 20.5 & 0.14
\end{tabular}

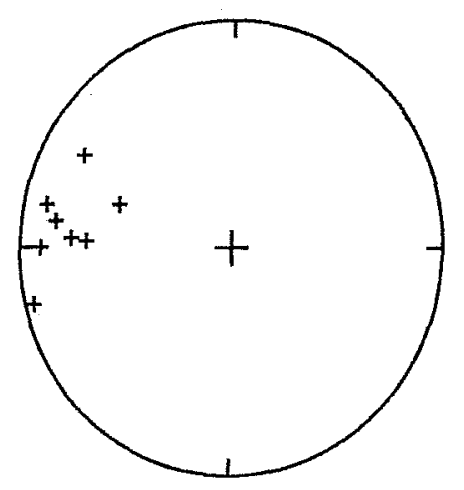

INTENSITY VS. DEMA GNETIZATION

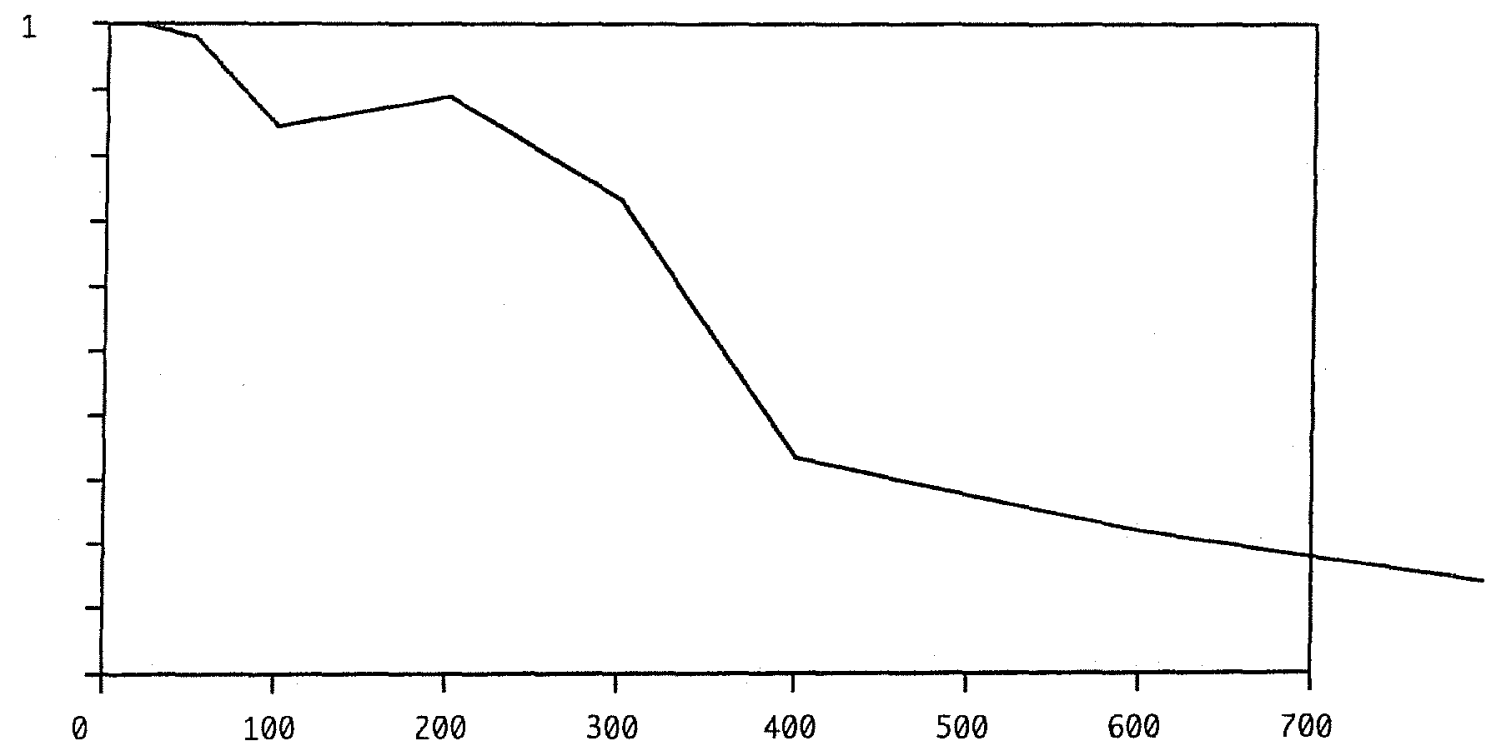




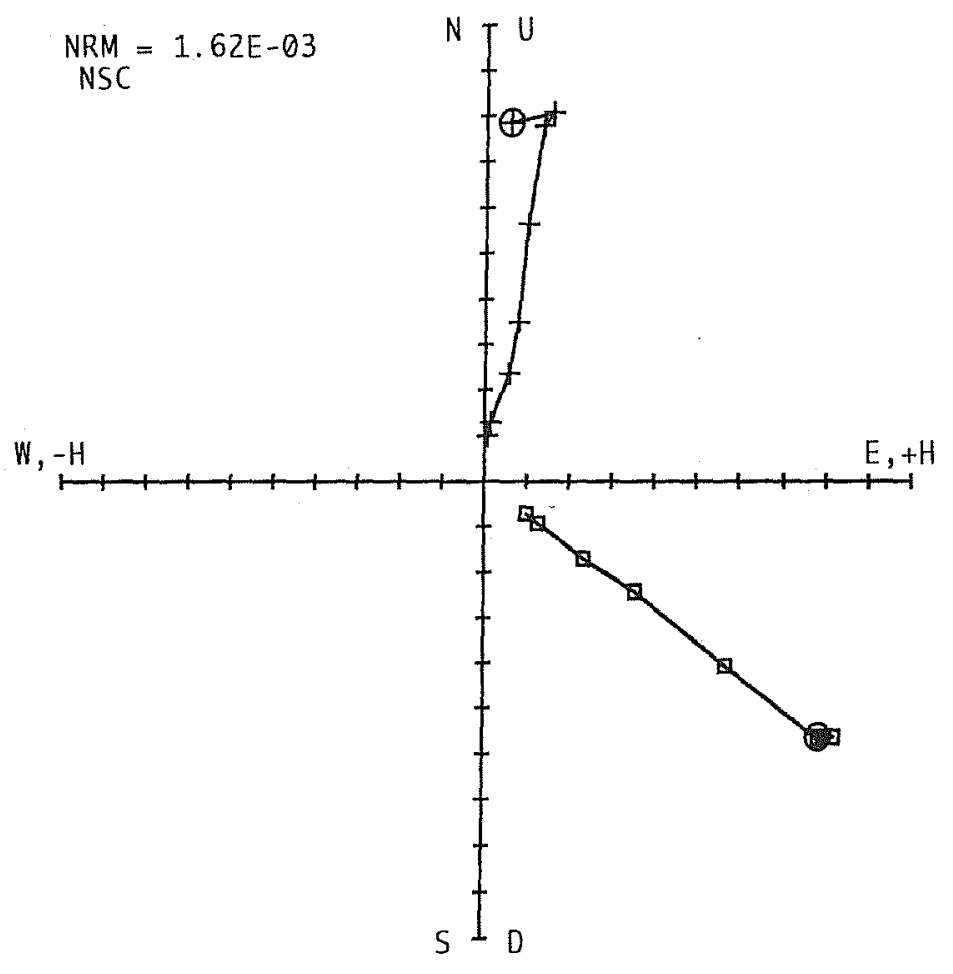

\begin{tabular}{llrlc}
\multicolumn{6}{c}{ MAV MAV29 } \\
STEP & DECL & INCL & AMP \\
& & & & \\
1 & NRM & 4.1 & 35.5 & 0.97 \\
2 & AF050 & 10.9 & 34.5 & 1.00 \\
3 & AF100 & 9.7 & 35.8 & 0.97 \\
4 & AF200 & 10.0 & 35.4 & 0.70 \\
5 & AF300 & 12.4 & 34.5 & 0.43 \\
6 & AF400 & 13.0 & 35.4 & 0.29 \\
7 & AF600 & 7.6 & 35.2 & 0.16 \\
8 & AF800 & 4.7 & 37.0 & 0.12
\end{tabular}

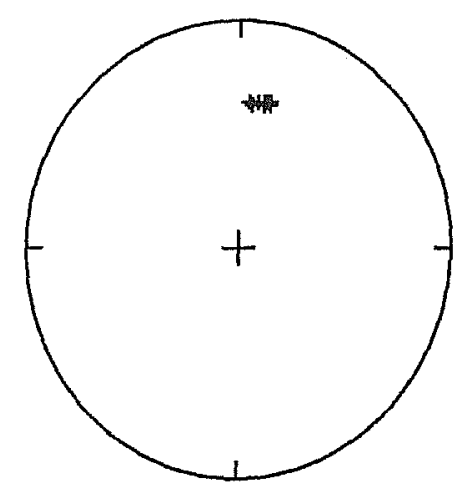

INTENSITY VS. DEMA GNETIZATION

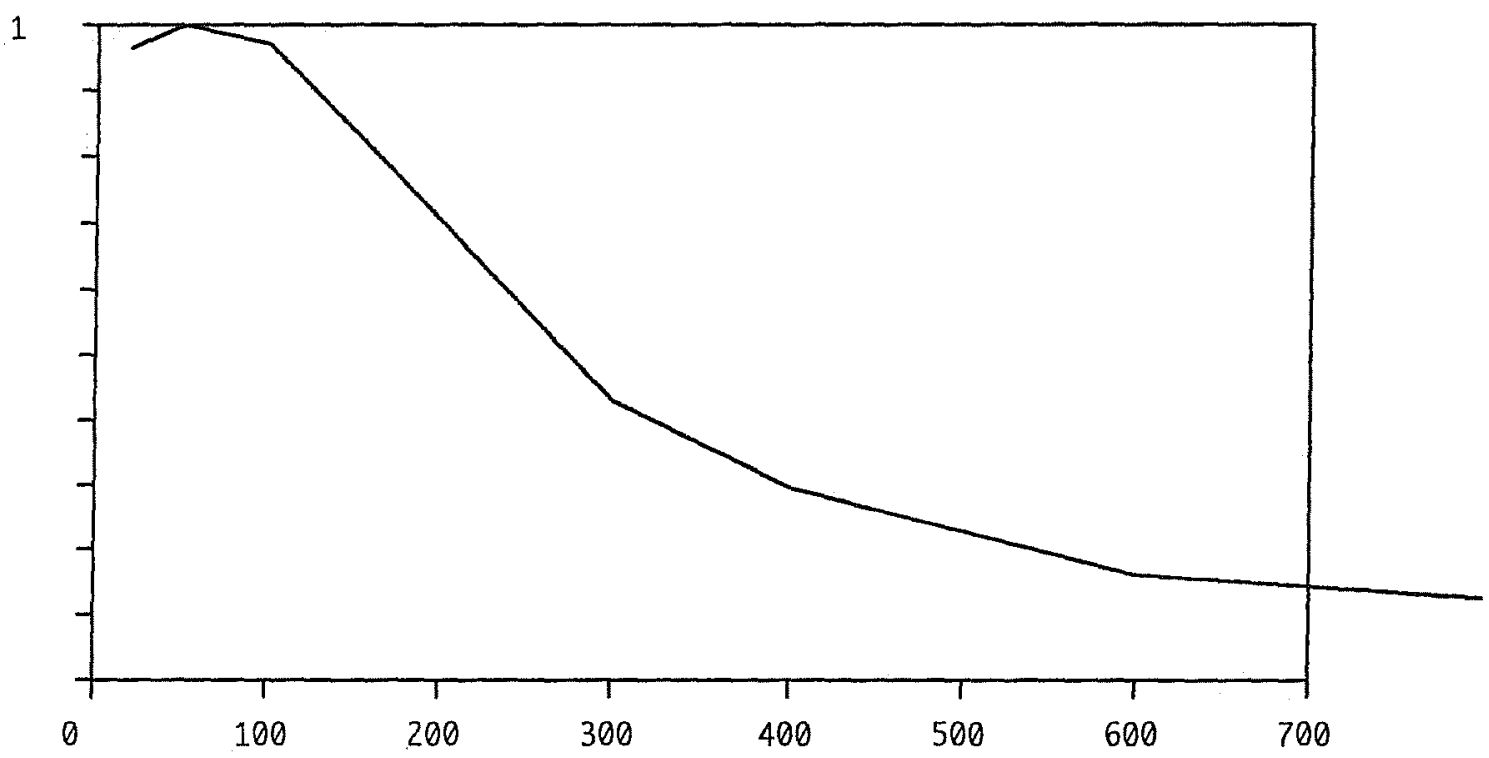



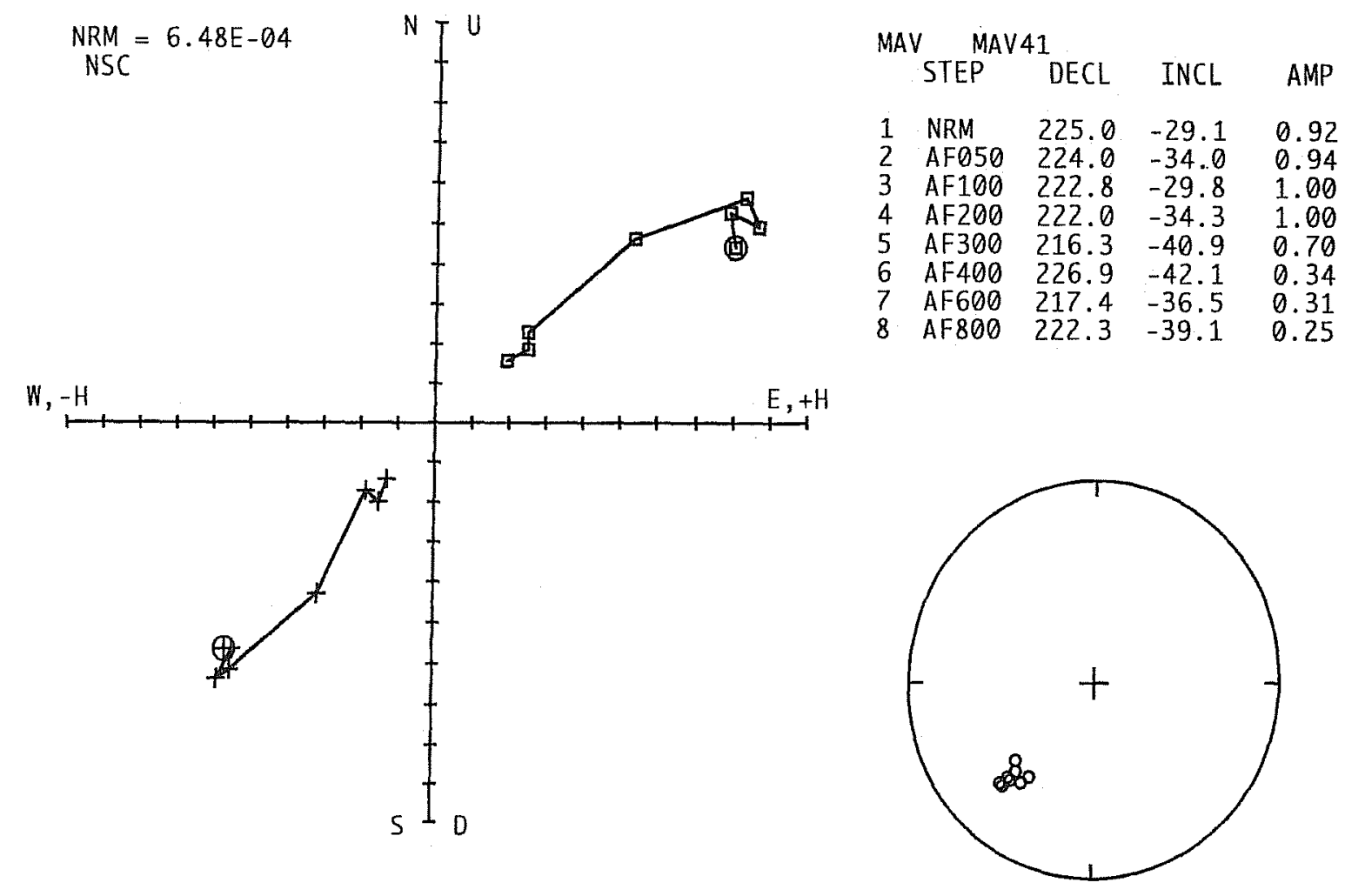

INTENSITY VS. DEMAGNETIZATION

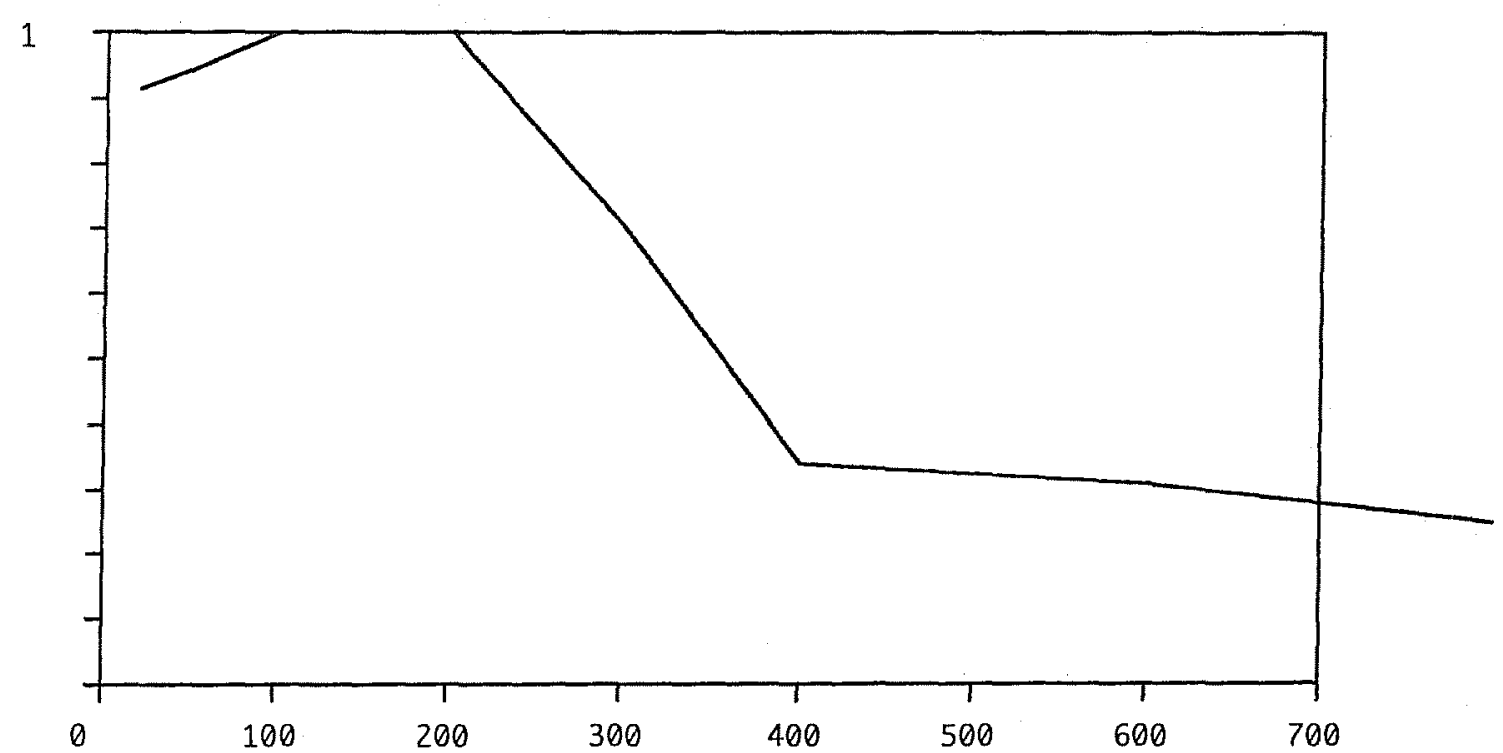



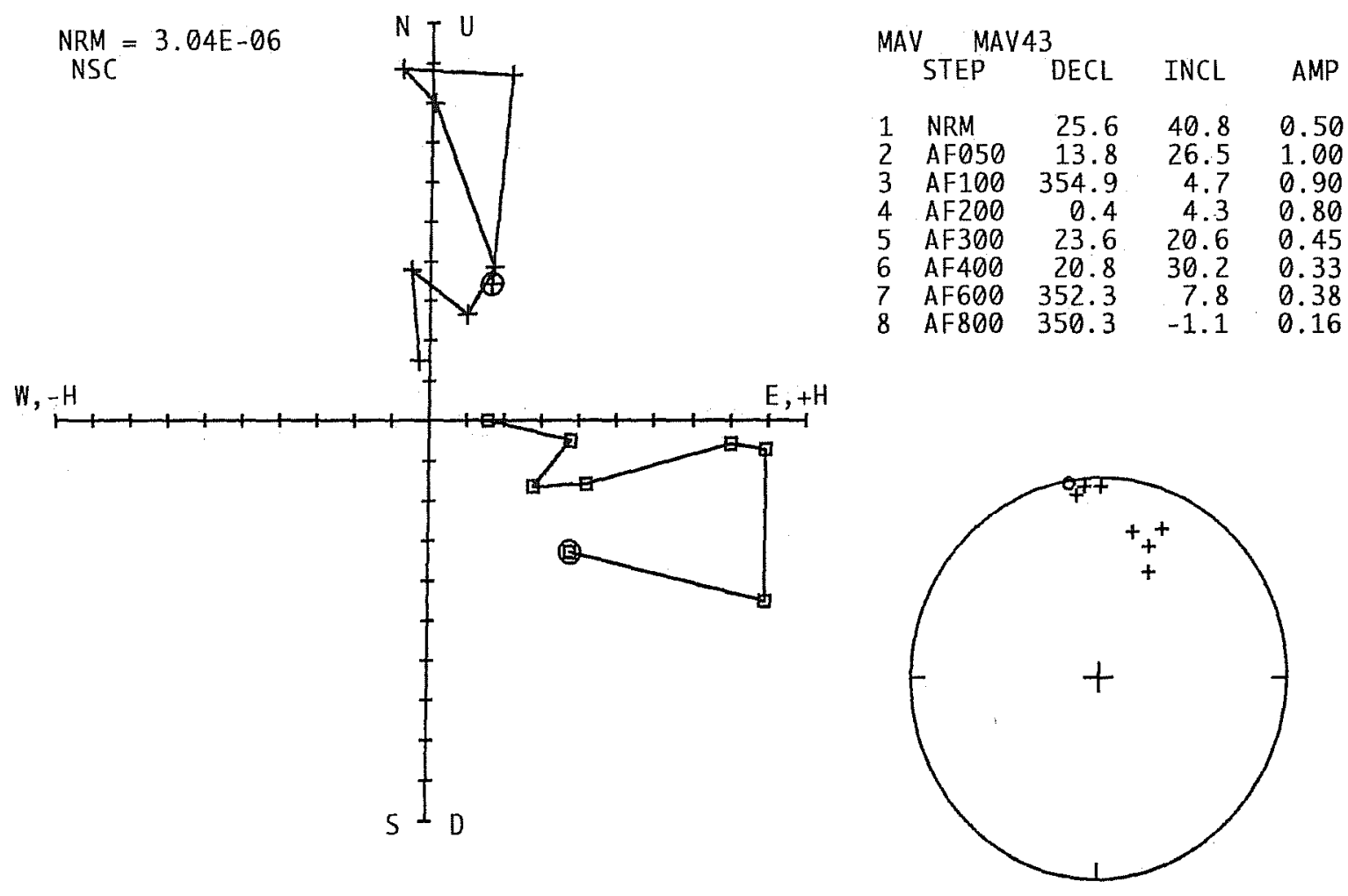

INTENSITY VS. DEMA GNETIZATION

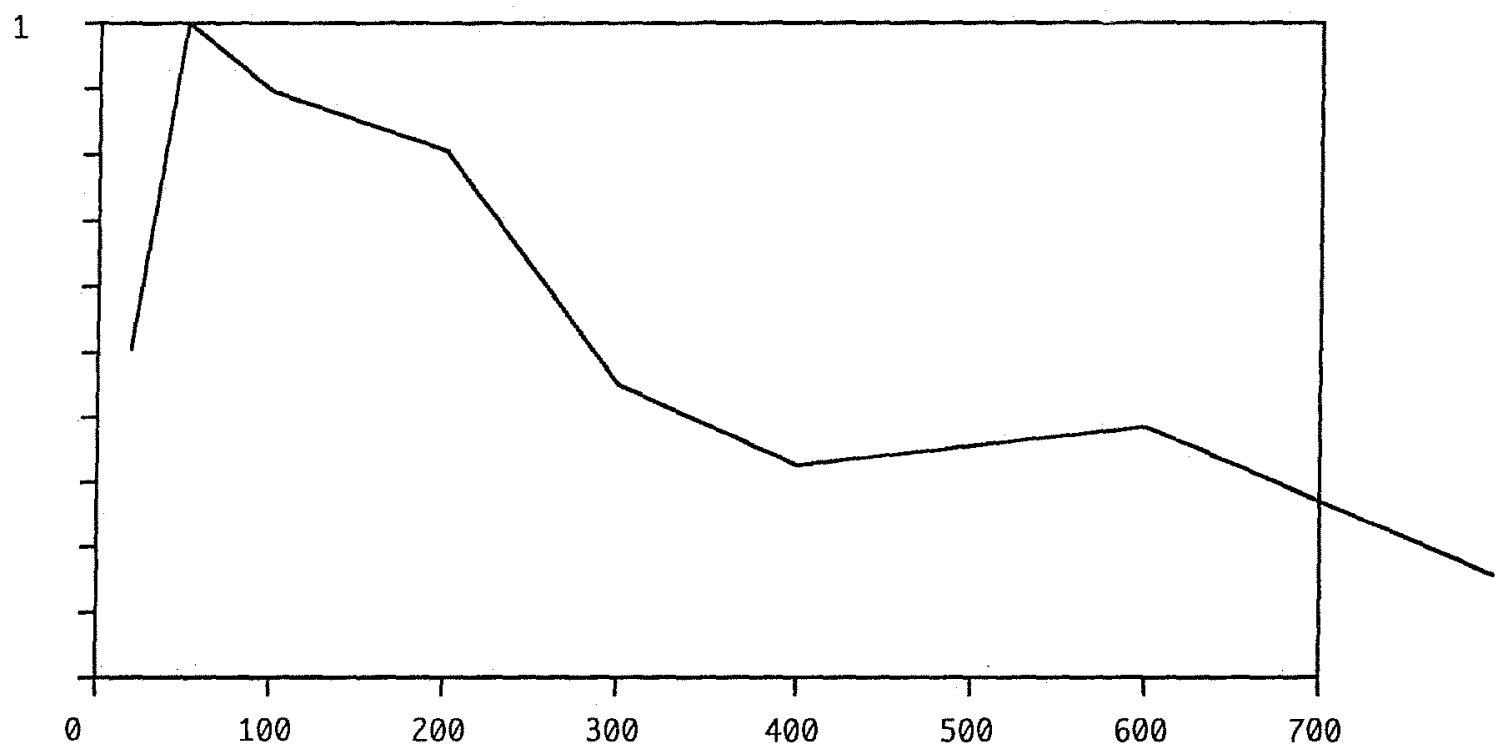




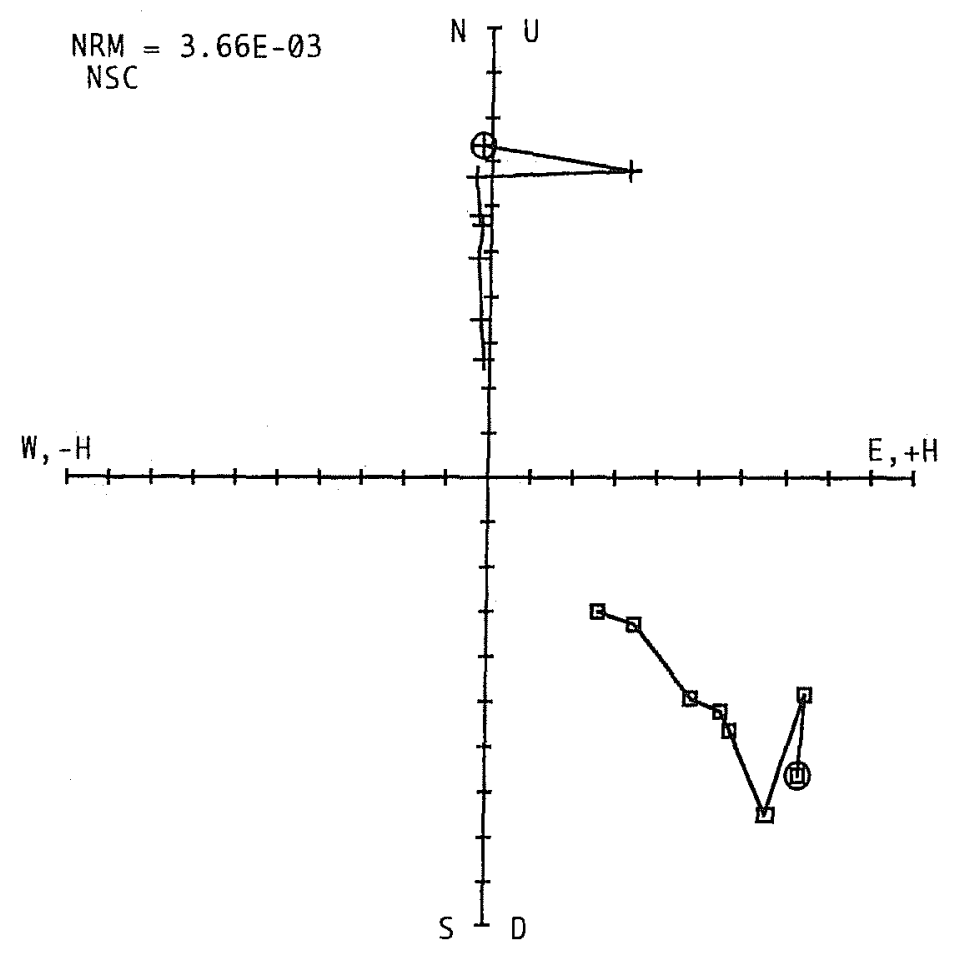

\begin{tabular}{llrrr}
\multicolumn{6}{c}{ MAV MAV44 } \\
STEP & DECL & INCL & AMP \\
& & & & \\
1 & NRM & 358.5 & 42.1 & 0.99 \\
2 & AFO50 & 25.9 & 33.0 & 0.90 \\
3 & AF100 & 357.0 & 48.4 & 1.00 \\
4 & AF200 & 357.2 & 44.3 & 0.81 \\
5 & AF300 & 357.9 & 43.1 & 0.77 \\
6 & AF400 & 356.8 & 45.4 & 0.70 \\
7 & AF600 & 356.8 & 43.3 & 0.48 \\
8 & AF800 & 356.1 & 48.7 & 0.40
\end{tabular}

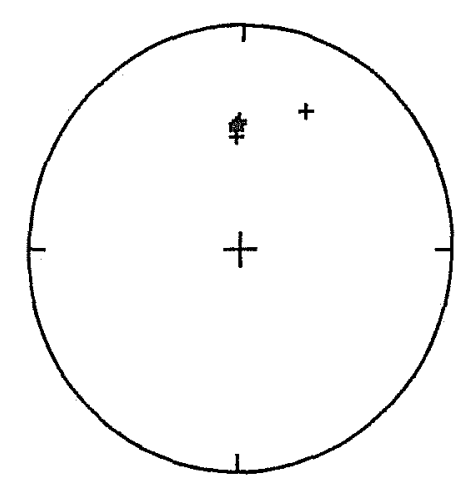

INTENSITY VS. DEMA GNETIZATION

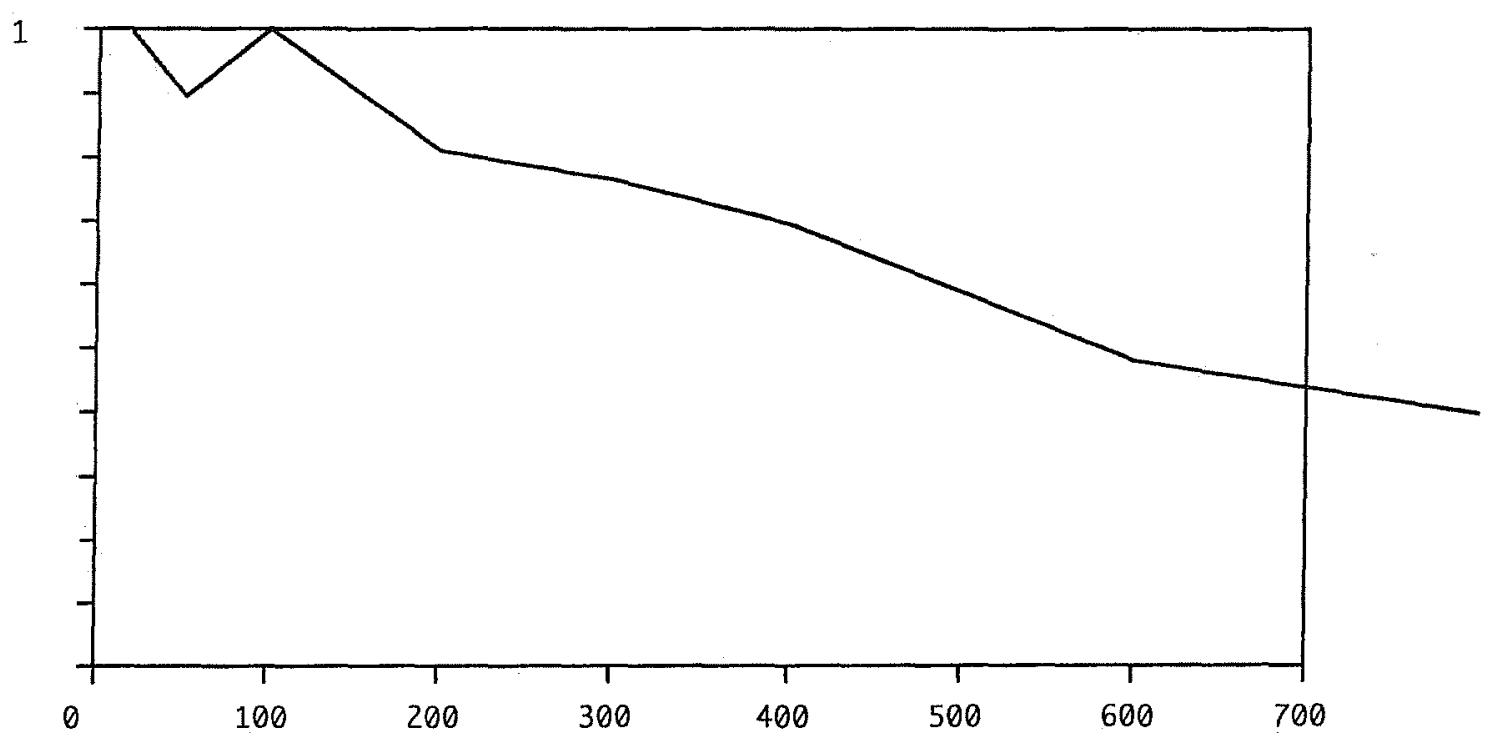


Appendix G: Mussel Shell Data

Robert G. Howells 
Table G-1. Identification of Freshwater Mussel Remains (Unionidae) from Archeological Site 41MV120 Adjacent to Elm Creek

Samples listed include those from EU-Units arranged by level. Species referenced include: Tampico pearlymussel (Cyrtonaias tampicoensis), yellow sandshell (Lampsilis teres), Texas lilliput (Toxolasma texasensis), and bleufer (Potamilus purpuratus). Weight of shell fragments from a marine Cretaceous oyster fossil (Exogyra) was not included in the sample weight listed. Percentage listed with some identified valves represents the approximate proportion of the valve present.

\begin{tabular}{ccccl}
\hline Unit & Level & Lot & Weight $(\mathrm{g})$ & Identification \\
\hline 7 & 1 & 77 & 0.18 & fragments \\
8 & 1 & 101 & 0.13 & fragments \\
8 & 1 & 104 & 1.23 & fragments \\
& & & & L. teres pseudocardinal teeth \\
10 & 1 & 327 & 0.64 & fragment \\
7 & 2 & 78 & 0.11 & fragment \\
8 & 2 & 106 & 0.92 & fragments \\
8 & 2 & 111 & 3.88 & fragments \\
& & & & T. texasensis left hinge \\
9 & 2 & 131 & 0.36 & T. texasensis left hinge \\
10 & 2 & 328 & 0.33 & fragments \\
10 & 2 & 329 & 3.71 & fragments \\
11 & 2 & 353 & 0.50 & fragments \\
14 & 2 & 577 & 0.56 & fragments \\
14 & 2 & 580 & 0.14 & fragments \\
16 & 2 & 627 & 1.33 & fragments \\
& & & & fragments (including lateral teeth) \\
20 & 2 & 677 & 0.65 & C. tampicoensis left pseudocardinal teeth \\
23 & 2 & 730 & 0.23 & fragments \\
23 & 2 & 731 & 0.38 & fragment \\
13 & 2 & 751 & 1.39 & L. teres right pseudocardinal tooth \\
13 & 2 & 755 & 0.20 & fragment \\
22 & 2 & 805 & 0.48 & fragment \\
37 & 2 & 952 & 1.33 & L. teres right pseudocardinal tooth \\
38 & 2 & 1126 & 1.15 & fragments (including lateral teeth) \\
& & & & fragments \\
21 & 2 & 1226 & 1.60 & L. teres right pseudocardinal teeth \\
& & & & fragment \\
& & & & C. tampicoensis right pseudocardinal tooth \\
& & & & T. texasensis left valve female $70 \%$ \\
& & & & unidentified left pseudocardinal tooth \\
7 & 3 & 80 & 1.99 & (atypically large $L$ eres?) \\
& & & fragments \\
& & & &
\end{tabular}


Table G-1. continued

\begin{tabular}{|c|c|c|c|c|}
\hline Unit & Level & Lot & Weight (g) & Identification \\
\hline 7 & 3 & 81 & 1.16 & fragments \\
\hline 8 & 3 & 110 & 5.61 & $\begin{array}{l}\text { fragments } \\
\text { L. teres left hinge }\end{array}$ \\
\hline 8 & 3 & 114 & 3.13 & fragments \\
\hline 8 & 3 & 115 & 3.21 & fragments \\
\hline 8 & 3 & 121 & 0.25 & fragments \\
\hline 9 & 3 & 134 & 0.03 & fragment \\
\hline 10 & 3 & 331 & 0.22 & fragments \\
\hline 10 & 3 & 332 & 0.17 & fragments \\
\hline 10 & 3 & 333 & 1.22 & fragments \\
\hline 11 & 3 & 356 & 1.26 & fragments \\
\hline 12 & 3 & 551 & 0.71 & fragment \\
\hline 14 & 3 & 579 & 2.28 & fragments \\
\hline 14 & 3 & 581 & 0.33 & fragments \\
\hline 16 & 3 & 629 & 0.61 & fragments \\
\hline 20 & 3 & 678 & 0.34 & fragments \\
\hline 20 & 3 & 684 & 0.43 & L. teres left anterior pseudocardinal tooth \\
\hline 23 & 3 & 733 & 0.61 & C. tampicoensis right pseudocardinal tooth \\
\hline 23 & 3 & 735 & 1.39 & fragments (including lateral teeth) \\
\hline 13 & 3 & 752 & 0.83 & fragments \\
\hline 13 & 3 & 756 & 0.11 & fragments \\
\hline 19 & 3 & 777 & 1.95 & fragment \\
\hline 22 & 3 & 806 & 0.89 & fragments \\
\hline 22 & 3 & 807 & 0.41 & fragments \\
\hline 37 & 3 & 955 & 16.2 & fragments \\
\hline & & & & $\begin{array}{l}\text { T. texasensis female left valve } 100 \% \\
\text { T. texasensis left valve } 90 \% \\
\text { T. texasensis right hinge } \\
\text { T. texasensis female right valve } 80 \%\end{array}$ \\
\hline 37 & 3 & 964 & 1.53 & $\begin{array}{l}\text { T. texasensis female right valve } 80 \% \\
\text { fragments }\end{array}$ \\
\hline 17 & 3 & 979 & 0.40 & fragments \\
\hline 39 & 3 & 1005 & 0.19 & fragments \\
\hline 38 & 3 & 1128 & 2.03 & fragments \\
\hline 24 & 3 & 1154 & 0.06 & fragment \\
\hline 21 & 3 & 1241 & 0.25 & fragment \\
\hline 18 & 3 & 1532 & 0.13 & fragments \\
\hline 7 & 4 & 82 & 0.74 & fragments \\
\hline 8 & 4 & 116 & 0.32 & fragments \\
\hline 8 & 4 & 119 & 0.65 & fragment \\
\hline 8 & 4 & 125 & 2.18 & fragments (including lateral teeth) \\
\hline 9 & 4 & 135 & 0.79 & C. tampicoensis psuedocardinal teeth \\
\hline 10 & 4 & 334 & 1.94 & fragments \\
\hline 10 & 4 & 335 & 0.44 & $\begin{array}{l}\text { fragments } \\
\text { L. teres right pseudocardinal tooth } \\
\text { L. teres right pseudocardinal tooth }\end{array}$ \\
\hline
\end{tabular}


Table G-1. continued

\begin{tabular}{|c|c|c|c|c|}
\hline Unit & Level & Lot & Weight $(\mathrm{g})$ & Identification \\
\hline 11 & 4 & 361 & 0.33 & fragments \\
\hline 11 & 4 & 357 & 0.18 & fragments \\
\hline 12 & 4 & 552 & 6.85 & fragments \\
\hline & & & & T. texasensis left valve \\
\hline 12 & 4 & 555 & 0.52 & fragments \\
\hline 14 & 4 & 582 & 6.48 & $\begin{array}{l}\text { L. teres left anterior pseudocardinal tooth } \\
\text { T. texasensis right valve female } 80 \%\end{array}$ \\
\hline 14 & 4 & 583 & 0.33 & fragments \\
\hline 16 & 4 & 630 & 0.25 & fragment \\
\hline 23 & 4 & 736 & 1.80 & fragments \\
\hline 23 & 4 & 743 & 0.08 & fragment \\
\hline 13 & 4 & 753 & 11.30 & fragments \\
\hline & & & & T. texasensis left pseudocardinal teeth \\
\hline & & & & T. texasensis left pseudocardinal teeth \\
\hline & & & & T. texasensis right lateral teeth \\
\hline 13 & 4 & 768 & 1.09 & $\begin{array}{l}\text { L. teres right pseudocardinal tooth } \\
\text { fragments } \\
\text { L. teres left pseudocardinal teeth }\end{array}$ \\
\hline 19 & 4 & 786 & 0.23 & fragment \\
\hline 22 & 4 & 809 & 0.45 & fragments \\
\hline 22 & 4 & 825 & 0.24 & fragment \\
\hline 37 & 4 & 956 & 0.83 & fragments \\
\hline 37 & 4 & 974 & 1.91 & fragments \\
\hline 17 & 4 & 980 & 4.38 & $\begin{array}{l}\text { fragments } \\
\text { L. teres left pseudocardinal teeth }\end{array}$ \\
\hline 38 & 4 & 1129 & 2.20 & $\begin{array}{l}\text { fragments } \\
\text { T. texasensis matched left and right } \\
\text { pseudocardinal teeth }\end{array}$ \\
\hline 24 & 4 & 1157 & 2.28 & fragment \\
\hline 24 & 4 & 1159 & 0.15 & fragment \\
\hline 24 & 4 & 1168 & 1.40 & fragments \\
\hline 21 & 4 & 1229 & 1.55 & fragments \\
\hline 7 & 5 & 84 & 0.56 & $\begin{array}{l}\text { fragments } \\
\text { T. texasensis right valve female } 80 \%\end{array}$ \\
\hline 8 & 5 & 309 & 0.83 & fragments \\
\hline 10 & 5 & 336 & 0.78 & fragments \\
\hline 12 & 5 & 556 & 2.07 & fragments \\
\hline 12 & 5 & 553 & 14.67 & $\begin{array}{l}\text { L. teres right valve } 80 \% \\
\text { L. teres left hinge }\end{array}$ \\
\hline 14 & 5 & 584 & 17.23 & $\begin{array}{l}\text { fragments } \\
\text { C. tampicoensis right pseudocardinal tooth } \\
\text { L. teres right pseudocardinal tooth } \\
\text { L. teres right pseudocardinal tooth } \\
\text { L. teres right pseudocardinal tooth } \\
\text { L. teres left pseudocardinal teeth }\end{array}$ \\
\hline
\end{tabular}


Table G-1. continued

\begin{tabular}{|c|c|c|c|c|}
\hline Unit & Level & Lot & Weight (g) & Identification \\
\hline 14 & 5 & 585 & 10.13 & unidentified unionid right pseudocardinal tooth \\
\hline 26 & 5 & 615 & 0.90 & C. tampicoensis left pseudocardinal teeth \\
\hline 26 & 5 & 620 & 0.62 & fragments \\
\hline 16 & 5 & 632 & 0.24 & $\begin{array}{l}\text { fragments } \\
\text { L. teres right pseudocardinal tooth }\end{array}$ \\
\hline 16 & 5 & 639 & 1.55 & fragments \\
\hline 20 & 5 & 699 & 0.16 & $\begin{array}{l}\text { C. tampicoensis right pseudocardinal tooth } \\
\text { fragments }\end{array}$ \\
\hline 13 & 5 & 754 & 4.08 & fragments \\
\hline 13 & 5 & 757 & 2.50 & $\begin{array}{l}\text { fragments } \\
\text { L. teres right pseudocardinal tooth }\end{array}$ \\
\hline 23 & 5 & 737 & 2.36 & fragments \\
\hline 13 & 5 & 769 & 0.66 & fragments \\
\hline 19 & 5 & 781 & 0.84 & fragments \\
\hline 22 & 5 & 812 & 0.13 & fragment \\
\hline 22 & 5 & 813 & 21.48 & $\begin{array}{l}\text { fragment } \\
\text { C. tampicoensis right valve } 80 \%\end{array}$ \\
\hline 37 & 5 & 958 & 2.16 & fragments \\
\hline 39 & 5 & 1008 & 5.17 & fragments \\
\hline 40 & 5 & 1037 & 0.51 & fragments \\
\hline 38 & 5 & 1131 & 5.61 & fragments \\
\hline 38 & 5 & 1141 & 0.76 & $\begin{array}{l}\text { fragments } \\
\text { L. teres right pseudocardinal tooth }\end{array}$ \\
\hline 41 & 5 & 1202 & 0.52 & fragment \\
\hline 42 & 5 & 1251 & 0.13 & fragment \\
\hline 37 & 5 & 1401 & 1.10 & fragments \\
\hline 6 & 6 & 51 & 10.92 & fragments \\
\hline 7 & 6 & 85 & 1.14 & $\begin{array}{l}\text { C. tampicoensis pseudocardinal teeth } \\
\text { fragments }\end{array}$ \\
\hline 8 & 6 & 303 & 3.52 & fragments \\
\hline 9 & 6 & 139 & 0.05 & fragment \\
\hline 10 & 6 & 337 & 0.46 & fragments \\
\hline 12 & 6 & 557 & 0.92 & $\begin{array}{l}\text { fragments } \\
\text { L. teres lateral tooth section }\end{array}$ \\
\hline 12 & 6 & 573 & 0.76 & fragments \\
\hline 14 & 6 & 586 & 1.49 & fragments \\
\hline 14 & 6 & 591 & 1.42 & $\begin{array}{l}\text { fragments } \\
\text { T. texasensis left pseudocardinal teeth }\end{array}$ \\
\hline 26 & 6 & 621 & 0.27 & fragments \\
\hline 16 & 6 & 634 & 0.17 & fragment \\
\hline 16 & 6 & 635 & 0.34 & fragments \\
\hline 16 & 6 & 640 & 0.13 & fragments \\
\hline 20 & 6 & 679 & 4.81 & fragments \\
\hline
\end{tabular}


Table G-1. continued

\begin{tabular}{|c|c|c|c|c|}
\hline Unit & Level & Lot & Weight $(\mathrm{g})$ & Identification \\
\hline \multirow[t]{6}{*}{13} & 6 & 758 & 27.35 & fragments \\
\hline & & & & L. tampicoensis left pseudocardinal teeth \\
\hline & & & & C. tampicoensis right anterior valve fragment \\
\hline & & & & L. teres right pseudocardinal tooth \\
\hline & & & & L. teres right pseudocardinal tooth \\
\hline & & & & $\begin{array}{l}\text { L. teres left pseudocardinal teeth and lateral } \\
\text { tooth fragment }\end{array}$ \\
\hline 13 & 6 & 762 & 0.64 & fragments \\
\hline 22 & 6 & 814 & 0.64 & fragments \\
\hline 22 & 6 & 815 & 0.66 & fragments \\
\hline \multirow[t]{2}{*}{37} & 6 & 960 & 0.90 & fragments \\
\hline & & & & L. teres left pseudocardinal teeth \\
\hline 38 & 6 & 1135 & 0.15 & fragment \\
\hline 38 & 6 & 1137 & 0.31 & L. teres right pseudocardinal tooth \\
\hline 24 & 6 & 1171 & 0.17 & fragments \\
\hline 41 & 6 & 1203 & 1.59 & fragments \\
\hline 41 & 6 & 1210 & 0.07 & fragment \\
\hline \multirow[t]{2}{*}{21} & 6 & 1231 & 0.83 & fragments \\
\hline & & & & Toxolasma sp.? fragment \\
\hline 42 & 6 & 1252 & 0.20 & fragments \\
\hline 42 & 6 & 1258 & 0.03 & fragments \\
\hline 6 & 7 & 54 & 0.22 & fragment \\
\hline 6 & 7 & 55 & 0.19 & fragments \\
\hline \multirow[t]{2}{*}{8} & 7 & 308 & 3.27 & fragments \\
\hline & & & & L. teres right pseudocardinal tooth \\
\hline 10 & 7 & 338 & 0.54 & fragments \\
\hline 11 & 7 & 365 & 0.09 & fragment \\
\hline 11 & 7 & 367 & 0.15 & L. teres left pseudocardinal teeth \\
\hline 12 & 7 & 558 & 0.24 & fragment \\
\hline 12 & 7 & 568 & 0.47 & fragments (possibly L. teres lateral teeth) \\
\hline \multirow[t]{2}{*}{14} & 7 & 587 & 3.81 & fragments \\
\hline & & & & L. tampicoensis left pseudocardinal teeth \\
\hline 14 & 7 & 592 & 2.13 & fragments (including lateral teeth) \\
\hline 26 & 7 & 623 & 0.41 & fragments \\
\hline \multirow[t]{2}{*}{20} & 7 & 681 & 0.78 & fragment \\
\hline & & & & L. teres right pseudocardinal teeth \\
\hline 20 & 7 & 682 & 1.22 & fragments \\
\hline \multirow[t]{2}{*}{23} & 7 & 739 & 3.46 & fragments \\
\hline & & & & T. texasensis left valve $60 \%$ \\
\hline 23 & 7 & 747 & 0.31 & fragment \\
\hline \multirow[t]{3}{*}{13} & 7 & 759 & 20.30 & fragments \\
\hline & & & & L. teres right valve male $80 \%$ \\
\hline & & & & L. teres left lateral teeth \\
\hline \multirow[t]{2}{*}{13} & 7 & 763 & 2.19 & fragments \\
\hline & & & & L. teres right pseudocardinal tooth \\
\hline
\end{tabular}


Table G-1. continued

\begin{tabular}{|c|c|c|c|c|}
\hline Unit & Level & Lot & Weight $(\mathrm{g})$ & Identification \\
\hline 19 & 7 & 783 & 0.11 & fragment \\
\hline 19 & 7 & 794 & 0.15 & fragment \\
\hline 22 & 7 & 816 & 0.88 & $\begin{array}{l}\text { fragments } \\
\text { Toxolasma sp.? right hinge }\end{array}$ \\
\hline 37 & 7 & 961 & 0.95 & fragments \\
\hline 37 & 7 & 971 & 1.91 & fragment \\
\hline 17 & 7 & 992 & 0.11 & fragment \\
\hline 31 & 7 & 1051 & 4.54 & $\begin{array}{l}\text { fragments } \\
\text { L. teres right pseudocardinal tooth } \\
\text { C. tampicoensis left pseudocardinal teeth }\end{array}$ \\
\hline 31 & 7 & 1064 & 4.35 & $\begin{array}{l}\text { fragments } \\
\text { T. texasensis left valve male }\end{array}$ \\
\hline 32 & 7 & 1076 & 0.56 & fragments \\
\hline 32 & 7 & 1091 & 0.76 & fragment \\
\hline 15 & 7 & 1112 & 0.61 & fragments \\
\hline 38 & 7 & 1136 & 1.95 & fragments \\
\hline 24 & 7 & 1172 & 0.10 & fragments \\
\hline 41 & 7 & 1206 & 0.41 & fragments \\
\hline 21 & 7 & 1232 & 0.20 & fragment \\
\hline 33 & 7 & 1251 & 12.76 & fragments (some probably L. teres) \\
\hline 33 & 7 & 1262 & 1.79 & fragments \\
\hline 34 & 7 & 1276 & 0.56 & L. teres left pseudocardinal teeth \\
\hline 25 & 7 & 1280 & 0.95 & fragments \\
\hline 34 & 7 & 1289 & 0.90 & fragments \\
\hline 36 & 7 & 1301 & 0.83 & fragments \\
\hline 36 & 7 & 1302 & 3.77 & fragments \\
\hline 36 & 7 & 1316 & 1.33 & $\begin{array}{l}\text { fragments } \\
\text { L. teres left hinge }\end{array}$ \\
\hline 6 & 8 & 60 & 0.48 & fragments \\
\hline 1 & 8 & 153 & 11.07 & fragments \\
\hline 1 & 8 & 154 & 0.11 & fragment \\
\hline 1 & 8 & 155 & 1.92 & fragments \\
\hline 1 & 8 & 161 & 2.79 & $\begin{array}{l}\text { fragments } \\
\text { L. teres left hinge }\end{array}$ \\
\hline 8 & 8 & 316 & 7.88 & fragments (including lateral teeth) \\
\hline 10 & 8 & 340 & 0.22 & fragments \\
\hline 10 & 8 & 349 & 2.08 & $\begin{array}{l}\text { fragments } \\
\text { unidentified unionid valve fragment (thin, } \\
\text { inflated, short lateral teeth) }\end{array}$ \\
\hline 11 & 8 & 369 & 0.32 & L. teres left pseudocardinal teeth \\
\hline 12 & 8 & 559 & 0.95 & fragments \\
\hline 12 & 8 & 569 & 0.07 & fragments \\
\hline
\end{tabular}


Table G-1. continued

\begin{tabular}{|c|c|c|c|c|}
\hline Unit & Level & Lot & Weight $(\mathrm{g})$ & Identification \\
\hline 14 & 8 & 588 & 42.08 & $\begin{array}{l}\text { fragments } \\
\text { C. tampicoensis right pseudocardinal tooth } \\
\text { C. tampicoensis right pseudocardinal tooth } \\
\text { C. tampicoensis right pseudocardinal tooth } \\
\text { C. tampicoensis right pseudocardinal tooth } \\
\text { L. teres right pseudocardinal tooth } \\
\text { L. teres right pseudocardinal tooth } \\
\text { L. teres right pseudocardinal tooth } \\
\text { L. teres left pseudocardinal teeth } \\
\text { L. teres left pseudocardinal teeth } \\
\text { L. teres right valve fragment } 60 \%\end{array}$ \\
\hline 14 & 8 & 598 & 1.18 & fragments \\
\hline 16 & 8 & 647 & 0.22 & fragment \\
\hline 23 & 8 & 740 & 1.06 & fragment (probably fossil) \\
\hline 13 & 8 & 764 & 7.59 & fragments \\
\hline 13 & 8 & 766 & 45.38 & $\begin{array}{l}\text { fragments } \\
\text { L. teres left valve male ca } 100 \% \\
\text { L. teres right hinge }\end{array}$ \\
\hline 13 & 8 & 767 & 16.80 & $\begin{array}{l}\text { C. tampicoensis right valve } 95 \% \\
\text { Unidentifed unionid right pseudocadinal tooth }\end{array}$ \\
\hline 13 & 8 & 774 & 1.68 & $\begin{array}{l}\text { L. teres right pseudocardinal tooth } \\
\text { L. teres left valve fragment }\end{array}$ \\
\hline 22 & 8 & 817 & 0.74 & $\begin{array}{l}\text { fragment } \\
\text { Toxolasma sp.? left pseudocardinal teeth }\end{array}$ \\
\hline 26 & 8 & 927 & 0.08 & fragments \\
\hline 31 & 8 & 1052 & 4.48 & $\begin{array}{l}\text { fragments } \\
\text { T. texasensis right valve } 80 \% \\
\text { L. teres right pseudocardinal tooth }\end{array}$ \\
\hline 31 & 8 & 1067 & 2.48 & fragments \\
\hline 32 & 8 & 1077 & 8.39 & $\begin{array}{l}\text { fragments } \\
\text { C. tampicoensis matched left and right } \\
\text { pseudocardinal teeth }\end{array}$ \\
\hline 32 & 8 & 1078 & 0.22 & fragments \\
\hline 32 & 8 & 1086 & 0.61 & fragments \\
\hline 15 & 8 & 1101 & 7.96 & fragments \\
\hline 15 & 8 & 1113 & 0.84 & $\begin{array}{l}\text { fragments } \\
\text { L. teres right pseudocardinal tooth }\end{array}$ \\
\hline 41 & 8 & 1207 & 0.50 & $\begin{array}{l}\text { fragment } \\
\text { L. teres left pseudocardinal teeth }\end{array}$ \\
\hline 21 & 8 & 1234 & 0.24 & fragment \\
\hline 21 & 8 & 1240 & 0.04 & fragments \\
\hline 33 & 8 & 1252 & 6.80 & $\begin{array}{l}\text { fragments } \\
\text { T. texasensis left valve } 70 \% \\
\text { L. teres right pseudocardinal tooth }\end{array}$ \\
\hline
\end{tabular}


Table G-1. continued

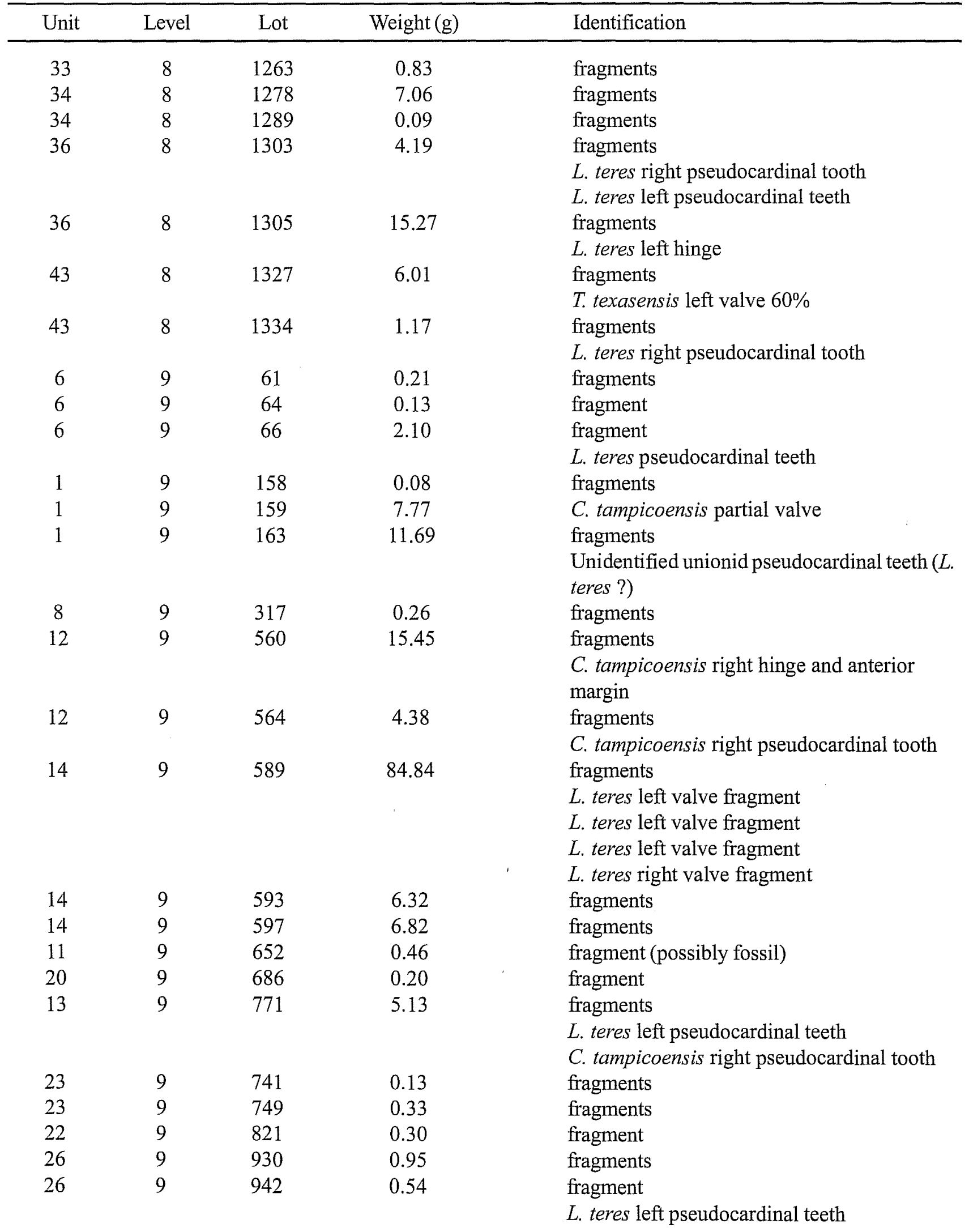


Table G-1. continued

\begin{tabular}{|c|c|c|c|c|}
\hline Unit & Level & Lot & Weight (g) & Identification \\
\hline 31 & 9 & 1056 & 2.53 & $\begin{array}{l}\text { fragments } \\
\text { L. teres right pseudocardinal tooth }\end{array}$ \\
\hline 31 & 9 & 1057 & 4.84 & $\begin{array}{l}\text { fragments } \\
\text { L. teres right pseudocardinal tooth }\end{array}$ \\
\hline 31 & 9 & 1063 & 0.65 & fragments \\
\hline 32 & 9 & 1080 & 15.84 & $\begin{array}{l}\text { fragments } \\
\text { L. teres right pseudocardinal tooth }\end{array}$ \\
\hline 32 & 9 & 1081 & 20.16 & $\begin{array}{l}\text { fragments } \\
\text { C. tampicoensis left valve } 50 \% \\
\text { C. tampicoensis right hinge } \\
\text { L. teres right valve fragment } 30 \%\end{array}$ \\
\hline 32 & 9 & 1088 & 2.20 & fragments \\
\hline 15 & 9 & 1103 & 9.30 & fragments \\
\hline 15 & 9 & 1116 & 1.75 & fragments \\
\hline 21 & 9 & 1235 & 0.09 & fragments \\
\hline 21 & 9 & 1236 & 0.05 & fragment \\
\hline 33 & 9 & 1253 & 6.35 & fragments \\
\hline 33 & 9 & 1254 & 39.77 & $\begin{array}{l}\text { fragments } \\
\text { C. tampicoensis left hinge } \\
\text { L. teres matched right and left pseudocardinal } \\
\text { teeth } \\
\text { L. teres left hinge }\end{array}$ \\
\hline 33 & 9 & 1266 & 12.45 & $\begin{array}{l}\text { fragments } \\
\text { C. tampicoensis right pseudocardinal tooth }\end{array}$ \\
\hline 34 & 9 & 1279 & 49.85 & $\begin{array}{l}\text { fragments } \\
\text { C. tampicoensis left valve } 90 \% \\
\text { C. tampicoensis two left valve fragments }\end{array}$ \\
\hline 34 & 9 & 1285 & 0.74 & fragments \\
\hline 36 & 9 & 1306 & 46.79 & $\begin{array}{l}\text { fragments } \\
\text { L. teres right pseudocardinal tooth } \\
\text { L. teres right pseudocardinal tooth } \\
\text { L. teres right pseudocardinal tooth } \\
\text { L. teres right pseudocardinal tooth } \\
\text { L. teres right shell fragment } \\
\text { T. texasensis left valve } 70 \%\end{array}$ \\
\hline 36 & 9 & 1320 & 11.25 & $\begin{array}{l}\text { fragments } \\
\text { C. tampicoensis left pseudocardinal teeth } \\
\text { L. teres right pseudocardinal tooth }\end{array}$ \\
\hline 43 & 9 & 1329 & 9.82 & $\begin{array}{l}\text { fragments } \\
\text { L. teres right pseudocardinal tooth }\end{array}$ \\
\hline 43 & 9 & 1333 & 4.65 & fragments \\
\hline 6 & 10 & 68 & 2.42 & $\begin{array}{l}\text { fragment } \\
\text { L. teres right pseudocardinal tooth }\end{array}$ \\
\hline 6 & 10 & 69 & 0.11 & fragment \\
\hline 1 & 10 & 162 & 1.23 & fragments \\
\hline
\end{tabular}


Table G-1. continued

\begin{tabular}{|c|c|c|c|c|}
\hline Unit & Level & Lot & Weight (g) & Identification \\
\hline \multirow[t]{3}{*}{1} & 10 & 165 & 31.10 & fragments \\
\hline & & & & C. tampicoensis left valve \\
\hline & & & & C. tampicoensis hinge \\
\hline 1 & 10 & 168 & 3.53 & fragments \\
\hline 8 & 10 & 320 & 0.62 & fragments \\
\hline 10 & 10 & 351 & 0.08 & fragment \\
\hline 11 & 10 & 371 & 0.38 & fragments \\
\hline \multirow[t]{3}{*}{12} & 10 & 562 & 24.10 & fragments \\
\hline & & & & L. teres left valve $60 \%$ \\
\hline & & & & L. teres left valve $40 \%$ \\
\hline \multirow[t]{7}{*}{12} & 10 & 561 & 35.73 & fragments \\
\hline & & & & C. tampicoensis left valve $99 \%$ \\
\hline & & & & C. tampicoensis right pseudocardinal tooth \\
\hline & & & & L. teres matched right and left valve fragments \\
\hline & & & & L. teres right pseudocardinal tooth \\
\hline & & & & L. teres right pseudocardinal tooth \\
\hline & & & & L. teres left pseudocardinal teeth \\
\hline 12 & 10 & 570 & 6.20 & fragments \\
\hline & 10 & 594 & 39.58 & $\begin{array}{l}\text { L. teres right valve fragment } \\
\text { fragments }\end{array}$ \\
\hline 14 & & & & C. tampicoensis right valve $98 \%$ \\
\hline 14 & 10 & 595 & 0.92 & fragments \\
\hline 22 & 10 & 822 & 0.18 & fragments \\
\hline 26 & 10 & 942 & 0.37 & firagments \\
\hline 37 & 10 & 966 & 0.01 & fragment \\
\hline 17 & 10 & 995 & 0.05 & fragment \\
\hline \multirow[t]{3}{*}{31} & 10 & 1058 & 15.92 & fragments \\
\hline & & & & L. teres right valve $50 \%$ \\
\hline & & & & C. tampicoensis left hinge \\
\hline 31 & 10 & 1066 & 1.48 & fragments \\
\hline \multirow[t]{2}{*}{32} & 10 & 1082 & 1.92 & fragments \\
\hline & & & & L. teres left pseudocardinal teeth \\
\hline \multirow[t]{2}{*}{32} & 10 & 1083 & 29.95 & $\begin{array}{l}\text { C. tampicoensis left valve fragmentsand } \\
\text { matching }\end{array}$ \\
\hline & & & & right pseudocardinal tooth \\
\hline 32 & 10 & 1089 & 2.62 & fragments \\
\hline \multirow[t]{4}{*}{15} & 10 & 1104 & 50.75 & fragments \\
\hline & & & & C. tampicoensis left valve $70 \%$ \\
\hline & & & & C. tampicoensis left valve $60 \%$ \\
\hline & & & & C. tampicoensis right valve $80 \%$ \\
\hline 15 & 10 & 1114 & 1.04 & fragments \\
\hline 41 & 10 & 1209 & 2.69 & fragments \\
\hline 33 & 10 & 1255 & 0.26 & fragment \\
\hline \multirow[t]{2}{*}{33} & 10 & 1256 & 5.14 & fragments \\
\hline & & & & C. tampicoensis right pseudocardinal tooth \\
\hline
\end{tabular}


Table G-1. continued

\begin{tabular}{|c|c|c|c|c|}
\hline Unit & Level & Lot & Weight (g) & Identification \\
\hline \multirow[t]{2}{*}{33} & 10 & 1264 & 7.20 & fragments \\
\hline & & & & $\begin{array}{l}\text { L. teres matched left and right pseudocardinal } \\
\text { teeth }\end{array}$ \\
\hline \multirow[t]{2}{*}{34} & 10 & 1281 & 2.69 & fragments \\
\hline & & & & L. teres left pseudocardinal teeth \\
\hline 34 & 10 & 1287 & 1.84 & fragments \\
\hline 36 & 10 & 1307 & 0.69 & fragments \\
\hline 36 & 10 & 1308 & 6.08 & fragments \\
\hline 36 & 10 & 1315 & 13.35 & fragments \\
\hline 43 & 10 & 1329 & 9.82 & fragments \\
\hline 43 & 10 & 1332 & 3.50 & fragments \\
\hline 4 & 11 & 26 & 0.05 & fragment \\
\hline \multirow[t]{2}{*}{4} & 11 & 27 & 4.61 & fragments \\
\hline & & & & C. tampicoensis hinge \\
\hline \multirow[t]{3}{*}{4} & 11 & 28 & 4.38 & fragments \\
\hline & & & & T. texasensis left valve male $80 \%$ \\
\hline & & & & L. teres right pseudocardinal tooth \\
\hline \multirow[t]{2}{*}{6} & 11 & 70 & 0.44 & fragment \\
\hline & & & & L. teres right pseudocardinal tooth \\
\hline \multirow[t]{2}{*}{6} & 11 & 72 & 8.40 & fragments \\
\hline & & & & L. teres pseudocardinal tooth \\
\hline 7 & 11 & 89 & 0.94 & fragment (possibly fossil) \\
\hline \multirow[t]{2}{*}{1} & 11 & 167 & 3.79 & fragments \\
\hline & & & & C. tampicoensis pseudocardinal teeth \\
\hline 1 & 11 & 169 & 2.32 & L. teres fragment with pseudocardinal tooth \\
\hline 6 & 11 & 379 & 0.55 & fragments \\
\hline 10 & 11 & 460 & 0.23 & fragment \\
\hline \multirow[t]{2}{*}{12} & 11 & 565 & 4.62 & fragments \\
\hline & & & & L. teres right valve fragment \\
\hline 12 & 11 & 571 & 1.06 & fragments \\
\hline 11 & 11 & 654 & 0.13 & fragment \\
\hline 19 & 11 & 792 & 0.16 & fragment \\
\hline \multirow[t]{2}{*}{14} & 11 & 851 & 17.13 & fragments \\
\hline & & & & C. tampicoensis right valve $80 \%$ \\
\hline 14 & 11 & 852 & 0.64 & fragments \\
\hline 14 & 11 & 853 & 1.13 & fragments (including lateral teeth) \\
\hline 23 & 11 & 877 & 2.99 & $\begin{array}{l}\text { unidentified unionid right lateral tooth } \\
\text { fragment (similar to P. purpuratus) }\end{array}$ \\
\hline 26 & 11 & 938 & 7.48 & C. tampicoensis left valve $30 \%$ \\
\hline 31 & 11 & 1057 & 3.05 & fragments (probably T. texasensis) \\
\hline 32 & 11 & 1084 & 7.00 & fragments \\
\hline 32 & 11 & 1090 & 0.74 & fragments \\
\hline 15 & 11 & 1106 & 2.14 & fragments (including lateral teeth) \\
\hline 15 & 11 & 1111 & 1.44 & $\begin{array}{l}\text { C. tampicoensis right pseudocardinal tooth } \\
\text { fragments (including lateral teeth) }\end{array}$ \\
\hline
\end{tabular}


Table G-1. continued

\begin{tabular}{|c|c|c|c|c|}
\hline Unit & Level & Lot & Weight $(\mathrm{g})$ & Identification \\
\hline \multirow[t]{2}{*}{33} & 11 & 1257 & 12.87 & fragments \\
\hline & & & & $\begin{array}{l}\text { L. teres matched left and right pseudocardinal } \\
\text { teeth }\end{array}$ \\
\hline 33 & 11 & 1265 & 3.32 & fragments \\
\hline 34 & 11 & 1283 & 0.17 & fragments \\
\hline 36 & 11 & 1310 & 1.05 & fragments \\
\hline 36 & 11 & 1311 & 0.43 & fragments \\
\hline 36 & 11 & 1312 & 13.96 & fragments (probably C. tampicoensis) \\
\hline \multirow[t]{3}{*}{36} & 11 & 1317 & 7.91 & fragments \\
\hline & & & & C. tampicoensis beak \\
\hline & & & & C. tampicoensis beak \\
\hline 43 & 11 & 1330 & 2.89 & fragments \\
\hline 43 & 11 & 1335 & 0.16 & fragments \\
\hline 2 & 12 & 2 & 0.30 & fragment \\
\hline 4 & 12 & 34 & 0.14 & fragments \\
\hline 4 & 12 & 35 & 0.74 & fragments \\
\hline 1 & 12 & $171 / 2$ & 4.19 & fragments \\
\hline 1 & 12 & 174 & 1.23 & fragments \\
\hline 6 & 12 & 376 & 0.15 & fragments \\
\hline 12 & 12 & 566 & 8.75 & fragments \\
\hline 12 & 12 & 572 & 1.29 & fragments \\
\hline 11 & 12 & 655 & 0.06 & fragment \\
\hline 11 & 12 & 666 & 0.02 & fragment \\
\hline 23 & 12 & 879 & 0.21 & fragments \\
\hline 31 & 12 & 1061 & 0.53 & T. texasensis left valve $50 \%$ \\
\hline \multirow[t]{3}{*}{32} & 12 & 1085 & 1.51 & fragments \\
\hline & & & & L. teres left hinge \\
\hline & & & & L. teres right pseudocardinal tooth \\
\hline \multirow[t]{2}{*}{32} & 12 & 1087 & 0.70 & fragment \\
\hline & & & & L. teres left pseudocardinal teeth \\
\hline \multirow[t]{2}{*}{15} & 12 & 1108 & 2.79 & L. teres left valve $40 \%$ \\
\hline & & & & $\begin{array}{l}\text { Exogyra Cretaceous oyster } 3 \text { fragments } \\
(103.66 \mathrm{~g})\end{array}$ \\
\hline \multirow[t]{2}{*}{33} & 12 & 1258 & 24.69 & fragments \\
\hline & & & & L. teres left hinge \\
\hline 33 & 12 & 1261 & 0.49 & fragments \\
\hline 34 & 12 & 1283 & 0.17 & fragments \\
\hline 34 & 12 & 1284 & 2.13 & fragments \\
\hline 34 & 12 & 1290 & 1.71 & fragments \\
\hline \multirow[t]{3}{*}{36} & 12 & 1314 & 2.24 & fragments \\
\hline & & & & T. texasensis left pseudocardinal teeth \\
\hline & & & & T. texasensis left pseudocardinal teeth \\
\hline 36 & 12 & 1318 & 0.12 & fragments \\
\hline \multirow[t]{2}{*}{43} & 12 & 1331 & 1.81 & fragments \\
\hline & & & & L. teres right pseudocardinal tooth \\
\hline
\end{tabular}


Table G-1. continued

\begin{tabular}{ccccl}
\hline Unit & Level & Lot & Weight $(\mathrm{g})$ & Identification \\
\hline 7 & 13 & 91 & 0.65 & fragments \\
10 & 13 & 452 & 0.31 & fragments \\
31 & 13 & 1068 & 1.03 & fragments \\
43 & 13 & 1451 & 5.55 & fragments \\
43 & 13 & 1451 & 0.33 & fragments \\
& & & & L. teres left pseudocardinal teeth \\
12 & 13 & 1501 & 0.96 & fragments \\
& & & & L. teres right pseudocardinal tooth \\
12 & 13 & 1501 & 0.39 & fragments \\
11 & 14 & 657 & 3.49 & T. texasensis right valve female $98 \%$ \\
31 & 14 & 1069 & 17.11 & fragments \\
31 & 14 & 1069 & 2.87 & fragments \\
& & & C. tampicoensis valve fragment \\
43 & 14 & 1452 & 0.40 & fragments \\
43 & 14 & 1452 & 0.06 & fragments \\
12 & 14 & 1502 & 0.05 & fragments \\
10 & 15 & 455 & 0.09 & fragments \\
10 & 15 & 464 & 0.14 & fragments \\
11 & 15 & 664 & 0.14 & fragment \\
10 & 16 & 465 & 0.74 & L. teres left hinge \\
11 & 16 & 660 & 0.16 & fragments \\
10 & 17 & 457 & 3.08 & T. texasensis left valve female $95 \%$ \\
11 & 17 & 662 & 0.02 & fragments \\
10 & 18 & 470 & 0.46 & fragments \\
10 & 19 & 467 & 0.03 & fragment \\
10 & 20 & 469 & 0.29 & fragment \\
& & & &
\end{tabular}


Table G-2. Identification of Freshwater Mussel Remains (Unionidae) from 41MV120

Samples include those from BHTs. Species referenced include Tampico pearlymussel (Cyrtonaias tampicoensis), yellow sandshell (Lampsilis teres), and Texas lilliput (Toxolasma texasensis). Percentage listed with some identified valves represents the approximate proportion of the valve present.

\begin{tabular}{ccccl}
\hline Unit & Level & Lot & Weight $(\mathrm{g})$ & Identification \\
\hline 7 & 195 & - & 1.43 & L. teres left valve fragment \\
7 & 194 & - & 0.06 & fragment \\
7 & 176 & upper & 2.40 & fragments \\
& & & $/ \mathrm{CT}$ & L. teres left pseudocardinal teeth \\
8 & 201 & - & 0.09 & fragment \\
8 & 157 & - & 2.66 & C. tampicoensis left pseudocardinal \\
& & & & tooth (large) \\
8 & 204 & - & 0.27 & fragments \\
8 & 161 & - & 0.02 & fragments (very small) \\
8 & 215 & - & 34.24 & L. teres right valve $80 \%$ (large) \\
9 & 229 & - & 0.19 & fragments \\
10 & 255 & - & 0.01 & fragments \\
10 & 251 & - & 1.50 & fragments \\
12 & 701 & - & 11.67 & L. teres left hinge
\end{tabular}




\section{Appendix H: Snail Data}

\section{Artie L. Metcalf}

In this appendix, the bags received are listed numerically by unit (EU, BHT) as indicated in column 1. Genus and species of the four species of gastropods identified in the assemblage are indicated in columns 2 to 5 . Where determination to species was not attempted, the term "Unidentified" is employed, in column 6 . Specimens with at least a partial columella are considered as individiual shells, and the quantity of these is indicated by a single or initial number. Shell parts not containing part of a columella are termed "fragments" and designated by the abbreviations "frag." or "frags." 


\begin{tabular}{|c|c|c|c|c|c|}
\hline Unit & $\begin{array}{l}\text { Rabdotus } \\
\text { alternatus }\end{array}$ & $\begin{array}{l}\text { Rabdotus } \\
\text { dealbatus }\end{array}$ & $\begin{array}{c}\text { Succinea } \\
\text { luteola } \\
\end{array}$ & $\begin{array}{c}\text { Linisa } \\
\text { texasiana }\end{array}$ & Unidentified \\
\hline EU 1 & 6 frag. & & & & \\
\hline EU 1 & & 6 & 4 & 2 & \\
\hline EU 1 & 1 & 5 frag. & 3 & & \\
\hline EU 1 & $1+2$ frag. & & & & \\
\hline EU 1 & $4+2$ frag. & 1 & & & \\
\hline EU 1 & 2 frag. & & & & \\
\hline EU 1 & 4 frag. & & & & \\
\hline EU 1 & $3+4$ frag. & 1 & & 1 & \\
\hline EU 2 & 2 & & & & \\
\hline EU 4 & $2+1$ frag. & & 3 & & \\
\hline EU 4 & 1 & & & & \\
\hline $\mathrm{EU} 4$ & & 2 & & 1 & \\
\hline EU 4 & 1 frag. & & 2 & & \\
\hline EU 6 & 2 & & 1 & & \\
\hline EU 6 & $2+5$ frag. & 1 & 19 & 2 & \\
\hline EU 6 & $3+5$ frag. & & 1 & & \\
\hline EU 6 & 2 & & & & \\
\hline EU 6 & 8 frags. & 10 frags. & 12 & & \\
\hline EU 6 & & & 4 & 1 & 3 \\
\hline EU 6 & 4 frag. & 1 frag. & $5+4$ frag. & & \\
\hline EU 6 & 3 frag. & & 10 & 1 & \\
\hline EU 6 & 3 frag. & & & & \\
\hline EU 6 & 1 & & & & \\
\hline EU 7 & $6+14$ frag. & $1+1$ frag. & 3 & & \\
\hline EU 7 & $1+4$ frag. & 1 & $1+1$ frag. & & \\
\hline EU 7 & 1 & & & & \\
\hline EU 7 & $5+14$ frag. & & 2 & & \\
\hline EU 7 & $1+1$ frag. & & 1 & & \\
\hline EU 8 & $1+10$ frag. & 5 frag. & & & \\
\hline EU 8 & 2 & & & & \\
\hline EU 8 & $2+10$ frag. & $1+2$ frag. & & & \\
\hline EU 8 & $2+32$ frag. & $1+3$ frag. & 7 & 3 & \\
\hline EU 8 & 1 & & & & \\
\hline EU 8 & 1 & & & & \\
\hline EU 8 & 1 & & & & \\
\hline EU 8 & 2 frag. & $1+1$ frag. & & & 4 frag. \\
\hline EU 8 & 1 & & & & \\
\hline EU 8 & 1 & & & & \\
\hline EU 8 & 1 & & & & \\
\hline
\end{tabular}




\begin{tabular}{|c|c|c|c|c|c|}
\hline Unit & $\begin{array}{l}\text { Rabdotus } \\
\text { alternatus }\end{array}$ & $\begin{array}{l}\text { Rabdotus } \\
\text { dealbatus }\end{array}$ & $\begin{array}{l}\text { Succinea } \\
\text { luteola }\end{array}$ & $\begin{array}{c}\text { Linisa } \\
\text { texasiana }\end{array}$ & Unidentified \\
\hline EU 8 & & 1 & & & \\
\hline EU 8 & 2 & & & & \\
\hline EU 8 & 1 & & & & \\
\hline EU 8 & & & & 1 & \\
\hline EU 9 & & & & & 1 frag. \\
\hline EU 9 & 25 frag. & & & & \\
\hline EU 9 & 3 frag. & & & & \\
\hline EU 10 & & & & & 1 frag. \\
\hline EU 10 & 3 frag. & & & & \\
\hline EU 10 & $1+3$ frag. & & & & \\
\hline EU 10 & & 1 & 2 & & \\
\hline EU 10 & $2+2$ frag. & & & & unionid frag \\
\hline EU 10 & & & 2 & & \\
\hline EU 10 & $1 \mathrm{frag}$. & & & & \\
\hline EU 10 & & 1 & 2 & & \\
\hline EU 10 & $1+2$ frag. & & & & \\
\hline EU 10 & & & & & $1 \mathrm{frag}$. \\
\hline EU 10 & 1 & & & & \\
\hline EU 11 & 3 frag. & & & & \\
\hline EU 11 & 3 frag. & & & & \\
\hline EU 11 & 2 & & 3 & 1 & \\
\hline EU 11 & 2 frag. & & & & \\
\hline EU 11 & 1 & & & & \\
\hline EU 11 & $1+1$ frag. & & & & \\
\hline EU 11 & & & 2 & & \\
\hline EU 11 & $2+1$ frag. & 1 & & 1 & \\
\hline EU 11 & $2+7$ frag. & 1 & & & \\
\hline EU 11 & & & & & 1 frag. \\
\hline EU 11 & $1+5$ frag. & & & & \\
\hline EU 11 & 3 & & & & \\
\hline EU 11 & $3+4$ frag. & & & & \\
\hline EU 11 & 1 frag. & & & & \\
\hline EU 11 & 1 & & & 1 & $1 \mathrm{frag}$ \\
\hline EU 11 & 3 frag. & 1 frag. & & & \\
\hline EU 11 & & & & & 1 frag. \\
\hline EU 11 & 3 & & & & \\
\hline EU 11 & 1 frag. & & & & \\
\hline EU 12 & $2+1$ frag. & & & 1 & \\
\hline EU 12 & & & 1 & & \\
\hline
\end{tabular}




\begin{tabular}{|c|c|c|c|c|c|}
\hline Unit & $\begin{array}{l}\text { Rabdotus } \\
\text { alternatus }\end{array}$ & $\begin{array}{l}\text { Rabdotus } \\
\text { dealbatus }\end{array}$ & $\begin{array}{c}\text { Succinea } \\
\text { luteola }\end{array}$ & $\begin{array}{c}\text { Linisa } \\
\text { texasiana } \\
\end{array}$ & Unidentified \\
\hline EU 12 & 2 & & & & \\
\hline EU 12 & 3 frag. & & & & \\
\hline EU 12 & 1 frag. & & & & \\
\hline EU 12 & 1 & & & & \\
\hline EU 12 & $2+1$ frag. & & & & \\
\hline EU 12 & 2 frag. & & & & \\
\hline EU 12 & $1+5$ frag. & & & & \\
\hline EU 12 & 2 & 2 & & 1 & \\
\hline EU 12 & & & 5 & 1 & \\
\hline EU 12 & $1+2$ frag. & 1 & & & \\
\hline EU 12 & 2 & & & & \\
\hline EU 13 & & & 1 & 1 & \\
\hline EU 13 & 5 frag. & & & & \\
\hline EU 13 & 1 & & 2 & 4 & \\
\hline EU 13 & 1 & & 3 & & \\
\hline EU 13 & 2 frag. & & & & \\
\hline EU 13 & 1 frag. & & & & \\
\hline EU 13 & 1 & 1 & & & \\
\hline EU 14 & 2 frag. & & 1 & 1 & \\
\hline EU 14 & $1+1$ frag. & 1 & & 1 & \\
\hline EU 14 & $1+2$ frag. & 1 & & & \\
\hline EU 14 & & & & & 3 frag. \\
\hline EU 14 & $1+3$ frag. & & & & \\
\hline EU 14 & & & 5 & 2 & \\
\hline EU 14 & 1 & & & & \\
\hline EU 14 & & 2 frag. & 4 & & \\
\hline EU 14 & 4 frag. & & 1 & 1 & \\
\hline EU 14 & & & & & 1 frag. \\
\hline EU 14 & & & & & 1 frag. \\
\hline EU 15 & & & & & 3 frag. \\
\hline EU 15 & 1 & & & & 1 frag. \\
\hline EU 15 & & & 3 & & \\
\hline EU 15 & 1 frag. & & & & \\
\hline EU 15 & & & 3 & 1 & \\
\hline EU 15 & 1 & & & & 1 frag. \\
\hline EU 15 & $1+1$ frag. & & & & \\
\hline EU 15 & 2 & & & & \\
\hline EU 15 & & & 1 & & \\
\hline EU 15 & $1+2$ frag. & & 1 & & \\
\hline
\end{tabular}




\begin{tabular}{|c|c|c|c|c|c|}
\hline Unit & $\begin{array}{l}\text { Rabdotus } \\
\text { alternatus }\end{array}$ & $\begin{array}{l}\text { Rabdotus } \\
\text { dealbatus }\end{array}$ & $\begin{array}{c}\text { Succinea } \\
\text { luteola } \\
\end{array}$ & $\begin{array}{c}\text { Linisa } \\
\text { texasiana } \\
\end{array}$ & Unidentified \\
\hline EU 15 & $2+1$ frag. & 1 & & & \\
\hline EU 15 & 1 & & 1 & 1 & \\
\hline EU 16 & 1 & & & & \\
\hline EU 16 & & 1 & $1+1$ frag. & & \\
\hline EU 16 & 1 & & & & \\
\hline EU 16 & 5 & & 1 frag. & & \\
\hline EU 16 & 2 & & & & \\
\hline EU 16 & 1 & & 1 & & \\
\hline EU 16 & 1 & & & & \\
\hline EU 16 & 2 & & & & \\
\hline EU 16 & 1 frag. & & & & \\
\hline EU 16 & & & & 1 & \\
\hline EU 16 & 1 & & & & \\
\hline EU 17 & 1 & & & & \\
\hline EU 17 & & & & & 1 frag. \\
\hline EU 17 & 1 & & & & \\
\hline EU 17 & 1 & & & & \\
\hline EU 17 & & 2 & 1 & & \\
\hline EU 17 & 3 & & & & \\
\hline EU 17 & 1 & & & & \\
\hline EU 17 & & & 2 & & \\
\hline EU 18 & 1 & & & & \\
\hline EU 18 & 2 frag. & & & & \\
\hline EU 18 & 2 & 1 & & 1 & \\
\hline EU 18 & 1 & & & & \\
\hline EU 18 & & & 1 & & 1 frag. \\
\hline EU 18 & 1 & & & & \\
\hline EU 19 & 2 & & 1 & & \\
\hline EU 19 & 1 frag. & & & & \\
\hline EU 19 & 1 frag. & & & & \\
\hline EU 19 & 1 & & & & \\
\hline EU 19 & 2 & & & & \\
\hline EU 19 & $1+3$ frag. & & & & \\
\hline EU 19 & 1 frag. & 1 & & & \\
\hline EU 19 & 1 & 1 & & & \\
\hline EU 19 & $1+3$ frag. & & & & \\
\hline EU 20 & 1 frag. & & & & \\
\hline EU 20 & 1 frag. & & & & \\
\hline EU 20 & & & 2 & & \\
\hline
\end{tabular}




\begin{tabular}{|c|c|c|c|c|c|}
\hline Unit & $\begin{array}{l}\text { Rabdotus } \\
\text { alternatus }\end{array}$ & $\begin{array}{l}\text { Rabdotus } \\
\text { dealbatus }\end{array}$ & $\begin{array}{c}\text { Succinea } \\
\text { luteola }\end{array}$ & $\begin{array}{c}\text { Linisa } \\
\text { texasiana }\end{array}$ & Unidentified \\
\hline EU 21 & & & & & 1 frag. \\
\hline EU 21 & 2 frag. & & & & \\
\hline EU 21 & 2 frag. & & & & \\
\hline EU 21 & & & 1 & & \\
\hline EU 22 & 2 frag. & & & & \\
\hline EU 22 & & & & & 1 frag. \\
\hline EU 22 & $1+1$ frag. & & & & \\
\hline EU 22 & 1 frag. & & & & \\
\hline EU 22 & $2+2$ frag. & & & & \\
\hline EU 22 & 2 frag. & & & & \\
\hline EU 22 & $3+2$ frag. & & & & \\
\hline EU 22 & $2+3$ frag. & & & & \\
\hline EU 22 & 1 & & 1 & & \\
\hline EU 22 & $3+2$ frag. & & & & \\
\hline EU 22 & & & 1 & & \\
\hline EU 22 & & & 1 & & \\
\hline EU 22 & $1+3$ frag. & & & & \\
\hline EU 22 & $2+2$ frag. & & & & \\
\hline EU 22 & & & 1 & & \\
\hline EU 22 & & & 1 & & \\
\hline EU 22 & $1+1$ frag. & & & 1 & \\
\hline $\mathrm{EU} 22$ & 1 frag. & & & 1 & \\
\hline EU 23 & & & 1 & & \\
\hline EU 23 & & & 1 & & \\
\hline EU 23 & 1 & & & 1 & \\
\hline EU 23 & 1 & & & & \\
\hline EU 23 & 1 & & & & \\
\hline EU 24 & 1 & & & & \\
\hline EU 24 & 1 & & & & \\
\hline EU 24 & 2 & & 1 & 1 & \\
\hline EU 24 & 1 & & & & \\
\hline EU 24 & 1 & & & & \\
\hline EU 24 & & & 1 & & \\
\hline EU 24 & & 1 & & & \\
\hline EU 24 & & 1 & & & \\
\hline EU 24 & 1 frag. & 1 & & & \\
\hline EU 24 & 2 & & & & \\
\hline EU 24 & 1 frag. & & & & \\
\hline EU 24 & 2 & & & & \\
\hline
\end{tabular}




\begin{tabular}{|c|c|c|c|c|c|}
\hline Unit & $\begin{array}{l}\text { Rabdotus } \\
\text { alternatus }\end{array}$ & $\begin{array}{l}\text { Rabdotus } \\
\text { dealbatus }\end{array}$ & $\begin{array}{c}\text { Succinea } \\
\text { luteola }\end{array}$ & $\begin{array}{c}\text { Linisa } \\
\text { texasiana }\end{array}$ & Unidentified \\
\hline EU 25 & & 1 & & & \\
\hline EU 26 & 1 & & & & \\
\hline EU 26 & 1 & & 1 & & \\
\hline EU 26 & & & 2 & & \\
\hline EU 26 & 1 & 1 & 1 & 2 & \\
\hline EU 26 & & 1 & & & \\
\hline EU 26 & & & 1 & & \\
\hline EU 26 & & & 1 & & \\
\hline EU 26 & & & 1 & & \\
\hline EU 26 & 1 & & & & \\
\hline EU 26 & & 1 & 1 & & \\
\hline EU 26 & & & & & 1 frag. \\
\hline EU 26 & $2+1$ frag. & & & & \\
\hline EU 26 & 2 & & & & \\
\hline EU 26 & & & 1 & & \\
\hline EU 26 & & & 1 & & 1 frag. \\
\hline EU 28 & & & 4 & & \\
\hline EU 28 & & & 4 & 3 & \\
\hline EU 30 & & & 2 & & \\
\hline EU 30 & & & 3 & & \\
\hline EU 30 & 2 & 1 & 3 & & \\
\hline EU 30 & & & 2 & & \\
\hline EU 31 & 2 & & & & \\
\hline EU 31 & $1+1$ frag. & & & & \\
\hline EU 31 & 1 frag. & & & & \\
\hline EU 31 & 1 & 2 & 4 & & \\
\hline EU 31 & 2 frag. & 1 & 2 & & \\
\hline EU 31 & 1 & & & & \\
\hline EU 31 & 2 frag. & 3 & 3 & 1 & \\
\hline EU 31 & & 2 & & & \\
\hline EU 31 & bag 11 & & & & bag $21 \mathrm{fr}$ \\
\hline EU 31 & $1+3$ frag. & & & & \\
\hline EU 32 & $1+1$ frag. & & & & \\
\hline EU 32 & 1 & & & & \\
\hline EU 32 & 1 frag. & & & 1 & \\
\hline EU 32 & 1 & & & & \\
\hline EU 32 & $1+1$ frag. & 1 & 5 & 2 & \\
\hline EU 32 & & & 3 & & \\
\hline EU 32 & 1 frag. & & & & \\
\hline
\end{tabular}




\begin{tabular}{|c|c|c|c|c|c|}
\hline Unit & $\begin{array}{l}\text { Rabdotus } \\
\text { alternatus }\end{array}$ & $\begin{array}{l}\text { Rabdotus } \\
\text { dealbatus }\end{array}$ & $\begin{array}{l}\text { Succinea } \\
\text { luteola }\end{array}$ & $\begin{array}{c}\text { Linisa } \\
\text { texasiana }\end{array}$ & Unidentified \\
\hline EU 32 & 1 & & & & \\
\hline EU 32 & & & 3 & 1 & 2 frag. \\
\hline EU 32 & $3+3$ frag. & 1 & & & \\
\hline EU 32 & 3 & 1 & 2 & 1 & 2 frag. \\
\hline EU 33 & & & & 1 & \\
\hline EU 33 & & & 1 & & 4 frag. \\
\hline EU 33 & 1 frag. & & & 1 & \\
\hline EU 33 & $1+1$ frag. & & & & \\
\hline EU 33 & $2+8$ frag. & & 4 & & \\
\hline EU 33 & 3 frag. & & & & \\
\hline EU 33 & 1 & & & & \\
\hline EU 33 & $1+6$ frag. & 1 & & & \\
\hline EU 33 & 12 frag. & 1 frag. & 1 & 2 frag. & \\
\hline EU 33 & $2+6$ frag. & & & & \\
\hline EU 33 & 2 & & & & \\
\hline EU 34 & 1 frag. & & & & \\
\hline EU 34 & 2 & & & & \\
\hline EU 34 & 1 frag. & & & & \\
\hline EU 34 & 1 & & & & \\
\hline EU 34 & 1 & & & & \\
\hline EU 36 & 1 frag. & & & & \\
\hline EU 36 & 1 frag. & & & & \\
\hline EU 36 & $3+1$ frag. & & & & \\
\hline EU 36 & 2 & & & & \\
\hline EU 36 & 1 & & & & \\
\hline EU 36 & 1 & & & & \\
\hline EU 36 & $5+8$ frag. & 1 & & 1 & \\
\hline EU 37 & & & 1 & & \\
\hline EU 37 & 2 frag. & & & & \\
\hline EU 37 & 1 & & & & \\
\hline EU 37 & $1+1$ frag. & 1 & & & \\
\hline EU 37 & $1+$ frags. & & & & \\
\hline EU 37 & & 1 & 2 & & \\
\hline EU 37 & 1 & & 1 & & \\
\hline EU 37 & 2 frag. & & & & \\
\hline EU 37 & 1 & & & & \\
\hline EU 37 & 1 frag. & 1 & & & \\
\hline EU 37 & & 1 & & & \\
\hline EU 37 & 1 frag. & & & & \\
\hline
\end{tabular}




\begin{tabular}{|c|c|c|c|c|c|}
\hline Unit & $\begin{array}{l}\text { Rabdotus } \\
\text { alternatus }\end{array}$ & $\begin{array}{l}\text { Rabdotus } \\
\text { dealbatus }\end{array}$ & $\begin{array}{c}\text { Succinea } \\
\text { luteola }\end{array}$ & $\begin{array}{c}\text { Linisa } \\
\text { texasiana }\end{array}$ & Unidentified \\
\hline EU 38 & 1 & & 4 & & \\
\hline EU 38 & 2 & & & & \\
\hline EU 38 & & 1 & & & \\
\hline EU 38 & 1 & & & & \\
\hline EU 38 & 1 frag. & & & & \\
\hline EU 38 & 1 & 1 & 1 & & \\
\hline EU 38 & & & & & 3 frag. \\
\hline EU 41 & & & 2 & & \\
\hline EU 41 & $1+2$ frag. & & & & \\
\hline EU 41 & $1+5$ frag. & 1 & 3 & & \\
\hline EU 41 & $1+3$ frag. & & & & \\
\hline EU 41 & $2+1$ frag. & & & & \\
\hline EU 41 & $3+1$ frag. & 1 & & & \\
\hline EU 41 & 4 frag. & & & & \\
\hline EU 41 & $1+2$ frag. & & & & \\
\hline EU 42 & $2+3$ frag. & & & & \\
\hline EU 42 & $3+5$ frag. & 2 & & & \\
\hline EU 42 & 1 & & & & \\
\hline EU 42 & 5 frag. & & & & \\
\hline EU 43 & 2 frag. & & & & \\
\hline EU 43 & & & & & 8 frag. \\
\hline EU 43 & $1+4$ frag. & & & & \\
\hline EU 43 & & & & & 2 frag. \\
\hline EU 43 & $1+2$ frag. & & & & \\
\hline EU 43 & $1+5$ frag. & & & & \\
\hline \multicolumn{6}{|l|}{ EU 43} \\
\hline EU 43 & $4+4$ frag. & & & & \\
\hline Eu 43 & & & & & $1 \mathrm{frag}$. \\
\hline EU 43 & 2 & 2 & & 2 & 3 frag. \\
\hline BHT 10 & 1 & & & & \\
\hline BHT 11 & 1 frag. & & & & \\
\hline BHT 7 & $2+1$ frag. & & & & \\
\hline BHT 7 & & & & & 1 frag. \\
\hline BHT 8 & & & & & 1 frag. \\
\hline
\end{tabular}




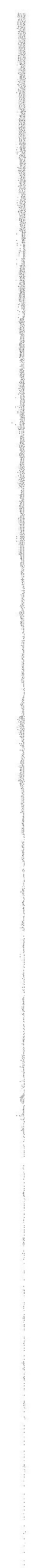

